Shengwei Wei

A. Asymmetrische Organokatalyse mit kleinen Peptiden und neuen bifunktionellen organischen Verbindungen

$B$. Ansätze zur asymmetrischen Produktkatalyse und zur Synthese der Naturstoffhybride

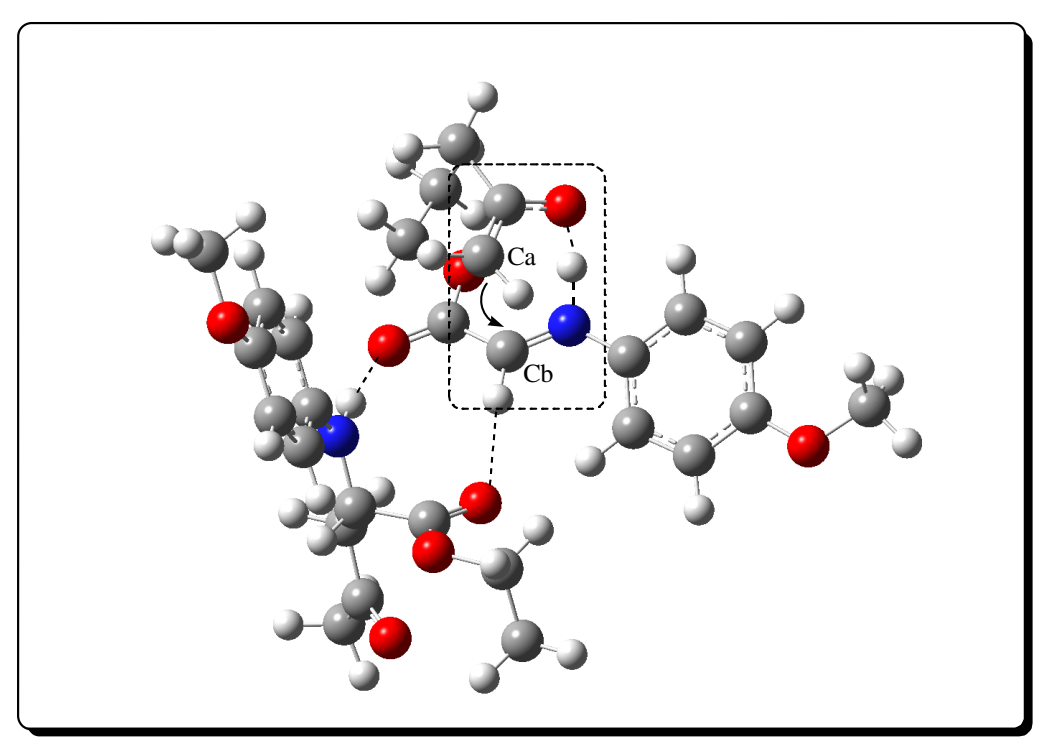

Göttingen 2007 



\title{
A. Asymmetrische Organokatalyse mit kleinen Peptiden und neuen bifunktionellen organischen Verbindungen \\ $B$. Ansätze zur asymmetrischen Produktkatalyse und zur Synthese der Naturstoffhybride
}

\author{
Dissertation \\ zur Erlangung des Doktorgrades \\ der Mathematisch-Naturwissenschaftlichen Fakultäten \\ der Georg-August-Universität zu Göttingen
}

vorgelegt von

Shengwei Wei

aus Shannxi, V.R China 
D 7

Referent:

Prof. Dr. S. B. Tsogoeva

Korreferent:

Prof. Dr. L. Ackermann

Tag der mündlichen Prüfung: $\quad$ 09.07.2007 
Die vorliegende Arbeit wurde in der Zeit von Februar 2004 bis März 2007 am Institut für Organische und Biomolekulare Chemie der Georg-August-Universität Göttingen unter der Leitung von Prof. Dr. S. B. Tsogoeva angefertigt.

Mein besonderer Dank gilt Frau Prof. Dr. S. B. Tsogoeva für die interessante Themenstellung sowie für die Unterstützung und Förderung während des Fortgangs dieser Arbeit. 


\section{$M$ einer $F$ amilie}




\section{Inhaltsverzeichnis}

1. ALLGEMEINER TEIL .................................................................................

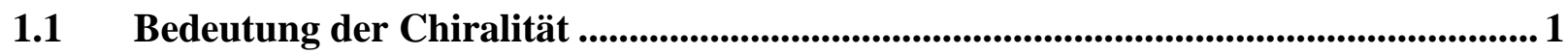

1.2 Klassifizierung der Methoden zur Enatiomerengewinnung ........................................ 4

1.2.1 Trennung von Enantiomeren (Racematspaltung) ................................................. 4

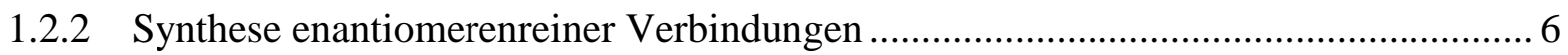

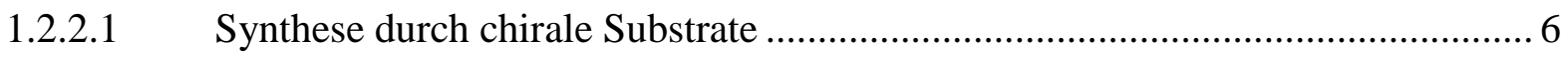

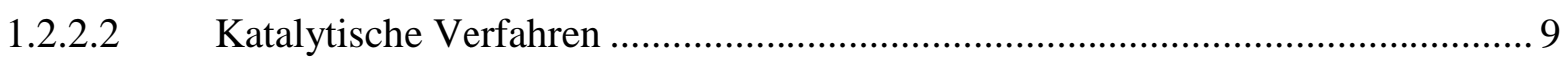

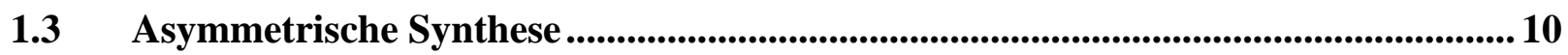

1.3.1 Asymmetrische Synthese mithilfe des Chiral Pools ............................................. 10

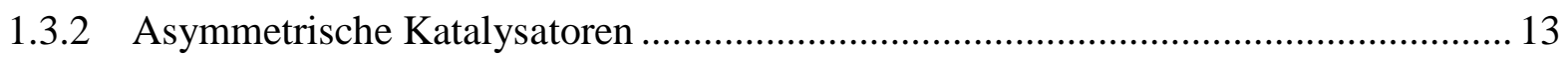

2 ASYMMETRISCHE ORGANOKATALYSATOREN .......................... 17

2.1 Allgemeinfunktionen der asymmetrischen Organokatalysatoren............................ 17

2.2 Asymmetrische bifunktonelle Organokatalysatoren .................................................22

3 ZIEL UND PLANUNG DER ARBEIT .............................................. 23

4 KLEINE PEPTIDE ALS ORGANISCHE KATALYSATOREN ...........25

4.1 Allgemeine Verwendung der kleinen Peptide bei der organischen asymmetrischen

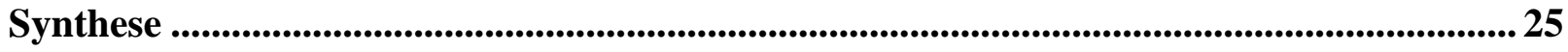

4.2 Anwendung der kleinen Peptide für Zielreaktionen ................................................ 34

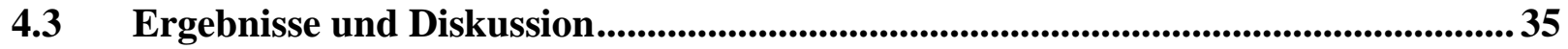

4.3.1 Anwendung der kleinen Peptide bei der asymmetrischen direkten Aldol-Reaktion .. 35

4.3.1.1 Untersuchung von Peptiden bei der Aldol-Reaktion von 4-Nitrobenzaldehyd und

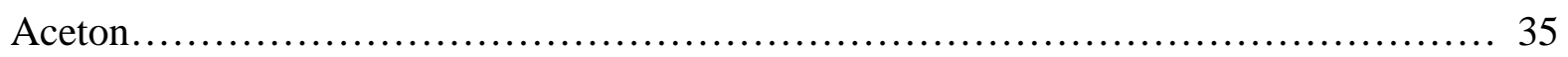

4.3.1.2 Entfernung der Schutzgruppe .............................................................. 41

4.3.1.3 Anwendung der entschützten Peptide bei der direkten Aldol-Reaktion ............. 43 


\subsubsection{Untersuchung der Aktivität der Koordination von Katalysator und Co-}

Katalysator .54

4.3.2 Verwendung der Dipeptide bei der Baylis-Hillmann Reaktion 59

4.3.2.1 Darstellung von peptidanalogen Verbindungen 46, 47,49 60

4.3.2.2 Optimierung des Lösungsmittels durch Anwendung von Kat. 10 bei der BaylisHillmann Reaktion zwischen 2-Nitrobenzaldehyde und Vinylmethylketon. .65

\section{SYNTHESE UND ANWENDUNG VON NEUEN BIFUNKTIONELLEN THIOHARNSTOFFHALTI-GEN VERBINDUNGEN ...................................70}

5.1 Allgemeine Entwicklung der bifunktionellen Verbindungen für die organische Synthese. 70

\subsection{Ziel der Arbeit in der Synthese und Anwendung von thioharnstoffhaltigen} bifunktionellen Katalysatoren .......................................................................................................... 79

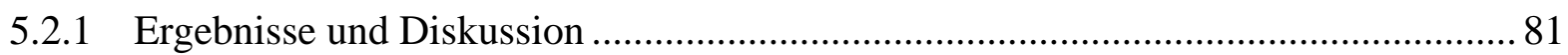

5.2.1.1 Synthese von neuen bifunktionellen thioharnstoffhaltigen Katalysatoren 81

5.2.1.2 Anwendung neuer chiraler Thioharnstoff-Katalysatoren bei der MichaelAddition. 84

\section{ASYMMETRISCHE ORGANOAUTOKATALYTISCHE}

REAKTIONEN

6.1 Entwicklung der autokatalytischen Reaktionen

6.2 Arbeitsplan für das Gebiet der autokatalytischen asymmetrischen Reaktion...... 118

6.3 Ergebnisse und Diskussion.

6.3.1 Die asymmetrische Autokatalyse bei der Mannich und Aldol-Reaktion durch

Produkt-Katalysatoren.

6.3.2 Die asymmetrische Autokatalyse bei der Mannich und Aldol-Reaktion ohne Zusatz von Produkt-Initiator.

\section{SYNTHESE VON HYBRID-MOLEKÜLEN AUS NATURSTOFFEN139}

7.1 Naturstoffe spielen bei der Entwicklung neuer Wirkstoffe eine wichtige Rolle... 139 
7.3 Darstellung von verschiedenen Hybride aus Betulin und Artesunat..................... 145

7.3.1 Synthese des Artesunat-Betulin-28-Acetat-Hybrids 106..................................... 145

7.3.2 Synthese des Betulin-28-Artesunat-Hybrids 107................................................. 146

7.3.3 Synthese des Artesunat-2-Betulin-28-Artesunat-Hybrids 108 ............................... 147

7.3.4 Darstellung des Artesunat-cyclohexyl-Artesunat-Hybrids 109 .............................. 148

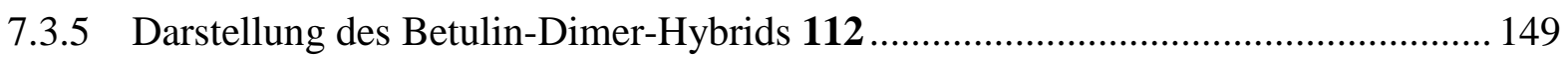

7.3.6 Darstellung des Artesunat-Propyl-Artesunat-Hybrids 114 …............................. 150

8 ZUSAMMENFASSUNG DER ARBEIT .............................................151

9 EXPERIMENTELLER TEIL ........................................................................ 161

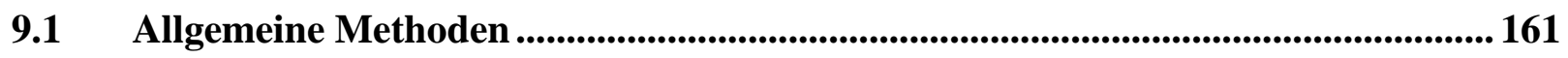

9.2 Instrumentelle Analytik und verwendete Geräte..................................................... 161

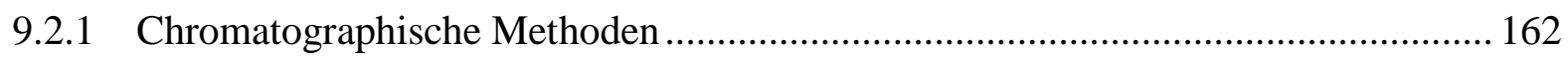

9.3 Darstellung der Peptide für Aldol-Reaktion ...................................................... 163

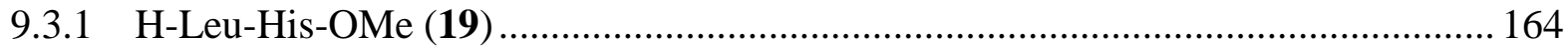

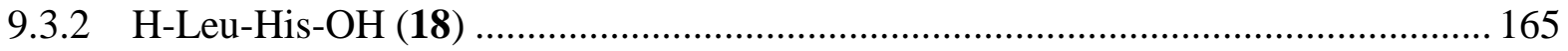

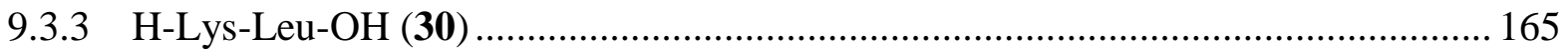

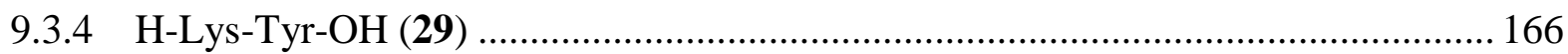

9.4 Allgemeine Methoden der Durchführung der Aldol-Reaktion ............................. 167

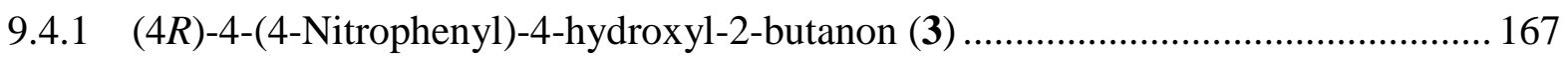

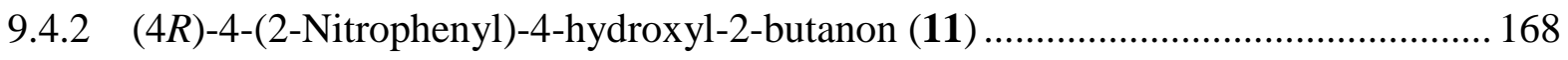

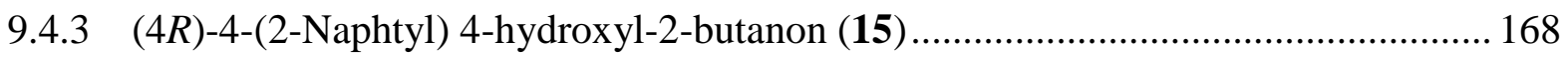

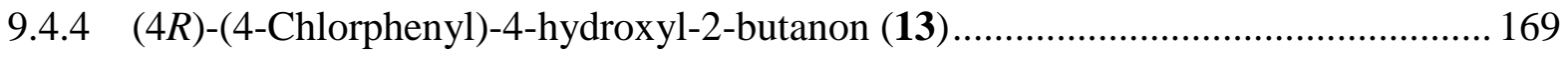

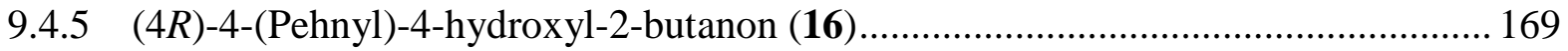

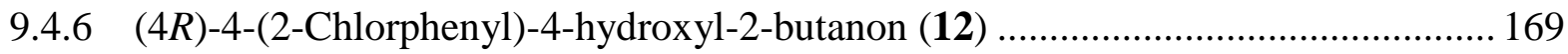

9.4.7 (4R)-(4-Bromphenyl)-4-hydroxyl-2-butanon (14) ............................................... 170

9.52 -[Hydroxy-(2-nitro-phenyl)-methyl]-acryl säure methyl ester (67)..................... 170

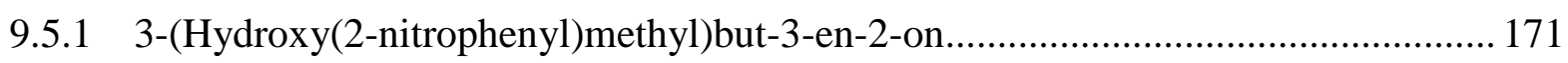

9.5.2 2-(Hydroxy(2-nitrophenyl)methyl)cyclohex-2-enon ......................................... 171 
9.6 Synthese der Thioharnstoffhaltigen Katalysatoren

9.6.1 (S)-1-(2-Phenoxyacetyl) pyrrolidine-2-carbonsäure .............................................. 172

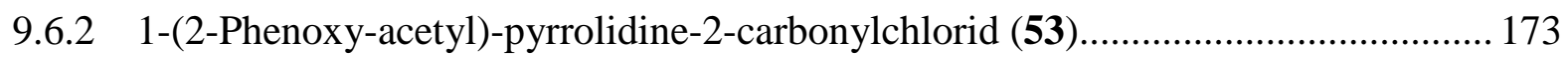

9.6.3 1-[1-(2-Phenoxy-acetyl)-pyrrolidine-2-carbonyl]-3-(1-phenyl-ethyl)-thioharnstoff (55)

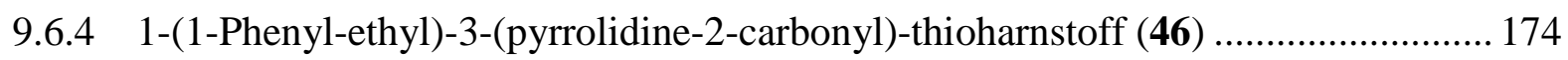

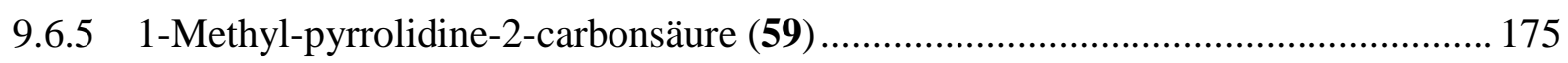

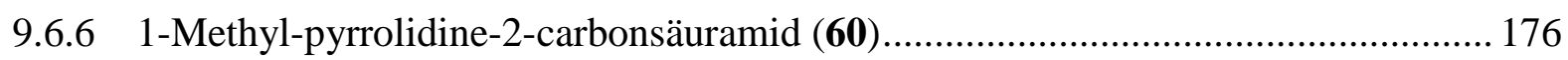

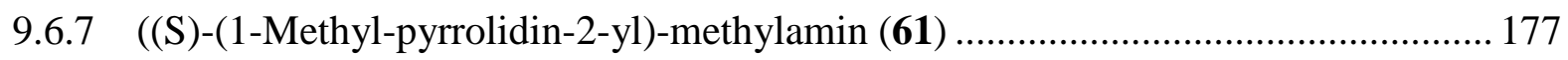

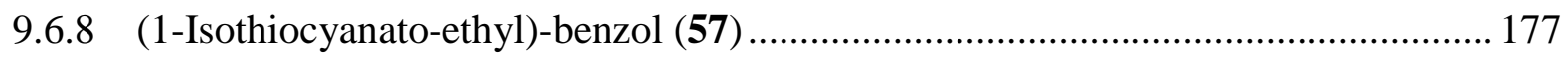

9.6.9 1-(1-Methyl-pyrrolidin-2-ylmethyl)-3-(1-phenyl-ethyl)-thioharnstoff (49) ............. 178

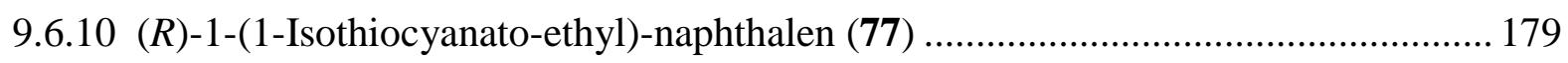

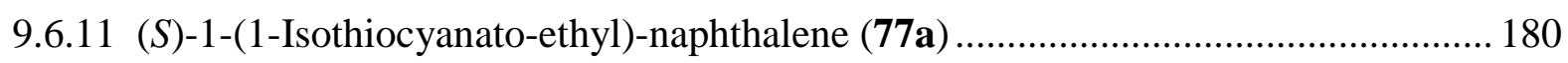

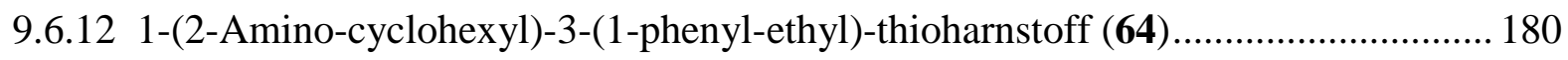

9.6.13 2-\{2-[3-(1-Phenyl-ethyl)-thioureido]-cyclohexylcarbamoyl\}-pyrrolidine-1-

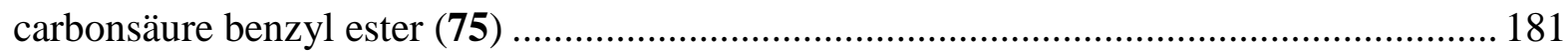

9.6.14 Pyrrolidine-2-carbonsäure\{2-[3-(1-phenyl-ethyl)-thioureido]-cyclohexyl\}amid (72)

9.6.15 1-(1-Phenyl-ethyl)-3-\{2-[3-(1-phenyl-ethyl)-thioureido]-cyclohexyl\}-thioharnstoff (47) .183

9.6.16 1-(2-Amino-cyclohexyl)-3-(1-naphthalen-1-yl-ethyl)-thiourea (73)........................ 184

9.6.17 1-(2-Amino-cyclohexyl)-3-(1-naphthalen-1-yl-ethyl)-thiourea (81)........................ 185

9.6.18 1-(2-Amino-cyclohexyl)-3-(1-naphthalen-1-yl-ethyl)-thiourea (82)........................ 185

9.6.19 1-(2-Amino-cyclohexyl)-3-(1-naphthalen-1-yl-ethyl)-thiourea (83)........................ 186

9.6.20 1-(2-Amino-1, 2-diphenyl-ethyl)-3-(1-naphthalen-1-yl-ethyl)-thiourea (74)........... 187

9.6.21 1-(2-Amino-1, 2-diphenyl-ethyl)-3-(1-naphthalen-1-yl-ethyl)-thiourea (79)........... 188

9.6.22 1-(2-Amino-1, 2-diphenyl-ethyl)-3-(1-naphthalen-1-yl-ethyl)-thiourea (80)........... 188

9.6.23 1-(2-Amino-1,2-diphenyl-ethyl)-3-(1-naphthalen-1-yl-ethyl)-thiourea (78)........... 189

\subsection{Allgemeine Methoden für Michael-Addition......................................................190}

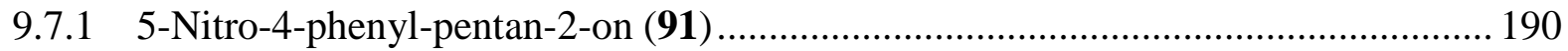

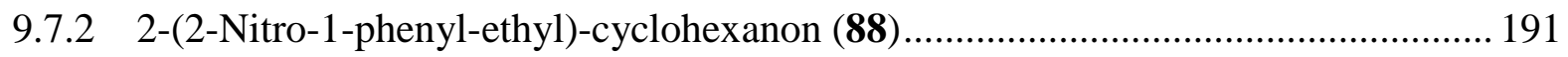

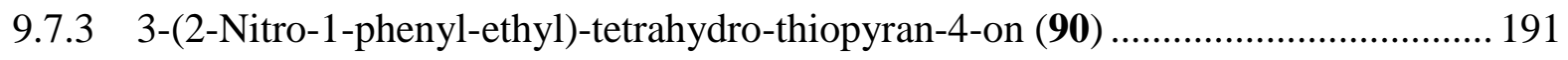

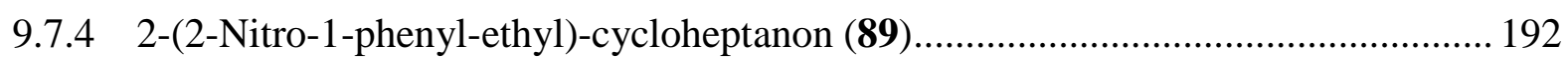

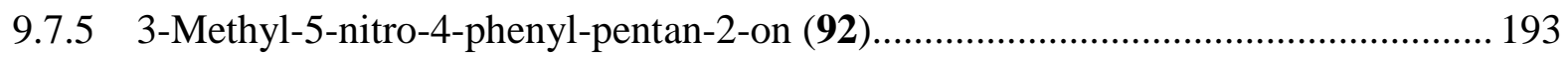




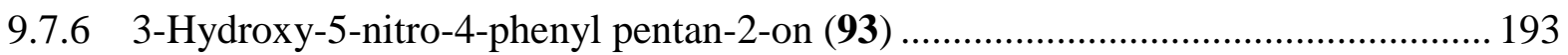

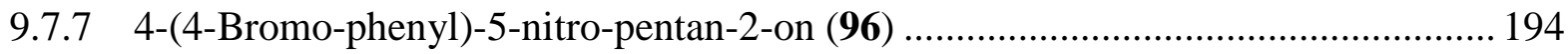

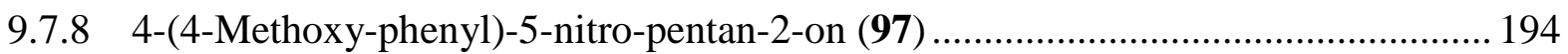

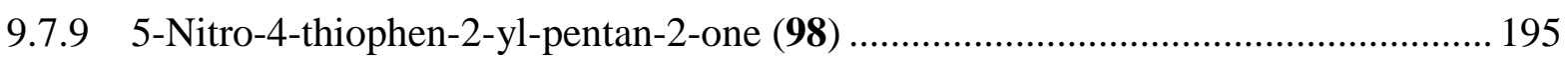

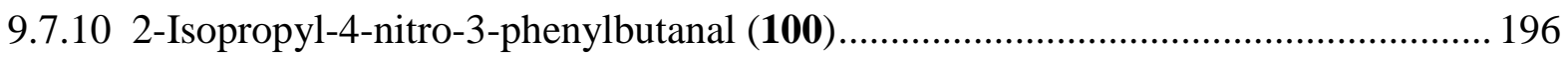

9.8 Allgemeine Methoden für autokatalytische Mannich Reaktionen ........................... 196

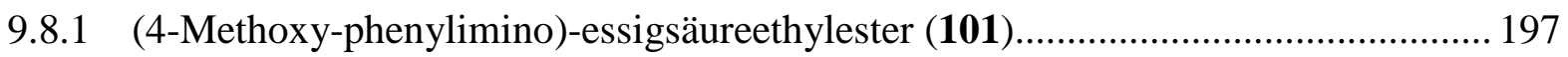

9.8.2 2-(4-Methoxy-phenylamino)-4-oxo-pentylsäureethylester (102) ............................ 197

9.9 Synthese von Hybride-Moleküle aus Naturstoffen........................................................ 199

9.9.1 ((1R,3aS,5aR,5bR,11aR)-icosahydro-9-hydroxy-5a,5b,8,8,11a-pentamethyl-1-(prop-

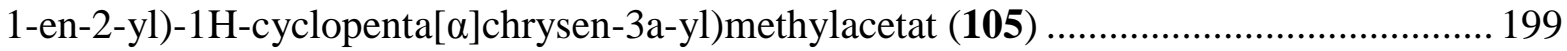

9.9.2 Verbindung 106 (Artesunat-Betulin-28-Acetet) .................................................. 200

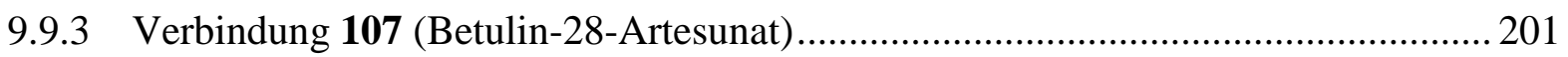

9.9.4 Synthese der Verbindung 108 (Artsunat-Betulin-Artesunat) ................................. 203

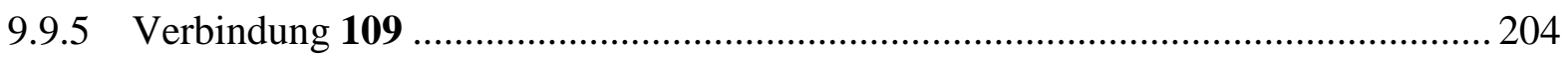

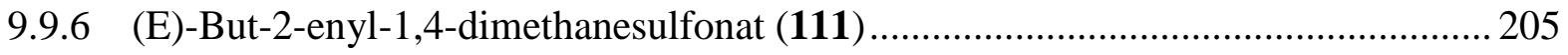

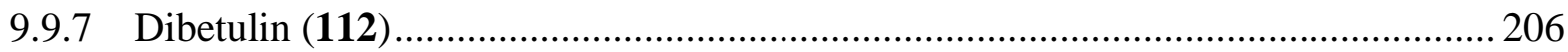

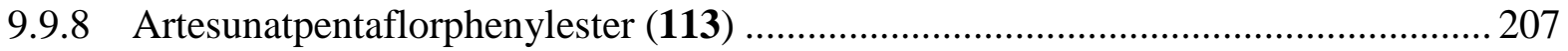

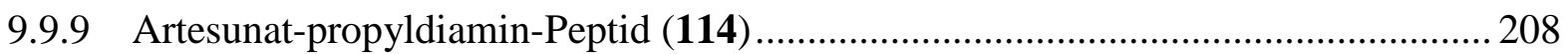

10 ABKÜRZUNGSVERZEICHNIS ............................................................. 209

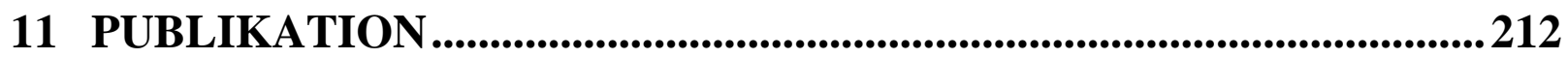

12 LITERATURVERZEICHNIS .........................................................213 


\section{Allgemeiner Teil}

\subsection{Bedeutung der Chiralität}

Objekte, die nicht mit ihrem Spiegelbild zur Deckung gebracht werden können, nennt man chiral (vom griechischen cheir, Hand). ${ }^{1}$

In der Chemie wird mit Chiralität des Moleküls die räumliche Anordnung von Atomen bezeichnet, bei denen bestimmte Symmetrieoperationen, die Spiegelung an einer Molekülebene, nicht $\mathrm{zu}$ einer Selbstabbildung führen. Z.B ein Kohlenstoffatom mit vier verschiedenen Substituenten stellt ein Stereozentrum dar, bei dem zwei verschiedene räumliche Anordnungen möglich sind. Das zentrale Kohlenstoffatom bezeichnet man als asymmetrisch und die Anordnung der Substituenten um das Zentralatom als Konfiguration. ${ }^{\text {a }}$ Neben dem Kohlenstoffatom sind auch andere Atome, zum Beispiel Phosphor und Stickstoff in der Lage, Stereozentren auszubilden. Die Hauptsache hierbei ist, dass die Substituenten ihre relative Lage zueinander nicht ändern können, was im Fall das Phosphor durch eine ausreichend große Inversionsbarriere gewährleistet sein kann. Beim Stickstoff und Phosphor als Chiralitätszentrum gilt das freie Elektronenpaar als vierter Substituent, dieser besitzt die niedrigste Priorität aller Substituenten. ${ }^{2}$

Beide unterscheidbaren spiegelbildlichen Formen eines chiralen Moleküls werden als Enantiomere bezeichnet. Die Enantiomere lassen sich durch ihre optische Aktivität der $R$-, $S$ Konfiguration zuordnen. Eine Mischung mit gleichen Anteilen beider Enatiomeren wird Racemat oder racemisches Gemisch genannt. Wenn Verbindungen mit zwei (allgemein n) asymmetrischen C-Atomen in vier $\left(2^{\mathrm{n}}\right)$ optisch aktiven Formen auftreten, haben diese also Enantiomerenpaare, beispielsweise die einfachste Zuckerverbindung $\mathrm{HOCH}_{2}-\mathrm{CHOH}-\mathrm{CHOH}-$ CHO (Tetrosen), hierbei sind (-)-und (+)-Erythrosen sowie (-)- und (+)-Threosen (Abb.1) ${ }^{1 \mathrm{~b}}$<smiles>O=C[C@H](O)[C@@H](O)CO</smiles>

$(R, R)-(-)$-Erythrose<smiles>O=C[C@H](O)[C@@H](O)CO</smiles>

$(S, S)$-(+)-Erythrose<smiles>O=C[C@H](O)[C@@H](O)CO</smiles><smiles>O=C[C@H](O)[C@@H](O)CO</smiles>

$(2 S, 3 R)-(-)$ Threose $\quad(2 R, 3 S)-(+)$ Threose

Abbildung 1. Chiralität am Beispiel der einfachsten Zuckerverbindungen

jeweils Spiegelbilder zueinander. Dagegen ist keine der Erythrosen Spiegelbild einer Threose. 
Stereoisomere, die sich nicht spiegelbildlich zueinander verhalten, nennt man Diastereomemere (Abb.1). Wenn ein Molekül mehrere Stereozentren aufweist, diese aber durch eine Spiegelung an einer Ebene ineinander übergeführt werden können, so ist das gesamte Molekül achiral, man spricht in diesem Fall von einer meso-Verbindung (z.B. meso-Weinsäure). ${ }^{1 \mathrm{~b}}$

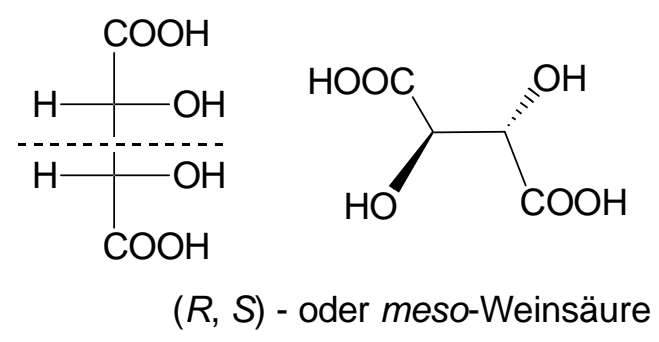

Abbildung 2. Beispiel einer meso-Verbindung.

Zucker und Aminosäuren werden heute noch nach der D- und L- Nomenklatur von Fischer benannt.

In der Natur gibt es große Menge chiraler Substanzen. Man fasst diese Substanzen in einer Gruppe zusammen, die als ,chiraler Pool” bezeichnet wird. Diese Substanzen liegen oftmals als reine Enantiomere vor. Beispielsweise stellt die Natur potentiell nur L-Aminosäuren und DZucker her. Die Chiralität wird in den aus den Molekülen zusammengesetzten Makromolekülen fortgesetzt (z. B. Peptide und Polysaccharide).

Bei genauer Betrachtung erkennt man, was für eine wichtige Bedeutung die Chiralität für die Biologie und Physiologie hat. Der Großteil der vorkommenden Stoffe im menschlichen Körper sind chirale Verbindungen. Diese Stoffe, z. B. Proteine, bestehen ausschließlich aus LAminosäuren und werden entweder durch Nahrung aufgenommen oder vom Körper selbst synthetisiert. Enzyme können nur D- aber nicht L-Glucose verwerten. Diese Eigenschaft spielt besonders in der Biochemie eine wichtige Rolle. Daraus ergeben sich auch für den Aufbau von DNA und RNA Konsequenzen, da Ribose und Desoxyribose aus D-Glucose synthetisiert werden.

Bei chemischen Reaktionen in biologischen Prozessen müssen die beteiligten Moleküle einander mit hoher Unterscheidungsfähigkeit erkennen. Weil die entscheidenden Strukturen wie Enzyme chiral sind, ist eine angemessene chirale Passform deshalb unerlässlich. Durch Abweichung erfolgt eine verminderte, fehlende oder sogar entgegengesetzte Wirksamkeit. ${ }^{2 \mathrm{c}}$ 
Die Chiralität ist besonders bei der Entwicklung von Arzneimitteln, die überwiegend als Stereoisomere vorkommen, von wichtiger Bedeutung. Denn die einzelnen Enantiomerere können unterschiedliche Wirkungen und auch Nebenwirkungen haben. Deshalb gewinnen enentiomerenreine Wirkstoffe in der pharmazeutischen Forschung immer mehr an Bedeutung. Seit etwa zwanzig Jahren konzentriert sich die Entwicklung chiraler Arzneimittel zunehmend auf einzelne Stereoisomere. ${ }^{2}$

Eine der wichtigsten Voraussetzungen ist es, stereochemisch reine und definierte Verbindungen zu synthetisieren. Die Unterschiede in der biologischen Aktivität zahlreicher optischer Isomere sind gut dokumentiert (vgl. Abb. 3). ${ }^{2-4}$<smiles>CC(C)NC[C@H](O)COc1cccc2ccccc12</smiles>

(R)-Propranolol

kontrazeptiv und Blutdruck-senkend ${ }^{3,4}$<smiles>O=C1CC[C](N2C(=O)c3ccccc3C2=O)C(=O)N1</smiles>

$(R)$-Thalidomid

nicht teratogen ${ }^{2,4}$<smiles>O=C(N[C@H](CO)[C@H](O)c1ccc([N+](=O)[O-])cc1)C(Cl)Cl</smiles>

$(R, R)$ - Chloramphenicol antibakteriell $^{3,4}$<smiles>CC(C)NC[C@H](O)COc1cccc2ccccc12</smiles>

(S)-Propranolol

anti-arrhythmisch ${ }^{3,4}$<smiles>O=C1CC[C@H](N2C(=O)c3ccccc3C2=O)C(=O)N1</smiles>

(S) -Thalidomid

extrem teratogen ${ }^{2,4}$<smiles>O=[N+]([O-])c1ccc(C(CO)CO)cc1</smiles>

(S,S) - Chloramphenicol

inaktiv $^{3,4}$ 
<smiles>CC[C@H](CO)NCCN[C@H](CC)CO</smiles>

$(R, R)$ - Ethambutol

verursacht Blindheit ${ }^{3,4}$<smiles>CC[C@H](CO)NCCN[C@H](CC)CO</smiles>

$(S, S)$ - Ethambutol

tuberkulostatisch ${ }^{3,4}$

Abbildung 3. Biologische aktive Verbindungen, deren Enantiomere unterschiedliche Wirkung haben

\subsection{Klassifizierung der Methoden zur Enatiomerengewinnung}

Es ist heutzutage völlig klar, dass optische Isomere der pharmakologisch aktiven Verbindungen sehr unterschiedliche Eigenschaften in Bezug auf ihre physiologische Aktivität, ihren Wirkungsmenchanismus, ihre Toxizität und Nebenwirkungen haben können. Deshalb wird es von Produzenten immer mehr verlangt, dass die optischen Isomere so rein herzustellen sind, dass die unerwünschten Nebenwirkungen in den Arzneimitteln festgestellt werden können.

Die enantiomerenreinen Arzneistoffe können aus dem chiral Pool der Natur gewonnen oder aus Naturstoffen isoliert werden. Eine racemische Synthese mit anschließender Trennung der Enantiomere ist eine weitere Möglichkeit, steroisomerenreine Produkte zu gewinnen. Zusammenfassend kann man folgende Methoden zur Enationmerengewinnung klassifizieren. ${ }^{5}$

\subsubsection{Trennung von Enantiomeren (Racematspaltung)}

a. Mechanische Enantiomerentrennung: Die beiden Enantiomere bilden unterschiedliche (spiegelsymmetrische) Kristalle, welche manuell ausgelesen werden können.

Dem französischen Wissenschaftler und Pionier auf dem Gebiet der Mikrobiologie, Louis Pasteur, gelang im Jahr 1848 die Racematspaltung für die Enantiomere eines Salzes der D- und L-Weinsäure. Sie unterschieden sich für ihn lediglich darin, dass ihre Kristalle spiegelbildlich aufgebaut waren. Nach sorgfältiger Kristallisation konnte er die verschiedenen Kristalle manuell trennen und er leitete damit die Erforschung der Enantiomere ein. Auch bei der Zusammenführung von optischer Aktivität einer Substanz und der absoluten Konfiguration der Moleküle durch Bijvoet spielte Weinsäure eine wichtige Rolle. ${ }^{6}$ 
b. Racematspaltung nach Überführen in Diastereoisomere: Durch Salzbildung mit einer chiralen Säure oder Base entstehen Diastereomere, welche aufgrund über unterschiedlichen physikalischen und chemischen Eigenschaften getrennt werden können. Anschließend wird die Säure oder Base freigesetzt. Es lässt sich durch folgendes Schema 1 eine fraktionierte Kristallisation verdeutlichen. ${ }^{7}$

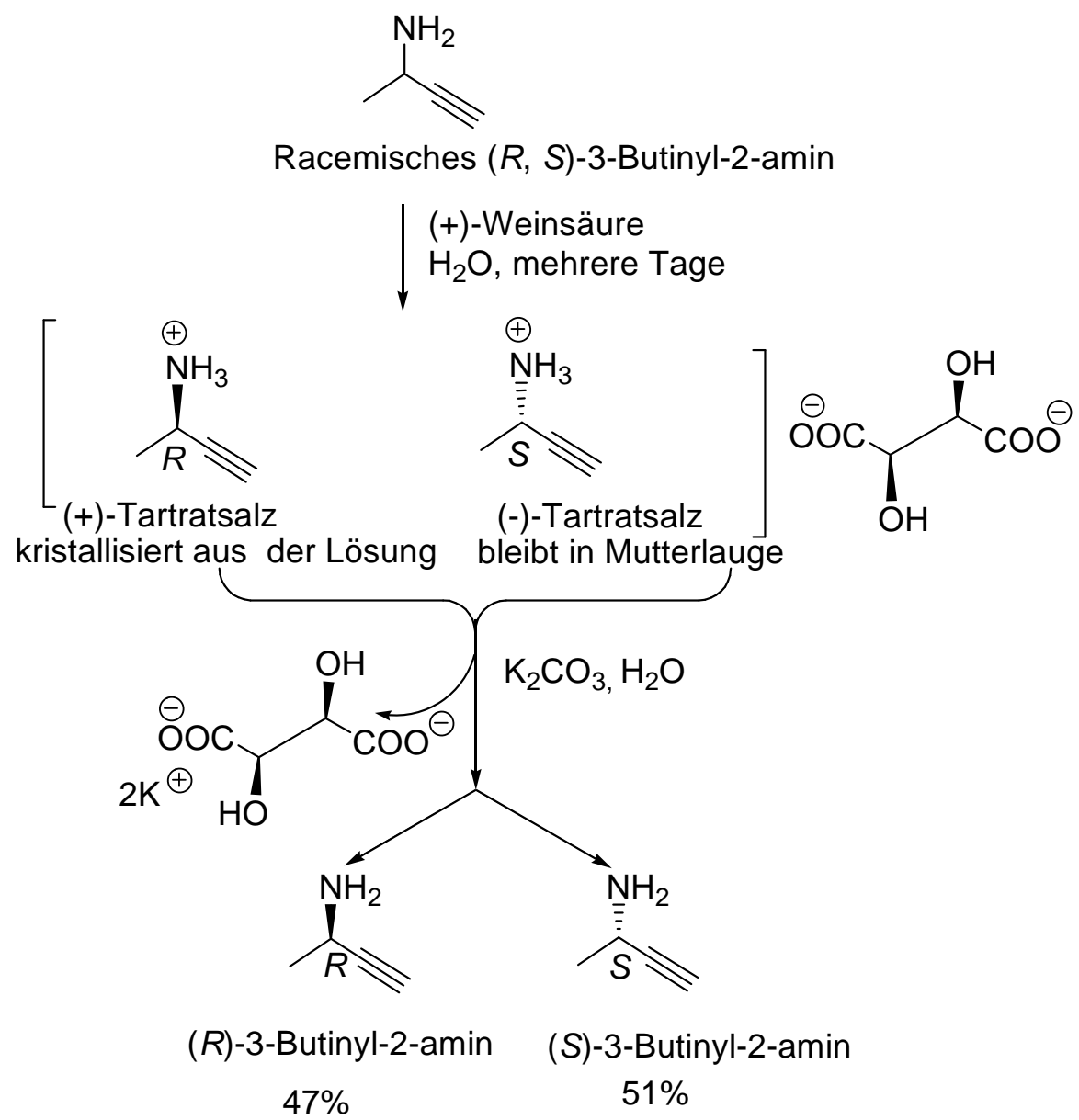

Schema 1. Racematspaltung von rac-3-Butinyl-2-amin mit (+)-Weinsäure

In diesem Beispiel lässt sich durch eine Behandlung mit (+)-Weinsäure gezielt ein Diasteromer als

Salz ((+)-Tartratsalz) (Schema 1) auskristallisieren und das andere (-)-Tartratsalz (Schema 1) verbleibt in der Mutterlauge. Nach Filtration und Behandelung mit einer $\mathrm{K}_{2} \mathrm{CO}_{3}$-Lösung erfolgt eine optimale Trennung der Diastereomere. Die als enantiomerenreine Komponente eingesetzte (+)-Weinsäure wird nach der Filtration von den beiden abgespalteten Enatiomeren abgetrennt. Man erhält dann zwei enantiomerenreine Verbindungen. 
Kovalente Derivatisierung mit chiralen Reagenzien führt auch zu Diastereoisomeren. Die entstande Verbindungen werden ebenfalls aufgrund der unterschiedlichen physikalischen und chemischen Eigenschaften voneinander getrennt. Danach wird das Derivat abgespalten. Bei der Komplexbildung mit chiralen Partnern entstehen je nach Enantiomer unterschiedliche stabile Komplexe. Die Trennung erfolgt chromatographisch durch GC, HPLC oder DC, wobei der chirale Komplexbildungspartner die stationäre Phase bildet.

c. Biochemische Racemattrennung: Da viele Enzyme Substrate enantioselektiv umsetzen, werden Mikroorganismen eingesetzt, welche das eine Enantiomer zersetzen; das erwünschte Enantiomer bleibt dann erhalten.

d. Kinetische Enantiomerentrennung: Enantiomere reagieren mit chiralen Reaktionspartnern mit unterschiedlicher Reaktionsgeschwindigkeit. Die Reaktion wird abgebrochen, wenn das eine Enantiomer umgesetzt ist.

\subsubsection{Synthese enantiomerenreiner Verbindungen}

Enantiomerenreine Verbindungen kann man auch durch synthetische Methoden erhalten, hierbei wird ein achirales oder prochirales Molekül durch eine chemische Reaktion in ein chirales Molekül überführt. Es werden ungleiche Mengen von beiden Enantiomeren oder Diastereomeren produziert. Bei der asymmetrischen Synthese sollte man diese unter dem Aspekt der eingesetzten Menge betrachten. Bei der Umsetzung von achiralen Ausgangsprodukten mit chiralen Reagenzien und Auxiliaren werden gleiche molare Mengen der Ausgangsprodukte verwendet. Der Vorteil dieser Vorgehensweise liegt im großen Anwendungsbereich und der Flexibilität der Substrate und Produkte. Das asymmetrische synthetische Verfahren lässt sich durch Folgendes verdeutlichen:

\subsubsection{Synthese durch chirale Substrate}

a. Synthese mit chiralen Auxiliaren (reagenzkontrolliert): ${ }^{6}$ Durch die Anwendung eines chiralen Auxiliars kann der Verlauf einer nicht stereoselektiven Reaktion so gesteuert werden, dass nach Abspaltung des Auxiliars dennoch bevorzugt ein Enantiomer erhalten wird. Ein chirales Auxiliar wird an die Substanz kovalent gebunden und bildet eine chirale Zwischenstufe. Diese 
Zwischenstufe reagiert mit einem weiteren Partner, wobei das Auxiliar die Diatereoselektivität der Reaktion bedingt und anschließend abgespaltet wird. Es ist auch möglich, ein chirales Reagenz mit einem achiralen Substrat zu einem chiralen Produkt reagieren zu lassen.

Eines der bekanntesten Beispiele eines chiralen Auxiliars ist das Evans-Auxiliar (ein chirales Oxazolidinon). ${ }^{6 \mathrm{~d}}$ Evans-Auxiliare leiten sich von den entsprechenden Aminosäuren (Schema 2) ab. Diese werden zuerst zum Aminoalkohol reduziert und anschließend zum Oxazolidinon kondensiert.
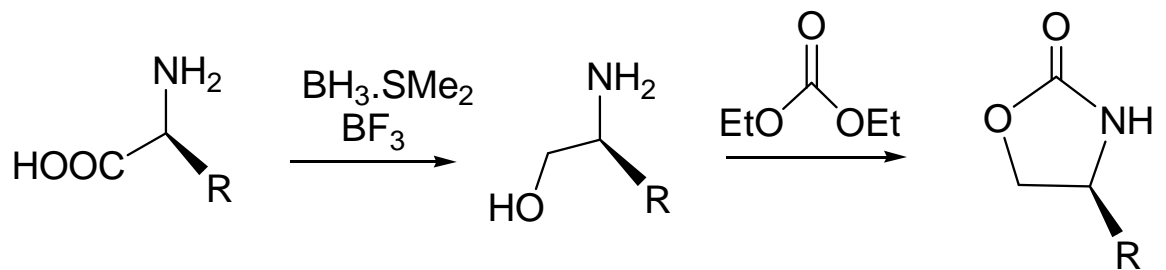

Schema 2. Darstellung von Evans-Auxiliaren.

Ohne die Anwendung eines Auxiliars erfolgt der Angriff eines Elektrophils, beispielsweise Methyliodid, auf ein Enolat unselektiv von beiden Seiten der Doppelbindung, wodurch beide Enantiomere im gleichen Verhältnis (racemisch) gebildet werden (Schema 3). Durch die stärkere Base LDA wird Edukt deprotoniert, dabei bildet sich das Enolat. Ein weiterer nucleophiler Angriff von Enolat an Methyliodid führt dazu, dass ohne räumliche Hinderung am Enolat durch ein chirales Auxiliar, Nucleophil von beiden Seiten substituieren kann. Es bildet sich deswegen ein racemisches Produkt.

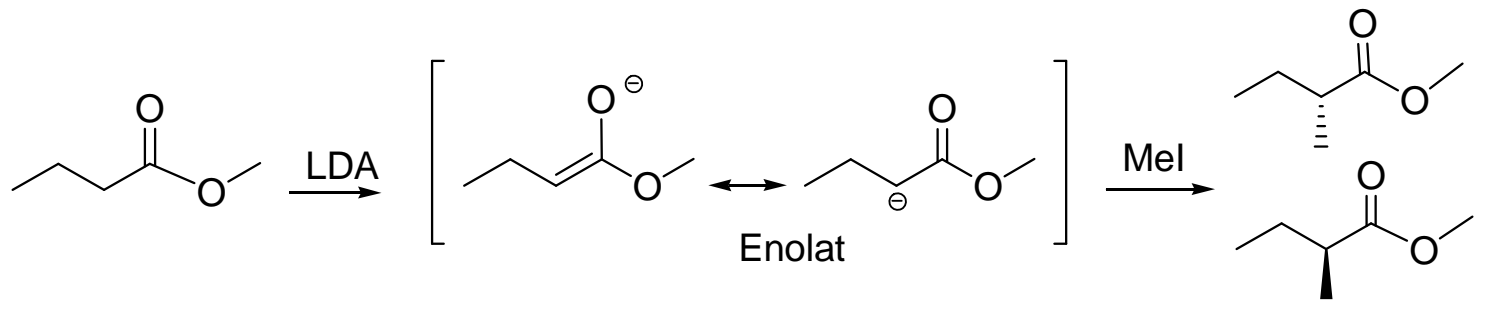

Schema 3. Ohne die Anwendung eines Auxiliars bei der Methylierung

Verwendet man jedoch statt des Methylesters das Evans-Auxiliar (Schema 4), das über eine Amid-Bindung an das Molekül gebunden ist, bildet sich mithilfe der stärkeren Base LDA ein chiralen Enolat Anordnung, sodass der Angriff von der sterisch weniger gehinderten Seite des Moleküls erfolgt. Durch das Stereozentrum im Auxiliar erfolgt die Reaktion jetzt diastereoselektiv. Die Vorderseite des Z-Enolats wird durch den Substituenten des Evans- 
Auxiliars abgeschirmt, sodass der Angriff von Methyliodid jedoch nur von der Unterseite des Enolates wahrscheinlich ist, So kann ein optisch hochreines Produkt erhalten werden. Nach der Abspaltung des Auxiliars erhält man das gewünschte enantiomere Produkt (ee > 95\%). Die sterische Information ist hier aber vom Evans-Auxiliar zu Produkt übertragen worden.

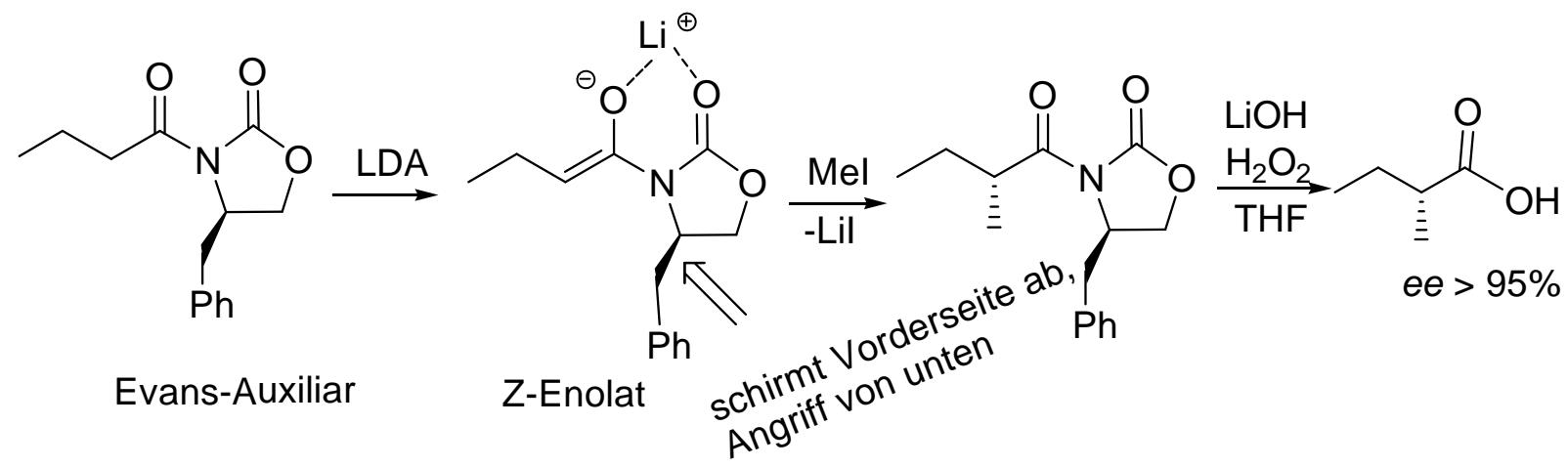

Schema 4. Anwendung des Evans-Auxiliars bei der Methylierung von Enolaten

b. Bausteinsynthese (Substratkontrolliert): Hier geht die Synthese von nachwachsenden chiralen Naturstoffen aus, eine Vielzahl von preiswerten optisch aktiven Ausgangsverbindungen wird von der Natur in großen Mengen angeboten. Diese Startmaterialien werden unter Erhaltung der Stereochemie modifiziert. ${ }^{7,8}$

Verbindungen direkt aus dem chiralen Pool sind sehr preiswerte Bausteine, sie können gut stöchiometrisch eingesetzt werden und eine Racemisierung ausschließen. So lassen sich Chiralitätszentren in bestehende Verbindungen einführen, oder die chiralen Bausteine können zu Reagenzien zweiter Klasse modifiziert werden.

Beispielsweise kann Zuckeralkohol Mannit als Baustein für die Synthese eines Tetraols dienen (Schema 5). Nachdem Mannit in das Diacetonid überführt worden ist, werden die beiden ungeschützten Alkoholfunktionen zuerst in das Mesylat umgewandelt, welches dann eine Eliminierung eingeht, wobei sich eine Doppelbindung im Diacetonid bildet. Nach Hydrierung der Doppelbindung und anschließender Entschützung der beiden Acetale entsteht das Tetraol. Die Chiralitätszentren von $\mathrm{C}_{2}$ und $\mathrm{C}_{5}$ bleiben also in ihrer Konfiguration erhalten, weil sie vorher durch Ketalisierung geschützt wurden. 


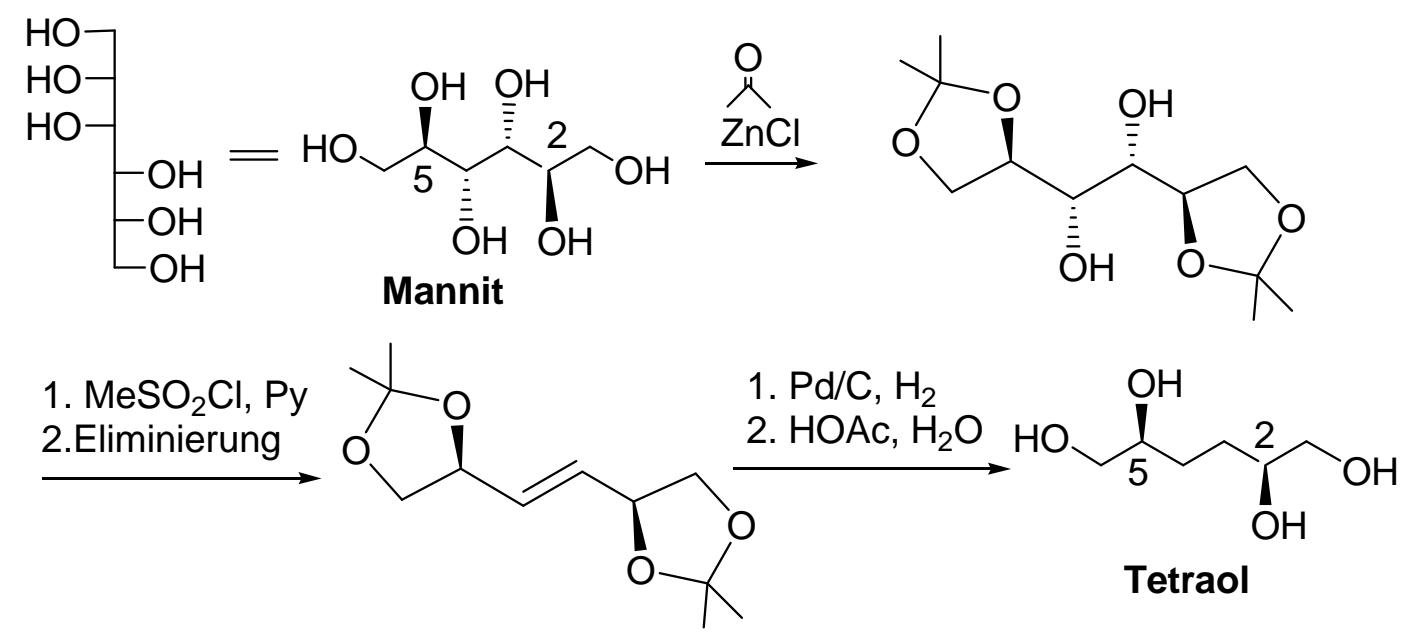

Schema 5. Beispiel zur Bausteinsynthese mit dem Naturstoff-Mannit. ${ }^{9}$

\subsubsection{Katalytische Verfahren}

a. Synthetische Katalysatoren: In der industriellen Synthese werden zunehmend Metallkatalysatoren mit chiralen Liganden eingesetzt. Die chirale Information wird aus den enantiomerenreinen Liganden bezogen. Eine im großen technischen Maßstab genutzte Reaktion ist der MONSANTO-Prozess für die L-DOPA-Herstellung. Dabei wird bei einem katalytischen Zwischenschritt ein asymmetrischer Rhodiumkatalysator eingesetzt, um ein chirales ZwischenProdukt zu gewinnen.

b. Enzyme: Enzyme setzen mit hoher Selektivität nur ein Enantiomer um. Ihr Nachteil liegt vor allem in den eingeschränkten Anwendungsmöglichkeiten, denn sie reagieren nur mit dem komplementären Substrat und unter annähernd physiologischen Reaktionsbedingungen. Enzyme spielen eine tragende Rolle im Stoffwechsel aller lebenden Organismen und sind spezifisch für bestimmte Enantiomere, da das aktive Zentrum eines Enzyms vielfach das eine Enantiomer leichter aufnehmen kann als das andere (das so genannte Schlüssel-Schloss-Prinzip, Substratspezifität). Daher sind viele natürlich vorkommende chirale Stoffe keine Racemate. Die Biosynthese führt überwiegend oder ausschließlich zu einem Enantiomer. Beispielsweise sind fast alle Aminosäuren in Lebewesen mit L-Konfiguration.

Um großen Menge eines chiralen Produktes zu erhalten, muss man Enzyme oder chirale Übergangsmetallkatalysatoren einsetzen. Der Nachteil ist der hohe Preis einiger Katalysatoren oder Enzyme und ihrer Cofaktoren und die Toxizität einiger Übergangsmetalle. 


\subsection{Asymmetrische Synthese}

\subsubsection{Asymmetrische Synthese mithilfe des Chiral Pools}

Durch die Racematspaltung eines Salzes der Para-Weinsäure entdeckte und legte Pasteur die Grundlagen der Stereochemie. ${ }^{6}$ Bei der asymmetrischen Synthese wird ein achirales- oder prochirales Molekül durch eine chemische Reaktion in ein chirales Molekül überführt. Die beiden Enantiomere oder Diastereomere entstehen in ungleichen Mengen. Als Maß für den Erfolg der asymmetrischen Synthese wird der Enantiomeren- bzw. Diastereomereüberschuß angegeben. ${ }^{10} R$ und $S$ beziehen sich auf den prozentualen Anteil der jeweiligen Stereoisomere.

$$
e e(\%)=|(R-S)| /(R+S) * 100
$$

Die asymmetrische Synthese, ausgehend von enantiomerenreinen Naturstoffen (z.B Aminosäuren, Kohlenhydraten, Alkaloiden usw.) aus dem „Chiral Pool “, die Herstellung durch gezielte Synthese oder über enzymatische Prozesse ist eine klassische Methode.

Bei einer Anwendung von Menthon als Auxiliar hat Spino ein quartäres Stereozentrum durch $\mathrm{S}_{\mathrm{N}} 2^{1}$-Reaktion aufgebaut (Schema 6). ${ }^{10}$

Nach der Modifizierung von Menton (Schema 6) mittels einer Wittig-Reaktion lässt es sich als chirales Auxiliar einsetzen.<smiles>CC(C)C1CC[C@@H](C(C)C)CC1=O</smiles><smiles>COC[Pb](Cl)(Cl)c1ccccc1</smiles>
2. $\mathrm{HCl} / \mathrm{CHCl}_{3}$ Menton

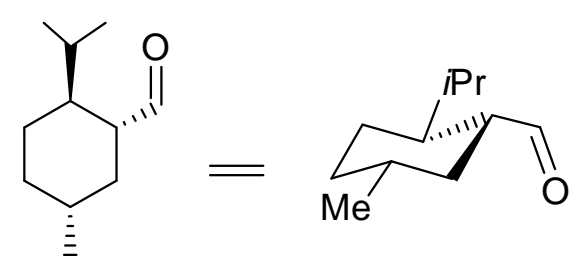

Auxiliar

Schema 6. Synthese des chiralen Auxiliars aus Menton

Aluminiumhaltiges Alken wird aus ein Alkin durch eine Carboaluminierung durchgeführt. Diese metallorganische Spezies wird durch vorher dargestelltes chirales Auxiliar (Schema 7) diastereoselektiv zum Alkohol umgesetzt. 

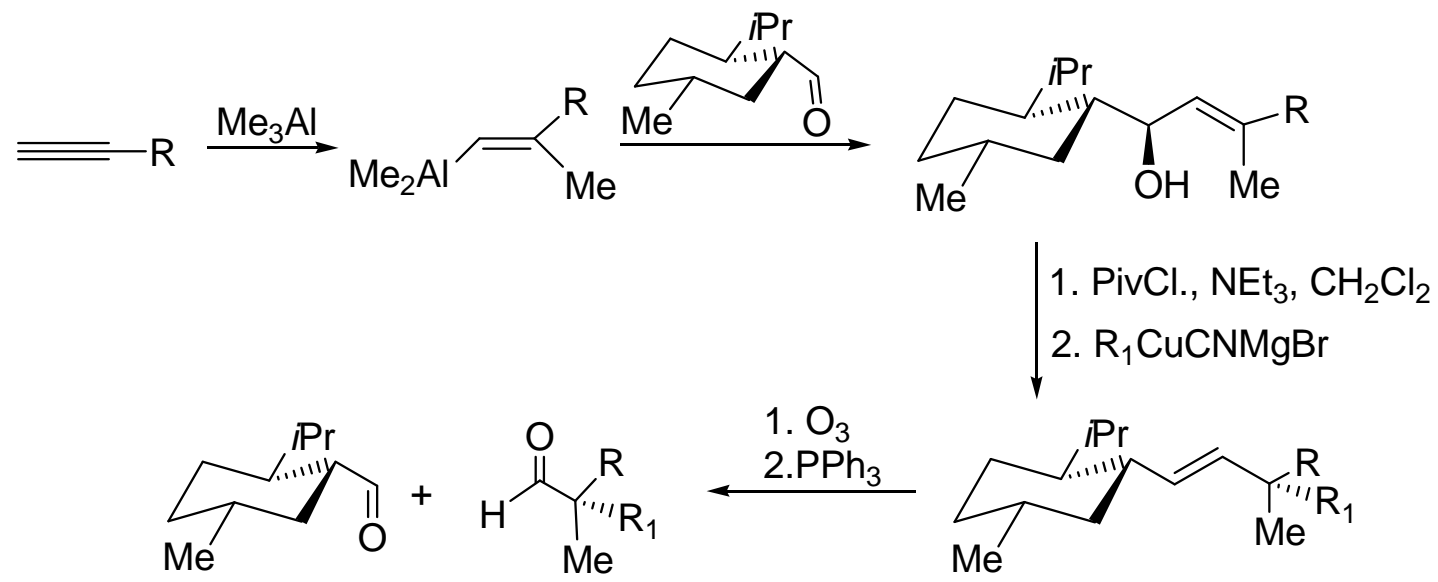

Schema 7. Aufbau eines quartären Stereozentrums mittels $\mathrm{S}_{\mathrm{N}} 2^{1}$-reaktion nach Spino durch ein chirales Auxiliar ${ }^{10}$

Hier wird durch Verwendung des chiralen Auxiliars die Diastereoselektivität gesichert. Die Hydoxyl-Gruppe kann nach Umsetzung mit PivCl und mit einem Cuprat (Schema 7) in einer $\mathrm{S}_{\mathrm{N}} 2^{1}$ Reaktion umgesetzt werden. Das gebildete Verbindung enthält nun das quartäre Stereozentrum. Durch die sterische Anordnung des Auxiliars wird der Angriff so ermöglicht, dass sich das Nucleophil nur in anti-Position zur Hydoxyl-Gruppe annähern kann. Das chirale Auxiliar wird durch Ozonolyse wieder reagiert und das gewüschte Produkt enantioselektiv erhalten.

Das in der Natur vorkommende L-Prolin hat sich beispielsweise als effizienter Katalysator für die Aldol-Reaktion und verwandte Reaktionen wie Mannich- oder Michael-Reaktionen bewährt (Schema 8). Es wird postuliert, dass hierbei als zentrales Intermediat ein Enamin gebildet wird, welches aufgrund einer dirigierenden Wasserstoffbrückenbildung seitenselektiv nucleophil angreifen kann. ${ }^{11}$

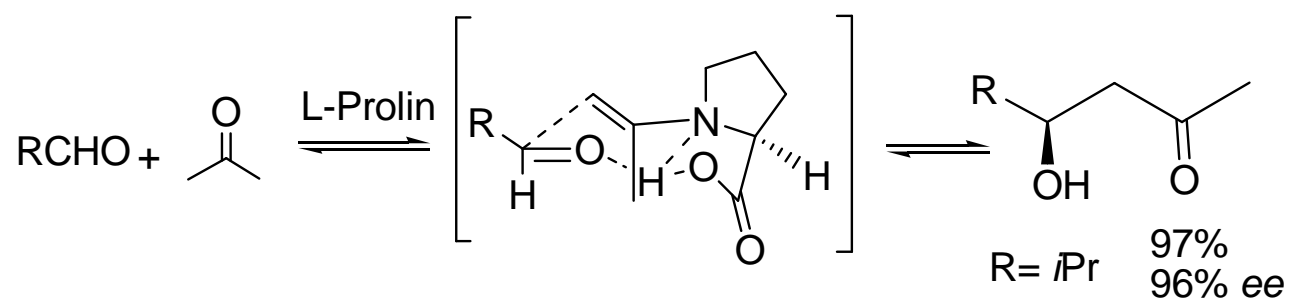

Schema 8. Intermolekulare asymmetrische Aldol-Reaktion mit L-Prolin als Katalysator 
Die in der Natur vorkommenden Alkaloide Chinin und Chinidin (China-Alkaloide) (Abb.4) und davon abgeleitete chirale Substanzen haben in asymmetrischen katalytischen Reaktionen zu beeindruckenden Ergebnissen geführt. ${ }^{12}$

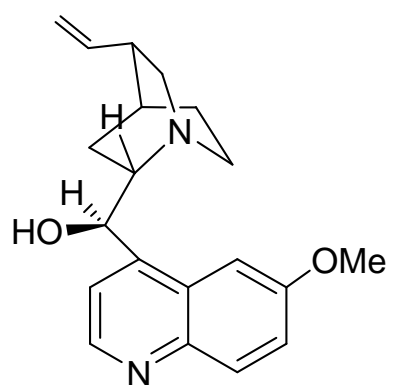

[(-)-Chinin]<smiles>C=CC1CC2CN(C1)CC2[C@H](O)c1ccnc2ccc(OC)cc12</smiles>

[(+)-Chinidin]

\section{Abbildung 4. Struktur von Chinin und Chinidin}

Typischerweise kann die einfache nucleophile und sterisch wenig gehinderte Base 1,4-Diazabicyclo[2.2.2] octan (DABCO) (Schema 9) die Reaktion von Aldehyden mit elektronenarmen Alkennen (Baylis-Hillman-Reaktion) katalysieren. ${ }^{13}$ Folgende hydroxyl chirale Amine (Schema 9) als Katalysator, eine von China-Alkaloiden abgeleitet sind, können effizient die asymmetrische Baylis-Hillman-Reaktion katalysieren (Schema 9). ${ }^{14}$

Die Reaktion lässt sich sowohl auf aromatische als auch aliphatische Aldehyde anwenden und liefert hohe Enantioselektivitäten. Die Selektivität kann durch die Bildung eines Intermadiats (I) (Schema 9) erklärt werden, das durch intramolekulare Wasserstoffbrückenbindungen zwischen dem negativ geladenen Sauerstoff und der phenolischen Hydoxy-Gruppe stabilisiert wird. Dieses Intermediat stabilisiert den aktivierten Komplex und erhöht die Selektivität. ${ }^{15}$ In diesem Fall ist die Konformation fast ideal für eine folgende Eliminierung, die für die Regenerierung des Katalysators verantwortlich ist. 

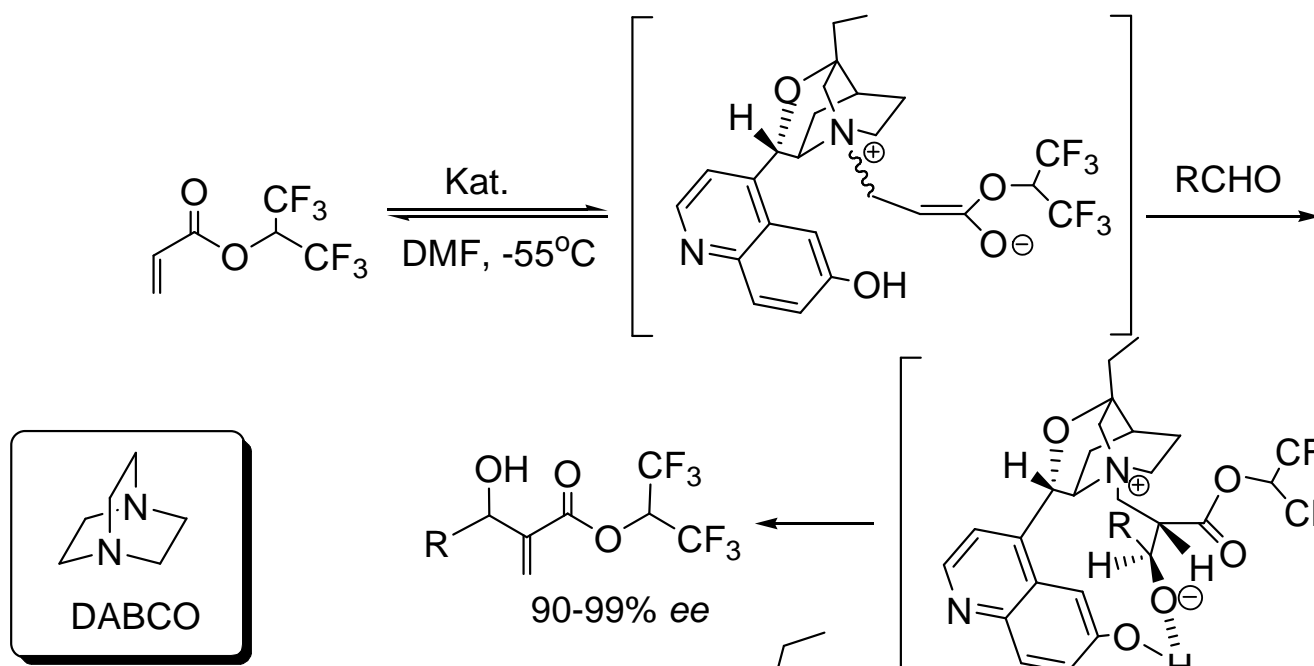<smiles>[R]C(O)C(=O)C(=O)OC(C(F)(F)F)C(F)(F)F</smiles>

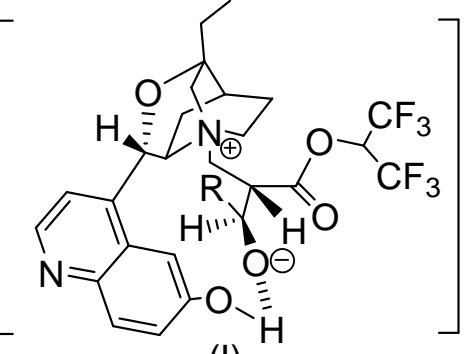

(I)

Schema 9. Die durch das China-Alkaloid-Derivat katalysierte asymmetrische Baylis-HillmanReaktionen

\subsubsection{Asymmetrische Katalysatoren}

Bis vor relativ kurzer Zeit beschränkten sich die chiralen Verbindungen hauptsächlich auf in der Natur vorkommende Strukturen. Heute wird diese große Vielfalt nicht nur durch natürliche Startmaterialien ergänzt, sondern auch mithilfe der asymmetrischen Synthese durch chirale Katalysatoren.

Die asymmetrischen Katalysatoren spielen eine wichtige Rolle bei der asymmetrischen Synthese. Der Zusatz von Katalysatoren ist auf kleine Mengen beschränkt, aber mit deren Mithilfe können stereogene Zentren oder Elemente in nicht-racemischer Form erzeugt werden. Die Entwicklung der homogenen enantioselektiven metallorganischen Katalysatoren hat einen entscheidenden Einfluss auf die Entwicklung der enantioselektiven organokatalytischen Reaktionen.

Im Jahr 1986 wurde ein chirales rhodiumhaltiges Molekül, das asymmetrische Hydrierungen katalysieren kann, vom US-Chemiker William S. Knowels entdeckt. Für die weitere Verwendung hat er rasch eine industrielle Synthese der Aminosäure L-DOPA (Schema 10), die 
sich für die Behandlung der Parkinson-Krankheit als nützlich erwiesen hat, entwickelt. Es war die erste industrielle katalytische asymmetrische Synthese. ${ }^{16}$

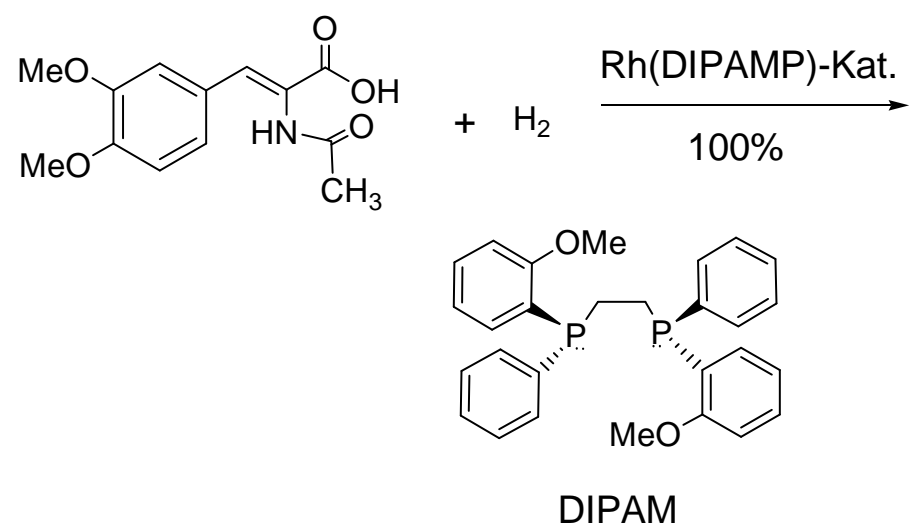<smiles>COc1ccc(C[C@H](NC(C)=O)C(=O)O)cc1OC</smiles>
$97.5 \%$ ee<smiles>COc1ccc(C[C@H](N)C(=O)O)cc1OC</smiles>

L-DOPA

$((S)$-DOPA)

Schema 10. Erste industriell verwendete katalytische asymmetrische Synthese der Aminosäure L-DOPA

Ryoji Noyori erkannte den Bedarf an selektiveren Katalysatoren mit einem breiteren Anwendungsbereich. Unter anderem entwickelte er den Katalysator Ru-BINAP, der zur Synthese von $(R)$-1,2-Propandiol eingesetzt wird. Einen Ausgangsstoff für die Herstellung des Antibiotikums Levofloxacin. Noyoris Katalysatoren finden große Anwendung in der Synthese von Feinchemikalien, pharmazeutischen Produkten und hoch entwickelten Materialien. ${ }^{16}$

Ryoji Noyori verbesserte die Systeme von Knowles und entwickelte an der Universität Nagoya Katalysatoren, mit denen an viele verschiedene Moleküle zwei Wasserstoffatome spezifisch in einer bestimmten räumliche Anordnung angelagert werden können. Seine RutheniumReaktionsbeschleuniger werden heute in der Synthese von vielen Substanzen, beispielsweise von Antibiotika, verwendet (Schema 11). ${ }^{17}$

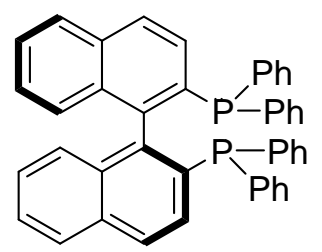

( $S$ )-BINAP

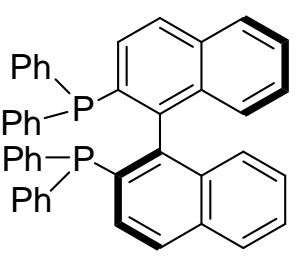

( $R$ )-BINAP

Abbildung 5. Die Struktur von $(S)-$; (R) -BINAP 
<smiles>COC(=O)C(CNC(=O)OCc1ccccc1)C(C)=O</smiles><smiles>COC(=O)[C@H](CNC(=O)OCc1ccccc1)[C@@H](C)O</smiles>

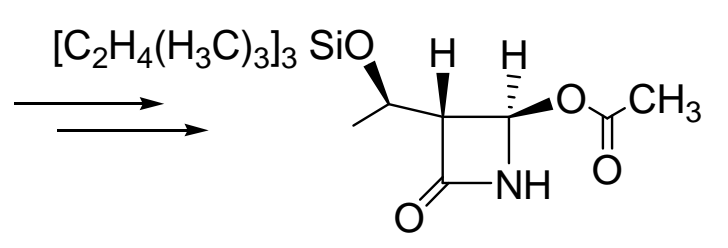<smiles>[R5]C1=C(C(=O)O)N2C(=O)[C@H]([C@@H](O)CC#CC)[C@H]2C1</smiles>

Schema 11. Stereoslektive Synthese von Carbapenem-Antibiotika mit einem Ru-BINAPKomplex

K. Barry Sharpless hat zu den Fortschritten der katalytischen Hydrierung der chiralen Synthese eine weitere Reaktionsart hinzugefügt. Ihm ist es als Erstem gelungen, Moleküle asymmetrisch zu oxidieren. Außerdem machte er viele wichtige Entdeckungen, darunter die katalytische asymmetrische Epoxidierung (Schema 12) durch einen chiralen, titanhaltigen Komplex. Epoxide sind wichtige Zwischenprodukte für eine ganze Synthesereihe, sowie die Herstellung von Blutdruck senkenden Wirkstoffen. Nach seiner Methode werden auch Herzmedikamente, so genannte Beta-Blocker hergestellt. ${ }^{18}$

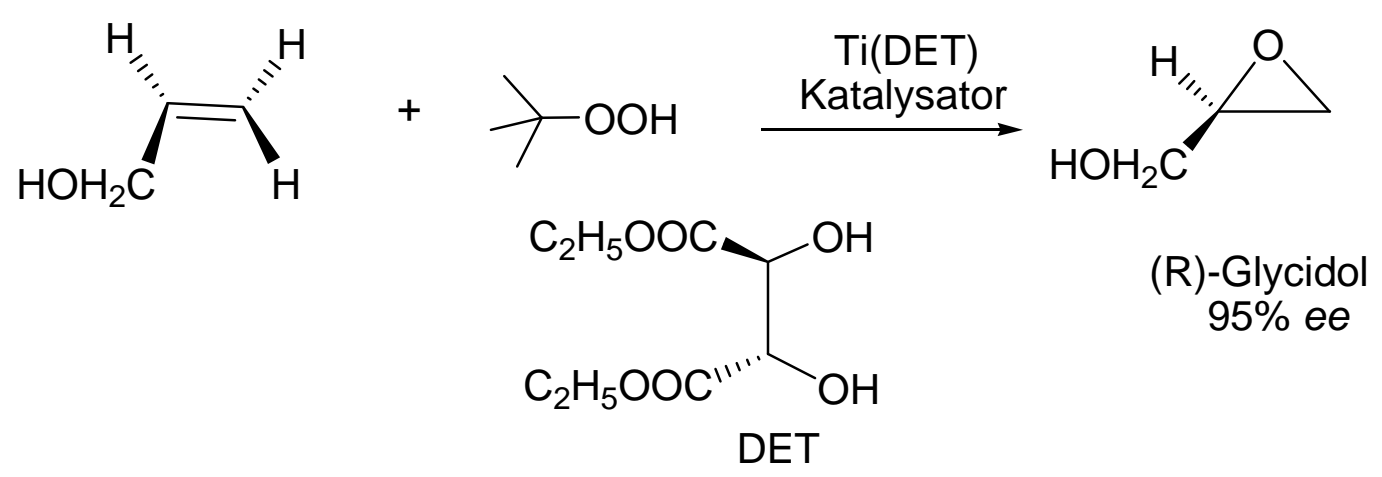

Schema 12. Epoxidierung durch Sharpless-Katalysator 
Sind aber Metalle wirklich für diese katalytischen Prozesse unerlässlich? Oder können einige ihrer Funktionen von einem Kohlenstoffsystem übernommen werden? Im Unterschied zu den meisten Synthesemethoden besteht in der Natur eine feine Balance zwischen metallfreien und metallvermittelten Prozessen. Metalle haben erhebliche Vorteile gegenüber organischen Substanzen wie eine höhere molekulare und strukturelle Derivation und sehr verschiedene Reaktivitäten, die leicht durch unterschiedliche Liganden kontrolliert werden können. Neben den beachtlichen Vorteilen haben Metallderivate aber auch Nachteile wie einen hohen Preis und Toxität, Umweltverschmutzung, komplizierte Abfallbeseitigung und Produktverunreinigung. ${ }^{19,20}$ 


\section{Asymmetrische Organokatalysatoren}

\subsection{Allgemeinfunktionen der asymmetrischen Organokatalysatoren.}

Die letzten Jahre waren geprägt von spektakulären Entwicklungen neuer katalytischer Methoden unter Einsatz metallfreien organischen kleinen Verbindungen, die hauptsächlich aus den Elementen Kohlenstoff, Wasserstoff, Sauerstoff, Schwefel und Phosphor aufgebaut sind. Der Vorteil der Organokatalyse gegenüber metallkatalysierten Verfahren besteht darin, dass die verwendeten Katalysatoren meist einfach, preiswert, unempfindlich gegenüber Luft und Feuchtigkeit, in den meisten Lösungsmitteln löslich und leicht von der Reaktionsmischung abzutrennen sind. ${ }^{21-22}$ Außerdem werden die Produkte nicht durch Spuren von Metallionen verunreinigt, was bei der Synthese von pharmazeutischen Präparaten von Interesse sein kann. Die Katalysatoren sind einfache niedermolekulare organische Verbindungen und leichter als metallorganische oder bioorganische Analoga an einer festen Phasen zu verankern und können somit wieder verwendet werden. Sie sind viel versprechende Reagenzien für das Hochdurchsatzscreening und industrielle Prozesse. In vielen Fällen verhelfen diese zu extrem hohen Enantioselektivitäten. Die Entwicklung organokatalytischer Verfahren ist ein aktuelles Forschungsgebiet der organischen Synthese und besitzt nicht nur akademisches, sondern auch großes industrielles Interesse. ${ }^{21,22}$

Die rein organischen Katalysatoren unterscheiden sich grundlegend sowohl von metallorganischen als auch von bioorganischen Katalysatoren hinsichtlich ihrer Reaktivitäten und ihrer Anwendungsgebiete. Sie stellen ein neuartiges Konzept dar und eröffnen neue Perspektiven für die Synthese.

Die meisten Organokatalysatoren lassen sich nach ihrer Funktionalität so klassifizieren:
a. Lewis-Base (B:)
b. Lewis-Säure (A)
c. Brønsted-Base (B:)
d. Brønsted-Säure (A-H)

Den katalytischen Zyklus kann man durch folgendes Schema 13 verdeutlichen (S: Substanz, P: Produkt): ${ }^{22}$ 

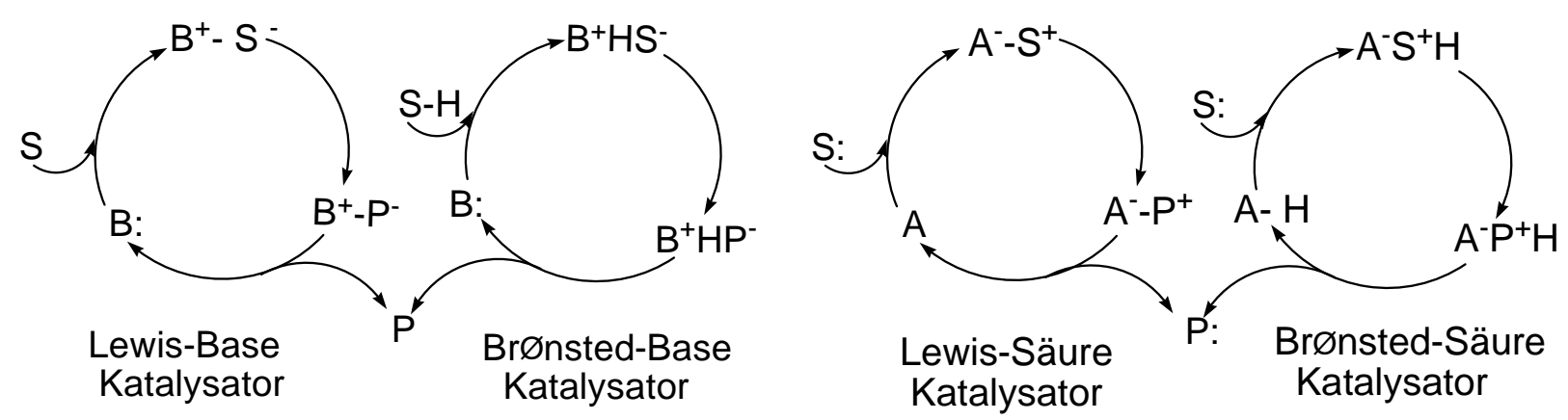

Schema 13. Organokatalytischer Zyklus

Eine Lewis-Base (B:) als Katalysator initiiert den katalytischen Zyklus (Schema 13) durch seine nucleophile Eigenschaft gegenüber der Substanz (S), wobei sich ein Komplex zwischen Katalysator und Substanz sowie Katalysator und Produkt als Übergangszustand bilden kann, nach der Aufarbeitung wird der Katalysator regeneriert. ${ }^{23}$

Als Lewis-Base funktionierende asymmetrische Organokatalysatoren sind meistens N-, C-, O-, P-, und S- haltige chirale Substanzen, in denen freie Elektronpaare vorliegen, bei dem katalytischen Prozess können die Substanzen entweder als nucleophile (1-4, 6, Schema 14) oder elektrophile (5, Schema 14) Zwischenprodukte gebildet werden, weitere elektronische Angriffe an einer anderen Substanz werden elektrophil oder nucleophil stattfinden. Typische reaktive Intermediate sind Iminiumion; Enamin; Acylamoniumion usw. als Reaktion bestimmende Katalysatoren. ${ }^{23}$ sie werden in Schema 14 zusammen dargestellt, eine absolute Intermediatform ist abhängig von der bei der Reaktion vorkommenden Substanz (als Elektrophil). 
<smiles>[R]C=C([O-])[N+](C)(C)CC[Si](C)(C)N(C)C</smiles>

1-Ammonium Enolat<smiles>C=CC(C)=O</smiles>

3-Ammonium Enolat

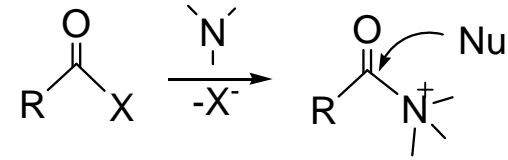

5
Acyl-Amonium Intermediat<smiles>[X]CC(C)=O</smiles>

2-Ammonium Enolat<smiles>[R]C[Si](C)(C)[Si]([R])C([R])[Si](C)(C)C[Si]</smiles>

4

S-ylide-Intermediat

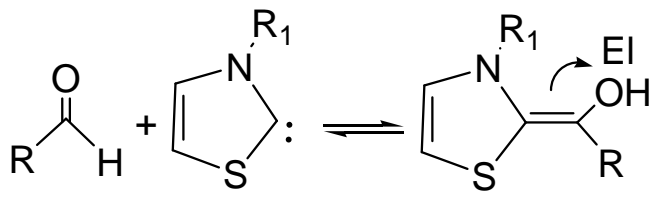

6

Carben Intermediat

Schema 14. Die durch Lewis-Base-Katalysatoren gebildeten reaktiven Intermediate

Sauerstoff- und Phosphor-Atome können direkt durch ihre Nucleophil mit der Substanz einen Übergangszustand bilden. Beispielsweise Phosphoramide stellen als Lewis-Basen einen konzeptionell neuen Ansatz bei der katalytischen Aldol Reaktion zwischen Aldehyden und aktivierten Ketonen dar (Schema 15).<smiles>O=CC1=C[C+]CCC1</smiles>

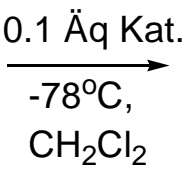<smiles>C1CCCCC1</smiles>

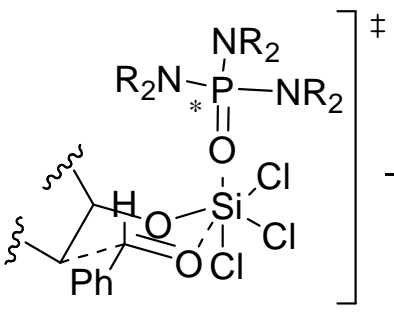

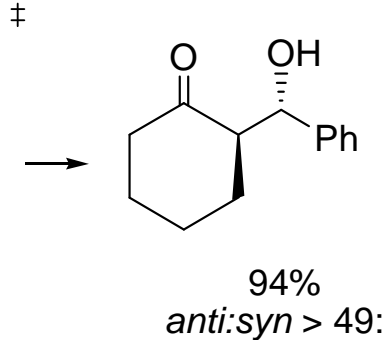<smiles>CCCCN1N2[C@@H]3CCCC[C@@H]3CN2P1(=O)N1CCCCC1</smiles>

ÜZ anti:syn > 49:1

Schema 15. Durch ein chirales Phosphoramid katalysierte asymmetrische Aldol-Reaktion ${ }^{24}$ 
Der Übergangszustand (ÜZ. Schema 15) zeigt, dass die Koordination außer in einem sechsgliedrigen Ring zwischen aktiviertem Keton und Benzaldehyd auch in einer elektrostationären Wechselwirkung zwischen dem elektronärmeren Siliziumatom und Sauerstoff im Phosphoramid (Kat. Schema 15) stattfindet, sodass sich die Reaktion nach einer guten sterischen Richtung orientieren kann.

Lewis-Säuren (A) (Schema 13) als Katalysatoren können eine nucleophile Substanz (S:) aktivieren, der katalytische Zyklus verläuft ähnlich wie bei der Lewis-Base. Organische LewisSäuren dienen als wichtige Phasen-Transfer Katalysatoren. Die Merck Gruppe entwickelte einen ersten Katalysator, ein N-Substituertes Cinchoninium Salz (Schema 16) für die asymmetrische $\alpha$-Methylierung von Indanon in $95 \%$ Ausbeute und $92 \% e e .^{25}$
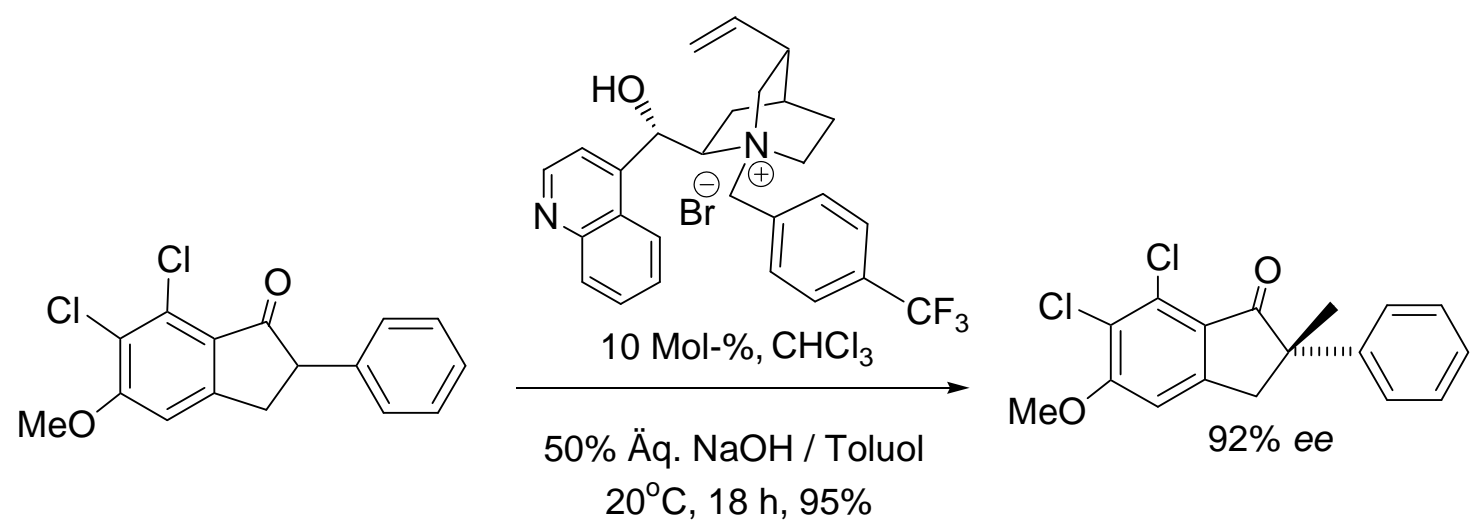

Schema 16. Lewis-Säure als Phase-Transfer Katalysator

Brønsted-Basen (B:) (Schema 13) und Brønsted Säuren (A-H) (Schema 13) initiieren den katalytischen Zyklus durch Deprotonierung- bzw. Protonierungsprozesse.

Typische chirale organische Brønsted-Basen (B:) katalysieren Hydrocyanierungen und die Strecker-Reaktion. Inoue und Mitarbeiter entwickelten die Addition von HCN an Aldehyd mithilfe von Cyclopeptiden (Schema 17). ${ }^{26}$ 


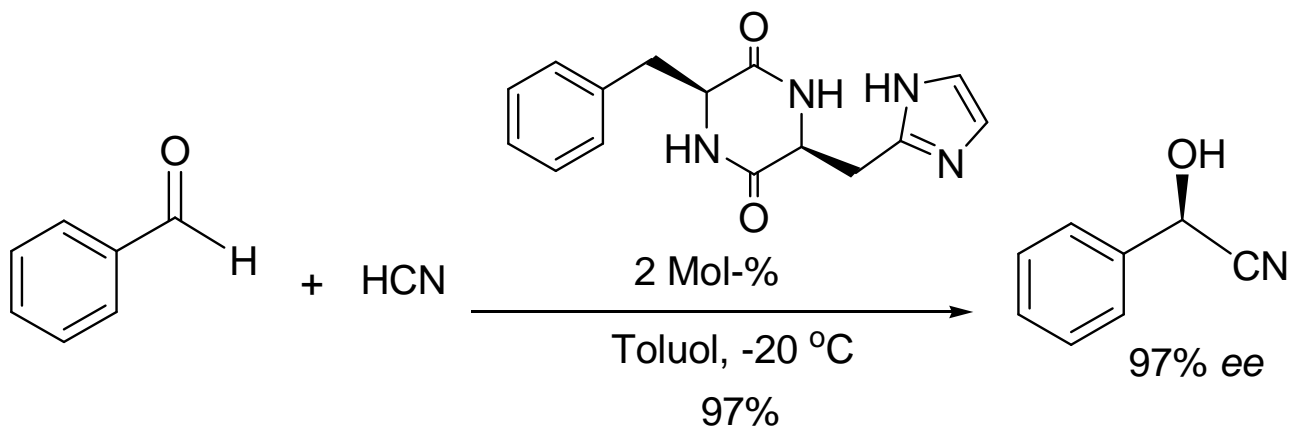

Schema 17. Beispiel für Brønsted-Basen (B:) als Katalysator

Thioharnstoff- und harnstoffhaltige chirale organische Moleküle wirken als Donotoren der Wasserstoffbrückenbindungen, also gehören sie zu Brønsted-Säure (A-H)-Katalysatoren. Jacobsen und Mitarbeiter entwickelten solche Katalysatoren für Stecke, ${ }^{27}$ Mannich (Schema 18), ${ }^{28}$ Hydrophosphonilierungs- ${ }^{29}$ und Pictet-Spengler-Reaktion ${ }^{30}$ von Iminen.<smiles>C=C([OH+])O[SbH2]</smiles>

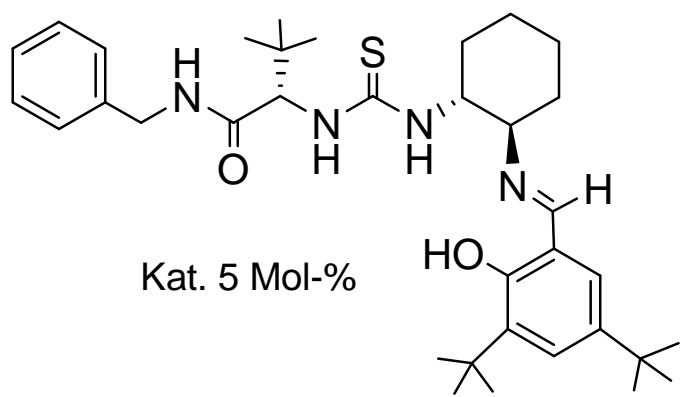

Schema 18. Beispiel einer Mannich-Reaktion durch einen Brønsted-Säure (A-H)-Katalysator 


\subsection{Asymmetrische bifunktonelle Organokatalysatoren}

Seite Mitte der neunziger Jahre wurde eine neue katalytische alternative Vorgehensweise für Organokatalysatoren entwickelt, bei der parallel das Elektrophil und das Nucleophil vom Katalysator aktiviert werden können. So entsteht eine doppelte Aktivierung. ${ }^{31}$

Beispielsweise wurden Katalysatoren hergestellt, die ein Zentrum mit einer Lewis-Säure als funktioneller Gruppe für die Koordination elektrophiler Substrate und ein anderes Zentrum für die Aktivierung elektrophiler Reagenzien enthalten. Die Reaktionspartner werden durch den Katalysator zusammen und räumlich günstig miteinander fixiert. Die beiden Effekte wirken so gut zusammen, dass die Reaktion ähnlich wie bei Enzymen erleichtert wird. Das Prinzip der doppelten Aktivierung lässt sich umfangreich beschreiben. ${ }^{32}$

Alle grundlegenden Informationen zu diesem Thema lassen sich im Folgenden zusammenfassen. ${ }^{30}$

1. Ein bifunktioneller Katalysator mit unterschiedlichen aktiven Einheiten wirkt gemeinsam in einem Molekül.

2. Zwei getrennte Katalysatoren lassen sich erfolgreich zu einem katalytischen System kombinieren, bzw. Co-Katalysator.

3. Die Aktivierung der Elektrophile (oder Nucleophile) entsteht durch einen Katalysator, daraus entwickelt sich ein reaktiver Übergangszustand, der wiederum Nucleophile (bzw. Elektrophile) aktivieren kann. Diese Strategie wurde mehrfach in der metallorganischen asymmetrischen Katalyse der asymmetrischen Synthese verwendet.

Einen rein organobifunktionellen asymmetrischen Organokatalysator zu synthetisieren sollte nicht ausgeschlossen werden. 


\section{Ziel und Planung der Arbeit}

1) Die asymmetrische Robinson-Annellierung, die durch die Aminosäure L-Prolin katalysiert wird, wurde von zwei Forschungsgruppen (Hajos, Parrish und Sauer, Wiechert) unabhängig voneinander entdeckt. Das riesige Potential der enantioselektiven Prolin-Katalyse ist dabei erst im Jahr 2000 erfasst und intensiv erforscht worden. Neue asymmetrische Aldol-; Mannich- und Michael-Reaktionen sowie Alkylierungs- und Aminierungsreaktionen wurden entdeckt und realisiert.

Die Verwendung kurzer Peptide in der organischen Katalyse zeigt ein großes Potential. Die strukturelle Vielfalt, die selbst Peptide mit Dipeptid-Sequenzen ermöglicht, macht diese Klasse von Molekülen vielversprechend für die Entwicklung neuer effektiver chiraler Organokatalysatoren. Wir haben uns daher sowohl mit der Synthese, als auch mit der Verwendung von linearen und zyklischen Dipeptiden für asymmetrische $\mathrm{C}-\mathrm{C}$-Bindungsknüpfungsreaktionen Aldol-, Michael-, Baylis-Hillman- und Allylierungsreaktionen beschäftigt.

2) Chirale organische Katalysatoren, welche sowohl saure als auch basische bzw. nukleophile funktionelle Gruppen besitzen, gewinnen heute im Bereich der asymmetrischen Synthese zunehmend an Bedeutung.

Eines der Ziele dieser Doktorarbeit war die gezielte Planung, Darstellung und Bewertung neuer und effektiver katalytischer Systeme für die asymmetrische Synthese, die bifunktionelle Strukturen aufweisen.

Weitere Interessensschwerpunkte waren die Optimierung der katalytischen Prozesse und die Erweiterung der entwickelten Methode auf weitere organische Reaktionen.

3) Durch Zugabe von chiralen Katalysatoren kann einerseits die Reaktion beschleunigt werden, andererseits können Produkte enantioselektiv gebildet werden.

Ohne Zugabe von chiralen Katalysatoren kann eine Reaktion auch von den eigenproduzierten Produkten katalysiert werden. Unser Interesse liegt insbesondere darin, die asymmetrische organische Autokatalyse bei den Adol- und Mannich-Reaktionen zu untersuchen.

4) Ein bedeutsames Ziel in der organischen Chemie ist die Entwicklung neuer Typen pharmakologisch wirksamer Substanzen. Eine der neuesten Methoden, dieses Ziel zu erreichen, ist die Entwicklung von Hybriden, gebildet aus verschiedenen Naturstoffen. Da dieser Ansatz 
ziemlich neu ist, sind nur einige wenige Beispiele in der Literatur bekannt, hauptsächlich für die Entwicklung von neuen Antitumor-Agenzien und Antibiotika. ${ }^{33}$

Des Weiteren ist die Therapie der Malaria eine der großen Herausforderungen der modernen Medizin. Ein möglicher und vielversprechender Ansatz hierzu ist die Entwicklung von hochwirksamen Hybridmolekülen auf Basis von bekannten Naturstoffanaloga.

Artesunate (semisynthetisches Derivat des Artemisins), eines Medikaments, die bereits gegen Malaria angewandt werden, zeigen darüber hinaus auch zytotoxische Aktivität in Krebszellen. Ein weiteres Ziel der Doktorarbeit war daher die Synthese von Artesunate-haltigen und anderen biologisch aktiven Hybridmolekülen zur Grundlagenforschung und Anwendung in der Medizin (in Zusammenarbeit mit dem Zentrum für Molekulare Biologie (ZMBH) der Ruprecht-KarlsUniversität Heidelberg). 


\section{Kleine Peptide als organische Katalysatoren}

\subsection{Allgemeine Verwendung kleiner Peptide in der organischen asymmetrischen Synthese}

Inoue, ${ }^{34,35}$ Lipton ${ }^{36}$ und andere waren die ersten Forscher, die kurzkettige Peptide als asymmetrische organische Katalysatoren verwendet haben.

Natürliche Verfahren für die asymmetrische Hydrocyanierung sind sehr früh durch den Einsatz von Katalysatoren wie Oxonitrilasen und Alkaloiden bekannt. ${ }^{37}$ Brauchbare Enantioselektivität bei der Hydrocyanierung ist 1982 durch die Anwendung von Diketonpiperazinderivaten (cyclo[S]-Phe[S]-His) durch Inoue realisiert worden (Schema 19). ${ }^{34}$

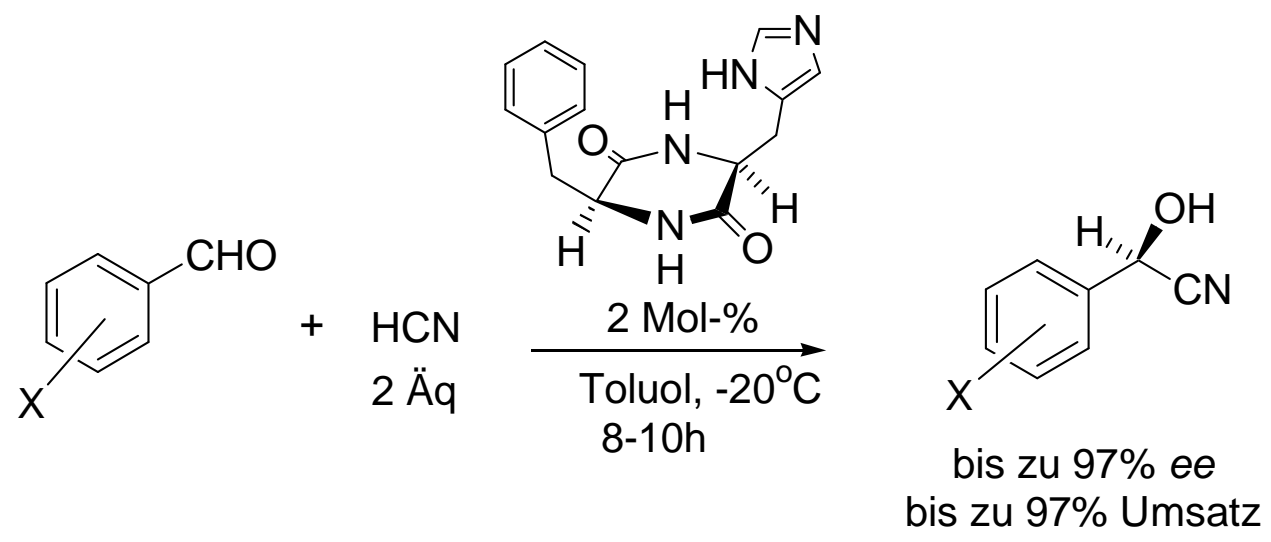

Schema 19. Hydrocanierung von Aldehyden durch Inoue-Peptidkatalysator

Die Aktivität von Benzaldehyden mit unterschiedlichen Substituenten ( $p-; o-; m$-OMe; $p$-Me; $p$ - $\mathrm{NO}_{2} ; p$-CN; $m$ - Oph, $m-\mathrm{NO}_{2}$ ) wurde von Inone erforscht. Die Verwendung von Benzaldehyd ohne Substituenten ermöglicht eine Enatioselektivität von 97\% ee (Schema 19) mit $R$ Konfiguration bei $97 \%$ Umsatz, und nur 8 Stunden Reaktionszeit. Hierbei ergibt sich der Stickstoff der Imin-Funktion des Imidazolrings im Katalysator als aktives Zentrum. HCN wird dadurch deprotoniert, sodass der nucleophile Angriff von $\mathrm{CN}^{-}$zur Cabonylgruppe vereinfacht und die Reaktion beschleunigt werden kann (97\% Umsatz). ${ }^{34}$ Es ist nicht auszuschließen, dass die sich anpassende räumliche Anordnung bei dieser Reaktion das gute Ergebnis des $e e$-Wertes (bis zu 97\% ee) ermöglicht. 
Lipton hat den Imidazolring durch eine Guanidingruppe ersetzt, so dass sich die Aktivität und Selektivität bei der Strecker-Reaktion zwischen Aldimin und Hydrocyanid um ein Vielfaches erhöht (Schema 20).

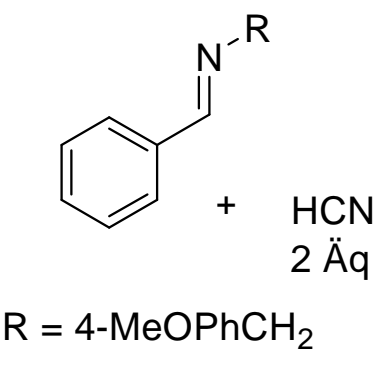

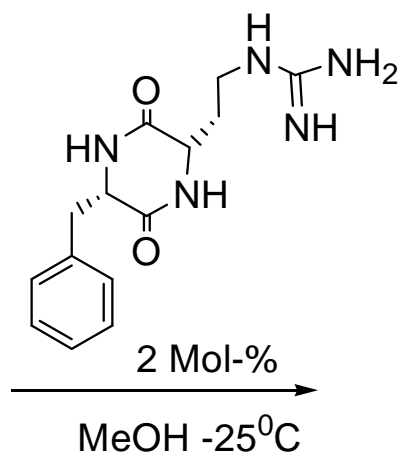

$>99 \%$ ee 97\% Ausbeute

Schema 20. Hydrocyanierung von Aldimin durch Lipton-Peptidkatalysator

Beispielsweise kann das in Schema 20 illustrierte Aldimin durch Verwendung des entsprechenden Katalysators mit einer Ausbeute von 97\% und 99\% ee in der S-Konfiguration gewonnen werden.

Jacobsen und Mitarbeiter haben im Jahr 2000 Schiffsche Basen, Derivate von Harn-und Thioharnstoff, als weitere Katalysatoren für die Strecker Synthese entwickelt. ${ }^{38,39}$<smiles>[R]C(NC1CCCC[C@H]1N=Cc1cc(OC(C)C)cc(C(C)(C)C)c1O)NC(C(=O)C([R2])C)C([R3])(C)C</smiles>

$R_{1}=M e, R_{2}=M e, R_{3}=P h ; X=O ; S$

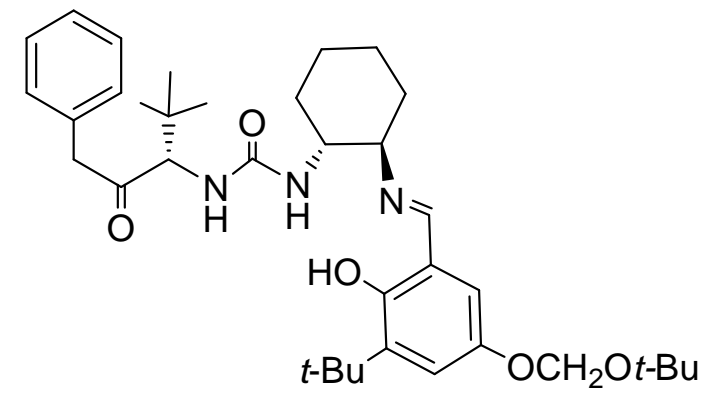

Schema 21. Jacobsen-Schiffsche-Base-Katalysatoren

Die Resultate weckten das weitere Interesse an weiteren unterschiedlichen Transformationen, ${ }^{40-}$ ${ }^{42}$ beispielsweise $\mathrm{zu}$ enantioselektiven konjugierten Additionen. ${ }^{43-45}$ Miller entwickelte die asymmetrische Addition von Aziden an $\alpha, \beta$-ungesättige Carbonylverbindungen durch 
katalytisch wirksame kleine Peptide (Schema 22). Die Reaktion verläuft also über das imidazolhaltige Peptid. Die sekundäre Aminogruppe von Imidazol ist dabei vor weiteren Angriffen geschützt.<smiles>CC(C)/C=C/C(=O)N1CCCC1=O</smiles>

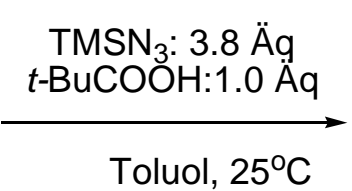<smiles>C[C@@H](NC(=O)[C@@H](NC(=O)[C@@H]1CCCN1C(=O)[C@@H](Cc1cn(Cc2ccccc2)cn1)NC(=O)OC(C)(C)C)C(C)(C)C)c1cccc2ccccc12</smiles><smiles>CC(C)[C@H](N)CC(=O)N1CCCC1=O</smiles>

$82 \%$ ee

Kat. $2.5 \mathrm{Mol}-\%$

Schema 22. Der Miller-Peptid-Katalysator in der asymmetrischen Addition von Aziden an eine $\alpha, \beta$-ungesättigten Carbonylverbindung

Hier ermöglicht der Stickstoff des Imidazolrings die konjugierte Addition. ${ }^{40}$ Miller hat den imidazolhaltigen Katalysator weiter modifiziert. Dieser Katalysator wurde für asymmetrische Acylierungsreaktionen ${ }^{46}$ und enantioselektive Phosphorylierungen ${ }^{47}$ verwendet. Diese Arbeiten zeigten deutlich, dass eine unterschiedliche Substituentenpositionen im Imidazolring unterschiedliche katalytische Wirkung haben kann. ${ }^{43,44}$

Eine Serie von Peptiden, die $N$-Methylimdazol beinhalten, wurde durch Miller und Mitarbeiter bei der Acylierung und Phosphorylierung ${ }^{46,47}$ untersucht. Bei der Analyse der kinetischen Resolution erscheinen diese aktiv.

In Schema 23 ist ein Oligopeptid mit $N$-terminalen Histidingruppen angeführt, welches sich bereits bei Acyltransferreaktionen bewährt hat. ${ }^{46,48}$ Der racemische Alkohol wird durch Anwendung des Peptid-Katalysators in enantiomerreines Acetat gespalten. 


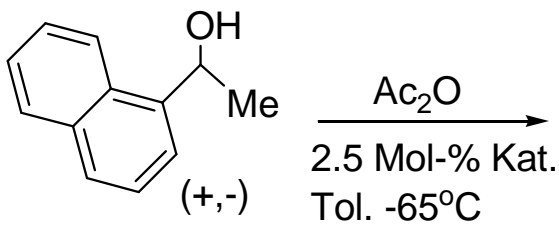<smiles>CC(=O)O[C@H](C)c1cccc2ccccc12</smiles>

$$
\mathrm{K}_{\text {rel. }}>50
$$

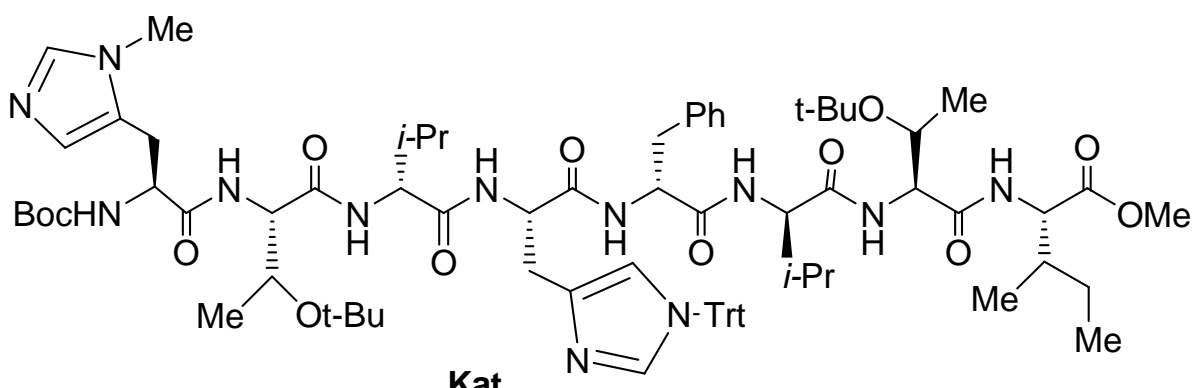

Kat.

Schema 23. Enantioselektive Acylierung mit Miller-Oligopeptid

Bei der Synthese von Mitosen-Gerüsten, ${ }^{49}$ wird die Bedeutung dieser Katalysatoren für die kinetische Racematspaltung verdeutlicht (Schema 24).
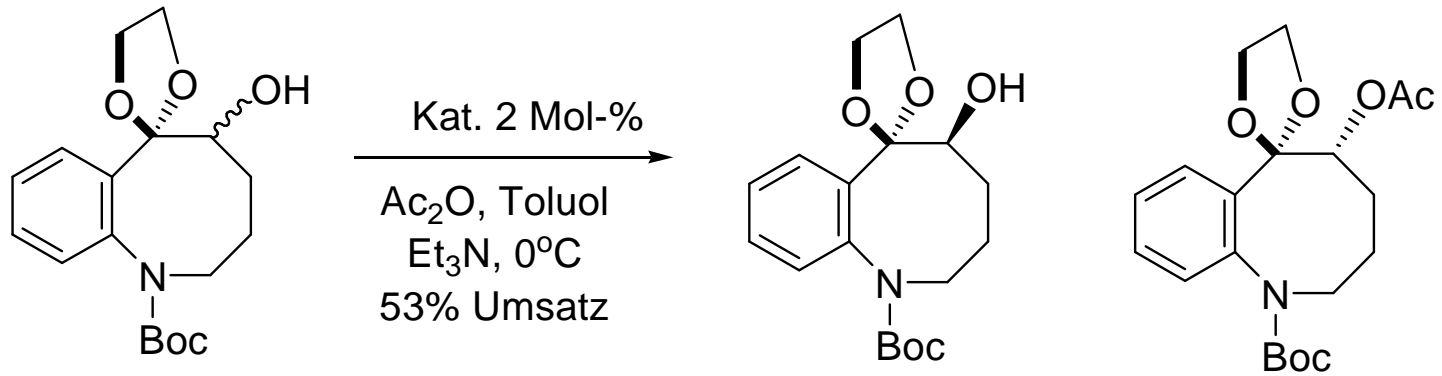

$90 \%$ ee

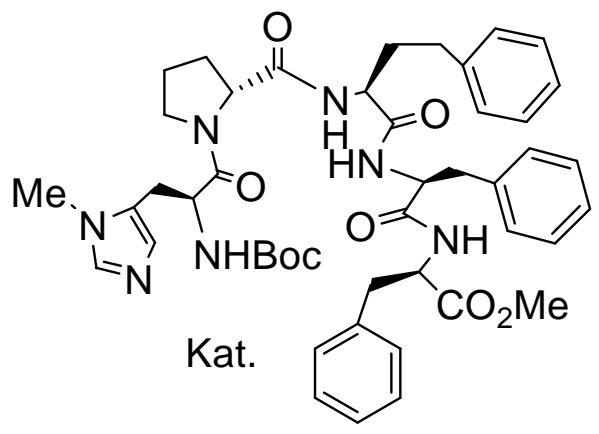

Schema 24. Kinetische Racematspltung durch ein Oligopeptid 
Die racemisch vorliegende alkoholische Verbindung wird mit Hilfe des Peptid-Katalysators zu einem Enantiomerüberschuss von 90\% umgewandelt. Andere Isomere bleiben als Acetat in der Reaktionsmischung.

Die asymmetrische Synthese von D-I-1P (Schema 25) (D-myo- inositol-1-phosphate) ${ }^{50}$ wird in der Natur enzymmatisch durch ein biosynthetisches Verfahren verwirklicht. ${ }^{49}$ In der Natur liegt häufig Phosphat selektiv an der Schlüsselposition innerhalb des polyfunktionalen Moleküls. Bei der asymmetrischen Phosphorylierung gelingt unter Verwendung des kurzkettigen Peptidkatalysators (Schema 25) nicht nur die kinetische Differenzierung zweier enantiotoper Stereozentren eines Myoinositolderivats, sondern auch eine regioselektive Umwandlung des Substrats. Solche „künstlichen Kinasen“ wurden durch „Screening“ einer Bibliothek von 39 Peptiden erhalten. ${ }^{51}$ Je nach Peptid-Struktur konnte jedes der Stereoisomere von Inositol selektiv hergestellt werden.

Die 6 sterisch aktiven Hydroxylgruppen des myo-Inositolrings (Schema 25) stellen eine sehr große Herausforderung bei der regioselektiven Phosphorylierung dar. ${ }^{46}$

Durch klassische Resolutionsverfahren mithilfe mehrerer OH-Schutzgruppe ist das Problem zwar bereits gelöst worden, ${ }^{52}$ aber diese Methode liefert zu niedrige Ausbeuten und fordert hohe Selektivitäten beim Auswählen von Lösungmitteln. ${ }^{46}$ Durch den Miller-Katalysator wurde sowohl die Ausbeute als auch die Enantioselektivität effizient (96\% Ausbeute, 98\% ee, Schema 25) realisiert. Hierbei fungiert der Methylimidazolring als Nucleophil (Lewis-Base) für einen Angriff auf das Phorsporatom. Als aktives Intermediat agiert der phosphorylierte Katalysator. Durch eine anschließende Entschützung mithilfe einer $\mathrm{S}_{\mathrm{N}} 2$ - Reaktion wird D-I-1P hoch selektiv und enantiomerenrein dargestellt. 
1) $\mathrm{HC}\left(\mathrm{OEt}_{3}\right), \mathrm{TSOH}\left(100^{\circ} \mathrm{C}\right)$
2) $\mathrm{BnBr}, \mathrm{NaH}, \mathrm{DMF}\left(25^{\circ} \mathrm{C}\right)$ myo-Inositol

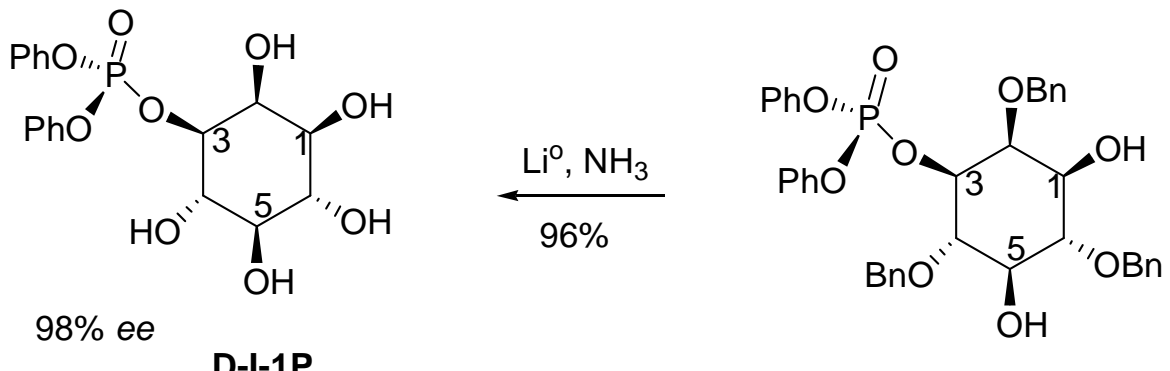<smiles>COC(=O)N[C@@H](Cc1cncn1C)C(=O)N[C@@H](CC(=O)NC(c1ccccc1)(c1ccccc1)c1ccccc1)C(=O)N[C@@H](Cc1cn(Cc2ccccc2)cn1)C(=O)N[C@@H](CC(=O)NC(C(=O)OC)C(=O)OC)C(=O)OC(C)(C)C</smiles>

Schema 25. Asymmetrische Phosphorylierung mit Miller-Katalysator

$N$-Methylimidazolhaltige Peptide wurden nicht nur bei der konjugierten Addition, Acylierung und Phosporylierung angewendet, sondern werden auch bei der Baylis-Hillman-Reaktion ${ }^{53}$ eingesetzt. Die Baylis-Hillman-Reaktion zwischen Methylvinylketon und Aldehyd haben Shibasaki, ${ }^{54}$ Satyanarayan, ${ }^{55}$ Lnager, ${ }^{56}$ Goodman ${ }^{57}$ und Hirama ${ }^{58}$ schon vor Miller erforscht, aber es wurde lediglich ee-Werte bis 50\% erzielt. Miller und Mitarbeiter haben kleine Peptide als Katalysatoren bei derartigen Reaktionen erforscht, und entdeckt, dass ein kleines Molekül als Co-Katalysator eine signifikante Rolle bei der asymmetrischen Baylis-Hillman-Reaktion spielen kann. 
<smiles>O=Cc1ccccc1[N+](=O)[O-]</smiles>

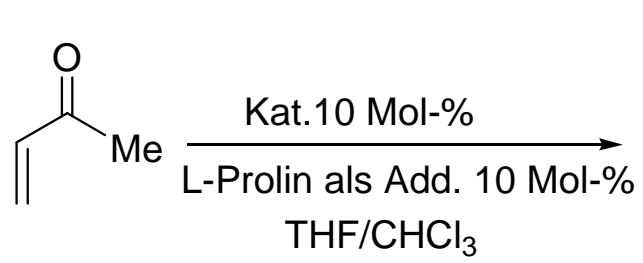
$\mathrm{THF} / \mathrm{CHCl}_{3}$<smiles>C=C(C(C)=O)C(=O)[C@@H](O)c1ccccc1[N+](=O)[O-]</smiles>

(R) $78 \%$ ee $81 \%$ Ausbeute<smiles>O=Cc1ccccc1[N+](=O)[O-]</smiles><smiles>C=CC(C)=O</smiles>
$\mathrm{THF} / \mathrm{CHCl}_{3}$<smiles>C=C(C(C)=O)[C@H](O)c1ccc(OC)cc1[N+](=O)[O-]</smiles>

$81 \%$ Ausbeute

(S) $39 \%$ ee<smiles>CCCCCCN[Z11](=O)c1ccccc1</smiles>

Schema 26. Oligopeptide mit Co-Katalysator (D-; L-Prolin) als Katalysator bei der BaylisHillman-Reaktion

L- und D-Prolin spielen wahrscheinlich wegen des sterischen Faktors, eine ganz unterschiedliche Rolle bei der Baylis-Hillman Reaktion (Schema 26). Ein kleines Oligopeptid mit L-Prolin (10 Mol-\%) als Co-Katalysator katalysiert die Reaktion bis zu 78\% ee liefert das $R$-Produkt (Schema 26). Im Vergleich zu L-Prolin wird mit D-Prolin als Co-Katalysator (ebenfalls 10 Mol-\%) mit nur 39\% ee des S-Produkt (Schema 26) gebildet. Zum sterischen Einfluss wurde keine plausible Begründung gegeben. Es ist aber dennoch eine spektakuläre Entdeckung.

C-Terminale pyrrolidinhaltige Peptide wurden von List und Mitarbeitern bei der MichaelAddition eingesetzt. ${ }^{59}$ Die Ergebnisse entsprachen nicht den Erwartungen. Der beste PeptidKatalysator war H-Pro-Gly-Gly-OH. Aber es resultiert nur 10\% ee und 79\% Ausbeute bei der Umsetzung von aromatischem Nitroolefin mit Aceton (Schema 27). Vermutlich ist der sterische Faktor des Katalysators nicht ausreichend, um die Enantioseletivität zu erhöhen, obwohl der Pyrrolidinring Aceton aktivieren kann. 


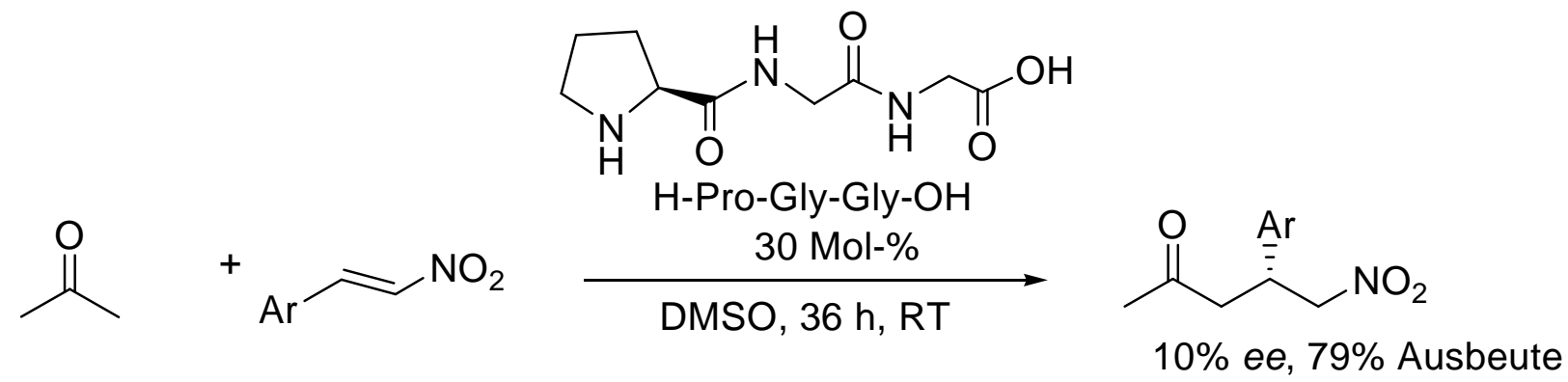

Schema 27. Peptidkatalysierte Michael-Addition.

Besonders erwähnenswert ist dabei, dass auch ein chiraler peptidhaltiger Photorezeptor katalytisch funktionieren kann (Schema 28). ${ }^{60}$ Die präparative Anwendung für enantioselektive Umsetzungen war lange auf eine Photoreaktion beschränkt. ${ }^{61}$ Kürzlich konnte aber gezeigt werden, dass auch geringere Mengen (25 Mol-\%) eines photosensiblen Rezeptors (Peptid, Schema 28) eine Photocycloaddition in quantitativer Ausbeute und mit 19\% ee ermöglichen können.

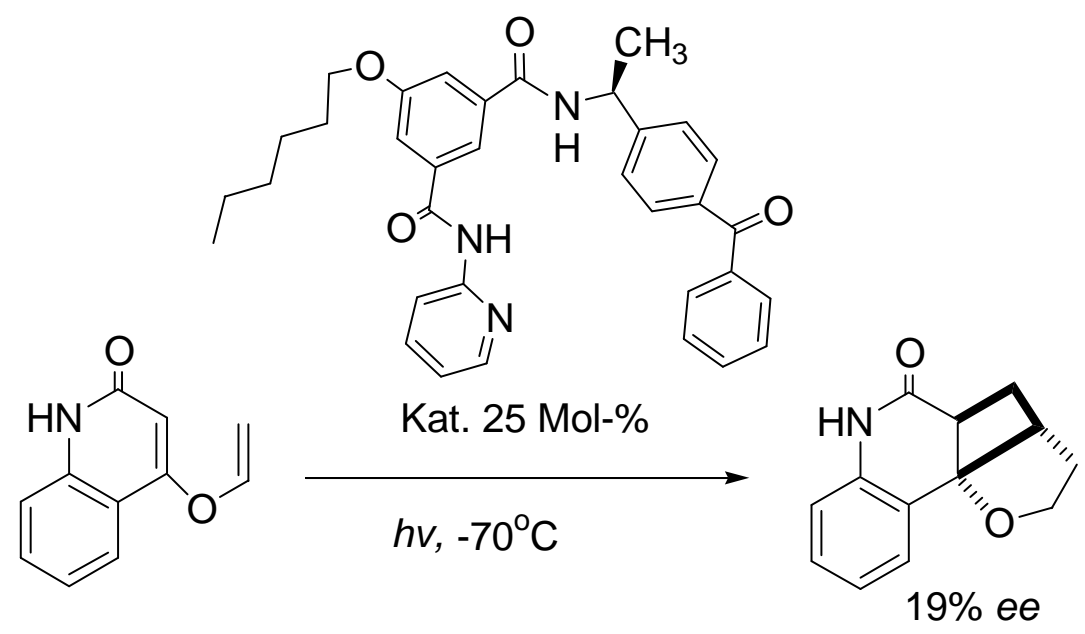

Schema 28. Intramolekulare [2+2]-Photocycloaddition eines Enon-Olefins mit dem chiralen peptidanalogen Rezeptor

Peptide mit einem Prolin- Leucin- und Alanin-Gerüst können auch bei der asymmetrischen Epoxidierung selektiv katalysieren. ${ }^{62-64}$

Die asymmetrische Aldol-Reaktion ist eine sehr wichtige Reaktion für die C-C-Bindungsbildung in der organischen Synthese. ${ }^{65,66}$ In der Natur existieren zwei Typen von Enzymen als Aldolase, die bei der direkten Aldol-Reaktion hoch selektiv katalysieren. Shibasaki hat zuerst 
durch einen Heterobimetallkomplex die asymmetrische direkte Aldol-Reaktion entwickelt. ${ }^{67}$ Trost hat einen Zink-Komplex für die asymmetrische direkte Aldol-Reaktion zu Gunsten höherer Enantioselektivität modifiziert. ${ }^{68}$ Nachdem List, Barbas ${ }^{69}$ und Mitarbeiter die intermolekulare direkte asymmetrische Aldol-Reaktion mithilfe des L-Prolins entdeckt haben, wurde diese Reaktion im Labor von mehreren Wissenschaftlern und Mitarbeitern (Wu, ${ }^{70}$ List,${ }^{71}$ Nielsen und Reymod, ${ }^{72}$ Li $^{73}$ und Bartók ${ }^{74}$ ) untersucht.

Das acide Proton des L-Prolins ist kritisch für die enantioselektive direkte Aldol-Reaktion. ${ }^{62}$

Ein L-Prolinamid ist ein ineffektiver Katalysator für die asymmetrische direkte AldolReaktion. ${ }^{61 \mathrm{~b}}$ Bei den L-Prolinamiden mit terminaler Hydroxylgruppe wurde von $\mathrm{Wu}$ und Mitarbeitern festgestellt, dass folgende Katalysatoren für die asymmetrische direkte AldolReaktion effektiv sind (Schema 29):

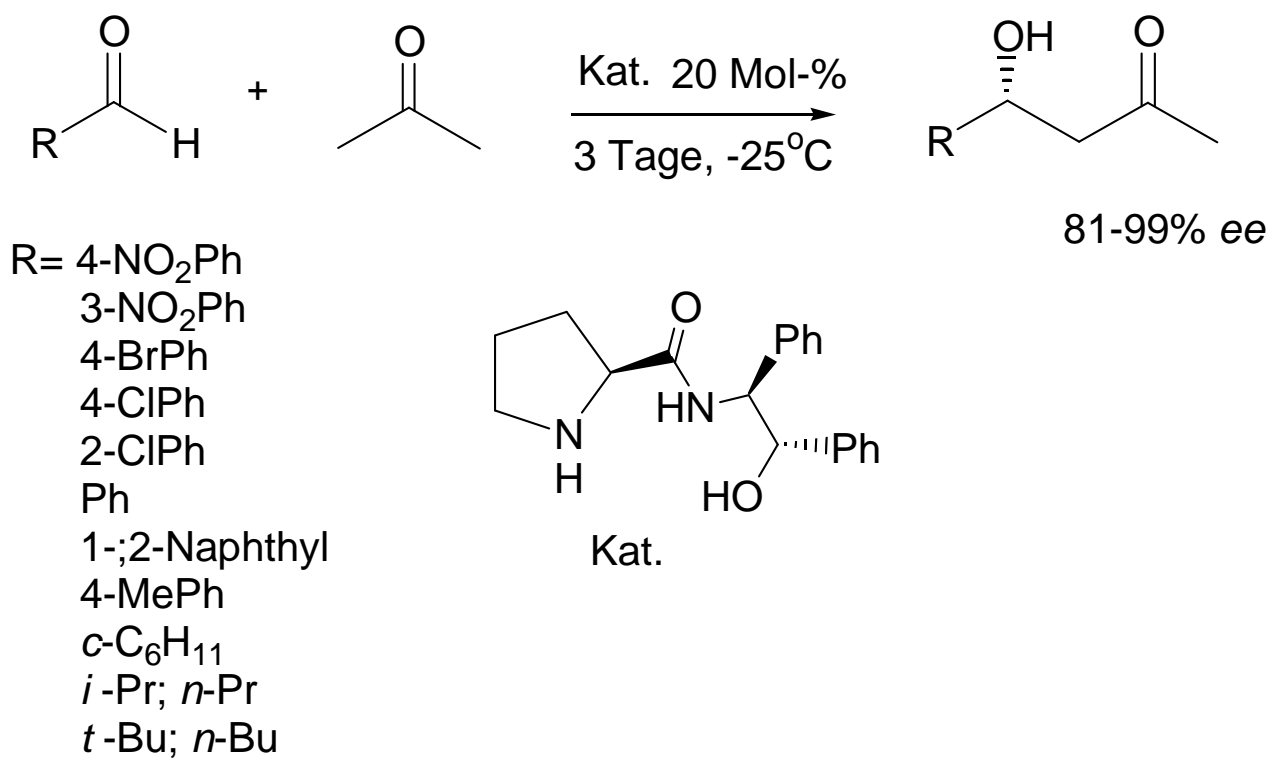

Schema 29. L-Prolinamidderivat als Katalysator in der asymmetrischen direkten AldolReaktion

Zu der Reaktionsmischung wurde kein Lösungsmittel gegeben, und unterschiedliche Aldehyde wurden untersucht. Dabei wurden die besten $e e$-Werte mit bis zu 99\% (mit $t$-Bu-CHO) erreicht. Dieser Katalysator ergab aber eine relativ niedrige Ausbeute. Aromatische Aldehyde mit elektronziehender Gruppe sind höher enantioselektiv bei gleich niedriger Ausbeute. Aromatische Verbindungen mit Eletrondonorgruppe sind relativ inaktiv bei der Reaktion, resultierend in niedrigeren $e e$-Werten und kleinerer Ausbeute. 


\subsection{Anwendung der kleinen Peptide für Zielreaktionen}

Lineare und zyklische Dipeptide, die (S)-Histidine beinhalten, wurden bereits erfolgreich für die asymmetrische Synthese von Cyanhydrinen ${ }^{75}$ benutzt.

Da keine weiteren Untersuchungen der von Inoue entdeckten Dipeptid-Katalysatoren für andere C-C-Bindungsreaktionen in der Literatur bekannt sind, sind wir ermutigt in diesem Gebiet weiter zu forschen.

a) Anwendung der kleinen Peptide bei der direkten asymmetrischen intermolekularen AldolReaktion zwischen Aceton und substituierten Benzaldehyden.

$$
\begin{aligned}
& \text { } \\
& \begin{array}{l}
2-\mathrm{NO}_{2} \mathrm{P} \\
4-\mathrm{BrPh}
\end{array} \\
& \text { 2-CIPh } \\
& \mathrm{Ph} \\
& \text { 2-Naphthyl } \\
& \text { 4-MePh } \\
& \text { c }-\mathrm{C}_{6} \mathrm{H}_{11} \\
& i \text {-Pr; n-Pr } \\
& t \text {-Bn; n-Bu }
\end{aligned}
$$

Schema 30. Peptid katalysierte Aldol-Reaktion

b) Erweiterung der Anwendbarkeit kleiner Peptide bei der Baylis-Hillman Reaktion zwischen 2-Nitrobenzaldehyden und Vinylketon.<smiles>C=CC(C)=O</smiles>

Schema 31. Peptid katalysierte Baylis-Hillman Reaktion 


\subsection{Ergebnisse und Diskussion}

4.3.1 Anwendung der kleinen Peptide bei der asymmetrischen direkten Aldol-Reaktion

4.3.1.1 Untersuchung von Peptiden bei der Aldol-Reaktion von 4-Nitrobenzaldehyd und Aceton.

Das preiswerte und in der Natur vorkommende L-Prolin und dessen kleinere Derivate wurden schon von mehreren Forschern sehr umfangreich bei der Aldol-Reaktion sowie verwandten CC Bindungsknüpfungen eingesetzt. L-prolinhaltige kleine Peptide werden hier eingehend untersucht.

Bei der klassischen Knüpfung von Peptidbindungen reagiert eine am $N$-Atom geschützte bzw. $\mathrm{COOH}$ aktivierte Aminosäure mit einer weiteren Aminosäure, in der nur die $\mathrm{CO}_{2} \mathrm{H}$-Gruppe geschützt ist. Anschließend werden die Schutzgruppen vom N-terminale und Carbonyl-Gruppe entfernt (Schema 32). ${ }^{76}$ Zweimalige Entschützung ist anschließend für das Entstehen des Dipeptids notwendig.

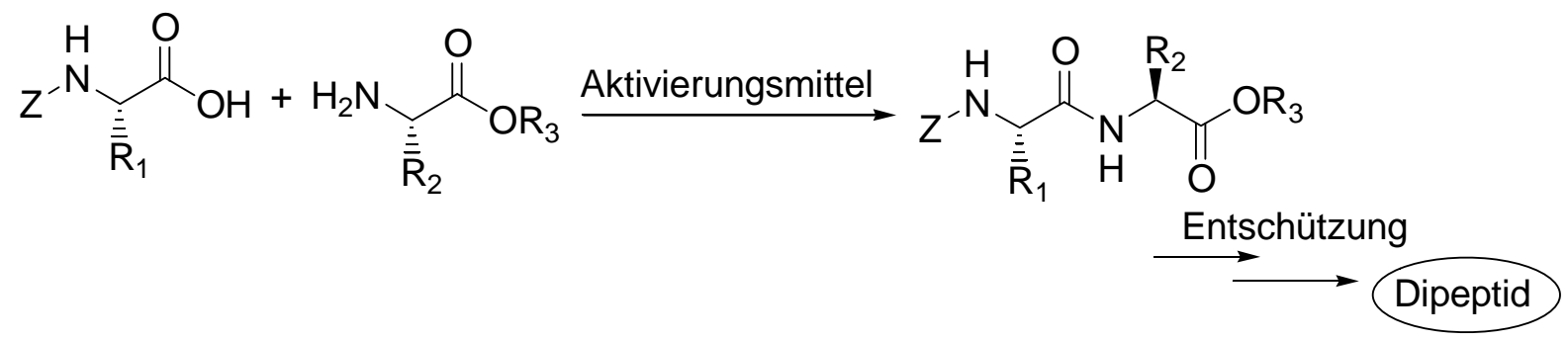

Schema 32. Illustration der Synthese eines Dipeptids

Peptide mit Schutzgruppen wurde von mehreren Gruppen bei der C-C-Bindungsknüpfungsreaktion untersucht. Um die Wirkung der kleinen Peptide bei der asymmetrischen direkten Aldol-Reaktion umfangreich zu erfassen, und ein optimales Peptiddesign zu ermöglichen, testeten wir am Anfang der Arbeit auch einige Peptide vor der Entfernung der Schutzgruppe bei der Folgenden asymmetrischen direkten Aldol-Reaktion.<smiles>CC(C)=O</smiles><smiles>CC(=O)CC(O)c1ccc([N+](=O)[O-])cc1</smiles> 
Es ist bekannt, dass das Proton der COOH-Gruppe in den Peptiden für die Aldol-Reaktion entscheidend ist. So bleiben bei diesen Tests die Peptide C-Teminal ungeschützt. 14 Peptide (Abbildung 6) ohne und mit $N$-Schutzgruppe, die in Tabelle 1 dargestellt sind, wurden für die direkte Aldoreaktion getestet.

Die Herstellung von solchen Peptiden erfolgt durch klassische literaturbekannte Methoden. ${ }^{77}$ Als Aktivierungsmittel (Schema 32) für geschützte Aminosäuren wurden entweder DCC oder Pentafluorpenol verwendet.

Wegen der eingeschränkten Löslichkeit der Peptide wurde keine Lösungsmitteloptimierung bei den Untersuchungen durchgeführt, und DMSO als Reaktionsmedium für die getestete Reaktion verwendet.

Die Untersuchung wurden folgendermaßen durchgeführt: 30 Mol-\% des Peptides gegenüber 4Nitrobenzaldehyd wurde in einer Mischung von getrocknetem DMSO/Aceton (Volumen 4:1) gelöst. Eine zwanzig minutige Aktivierung des Acetons durch das Peptid vor der Zugabe des Aldehyds ist dabei notwendig. Die Reaktionsmischung wurde bei RT unter Stickstoffatomsphäre und ständiger DC-Kontrolle bis zu 6 Tage lang gerührt. Die Aufarbeitung erfolgte nach Literatur-Methoden. ${ }^{78}$ Der Umsatz sowie Ausbeute wurden mittels ${ }^{1} \mathrm{H}-\mathrm{NMR}$ spektroskopischer Aufnahmen des Rohprodukts bestimmt. Der Enantiomerenüberschuss wurde durch chirale HPLC (Daicel Chiralpak AS-Säule, $n$-Hexan: $i$-Propanol 75:25, flow rate 1mL / min) gemessen. Alle Produkte stimmen mit den Literatur-Daten überein.

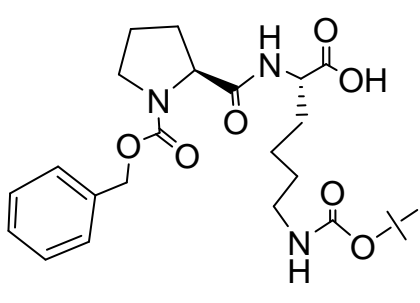

Z-Pro-Lys(Boc)OH

4<smiles>CC(C)(C)OC(=O)N[C@@H](Cc1ccccc1)C(=O)N[C@@H](CCCNC(=N)N)C(=O)O</smiles>

Boc-Phe-Arg-OH<smiles>COC(=O)NCCCCC(=O)N[C@@H](C(=O)O)C(=O)N1CCCN1</smiles>

H-Pro-Lys(Boc)OH

5<smiles>O=C(N[C@@H](O)C(=O)N1CCC[C@H]1C(=O)O)OCc1ccccc1</smiles>

Z-Ser-Pro-OH

6

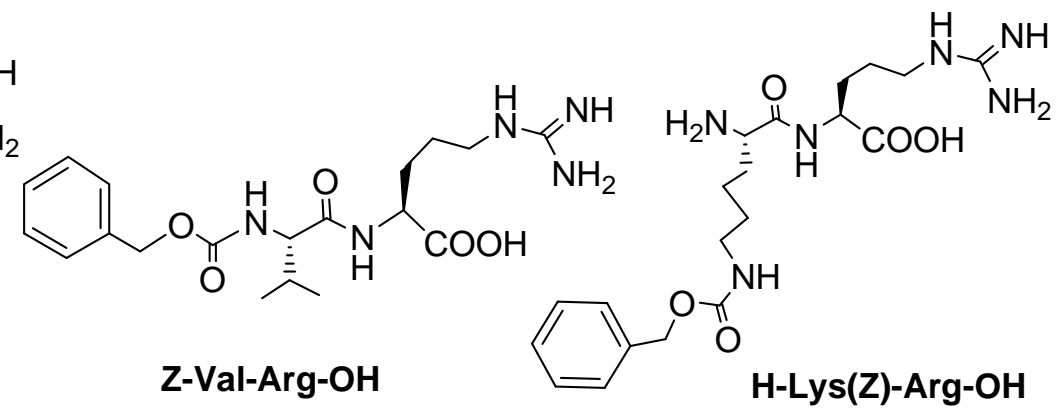


<smiles>CC(C)C[C@H](NC(=O)[C@H](N)CCCCNC(=O)OCc1ccccc1)C(=O)O</smiles>

H-Lys(Z)-Leu-OH

10<smiles>N=C(N)NCCC[C@H](NC(=O)[C@@H]1CCCN1C(=O)OCc1ccccc1)C(=O)N1CCC[C@H]1C(=O)O</smiles>

Z-Pro-Arg-Pro-OH

11<smiles>CC1C[C@H](C(=O)N[C@@H](Cc2c[nH]cn2)C(=O)O)NC(OCc2ccccc2)O1</smiles>

Z-Leu-His-OH

12<smiles>COC(=O)N[C@@H](Cc1c[nH]cn1)C(=O)N[C@H](CC(C)C)C(=O)OCc1ccccc1</smiles>

Z-Leu-His-OMe

13<smiles>CC(C)C[C@H](N)C(=O)N[C@@H](CCCCNC(=O)OC(C)(C)C)C(=O)O</smiles>

H-Leu-Lys(Boc)OH

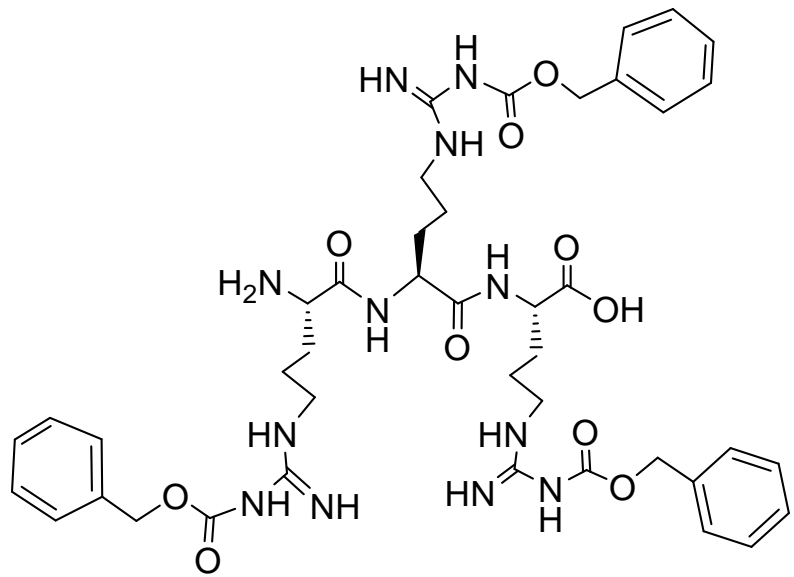

H-Arg(Z)-Arg(Z)-Arg(Z)OH

14<smiles>CC(C)C[C@H](NC(=O)[C@H](N)CCCCNC(=O)OC(C)(C)C)C(=O)O</smiles>

H-Lys(Boc)-Leu-OH

\section{Boc-Leu-His-OMe}

17

Abbildung 6. Geschützte Peptide für die Untersuchung der Aldol-Reaktion zwischen Aceton und 4-Nitrobenzyaldhyd 
Die Untersuchungsergebnisse sind in Tabelle 1 angeführt. Um die Aktivität gut zu vergleichen wurde die Reaktionszeit auf 6 Tage festgelegt. Bei geringer Produktbildung wurde der Umsatz und $e e$-Werte nicht bestimmt.

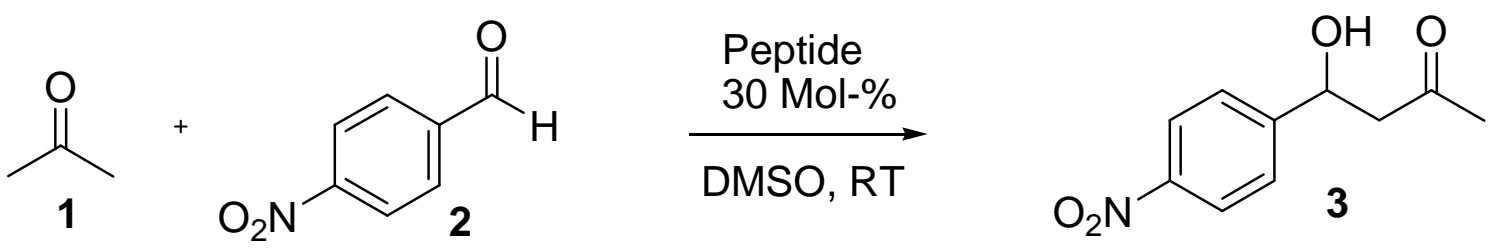

Tabelle 1 Geschützte und nicht geschützte Dipeptide als Katalysatoren bei der AldolReaktion von 4-Nitrobenzaldehyd und Aceton.

\begin{tabular}{|c|l|c|c|c|c|c|}
\hline Eintrag & \multicolumn{1}{|c|}{ Peptide (0.3 Äq) } & $\begin{array}{c}\text { Umsatz } \\
(\%)^{\mathrm{a}}\end{array}$ & $\begin{array}{c}\text { Ausbeute } \\
(\%)^{\mathrm{b}}\end{array}$ & $\begin{array}{c}\text { Zeit } \\
(\mathrm{Tag})\end{array}$ & $\begin{array}{c}e e \\
(\%)^{\mathrm{c}}\end{array}$ & Konfig. \\
\hline 1 & Z-Pro-Lys(Boc)-OH (4) & kein & kein & 6 & - & - \\
\hline 2 & H-Pro-Lys(Boc)-OH (5) & & \\
\hline 3 & Z-Ser-Pro-OH (6) & 95 & 86 & 7 & 76 & $R$ \\
\hline 4 & Boc-Phe-Arg-OH (7) & 30 & Spur & 6 & 0 & - \\
\hline 5 & Z-Val-Arg-OH (8) & 41 & Spur & 6 & 0 & - \\
\hline 6 & H-Lys(Z)-Arg-OH (9) & 23 & Spur & 6 & 0 & - \\
\hline 7 & H-Lys(Z)-Leu-OH (10) & 50 & 23 & 6 & 9 & $R$ \\
\hline 8 & Z-Pro-Arg-Pro-OH (11) & 34 & Spur & 6 & - & - \\
\hline 9 & Z-Leu-Phe-OH (12) & kein & - & - & - & - \\
\hline 10 & Z-Leu-His-OMe (13) & 31 & 12 & 6 & 20 & $R$ \\
\hline 11 & H-Arg(Z)Arg(Z)Arg(Z)-OH (14) & 10 & Spur & - & - & - \\
\hline 12 & H-Leu-Lys(Boc)-OH (15) & 51 & 34 & 6 & 45 & $R$ \\
\hline 13 & H-Lys(Boc)-Leu-OH (16) & 95 & 81 & 6 & 49 & $R$ \\
\hline 14 & Boc-Leu-His-OMe (17) & 32 & 21 & 6 & 62 & $R$ \\
\hline 15 & H-Leu-His-OMe (19) & 92 & 81 & 6 & 20 & $R$ \\
\hline 16 & H-Leu-Phe-OH (21) & 18 & 11 & 6 & 67 & $R$ \\
\hline 17 & H-Val-Arg-OH (27) & 21 & 16 & 6 & 30 & $R$ \\
\hline 18 & H-Lys-Arg-OH (25) & 58 & 6 & 21 & $R$ \\
\hline
\end{tabular}

a),b) Umsatz und Ausbeute-Analyse durch ${ }^{1} \mathrm{H}-\mathrm{NMR}$ der Reaktionsmischung,

c) Bestimmung durch chirale HPLC-Analyse (Daicel Chiralpak AS), Vergleich mit racemischen Produkten,

d) Reaktionszeit: $7 \mathrm{~h}$. 
Anhand dieser Untersuchungen am Anfang wurden 6 Peptide (5, 10, 13, 15, 16, 17, Tabelle 1), die Schutzgruppe enthalten, ausgewählt, die eine freie basische stickstoffhaltige Nucleophilgruppe enthalten. Peptid 5 mit sekundärer Amino-Gruppe im Pyrrolidinring, 10 und 15 mit primären Aminogruppen, die sich entweder in N-terminal wie bei H-Leu-Lys(Boc)-OH (Peptid 15, Tabelle 1) befindet, oder in C-terminal mit freier Aminogruppe (Peptide: 10, 16) steht, beträchtlich beinhalten Peptide 13 und 17 basische Imidazol Ringe. Alle o.g Peptide bewirken gute oder schlechte Resultate. Der Mechanismus ist in Schema 33 dargestellt. Die Aminogruppe bildet mit Aceton ein Enamin Intermediat, welches durch seine Nucleophieleigenschaft den Aldehyd angreift. Durch wässerige Aufarbeitung entsteht das Aldolprodukt. Die Aminogruppe ist also das aktive Zentrum des Katalysators. Eintrag 2, das Peptid H-Pro-Lys(Boc)OH (5) ist überhaupt das aktivste (95\% Umsatz, 76\% ee in nur 7 h). Als Grund wird einerseits die Anwesenheit der relativ stark basischen Pyrrolidingruppe, andererseits die wohl passende räumliche Anordnung zwischen dem Katalysator und den Substanz angenommen. Die Reaktion durch H-Lys(Boc)-Leu-OH (16) verläuft ebenfalls katalytisch gut (95\% Umsatz, 49\% ee), obwohl die Reaktionszeit 6 Tage beträgt. H-LeuLys(Boc)OH (15), Z-Leu-His-OMe (13) und Boc-Leu-His-OMe (17) ergaben relativ schlechte Resultate (durch Kat. 13: 31\% Umsatz und 12\% ee, Eintrag 10, durch Kat. 15: 51\% Ausbeute und 34\% ee Eintrag 12; und durch Kat. 17: 32\% Umsatz, 62\% ee, Eintrag 14). Katalysator HLys(Z)-Leu-OH (10) ist der schlechteste der sechs eingesetzten Katalysatoren (50\% Ausbeute und 9\% ee, Eintrag 7). Der geringe Enantiomerenüberschuss ist wahrscheinlich auf die räumliche Anordnung der Peptide zurückzuführen.

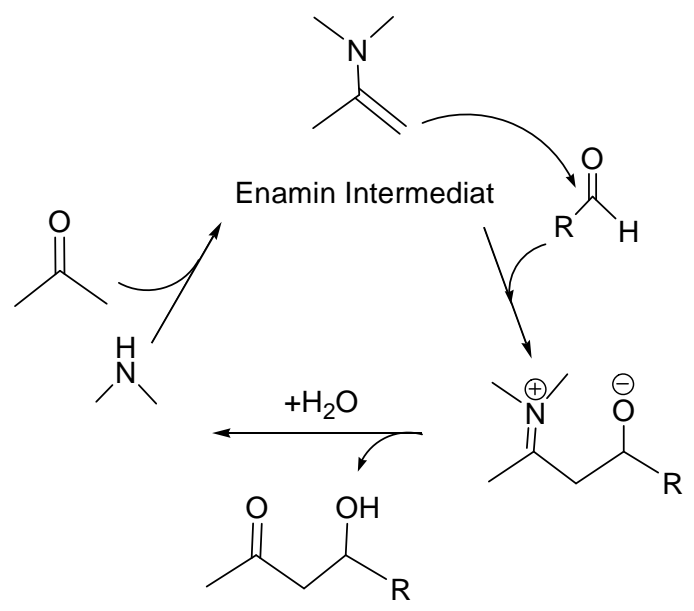

Schema 33. Aldol-Reaktion zwischen Aceton und Aldehyd katalysiert durch Amin-haltige Peptide $^{79}$ 
Die Peptide in den Einträgen 4, 5, 6, 8 und 11 (Tabelle 1) enthalten ein Arg-OH-Gerüst. Vermutlich aufgrund der stärkeren Basizitäten erfolgt bei der Reaktion zwar Umsatz, der aber ausschließlich Aldolkondensationsprodukte erhält. Zur Ermittlung eines ee-Wertes werden hier zu geringe Mengen des Produkts gebildet.

Es stellt sich die Frage nach dem Unterschied der Aktivität zwischen einem geschützten und ungeschützten Peptid. Ungeschützte sowie Peptide 19, 21, 27 und 25 (Tabelle 1) wurden weiter bei der Aldol-Reaktion untersucht.

Eine hohe Ausbeute gleicher Enantioselektivität wurde mit Kat. 19 (81\% Ausbeute und 20\% ee) liefert. das im Gegensatz zum geschützten Katalysator (Peptid 13: 12\% Ausbeute und 20\% ee, Eintrag 10, Tabelle 1). Bei Katalysator 9 mit Z-Gruppe bildet sich nur das Kondensationsprodukt (Eintrag 6, Tabelle 1). Ohne Schutzgruppe (Katalysator 25) erhöht sich die Ausbeute auf 58\%, bei einem ee-Werte von 21\% (Eintrag 18, Tabelle 1), Katalysator 21 und 27 zeigen auch die Tendenz, dass Katalysatoren ohne Schutzgruppe besser funktionieren (Eintrag: 16 und 17). Das bedeutet, dass die Schutzgruppe des Peptids bei der asymmetrischen direkten Aldol-Reaktion ein Hindernis ist. Betrachtet man die Reduzierte ReaktionsGeschwindigkeit nimmt sie nach der Entfernung der Schutzgruppen tendenziell zu. Eine Ausnahme stellt Eintrag 5 (Tabelle 1) dar, die jedoch mit der hohen Produktion von Nebenprodukten zu begründen ist (41\% Umsatz bei einer Spur von Ausbeute, Z-Val-Arg-OH). Nicht nur die für die Enamin-Bildung wichtige freie Amino-Gruppe, sondern auch das freie Proton an der Carboxylgruppe spielt aufgrund der Wasserstoffbrückenbindung zum AldolAkzeptor eine wichtige Rolle.

Durch diese Untersuchungen zeigt sich deutlich, dass die freie Amino-Gruppe bei der Reaktion eine wichtige Rolle spielt. Für weitere Untersuchungen wurden die Z- und Boc-Schutzgruppe nach Literatur bekannten Methoden ${ }^{80}$ entfernt. 
4.3.1.2 Entfernung der Schutzgruppe<smiles>CC(=O)N[C@@H](Cc1c[nH]cn1)C(=O)N[C@@H](CC(C)C)C(=O)OCc1ccccc1</smiles>

13

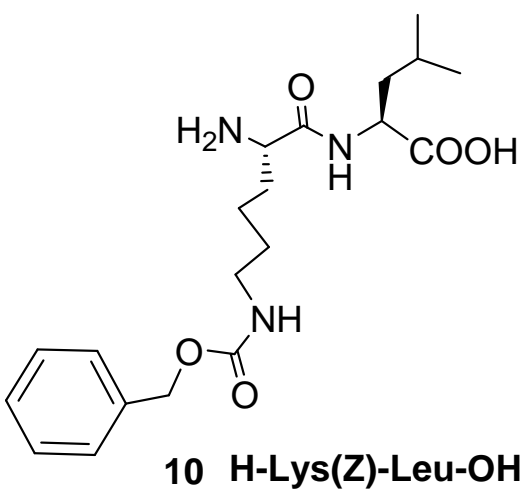

$\mathrm{H}_{2}, \mathrm{Pd} / \mathrm{C}$ $\mathrm{MeOH}, \mathrm{RT}, 48 \mathrm{~h}$

$\mathrm{H}_{2}, \mathrm{Pd} / \mathrm{C}$

$\mathrm{MeOH}, \mathrm{RT}, 48 \mathrm{~h}$<smiles>CO[C@H](Cc1c[nH]cn1)[C@@H](Cc1c[nH]cn1)NC(=O)[C@H](N)CC(C)C</smiles>

95\% Ausbeute

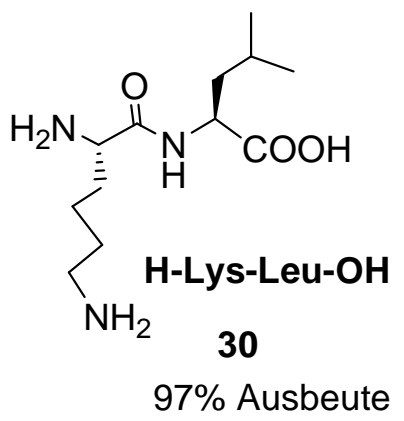

Schema 34. Darstellung von Peptiden 19 und 30

Die Peptide 19, 30 (Schema 34) sowie 21, 25 und 27 wurden nach durch Abspaltung der ZGruppe in getrocknetem $\mathrm{MeOH}$ mit Hilfe von $10 \mathrm{Mol}-\% \mathrm{Pd} / \mathrm{C}$ als Katalysator gewonnen, wobei Ausbeuten von bis zu 97\% erhalten wurden.

Die Entfernung der Boc-Schutzgruppe wurde mit bekannten Literatur Methoden ${ }^{81}$ durchgeführt (Schema 35). Die Peptide bilden nach Zugabe von kaltem Ether einen Niederschlag aus. Die weitere Reinigung wurde durch Säulenchromatographie an RP-Gel durchgeführte. Die Produkte 19, 30 (Tabelle 2) wurden durch gleiche Methoden mit guten Ausbeuten (70-80\%) dargestellt. 
<smiles>CC(C)C[C@H](NC(=O)[C@H](N)CCCCNC(=O)OC(C)(C)C)C(=O)O</smiles>

H-Lys(Boc)-Leu-OH

16<smiles>CC(=O)[C@H](Cc1c[nH]cn1)NC(=O)[C@H](CC(C)C)NC(=O)OC(C)(C)C</smiles>

Boc-Leu-His-OMe

17

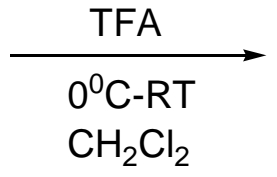

$\underset{\mathrm{MeOH}, \mathrm{RT}, 48 \mathrm{~h}}{\stackrel{\mathrm{H}_{2}, \mathrm{Pd} / \mathrm{C}}{\longrightarrow}}$

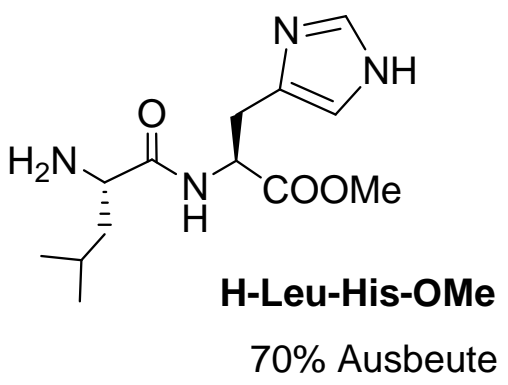

19

Schema 35. Darstellung von Peptid 19 und 30

Peptid H-Lys-Tyr-OH 29 (Schema 36) wurde nach der Aufarbeitung von H-(Lys-Tyr)- Acetat erhalten. Dazu wurde Amberlyst A-26 $(\mathrm{OH})$ (ion exchange resin 0.35mm) zu einer Mischung des Peptid-Salzes in Wasser gegeben bis ein $\mathrm{pH}-$ Wert von 8 erreicht werden.<smiles>CC(=O)[C@H](Cc1ccc(O)cc1)NC(=O)[C@H]([NH3+])CCCC[NH3+]</smiles>

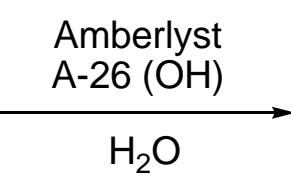<smiles>NCCCCC(N)C(=O)N[C@@H](Cc1ccc(O)cc1)C(=O)O</smiles>

Schema 36. Darstellung von Verbindung 29 
Anschließend wurde das Amberlyst abfiltriert, das Wasser entfernt und das Peptid 29 mit einer Ausbeute von $70 \%$ erhalten (Schema 36).

Die Darstellung des Peptids H-Leu-His-OMe 19 erfolgt durch Umwandlung des kommerziell erhältlichen 2HCl(H-Leu-His-OMe) Salzes mit Dowex:<smiles>CC(=O)[C@H](Cc1c[nH]cn1)NC(=O)[C@H](N)CC(C)CCl</smiles>

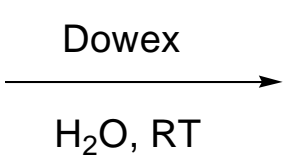

$\mathrm{H}_{2} \mathrm{O}, \mathrm{RT}$<smiles>CC(=O)[C@H](Cc1c[nH]cn1)NC(=O)[C@H](N)CC(C)C</smiles>

H-Leu-His-OMe

Schema 37. Darstellung des Peptid-Katalysators 19

Basisches Dowex-Ionenaustauscher wurde stufenweise in eine wässrige Lösung von $2 \mathrm{HCl}^{\circ}(\mathrm{H}-$ Leu-His-OMe) Salz eingebracht, der pH-Wert auf 7 eingestellt. Man filtriert das Dowex ab, entfernt das Wasser, und erhält das Produkt mit einer Ausbeute von 60\% (Schema 37).

Alle weiteren untersuchten Peptide waren kommerziell verfügbar und wurden an der gleichen Reaktion getestet.

\subsubsection{Anwendung der entschützten Peptide bei der direkten Aldol-Reaktion}

Die Reaktionen wurden mit den entschützten Peptiden durch ähnliche Methoden wie in Tab. 1 durchgeführt. Die Ergebnisse sind in Tabelle 2 zusammengefasst.

Es wurde DMSO als Lösungsmittel für alle Reaktionen verwendet. Im Vergleich zu Tabelle 1 war die Reaktionszeit ein bis drei Tage länger. Es scheint viele Verbesserungen sowohl in Ausbeute als auch in $e e$-Werten zu geben.

Im Zuge unserer Untersuchungen zu Aldol-Reaktionen wurde dabei beispielsweise gefunden, dass Dipeptide mit Aminosäuren, welche sowohl einen basischen als auch einen neutralen Rest in den Seitenketten enthalten, im allgemeinen besser geeignet sind, um gute Umsätze und Enantioselektivitäten zu erzeugen, als Dipeptide aus Aminosäuren mit zwei basischen oder zwei neutralen Funktionalitäten in der Seitenketten. 
Wenn man Tabelle 2 betrachtet, findet man sechs Peptide (18, 23, 24, 29, 31, 5), die bei längerer Reaktionszeit eine höhere Ausbeute und deutlichen Enantiomerenüberschuss liefern. Im Gegensatz zum Prolin-haltigen Peptid H-Pro-Lys(Boc)OH 5, enthalten diese 5 Dipeptide primäre Amino-Gruppen zur asymmetrischen direkten Aldol-Reaktion. Wegen der sterischen Faktoren und des Sequenzen von Aminosäuren wirken sie unterschiedlich.

H-Leu-His-OH (18) ist der beste getestete Katalysator, mit dem sich das Produkt in einer Ausbeute von $87 \%$ und $71 \%$ ee in 6 Tagen bildet. Vergleichbare Strukturen mit ImidazolGerüst wie die Peptide H-Lys-His-OH (23), H-Leu-His-OMe (19) und H- $\beta$ Ala-His-OH (22) besitzen eine schwache katalytische Wirkung (Abb. 7). Das bedeutet, dass die N-terminale Aminosäure eine entscheidende Rolle spielt. Verschiedene Seitenketten von Peptide 23, 19, und 22 verursachen unterschiedliche katalytische Wirkungen (Einträge 6, 2, 5 in Tabelle 2)

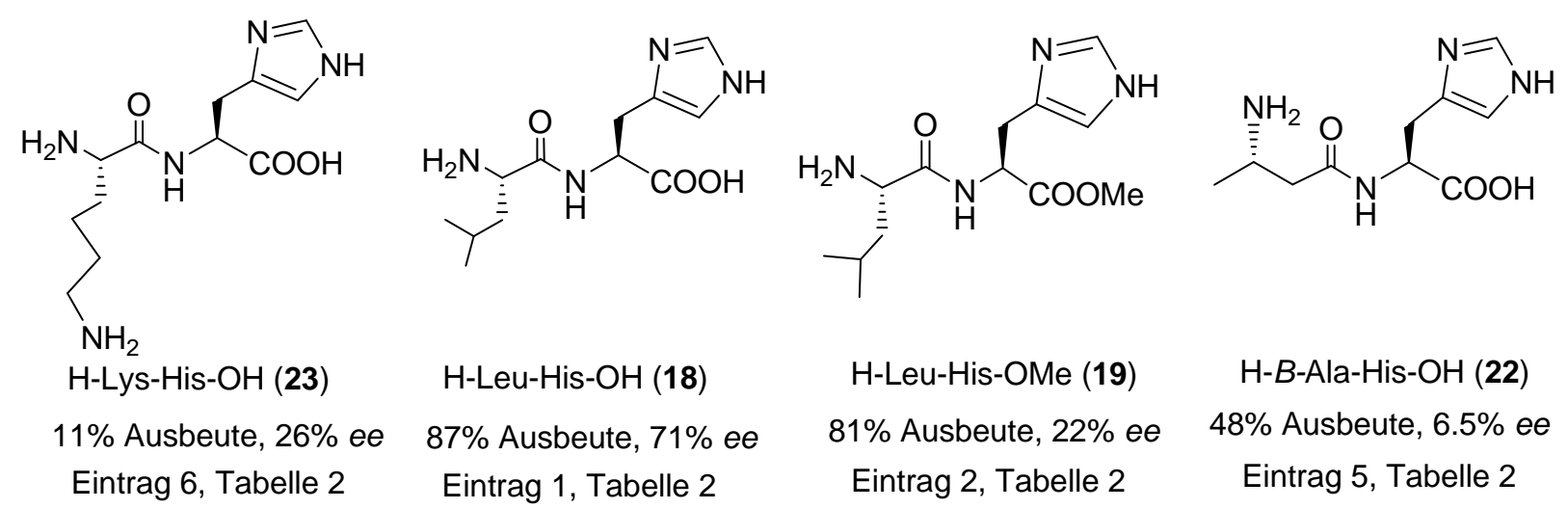

Abbildung 7. Untersuchte Imidazol-Gerüst haltige Dipeptide

Vergleichen wir H-Leu-His-OH (18) und H-Leu-His-OMe (19), zeigt sich, dass die freie Carboxyl-Gruppe eine sehr wichtige Rolle spielt. Die Anwesenheit der OMe-Schutzgruppe scheint ungünstige Wechselwirkung zu verursachen, sodass Produkte mit geringen $e e$-Werten (22\% ee und $81 \%$ Ausbeute) entstehen. Ebenso wirkt 2HCl(H-Leu-His-OMe) noch weniger reaktiv und stereoselektiv (54\% ee jedoch 4\% Ausbeute, Eintrag 3, Tab. 2) als H-Leu-His-OH (18) (71\% ee und 87\% Ausbeute Eintrag 1, Tabelle 2). Möglicherweise verhindert die OMeGruppe die Ausbildung einer Wasserstoffbrückenbindung, wie es sonst durch die freie Carboxy-Gruppe bei der Aminosäure der Fall wäre. Diese zusätzliche Wechselwirkung könnte für die höhere Stereoselektivität verantwortlich sein. 
Tabelle 2 Untersuchung Unterschiedlicher Peptide für die direkte Aldol-Reaktion<smiles>CC(=O)CC(O)c1ccc([N+](=O)[O-])cc1</smiles>

\begin{tabular}{|c|c|c|c|c|c|c|}
\hline Eintrag & Peptide & $\begin{array}{l}\text { Zeit } \\
\text { (Tag) }\end{array}$ & $\begin{array}{c}\text { Umsatz } \\
(\%)^{\mathrm{a}}\end{array}$ & RRG. $^{\mathrm{d}}$ & $\begin{array}{c}\text { Ausbeute } \\
(\%)^{\mathrm{b}}\end{array}$ & $\begin{array}{c}e e \\
(\%)^{\mathrm{c}}\end{array}$ \\
\hline 1 & H-Leu-His-OH (18) & 6 & 96 & 0.67 & 87 & 71 \\
\hline 2 & H-Leu-His-OMe (19) & 10 & 92 & 0.38 & 81 & 20 \\
\hline 3 & 2HCl'H-Leu-His-OMe (20) & 10 & 8 & 0.03 & 4 & 54 \\
\hline 4 & H-Leu-Phe-OH (21) & 7 & 18 & 0.11 & 11 & 67 \\
\hline 5 & H- $\beta$ Ala-His-OH (22) & 9 & 66 & 0.31 & 48 & 6,5 \\
\hline 6 & H-Lys-His-OH (23) & 10 & 13 & 0.05 & 11 & 26 \\
\hline 7 & H-Lys-Phe-OH (24) & 9 & 96 & 0.44 & 78 & 60 \\
\hline 8 & H-Lys-Arg-OH (25) & 10 & 70 & 0.29 & 58 & 21 \\
\hline 9 & H-Leu-Arg-OH (26) & 15 & 70 & 0.19 & 65 & 40 \\
\hline 10 & H-Val-Arg-OH (27) & 7 & 21 & 0.13 & 16 & 30 \\
\hline 11 & Cyclo-[(S)-Leu- $(S)$-His] $(\mathbf{2 8})$ & 10 & 31 & 0.13 & 24 & 3 \\
\hline 12 & H-Lys-Tyr-OH (29) & 10 & 84 & 0.35 & 65 & 53 \\
\hline 13 & H-Lys-Leu-OH $(\mathbf{3 0})^{\mathrm{e}}$ & 30 & 100 & 3.3 & 80 & 39 \\
\hline 14 & H-His-Phe-OH (31) & 3 & 87 & 1.2 & 77 & 40 \\
\hline 15 & H-Pro-Lys(Boc)OH (5) ${ }^{\mathrm{f}}$ & 95 & 86 & 0.95 & 7 & 76 \\
\hline
\end{tabular}

a), b) Umsatz und Ausbeute-Analyse durch ${ }^{\mathrm{I}} \mathrm{H}-\mathrm{NMR}$ der Reaktion

c) Bestimmung durch chirale HPLC-Analyse (Daicel Chiralpak AS), vergleichen mit Racemat-Produkt

d) RRG-Reduzierte Reaktionsgeschwindigkeit (Umsatz(\%)/Reaktionszeit (h)); e) Reaktionszeit:30h,

f) Reaktionszeit: $95 \mathrm{~h}$

Diese leucinhaltige Peptide neben Leu-His-OH (18) wie H-Leu-Arg-OH (26) und H-Leu-Phe$\mathrm{OH}$ (21) sind auch unterschiedlich in ihrer Effizienz (Abb. 8): Aufgrund der Anwesenheit von basischem Guanlidin-Gerüst ergab sich höhere eine Ausbeute mit Peptide 26 als mit 21. 
<smiles>CC(C)C[C@H](N)C(=O)N[C@@H](Cc1ccccc1)C(=O)O</smiles>

H-Leu-Phe-OH (21) $11 \%$ Ausbeute, $76 \%$ ee (Eintrag 4, Tabelle 2)<smiles>CC(C)C[C@H](N)C(=O)N[C@@H](Cc1c[nH]cn1)C(=O)O</smiles>

H-Leu-His-OH (18) $87 \%$ Ausbeute, $71 \%$ ee (Eintrag 1, Tabelle 2)<smiles>CC(C)C[C@H](N)C(=O)N[C@@H](CCCNC(=N)N)C(=O)O</smiles>

H-Leu-Arg-OH (26) $65 \%$ Ausbeute, $40 \%$ ee (Eintrag 9, Tabelle 2)

Abbildung 8. Untersuchte Leucin-haltigen Dipeptide bei der Aldol-Reaktion

Auch Lysin-haltige Peptide wie H-Lys-His-OH (23), H-Lys-Phe-OH (24), H-Lys-Arg-OH (25), H-Lys-Tyr-OH (29), H-Lys-Leu-OH (30) wirken unterschiedlich aktiv und selektiv wegen der unterschiedlichen C-terminaler Aminosäuren.<smiles>NCCCC[C@H](N)C(=O)N[C@@H](Cc1c[nH]cn1)C(=O)O</smiles>

H-Lys-His-OH (23)

$11 \%$ Ausbeute, $26 \%$ ee

Eintrag 6, Tabelle 2<smiles>NCCCC[C@H](N)C(=O)NC(Cc1ccccc1)C(=O)O</smiles>

H-Lys-Phe-OH (24) $78 \%$ Ausbeute, $60 \%$ ee Eintrag 7, Tabelle 2<smiles>N=C(N)NCCC[C@H](NC(=O)[C@H](N)CCCCN)C(=O)O</smiles>

H-Lys-Arg-OH (25) $58 \%$ Ausbeute, $21 \%$ ee Eintrag 8, Tabelle 2<smiles>NCCCC[C@H](N)C(=O)N[C@@H](Cc1ccc(O)cc1)C(=O)O</smiles>

H-Lys-Tyr-OH (29)

$65 \%$ Ausbeute, $53 \%$ ee

Eintrag 12, Tabelle 2<smiles>CC(C)C[C@H](NC(=O)[C@H](N)CCCN)C(=O)O</smiles>

H-Lys-Leu-OH (30)

$80 \%$ Ausbeute, $39 \%$ ee

Eintrag 13, Tabelle 2

Abbildung 9. Untersuchte Lysin-haltigen Dipeptide bei der Aldol-Reaktion 
Es ist interessant, dass das zyklische Dipeptid Cyclo-[(S)-Leu- $(S)$-His] (28) die asymmetrische Strecker-Synthese katalysieren kann, bewiesen von Inoue und Mitarbeiter, ${ }^{34}$ während es für die direkte Aldol-Reaktion unwirksam ist.

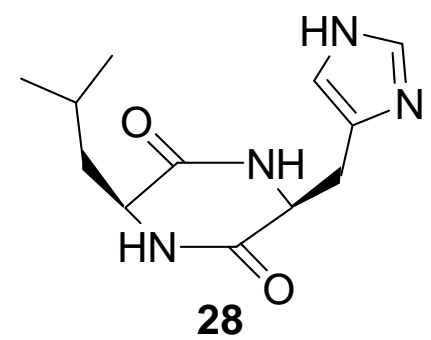

(24\% Ausbeute, 3\% ee, Eintrag 11, Tabelle 2)

Anhand der Ergebnisse kann man Dipeptide zur bifunktionelle Organokatalysator zuordnen. Ein vorgeschlagener Mechanismus zur peptidkatalysierten Aldol-Reaktion wird in Schema 38 gegeben.

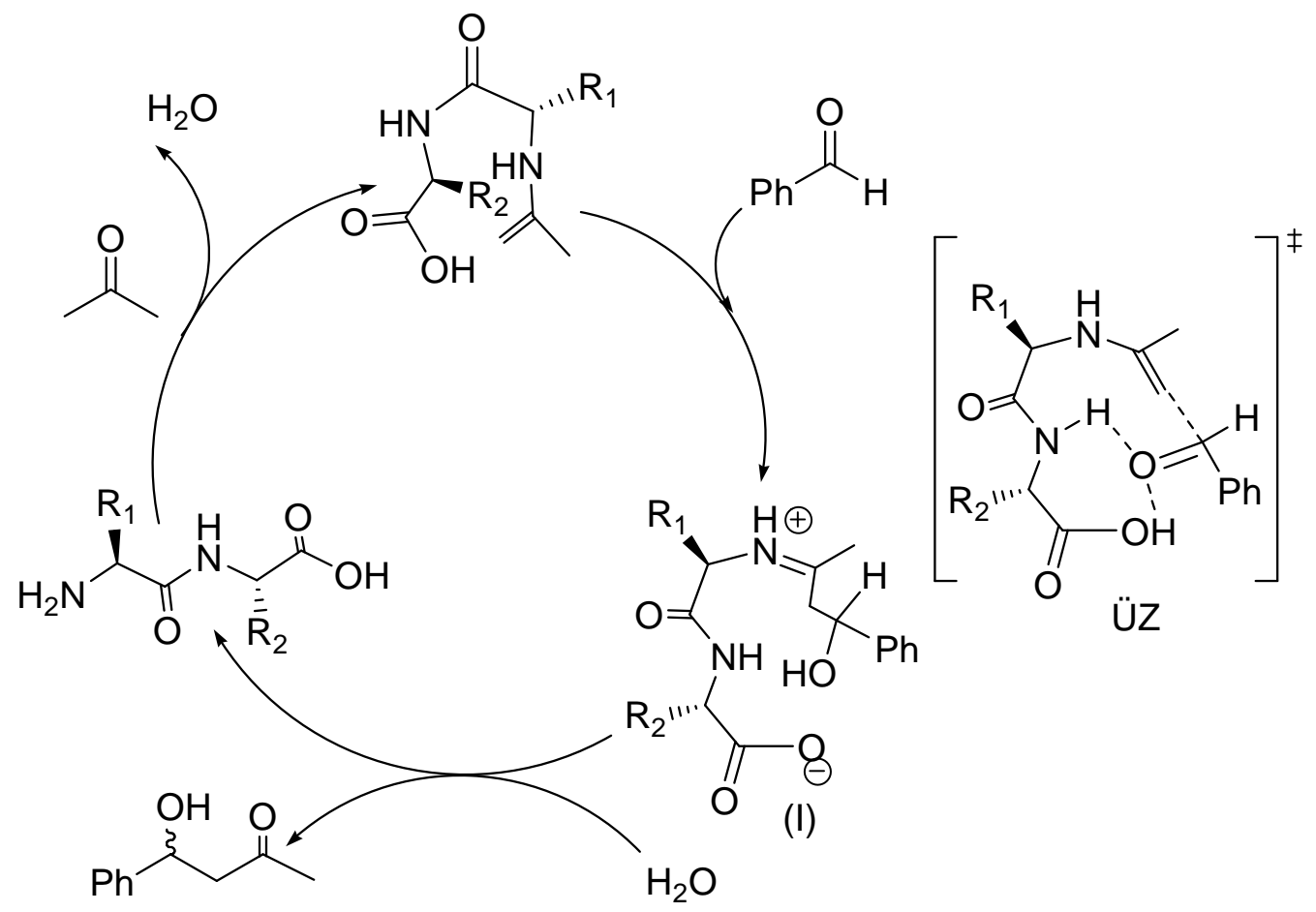

Schema 38. Vermutlicher Mechanismus der durch Dipeptide katalysierten Aldol-Reaktion

Es existieren zwei aktive Zentren. Eines davon liegt am nukleophilen Stickstoffatom, das zu einer freien Amino-Gruppe bzw. zu einem Gerüst wie dem Imidazol-Ring oder GuanidinGerüst gehören, das andere ist die Carboxylgruppe. Aceton wird durch ein freies Elektronpaar 
am Stickstoffatom (Lewis-Base: Sekundäre oder Primäre Amine) fixiert, dabei bildet sich ein Eamin-Intermediat (Schema 38), das leicht mit dem elektrophilen Aldehyd konjugieren kann. Im Übergangszustand (ÜZ, Schema 38) ist die Protonübertragung von der Carboxylgruppe des Peptides auf die Carbonylgruppe des Aldehyds ermöglicht. Das Intermediat (I) wird gebildet. Durch Zugabe von Wasser wandelt sich das Iminium-Ion zur Amino-Gruppe um, wobei der Peptid-Katalysator regeneriert wird.

Ob die ausgewählten besseren Peptide auch erfolgreich andere Aldehyd-Derivate bei der asymmetrischen direkten Aldol-Reaktion katalysieren können, wurde im Folgenden überprüft. Die Ergebnisse werden in Tabelle 3 zusammengefasst.

Unterschiedlich substituierte Benzaldehyde wurden für die Untersuchung verwendet. Bei identischen Peptiden resultierten wegen unterschiedlicher Substitution, beispielsweise 2- und 4Nitrobenzaldehyde, unterschiedliche Ergebnisse. Das Produkt 3 (Eintrag 1, Tabelle 3) entstand mit H-Lys-Phe-OH (24) in einer Ausbeute von 78\% und 60\% ee in 9 Tagen; Produkt 11 (Eintrag 2, Tabelle 3) mit 89\% Ausbeute und 71\% ee in 10 Tagen. Auch H-Pro-Lys(Boc)-OH (5) liefert Produkt 3 (Eintrag 1, Tabelle 4) mit hoher Ausbeute (86\%) und guter Stereoselektivität $(76 \%$ ee) in nur 7 h. Bei Verwendung des gleichen Katalysators ergab sich das Produkt 11 (Eintrag 2, Tabelle 4) mit 91\% Ausbeute und 53\% ee, jedoch in 10 Tagen. Das gleiche Peptid H-His-Leu-OH (32) katalysiert die Aldol-Reaktion zum Produkt 3 (Eintrag 1, Tabelle 3) mit einer Ausbeute von 86\% und 22\% ee in 3 Tagen; das Produkt 11 (Eintrag 2, Tabelle 3) bildet sich durch das gleich Peptid mit einer Ausbeute von 92\% als Racemat. Durch H-His-Phe-OH (31) ergab sich bei beiden Produkten ebenfalls eine unterschiedliche Ausbeute (77\%; 89\% Eintrag 1 und 2) und ein Enantiomerenüberschuss (40\% ee; 60\% ee Eintrag 1 und 2, Tabelle 3). Durch H-Lys-Tyr-OH (29) ergab sich bei beiden Produkten ähnliche Ergebnissen (Eintrag 1 und 2, Tabelle 3). Bei in ortho- und para- Position Chlor-substituierten Benzaldehyden resultierten noch größere Unterschiede in den Ergebnisse bei gleichen Peptiden: H-Leu-His-OH (18) bildet das Produkt 12 (Eintrag 3, Tabelle 3) zu 96\% Ausbeute und 76\% ee in 10 Tagen. Im Gegensatz dazu ergab das Produkt 13 nur 67\% Ausbeute und 60\% ee bei gleicher Reaktionszeit. Durch H-Lys-Tyr-OH (29) ist das Produkt 12 (Eintrag 3, Tabelle 3) bei 57\% Ausbeute und 53\% ee in 10 Tagen entstanden, während sich das Produkt 13 nur zu 36\% Ausbeute aber 78\% ee ebenfalls in 10 Tagen gebildet hat. H-Lys-Phe-OH (24) hat bei dem Produkt 12 (Eintrag 3, Tabelle 3) nur 14\% Ausbeute trotz 59\% ee 
Tabelle 3 Anwendung verschiedener Peptide bei Aldol-Reaktion der unterschiedlichen Aldehyde.

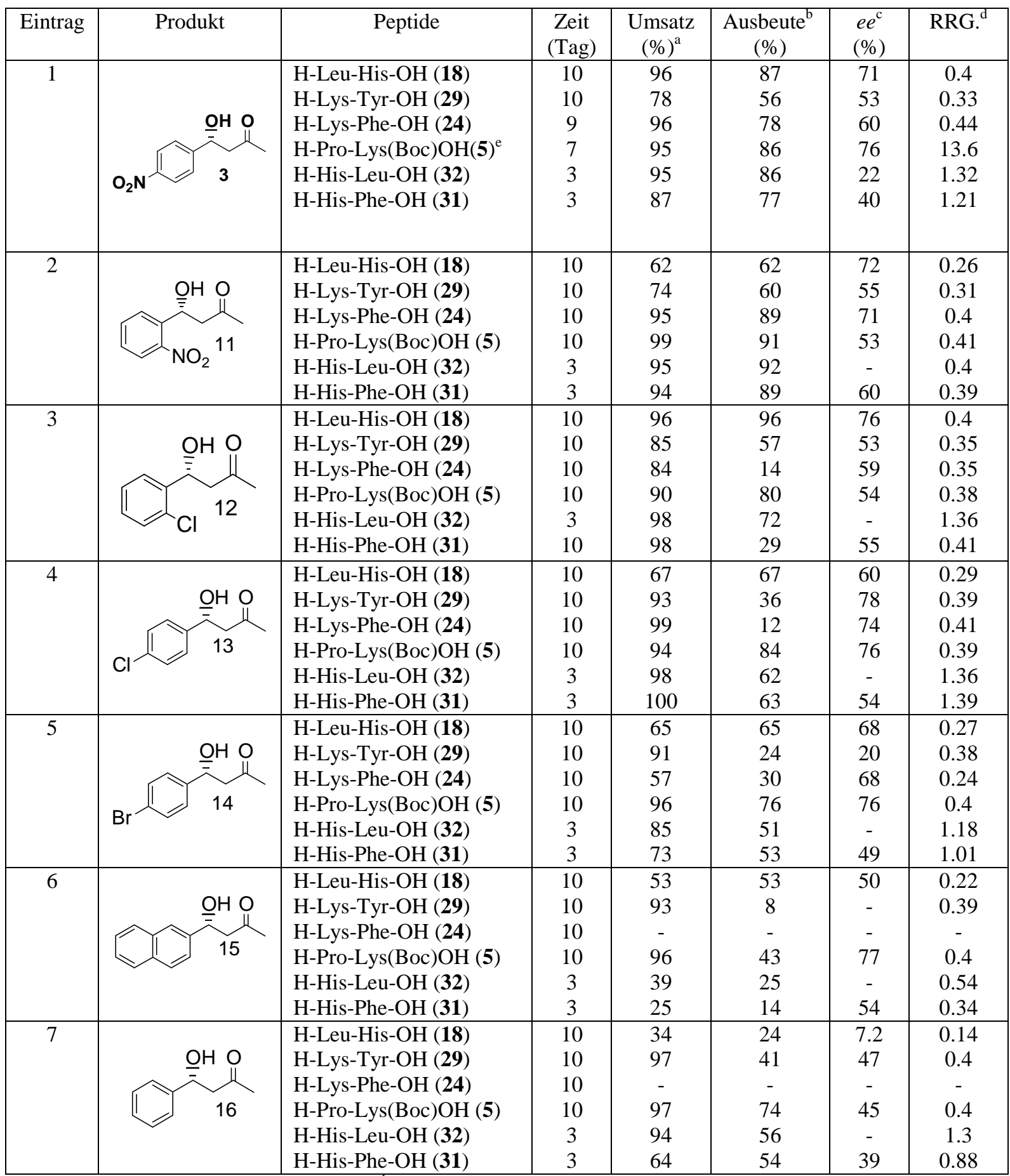

a) b) Umsatz und Ausbeute-Analyse durch ${ }^{1} \mathrm{H}-\mathrm{NMR}$ der Reaktion

c) Bestimmung durch chirale HPLC-Analyse (Daicel Chiralpak AS), vergleichen mit Racemat-Produkt

d) RRG: Reduzierte Reaktionsgeschwindigkeit (Umsatz (\%)/Reaktionszeit (h)); e) Reaktionszeit:7h.

bewirkt. Das Produkt 13 mit ebenfalls geringer Ausbeute (12\%), entstand aber mit relativ höherem Enantiomerenüberschuss (74\% ee). Durch H-His-Leu-OH (32) wurden bei beiden Produkten ähnliche Ausbeuten und gleichermaßen racemische Produkte erhalten. Die unter- 
schiedliche Substitution am Aromaten steuert also die Wechselwirkung des Aldolakzeptors mit dem Enamin-Intermediat (Schema 38) unterschiedlich, da unterschiedlich sterische Hinderungen bei dem nucleophilen Angriff am Aldehyd auftreten können.

Es wurde die entsprechende Reaktion mit einer Gruppe verschiedener aromatischer Aldehyde in Gegenwart des Dipeptids H-Leu-His-OH und 4 anderer Peptide, die vorher als gute Katalysatoren ausgewählt wurden, untersucht. Die effektivste Aldol-Reaktion in Hinsicht auf die Reaktionsausbeute (87\%) und die Enantioselektivität (71\% ee), wurde durch H-Leu-His$\mathrm{OH} 18$ (Aldol-Reaktion von 4-Nitrobenzaldehyd und Aceton) katalysiert. Wir haben beobachtet, dass H-Leu-His-OH die Aldol-Reaktion mit unterschiedlichen aromatischen Aldehyden bei verschiedenen Ausbeuten und Enantioselektivitäten katalysieren kann. Im Vergleich zu anderen Peptiden ist der Unterschied jedoch relativ gering. Die Varianz in der Ausbeute und dem eeWert ist abhängig von den spezifischen Eigenschaften des benutzten Substrats. Die Bildung vieler anderer Adolkondensationsprodukte wurde ebenfalls untersucht (Tabelle 3). Es ist auch interessant zu erwähnen, dass eine gute Ausbeute (bis zu 96\%) und Enantioselektivität bis 78\% durch elektronenarme Aldehyde wie z.B. 2- oder 4-Nitrobenz-aldehyd; 2- oder 4-Chlorbenzaldehyd erreicht werden können, (Einträge 1-5, Tabelle 3) im Gegensatz zu den weniger aktiven Naphthyl- und Benzaldehyd. (Einträge 6-7, Tabelle 3).

Zusammenfassend ist Dipeptid H-Leu-His-OH 18 der am aktivsten. Mit dem bildet sich das Aldol-Produkt mit $R$-Konfiguration. Anhand unserer Ergebnisse können wir eine Arbeitshypothese für den H-Leu-His-OH-Katalysator folgend vorschlagen (Abb. 10):

Der Aldehyd kann über nicht-kovalente Wechselwirkungen, nämlich Wasserstoffbrückenbindungen mit der NH-Gruppe der Peptidbindung und der Carboxylgruppe des Dipeptides aktiviert und orientiert werden. Das an der N-terminalen Aminogruppe gebildete Enamin greift dann den Benzaldehyd von der Re-Seite an. Das kann die bevorzugte Bildung des $R$-Enantiomers erklären.

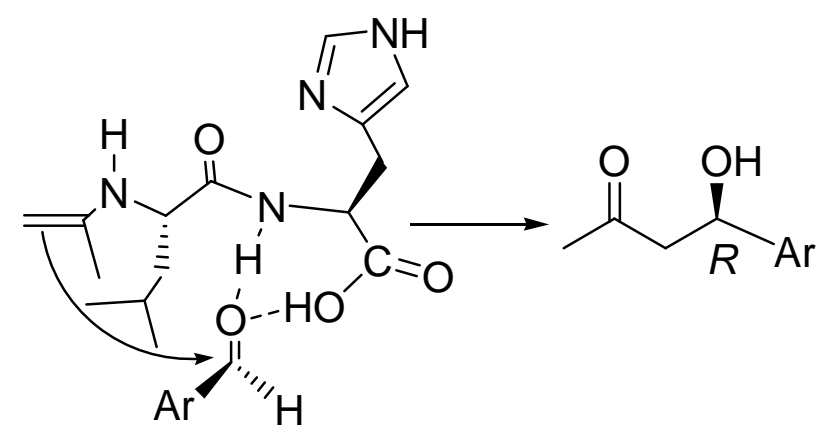

Abbildung 10. Arbeitshypothese des Dipeptids (H-Leu-His-OH 18) bei der Aldol-Reaktion 
Die aktive Konformation des Dipeptid-Katalysators kann durch eine Wasserstoffbrückenbindung zwischen dem basischen Stickstoffatom des Imidazols im Histidin und der freigebliebenen terminalen NH-Gruppe stabilisiert werden.

Aus dieser Arbeitshypothese ist der bifunktionelle Charakter des Dipeptid-Katalysators deutlich erkennbar, da dieser sowohl den Donor als auch den Akzeptor aktiviert.

Um zu wissen, ob die unterschiedliche Sequenz der Aminosäuren, die bei der Verknüpfung von Peptiden verwendet wird, auch bei katalytischen Wirkungen eine große Rolle spielt, unter gleichen Reaktionsbedingungen haben wir das Peptid H-His-Leu-OH 32, mit dem eine umgekehrte Sequenz gegenüber dem besten Peptid H-Leu-His-OH 18 hat (Abb. 11), und HPhe-His-OH 33, das mit umgekehrtem Sequenz gegenüber H-His-Phe-OH 31 hat (Abb.11), untersucht. Die Ergebnisse werden in der Tabelle 4. zusammengestellt.

Die Reaktivitäten und Stereoselektivitäten scheinen abhängig von intramolekularen Wechselwirkungen der Seitenkette und funktionelle Gruppe sowie der passenden Kombination und Sequenz der Aminosäuren zu sein (Abbildung 11). Peptid H-His-Leu-OH 32 hat eine umgekehrte Sequenz der Aminosäurenreste, ist daher weniger stereoselektiv als Peptid H-LeuHis-OH 18. Es zeigt auch eine höhere Umwandlungsrate (Reduzierte Reaktionsgeschwindigkeit: 1.31 mit H-His-Leu-OH 32 gegenüber 0.40 mit H-Leu-His-OH 18, Tabelle. 4). Das interessante Ergebnis ist, dass ein schlechter ee-Wert und Ausbeute beim Produkt 3 mit Katalysator 32 (86\% Ausbeute, 22\% ee) als mit 18 (87\% Ausbeute, 71\% ee) entstehen. Im Beispiel von H-HisPhe-OH 31 und H-Phe-His-OH 33 haben wir zwar ähnliche Ergebnisse bezüglich der Enantioselektivität erhalten: (H-His-Phe-OH (31) 40\% ee; H-Phe-His-OH (33) 27\% ee), jedoch ein umgekehrtes Verhalten bezüglich der Reduzierten Reaktionsgeschwindigkeit (His-Phe-OH (31) 1.21; H-Phe-His-OH (33) 0.48) beobachtet. Im Hinblick auf die Position des basischen Rests kann man sagen, dass H-His-Phe-OH 31 die Reaktion viel schneller katalysiert und daher bessere ee Wert (Tabelle 4, Reduzierte Reaktionsgeschwindigkeit 1.21; 77\% Ausbeute, 40\% ee, Eintrag 3, Tabelle 4) als H-Phe-His-OH 33 (Reduzierte Reaktionsgeschwindigkeit 0.48; 79\% Ausbeute; 27\% ee, Eintrag 4, Tabelle. 4) liefert. Wir vermuten, dass die Unterschiede in der Selektivität, die bei der Katalyse mit diesen Peptiden beobachtet wurden, von einer Kombination sterischer und struktureller Einflüsse verursacht werden. 
<smiles>CC(C)C[C@H](NC(=O)[C@H](N)Cc1c[nH]cn1)C(=O)O</smiles>

H-His-Leu-OH (32) $86 \%$ Ausbeute, $22 \%$ ee (Eintrag 1, Tabelle 4)<smiles>CC(C)C[C@H](N)C(=O)N[C@@H](Cc1c[nH]cn1)C(=O)O</smiles>

H-Leu-His-OH (18) $87 \%$ Ausbeute, $71 \%$ ee (Eintrag 2, Tabelle 4)<smiles>N[C@@H](Cc1ccccc1)C(=O)N[C@@H](Cc1c[nH]cn1)C(=O)O</smiles>

$\mathrm{H}-\mathrm{Ph}-\mathrm{His}-\mathrm{OH}$ (33) 79\% Ausbeute, 27\% ee (Eintrag 4, Tabelle 4)<smiles>NC(Cc1c[nH]cn1)C(=O)N[C@@H](Cc1ccccc1)C(=O)O</smiles>

$\mathrm{H}-\mathrm{His}-\mathrm{Phe}-\mathrm{OH}$ (31)

$77 \%$ Ausbeute, $40 \%$ ee (Eintrag 3, Tabelle 4)

Abbildung 11. Die untersuchten Dipeptide mit unterschiedlichen Sequenzen der Aminosäuren

Des Weiteren stellt sich die Frage, ob die Aminosäuren asymmetrische Aldol-Reaktion für sich allein oder als Mischung katalysieren. Die Ergebnisse dieser weiteren Untersuchungen sind in der Tabelle 4 zusammengefasst.

Die separat eingesetzten Aminosäuren, die als Bauteil für Peptide fungiert, funktionieren schlechter als die daraus aufgebauten Peptide. Mit H-Lys-Tyr-OH (29) bildet sich Produkt 3 mit einer Ausbeute von 56\% und einem ee von 53\% (Eintrag 1, Tabelle 4). Produkt 3 bildet sich mit 41\% Ausbeute und 31\% ee bei einer Mischung von 15 Mol-\% H-Lys-OH und 15 Mol\% H-Tyr-OH (Eintrag 11, Tabelle 4). während 56\% (Ausbeute) Produkt 3 mit 28\% ee bei der Zugabe von 30 Mol-\% L-Tyr-OH (Eintrag 7, Tabelle. 4) und 51\% Ausbeute und 39\% ee bei der Verwendung von 30 Mol-\% L-Lys-OH erhalten werden (Eintrag 8, Tabelle. 4). Die Resultate von Eintrag 3, Eintrag 12 (Tabelle 4) Eintrag 6 
Tabelle 4 Untersuchung verschiedener Peptide und Aminosäure<smiles>CC(=O)CC(O)c1ccc([N+](=O)[O-])cc1</smiles>

\begin{tabular}{|c|l|c|c|c|c|l|}
\hline Eintrag & \multicolumn{1}{|c|}{ Katalysator } & $\begin{array}{c}\text { Zeit } \\
(\mathrm{Tag})\end{array}$ & $\begin{array}{c}\text { Umsatz } \\
(\%)^{\mathrm{a}}\end{array}$ & $\begin{array}{c}\text { RRG. } \\
(\%)^{\mathrm{b}}\end{array}$ & $\begin{array}{c}\text { Ausbeute } \\
(\%)^{\mathrm{c}}\end{array}$ & \multicolumn{1}{c|}{$\begin{array}{l}e^{\mathrm{e}} \\
(\%)\end{array}$} \\
\hline 1 & H-His-Leu-OH (32) & 3 & 94 & 1.31 & 86 & 22 \\
\hline $\mathbf{2}$ & H-Leu-His-OH (18) & $\mathbf{1 0}$ & $\mathbf{9 6}$ & $\mathbf{0 . 4}$ & $\mathbf{8 7}$ & $\mathbf{7 1}$ \\
\hline 3 & H-His-Phe-OH (31) & 3 & 87 & 1.21 & 77 & 40 \\
\hline 4 & H-Phe-His-OH (33) & 8 & 92 & 0.48 & 79 & 27 \\
\hline 5 & L-Arg-OH & 4 & 98 & - & 60 & 2 \\
\hline 6 & L-His-OH & 4 & 81 & - & 66 & 41 \\
\hline 7 & L-Tyr-OH & 4 & 92 & - & 56 & 28 \\
\hline 8 & L-Lys-OH & 4 & 95 & - & 51 & 39 \\
\hline 9 & L-Phe-OH & 4 & 59 & - & 38 & 26 \\
\hline 10 & H-Imdazol & 20 & 25 & - & 6 & - \\
\hline 11 & $\begin{array}{l}15 \text { Mol-\% H-Lys-OH; } \\
15 \text { Mol-\% H-Tyr-OH }\end{array}$ & 4 & 80 & - & 41 & 31 \\
\hline 12 & $\begin{array}{l}15 \text { Mol-\% H-His-OH; } \\
15 \text { Mol-\% H- Phe-OH }\end{array}$ & 4 & 93 & - & 68 & 20 \\
\hline 13 & $\begin{array}{l}15 \text { Mol-\% H-Lys-OH; } \\
15 \text { Mol-\% H- Phe-OH }\end{array}$ & 4 & 89 & - & 57 & 28 \\
\hline
\end{tabular}

a),c) Umsatz und Ausbeute-Analyse durch ${ }^{1} \mathrm{H}-\mathrm{NMR}$ der Reaktion e) Bestimmen durch chirale HPLC-Analyse (Daicel Chiralpak AS), vergleichen mit Racemat-Produkt, b) Reduzierte Reaktionsrate: RRG-Reduzierte Reaktionsgeschwindigkeit (Umsatz(\%)/Reaktionszeit (h))

und 9 zeigen ebenfalls, dass ein Peptid effektiver ist als die gemischt oder separat eingesetzten Aminosäuren. Die zwei Gruppen (Einträge 8, 9 und Eintrag 13, Tabelle 4) und (Eintrag 7, 8 und Eintrag 11, Tabelle 4) geben ein ähnliches Resultat, nämlich dass gemischte Aminosäuren effektiver als die separat eingesetzten sind. 
Diese Untersuchungen beweisen, dass nicht nur die funktionelle Gruppe sondern auch eine richtige Kombination, sowie die Sequenz der Aminosäuren für Aktivität und Selektivität des Peptid-Katalysators wichtig sind.

\subsubsection{Untersuchung der Aktivität der Koordination von Katalysator und Co-Katalysator}

Der homogene asymmetrische Katalysator wurde nur bei der Hydrierung, ${ }^{82}$ Isomerisierung, ${ }^{83}$ Cycloaddition, ${ }^{84}$ und Epoxidierung ${ }^{85}$ erfolgreich in der industriellen Chemie eingesetzt. Obwohl sehr häufig ee-Werte von $90 \%$ bis $95 \%$ möglich sind, ist aber, insbesondere bei der pharmazeutischen Beurkundung ein $e e$-Wert bis zu $99 \%$ und sogar noch höher erforderlich. ${ }^{86}$ Um derart exzellente ee-Werte $\mathrm{zu}$ erreichen, ist es notwendig, die Enantioselektivität, die Aktivität und die Stabilität der verwendeten Katalysatoren zu verbessern.

Die Tatsache, dass geeignete achirale oder chirale Additive als Co-Katalysatoren die Ausbeute, in vielen Fällen auch die Enantioselektivität erhöhen können, wurde von Shibasaki ${ }^{87}$ und Mitarbeitern in ihren Veröffentlichungen umfangreich diskutiert. Das Peptid H-Leu-His-OH (18) katalysiert gut bei der asymmetrischen direkten Aldol-Reakton (87\% Ausbeute und 71\% $e e$ ), die Reaktionszeit ist dabei jedoch zu lang (10 Tage). Um zu erfahren, ob man auch diese Reaktion durch Zugabe von Additiven beschleunigen kann, wurde eine Aldol-Reaktion zwischen Aceton und 4-Nitrobenzaldehyd in Anwesenheit des Katalysators H-Leu-His-OH (18) und verschiedenen Co-Katalysatoren (Abb. 12) getestet.

Wir haben bevorzugt chirale $(34,35,37,41,43$ und 44) und achirale $(40,36,38,39)$ Basen mit unterschiedlicher Basizität als Additive gewählt. Laut Literatur ${ }^{72}$ können sie bei der Bildung von aktiven Intermediaten (Enamin) mitwirken und die Reaktion beschleunigen. Bei den Untersuchungen wurden 10 Mol-\% Co-Katalysator, vom Peptid-Katalysator 30 Mol-\% gegenüber der Substanz eingesetzt, damit die Additive keine überwiegende Wirkung gegenüber dem Katalysator haben. Katalysatoren und Additive wurden gleichzeitig zu einer Mischung von getrocknetem DMSO und Aceton (Volumenverhältnis: 1:4) zugegeben, und bei RT unter Stickstoffatmosphäre so lange gerührt, bis die Reaktion abgeschlossen ist. Der Verlauf der Reaktion wurde durch DC verfolgt. Anschließend wurde zur Aufarbeitung eine entsprechende Menge gesättigter $\mathrm{NH}_{4} \mathrm{Cl}$-Lösung zugegeben, extrahiert und aufgereinigt. 
<smiles>CC(N)[C@H](O)c1ccccc1</smiles>

34<smiles>C[C@H](N)c1ccccc1</smiles>

35<smiles>CN(C)C(=N)N(C)C</smiles>

36

L-Norephedrin

(R)-Phenylethylamin

1,1,3,3-Tetrametylguanidin<smiles>N[C@H](c1ccccc1)[C@H](N)c1ccccc1</smiles>

37<smiles>C1CCC2=NCCCN2CC1</smiles>

38<smiles>N=C(Nc1ccccc1)Nc1ccccc1</smiles>

39

1S,2S-1,2-Diphenylethyldiamin

DBU

1,3-Diphenylguanidin<smiles>C[C@H]1CN[C@H](C)CN1</smiles>

40<smiles>N[C@@H](CC(=O)O)C(=O)O</smiles>

41<smiles>C[C@H]1CNCCN1</smiles>

43<smiles>C[C@@H]1CNCCN1</smiles>

44

trans-2,5-Dimethylpiperazin L-Asparaginsäure (R)-2-Methylpiperazin (S)-2-Methylpiperazin

Abbildung 12. Verschiedene Additive als Co-Katalysatoren für die Aldol-Reaktion

Die Aldol-Reaktion von 4-Nitrobenzaldehyd und Aceton wurde unter Verwendung des Peptids H-Leu-His-OH mit Additiv durchgeführt. Um den Einfluss des Additivs zu beurteilen, wurde die gleiche Reaktion auch nur mit Additiv getestet. Die Ergebnisse werden in Tabelle 5 zusammengestellt.

Die Reaktionszeit wurde in Gegenwart von (R)-2-Methylpiperazin 43 (0.3 Äq) von 168 h (56\% Umsatz, Eintrag 9, Tabelle 5) auf 25 h, bei der Kombination von (R)-2-Methylpiperazin (0.1 Äq) mit Kat. 18 (80\% Umsatz, Eintrag 19; Tabelle 5), verkürzt. Bei Anwesenheit seines Enantiomers, $(S)$-2-Methylpiperazin 44 (0.1 Äq), wurde die Reaktionszeit von 168 h (48\% Eintrag 10, Tabelle 5) auf 72 h (gleich mit Kat. 18) reduziert (90\% Umsatz, Eintrag 20, Tabelle 5). Ähnliche Resultate wurden auch bei weiteren chiralen Co-Katalysatoren beobachtet: LNorephedrin 34 (Eintrag 1: 10 Tage, 72\% Umsatz; Eintrag 11 mit Kat. 18: 72 h, 96\%), $(R)$ Phenylethylamin 35 (Eintrag 2: 10 Tage, 53\%; Eintrag 12 mit Kat. 18: 72 h, 84\% Umsatz) 
Tabelle 5 Verwendung der Co-Katalysatoren bei der direkten Aldol-Reaktion<smiles>CC(C)=O</smiles>

\begin{tabular}{|c|c|c|c|c|c|c|c|}
\hline Eintrag & $\begin{array}{l}\text { Kat. } \\
(\ddot{A ̈ q})\end{array}$ & Co-Katalysator & Zeit & $\begin{array}{c}\text { Umsatz } \\
(\%)^{\mathrm{a}}\end{array}$ & RRG. $^{\text {d }}$ & $\begin{array}{c}\text { Ausbeute } \\
(\%)^{\mathrm{b}}\end{array}$ & $\begin{array}{l}e e^{\mathrm{c}} \\
(\%)\end{array}$ \\
\hline 1 & - & (34) L-Norephedrin (0.3) & $240 \mathrm{~h}$ & 72 & 0.3 & 54 & 2 \\
\hline 2 & - & (35) $(R)$-Phenylethylamin $(0.3)$ & $240 \mathrm{~h}$ & 53 & 0.22 & 28 & 4 \\
\hline 3 & - & (36) $1,1,3,3$-Tetrametylguanidin $(0.3)$ & $4 \mathrm{~h}$ & 100 & 25 & 95 & 0 \\
\hline 4 & - & $\begin{array}{ll}\mathbf{3 7}) & 1 R, 2 R-1,2-D i p h e n y l e t h y l d i a m i n \\
(0.3)\end{array}$ & $408 \mathrm{~h}$ & 35 & 0.09 & 10 & 0.5 \\
\hline 5 & - & (38) DBU $(0.3)$ & 40 min. & 100 & 150 & 98 & 0 \\
\hline 6 & - & (39) Diphenylguanidin (0.3) & $4 \mathrm{~h}$ & 100 & 25 & 81 & 0 \\
\hline 7 & - & (40) trans-2,5-Dimethylpiperazin (0.3) & $168 \mathrm{~h}$ & 28 & 0.17 & 26 & 0 \\
\hline 8 & - & (41) L-Asparaginsäure (0.3) & $120 \mathrm{~h}$ & 86 & 0.72 & 65 & 14 \\
\hline 9 & - & (43) (R)-2-Methylpiperazin $(0.3)$ & $168 \mathrm{~h}$ & 56 & 0.33 & 56 & 1 \\
\hline 10 & - & (44) (S)-2-Methylpiperazin $(0.3)$ & $168 \mathrm{~h}$ & 48 & 0.35 & 48 & 1 \\
\hline 11 & 18 & L-Norephedrin $(0.1)$ & $72 \mathrm{~h}$ & 96 & 1.33 & 86 & 42 \\
\hline 12 & 18 & $(R)$-Phenylethylamin $(0.1)$ & $72 \mathrm{~h}$ & 84 & 1.17 & 78 & 43 \\
\hline 13 & 18 & $1,1,3,3$-Tetrametylguanidin $(0.1)$ & $72 \mathrm{~h}$ & 91 & 1.26 & 90 & 40 \\
\hline 14 & 18 & $1 R, 2 R$-1,2-Diphenylethyldiamin $(0.1)$ & $96 \mathrm{~h}$ & 87 & 0.91 & 80 & 55 \\
\hline 15 & 18 & DBU $(0.1)$ & $2 \mathrm{~h}$ & 97 & 48.5 & 95 & 8 \\
\hline 16 & 18 & Diphenylguanidin (0.1) & $4 \mathrm{~h}$ & 100 & 25 & 89 & 0 \\
\hline 17 & 18 & trans-2,5-Dimethylpiperazin $(0.1)$ & $22 \mathrm{~h}$ & 97 & 4.41 & 97 & 55 \\
\hline 18 & 18 & L-Asparaginsäure (0.1) & $72 \mathrm{~h}$ & 97 & 1.35 & 87 & 44 \\
\hline 19 & 18 & $(R)$-2-Methylpiperazin $(0.1)$ & $25 \mathrm{~h}$ & 80 & 3.2 & 80 & 53 \\
\hline 20 & 18 & $(S)$-2-Methylpiperazin $(0.1)$ & $72 \mathrm{~h}$ & 90 & 1.25 & 90 & 42 \\
\hline 21 & 18 & (45) Wasser (10) & $96 \mathrm{~h}$ & 89 & 0.93 & 62 & 54 \\
\hline 22 & 33 & (45) Wasser (10) & $96 \mathrm{~h}$ & 53 & 0.55 & 34 & 21 \\
\hline 23 & 21 & (45) Wasser (10) & $96 \mathrm{~h}$ & 100 & 1.04 & 60 & 72 \\
\hline
\end{tabular}

a),b) Umsatz und Ausbeute-Analyse durch ${ }^{1} \mathrm{H}-\mathrm{NMR}$ der Reaktion; c) Bestimmung durch chirale HPLC-Analyse (Daicel Chialpak AS), verglichen mit Racemat-Produkt; d) RRG-Reduzierte Reaktionsgeschwindigkeit (Umsatz(\%)/Reaktionszeit (h)) 
und L-Asparaginsäure 41 (Eintrag 8: 120 h, 86\% Umsatz; Eintrag 18 mit Kat. 18: 72 h, 97\%). Ein Kondensationsprodukt wurde bei Einsatz von $(R)$-2-Methylpiperazin und (S)-2-Methylpiperazin (Tabelle 5, Einträge 19 und 20 mit Kat. 18) auch allein (Eintrag 9, 10) nicht beobachtet. Der Co-Katalysator $(1 R, 2 R)$-1, 2-Diphenylethyldiamin zeigt eine Zeitverkürzung von 408 h (Eintrag 4, 35\% Umsatz) auf 96 h (Eintrag 14 mit Kat. 18, 87\% Umsatz). Der Gebrauch von L-Norephedrin, $(R)$-Phenylethylamine, $(R)$-2-Methylpiperazine und LAsparaginsäure als Co-Katalysatoren bewirkt eine Reduzierte ReaktionsgescgwindigkeitVerkürzung und Erhöhung der Ausbeute, jedoch leisten alle o.g. Co-Katalysatoren keinen Beitrag zur Erhöhung der Enantioselektivität.

Des weiteren wurden 1,1,3,3-Tetramethylguanidine 36 und trans-2,5-Dimethylpiperazine $\mathbf{4 0}$ als achirale Co-Katalysatoren getestet, welche bereits von Hanessian und $\mathrm{Pham}^{88}$ als Additive für L-Prolin-katalysierte konjugierte Additionen verwendet worden sind. Während allein trans-2,5Dimethylpiperazin das Produkt mit 26\% Ausbeute in 168 h (Eintrag 7, Tab. 6) entstehen lässt, produziert 1,1,3,3-Tetramethylguanidin ohne Co-Katalysator das Aldolprodukt mit einer Ausbeute von 95\% innerhalb von 4 h (Eintrag 3, Tab. 6). Diese Ergebnisse lassen vermuten, dass die Applikation von 1,1,3,3-Tetramethylguanidin als Co-Katalysator die Reaktionsrate im Gegensatz zu trans-2,5-Dimethylpiperazin verbessern könnte. Shibasaki und Mitarbeiter ${ }^{80}$ haben bereits berichtet, von der Schwierigkeit vorteilhafte Variationen von Additiven abzuschätzen.

In der Tat ist es überraschend, dass die Kombination aus den Dipeptiden H-Leu-His-OH und 1, 1, 3, 3-Tetramethylguanidin ein Produkt mit einer 90\%igen Ausbeute und $40 \%$ ee in $72 \mathrm{~h}$ (Eintrag 13, Tab. 6) liefert während die Kombination von H-Leu-His-OH und trans-2,5Dimethylpiperazin das Aldolprodukt mit einer Ausbeute von 97\% und 55\% ee in nur $22 \mathrm{~h}$ produziert (Tab. 6, Eintrag 17). Ein Kondensationsprodukt wurde in keinem Fall beobachtet. Die Kombination von DBU und Diphenylguanidin ergibt überraschend eine Erhöhung der reduzierten Reaktionsgeschwindigkeit (Eintrag 5, 150; Eintrag 15, 48.5 (mit Kat. 18) und Eintrag 6, 16 (mit Kat. 18)). Dies reduziert zwar die Reaktionszeit, resultierte aber in einer niedrigeren Enantioselektivität (Eintrag 15, 8\% ee) oder Racematbildung (Eintrag 16). Im Vergleich $\mathrm{zu}$ anderen Co-Katalysatoren leistet $1 R, 2 R$-1,2-Diphenylethyldiamin (Eintrag 14, Tab. 6) sowohl in Ausbeute als auch in Enantioselektivität einen großen Beitrag (96 h, 80\% Ausbeute; 55\% ee). Immerhin ist dieses weniger aktiv als trans-2,5-Dimethylpiperazin 40. Eine höhere Reaktionsrate zeigt sich allgemein bei Einsatz des Dipeptids H-Leu-His-OH mit CoKatalysator im Gegensatz zur alleinigen Verwendung des Dipeptids (H-Leu-His-OH 18, Eintrag 2, Tab. 5; oder Eintrag 1, Tab. 4) oder des Co-Katalysators (Eintrag 1-10, Tab. 6). 
Besonders nennenswert ist die katalytische Aktivität des achiralen trans-2,5-Dimethylpiperazin mit exzellenter Ausbeute (bis 97\%) und einer Enantioselektivität bis 55\% ee (Eintrag 17, Tabelle 5, vgl. 71\% ee, Tabelle 4, Eintrag 2). Die erhaltenen Ergebnisse demonstrieren, dass die alleinige Verwendung der Co-Katalysatoren nur 0-14\% ee (Eintrag 1-10, Tabelle 5) bewirkt. Der dominante Einfluss auf Ausbeute und ee-Werte (Einträge 11-23) rührt also vom Dipeptid H-Leu-His-OH her.

Diese Ergebnisse beweisen, dass der Einsatz geeigneter Co-Katalysatoren mit passender Chiralität höhere eine Ausbeute und Enantioselektivität erzielt, sowie beschleunigte Reaktionen ohne Nebenprodukte ermöglichen kann.

Als weiterer Co-Katalysator wurde Wasser gewählt, das ein wichtiges Medium für fast alle enzymatischen Reaktionen in lebenden Organismen ist. Die Aldolase, die stereoselektiv AldolReaktionen katalysieren kann, hat sich im wässrigen Medium entwickelt. ${ }^{89}$ Ohne Wasser funktioniert keine biologische Entwicklung. Ob die von Peptiden katalysierte Aldol-Reaktion auch in wässerigen Medin effizient verlaufen kann, wurde weiter unter gleichen Bedingungen untersucht. Beim Katalysator H-Leu-His-OH (18) und Kat. 33 wurde die Reaktion nach Zugabe von Wasser behindert. Sowohl Ausbeute also auch Enantioselektivität wurden reduziert, (mit Kat. 18: von 87\% Ausbeute, 71\% ee (Eintrag 1, Tabelle 2) auf 62\% Ausbeute, 54\% ee (Eintrag 21, Tabelle 5)), obwohl die Reduzierte Reaktionsgeschwindigkeit sich von 0.67 (Eintrag 1, Tabelle 4) auf 0.93 (Eintrag 21, Tabelle 6) erhöht hat. Von Kat. 33 wurden ebenfalls beide Parameter (Ausbeute und Enantioselektivität) verschlechtert, (von 79\% Ausbeute und 27\% ee (Eintrag 4, Tabelle 4) auf 34\% Ausbeute und 21\% ee (Eintrag 22, Tabelle 5). Auch hier ist die Reduzierte Reaktionsgeschwindigkeit erhöht. Wasser scheint ein Beschleunigungsmittel in vielen organischen Reaktionen zu sein. Vermutlich stört Wasser einerseits die Bildung der Wasserstoffbrückenbindung zwischen dem Peptid und der umzusetzenden Substanz, andererseits beeinflusst das Wasser den Phasen-Transfer im zweiphasigen Medium, da sich Peptide eher in der wässrigen Phase lösen, und somit eine katalytische Funktion erschweren. Eine Ausnahme bildet Kat. 21 wahrscheinlich wegen seiner Polarität bei Zugabe von Wasser eine bessere Ausbeute und eine Zunahme des ee-Wertes (von 18\% Ausbeute, 67\% ee (Eintrag 4. Tabelle. 2) auf 60\% Ausbeute, 72\% ee (Eintrag 23, Tabelle 5), auch die Reduzierte Reaktionsgeschwindigkeit vergrößert sich von 0.11 auf 1.04 .

Zum ersten Mal wurden die Struktur-Aktivitäts-Beziehungen für lineare $(S)$-Histidin basierte Dipeptid Katalysatoren durch mehrere Untersuchungen an bekannten Aldol-Reaktionen beschrieben. 
Die Reaktivität und Stereoselektivität scheinen abhängig von den intramolekularen Wechselwirkungen der Seitenketten, funktionellen Gruppen sowie einer passenden Kombination und Sequenz der Aminosäuren zu sein.

Die Einsatzmöglichkeit eines ausgewählten Dipeptid Katalysators (H-Leu-His-OH) wurde gezeigt. Hohe Ausbeute (bis 96\%) und gute Enantioselektivitäten (bis 76\% ee) wurden am aromatischen Aldehyd gezeigt.

Weiterhin wurde der Einfluss verschiedener chiraler und achiraler Co-Katalysatoren auf die Reduzierte Reaktionsgeschwindigkeit, Ausbeute und Enantioselektivität untersucht. Signifikantes Wachstum der Reduzierte Reaktionsgeschwindigkeit, insbesondere für achirales trans-2, 5-Dimethylpiperazin (22 h Reaktionszeit) bei verbesserter Ausbeute und mäßigem Enantioselektivitäten, wurden entdeckt.

\subsubsection{Verwendung der Dipeptide bei der Baylis-Hillmann Reaktion}

Peptide als Katalysatoren für die Baylis-Hillman Reaktionen ${ }^{90}$ wurden von Miller und Mitarbeitern entwickelt. In dieser Arbeit wurden die Peptid-Katalysatoren 10, 16, 24, 29, 30, 32 analoge Verbindungen 46, 47, 48, 49 und die tertiäre Base 50 für die Baylis-Hillmann Reaktion zwischen Benzaldehyd und Vinylketon ausprobiert.

Gemäß den Arbeiten von Nagasawa, ${ }^{91}$ bei den thioharnstoffhaltigen Katalysatoren mit Peptidgruppe für die Baylis-Hillman Reaktion entwickelt wurden, sind Verbindungen 46, 47 und 49 (Abb. 13) als Katalysator für die weitere Forschung geplant. Sie können einerseits als Nucleophil (Base) fungieren, so dass Ketone oder Aldehyde aktiviert werden, andererseits können Wasserstoffbrückenbindungen zwischen Edukt und 46 bzw. 47 und 49 gebildet werden, ${ }^{92}$ und damit die Reaktion beschleunigt werden. Verbindung 48 wurde von D. Yalolov hergestellt, und wegen der Anwesenheit eines relativ stark basischen Imidazolrings und Wasserstoff-Donors im Thioharnstoff-Gerüst für die Baylis-Hillman-Reaktion getestet. Die Anwendung von Verbindung 50 diente dazu, die Rolle von DMAP bei der Baylis-Hillmann Reaktion aufzuklären. Für weitere Synthesen von Katalysatoren könnte bei entsprechenden Resultaten ein DMAP-Grüst in einen Katalysator eingefügt werden. 
<smiles>CC(NC(=S)NC(=O)C1CCCN1)c1ccccc1</smiles><smiles>C[C@H](NC(=S)N[C@H]1CCCC[C@H]1N=Cc1ncc[nH]1)c1ccccc1</smiles><smiles>CN(C)c1ccncc1</smiles>

50

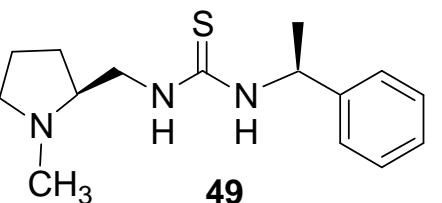

Abbildung 13. Bei der Baylis-Hillman als Katalysatoren verwendete Verbindungen, davon ist Verbindung 48 von D. Yalolov hergestellt worden

\subsubsection{Darstellung von peptidanalogen Verbindungen 46, 47,49}

Verbindung 46 kann man aus den preiswerten Ausgangssubstanzen L-Prolin (Schema 39), $\mathrm{CS}_{2}$ und Phenylethylamin in fünf Stufen darstellen. Z-geschütztes L-Prolin wurde als erste wichtige Verbindung durch literaturbekannte Methoden ${ }^{93}$ mit Hilfe der Base TEA (oder $\mathrm{NaHCO}_{3}$ in Wasser) und Cbz-Cl in das Produkt 52 bei einer Ausbeute von 99\% überführt. Z-Prolin-chlorid 53 kann man entweder mit Oxalylchlorid ${ }^{94}$ oder Thionylchlorid ${ }^{95}$ durch eine $\mathrm{S}_{\mathrm{N}} 2$-Reaktion in guter Ausbeute von 90-100\% darstellen. Aufgrund der geringen Stabilität der Verbindung 53 wurde sie nicht aufgereinigt, und mit Ammoniumisothiocyanat ${ }^{96}$ direkt zu Produkt 54 umgesetzt. Die Reaktion verläuft unter Stickstoff-Atmosphäre in getrocknetem Aceton für $6 \mathrm{~h}$ bei $60^{0} \mathrm{C}$, danach gab man ohne weitere Reinigung das Amin $59 \mathrm{zu}$. Durch nukleophile Addition erhält man den Z-geschützten Katalysator 55. Die Anwesenheit eines Schwefel-Atoms erschwert die weitere Z-Entfernung. Hier wurde eine neue Methode entwickelt. Das Zwischen-Produkt 55 wurde in getrocknetem Dichlormethan gelöst, eine Mischung von 33\% HBr-HOAc bei RT langsam zugetropft, die Reaktionsmischung nach einer halben Stunde Rühren mit konzentrierter $\mathrm{NaHCO}_{3}$-Lösung neutralisiert und mit $\mathrm{CH}_{2} \mathrm{Cl}_{2}$ extrahiert. Anschließend wurde das Produkt durch Säulenchromatographie an Kieselgel gereinigt. Man erhält bis zu 67\% Ausbeute. 


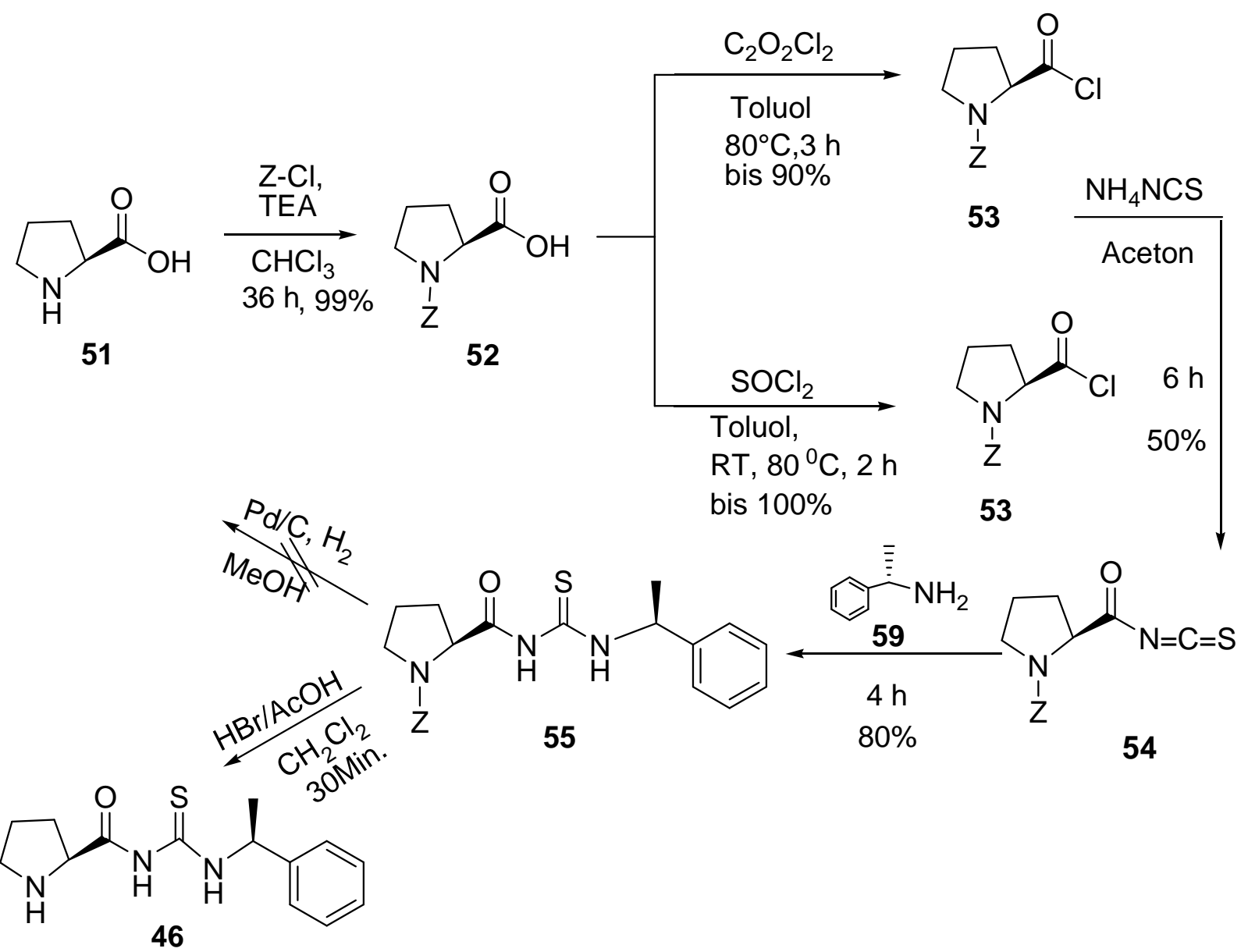

Schema 39. Synthese der Verbindung 46

Das ${ }^{1} \mathrm{H}-\mathrm{NMR}$ Spektrum (Abb. 14) zeigt, dass die Abspaltung der Z-Gruppe erfolgreich war. Im aromatischen Bereich erscheinen nur 5 Protonen (Abb. 14), die zu der Thioharnstoff-Gruppe benachbarten Phenylgruppe gehören. $\mathrm{H}_{\mathrm{a}}$ zeigt ein Singnlett bei $\delta=10.75, \mathrm{H}_{\mathrm{c}}$ zeigt ein Mutiplett bei $\delta=5.78-5.80$ und das Mutiplette bei $\delta=3.71-3.73$ sowie 2.75-2.82 und andere Mutiplette sind dem Pyrrolidinring zuzuordnen. Das Dublett bei $\delta=1.81$ beweist die Anwesenheit der Methylgruppe deutlich.

Ein HR-MS bekräftigt dies mit $\mathrm{M}+\mathrm{H}^{+} 278.13218$ und 279.1355 (erwartet: 278.13216) (Abb. $14)$. 

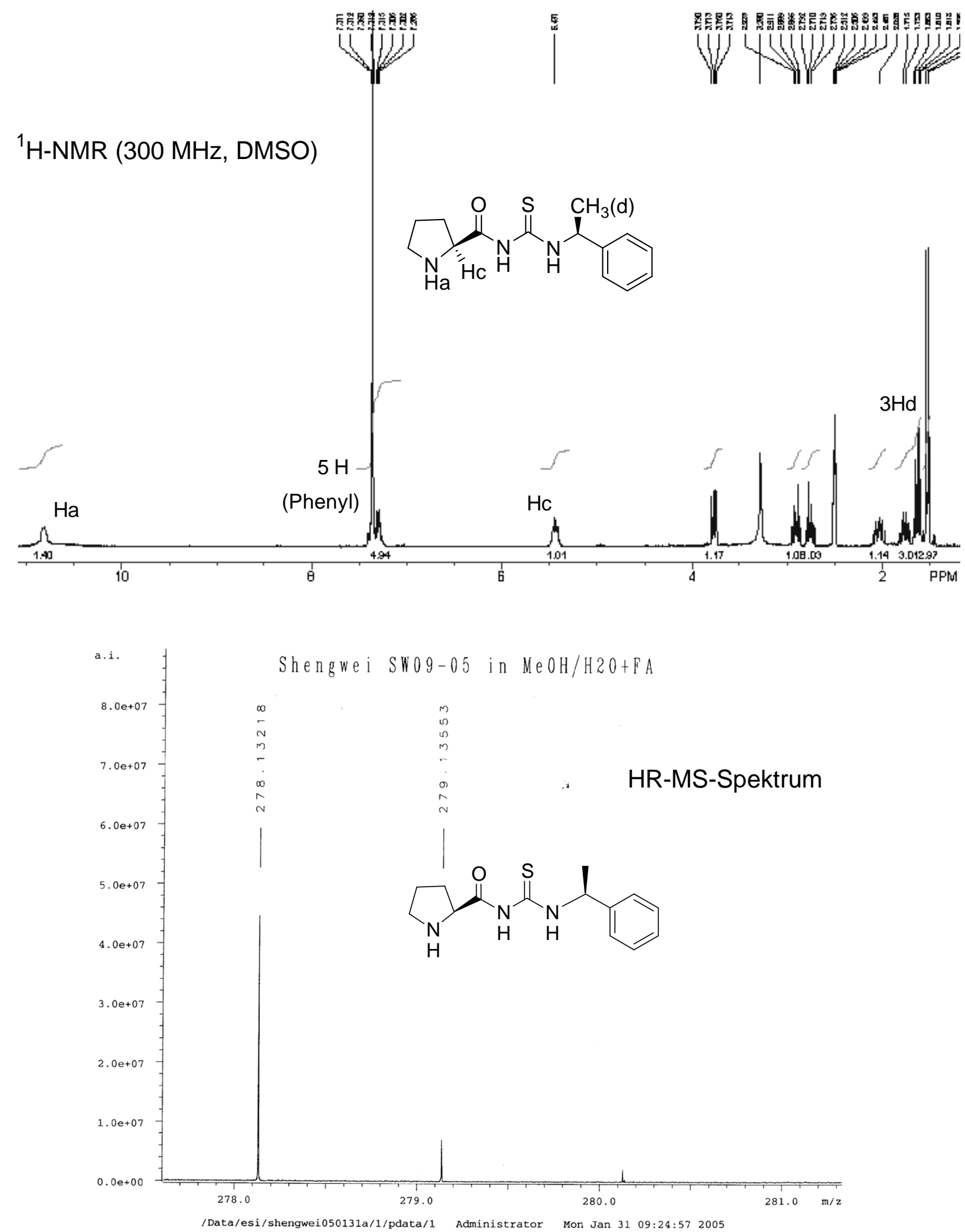

Abbildung 14. $\quad{ }^{1}$ H-NMR und HR-MS-Spektrum der Verbindung 46 
Eine andere Synthesemethode für Verbindung 46 wurde auch mehrmals ausprobiert (Schema

40). Zunächst wurde Pyrrolidin-Amid 60 nach Literaturmethoden ${ }^{97}$ bei Anwesenheit von $\mathrm{Boc}_{2} \mathrm{O}, \mathrm{NH}_{4} \mathrm{HCO}_{3}$ und dem Katalysator Pyridin in Dioxan bei Raumtemperatur mit einer Ausbeute von $70 \%$ hergestellt. Um eine Neben-Reaktion $\mathrm{zu}$ vermeiden, wurde zuerst $\mathrm{NH}_{4} \mathrm{HCO}_{3}$ und Pyridin in Dioxan 10 Minuten gerührt, danach $\mathrm{Boc}_{2} \mathrm{O}$ zugegeben. Aus der Reaktionsmischung wurde nach 6 Stunden Rühren das entstandene Salz abfiltriert, die Mutterlauge mit $\mathrm{H}_{2} \mathrm{SO}_{4}$ neutralisiert, mit EE extrahiert, mit Wasser gewaschen und über $\mathrm{Na}_{2} \mathrm{SO}_{4}$ getrocknet. Eine weitere Reinigung erfolgt durch Säulenchromatographie. Eine nukleophile Addition zwischen Amid 56 und Isothiocanat 57 war jedoch nicht erfolgreich.

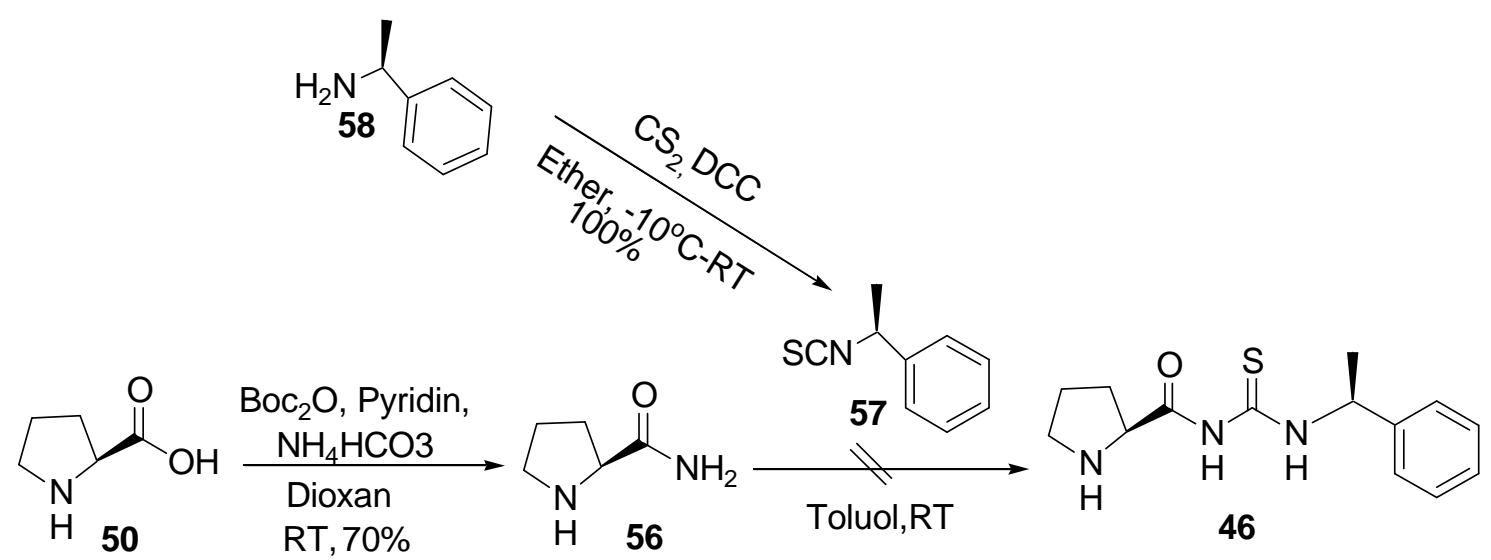

Schema 40. Versuchte Darstellung der Verbindung 46

Die Synthese von Verbindung 49 (Schema 41) wurde in fünf Schritten realisiert. Das erste benötigte Zwischenprodukt $\mathbf{5 9}^{98}$ wurde durch Pd/C katalytisch in einer Ausbeute von 80\% hergestellt. Man gab mit Lösungsmittel befeuchteten Katalysator Pd/C zu einer Mischung von L-Prolin in 40\% wässerigem Formaldehyd in Methanol zu. Die Reaktionsmischung wurde dann unter Wasserstoffatmosphäre über Nacht gerührt. $\mathrm{Pd} / \mathrm{C}$ wurde dann durch Celite abfiltriert und eine weitere Reinigung wurde durch Umkristallisieren aus Methanol-Ether durchgeführt. Verbindung 60 wurde nach Literaturmethoden ${ }^{99}$ mit gleicher Methode wie Verbindung 56 (Schema 40) dargestellt. Nach einer klassischen Reduktionsmethode ${ }^{100}$ erhält man das primäre 
Amin 61. Die benötigte Verbindung $\mathbf{5 7}{ }^{101}$ wurde durch Reaktion des primären Amins $\mathbf{5 8}$ mit DCC und $\mathrm{CS}_{2}$ in Ether in sehr guter Ausbeute von bis zu 100\% gewonnen. Nach einer Addition ${ }^{102}$ zwischen Verbindung 61 und 57 in Toluol wurde das Zielprodukt 49 nach $4 \mathrm{~h}$ Rühren und einer Reinigung in guter Ausbeute von 90\% erhalten.<smiles>CN1CCC[C@H]1C(=O)O</smiles>

59

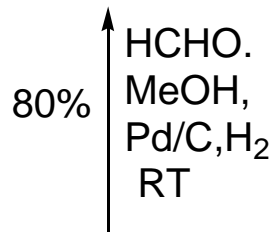<smiles>O=C(O)[C@@H]1CCCN1</smiles>

50

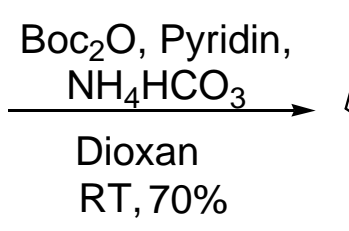

60<smiles>CN1CCCC1C(N)=O</smiles>

60

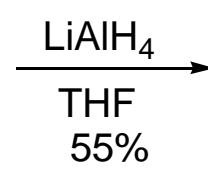

5<smiles>C[C@H](N)c1ccc(C(=O)OCc2ccccc2)cc1</smiles><smiles>CN1CCC[C@H]1CN</smiles>

61

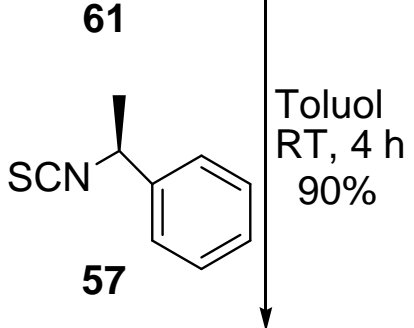

Schema 41. Synthese von Verbindung 49

Verbindung 47 (Schema 42) wurde durch nucleophile Addition in $\mathrm{CH}_{2} \mathrm{Cl}_{2}$ bei RT hergestellt. Als Edukt wurde Verbindung 62 mit den gleichen Synthesemethoden wie 57 unter Verwendung anderer Isomere des Ethylphenylamins und größerem Überschuss (bis 2.2 Äq) für die Synthese von 47 (Ausbeute von bis 90\%) verwendet (Schema 40). ${ }^{89}$ Die Reinigung wurde durch Säulenchromatographie an Kieselgel durchgeführt. Im Zuge dieser Darstellung von 47 entstanden auch geringe Mengen der Verbindung 64 als Mono-Addukt. Diese wurde später für die Michael-Addition verwendet. 
<smiles>C[C@H](N=[Se])c1ccccc1</smiles>

62

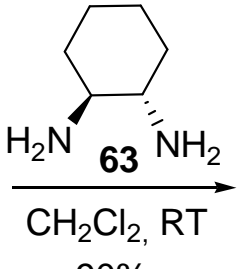

$90 \%$<smiles>C[C@H](NC(=S)N[C@H]1CCCC[C@H]1NC(=S)N[C@H](C)c1ccccc1)c1ccccc1</smiles>

47<smiles>CC(NC(=S)NC1CCCCC1)c1ccccc1</smiles>

Schema 42. Synthese von Verbindung 47

4.3.2.2 Optimierung des Lösungsmittels durch Anwendung von Kat. 10 bei der BaylisHillmann Reaktion zwischen 2-Nitrobenzaldehyde und Vinylmethylketon.

Tabelle 6 Auswählen eines geeignetesten Lösungsmittels für die Baylis-Hillman Reaktion<smiles>O=Cc1ccccc1[N+](=O)[O-]</smiles>

65<smiles>C=CC(C)=O</smiles>

66

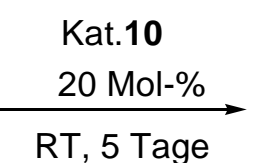

RT, 5 Tage<smiles>C=C(C(C)=O)C(O)c1ccccc1[N+](=O)[O-]</smiles>

67

\begin{tabular}{|c|c|c|c|}
\hline Eintrag & Lösungsmittel $^{\mathrm{a}}$ & $\begin{array}{c}\text { Ausbeute } \\
(\%)^{\mathrm{b}}\end{array}$ & $\begin{array}{c}e e \\
(\%)^{\mathrm{c}}\end{array}$ \\
\hline 1 & $\mathrm{DMSO}$ & 17 & 40 \\
\hline 2 & $\mathrm{CHCl}_{3}$ & 29 & 0 \\
\hline 3 & Toluol & 12 & 0 \\
\hline 4 & $\mathrm{CHCl}_{3} / \mathrm{THF}(1: 2)$ & 18 & 0 \\
\hline 5 & $\mathrm{CH}_{2} \mathrm{Cl}_{2}$ & 5 & 3 \\
\hline 6 & $\mathrm{MeOH}$ & Spur & - \\
\hline 7 & $\mathrm{THF}$ & 4 & 1 \\
\hline
\end{tabular}

a. Alle Lösungsmittel sind getrocknet, b. Isolierte Ausbeute; c, analysiert durch HPLC 
Als Lösungsmittel wurden polares protisches $\mathrm{MeOH}$, polar aprotisches DMSO, polares $\mathrm{CH}_{2} \mathrm{Cl}_{2}$, bzw. $\mathrm{CHCl}_{3}$; schwach polares (THF, Toluol) und eine Mischung von $\mathrm{CHCl}_{3} / \mathrm{THF}(1: 2)$ in Gegenwart von Kat. 10 (Z-Lys-Leu-OH) ausprobiert. Aufgrund der guten Löslichkeit ist DMSO das geeignetste aller Lösungsmittel. Das schlechteste Lösungsmittel ist das polare protische $\mathrm{MeOH}$. Auf Grund der Polarität und des vorhandenen Protons wird vermutlich die Wechselwirkung zwischen Katalysator und Substanz verhindert. In $\mathrm{CHCl}_{3}$ bildet sich zwar mehr Produkt, dieses wird aber in ein Racemat überführt. Im Falle der Mischung von $\mathrm{CHCl}_{3} / \mathrm{THF}$ (1:2) bzw. Toluol als Lösungsmittel wurden ebenfalls keine guten Resultate erhalten. Auf Grund der leichten Flüchtigkeit wurde $\mathrm{CH}_{2} \mathrm{Cl}_{2}$ von uns nicht verwendet. Da bei der weiteren Untersuchung überwiegend mit Peptiden gearbeitet wurde, war DMSO das Lösungsmittel der Wahl (Tabelle 7).

Allgemein ist zu sagen, dass die Untersuchungen bei der Baylis-Hillmann Reaktion nur wenig erfolgreich waren (Tabelle 7). Die besten Ergebnisse lieferte Katalysator 10. Die fünf untersuchten Verbindungen (Kat. 16, 10, 24, 29, 30) zeigten nur geringe Aktivität mit mäßigem sterischem Einfluss. Vermutlich sind die verwendeten Katalysatoren nicht basisch genug für den nukleophilen Angriff am Vinylmethylketon

Der Mechanismus (Schema 43) zeigt, ${ }^{103}$ dass eine starke Base als Nucleophil benötigt wird, um das Vinylmethylketon ins nucleophile Intermediat (1) zu überführen.

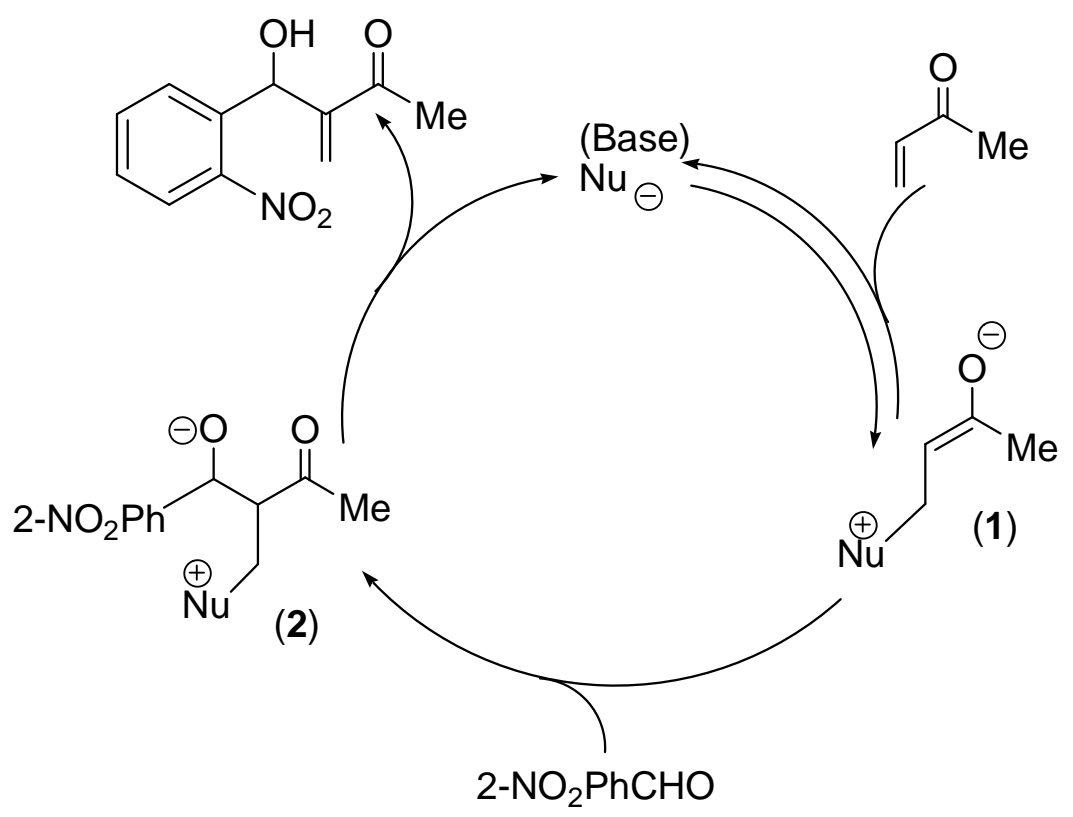

Schema 43. Beispiel des katalytischen Zyklus der Baylis-Hillman Reaktion 
Dieser Schritt ist bestimmend für die Reaktionsgeschwindigkeit. Der zweite wichtige Schritt ist die Bildung des Intermediats (2). Er ist abhängig von der Stabilität des Intermediats (2) und der Aktivität des Aldehyds sowie von der räumlichen Anordnung. Die in dieser Arbeit getesteten Katalysatoren sind wahrscheinlich nicht basisch genug, um das Intermediat (1) zu bilden.

Tabelle 7 Untersuchung der Baylis-Hillman Reaktion<smiles>C=CC(C)=O</smiles>

\begin{tabular}{|c|c|c|c|c|c|c|c|c|}
\hline Eintrag & $\begin{array}{l}\text { Kat. } \\
(\ddot{A q q})\end{array}$ & $\begin{array}{l}\text { Additiv } \\
(\ddot{A} q)\end{array}$ & Lös. & Temp & $\begin{array}{l}\text { Zeit } \\
\text { (Tag) }\end{array}$ & RRG. $^{a}$ & $\begin{array}{c}\text { Ausbeute } \\
(\%)^{\mathrm{b}}\end{array}$ & $\begin{array}{l}e e^{\mathrm{c}} \\
(\%)\end{array}$ \\
\hline 1 & $16(0.15)$ & - & DMSO & RT & 5 & - & Spur & - \\
\hline 2 & $\mathbf{1 0}(0.15)$ & - & DMSO & RT & 5 & 0.14 & 17 & 40 \\
\hline 3 & $24(0.15)$ & - & DMSO & RT & 5 & 0.06 & 7 & 10 \\
\hline 4 & $29(0.15)$ & - & DMSO & RT & 5 & 0.05 & 6 & 20 \\
\hline 5 & $30(0.15)$ & - & DMSO & RT & 5 & 0.09 & 11 & 20 \\
\hline 6 & $30(0.15)$ & Kat. $32(0.15)$ & DMSO & RT & 5 & 0.23 & 28 & 2 \\
\hline 7 & $30(0.15)$ & L-Prolin $(0.15)$ & DMSO & RT & 5 & 0.27 & 32 & 1 \\
\hline 8 & $30(0.15)$ & $\begin{array}{l}R, R \text {-Diaminocyclohexan } \\
(0.15)\end{array}$ & DMSO & RT & 5 & - & Spur & - \\
\hline 9 & $32(0.15)$ & $\begin{array}{l}R, R \text {-Diaminocyclohexan } \\
(0.15)\end{array}$ & DMSO & RT & 5 & - & Spur & - \\
\hline 10 & $32(0.15)$ & L-Prolin $(0.15)$ & DMSO & RT & 5 & 0.28 & 33 & 3 \\
\hline 11 & $48(0.2)$ & - & Toluol & RT & 5 & 0.17 & 20 & 16 \\
\hline 12 & $47(0.2)^{\mathrm{d}}$ & - & Toluol & RT & 14 & 4.86 & 68 & 0 \\
\hline 13 & $47(0.2)$ & $\mathbf{5 0}(0.2)$ & - & $-5^{\circ} \mathrm{C}$ & 5 & - & - & - \\
\hline 14 & $\mathbf{5 0}(0.2)$ & - & Toluol & RT & 6 & 6.8 & 41 & 0 \\
\hline 15 & $46(0.2)$ & - & Toluol & $11^{\circ} \mathrm{C}$ & - & - & - & - \\
\hline 16 & $46(0.2)$ & & Toluol & RT & 3 & - & Spur & - \\
\hline 17 & $46(0.2)$ & $38(0.1)$ & Toluol & $11^{\circ} \mathrm{C}$ & - & - & - & - \\
\hline 18 & $49(0.15)$ & - & Toluol & RT & 3 & - & Spur & - \\
\hline
\end{tabular}

a) RRG: Reduzierte Reaktionsgeschwindigkeit (Ausbeute (\%)/Zeit (h); b) Isolierte Ausbeute, c) Messung durch Chirale HPLC (Daicel Chiralpak AS-Säule); d) Reaktionszeit: 14h, e) Reaktionszeit 6h. 
Weitere Untersuchungen widmeten sich der Funktionalität des Additivs. Die Kombination von $(R, R)$-Diaminocyclohexan und Katalysator 30, 32 waren nicht effektiv; die Synthesen zeigten kaum Produktbildung. Die Kombination von Kat. 30 (32\% Ausbeute, 1\% ee Eintrag 7, Tabelle 7) und 32 (33\% Ausbeute, 3\% ee Eintrag 10, Tabelle 7) mit L-Prolin ergab zwar ein Produkt, aber nur in schlechten Ausbeuten und miserablem Enantiomerenüberschuss. Die Thioharnstoffund Pyrrolindin-haltigen Verbindungen (46, 47, 48, 49) wurden eingehender untersucht. Aufgrund der Löslichkeiten wurde Toluol als Lösungsmittel verwendet. Es zeigt sich bereits, dass Wasserstoffbrückenbindungen eine wichtige Rolle bei der Verbindung 47 spielen (Eintrag 12, Tabelle 7), weil die Reaktionsgeschwindigkeit deutlich verbessert wurde (68\% Ausbeute in 14h). Durch Katalysator 48 bilden sich ee-Werte (16\% ee), doch war die Ausbeute ebenfalls sehr gering (20\%). Bemerkenswert ist aber, dass bei Einsatz von Verbindung 50 im Vergleich zu anderen die Reaktion schnell laufen kann, das bedeutet, dass Verbindung $\mathbf{5 0}$ ein gutes geeignetes basisches Gerüst für die Baylis-Hillman Reaktion besitzt. So wurden des Weiteren die in Abb.15 illustrierten Katalysatoren synthetisiert.
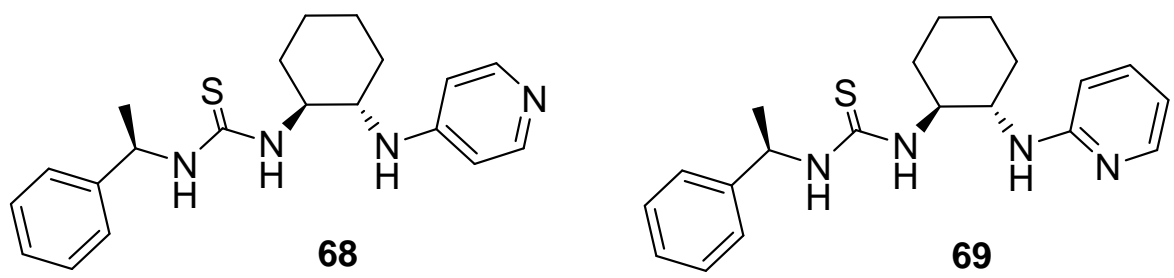

Abbildung 15. Zwei Katalysatoren für die Baylis-Hillman Reaktion

Es wurden zwei unterschiedliche Synthesewege gewählt. Für den ersten Versuch der Synthese von Verbindung 68 wurde zunächst das Salz von $p$-Bromo-Pyridin mit Hilfe der Base $\left(\mathrm{Na}_{2} \mathrm{CO}_{3}\right)$ in Dioxan bei $60^{\circ} \mathrm{C}$ umgesetzt (Schema 44). Nach der Aufarbeitung lag nur das nicht umgesetzte Edukt vor. In einem zweiten Versuch wurde $o$-Bromo-Pyridin direkt als Edukt (Schema 44) eingesetzt und $\mathrm{NaH}$ als stärkere Base verwendet. Es bildete sich ebenfalls kein Produkt. Das notwendige Anion sollte (quasi) mit Hilfe der Base entweder aus der Verbindung 64 oder aus dem Pyridinring entstehen, sodass die schwierige nucleophile Substitution am Aromaten durchgeführt werden kann. Möglichweise, oder wegen der Feuchtigkeit in situ konnte ein Nukleophil nur schwer produziert werden. Es kann auch sein, dass die Reaktionsbedingungen (z.B. basisches Medium) noch zu mild sind. 


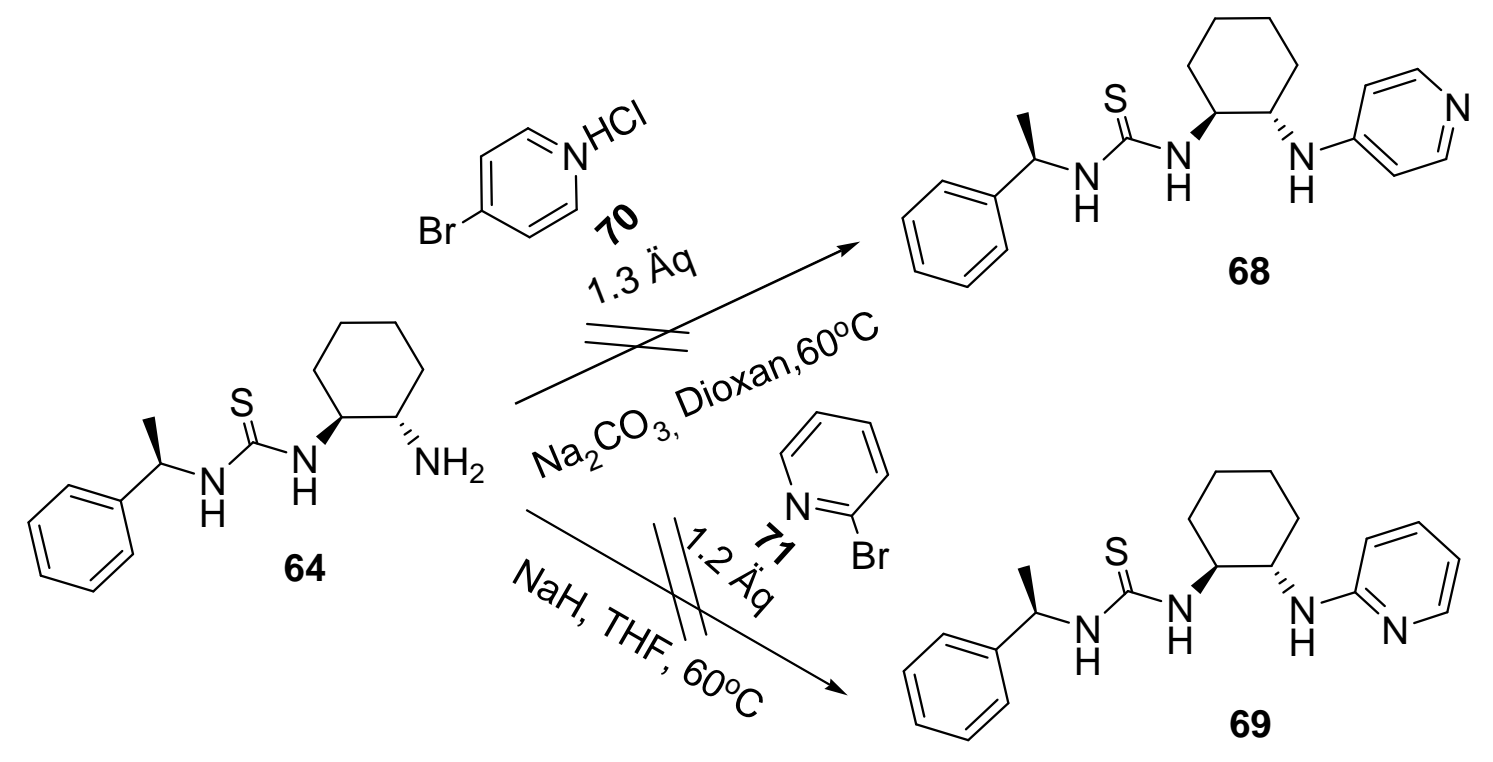

Schema 44. Syntheseroute für die Verbindungen 68 und 69

Weiter wurden auch Michael-, Allylierungs- und Henry-Reaktionen durch o.g. Peptide untersucht, es konnte jedoch kein gutes Ergebnis erzielt werden.

Zusammenfassend wurden Dipeptide und deren Analoga als Katalysatoren für C-CBindungsknüpfungsreaktionen untersucht. H-Leu-His-OH wurde als einer für AldolReaktionen gut geeigneter Katalysator im Rahmen dieser Arbeit entdeckt. Anhand der Ergebnisse wird deutlich, dass ein besonders aktiver Katalysator durch seine Bifunktionalität gekennzeichnet ist. Eine anpassende räumliche Anordnung ist entscheidend. Das aktivste Dipeptid H-Leu-His-OH zeigt diese passende sterische Anordnung der beiden funktionellen Aktivitätszentren. Im Folgenden wurden organische bifunktionelle Katalysatoren synthetisiert und in C-C-Bindungsknüpfungsreaktionen getestet. 


\section{Synthese und Anwendung von neuen bifunktionellen thioharnstoffhalti- gen Verbindungen}

\subsection{Allgemeine Entwicklung der bifunktionellen Verbindungen für die organische Synthese.}

Die Entwicklung neuer effizienter Katalysatoren für die asymmetrische katalytische Reaktion im Bereich der organischen Chemie ist dauerhaft von Interesse. Eine aktuelle Methode der stereoselektiven Synthese stellt die Verwendung einer Kombination von Lewis-Säure und Lewis-Base dar. Bifunktionelle organische Katalysatoren $\mathrm{zu}$ synthetisieren ist daher von besonderer Bedeutung. Der Synergieeffekt durch die Aktivierung mithilfe von zwei reaktiven Zentren führt zu hohen Reaktionsgeschwindigkeiten und zu einem hervorragenden Transfer der stereochemischen Information.

Itsuno und Mitarbeiter entwickelten in den 1980er Jahren erstmals die enantioselektive Reaktion zwischen Ketonen und Boranen. ${ }^{104}$ Corey und Mitarbeiter erneuerten dann die bifunktionelle katalytische Reaktion durch CBS-Reduktion (Corey-Bakshi-Shibata-Reaktion) mit chiralen Oxaborolidinkatalysatoren. ${ }^{105}$ Die CBS-Reduktion ist ein ausgezeichnetes Beispiel für einen bifunktionellen Reaktionsmechanismus (Schema 45). 

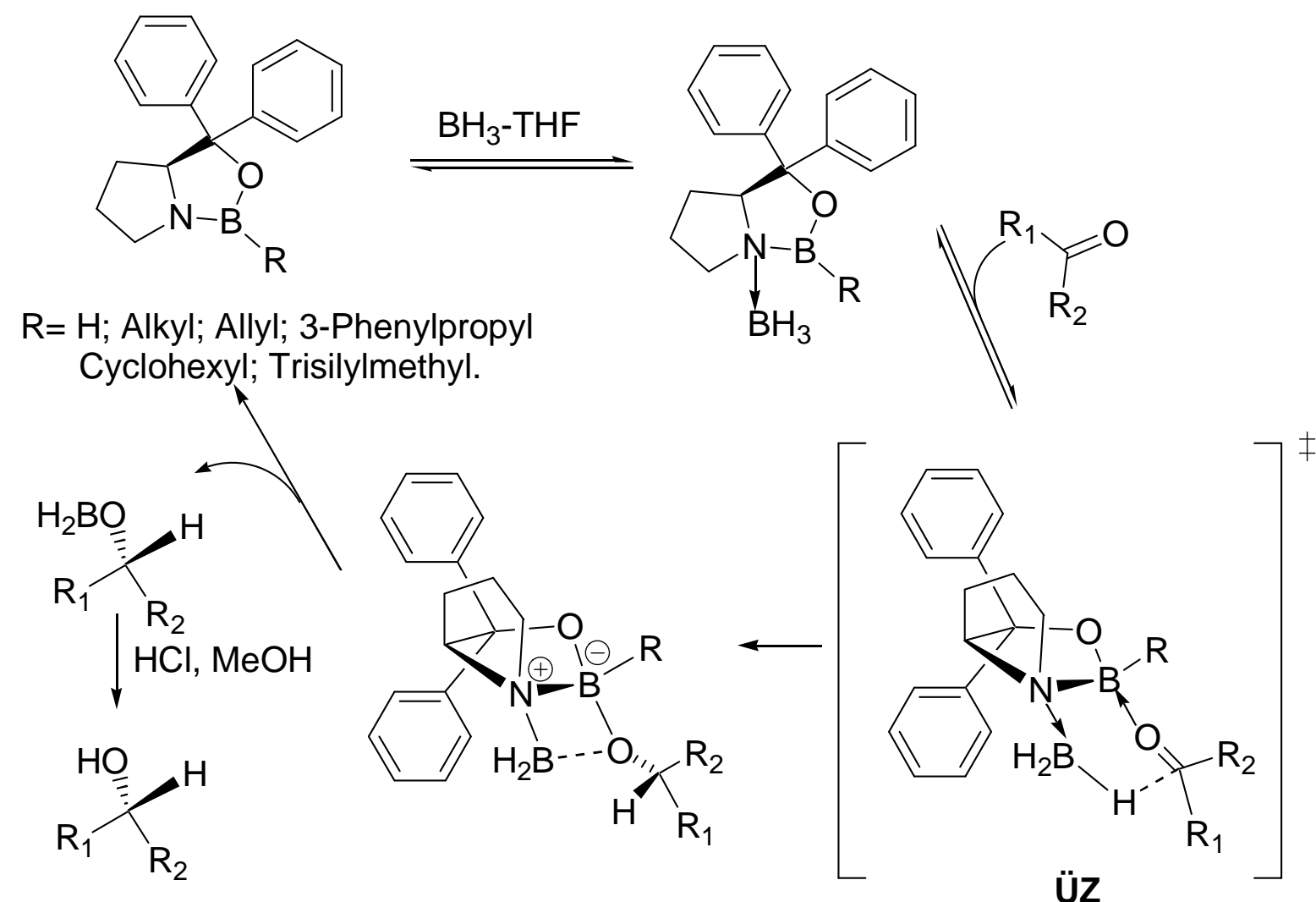

Schema 45 Vorgeschlagener Biaktivierungsmechanismus der CBS-Reduktion

Zuerst findet eine schnelle Koordination von Boran an dem Lewis-basischen Stickstoffatom des

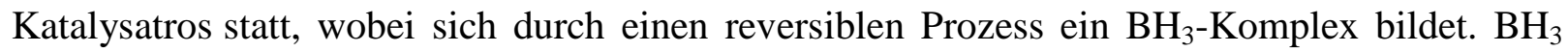
wird dadurch aktiviert (Schema 45) und gleichzeitig die Lewisacidität des endocyclischen Boratoms erhöht. Diese Aktivierung ist sehr wichtig, um den dann folgenden Übergangszustand (ÜZ. in Schema 45) zu bilden. Die erhöhte Elektrophilie des endocyclischen Boratoms erleichtert die Koordination des Ketons über das am geringsten sterisch gehinderte freie Elektronpaar am Sauerstoffatom. Die resultierende räumliche Anordnung reduziert die sterische Wechselwirkungen zwischen dem Oxazaborolidin und dem Keton. Gleichzeitig orientiert sich die elektronenarme Carbonylgruppe zur elektronisch aktivierten BorWasserstoff-Bindung so, dass sich ein sechsgliedriger Übergangszustand (ÜZ Schema 45) bildet. Durch den Hydridtransfer und der folgenden sauren Aufarbeitung wird das Reduktionsprodukt erhalten und der Katalysator regeneriert.

Nach den Pionierarbeiten von Itsuno und Corey wurden die bifunktionellen Katalysatoren für die Reduktion von Ketonderivaten weiter entwickelt (Abb. 16). 

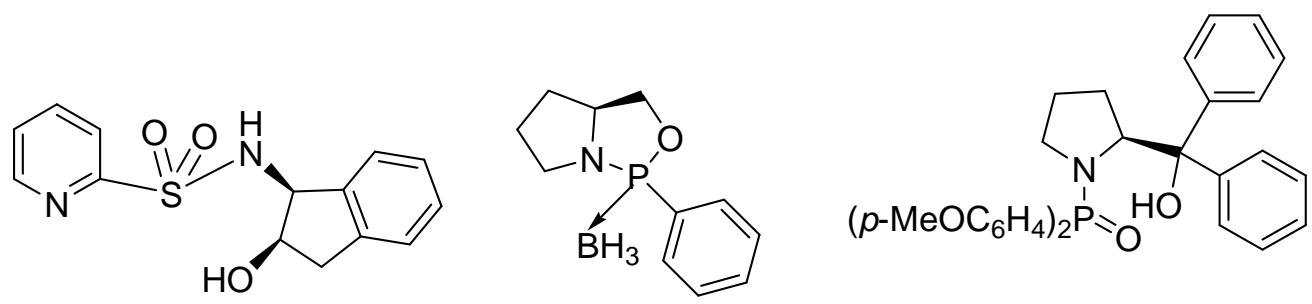

Abbildung 16. Beispiele von bifunktionellen Katalysatoren für die Reduktion von Ketonen

Die Verbindung mit einer 2-Pyridylsulfonylgruppe (Abb. 16) liefert einen Enantiomerenüberschuss von $71-89 \%$ bei der Reduktion von Acetophenon-Derivaten. ${ }^{106}$ Buono beschrieb den Oxazaphospholidin-Boran-Komplex (Abb. 16), der enantioselektiv Reduktionen (bis $99 \%$ ee) vermitteln kann. ${ }^{107}$ Wills und Mitarbeiter setzten ein Phosphinamid (Abb. 16) für die gleiche Reaktion ein und erhielten bis zu 93\% ee. ${ }^{108}$ Alle drei Katalysatoren enthalten nicht nur ein basisches Stichstoffatom bzw. Sauerstoffatom sondern auch Lewis-Säure-Zentren wie die Hydroxyl-Gruppe oder das $\mathrm{BH}_{3}$. Zwei der größten Vorteile dieser Katalysatoren gegenüber den metallhaltigen bifunktionellen Katalysatoren sind ihre Stabilität gegenüber geringer Feuchtigkeit und ihre einfache Möglichkeit der Rückgewinnung aus dem Reaktionsgemisch.

Die moderne Carbonylchemie wurde von mehreren Forschern intensiv und aufmerksam bearbeitet. Ein Grundprinzip dieser Arbeit ist die selektive Aktivierung von Carbonylgruppen durch Lewis-Säuren. Die freien Elektronpaare des Carbonylsauerstoffatoms können als harte Lewis-Base durch Protonen oder Lewis-Säuren koordiniert werden. Durch diese Anlagerung an eine Lewis-Säure kann die Elektronendichte am Sauerstoff verringert werden und dadurch die Energie des HOMO-Orbitals $\left(\mathrm{C}=\mathrm{O}-\pi^{*}\right)$ erniedrigt und gleichzeitig die Carbonylgruppe für einen nucleophilen Angriff aktiviert werden. Die selektive Aktivierung von Carbonylgruppen kann man auch durch Lewis-Basen durchführen. Durch die nucleophile Lewis-Base, beispielsweise N-haltige Verbindungen, kann unter Wasserabspaltung ein aktives enaminanaloges Intermediat gebildet werden, sodass dadurch ein nucleophiler Angriff am Kohlenstoffatom des Reaktionspartners zur C-C-Bindungsknüpfung erleichtert werden kann.

Prolinkatalysierte Aldol-Reaktionen sind auf Grund der Einfachheit und leichten Verfügbarkeit des Katalysators sehr intensiv untersucht worden. ${ }^{109}$ Das Houk-List Model ${ }^{110}$ prolinkatalysierter Aldol-Reaktionen (Abb. 17) wurde erst kürzlich publiziert. Dieses Modell illustriert, dass dem L-Prolin zwei Aktivierungszentren zur Verfügung stehen. Das Lewis-basische Stickstoffatom am Pyrrolidinring aktiviert das Keton, wobei ein Enamin als aktive nucleophile Spezies 
gebildet wird. Eine Wasserstoffbrückenbindung zum Aldehyd steuert den nucleophilen Angriff des Enamins an den Aldehyd, sodass die Enantioselektivität gesteigert werden kann.

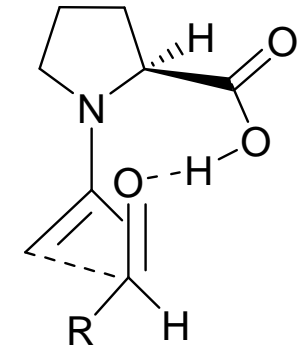

Houk-List-Modell Prolinkatalysierte Aldolreaktion

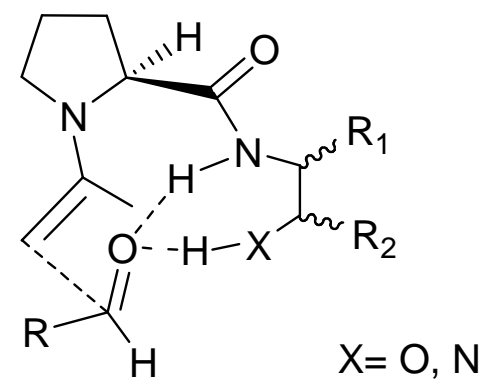

aktiverer Katalysator durch doppelte Wasserstoffbrückbindung

Abbildung 17. Das Houk-List Modell und der Übergangszustand bei der Aldol-Reaktion von Gong-Wu Katalysatoren

Der L-Prolin-haltige Gong-Wu-Katalysator (Schema 46) wurde als noch besserer Katalysator $^{111}$ ermittelt. Kleine, von Prolin abgeleitete Carboxamidalkohole sind im Vergleich $\mathrm{zu}$ L-Prolin effizientere Katalysatoren, weil im Übergangszustand doppelte Wasserstoffbrückenbindungen zum Aldehyd vorliegen (Abb. 17). Das Resultat ist in Schema 46 gezeigt.

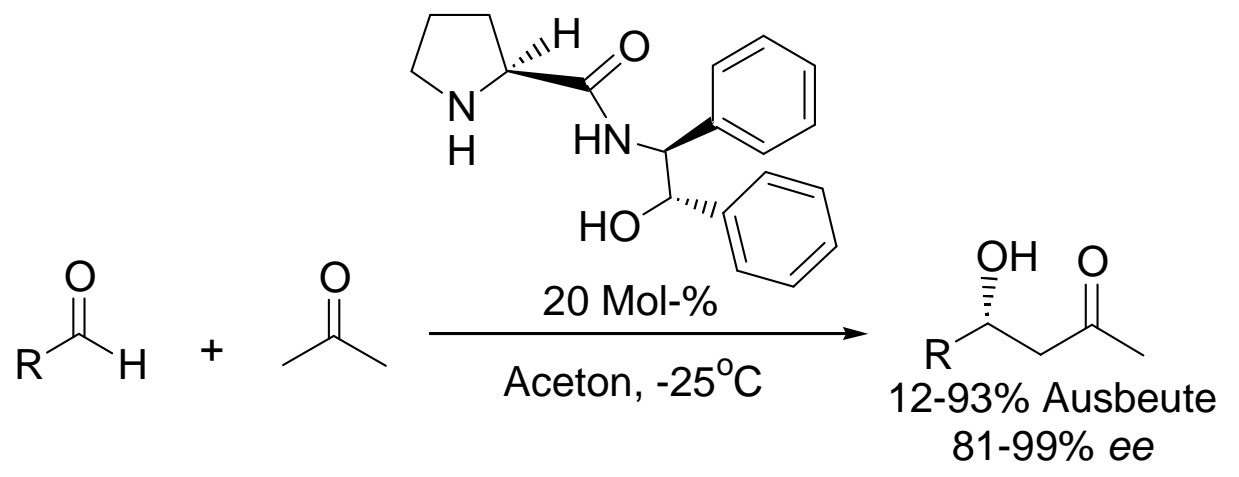

Schema 46. Enantioselektive Aldol-Reaktion mit dem bifunktionellen Gong-Wu-Katalysator

Der Gong-Wu-Katalysator beeinflusst die Aldol-Reaktion deutlich selektiver als L-Prolin (Schema 46). Die Reaktionen verschiedener Aldehyde mit Aceton resultieren in 81-99 \% ee, 12-93\% Ausbeute (Schema 46) (mit L-Prolin, bis 76\% ee und < 80\% Ausbeute). Das 
Übergangsmodell (Abb. 17), das durch zwei Aktivierungs-Zentren charakterisiert ist, wurde von den Autoren durch Ab-initio-Rechnungen mit Wasserstoffbrückenbindungen von der Amid- und der Hydoxyl- zur Aldehyd-Gruppe gestützt.

Chirale, bifunktionelle Thioharnstoff-Organokatalysatoren sind umfangreich für asymmetrische organische C-C-Bindungsknüpfungsreaktionen entwickelt worden. Das Thioharnstoff-Gerüst kann als Brönsted-Säure fungieren. Damit werden Carbonyl-, Imin-, Nitro- und PhosphorylGruppen durch doppelte Wasserstoffbrückenbindungen aktiviert, die weiteren nucleophilen Angriffe für die C-C-Bindungsknüpfung werden erleichtert und enantioselektiv gefördert. Die bifunktionelle Wirkung wird durch eine basische Gruppe vervollständigt.

Takemoto und Mitarbeiter ${ }^{112}$ haben einen bifunktionellen thioharnstoffhaltigen Katalysator für die enatioselektive Aza-Henry Reaktion entwickelt. Wie in Abb. 18 gezeigt, fixiert das Thioharnstoff Gerüst als Brönsted-Säure die Nitro-Gruppe durch Wasserstoffbrückenbindungen. Eine $N, N$-Dimethylamino-Gruppe fungiert als Lewis-Base und aktiviert zum Beispiel Nitromethan durch Deprotonierung. Das Nitronat greift als nucleophiles Intermediat am eletrophilen Aldimin an (Abb. 18). Der vorgeschlagene Mechanismus wird in Abb. 18 gezeigt. ${ }^{112}$ Auf Grund der passenden räumlichen Anordnung und der optimalen Aktivität (der von zwei Trifluormethyl-gruppen substituierten Phenylrings verstärkt die Acidität des Thioharnstoff-Gerüsts) des Katalysators resultieren gute Enantioselektivitäten und Ausbeuten (ein Beispiel in Schema 47).
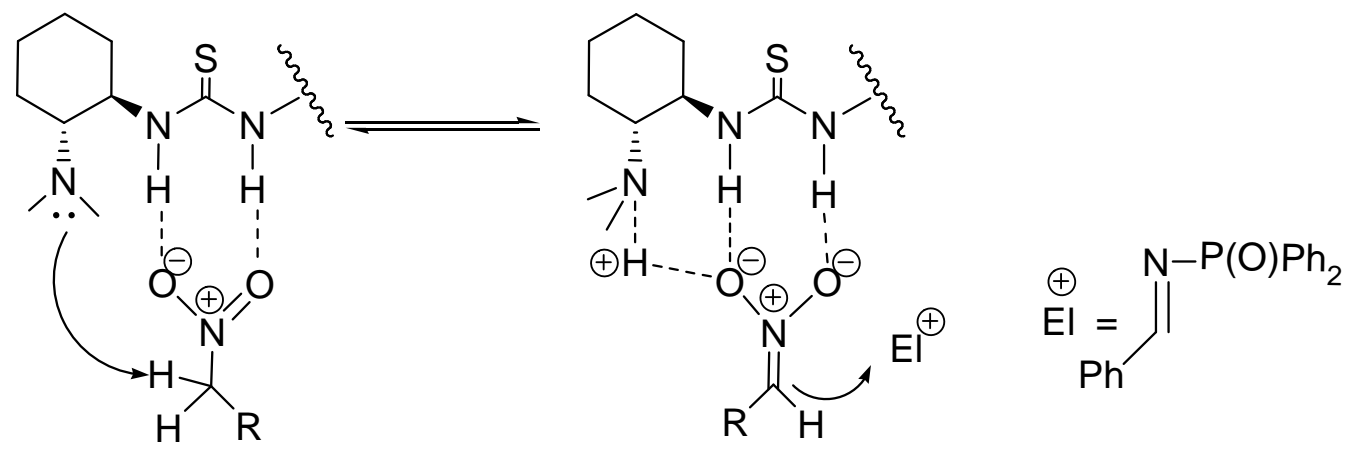

Abbildung 18. Vorgeschlagener Mechanismus der Aza-Henry Reaktion bei Aktivierung durch einen bifunktionellen Katalysator 


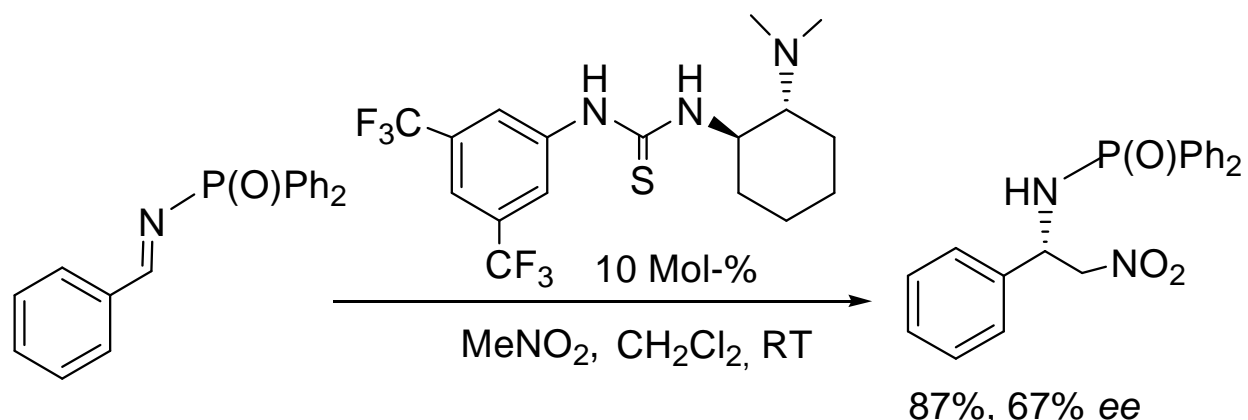

Schema 47. Aza-Henry Reaktion durch Takemoto-Katalysator

Ein ähnlicher Takemoto-Katalysator wurde von Wang und Mitarbeitern für die Umsetzung von $\alpha, \beta$-ungesättigten Ketonen und Aldehyden publiziert. ${ }^{113}$

Das chirale Binol-Gerüst mit tertiärer Aminogruppe wurde bei diesem Katalysator an Thioharnstoff geknüpft (Schema 48).

In Schema 49 wird ein vorgeschlagener Mechanismus illustriert. Die Carbonylgruppe des $\alpha, \beta-$ ungesättigten Ketons wird durch das Thioharnstoff-Gerüst über Wasserstoffbrückenbindungen fixiert und elektrophil aktiviert, sodass es von der tertiären Amino-Gruppe am Binol-Gerüst leicht nucleophil angegriffen werden kann. Dieser Angriff läuft in Analogie zur Michael Addition (Schema 49), als nächstes folgt nun eine Aldol-Reaktion. Als letzter Schritt (Schema 49) wird eine wässrige Aufarbeitung durchgeführt, wobei der Katalysator regeneriert wird.

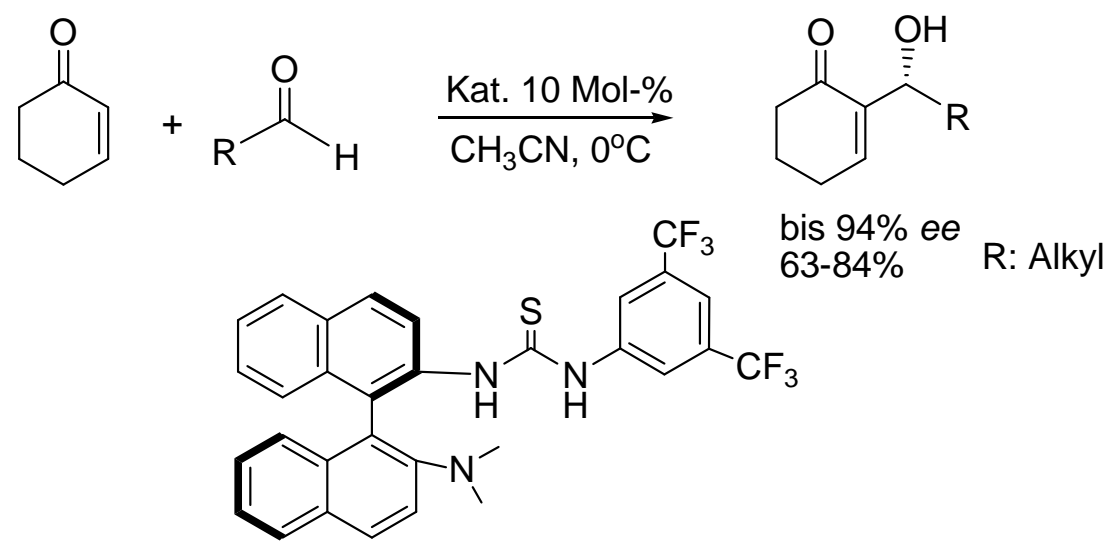

Schema 48 Beispiel der Anwendung vom Wang-Katalysator bei der Morita-Baylis-Hillman Reaktion 
Ein passendes Katalysatordesign steuert den erwarteten Mechanismus. Die sterische Anordnung der Reaktion ist bei diesem Katalysator so gut, dass ein gutes Ergebnis von bis zu 94\% ee und $84 \%$ Ausbeute resultiert.

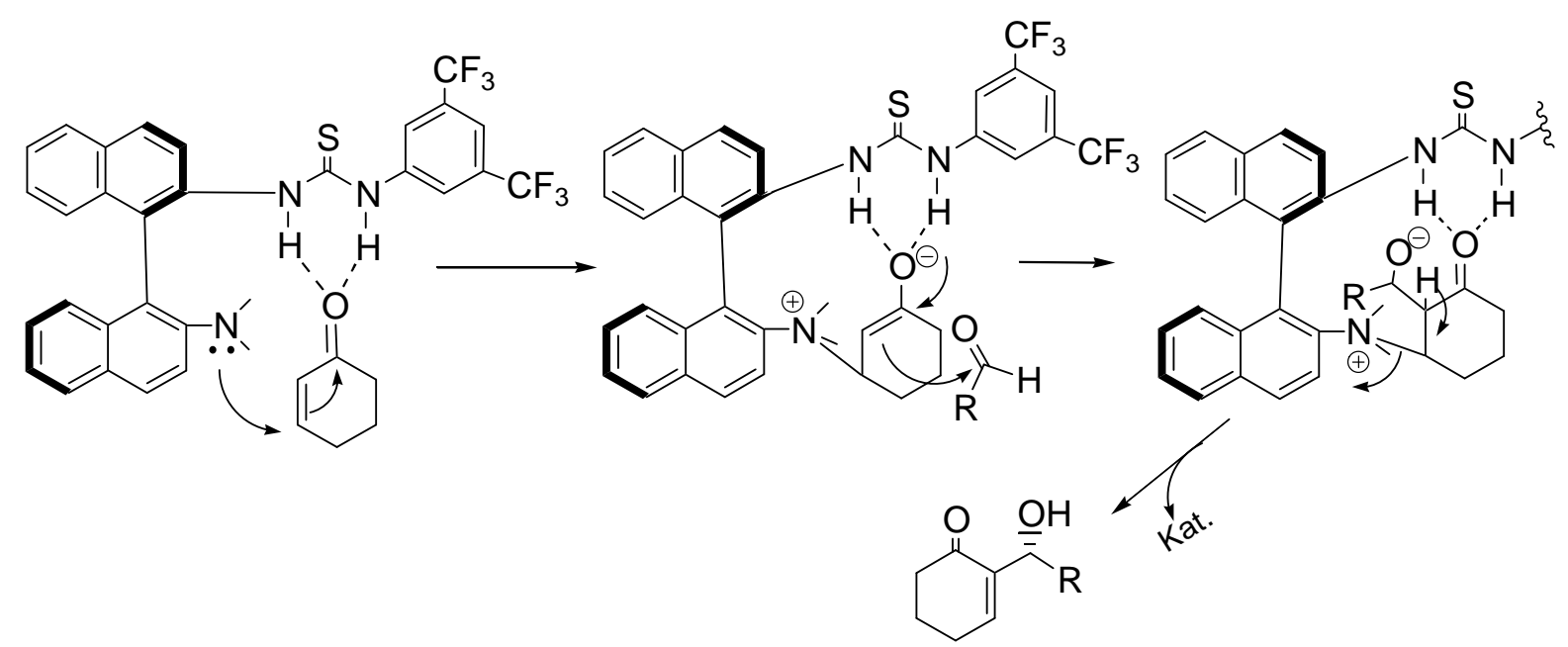

Schema 49. Vorgeschlagener Mechanismus für Morita-Baylis-Hillman Reaktion durch WangKatalysator

Eine weitere Verwendung der bifunktionellen thioharnstoffhaltigen Katalysatoren bei der Hydrophosphorylierung wurde von Jacobsen veröffentlicht. ${ }^{114} \alpha$-Aminophosphat-Derivate werden auf Grund ihrer biologischen antibakteriellen ${ }^{115}$ und antifungalen ${ }^{116}$ Aktivität synthetisiert. Ihre Aktivität ist abhängig von ihrer absoluten Konfiguration, ${ }^{117}$ deswegen ist es besonders wichtig, eine hoch enantioselektive Synthese zu entwickeln. Schema 50 zeigt beispielsweise ein gutes Ergebnis von höherer Enantioselektivtät (98\%) und Ausbeute (87\%). Nicht nur aromatische, sondern auch aliphatische Aldimin-Derivate wurde von Jacobsen und Mitarbeitern mit guten Resultaten untersucht. ${ }^{110}$ Es erscheinen sogar drei aktive Zentren in seinem Katalysator. Als Brönsted-Säure wirken das Thioharnstoff-Gerüst und die Hydroxylgruppe am Phenylring. Die Schiffsche Base spielt eine Rolle als basisches Aktivitätszentrum. Es liegen mehrere basische Funktionen im Substrat vor, nämlich der Stickstoff der Amino- oder Imin-Gruppe. Welcher Mechanismus richtig ist, wurde in der Publikation nicht geklärt. 
<smiles>CCCCC(C)(C)C</smiles><smiles>CCOC(=O)c1ccccc1/C=N/Cc1ccccc1</smiles><smiles>O=[N+]([O-])c1ccccc1COP(=O)(OCc1ccccc1[N+](=O)[O-])[C@H](NCc1ccccc1)c1ccccc1</smiles>

$98 \%$ ee, $87 \%$

Schema 50. Hydorphosphorylierung durch Jacobsen-Katalysator

Jacobsen ist führend bei der Darstellung von Thioharnstoff-Katalysatoren. Viele Schiffsche Basen-haltige, bifunktionelle Thioharnstoff-Katalysatoren wurden von Jacobsen entwickelt und mit sehr gutem Ergebnis untersucht. Beispielsweise hat er eine Serie von ThioharnstoffKatalysatoren für die asymmetrische Strecker Reaktion untersucht. (Schema 51, Verbindungen $\mathbf{a}^{118,119}, \mathbf{b}^{120}, \mathbf{c}^{121}, \mathbf{d}^{122}$ und $\left.\mathbf{e}^{123}\right)$. 


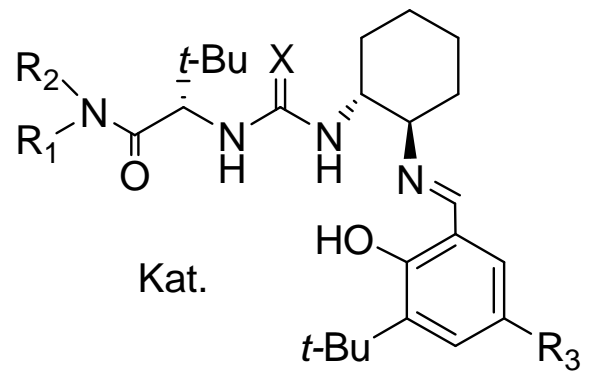

a: $X=S ; R_{1}=P h, R_{2}=H, R_{3}=O M e$

b: $X=S ; R_{1}=P h, R_{2}=H, R_{3}=$ OPiv

c: $X=O ; R_{1}=P h, R_{2}=H, R_{3}=$ OPiv

$\mathrm{d}: X=\mathrm{S} ; \mathrm{R}_{1}=\mathrm{H}, \mathrm{R}_{2}=\mathrm{Me}, \mathrm{R}_{3}=$ OPiv

$\mathrm{e}: \mathrm{X}=\mathrm{S} ; \mathrm{R}_{1}=\mathrm{Ph}, \mathrm{R}_{2}=\mathrm{Me}, \mathrm{R}_{3}=t \mathrm{Bu}$

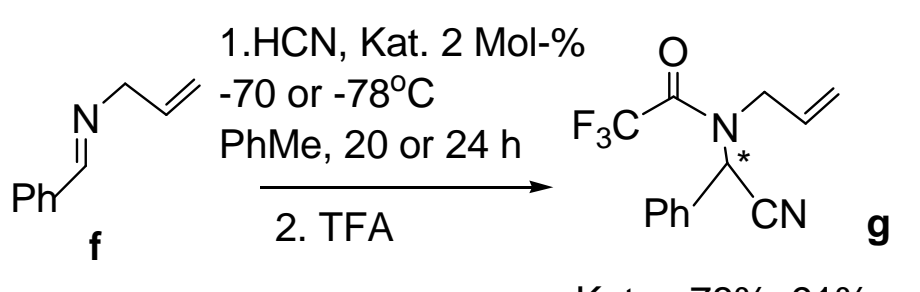

Kat. a $78 \%, 91 \%$ ee

Kat. b $74 \%, 95 \%$ ee<smiles>C/C(=N/N=[W]Nc1ccccc1)c1ccccc1</smiles>

h

Kat. c $97 \%$, 93\% ee

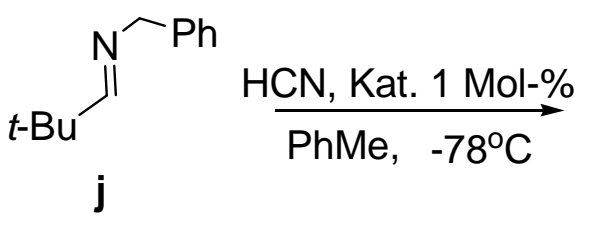<smiles>CC(C)(C)C(C#N)NCc1ccccc1</smiles>

Kat. a $96 \%$ ee Kat. d $99.3 \%$ ee

Schema 51. Verschiedene Jacobsen-Thioharnstoffkatalysatoren bei der Strecker Reaktion

Auf Grund der verschiedenen Substituenten an den Thioharnstoff-Katalysatoren (Schema 51) ist die katalytische Wirkung bei der Strecker Reaktion unterschiedlich: Kat. a (Schema 51) ist der aktivste; mit diesem ergeben sich bei der Strecker Reaktion von HCN und dem aromatischen und aliphatischen $N$-Allyl Imin $78 \%$ und $91 \%$ ee (g, in Schema 51). Kat. c ist aktiver bei der Reaktion von HCN und Ketimin als andere (i 97\%; 93\% ee); Kat a und d leisten bei der Reaktion für das Produkt k (96\% Ausbeute, 99.3\%) den fast gleichen Beitrag.

Es ist interessant, dass die vereinfachte Struktur des o.g. Katalysators bei anderen asymmetrischen Reaktionen nicht an seiner Aktivität verliert. (Schema $52^{124}$ und Schema $53^{125}$ ). 


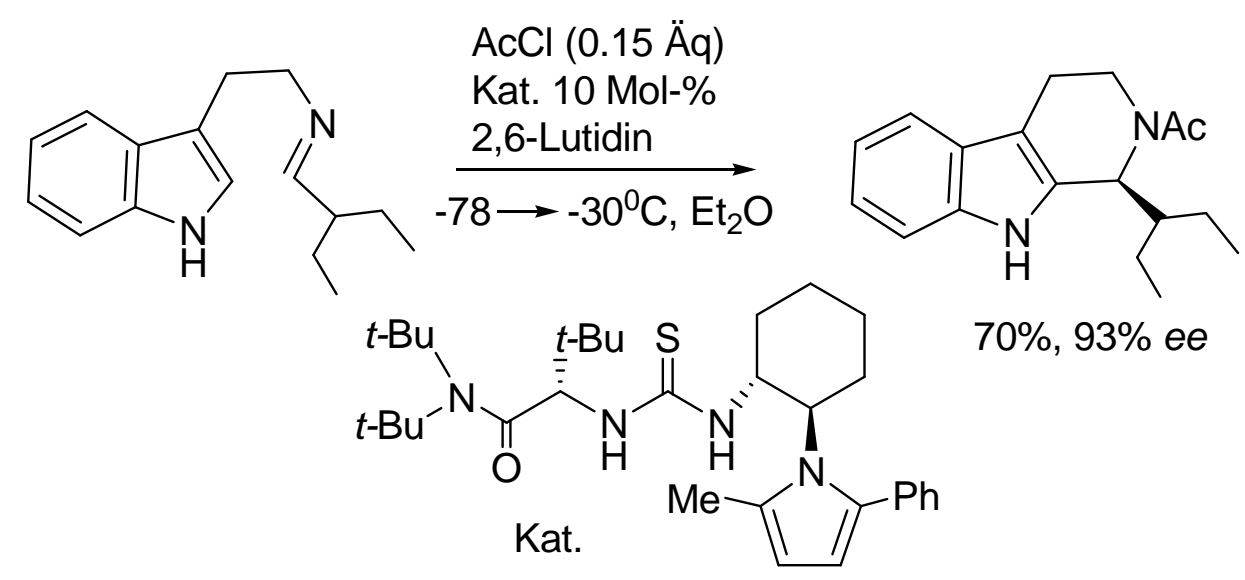

Schema 52 Pictet-Spengler Reaktion durch vereinfachten Thioharnstoff-Katalysator<smiles>CCC[N+](=O)[O-]</smiles>

Schema 53. Nitro-Mannich Reaktion durch vereinfachten Thioharnstoff-Katalysator

\subsection{Ziel der Arbeit in der Synthese und Anwendung von thioharnstoffhaltigen bifunktionellen Katalysatoren}

Die Michael-Addition von Nitroolefinen und Ketonen ist eine sehr wichtige C-C-Bindungsknüpfungsreaktion in der organischen Synthesechemie. ${ }^{126}$ Gleichzeitig und unabhängig voneinander haben Barbas, ${ }^{127}$ List, ${ }^{128}$ Enders ${ }^{129}$ und deren Mitarbeiter festgestellt, dass für die Reaktion von trans- $\beta$-Nitrostyrol und Aceton das L-Prolin ein Katalysator ist, aber dieser natürlich vorkommende Katalysator nur niedrige Enantioselektivitäten bewirkt. ${ }^{125-127}$ Seit einigen Jahren wurden pyrrolidinhaltige Katalysatoren bei der Michael-Addition von 
Nitroolefin und Ketonen entwickelt. ${ }^{130-133}$ Die höhere Enatioseletivität und Diastereoselektivität wurde von Kosuki und Mitarbeitern besonders mit Cyclohexanon und Tetrahydrothiopyran bei der Michael-Addition durch den Pyrrolidin-Pyridin-Katalysator gezeigt. $^{131}$ Die Enantioselektivität bleibt aber niedrig, wenn man Aceton $(12-42 \% e e)^{127-130}$ oder Methylethylketon (10-51\% ee syn) ${ }^{126,129}$ als Michael-Donor verwendet.

Die Verwendung chiraler bifunktioneller asymmetrischer Organokatalysatoren für die Synthese von optisch aktiven Substanzen wurde schon umfangreich dokumentiert. ${ }^{134,135}$

Die Anwendung chiraler thioharnstoffhaltiger Derivate als organische Katalysatoren in der organischen Synthese fand bei mehreren Wissenschaftlern eine große Aufmerksamkeit. ${ }^{136}$ In unserer Gruppe wurde eine thioharnstoffhaltige chirale Verbindung mit einem Imidazol-Gerüst als basischem Zentrum für die Michael-Addition von Aceton und trans- $\beta$-Nitrostyrol untersucht. ${ }^{137}$ Der Enantiomerenüberschuss liegt aber erst bei $87 \%$ und die Ausbeute bei $55 \%$.

Es ist eine Tatsache, dass ein Keton durch primäre oder sekundäre Amine aufgrund einer Enaminbildung aktiviert wird ${ }^{138}$ und die benachbarte Thioharnstoffgruppe durch Wasserstoffbrückenbindung die Elektrophilie der Nitroolefine erhöhen kann. ${ }^{139}$ Bei einem Zusatz des Arylethyl-Gerüstes kann man erwarten, dass Nitroolefin von einer Seite bevorzugt angegriffen wird.

Dank dieser Informationen haben wir uns vorgestellt, dass eine Verbindung mit ThioharnstoffGerüst als Brönsted-Säure und einer Aminogruppe als Base ein geeigneter bifunktioneller Katalysator für die Michael-Addition sein muss (Abb. 19). Von dieser Idee ausgehend wurden dann fünf neue Katalysatoren für die Michael-Addition geplant (Abb. 20).

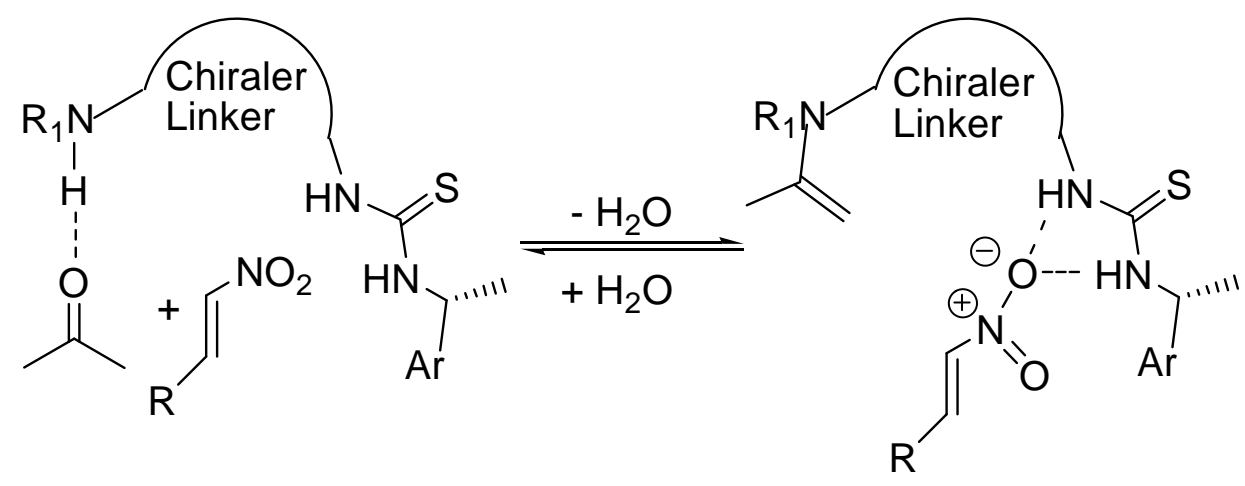

Abbildung 19. Eines bifunktionellen Katalysators-Design 
Diesbezüglich wurden Verbindung 46 und 64 bereits für die Aldol-Reaktion untersucht. Unterschiedliche Isomere der Verbindungen $\mathbf{7 3}$ und $\mathbf{7 4}$ wurden ebenfalls synthetisiert und in der Michael-Addition verwendet.
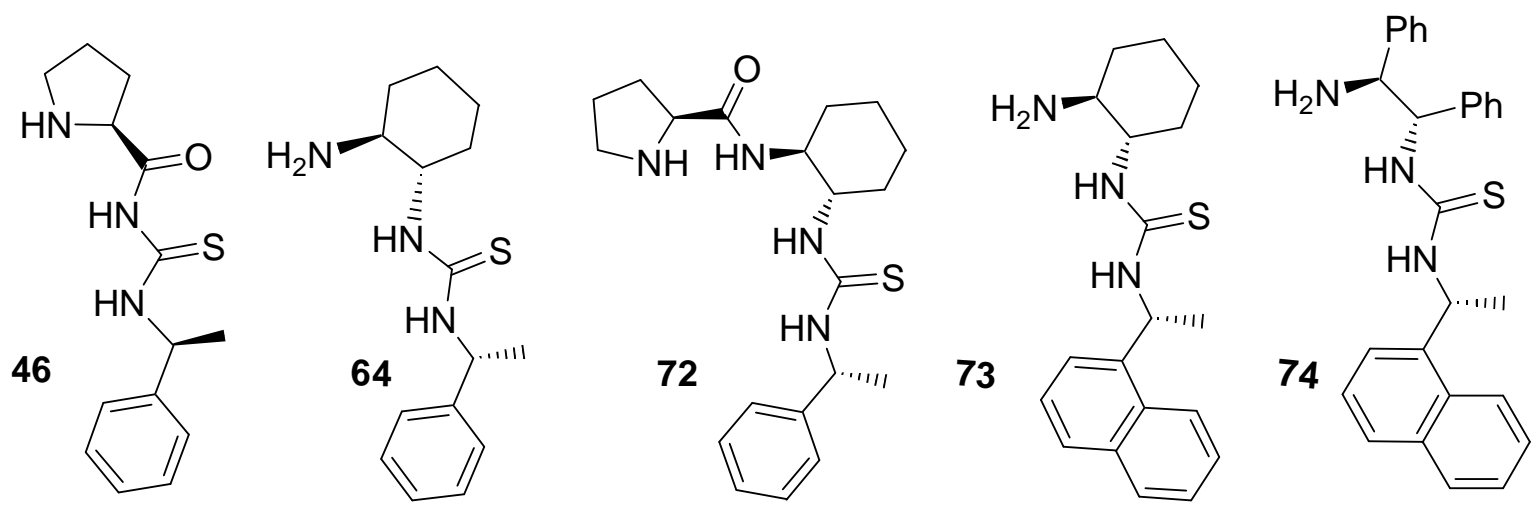

Abbildung 20 Chirale bifunktionelle thioharnstoffhaltige Katalysatoren

\subsubsection{Ergebnisse und Diskussion}

\subsubsection{Synthese von neuen bifunktionellen thioharnstoffhaltigen Katalysatoren}

Die Synthese von Verbindung 64 wurde schon in Schema 42 beschrieben, hier wird sie als wichtige Ausgangssubstanz verwendet. Die Verbindung 72 (Schema 54) wurde in einer zweistufigen Synthese dargestellt. Das wichtige Zwischenprodukt 75 wurde durch Reaktion von Z-Prolin 52 mithilfe von DCC, das zur Aktivierung der Carboxylgruppe in Prolin eingesetzt wird, und dem Katalysator DMAP bei RT in einer Lösungsmittel-Mischung in $\mathrm{CH}_{2} \mathrm{Cl}_{2} / \mathrm{DMF}$ nach literaturbekannten Methoden ${ }^{140}$ erhalten. Um eine bessere Ausbeute zu erhalten, wurde zunächst Z-Prolin in einem Gemisch von $\mathrm{CH}_{2} \mathrm{Cl}_{2} / \mathrm{DMF}$ gelöst und danach DCC und DMAP zugegeben. Nach 20 Minuten Rühren, wurde Verbindung 64 zugegeben und die Reaktionsmischung bei RT $18 \mathrm{~h}$ gerührt, bis sich kein weiter Niederschlag von Dicyclohexylharnstoff mehr gebildet hat. Nach der säulenchromatographischen Reinigung wurde das Produkt 75 in bis zu 73\% Ausbeute isoliert. 


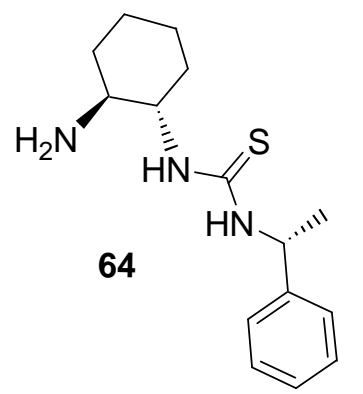

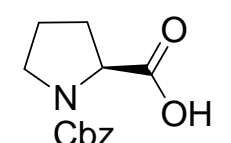

52

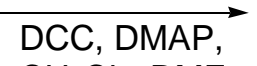

$\mathrm{CH}_{2} \mathrm{Cl}_{2}$, DMF

$\mathrm{RT}, 73 \%$

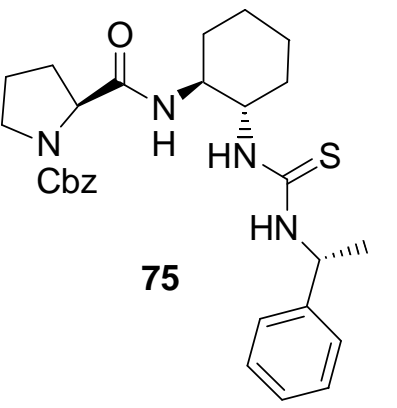

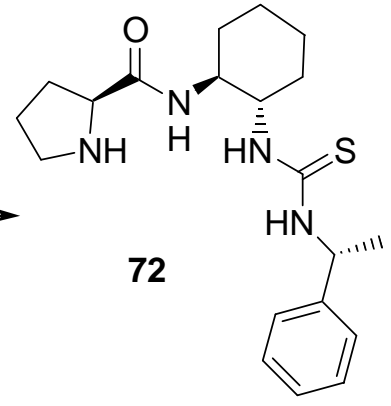

Schema 54. Synthese von Verbindung 72

Die Abspaltung der Z-Gruppe von Verbindung 75 ist identisch zur Entfernung der Schutzgruppe von Verbindung 46, die in Schema 38 illustriert ist. Man erhält aber eine bei der Darstellung der Verbindung $\mathbf{7 2}$ bessere Ausbeute von 83\%.

Die Synthese von Verbindung $\mathbf{7 3}$ und $\mathbf{7 4}$ wird durch Schema 55 verdeutlicht.<smiles>C[C@H](N)c1cccc2ccccc12</smiles>

76

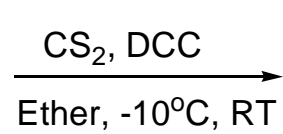

$99 \%$<smiles>[Z7]c1ccc2ccccc2c1[C@H](C)NS(=O)(=O)[O-]</smiles>

$$
\mathrm{Ph}
$$

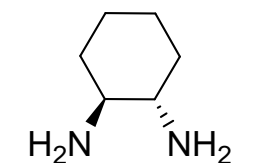<smiles>NCCN</smiles><smiles>CC(C)[Mg]Br</smiles>

Schema 55. Synthese von Verbindung 73 und 74 
Die für die weitere Synthese als Elektrophil benötigte Verbindung 77 wurde in Analogie zur Verbindung $62(R)$-1-Phenylethylisothiocyanat dargestellt. Nach literaturbekannter Methode wurde sie aus (R)-1-Napthylethylamin mit Schwefelkohlenstoff mithilfe von DCC in getrocknetem Ether quantitativ dargestellt. Die Aktivitäten von $(R)$-1-Phenylethylamin und $(R)$ 1-(1-Naphthyl)ethylamin sind unterschiedlich, und um eine höhere Ausbeute bei der Synthese von (R)-1-(1-Naphthyl)ethylisothiocyanat zu bekommen, sollte $\mathrm{CS}_{2}$ in kleinem Überschuss

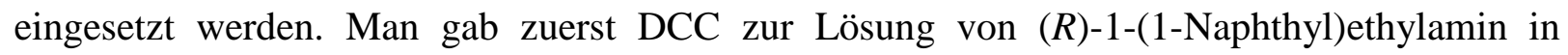
getrocknetem Ether bei $-10^{\circ} \mathrm{C}$. Nachdem sich eine klare Lösung gebildet hat, wurde $\mathrm{CS}_{2}$ tropfenweise bei gleicher Temperatur zugegeben. Die Reaktionsmischung wurde stufenweise bis RT erwärmt, und über Nacht gerührt. Nach der Reinigung wurde das Produkt in $99 \%$ Ausbeute erhalten.

Vom Isothiocyanat ausgehend wurde die Synthese der Verbindungen $\mathbf{7 3}$ und $\mathbf{7 4}$ durch die gleichen Literatur-Methoden wie bei Verbindung 64 durchgeführt. Die Ausbeute für beide Produkte liegt bei 61-62\%. Eine doppelte Addition an Diamine 37 und 63 ist nicht vermeidbar. Dabei bilden sich Produkte, die zwei Thioharnstoff-Gerüste beinhalten, sodass hierbei das basische aktive Zentrum verloren geht.

Weitere Isomere 78, 79, 80, 81, 82, 83 (Abb.21) von Verbindung 74 und 73 wurden analog dargestellt.
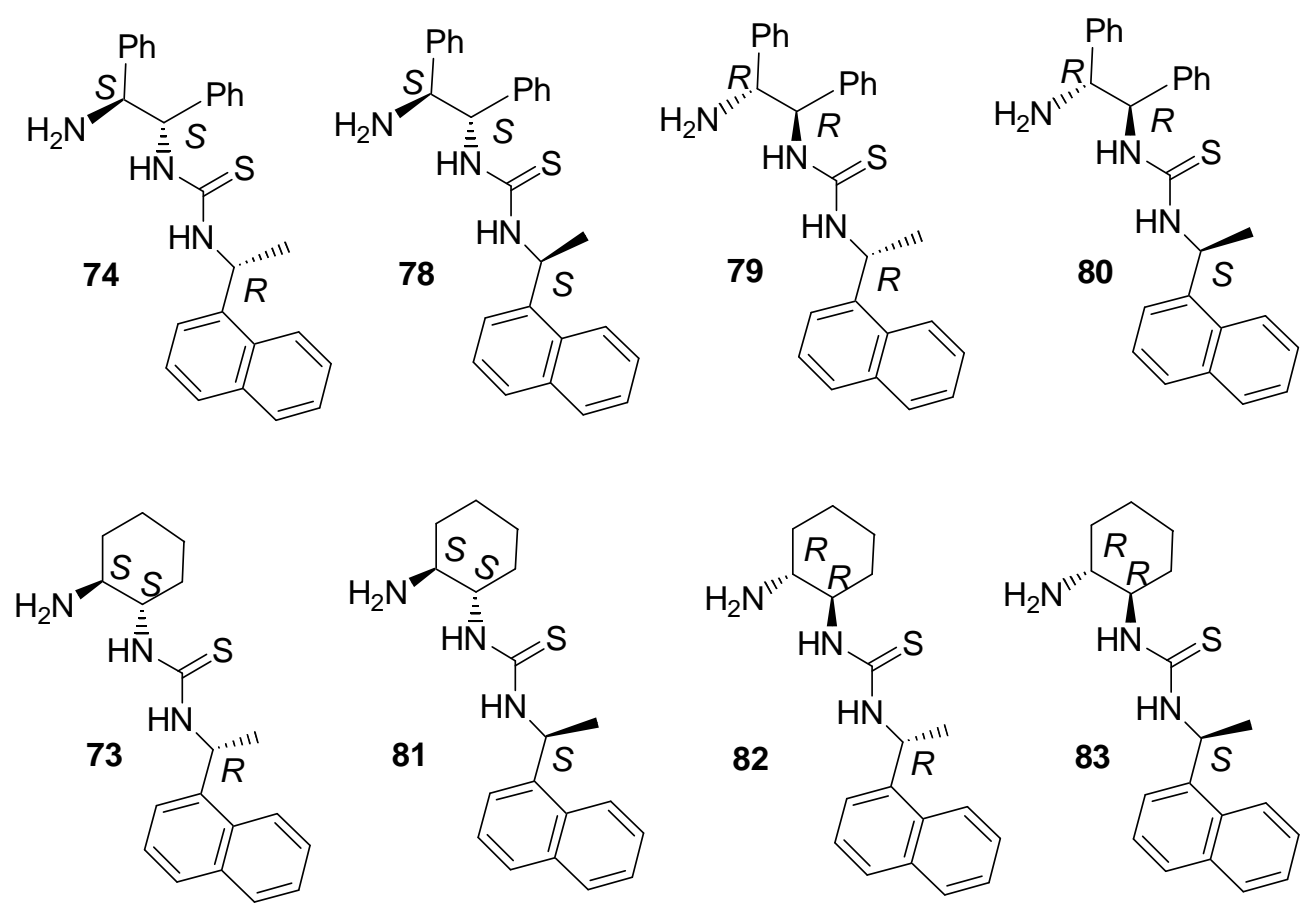

Abbildung 21. Isomere von Verbindung 74 und 73 
5.2.1.2 Anwendung neuer chiraler Thioharnstoff-Katalysatoren in der Michael-Addition.

A) Anwendung der Verbindung $\mathbf{4 6}$ bei der Michael-Addition

Durch die Addition von entsprechenden Ketonen an trans- $\beta$-Nitrostryrol unter Katalyse mit 46 und verschiedenen Additiven bei RT unter Verwendung unterschiedliche Lösungsmittel wurden die Verbindungen 88, 89, 90 und 91 erhalten (Tabelle 8).

Die Untersuchungen wurden bei der Anwesenheit von azidischen neutralen bis hin zu basischen Additiven in verschiedenen Lösungsmitteln und sogar ohne Lösungsmittel durchgeführt. 
(25)

Tabelle 8 Michael-Addition durch Katalysator 46

\begin{tabular}{|c|c|c|c|c|c|c|}
\hline Eintrag & Produkt & $\begin{array}{l}\text { Additiv } \\
(\ddot{A} q)\end{array}$ & Lösungsmittel & $\begin{array}{l}\text { Ausb. } \\
(\%)^{\mathrm{a}}\end{array}$ & $\begin{array}{c}e e(\%) \\
\text { syn }^{\mathrm{b}}\end{array}$ & syn:anti \\
\hline 1 & 91 & - & Toluol & 20 & 0 & - \\
\hline 2 & $\mathbf{8 8}^{\mathrm{f}}$ & - & $\mathrm{MeOH}$ & 10 & 37 & - \\
\hline 3 & 88 & - & $\mathrm{CHCl}_{3}$ & 21 & 37 & - \\
\hline 4 & 88 & $\begin{array}{l}\mathrm{NH}_{4} \mathrm{Cl}(1) \\
\mathrm{H}_{2} \mathrm{O}(1)\end{array}$ & $\mathrm{CHCl}_{3}$ & 88 & 51 & $99: 1$ \\
\hline 5 & 88 & - & Toluol & 78 & 51 & $99: 1$ \\
\hline 6 & 88 & $\mathrm{H}_{2} \mathrm{O}(1)$ & Toluol & 92 & 54 & $99: 5$ \\
\hline 7 & 88 & $\mathrm{NH}_{4} \mathrm{Cl}(1)$ & Toluol & 87 & 34 & $97: 3$ \\
\hline 8 & 88 & $\begin{array}{l}\mathrm{NH}_{4} \mathrm{Cl}(1) \\
\mathrm{H}_{2} \mathrm{O}(1)\end{array}$ & Toluol & 80 & 51 & $88: 12$ \\
\hline 9 & 88 & $\mathrm{H}_{2} \mathrm{O}(2)$ & Toluol & 90 & 38 & $97: 3$ \\
\hline 10 & 88 & $\begin{array}{l}\mathrm{H}_{2} \mathrm{O}(2) \\
\mathrm{HOAc}(0.15)\end{array}$ & Toluol & 96 & 8 & $99: 1$ \\
\hline 11 & 88 & PhCOOH $(0.15)$ & Toluol & 87 & 5 & - \\
\hline 12 & 88 & - & Benzol & $100^{\mathrm{d}}$ & 29 & $99: 1$ \\
\hline 13 & 88 & $\mathrm{H}_{2} \mathrm{O}(1)$ & Benzol & $92^{\mathrm{d}}$ & 46 & 99:1 \\
\hline 14 & 88 & $\mathrm{H}_{2} \mathrm{O}(2)$ & Benzol & $74^{\mathrm{d}}$ & 45 & $99: 1$ \\
\hline 15 & 88 & $\begin{array}{l}\mathrm{NH}_{4} \mathrm{Cl}(1), \\
\mathrm{H}_{2} \mathrm{O}(1)\end{array}$ & - & $100^{\mathrm{d}}$ & 28 & $88: 12$ \\
\hline 16 & 88 & $\mathrm{H}_{2} \mathrm{O}(2)$ & - & $100^{\mathrm{d}}$ & 31 & $88: 12$ \\
\hline 17 & 88 & Buttersäure $(0.1)^{\mathrm{e}}$ & - & $100^{\mathrm{d}}$ & 6 & $99: 1$ \\
\hline 18 & 88 & $\begin{array}{l}\text { Trans-2,5-Dimethyl- } \\
\text { Piperazin }(0.15)\end{array}$ & - & $100^{\mathrm{d}}$ & 17 & $99: 1$ \\
\hline 19 & 89 & - & Toluol & 10 & 87 & - \\
\hline 20 & $89^{f}$ & - & $\mathrm{MeOH}$ & - & - & - \\
\hline 21 & 89 & - & $\mathrm{CHCl}_{3}$ & - & - & - \\
\hline 22 & 89 & $\begin{array}{l}\mathrm{NH}_{4} \mathrm{Cl}(2) \\
\mathrm{H}_{2} \mathrm{O}(2)\end{array}$ & $\mathrm{CHCl}_{3}$ & 29 & 48 & - \\
\hline 23 & 89 & $\mathrm{PhCOOH}(0.15)$ & Toluol & $15^{\mathrm{d}}$ & 5 & - \\
\hline 24 & 89 & $\mathrm{NH}_{4} \mathrm{Cl} ; \mathrm{H}_{2} \mathrm{O}(1)$ & Toluol & $36^{\mathrm{d}}$ & 75 & - \\
\hline 25 & $90^{f}$ & - & $\mathrm{MeOH}$ & 10 & 45 & - \\
\hline 26 & 90 & - & $\mathrm{CHCl}_{3}$ & - & - & - \\
\hline 27 & 90 & $\begin{array}{l}\mathrm{NH}_{4} \mathrm{Cl}(1) \\
\mathrm{H}_{2} \mathrm{O}(1)\end{array}$ & $\mathrm{CHCl}_{3}$ & 57 & 49 & \\
\hline 28 & 90 & - & Toluol & 77 & 20 & \\
\hline 29 & 90 & $\mathrm{PhCOOH}(0.15)$ & Toluol & 90 & 10 & \\
\hline 30 & 90 & $\mathrm{NH}_{4} \mathrm{Cl} ; \mathrm{H}_{2} \mathrm{O}(1)$ & Toluol & 87 & 32 & \\
\hline
\end{tabular}

a) Isolierte Ausbeute; b) Analyse durch chirale HPLC (Daicel Chiralpack);

c) d) Analyse durch ${ }^{1} \mathrm{H}-\mathrm{NMR}$ Spektrum; e) Reaktionszeit 8 h;

f) In Isopropanol bildet sich kein Produkt. 
Alle Lösungsmittel wurden ohne vorherige Trocknung analytisch rein verwendet.

Zunächst wurde Aceton als Kandidat mit trans- $\beta$-Nitrostyrol durch Katalysator 46 getestet. Diese ergaben nur 20\% Produkt als Racemat in 3 Tagen (Eintrag 1 Tabelle 8). Bei dem Katalysator existieren zwei Aktivzentren, eines ist die basische sekundäre Aminogrupe am Pyrrolidinring, das andere ist das Thioharnstoff-Gerüst als Brönsted-Säure. Das unerwartete Ergebnis ist vermutlich auf die nicht passende räumliche Anordnung im Übergangszustand zwischen Enamin und Nitrostyrol zurückzuführen.

Des Weiteren wurden zyclische Ketone mit demselben Katalysator in unterschiedlichem Medium getestet (Tabelle 8). Einträge 2-18 gehören zu den Ergebnissen von Cyclohexanon; Eintrag 19-24 zu Cycloheptanon. Einträge 25-30 stammen von Tetrahydro-4H-thiopyran-4-on. Drei unterschiedliche polare Lösungsmittel (Toluol: Eintrag 5, 19, 28, MeOH (Isopropanol): Eintrag 2, 20, 25 und $\mathrm{CHCl}_{3}$ : Eintrag 3, 21, 26 Tabelle 8) wurden für die drei zyklischen Ketone untersucht. Aufgrund der Löslichkeit des Katalysators war Toluol vermutlich ein geeignetes Lösungsmittel, polare Lösungsmittel wie $\mathrm{MeOH}$ und $\mathrm{CHCl}_{3}$ könnten das Aktivzentrum des Thioharnstoffs solvatisieren, sodass keine oder nur wenige Wechselwirkungen zwischen Nitrostyrol und Thioharnstoff vorliegen. Für Produkt $\mathbf{8 8}$ mit dem wenig polarem Toluol ergaben sich 78\% Ausbeute; 51\% ee (syn:anti bis 99:1) in 3 Tagen (Eintrag 5 der Tabelle 9), dagegen mit $\mathrm{MeOH}$ nur 10\% Ausbeute und 37\% ee (Eintrag 2, Tabelle 9) und mit $\mathrm{CHCl}_{3} 21 \%$ Ausbeute; 37\% ee (Eintrag 3, Tabelle 8) im gleichen Zeitraum. Für Produkt 90 (77\% Ausbeute 20\% ee in 3 Tagen, Eintrag 28, Tabelle 8) und 89 (10\% Ausbeute, 87\% ee in 3 Tagen, Eintrag 19, Tabelle 8) zeigt sich mit Toluol ebenfalls ein besseres Ergebnis als mit $\mathrm{MeOH}$ (Isopropanol) (Eintrag 20 kein Umsatz und Eintrag 25 mit $\mathrm{MeOH}$ nur $10 \%$ und $45 \%$ ee in 3 Tagen) und $\mathrm{CHCl}_{3}$ (Eintrag 21 und Eintrag 26 in 3 Tagen kein Umsatz). Der Einfluss verschiedener Additive wurde auch untersucht. Zuerst wurde Wasser in

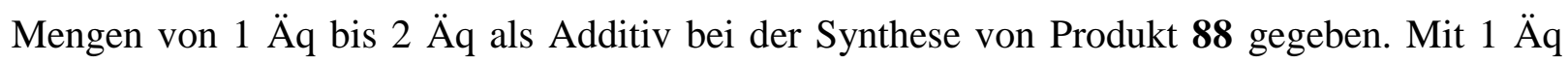
Wasser resultierte ein besseres Ergebnis als mit 2 Äq; die Ausbeute war auch besser als ohne Wasser (92\% Ausbeute, 54\% ee, Eintrag 6; 90\% Ausbeute, $38 \%$ ee, Eintrag 9 und 78\% Ausbeute, 51\% ee, Eintrag 5, Tabelle 8). Das gleiche System wurde mit 1Äq schwacher Säure $\left(\mathrm{NH}_{4} \mathrm{Cl}\right)$ untersucht, wobei eine bessere Ausbeute als ohne Additiv erhalten wurde, aber eine schlechtere Enantioselektivität gegeben war (87\% Ausbeute, 34\% ee Eintrag 7 und $78 \%$ Ausbeute, 51\% ee Eintrag 5). Kombinierte Additive von $\mathrm{NH}_{4} \mathrm{Cl}$ (1 $\ddot{\mathrm{Aq}}$ ) und $\mathrm{H}_{2} \mathrm{O}$ (1 ̈̈q) wurden ohne Lösungsmittel und einmal in Toluol eingesetzt. Beim ersten Fall ergab sich zwar eine bessere Ausbeute (100\% laut ${ }^{1} \mathrm{H}-\mathrm{NMR}$ Eintrag 15) als beim zweiten (isolierte $80 \%$ Ausbeute, Eintrag 8) aber auch eine schlechtere Enantioselektivität (28\% ee Eintrag 15, 51\% ee Eintrag 8). 
Weiterhin wurden auch die relativ stärkeren Säuren $\mathrm{AcOH}, \mathrm{PhCOOH}$ und Buttersäure und die Base trans-2,5-Dimethylpiperazin als Additive im Reaktionsmedium mit und ohne Lösungsmittel getestet. Die Ausbeuten waren alle besser (96\%, Eintrag 10; 87\%, Eintrag 11; 100\% laut ${ }^{1} \mathrm{H}-\mathrm{NMR}$, Eintrag 17 und $100 \%$ laut ${ }^{1} \mathrm{H}-\mathrm{NMR}$, Eintrag 18) als ohne Additiv. Die Enantioselektivität war aber viel zu niedrig (8\% ee; Eintrag 10; 5\% ee, Eintrag 11; 6\% ee, Eintrag 17; 17\% ee, Eintrag 18). Benzol als Lösungsmittel führte zu einem etwas schlechteren Ergebnis als Toluol (100\% laut ${ }^{1} \mathrm{H}-\mathrm{NMR}, 29 \%$ ee syn:anti 99:1; Eintrag 12; mit 1 Äq Wasser 92\% (Ausbeute) laut ${ }^{1} \mathrm{H}-\mathrm{NMR}, 46 \%$ ee syn:anti 99:1, Eintrag 13; mit 2 Äq Wasser 74\% laut ${ }^{1} \mathrm{H}$ NMR, 45\% ee syn:anti 99:1 (Eintrag 14) besser als Toluol.

Um bessere Additive für diese Reaktion zu finden, wurden azide Additive bei den Untersuchungen für Produkt 90 und 89 verwendet. Es scheint sich der Trend abzuzeichnen, dass eine bessere Ausbeute eine schlechtere Enantioseletivität bedeutet und umgekehrt. Für Produkt 90 wurden 57\% Ausbeute mit 49\% ee (Eintrag 27) durch die Zugabe von $\mathrm{NH}_{4} \mathrm{Cl}$ (1 Äq) und $\mathrm{H}_{2} \mathrm{O}\left(1 \ddot{\mathrm{A} q}\right.$ ) in $\mathrm{CHCl}_{3}$ erhalten, $90 \%$ Ausbeute und $10 \%$ ee (Eintrag 29) mit Additiv PhCOOH (0.15 Äq) in Toluol und 87\% Ausbeute und 32\% ee (Eintrag 30) mit Additiv von $\mathrm{NH}_{4} \mathrm{Cl}(1 \ddot{\mathrm{A} q})$ und $\mathrm{H}_{2} \mathrm{O}(1 \ddot{\mathrm{Aq}})$ in Toluol; für Produkt 89 war es ähnlich: 29\% Ausbeute und $48 \%$ ee (Eintrag 22) mit $\mathrm{NH}_{4} \mathrm{Cl}(1 \ddot{\mathrm{Aq}})$ und $\mathrm{H}_{2} \mathrm{O}(1 \mathrm{Äq})$ in $\mathrm{CHCl}_{3}, 15 \%$ Ausbeute laut ${ }^{1} \mathrm{H}-\mathrm{NMR}$ und 75\% ee (Eintrag 23) mit Additiv $\mathrm{PhCOOH} \mathrm{(0.15} \mathrm{Äq)} \mathrm{in} \mathrm{Toluol,} \mathrm{und} \mathrm{36 \%} \mathrm{Ausbeute} \mathrm{laut}{ }^{1} \mathrm{H}$ NMR, 75\% ee (Eintrag 24) mit $\mathrm{NH}_{4} \mathrm{Cl} ; \mathrm{H}_{2} \mathrm{O}(1 \ddot{\mathrm{Aq}})$ in Toluol.

Zusammenzufassend lässt sich davon ausgehen, dass Verbindung 46 kein geeigneter Katalysator für die Michael-Addition von zyklischen Ketonen an Nitrostyrol ist.

B) Anwendung der Verbindung $\mathbf{7 2}$ bei der Michael-Addition

Weitere Untersuchungen wurden nach Tabelle 9 durch die Verwendung der bifunktionellen Verbindung 72 durchgeführt. Als Produkte wurden 88, 89, 90, 91 erhalten und das sterisch relativ gehinderte Ethylmethylketon mit seinem Produkt 92 betrachtet.

Angesichts der vorangegangenen Untersuchung bei Verbindung 46 wurde Toluol als Lösungsmittel für die Reaktion verwendet. Einträge 1-4 und 13 in der Tabelle 10 zeigen, dass die beste Ausbeute von 87\% (Eintrag 2) bei Produkt 88 liegt. Die beste Enantioselektivität von 33\% ee (Eintrag 4) wurde bei der Verbindung 89 erreicht. Das Produkt 92 ist bei der Verwendung von Verbindung 72 gar nicht entstanden. Diese Systeme wurden mit verschiedenen Additiven versetzt. Bei Verbindung $\mathbf{8 9}$ ergab sich mit allen Additiven in Toluol relativ gesehen bessere Resultate als nur in Toluol (71\% Ausbeute, 47\% ee syn:anti 95:5 mit 
PhCOOH (0.15 ̈̈q) in $21 \mathrm{~h}$ (Eintrag 5); 20\% Ausbeute, 94\% ee mit L-Asp (0.15 ̈̈q) (Eintrag 6); 67\% Ausbeute, 64\% ee syn:anti 99:1 mit $\mathrm{H}_{2} \mathrm{O}$ (1 $\left.\mathrm{Aq}\right)$ Eintrag 7; 57\% Ausbeute, 54\% ee syn:anti 97:3 mit $\mathrm{NH}_{4} \mathrm{Cl}$ (1 Äq) Eintrag 8 und 58\% Ausbeute, 51\% ee syn:anti 76:24 Eintrag 9 der Tabelle 9), (R)-; und (S)-2-Phenylpropionsäure zeigten als Additive bei der Anwesenheit der katalytischen Verbindung $\mathbf{7 2}$ keine Wirkung.

Tabelle 9 Verwendung der Verbindung 72 bei der Michael-Addition.

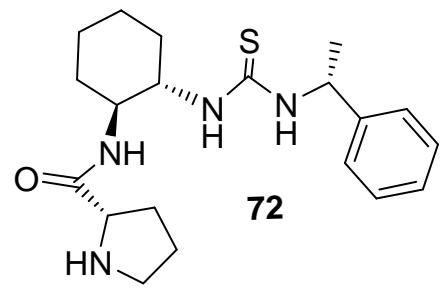<smiles>CC(=O)C(C)C(C[N+](=O)[O-])c1ccccc1</smiles>

\begin{tabular}{|c|c|c|c|c|c|c|}
\hline Eintrag & Produkt $^{\mathrm{c}}$ & $\begin{array}{l}\text { Additiv } \\
\text { ( } \ddot{A} q)\end{array}$ & Lösungsmittel $^{\mathrm{a}}$ & $\begin{array}{l}\text { Ausbeute } \\
\qquad(\%)^{\mathrm{b}}\end{array}$ & $\begin{array}{c}e e \\
(\%)^{\mathrm{c}}\end{array}$ & syn:anti \\
\hline 1 & 91 & - & Toluol & 36 & 0 & - \\
\hline 2 & 88 & - & Toluol & 87 & 17 & - \\
\hline 3 & 90 & - & Toluol & 72 & 13 & - \\
\hline 4 & 89 & - & Toluol & 29 & 33 & - \\
\hline 5 & $89^{e}$ & $\mathrm{PhCOOH}(0.15)$ & Toluol & 71 & 47 & $95: 5$ \\
\hline 6 & 89 & L-Asp (0.15) & Toluol & 20 & 94 & - \\
\hline 7 & 89 & $\mathrm{H}_{2} \mathrm{O}(1)$ & Toluol & 67 & 64 & 99:1 \\
\hline 8 & 89 & $\mathrm{NH}_{4} \mathrm{Cl}(1)$ & Toluol & 57 & 54 & $97: 3$ \\
\hline 9 & 89 & $\begin{array}{l}\mathrm{NH}_{4} \mathrm{Cl}(1) \\
\mathrm{H}_{2} \mathrm{O}(1)\end{array}$ & Toluol & 58 & 51 & $76: 24$ \\
\hline 10 & 89 & - & Isopropanol & - & - & \\
\hline 11 & 89 & $\begin{array}{l}(R) \text {-2-Phenylpropionsäur } \\
(0.15)\end{array}$ & Toluol & - & - & - \\
\hline 12 & 89 & $\begin{array}{l}\text { (S)-2-Phenylpropionsäur } \\
(0.15)\end{array}$ & Toluol & - & - & - \\
\hline 13 & 92 & - & Toluol & - & - & \\
\hline
\end{tabular}

a) Lösungsmitteln sind p.a Qualität; b) isolierte Ausbeute;

c) Analyse durch chirale HPLC (Daicel Chiralpack); Reaktionszeit betragen 3 Tage, d) Analyse durch ${ }^{1} \mathrm{H}$ NMR Spektrum; e) Reaktionszeit: $21 \mathrm{~h}$. 
C) Anwendung der Verbindung 64 als Katalysator bei der Michael-Addition

Weitere Untersuchungen fanden am primären Amin- und thioharnstoffhaltigen Katalysator 64 statt. Als Lösungsmittel der Wahl wurde wie für Verbindungen 46 und $\mathbf{7 2}$ Toluol genommen und es wurden unterschiedliche Säuren als Additiv zugegeben. Neben der Darstellung von Produkt 91 erfolgte noch die Sythese von Verbindung 96, 97 und 98 mit Katalysator 64 (Tabelle 10). Die Nitroolefine, die als Edukte für Verbindungen 96, 97, 98 zur Verfügung gestellt waren, sind wegen der verschiedenen Elektronendichte am aromatischen Ring unterschiedlich aktiv. $p$-Methoxynitrostyrol ist am inaktivsten, $p$-Bromnitrostyrol ist aufgrund des elektronenziehenden Bromatoms ebenfalls relativ aktiv. Betrachtet man die Ausbeute der drei Produkte, sind diese Eigenschaften nachvollziehbar (Einträge 7-9, Tabelle 10).

Die Verbindung 64 ist bei der katalytischen Michael-Addition von Nitrostyrol und Ketonen wesentlich aktiver als die Verbindungen 46 und 72. Die Enantioselektivtät erreicht bei Verbindung 91 86\% (Eintrag 2), und die Ausbeute erreicht bis 85\%, obwohl Additive zugegeben wurden. Der Unterschied liegt wohl am primären (Verbindung 64) und sekundären Amin (Verbindung 46 und 72) und der unterschiedlichen räumlichen Anordnung der beiden Verbindungsgruppen.

In den folgenden Beispielen wurden bevorzugt Säuren als Additiv verwendet. Als beste Kombination stellte sich $\mathrm{H}_{2} \mathrm{O}$ (2 $\ddot{\mathrm{A} q}$ ) mit HOAc (0.15 $\ddot{\mathrm{A} q}$ ) bei der Reaktion von Nitrostyrol und Aceton heraus; wobei sich 85\% Ausbeute und 86\% ee (Eintrag 2 der Tabelle 10) nach $16 \mathrm{~h}$ ergaben, während (R)-2-Phenylpropionsäure (81\% Ausbeute, 88.5\% ee in 12 h, Nr. 4 ); $(S)$-2Phenylpropionsäure (75\% Ausbeute, $89 \%$ ee in 12 h, Eintrag 5) und PhCOOH (0.15 Äq) (71\% Ausbeute, 89.5\% ee in 20 h, Eintrag 3) vergleichbar gute Resultate lieferten. Die schlechtesten Ergebnisse bei dieser Reaktion zu Produkt 91 wurden mit Additiv L-Asp erhalten (0.15 Äq) (54\% Ausbeute, $85 \% e e$, Eintrag 6). Vermutlich aufgrund der ungünstigen Struktur wurde bei den Produkten 96-98 bei gleichem Additiv L-Asp (0.15 Äq) kein besseres Ergebnis als bei der Verbindung 91 erreicht. Die besten Ergebnisse mit dieser Verbindung (Einträge 7-9) wurden beim Produkt 96 erzielt (50\% Ausbeute, 80\% ee, Eintrag 7); bei der Verbindung 98 (36\% Ausbeute, 87\% ee) und 97 (32\% Ausbeute, 87\% ee) sind Katalysator und Additiv wenig aktiv. 


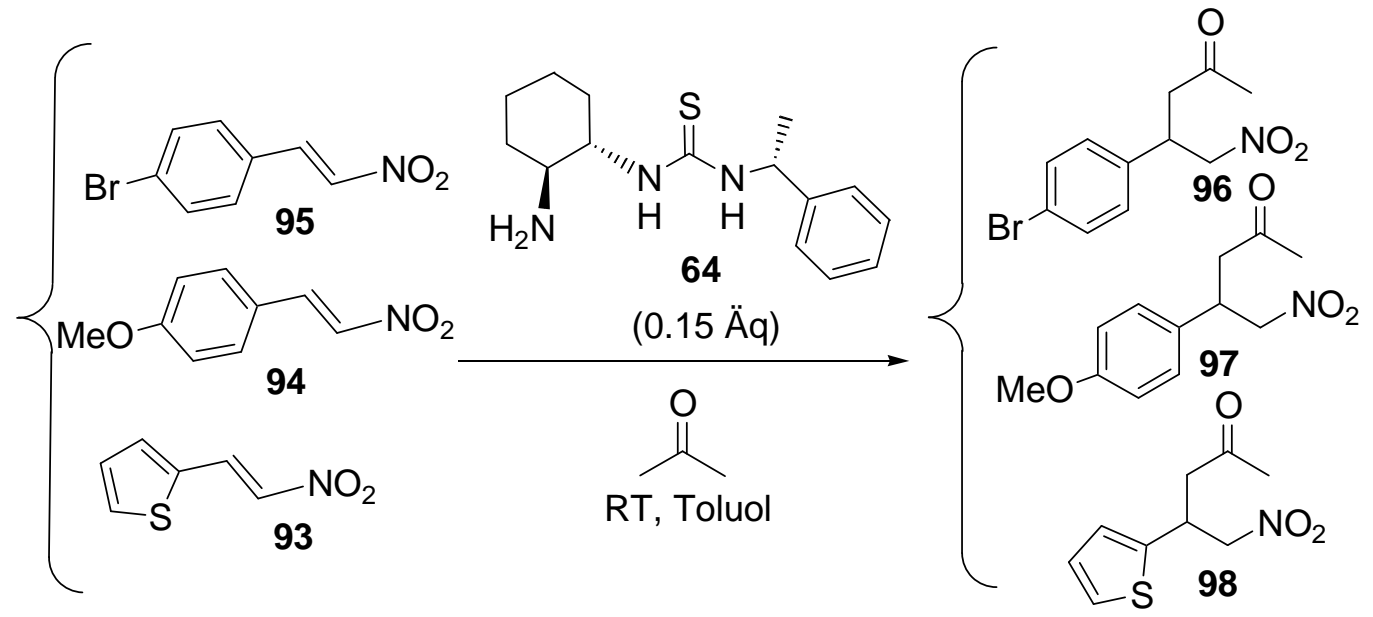

Tabelle 10 Anwendung der Verbindung 64 als Katalysator bei der Michael-Addition

\begin{tabular}{|c|c|c|c|c|c|c|}
\hline Eintrag & Produkt & $\begin{array}{c}\text { Additiv } \\
(\ddot{A ̈ q})\end{array}$ & $\begin{array}{c}\text { Zeit } \\
(\%)^{\mathrm{a}}\end{array}$ & $\begin{array}{c}\text { Ausbeute } \\
(\%)^{\mathrm{b}}\end{array}$ & Konfig. $^{\mathrm{c}}$ \\
\hline 1 & $\mathbf{9 1}$ & $\mathrm{NH}_{4} \mathrm{Cl}(1) ; \mathrm{H}_{2} \mathrm{O}(1)$ & $18 \mathrm{~h}$ & 59 & 84 & $R$ \\
\hline 2 & $\mathbf{9 1}$ & $\mathrm{H}_{2} \mathrm{O}(2), \mathrm{HOAc}(0.15)$ & $16 \mathrm{~h}$ & 85 & 86 & $R$ \\
\hline 3 & $\mathbf{9 1}$ & PhCOOH $(0.15)$ & $20 \mathrm{~h}$ & 71 & 89.5 & $R$ \\
\hline 4 & $\mathbf{9 1}$ & $(R)-2-$ Phenylpropionsäure & $12 \mathrm{~h}$ & 81 & 88.5 & $R$ \\
\hline 5 & $\mathbf{9 1}$ & $(S)-2-$ Phenylpropionsäure & $12 \mathrm{~h}$ & 75 & 89 & $R$ \\
\hline 6 & $\mathbf{9 1}$ & L-Asp (0.15) & 3 Tage & 54 & 85 & $R$ \\
\hline 7 & $\mathbf{9 6}$ & L-Asp (0.15) & 3 Tage & 50 & 80 & $R$ \\
\hline 8 & $\mathbf{9 7}$ & L-Asp (0.15) & 3 Tage & 32 & 87 & $R$ \\
\hline 9 & $\mathbf{9 8}$ & L-Asp (0.15) & 3 Tage & 36 & 87 & $R$ \\
\hline
\end{tabular}

a) Isolierte Ausbeute; b) Analyse durch chirale HPLC (Daicel Chiralpack); c) Konfiguration stimmen mit Literaturdaten überein.

Die Synthese führte nur zu einer $R$-Konfiguration. Die Übergangszustände wurden bereits diskutiert (Schema 56). ${ }^{141}$ Die Berechnung des Übergangszustandes fand in der isolierten Gasphase unter Zuhilfenahme des Programms Gaussian 03 statt. Lösungsmittel-Effekte wurden nicht betrachtet. ${ }^{141}$ Die Übergangszustände der $R$ - und $S$-Isomere zeigen, dass kein planeres Arrangement zwischen dam Sauerstoff der Nitro-Gruppe und den Thioharnstoff-Wasserstoffen eintritt. Der Katalysator ist zusätzlich durch eine Wasserstoffbrückenbindung zwischen dem Schwefelatom und dem Wasserstoffatom $H_{\boldsymbol{c}}$ fixiert. ${ }^{141}$ Die Distanz zwischen dem Sauerstoffatom an der Nitrogruppe und den beiden Wasserstoffatomen im Thioharnstoff ist im 
Übergangszustand der $S$-Konfiguration um $0.04 \AA$ länger als in der $R$-Konfiguration, Abstände $\mathrm{C}_{\mathrm{a}}-\mathrm{C}_{\mathrm{b}}$ und $\mathrm{S}-\mathrm{H}_{\mathrm{c}}$ unterscheiden sich bei $S$ - und $R$-Konfiguration ebenfalls um $0.08 \AA$ bzw. 0.22 $\AA$.

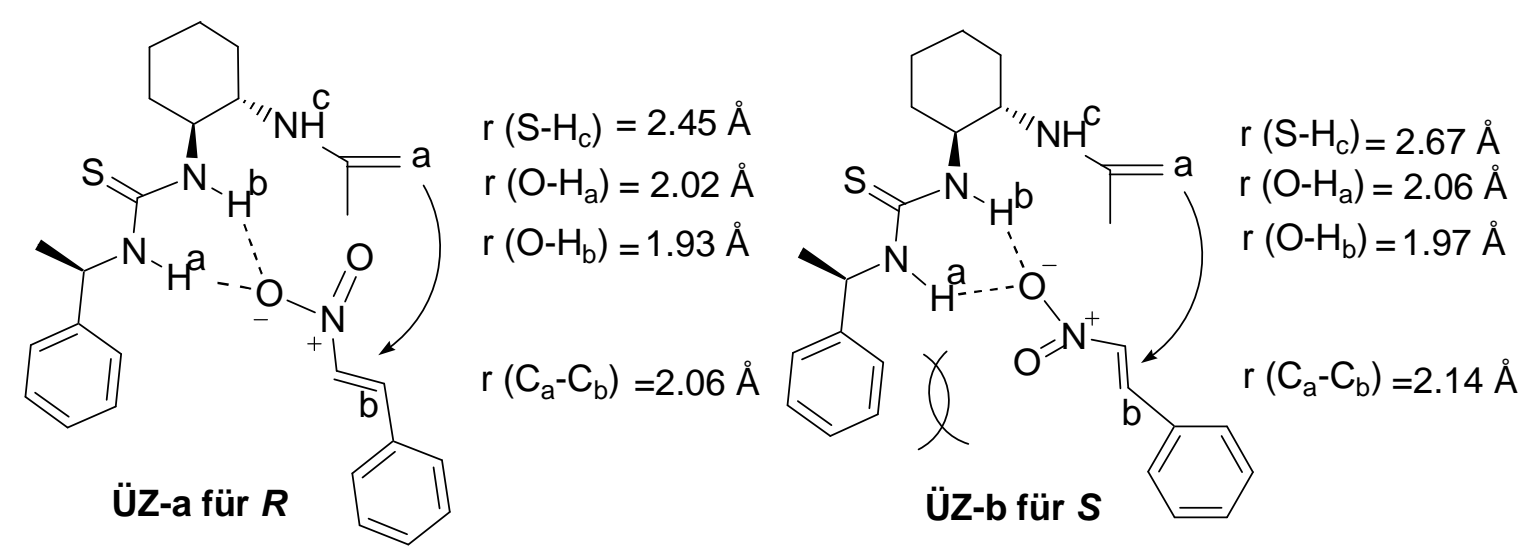

Schema 56. Übergangszustände für $(R)$ - und $(S)$-Isomere der Verbindung 91.

Im ÜZ-a (Schema 56) ist eine der beiden Sauerstoffatome der Nitrogruppe, das nicht an der Wasserstoffbrückenbindung beteiligt ist, weiter vom aktiven Zentrum des Katalysators entfernt, während im $S$-Übergangszustand eine Abstoßung zwischen diesem Sauerstoffatom und der Phenylgruppe des Katalysators auftritt. Also ist der $R$-Übergangszustand energetisch günstiger als der für $S$. Dies begründet, dass $R$-Enantiomere als überschüssiges Produkt gewonnen wurden.

Im Vergleich zu anderen Mitteilungen ${ }^{142}$ geben wir eine andere Erklärung, nämlich dass nur ein Sauerstoffatom der Nitrogruppe mit dem Thioharnstoff eine Wasserstoffbrückenbindung bildet. Im Vergleich zu Katalysatoren 72 und 46 bewirkt Katalysator 64 mit $\mathrm{H}_{2} \mathrm{O}$ (2 $\ddot{\mathrm{Aq}}$ ) und $\mathrm{HOAc}$ (0.15 ̈̈q) als Additiv bei der Reaktion zwischen Nitrostyrol und Aceton sowohl eine bessere Enantioselektivität als auch eine erhöhte Ausbeute. Zum Beweis der Übergangszustände wurden ESI-MS Messungen durchgeführt. Katalysator 64 (1 $̈$ Äq) wurde mit Nitrostyrol (1 Äq) in Aceton vermengt. Nach 24 h wurde das Lösungsmittel im Vakuum entfernt, der Rückstand wurde mit ESI-MS gemessen. Das Spektrum und dessen Auswertung sind in Abb. 22 gegeben. Es zeigt die exakten Werte von $\mathrm{m} / \mathrm{z}$ (318.1) und $[\mathrm{M}+\mathrm{H}]^{+}$. Dieses reicht, einen Angriff vom Enamin-Intermediat an das aktivierte Kohlenstoffatom von Nitrostyrol durchzuführen. Ein zweites wichtiges Signal m/z (467.2) von $[\mathrm{M}+\mathrm{H}]^{+}$unterstreicht die Bedeutung des EnaminIntermediats für die Reaktion. 


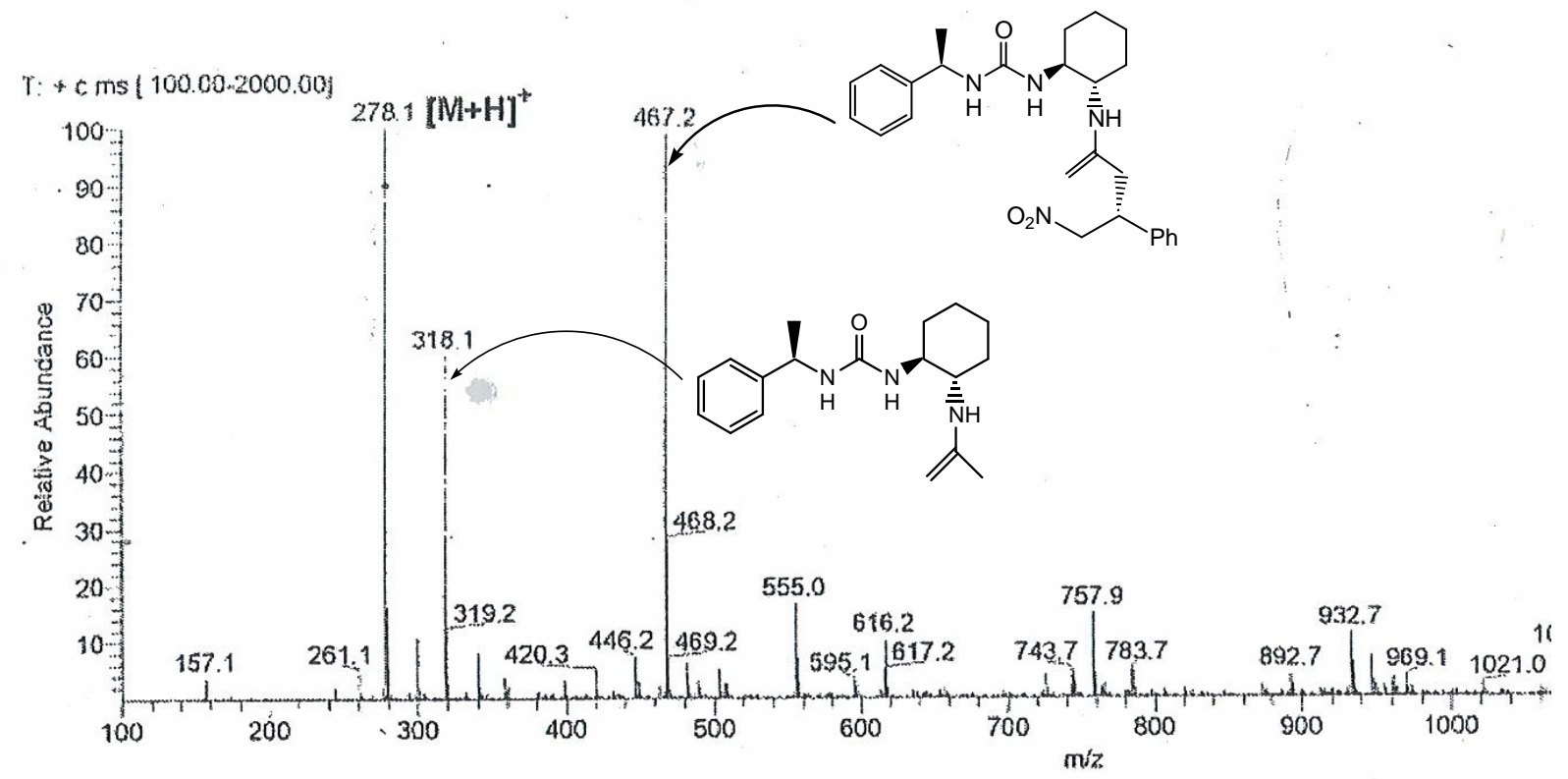

Abbildung 22. ESI-MS-Spektrum einer Mischung von Kat. 64, Nitrostyrol und Aceton

D) Anwendung der Verbindung $\mathbf{7 3}$ und deren Stereoisomere bei der asymmetrischen MichaelAddition

Die Arylethylgruppe, die dem Thioharnstoff-Gerüst benachbart ist, spielt bei der Enantioselektivität eine wichtige Rolle. Diese Gruppe kann entweder sterisch die Koordination zwischen dem Sauerstoffatom der Nitrogruppe und Wasserstoff am Thioharnstoff steuern oder die Acidität vom Thioharnstoff beeinflussen. An dieser Stelle sollte die Ursache gefunden werden, warum Verbindung 64 nicht aktiv genug ist, um die Bildung der Produkt 96, 97, $98 \mathrm{zu}$ katalysieren. Aus diesem Grund wurden die 4 Isomere 73, 81, 82 und 83 als neue Katalysatoren synthetisiert (Tabelle 11). 
<smiles>N[C@H]1CCCC[C@@H]1N</smiles><smiles>[CH]NC(=S)N[C@@H](C)c1cccc2ccccc12</smiles><smiles>NC1CCCCC1</smiles><smiles>C[C@H](NC(N)=S)c1cccc2ccccc12</smiles><smiles>C[C@@H](NC(=S)N[C]1CCCC[C]1N)c1cccc2ccccc12</smiles><smiles>C[C@H](NC(=S)N[C@H]1CCCC[C@H]1N)c1cccc2ccccc12</smiles>

Nur die unterschiedlichen Arylreste von Verbindung 64 und 73 ergeben die verschiedenen Resultate (Tabelle 11). Verbindung 73 ist unter gleichen Bedingungen aktiver als 64 (vgl. Eintrag 1, Tabelle 11 und Eintrag 2, Tabelle 10). Die drei anderen Isomere von Verbindung 73 wurden unter absolut gleichen Bedingungen bei der Michael-Addition von Nitrostyrol und Aceton eingesetzt. Das beste Ergebnis wurde mit der $S, S, R$-konfigurierten Verbindung 73 erzielt. 97\% Ausbeute und 84\% ee mit $R$-Konfiguration in nur 2 Tagen. Die Verbindung 83, die $R, R, S$-Konfiguration aufweist, lieferte $89 \%$ Ausbeute und $87 \%$ ee mit $S$-Konfiguration in 3Tagen. Beide Katalysatoren mit unterschiedlichen Konfigurationen sollten die gleichen Werte von Ausbeute und Enantioselektivität erzielen. Die Ursache der beobachteten Abweichung ist nicht offensichtlich. Einträge 2 und 3 zeigen uns, dass die Produkte durch die beiden Eantiomere 81 und 82, die $S, S, S$ - bzw. $R, R, R$-Konfiguration besitzen, im Gegenteil oben genanten Beispielen nahezu gleichwertige Ergebnisse lieferten (76\% Ausbeute, 69\% ee REnantiomer Eintrag 2; 72\% Ausbeute, 73\% ee S-Enantiomer, Eintrag 3). 
Tabelle 11 Vergleich der katalytischen Aktivität verschiedener Stereoisomere von Verbindung $\mathbf{7 3}$ bei der Michael-Addition von Nitrostyrol und Aceton

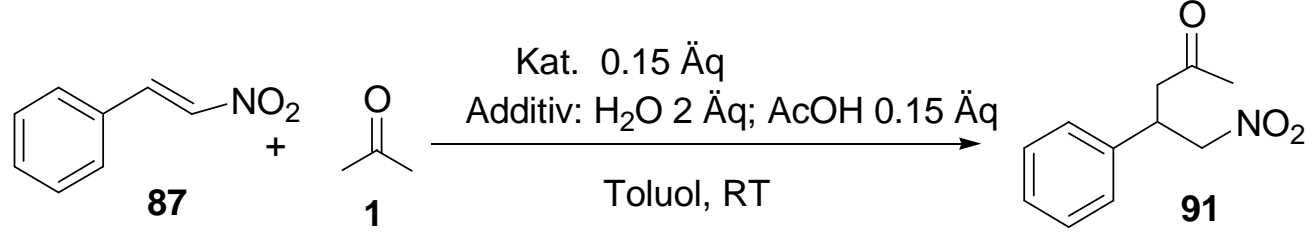

\begin{tabular}{|c|c|c|c|c|c|}
\hline Eintrag & Kat. & $\begin{array}{c}\text { Zeit } \\
(\mathrm{Tag})\end{array}$ & $\begin{array}{c}\text { Ausbeute } \\
(\%)^{\mathrm{a}}\end{array}$ & $\begin{array}{c}e e \\
(\%)^{\mathrm{b}}\end{array}$ & Konfig. $^{\mathrm{c}}$ \\
\hline 1 & $\mathbf{7 3}$ & 2 & 97 & 84 & $R$ \\
\hline 2 & $\mathbf{8 1}$ & 3 & 76 & 69 & $R$ \\
\hline 3 & $\mathbf{8 2}$ & 3 & 72 & 73 & $S$ \\
\hline 4 & $\mathbf{8 3}$ & 3 & 89 & 87 & $S$ \\
\hline
\end{tabular}

a) Isolierte Ausbeute; b) Analyse durch chirale HPLC (Daicel Chiralpack);

c) Konfiguration stimmen mit Literatur Daten überein.

Somit wurde der Katalysator $\mathbf{7 3}$ in Bezug auf die Konfiguration als der am besten geeignetste bestimmt. Das bedeutet wiederum, dass nicht nur die aktiven Zentren, sondern auch die räumliche Anordnung der Katalysatoren eine wichtige Rolle für den katalytischen Verlauf spielt. Weitere Untersuchungen dieser bezüglich werden nun mit Katalysator $\mathbf{7 3}$ durchgeführt.

Zunächst wurde die Reaktion in unterschiedlichen Lösungsmitteln durchgeführt (Tabelle 12).

Protisches $\mathrm{MeOH}$, mit der Eigenschaft selbst Wasserstoffbrücken auszubilden, behindert die Wasserstoffbrückenbindung zwischen Katalysator und Substraten, womit die niedrige Ausbeute von $50 \%$ und das ee-Wert von $56 \%$ in $82 \mathrm{~h} \mathrm{zu}$ erklären sind. Das besser geeignete Lösungsmittel ist Toluol (97\% Ausbeute und 84\% ee in 48 h), dem ein Additiv $\left(\mathrm{H}_{2} \mathrm{O}: 2\right.$ Äq, AcOH: 0.15 Äq) zugesetzt wird. DMSO ist aufgrund der Löslichkeit des Katalysators nicht für die Reaktion geeignet (45\% Ausbeute und 6\% ee in 82 h). Die Reaktion in $\mathrm{CH}_{2} \mathrm{Cl}_{2}$ und $\mathrm{CHCl}_{3}$ verläuft zwar besser (Einträge 1 und 2, Tabelle 12) als in $\mathrm{MeOH}$ und DMSO, jedoch schlechter als in Toluol. 
Tabelle 12 Lösungsmittel-Optimierung bei Anwendung der Verbindung $\mathbf{7 3}$ als Katalysator in der Michael-Addition

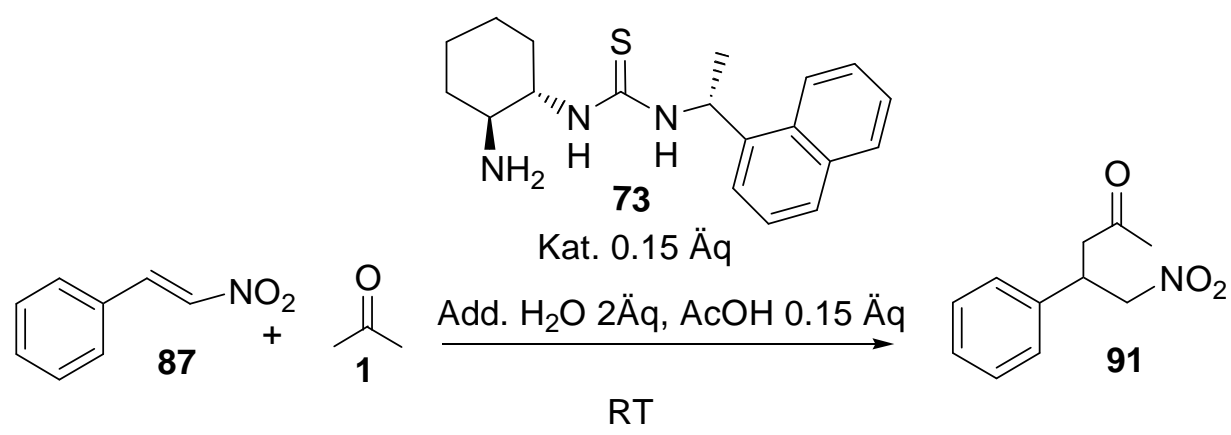

\begin{tabular}{|c|c|c|c|c|c|}
\hline Eintrag & Lösungsmittel $^{\mathrm{a}}$ & $\begin{array}{c}\text { Zeit } \\
(\mathrm{h})\end{array}$ & $\begin{array}{c}\text { Ausbeute } \\
(\%)^{\mathrm{b}}\end{array}$ & $\begin{array}{c}e e \\
(\%)^{\mathrm{c}}\end{array}$ & Konfig. $^{\mathrm{d}}$ \\
\hline 1 & $\mathrm{CH}_{2} \mathrm{Cl}_{2}$ & 56 & 57 & 84 & $R$ \\
\hline 2 & $\mathrm{CHCl}_{3}$ & 52 & 78 & 84 & $R$ \\
\hline 3 & Aceton & 28 & 80 & 70 & $R$ \\
\hline 4 & MeOH & 82 & 50 & 56 & $R$ \\
\hline 5 & DMSO & 82 & 45 & 6 & $R$ \\
\hline 6 & Toluol & 48 & 97 & 84 & $R$ \\
\hline 7 & Toluol & 82 & 60 & 87 & $R$ \\
\hline
\end{tabular}

a) alle Lösungsmittel sind getrocknet b) Isolierte Ausbeute;

c) Analyse durch chirale HPLC (Daicel Chiralpack);

d) Konfiguration stimmten mit Literaturdaten überein; e) Ohne Additiv

Die Verbindung 73 wurde für die Synthese der Produkte 88-99 auf ihre katalytische Wirkung ebenfalls in 0.15 Äq eingesetzt (Tabelle 13). Angesichts des gleichen Reaktionsmechanismus wurden die gleichen Additive (Kombination von $2 \ddot{\mathrm{Aq}} \mathrm{H}_{2} \mathrm{O}$ und1.5 $\mathrm{A} q \mathrm{AcOH}$ ) wie für 64 herangezogen, lediglich zur Darstellung von Verbindung 88 wurde die anorganische Base $\mathrm{NaOH}(0.18 \ddot{\mathrm{Aq}})$ und $\mathrm{H}_{2} \mathrm{O}(2 \ddot{\mathrm{A} q})$ als Additiv verwendet (Eintrag 5, Tabelle 13). Im Vergleich $\mathrm{zu} \mathrm{H}_{2} \mathrm{O}(2 \mathrm{Äq})$ und $\mathrm{AcOH}(0.15$ Äq) als Additiv (45\% Ausbeute und 66\% ee in 3 Tage, Eintrag 5, Tabelle 13) läuft die Reaktion mit $\mathrm{NaOH}\left(0.18\right.$ Äq) und $\mathrm{H}_{2} \mathrm{O}$ (2 $\ddot{\mathrm{A} q}$ ) viel schneller (91\% Ausbeute in 12 h), aber bei niedrigerer Enantioselektivität (40\% ee). Die Ursache dafür wird in Schema 57 verdeutlicht. $\mathrm{NaOH}$ als starke Base greift direkt das acide Proton des Acetons an (Schema 57), wobei sich das Enolat (E-1), (E-2) oder (E-3) bildet. 
$\overbrace{\mathrm{H}_{\mathrm{HaOH}}^{\mathrm{O}}}^{\mathrm{O}} \underset{\mathrm{H}^{+} \mathrm{O}}{\longrightarrow}+\underset{\substack{\mathrm{Na}_{(\mathrm{E}-1)}^{+} \\ \mathrm{H}}}{\mathrm{O}}=\underbrace{\mathrm{ONa}}_{(\mathrm{E}-2)}$

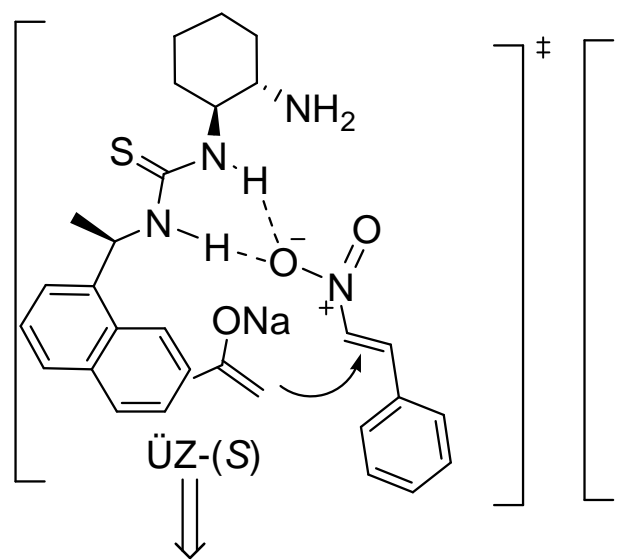

(R)<smiles>CC(=O)C[C@H](C[N+](=O)[O-])c1ccccc1</smiles>

91-S<smiles>CC(=O)CC(C[N+](=O)[O-])c1ccccc1</smiles>

91-R

Schema 57. $\mathrm{NaOH}$ und Wasser als Additiv reduziert die Selektivität des Katalysators 
Tabelle 13 Anwendung der Verbindung 73 (0.15 Äq) in der Michael-Addition von verschiedenen Ketonen

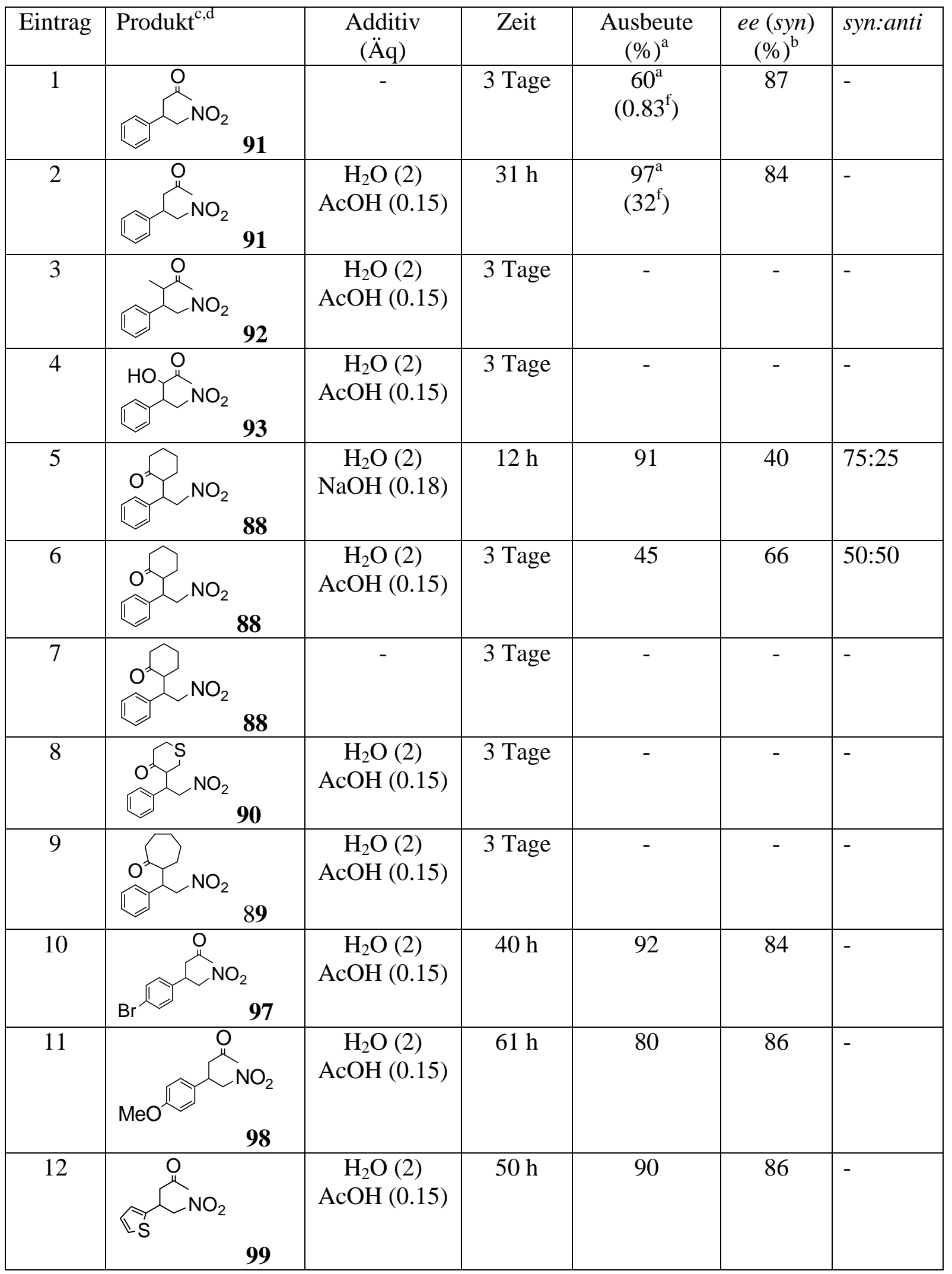

a) Isolierte Ausbeute; b) Analyse durch chirale HPLC (Daicel Chiralpack AS); c) Produkt 91 hat R-Konfiguration; d) alle Lösungsmittel sind getrocknet; d) Alle Reaktionen laufen in Toluol ab; f) Reduzierte Reaktionsgeschwindigkeit: Ausbeute (\%)/Zeit (h). 
Dies kann einerseits die Enaminbildung durch die Aminogruppe am Katalysator behindern, andererseits ist das Enolat nicht wie das katalysatorgebildete Enamin fixiert, sondern im Reaktionsmedium frei beweglich. Es kann beide Seiten des aktivierten Nitrostyrols angreifen. Dieser Sachverhalt lässt sich anhand zweier Übergangszustände (ÜZ-(S) und ÜZ- $(R)$ ) verbildlichen (Schema 57).

Zwei Übergangszustände führen zum Produkt 91 mit $S$ - bzw. $R$-Konfiguration. Dies erklärt, warum die Reaktion bei der Zugabe von $\mathrm{H}_{2} \mathrm{O}(2$ Äq) und $\mathrm{NaOH}(0.18$ Äq) schnell verläuft. Gleichzeitig ist diese Reaktion wenig enantioselektiv, jedoch überwiegt steht die $R$ Konfiguration, da beim Übergangszustand ÜZ-(S) (Bildung für S-Isomer, Schema 57) eine große sterische Hinderung zwischen der $\alpha$-Phenylethylgruppe und dem Enolat existiert.

Die Kombination von $\mathrm{H}_{2} \mathrm{O}(2 \ddot{\mathrm{A} q})$ und $\mathrm{AcOH}(0.15$ Äq) initiiert ebenfalls sehr effektiv diesen Effekt der Verbindung 73. Vergleicht man Eintrag 1 (ohne Additiv, 60\% Ausbeute, 87\% ee in 3 Tagen, Redutionsrat: 0.83) und Eintrag 2 (97\% Ausbeute, 84\% ee in 31 h, Reduktinsrate: 32), bei der die Reduktionsgeschwindigkeit erhöht ist. Ohne Additiv kommt es nicht zur ProduktBildung 88 (Eintrag 7, Tabelle 13). Mit Additiv bilden sich jedoch 45\% Ausbeute und 66\% ee syn:anti: 50:50 (Eintrag 6, Tabelle 13). Die Verbindungen 97, 98 und 99 konnten durch Katalysator $\mathbf{7 3}$ dargestellt werden, das elektronärmere aromatische Nitroolefin reagiert dabei besonders gut. Gemäß Eintrag 10 wurden $92 \%$ Ausbeute und $84 \%$ ee in 40 h ereicht

Das elektronreichere aromatische Nitroolefin (z.B Verbindung 98) reagiert relativ gering effektiv (80\% Ausbeute, 86\% ee in 50 h Eintrag 11, Tabelle 13). Zyclische Ketone reagieren kaum. bei den Einträge 8 und 9 wurden keine Produkte erhalten. Wahrscheinlich einerseits aufgrund der Inaktivität der Ketone, anderseits wegen der nicht passenden räumlichen Anordnung zwischen Katalysator und den Substanzen. Methylethylketon und 1-Hydoxypropan2-on reagieren ebenfalls nicht mit Nitrostyrol. Vermutlich liegt es daran, dass die sterische Hinderung sowie die Polarität der $\mathrm{OH}-$ Gruppe am 1-Hydoxypropan-2-on die Enaminbildung behindern.

Somit ist die Verbindung $\mathbf{7 3}$ als Katalysor für die Michael-Addition nicht gut. Um die Reaktivität zu erhören, wurde die primäre Amino-Gruppe und das Thioharnstoff-Gerüst nicht wie durch den relativ starren Cyclohexanring fixiert, sondern durch ein etwas flexibleres Gerüst verbunden. Ein Test soll diese Vermutung höher beleuchten (Tabelle 14). 
Tabelle 14 (1S, 2S)- (-)-1,2-Diphenylethylendiamin als Katalysator für die Michael-Addition

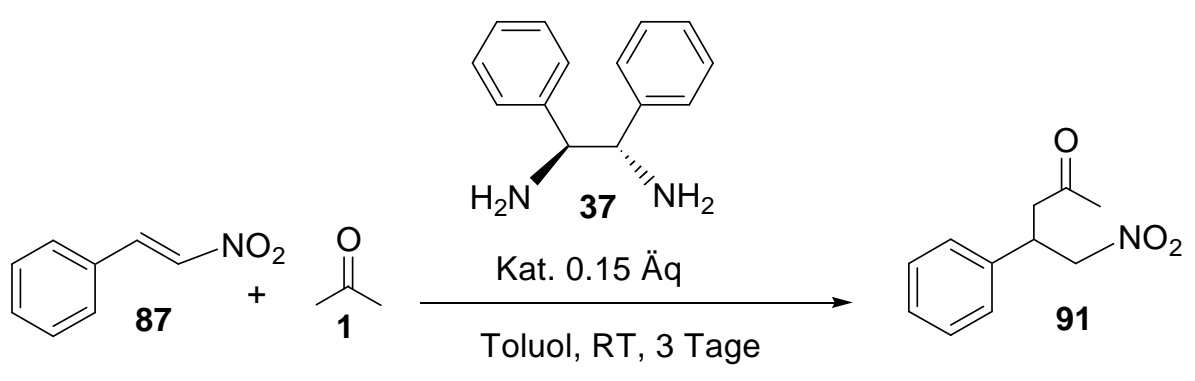

\begin{tabular}{|c|c|c|l|c|c|}
\hline Eintrag & $\begin{array}{c}\text { Additiv } \\
(\ddot{\mathrm{Aq}})\end{array}$ & $\begin{array}{c}\text { Ausbeute } \\
(\%)^{\mathrm{a}}\end{array}$ & RRG. $^{\mathrm{b}}$ & $e e(\%)^{\mathrm{c}}$ & Konfig. \\
\hline 1 & - & 10 & 0.14 & 11 & $R$ \\
\hline 2 & $\begin{array}{c}\mathrm{H}_{2} \mathrm{O}(2) \\
\mathrm{AcOH}(0.15)\end{array}$ & 25 & 0.34 & 60 & $R$ \\
\hline
\end{tabular}

a) Isolierte Ausbeute; b) Reduzierte Reaktionsgeschwindigkeit (Ausbeute (\%)/Zeit (h)); c) Analyse durch chirale HPLC (Daicel Chiralpack AS).

Es wurde $(1 S, 2 S)-(-)-1,2-D i p h e n y l e t h y l d i a m i n$ als Katalysator in 0.15 Äq gegenüber

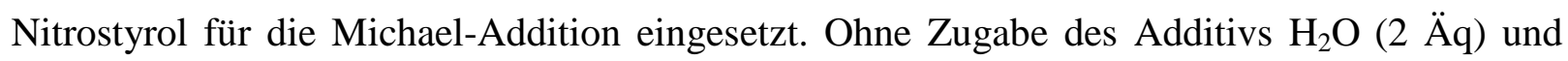
$\mathrm{AcOH}(0.15 \ddot{A q})$ ergaben sich eine Ausbeute von $10 \%$ und $11 \%$ ee mit $R$-Konfiguration nach 3 Tagen, die Reduzierte Reaktionsgeschwindigkeit beträgt 0.14 (Eintrag 1, Tabelle 14). Bei gleichem Additiv ergeben sich 25\% Ausbeute und 60\% ee bei $R$-Konfiguration des Produkts; die Reduzierte Reaktionsgeschwindigkeit erhöht sich hier auf 0.34 (Eintrag 2). Dieser Test zeigt, dass die Säure als Additiv die Ausbeute und Enantioselektivtät wie bei der MichaelAddition nicht verringert, sondern im Gegenteil die Reaktivität noch erhöht wird. Dies ist eine Bestätigung für die Aktivität von Säuren bei bifunktionellen primären Aminen und thioharnstoffhaltigen Katalysatoren. Weiter führend wurden (1S, 2S)-(-)-(1,2)-Diphenylethylendiamin als basische funktionelle Gruppe mit dem Thioharnstoff-Gerüst verbunden. Dabei wurden vier katalytisch wirksame Isomere dargestellt (Abb. 23) 

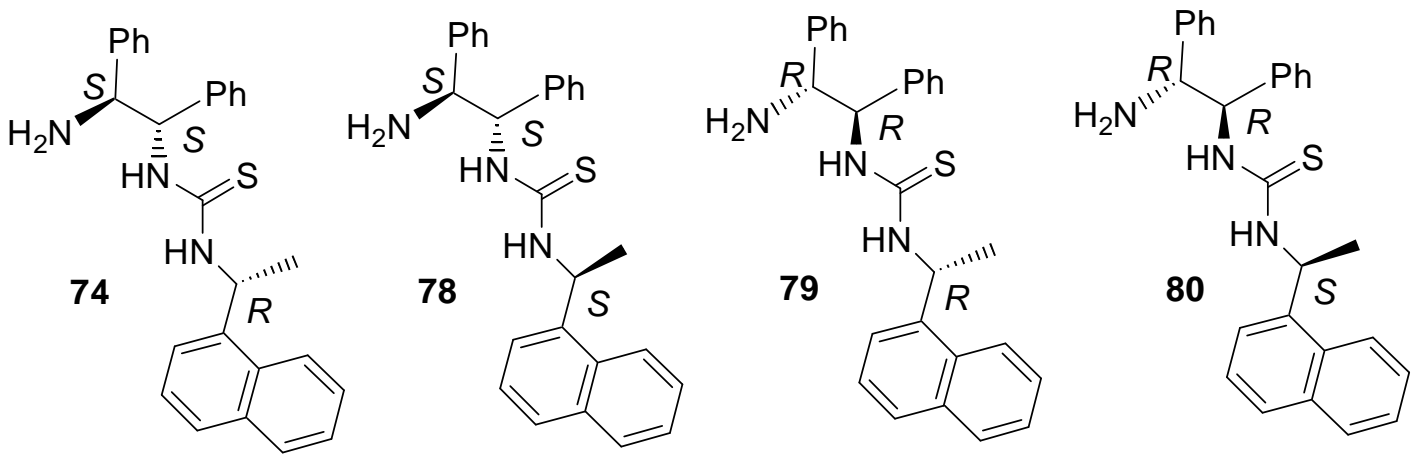

Abbildung 23. Isomere der Verbindung 74

F) Anwendung der Verbindung $\mathbf{7 4}$ und seiner Stereoisomere als Katalysatoren bei der MichaelAddition

Die Effizient der Verbindungen aus Abb. 23 wurde nach Tabelle 15 untersucht. Alle Isomere sind unter gleichen Bedingungen wie bei der Michael-Addition von Nitrostyrol und Aceton unersucht worden. Das beste Katalysator-Design zeigt Verbindung 74 mit $S, S, R$-Konfiguration, bei der sich $98 \%$ Ausbeute $90 \%$ ee mit $R$-Konfiguration nach 2 Tagen bilden (Eintrag 1, Tabelle 15).

Tabelle 15 Vergleich der katalytischen Wirkung verschiedener Stereoisomere von Verbindung $\mathbf{7 4}$ bei der Michael-Addition von Nitrostyrol und Aceton

Kat:: 0.15 Äq<smiles></smiles>
Additiv: $\mathrm{H}_{2} \mathrm{O}(2 \mathrm{Äq}) ; \mathrm{AcOH}(0.15) \mathrm{Äq}$ Toluol, RT<smiles>CC(=O)CC(C[Hg])c1ccccc1</smiles>

\begin{tabular}{|c|c|c|c|c|c|}
\hline Eintrag & Katalysator & $\begin{array}{c}\text { Zeit } \\
(\mathrm{Tag})\end{array}$ & $\begin{array}{c}\text { Ausbeute } \\
(\%)^{\mathrm{a}}\end{array}$ & $\begin{array}{c}e e \\
(\%)^{\mathrm{b}}\end{array}$ & Konfig $^{\mathrm{c}}$ \\
\hline 1 & $\mathbf{7 4}$ & 2 & 98 & 90 & $R$ \\
\hline 2 & $\mathbf{7 8}$ & 3 & 62 & 77 & $R$ \\
\hline 3 & $\mathbf{7 9}$ & 3 & 80 & 78 & $S$ \\
\hline 4 & $\mathbf{8 0}$ & 3 & 92 & 92 & $S$ \\
\hline
\end{tabular}

a) Isolierte Ausbeute; b) Reduzierte Reaktionsgeschwindigkeit (Ausbeute(\%)/Zeit (h));

c) Analyse durch chirale HPLC (Daicel Chiralpack AS). 
Eine geringe Abweichung erscheint bei der Untersuchung der Verbindung 80, dem Enantiomer von 74. Es bildete sich wie erwartet eine ähnliche Ausbeute von $92 \%$ bei einem Enatiomerenüberschuss von $92 \%$ ee mit $S$ - Konfiguration, aber die Reaktionszeit beträgt bis zu 3 Tagen. Verbindung 78 mit $S, S$, S-Konfiguration katalysierte $62 \%$ Ausbeute und $77 \%$ ee mit $R$-Konfiguration des Produkts in 3 Tagen, während bei der Verwendung von Verbindung 79 mit $S, S, S$ - Konfiguration sich $80 \%$ Ausbeute und $78 \%$ ee mit $S$-Konfiguration in ebenfalls 3 Tagen bildeten. Bemerkenswert ist, dass die Konfiguration des Produkts von der Konfiguration des 1,2-Diphenylethyldiamins abzuhängen scheint. Ein (1S, 2S)-(-)-1,2-Diphenylenethyldiamin im Katalysator (Kat. 74 und 84) steuert die $R$-Konfiguration des Produkt und sonst umgekehrt

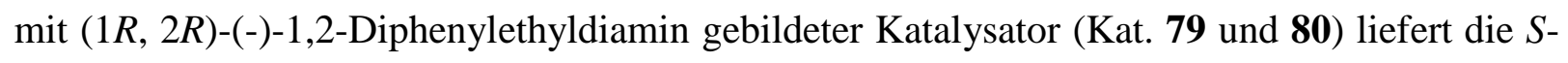
Konfiguration.

Der effizienteste Katalysator ist also die Verbindung $\mathbf{7 4 .}$

Zunächst wurden sechs unterschiedliche polare Lösungsmittel zur Anwendung von Verbindung 74 getestet. Das Lösungsmittel der Wahl ist das wenig polare Toluol, welches die Reaktion fast quatitativ erlaubt (98\% Ausbeute, 91\% ee in 48 h). DMSO ist wiederum das schlechteste Lösungsmittel bei der Untersuchung der thioharnstoffhaltigen Katalysatoren (50\% Ausbeute, 9\% ee in $82 \mathrm{~h}$ ). Wobei die Erklärung dafür bereits zuvor bei den anderen ThioharnstoffKatalysatoren gegeben wurde. 
Tabelle 16. Lösungsmittel-Optimierung bei der Anwendung der Verbindung 74 als Katalysator in der Michael-Addition

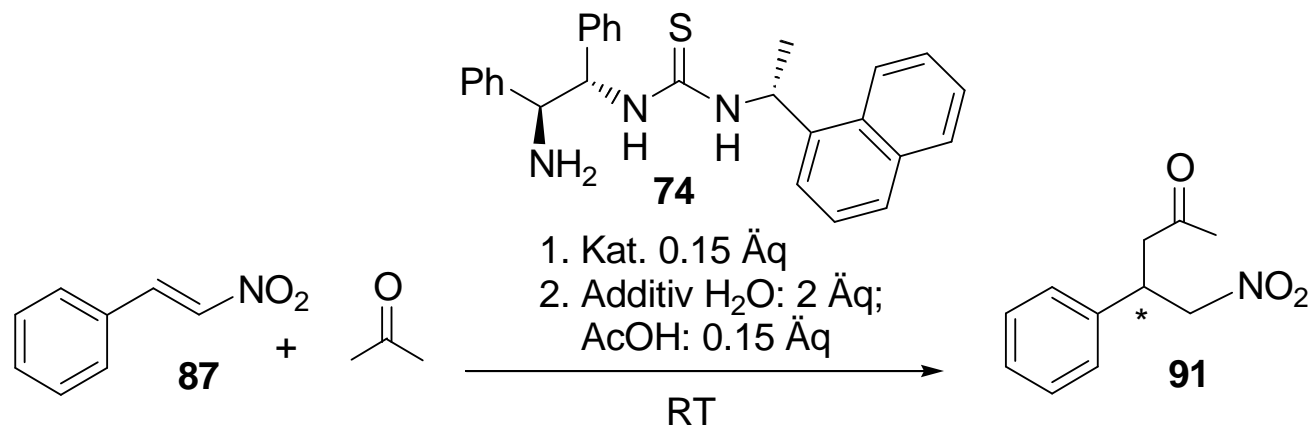

\begin{tabular}{|c|c|c|c|c|c|}
\hline Eintrag & Lösungsmittel & $\begin{array}{c}\text { Zeit } \\
(\mathrm{h})\end{array}$ & $\begin{array}{c}\text { Ausbeute } \\
(\%)^{\mathrm{a}}\end{array}$ & RRG. $^{\mathrm{b}}$ & $\begin{array}{c}e e \\
(\%)^{\mathrm{c}}\end{array}$ \\
\hline 1 & $\mathrm{CH}_{2} \mathrm{Cl}_{2}$ & 82 & 82 & 1 & 89 \\
\hline 2 & $\mathrm{CHCl}_{3}$ & 52 & 90 & 1.7 & 87 \\
\hline 3 & Aceton & 82 & 91 & 1.1 & 89 \\
\hline 4 & MeOH & 82 & 91 & 1.1 & 74 \\
\hline 6 & DMSO & 82 & 50 & 0.6 & 9 \\
\hline
\end{tabular}

a) Isolierte Ausbeute; b) Reduzierte Reaktionsgeschwindigkeit (Ausbeute(\%)/Zeit (h));

c) Analyse durch chirale HPLC (Daicel Chiralpack AS).

Mit anderen polaren $\left(\mathrm{CH}_{2} \mathrm{Cl}_{2} ; \mathrm{CHCl}_{3}\right.$ und Aceton) oder sogar polar protischen Lösungsmitteln $(\mathrm{MeOH})$ ist das Produkt mit besserem Ergebnis entstanden, aber schlechter als mit Toluol. Um eine bessere Aktivität aller Vergleichbarkeit der Thioharnstoff-Katalysatoren zu gewährleisten, wurde Toluol für die weitere Untersuchung von Verbindung 74 verwendet.

In Tabelle 17 wurden die Ergebnisse unter Verwendung von Verbindung $\mathbf{7 4}$ zusammengefasst. Im Vergleich zu Verbindung $\mathbf{7 3}$ wurde nicht nur die Ausbeute und Enantioselektivität durch die Verwendung der Verbindung $\mathbf{7 4}$ gesteigert, sondern auch dessen Anwendbarkeit auf verschiedene Ketone verbessert. Bei Diastereomeren bildeten sich mit Hilfe der Verbindung $\mathbf{7 4}$ mehr syn- als anti-Produkt. Es ergibt sich für Produkt 88 82\% Ausbeute, 96\% ee von synProdukt und syn:anti 80:20 in 3 Tagen (Eintrag 4, Tabelle 17); auch Produkt 90 
Tabelle 17 Anwendung der Verbindung $\mathbf{7 4}$ bei der asymmetrischen Michael-Addition

\begin{tabular}{|c|c|c|c|c|c|c|}
\hline Eintrag & Produkt ${ }^{\mathrm{c}, \mathrm{d}}$ & $\begin{array}{l}\text { Additiv } \\
(\ddot{A} q)\end{array}$ & Zeit & $\begin{array}{c}\text { Ausbeute } \\
(\%)^{\mathrm{a}}\end{array}$ & $\begin{array}{c}e e(s y n) \\
(\%)^{\mathrm{b}}\end{array}$ & syn:anti \\
\hline 1 & & $\begin{array}{l}\mathrm{H}_{2} \mathrm{O}(2) \\
\mathrm{AcOH}(0.15)\end{array}$ & 2 Tage & 98 & 90 & - \\
\hline 2 & 92 & $\begin{array}{l}\mathrm{H}_{2} \mathrm{O}(2) \\
\mathrm{AcOH}(0.15)\end{array}$ & 3 Tage & 88 & $>99$ & $14: 86$ \\
\hline 3 & 93 & $\begin{array}{l}\mathrm{H}_{2} \mathrm{O}(2) \\
\mathrm{AcOH}(0.15)\end{array}$ & 3 Tage & 60 & 75 (anti) & $28: 72$ \\
\hline 4 & & $\begin{array}{l}\mathrm{H}_{2} \mathrm{O}(2) \\
\mathrm{AcOH}(0.15)\end{array}$ & 3 Tage & 82 & 96 & $80: 20$ \\
\hline 5 & & $\begin{array}{l}\mathrm{H}_{2} \mathrm{O}(2) \\
\mathrm{NaOH}(0.18)\end{array}$ & 3Tage & 89 & 97 & $83: 17$ \\
\hline 6 & & $\begin{array}{l}\mathrm{H}_{2} \mathrm{O}(2) \\
\mathrm{AcOH}(0.15)\end{array}$ & 3 Tage & 85 & 84 & $87: 13$ \\
\hline 7 & & $\begin{array}{l}\mathrm{H}_{2} \mathrm{O}(2) \\
\mathrm{AcOH}(0.15)\end{array}$ & $40 \mathrm{~h}$ & 98 & 90 & - \\
\hline 8 & & $\begin{array}{l}\mathrm{H}_{2} \mathrm{O}(2) \\
\mathrm{AcOH}(0.15)\end{array}$ & $61 \mathrm{~h}$ & 84 & 91 & - \\
\hline 9 & & $\begin{array}{l}\mathrm{H}_{2} \mathrm{O}(2) \\
\mathrm{AcOH}(0.15)\end{array}$ & $50 \mathrm{~h}$ & 98 & 90 & - \\
\hline 10 & & $\begin{array}{l}\mathrm{H}_{2} \mathrm{O}(2) \\
\mathrm{AcOH}(0.15)\end{array}$ & 3 Tage & - & - & - \\
\hline
\end{tabular}

a) Isolierte Ausbeute; b) Analyse durch chirale HPLC (Daicel Chiralpack AS); c) Produkt 91 hat $R$-Konfiguration;

d) Alle Reaktionen laufen in Toluol ab. 
89\% Ausbeute, 97\% ee und syn:anti 83:17 (Eintrag 5, Tabelle 17) wurde in der gleichen Zeit gebildet. Gleichermaßen wurde Produkt 89 in einer Ausbeute von 85\% und 84\% ee syn:anti 87:13 ebenfalls in 3 Tagen erhalten. Andere Diastereomere sind bei den aliphatischen Ketonen überwiegend als anti-Isomer vorgekommen. Eintrag 2 in der Tabelle 17 zeigt 88\% Ausbeute, > 99\% ee und syn:anti 14:86 in 3 Tagen bei der Synthese von Verbindung 92; während 60\% Ausbeute und 75\% ee syn:anti 28:72 bei Produkt 93 resultieren. Die neu vorkommenden Diasteromere zeigen noch einmal, dass Verbindung $\mathbf{7 4}$ ein effizienter Katalysator ist. Angesicht der Ergebnisse kann angenommen werden, dass der Übergangszustand ÜZ-2 für (Abb. 24) das überwiegende syn-Produkt von

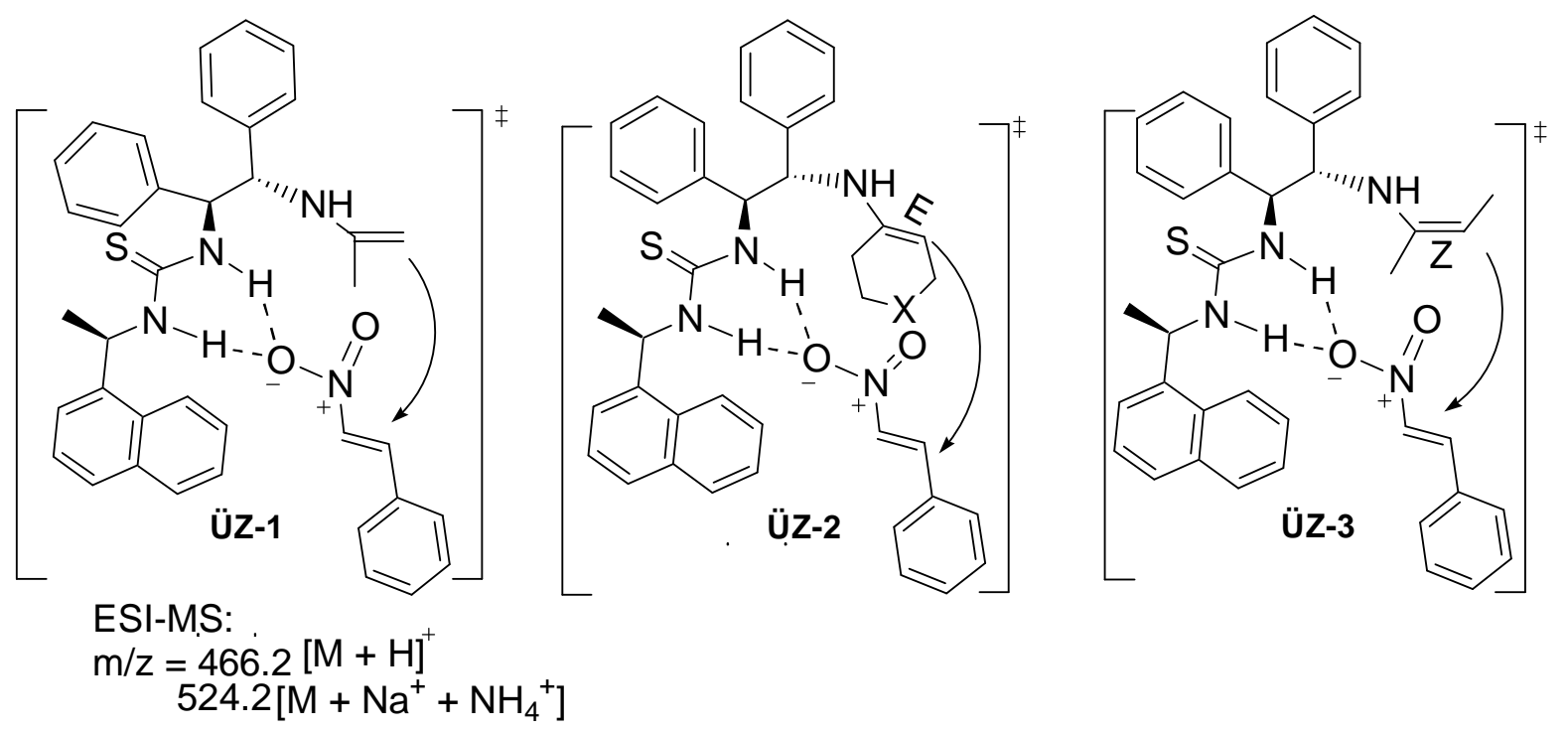

Abbildung 24. Vorgeschlagene Übergangszustände für symmetrische a und asymmetrische Keton bei der Michael-Addition.

Verbindung 88, 90 und 89 verantwortlich ist, und dass der ÜZ-3 (Abb. 24) bei Verbindungen 92 und 93 auftritt.

Im Folgenden werden die Ergebnisse mit verschiedenen Methoden untersucht.

Katalysator 74 wurde mit Nitrostyrol 1:1 in Toluol gemischt und geprüft, ohne Rühren nach 24 Stunden ein ${ }^{1}$ H-NMR dieser Mischung gemessen. Die unterschiedliche chemische Verschiebung von Probe der CH-Gruppe, die den beiden Phenyl-Gruppe benachbart ist, zeigt, dass sich zwischen dem Katalysator und dem Olefin ein Komplex bildet. Als zweite Untersuchung wurde die Mischung von Katalysator und Aceton im ESI-MS vermessen. Zwei Signale $(\mathrm{m} / \mathrm{z}=466.2$ und 524.2) in der Abb. 25 zeigen, dass Enamin-Intermediate zwischen Katalysator und Aceton gebildet wurden. 
C:IXcaliburldatalshe1 050913090404

$\mathrm{MeOH}$

she1_050913090404\#1-9 RT. 0 02-022 AV: 9 NL 974 E7

$\mathrm{T}$ : + $\overline{\mathrm{c}} \mathrm{ms}$ [100.00-2000.00]

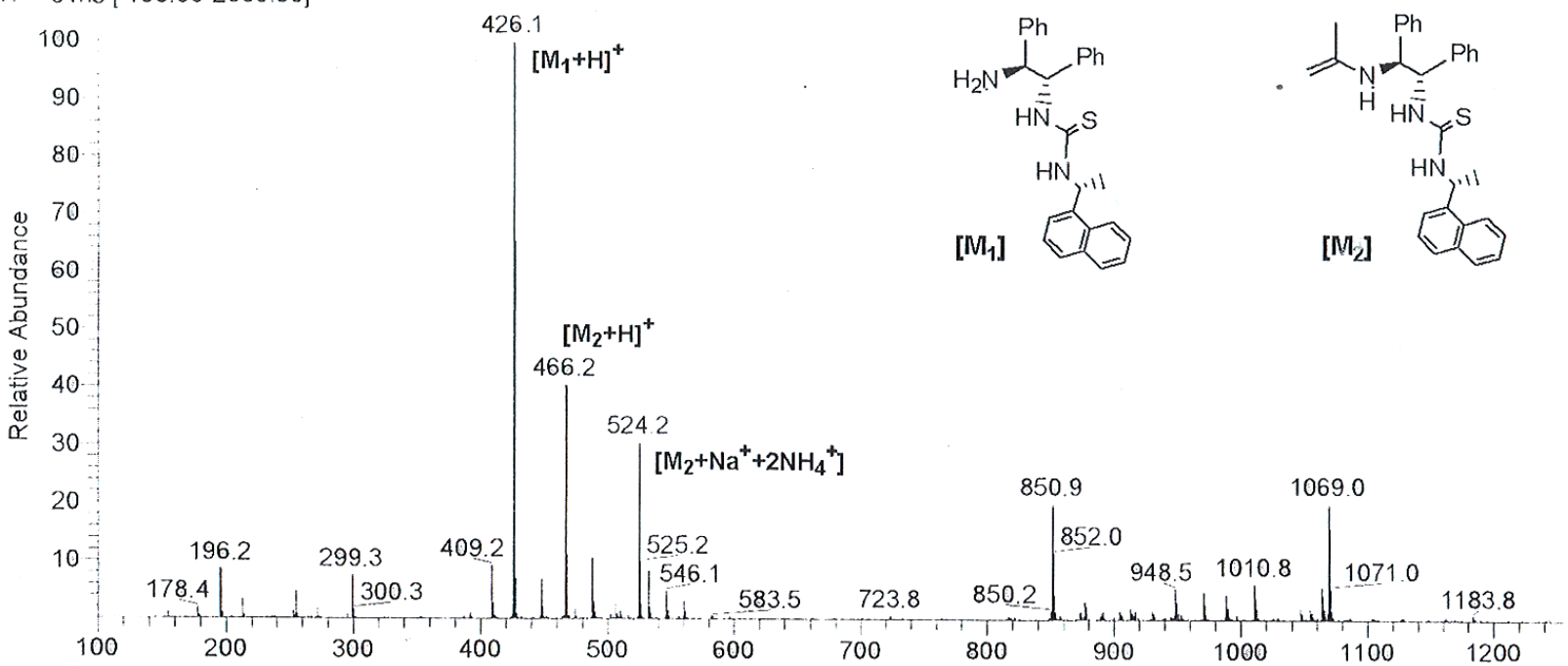

Abbildung 25. ESI-MS-Spektrum der Mischung von Katalysator 74 und Aceton

Bei dem elektronämeren aromatischen Nitroolefin (Eintrag 7), bildet sich das Produkt 97 bis zu 98\% Ausbeute mit 90\% ee in nur 40 h, bei dem elektronreicheren aromatischen Nitroolefin wurden kleinere Ausbeuten und ee-Werte (84\% Ausbeute, 91\% ee in 61 h Eintrag 8, Tabelle 18) und (98\% Ausbeute, 90\% ee in $50 \mathrm{~h}$ Eintrag 9) erzielt. Es scheint klar zu sein, dass Substituenten von Nitroolefin die Enantioselektivität und Ausbeute nicht wesentlich beeinflussen.

Eintrag 10 in der Tabelle 18 zeigt, dass die Aktivität der Verbindung $\mathbf{7 4}$ zu begrenzt ist, um eine weitere Michael-Reaktion zwischen Nitroolefin und Aldehyd zu katalysieren.

Im Vergleich zu Katalysator 73 mit $\mathrm{H}_{2} \mathrm{O}$ (2 $\left.\ddot{\mathrm{Aq}}\right)$ und HOAc (0.15 Äq) als Additiv brachte Katalysator 74 sowohl bessere Enantioselektivitäten als auch höhere Ausbeute bei der Reaktion zwischen Nitrostyrol und Aceton (vgl. Eintrag 2 Tabelle 14 und Eintrag 1 Tabelle 18). Aufgrund der ähnlichen sterischen Faktoren ergab sich in beiden Fälle die $R$-Konfiguration von Produkt 91. Aufgrund der Messergebnisse von ESI-MS und ${ }^{1} \mathrm{H}-\mathrm{NMR}$ wird der Mechanismus wie in Schema 58 vorgeschlagen

Nitrostyrol wird durch eine Wasserstoffbrückenbindung zwischen einem Nitro-Sauerstoffatom und den beiden Wasserstoffatomen am Thioharnstoff-Gerüst fixiert. Das Proton $\mathrm{H}^{+}$des $\mathrm{AcOH}$ aktiviert 


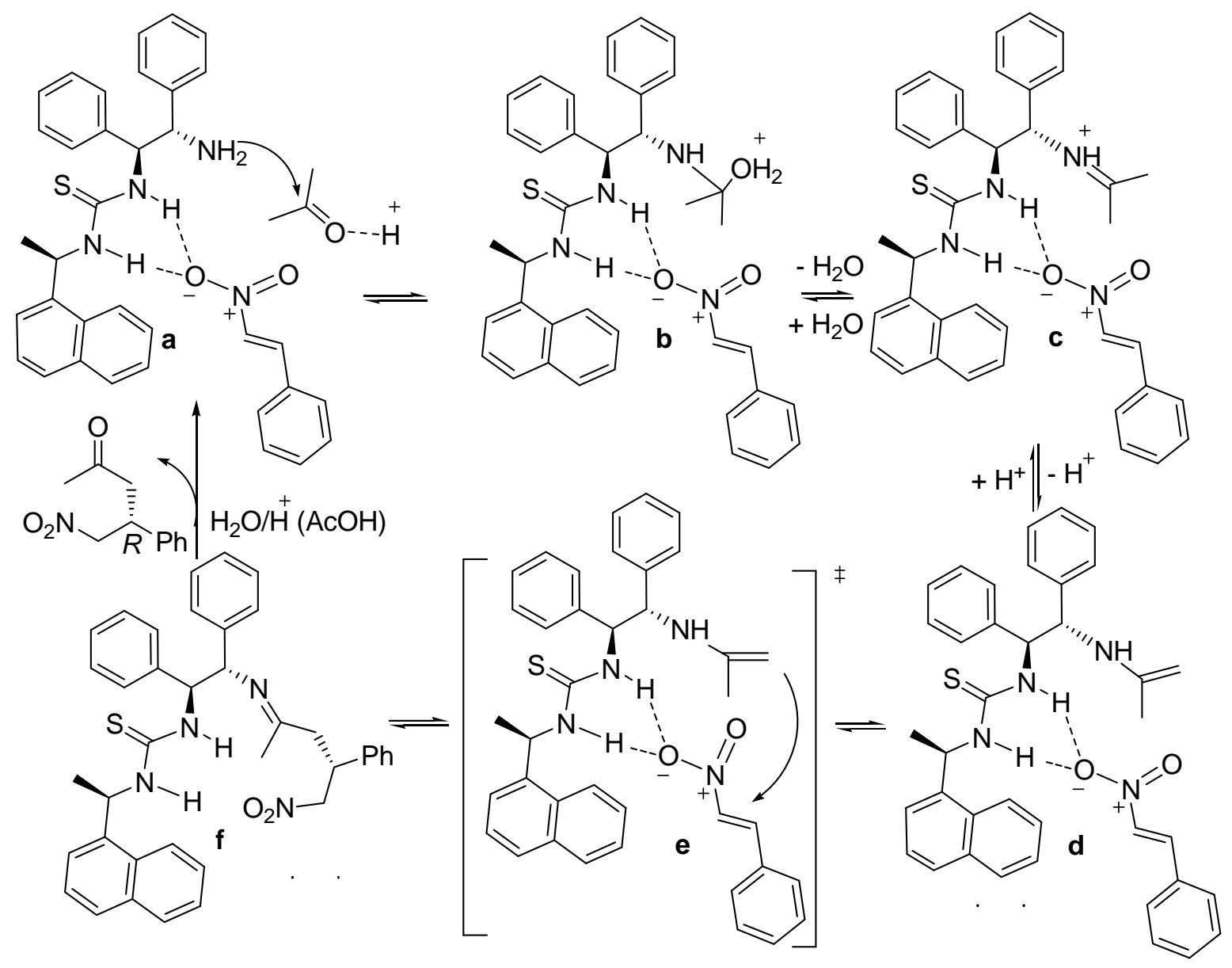

Schema 58. Vorgeschlagener Mechanismus bei der Michael-Addition durch Katalysator 74

Aceton aufgrund der Wechselwirkung mit dem Lewis-Base Sauerstoff, sodass die Elektrondichte am Sauerstoff verringert und die Energie des NOMO-Orbitals $\left(\mathrm{C}=\mathrm{O}-\pi^{*}\right)$ erniedrigt wird. Der nucleophile Angriff durch die Aminogruppe der Verbindung 74 wird dadurch erleichtert (a, Schema 58). Durch eine Übertragung eines Protons bildet sich b. Durch den reaktionsgeschwindigkeitsbestimmenden Schritt, der Wasserabspaltung von b und der Deprotonierung von c, wird das wichtige Enamin-Intermediat d (ESI-MS: m/z = $466.2[\mathrm{M}+\mathrm{H}]^{+}$) gebildet. Dieses ist ausreichend nucleophil, um mit dem aktivierten Kohlenstoffatom des Nitrostyrol zu zeigen (Übergangszustand e (Schema 58)). Das zweite wichtige Intermediat ist f, durch die der Synthese-Zyklus sich genau nach der wässrigen Aufarbeitung von $f$ nach a orientieren kann. Das Produkt wurde in $R$-Konfiguration liefert.

Um zu klären, ob das 80 Enantiomer genau so gut wie Kat. 74 wirkt, wurden mehrere Konkurrenzreaktionen durchgeführt. 
Es wurde zunächst der beste Kat. 74 seinem Enatiomer 80 gegenübergestellt. x\% von Kat. 74 wurde mit $(100-x) \%$ von Kat. 80 gemischt. Dann wurden 15 Mol-\% von der KatalysatorMischung (Kat. 74 plus Kat. 80) gegenüber Nitrostyrol verwendeten. Die Reaktion verlief wie in Tabelle 17 geführt für 3 Tage. Nach derselben Aufarbeitungsmethode wurden die Enantiomerenüberschüsse des Produkts gemessen (Tabelle 18). In der Reaktionsmischung steht immer $R$-konfiguriertes Produkt 91 im Überschuss.

Es wurde eine Funktion der $R$-, bzw. $S$-Enantiomere vom Produkt in Abhängigkeit vom prozentualen Anteil des Katalysator 74 bzw. Katalysator 80 an der Mischung bestimmt.

Tabelle 18 Wirkung einer Mischung aus Kat. 74 und dessen Enantiomer 80

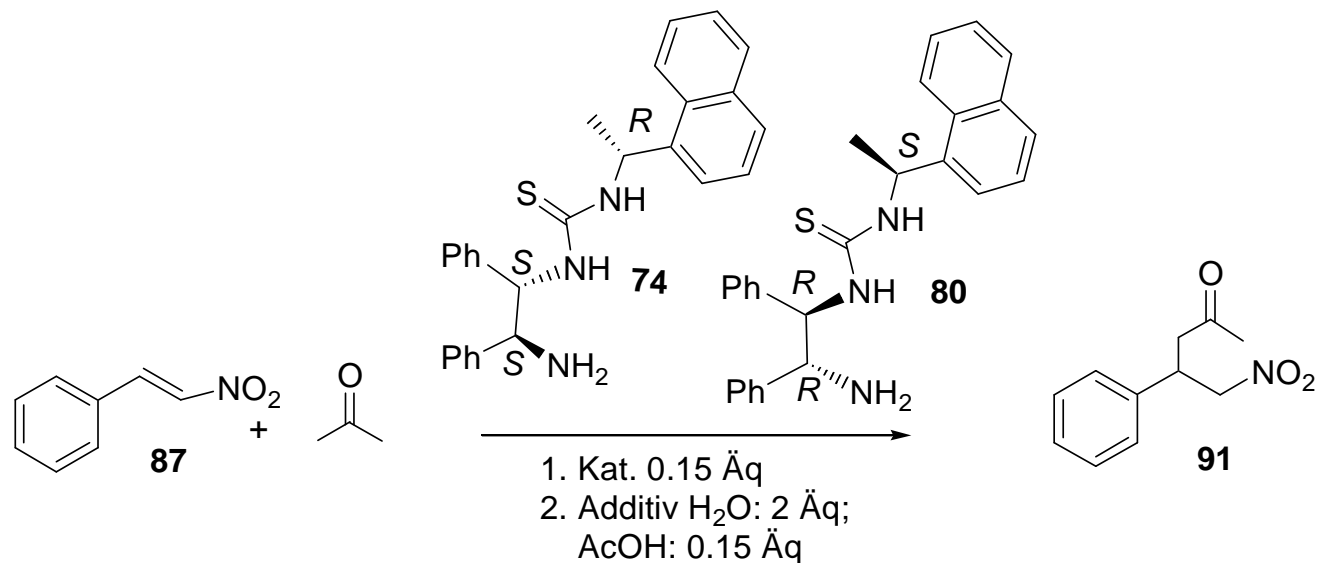

\begin{tabular}{|c|c|c|c|c|}
\hline Eintrag & ${\text { Kat. 74 }(\%)^{\mathrm{a}} /(\mathrm{Mol}-\%)^{\mathrm{b}}}$ & ${\text { Kat. 80 }(\%)^{\mathrm{a}} /(\mathrm{Mol}-\%)^{\mathrm{b}}}$ & $\begin{array}{c}e e(\%) / R \\
{\left[e e(\%) / R^{c}\right]}\end{array}$ & \\
\hline 1 & $100 /(15)$ & $0 /(0)$ & $91(-)$ & $95.5 \% / 0.5 \%$ \\
\hline 2 & $81.95 /(12.29)$ & $18.05 /(2.71)$ & $67.26(74.5)$ & $83.63 \% / 16.37 \%$ \\
\hline 3 & $62.53 /(9.38)$ & $37.47 /(5.32)$ & $55.95(56.91)$ & $77.98 \% / 22.03 \%$ \\
\hline 4 & $51.6 /(7.74)$ & $48.4 /(7.27)$ & $42(46.97)$ & $71 \% / 29 \%$ \\
\hline 5 & $34.24 /(4.86)$ & $65.76 /(10.14)$ & $28.45(29.48)$ & $64.23 \% / 35.78 \%$ \\
\hline 6 & $20.57 /(3.09)$ & $79.43 /(11.91)$ & $15.51(18.75)$ & $57.76 \% / 42.25 \%$ \\
\hline 7 & $2.32 /(0.35)$ & $97.68 /(14.65)$ & $4.85(2.12)$ & $52.43 \% / 47.58 \%$ \\
\hline
\end{tabular}

a) Hundertprozentige Zahl der Mischung von $R$-; $S$-Isomer; b) Mol-\% gegenüber Nitrostyrol; c) Nach proportioneller Tendenz gerechnete Werte

Die Grafik (A) in Abb. 26 zeigt deutlich, dass eine Zunahme des Anteils von 74 in der Mischung von $\mathbf{7 4}$ und 80 auch die Mengesteigerung des $R$-Produkts folgte. 


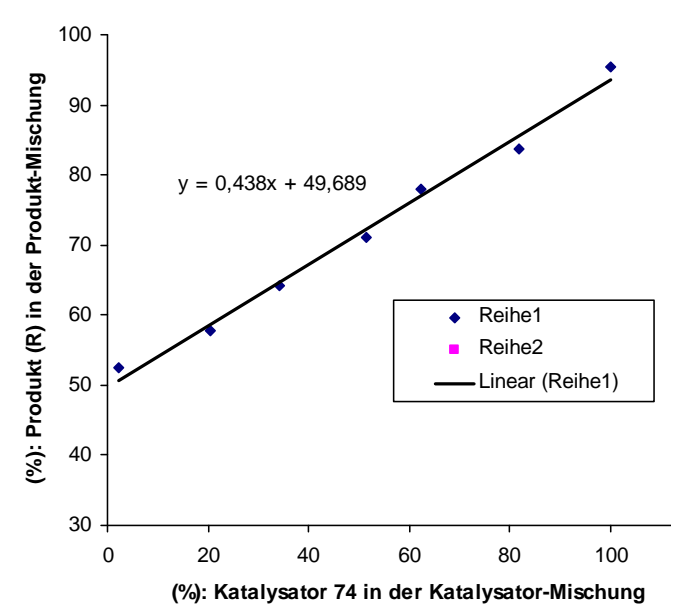

(A)

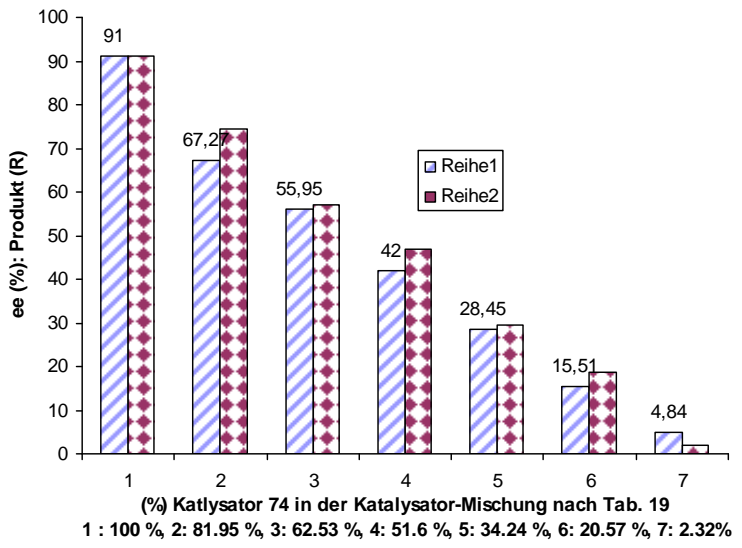

(B)

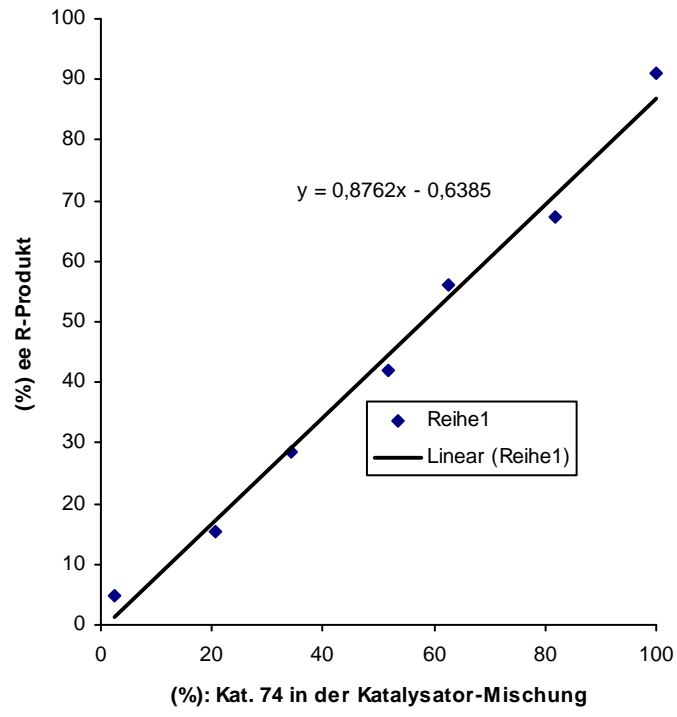

(C)

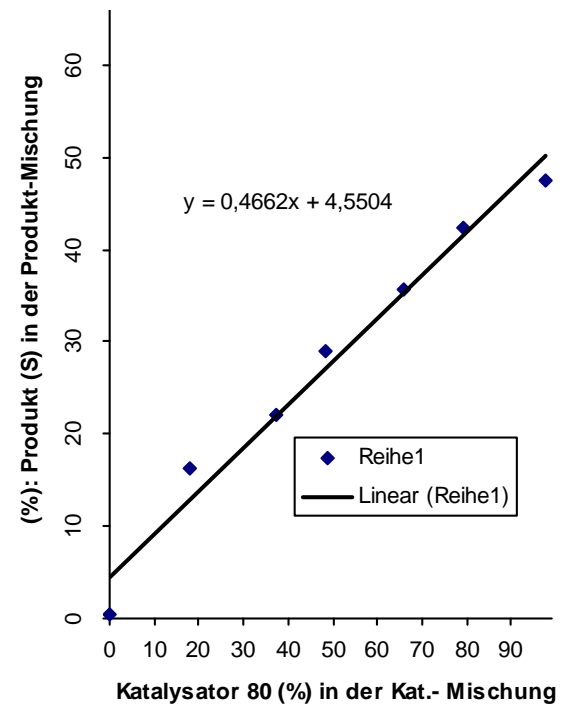

(D)

Abbildung 26. Katalytischer Effekt von unterschiedlichen Mischung des Katalysator-Isomers (74 und 80)

Der prozentuale Anteil des $R$-Produkts ist jedoch nicht direkt proportional zum Anteil von Katalysator 74. Beispielsweise sollten $81.95 \% \mathbf{7 4}$ in der Mischung $74.5 \%$ ee mit $R$ Konfiguration (Eintrag 2, Tabelle 19) bei direkter Proportionalität ergeben, wobei der Einfluss von 80 nicht betrachtet wird. Die Abweichung kann man durch (B) in der Abb. 26 erkennen (s. 
$e e \%-R^{\mathrm{c}}$, Tabelle 19). Die Säule von Reihe 2 in der Grafik zeigt die Werte, die proportional zu der Veränderung des prozentualen Anteils des Katalysators (74) ohne Zugabe von Katalysator 80 sind. Diese sind größer als die experimentellen Werte (mit 91\% ee ohne Zugabe von Kat. 80). Durch Grafik (B) kann man verstehen, dass der Katalysator 80 in der Mischung die Katalyse-Wirkung von $\mathbf{7 4}$ geringfügig behindert, weil die nur von Kat. 74 allein gelieferten $e e-$ Werte größer als die der Mischung sind (vgl. Reihe 2 und 1).

Man kann auch sagen, dass Katalysator $\mathbf{7 4}$ etwas effektiver als Katalysator $\mathbf{8 0}$ ist, obwohl sie beide Enantiomere sind. Graphik (C) zeigt die Ergebnisse der Konkurrenzreaktion von Katalysator 74 und 80, die $R$-Konfiguration in der Produkt-Mischung ist immer im Überschuss und nach Zunahme des prozentualen Anteils des Katalysators (74) in der Katalysator-Mischung ist auch der Anteil vom $R$-Produkt gestiegen. Das bedeutet, dass Kat. 74 aktiver als Kat. 80 ist, obwohl die Veränderung der Menge von S-Produkt nach der Zunahme des prozentualen Anteils des Katalysators (80) in der Katalysator-Mischung ebenfalls vergrößert ist (D).

Es lässt sich durch einige Daten verdeutlichen, dass mit Hilfe von Katalysator 74, mit 50\% Anteil in der Mischung, sich das Produkt zu 71\% mit $R$-Konfiguration in der Produkt-Mischung bildet. Im Gegensatz dazu resultiert nur 30\% Produkt mit $S$-Konfiguration bei $50 \%$ Anteilen von Katalysator 80 (vgl. A und D, Abb. 26). Auch mit 80\% Katalysator 74 ergaben sich 83\% Produkt mit $R$-Konfiguration, während mit $80 \%$ Katalysator 80 nur $42 \%$ Produkt mit $S$ Konfiguration erzielt werden konnten. Es ist natürlich sehr interessant zu wissen, warum der Katalysator mit $S, S, R$ chirale Zentren aktiver als der mit $R, R, S$-Konfiguration ist.

Einer von fünf (74, Abb. 20) sehr effizienten Katalysatoren, der die Michael-Addition von symmetrischen und asymmetrischen aliphatischen Ketonen mit Nitrostyrol, und auch elektronreichere und -ärmere Nitronolefine als Substrat-hochselektiv katalysieren kann, wurden in dieser Arbeit entwickelt. Die Selektivität ist gegenteilig zu den, was für dieses Beispiel in der Literatur gefunden wird. ${ }^{143-145}$

Es wurde zuerst eine Verknüpfung von primären Aminen und Thioharnstoff als Katalysator für die Nitro-Michael-Addition dargestellt. Die exzellenten Ergebnisse wurden auch durch NMR; ESI-MS und Computerberechnung bestätigt. Alle praktischen Ergebnisse stimmen mit den theoretischen überein.

Alle fünf geplanten thioharnstoffhaltigen bifunktionellen Katalysatoren wurden auch bei der Allylierung von verschiedenen Aldiminen und Ketiminen, direkten $\alpha$-Amination von Ketonen 
und Azoverbindungen sowie $\alpha$-Oxidation von Aldehyden und Nitrosobenzen und MichaelAddition von Chalcon und Cycloketonen getestet. Die Resultate sind hierbei nicht ausreichend. 


\section{Asymmetrische organoautokatalytische Reaktionen}

\subsection{Entwicklung der autokatalytischen Reaktionen}

Chiralität spielt eine zentrale Rolle in den chemischen, biologischen, pharmazeutischen und materialwissenschaftlichen Gebieten. ${ }^{146}$ In den letzten Jahren hat sich die asymmetrische Katalyse zur Herstellung bestenfalls enantiomerenreiner Produkte überraschend entwickelt. Mit geeigneten Katalysatoren oder mit Additiven werden oftmals exzellente Enantioselektivitäten und hohe Ausbeuten erreicht. Dabei sollten die Katalysatoren von den sich stets neu bildenden Produkten nicht beeinflusst werden, ${ }^{147}$ und können weiter während des Katalysezyklus regeneriert werden. Um konstant hohe Stereoselektivitäten oder auch gute Ausbeuten bei den Reaktionen zu erreichen, ist in der Regel das Einsetzen einer kleinen Menge von Katalysatoren in die Reaktionsmischung eine Voraussetzung für dieses asymmetrische Verfahren. Die Katalysatoren entwickeln sich effektiv von metallorganischen über metallfreie organische zu bifunktionellen organischen chiralen Verbindungen.

Was passiert, wenn das Produkt selbst ein Katalysator ist und seine eigene asymmetrische Synthese katalysiert? Ein großes Potential der ,asymmetrischen Autokatalyse” für die Synthese wurde schon von Wynberg früh erkannt ${ }^{146}$ und er stellt bereits 1989 die herausfordernde Frage, ob die asymmetrische Autokatalyse die nächste Generation der asymmetrischen Synthesen sein würde. ${ }^{148}$ Für die asymmetrische autokatalytische Reaktion kann man von zwei chemischen Möglichkeiten ausgehen (Schema 59), wobei durch (1) illustriert wird, dass das chirale

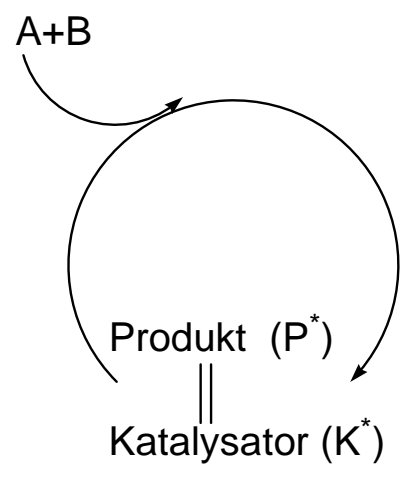

(1)

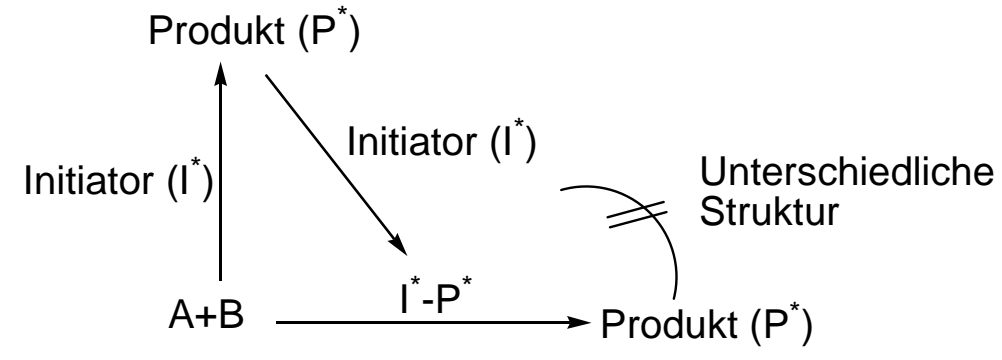

(2)

Asymmetrische automatische Vermehrung des Produkts Vermehrung des Produkts

Schema 59. Illustration der asymmetrischen Autokatalyse 
Produkt, das von irgendeiner chemischen treibenden Kraft aus achirales Edukt produziert wurde, als Katalysator die eigene Bildung asymmetrisch katalysieren kann, sodass das Produkt vermehrt stereoselektiv entsteht.

Im Gegensatz zu (1) wird in (2) (Schema 59) eine ganz kleine Menge eines chiralen Initiators $\left(\mathrm{I}^{*}\right)$, der die Reaktion asymmetrisch steuern kann, am Anfang der Reaktion eingesetzt. Dann bildet dieser mit dem entstandenen chiralen Produkt $\left(\mathrm{P}^{*}\right)$ weiter einen neuen Komplex I*-P*, welcher die Reaktion stereoselektiv weiter katalysieren kann. Der Initiator kann entweder eine überhaupt andere chirale Substanz oder das eigene Produkt sein.

Die genannte Möglichkeit, dass das chirale Produkt, das selbst ein Katalysator für die eigene Bildung aus achirales Edukt sein kann (Schema 59, (1)), ist interessant. Für diese asymmetrische Autokatalyse hat Frank schon 1953 ein mathematisches Modell formuliert. Dabei zeigte er, dass eine „spontane asymmetrische Synthese“ ein grundsätzlich möglicher Prozess ist (Schema 60). ${ }^{149}$ Frank hat beschrieben, dass zwei achirale Substanzen A und B zu optisch aktiven Produkten $(R)$-C und $(S)$-C reagieren könnten, und die neu gebildeten Produkte $(R)$-C und $(S)-\mathrm{C}$ ihre eigene Bildung katalysieren könnten (a Schema 60). Dies ist das Prinzip der herkömmlichen Autokatalyse. Man kann annehmen, dass die beiden Enantiomere Katalysatoren sich gegenseitig in ihrer Wirkung abschwächen oder vernichten könnten (b, Schema 60). Als Konseguenz wird dieses System nicht stabil sein, wenn es durch kleine statistische Fluktuationen gestört wird, so Frank. Man kann dies beispielsweise dadurch verdeutlichen, dass die $(R)$-C katalysierte Reaktion zur Produktion des Produkts $(R)-\mathrm{C}$ bevorzugt abläuft, die Konzentration katalytisch wirksamen
a) $\mathbf{A}+\mathbf{B} \underset{(S)-\mathrm{C} \text { Kat. }}{\stackrel{(\mathrm{R}) \text {-C Kat. }}{\longrightarrow}}($ (S)-C
b) $(R)-\mathrm{C}+(S)-\mathrm{C}$
$[(R)-\mathrm{C} \cdot(S)-\mathrm{C}]$
inaktiv

Schema 60. a) Modell zur „, spontanen asymmetrischen Synthese“ nach Frank

b) Deaktivierung der chiralen katalytisch aktiven Produkte 
von $(S)$-C sinkt und sich deshalb neues $(R)$-C immer bevorzugt bildet. Deshalb sollte am Anfang der Reaktion bereits eine Spur einer chiralen Substanz ausreichen, um durch Autokatalyse genau diese im Überschuss zu produzieren. Der Initiator braucht dabei nicht enantiomerenrein zu sein, weil dieses Modell das Prinzip der Chiralitätsverstärkung implizieren kann. Dies wird durch Schema 59 (2) illustriert.

Ein anderes, mehr physikalisches Verfahren für die Untersuchung der ,absoluten asymmetrischen Synthese ${ }^{\text {"150 }}$ basiert auf der Bestrahlung mit zirkular polarisiertem Licht, ${ }^{151}$ wobei Hepta- und Octahelicene mit bis zu 7.3\% ee entstehen. Eine weitere Methode ist die Enantiomorphe-Kristallisation ${ }^{152}$ und die asymmetrische Synthese durch gekreuzte elektrische und magnetische Felder. ${ }^{153}$

Seebach, Dunitz und Mitarbeiter zeigten, dass es bei den asymmetrischen Reaktionen mit metallorganischen Reagenzien im Verlauf der Produktbildung aufgrund des Entstehens von gemischten Aggregaten zu sich verändernden Diastereo- und Enantioselektivitäten kommen kann. ${ }^{154,155}$ Die asymmetrische nicht reversible Addition von metallorganischen KohlenstoffNucleophilen, beispielsweise Ethyllithium an Benzaldehyd (Schema 61) wurde daraufhin von Alberts und Wynberg ${ }^{156}$ untersucht und sie zeigten, dass der stereo-chemische Verlauf von stöchiometrischen und katalysierten Reaktionen durch die entsprechenden metallhaltigen Produktmoleküle (hier Lithiumalkoholate) beeinflusst wird.<smiles>O=Cc1ccccc1</smiles><smiles>CCOC(=O)OCC</smiles><smiles>CCC(O)c1ccccc1</smiles>

$\mathrm{P}-\mathrm{H}$<smiles>[2H]C(O)(O)c1ccccc1</smiles>

P-D

Schema 61. Asymmetrische Addition von Ethyllithium an Benzaldehyd

Die kleine Zugabe von (+)-PhCD(OLi)Et als Initiator führt selbstverständlich zum Produkt P-D. Die Produktmischung beinhaltet aber 94\% P-H. Das Produkt P-H ist dabei kein vorher eingesetzter Katalysator, (+)-PhCD(OLi)Et initiiert die Bildung von $\mathrm{P}-\mathrm{H}$, seine Gegenwart führt dazu, dass neu gebildetes Produkt P-H optisch aktiv und überwiegend (94\%) 
vorhanden ist. Für diesen Effekt prägten Alberts und Wynberg den Begriff „enantioselektive Auto-Induktion“.

Die erste erfolgreiche asymmetrische Autokatalyse (Schema 62) wurde von Soai und Mitarbeitern ${ }^{157} 1990$ anhand der Addition von Diisoproylzink an Pyridin-3-carbaldehyd

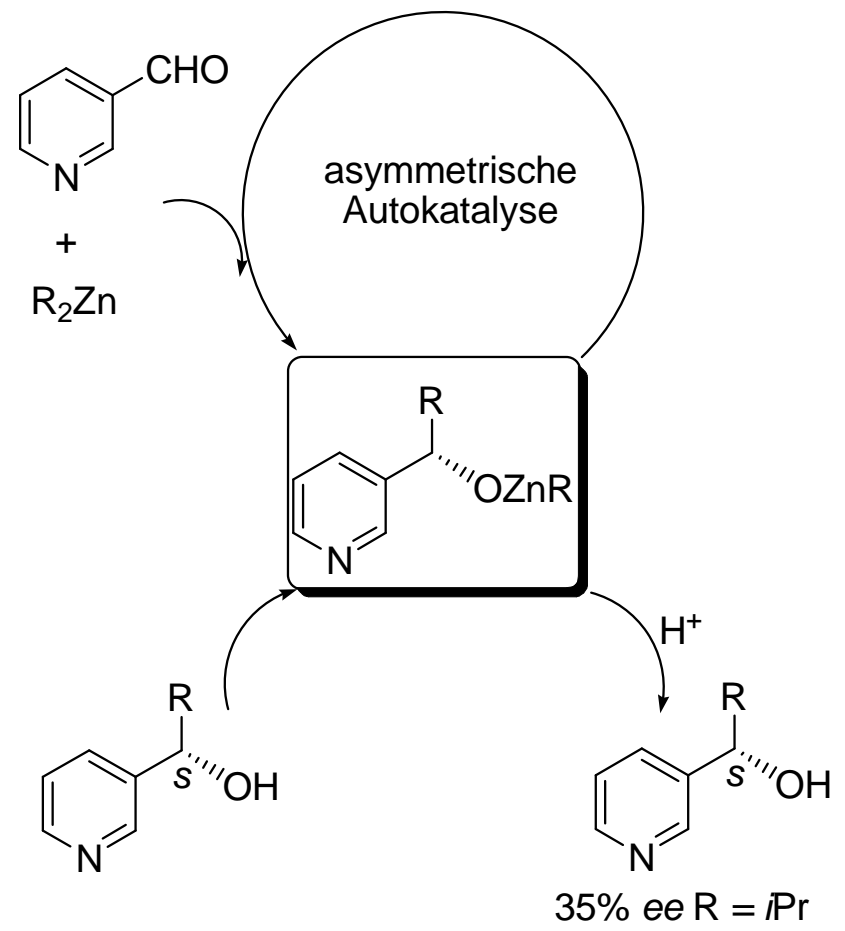

Schema 62. Soai-Autokatalytische Addition von Diisoproylzink an Aldehyd

unter Zugabe von (S)-2-Methyl-1-(3-pyridyl)-1-propanol $(86 \%$ ee $)$ berichtet. Das neue automultiplizierte Produkt (67\% Ausbeute) weist die gleiche Konfiguration ( $S$-Enantiomer, $35 \%$ ee) wie das zugegebene Produkt auf. Sie fanden, dass der Pyridylalkohol über das entsprechende Isopropylalkoholat seine asymmetrische Bildung aus Pyridin-3-carbaldehyd und Diisopropyl-zink katalysiert.

Auch bei anderen enantioselektiven Additionen von Organozinkverbindungen an Aldehyd wurde die asymmetrische Autokatalyse festgestellt, ${ }^{158}$ wobei das neu entstandene Produkt allerdings immer einen erheblich niedrigeren Eantiomerenüberschuss als der eingesetzte Katalysator hatte. Soai und Mitarbeiter haben aber dann Ende 1995 gezeigt (Schema 63), dass in Gegenwart von 20 Mol-\% des Pyrimidylalkohols ( $\mathrm{R}=\mathrm{Me}$-94.8\% ee) in der Reaktion des entsprechenden Aldehyds $(\mathrm{R}=\mathrm{Me})$ mit Diisoproylzink das Produkt in $48 \%$ Ausbeute mit $95.7 \%$ ee $(S)$ gebildet wird. 


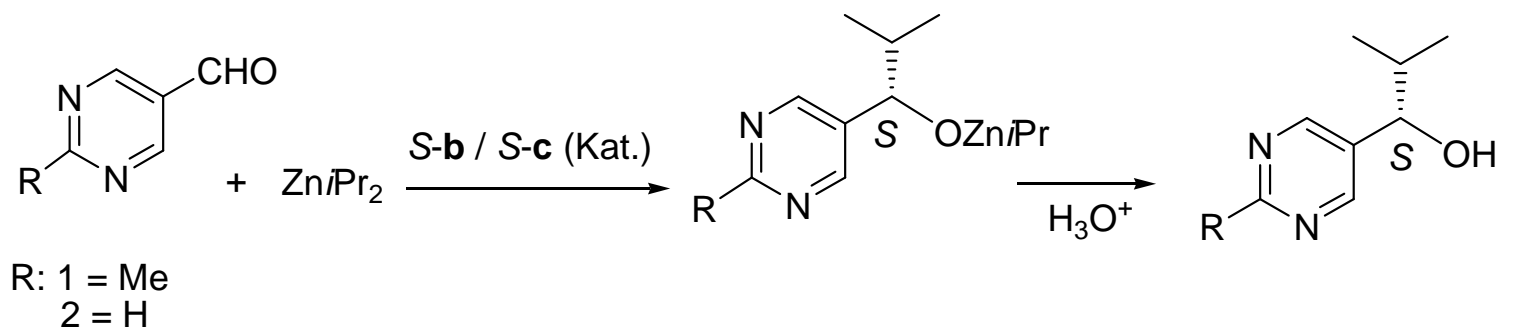

Schema 63. Soai-Autokatalytische Addition von Aldehyd und Diisoproylzink

Obwohl das Produkt sich ohne wesentliche Veränderung des Enantiomerenüberschusses automultipliziert, hat das neu gebildete Produkt doch einen höheren Enantiomerenüberschuss als der zugegebene (S)-Pyrimidylalkohol. Sie haben dann weiter 20 Mol-\% des PyrimidylAlkohols $(\mathrm{R}=\mathrm{H})$ nur mit $(S)-2 \%$ ee untersucht, nachher erhielten sie autokatalytisch produziertes $(S)$-Produkt mit 10\% ee. Weitere vier Reaktionszyklen wurden untersucht, in denen die Menge an $(S)$-Pyrimidylalkohol $(\mathrm{R}=\mathrm{H})$ nach vier Zyklen auf das 942-fache gesteigert werden konnte. Der Enantiomerenüberschuss hat ebenfalls von $10 \%$ über $57 \%$ und $81 \%$ auf $88 \%$ zugenommen. Ein in diesem Produkt sich stereospezifisch replizierendes System ist gleichbedeutend mit der Verstärkung des Enantiomerenüberschusses. Darüber gab es schon früh eine Vorstellung, die Frank in seinem mathematischen Modell ${ }^{147}$ formulierte.

Das prominenteste Beispiel ist die Soai-Reaktion ${ }^{159}$ (Schema 64) wegen der Fähigkeit, von einem chiralen Pyrimidyl-Alkanol mit einem kleinen Enantiomerenüberschuss (ca. 0.00005\% $e e$ ) in der Addition von Diisoproylzink an Pyrimidylaldehyd (Schema 64) die Produktmenge stereoselektiv zu vergrößern, sodass eine fast vollständige Enantiomerenreinheit (> 99.5\% ee) nach mehrmaliger Zugabe des Initiators (Pyrimidyl-Alkohol) erreicht wird. 


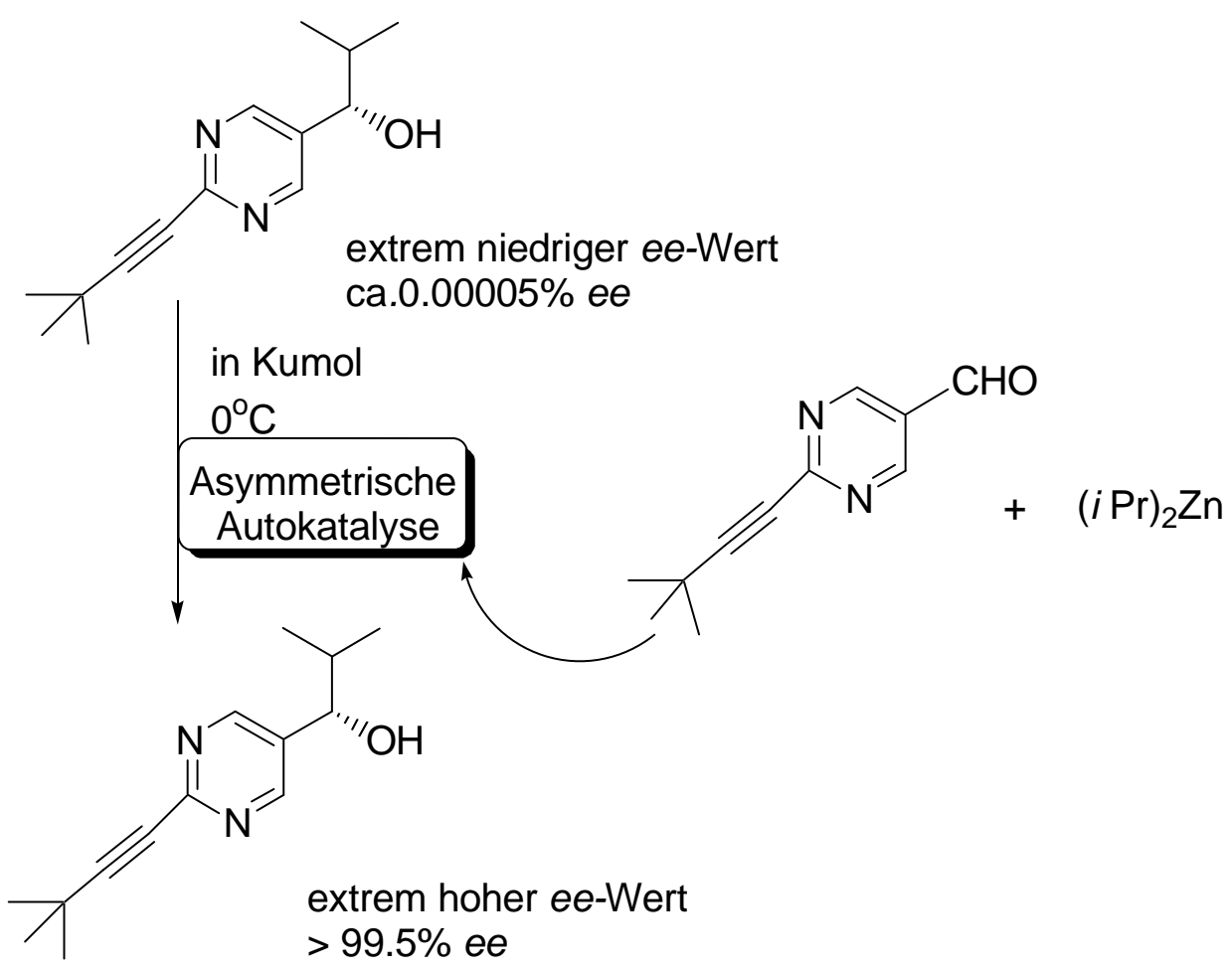

Schema 64. Soai-Autokatalyse bei der Alkylierung

Eine katalytische asymmetrische autoinduktive Aldol-Reaktion in der Gegenwart von Ti-BinolKomplexen wurde von Szlosek und Figadère ${ }^{160}$ beschrieben. Während ein rein organischer Fall der Produkt-Katalyse bereits bekannt ist, wie autokatalytische Aldol-Reaktion, ${ }^{161}$ sind aber keine Berichte über asymmetrische Beispiele dieser Reaktionen vorhanden (Schema 65). Eine Lithium-Lewis-Base (Alkoxid) wurde als Initiator bei der Aldol-Reaktion von Trimethylsilylketen und Aldehyd in DMF eingesetzt, das dadurch gebildete Intermediat (als Salz) kann effektiv am Aldehyd nucleophil angreifen und bildet die Zwischenstufen (I). Nach der Silylierung von (I) wird das Produkt gebildet und gleichermaßen die Lithium-Lewis-Base regeneriert. Durch dieses zyklische katalytische Verfahren werden Produkte multipliziert, wobei keine asymmetrische Multiplikation beteiligt ist. 


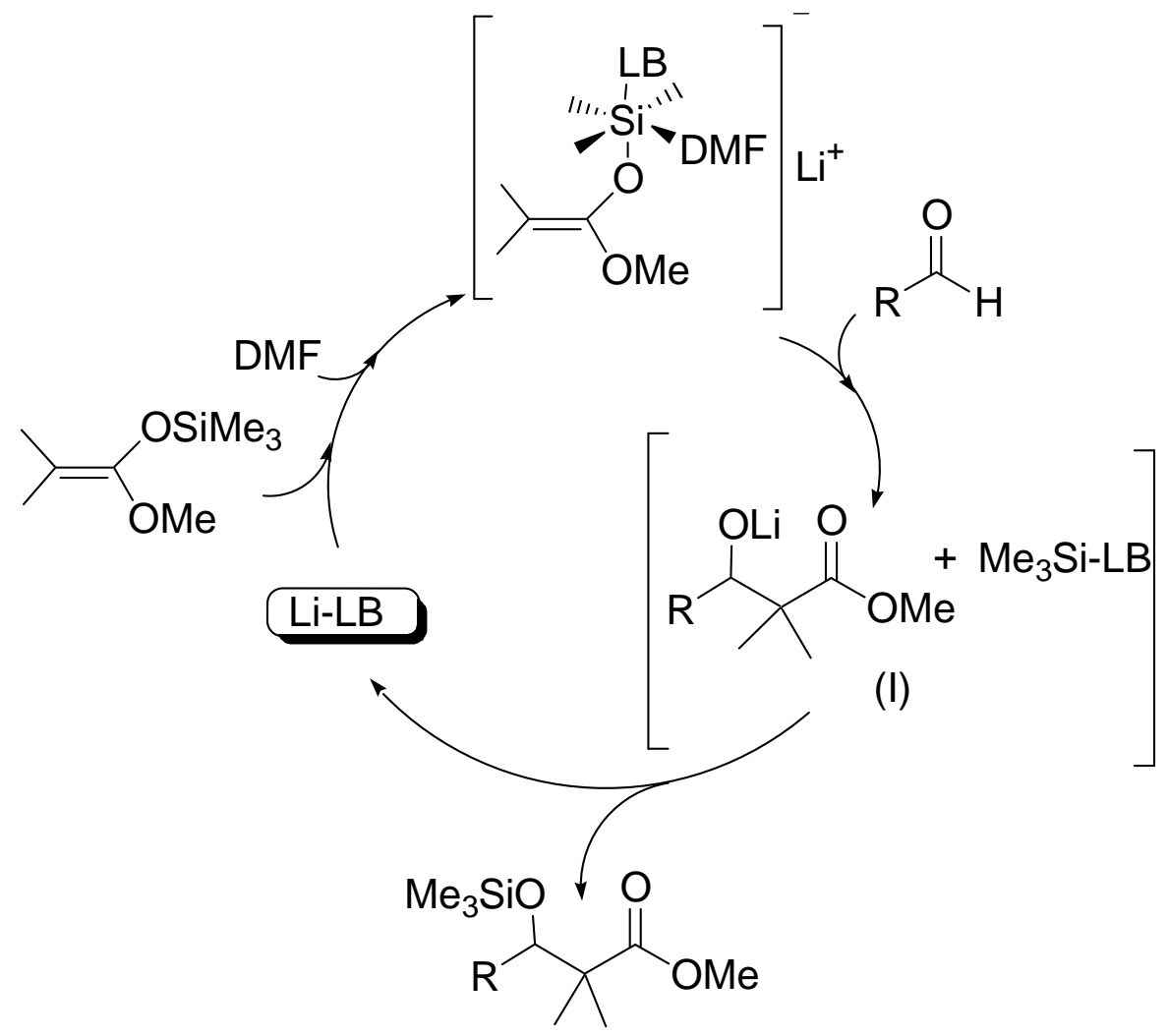

Schema 65. Autokatalytische Aldol-Reaktion ${ }^{161}$

Sievers und Kiedrowski haben einen schablonenartigen Mechanismus von autokatalytischer Selbstreplikation (Asymmetrie der Natur) von Oligonucleotidsträngen vorgestellt. ${ }^{162}$ Darüber hinaus haben Bolm und Mitarbeiter ein vollständig organokatalytisches Beispiel von enantioselektiver Autoinduktion bei der durch ein Cyclopeptid katalysierten Synthese von chiralen Cyanhydrinen angeführt. Das Produkt und der hinzugefügte Katalysator stellen hier eine effizientere katalytische Spezies dar, welche hohe ee-Werte und Ausbeuten erzielen kann. $^{163}$

Es wurde im Jahr 1995 die asymmetrische autokatalytische Amplifikation der Chiralität in der irreversiblen Reaktion von Pyrimdiyl-5-carbaldehyd und Diisopropylzink ${ }^{164}$ berichtet, mit der später in wiederholender Durchführung Selektivitäten bis $86 \%$ ee erreicht wurden.

Merkwürdig ist, dass das Ausgangsmaterial völlig achiral ist! ${ }^{165}$ Solcher spontaner Symmetriebruch in nicht-linear autokatalytischen chemischen Prozessen wurde von Tennakone theoretisch, basierend auf einer ähnlichen Verwendung in der Nuklearphysik vorgeschlagen. ${ }^{166,167}$ Reversible Reaktionen erscheinen ungeeignet für die entsprechende 
experimentelle Bestätigung in einem geschlossenem System, da eine Racemisierung über die Rückreaktion auftreten kann. Saito und Hyuga haben aber demonstriert, ${ }^{168}$ dass die Amplifikation von Chiralität zu Homochiralität eine reversible Reaktion benötigt, weil mehr vom dominierenden Enantiomer aus dem bei der Rückreaktion gebildeten Edukt entstehen kann. ${ }^{166,169}$

Es ist noch hinzuzufügen, falls die reaktionsbeschleunigende Eigenschaft des Produkts schlecht entwickelt ist, beschränkt sich der Vergleich mit der unkatalysierten Reaktion mehr auf den erreichbaren Enantiomerenüberschuss

\subsection{Arbeitsplan für das Gebiet der autokatalytischen asymmetrischen Reaktion}

Die Mannich und Aldol-Reaktion wollen wir als erstes für die Autokatalyse auswählen, und anhand zweier unterschiedlicher Bedingungen beweisen, wie die asymmetrische Autokatalyse ohne Zugabe von Produkt-Katalysator und mit Einsatz von Produkt als Katalysator bei der Mannich- und Aldol-Reaktion verlaufen kann.

\subsection{Ergebnisse und Diskussion}

6.3.1 Die asymmetrische Autokatalyse bei der Mannich und Aldol-Reaktion durch ProduktKatalysatoren.

Wir haben zunächst durch unsere Untersuchung bewiesen, dass eine organische optisch aktive Verbindung bei einer reversiblen Reaktion ebenfalls ihre eigene Bildung katalysieren kann.

Die Wahl ist auf ein Beispiel gefallen, in welchem der Komplex spezifisch durch Wasserstoffbrückenbindung sowie durch Produkt-Substrat Interaktionen gebunden werden kann, und aus dem prochiralen Substrat sich ein optisch aktives Produkt bilden kann. Unsere Wahl feil dabei auf die Mannich Reaktion ${ }^{170}$ unter unterschiedlichen Reaktionsbedingungen mehrmals untersucht haben. 


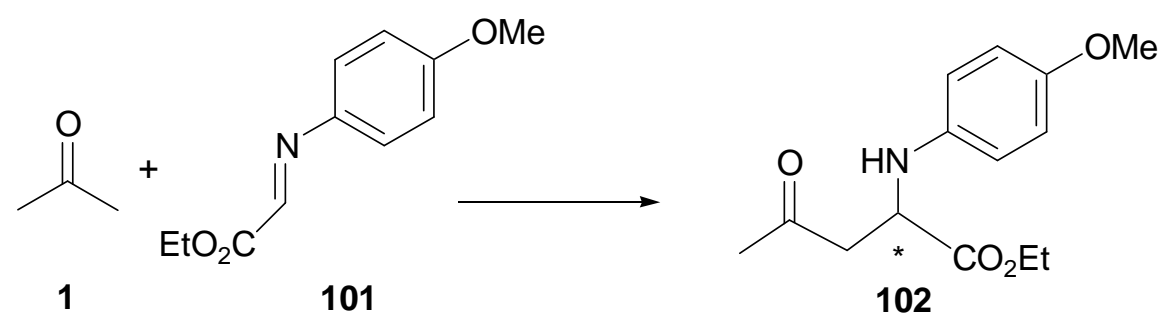

Zunächst wurde der Produkt-Katalysator durch L-Prolin Katalyse extrem enantiomerenrein (98\% ee) mit $S$-Konfiguration und durch D-Prolin 99\% ee mit $R$-Konfiguration nach literaturbekannten Methoden ${ }^{170}$ dargestellt. Wir können nicht ausschließen, dass das Produkt während seiner Bildung in der Anwesenheit des Prolins auch eine Rolle als Katalysator gespielt hat.

Reaktionen wurden unter unterschiedlichen Bedingungen (unterschiedliche EduktKonzentration, verschiedene Lösungsmittel und $e e$-Werte des Produkt-Katalysators; absolute Konfiguration und unterschiedliche Menge von Produkt-Katalysator und auch bei unterschiedlicher Temperatur und nicht gleicher Reaktionszeit) in trockener und stickstoffhaltiger Atomsphäre durchgeführt. Die Ergebnisse werden in Tabelle 19 zusammengefasst. Um den Effekt der asymmetrischen Induktion zu bestimmen, haben wir die reduzierten $e e$-Werte nach der Reaktion laut folgender Gleichung berechnet. ${ }^{171}$

$$
e e_{\mathrm{p}}=\left(\mathrm{n}_{1} /\left(\mathrm{n}_{1}-\mathrm{n}_{0}\right) \cdot\left(e e_{p}^{\prime}-\left(\mathrm{n}_{0} \cdot e e_{0} / \mathrm{n}_{1}\right)\right)\right.
$$

$e e_{\mathrm{p}}$ : reduzierter Enantiomerenüberschuss von Produkten nach der Reaktion; $\mathrm{n}_{1}$ : insgesamt isolierte Produkt-Menge in Mol; $\mathrm{n}_{0}:$ Menge in Mol der Produkte als Initiator; $e e_{p}$ : gemessene $e e$-Werte von isolierten Produkten; $e e_{0}$ : der $e e$-Werte des Produkt-Katalysators. 
Tabelle 19 Untersuchung der Autokatalyse bei der Mannich Reaktion<smiles>CCOC(=O)CC(CC(=O)OCC)Nc1ccc(OC)cc1</smiles>

\begin{tabular}{|c|c|c|c|c|c|c|}
\hline \multirow[t]{2}{*}{ Eintrag $^{j}$} & \multicolumn{2}{|c|}{ Katalysator $\mathbf{1 0 2}$} & \multirow{2}{*}{$\begin{array}{c}\text { Temp. } \\
\left({ }^{0} \mathrm{C}\right)\end{array}$} & \multirow{2}{*}{$\begin{array}{l}\text { Reaktionszeit } \\
\text { (Tag) }\end{array}$} & \multicolumn{2}{|c|}{ Produkt 102} \\
\hline & $\begin{array}{l}\text { Mol-\% } \\
\text { (Einsatz) }\end{array}$ & $\begin{array}{c}e e(\%) \\
\text { (Konfig.) }\end{array}$ & & & $\begin{array}{c}\text { Ausbeute } \\
(\%)^{\mathrm{a}}\end{array}$ & $\begin{array}{c}e e(\%) \\
(\text { red, } e e)^{\mathrm{b}}\end{array}$ \\
\hline $1^{(\mathrm{c}, \mathrm{d})}$ & 15 & $98(S)$ & 25 & 2 & 20 & $87(79, S)$ \\
\hline $2^{(\mathrm{c}, \mathrm{d})}$ & 15 & $98(S)$ & 25 & 4 & 48 & $85(81, S)$ \\
\hline $3^{(\mathrm{c}, \mathrm{d})}$ & 15 & $98(S)$ & 25 & 6 & 45 & $91(89, S)$ \\
\hline $4^{(\mathrm{c}, \mathrm{f})}$ & 15 & $98(S)$ & 25 & 4 & 53 & $86(83, S)$ \\
\hline $5^{(\mathrm{c}, \mathrm{d})}$ & 5 & $98(S)$ & 25 & 4 & 38 & $28(19, S)$ \\
\hline $6^{(\mathrm{c}, \mathrm{d})}$ & 5 & $98(S)$ & 25 & 6 & 32 & $23(11, S)$ \\
\hline $7^{(\mathrm{c}, \mathrm{d})}$ & 1 & $98(S)$ & 25 & 4 & 33 & $29(27, S)$ \\
\hline $8^{(\mathrm{c}, \mathrm{d})}$ & 1 & $98(S)$ & 25 & 6 & 32 & $23(20, S)$ \\
\hline $9^{(\mathrm{d}, \mathrm{g})}$ & 15 & $25(S)$ & 0 & 4 & 25 & $25(22, S)$ \\
\hline $10^{(\mathrm{d}, \mathrm{g})}$ & 15 & $55(S)$ & 0 & 4 & 27 & $56(57, S)$ \\
\hline $11^{(\mathrm{d}, \mathrm{g})}$ & 15 & $75(S)$ & 0 & 4 & 27 & $69(66, S)$ \\
\hline $12^{(\mathrm{c}, \mathrm{d})}$ & 15 & $99(R)$ & 25 & 4 & 42 & $94(92, R)$ \\
\hline $13^{(\mathrm{c}, \mathrm{d})}$ & 30 & $99(R)$ & 25 & 4 & 40 & $96(94, R)$ \\
\hline $14^{(\mathrm{c}, \mathrm{d})}$ & 50 & $99(R)$ & 25 & 4 & 38 & $95(90, R)$ \\
\hline $15^{(\mathrm{c}, \mathrm{d})}$ & 30 & $98(S)$ & 25 & 4 & 39 & $94(90, S)$ \\
\hline $16^{(\mathrm{c}, \mathrm{d})}$ & 50 & $98(S)$ & 25 & 4 & 41 & $95(91, S)$ \\
\hline $17^{(\mathrm{i}, \mathrm{d})}$ & 15 & $99(S)$ & 25 & 4 & 0.2 & $98(S)$ \\
\hline $18^{(\mathrm{h}, \mathrm{c})}$ & 25 & $99(S)$ & 25 & 4 & 6.6 & $98(S)$ \\
\hline $19^{(\mathrm{c}, \mathrm{d})}$ & 15 & $99(S)$ & 0 & 6 & 5.6 & $98(S)$ \\
\hline
\end{tabular}

a) Absolute Ausbeute ohne eingesetzte Produkt-Kat.; b) Analyse durch chirale HPLC (Daicel Chiralpack OD); Reduzierter ee aus Rechnung ${ }^{171}$; c) Edukt Konzentration $0.25 \mathrm{Mol} / \mathrm{L}$; d) Aceton als Lösungsmittel; f) DMSO als Lösungsmittel; g) Edukt Konzentration $0.5 \mathrm{Mol} / \mathrm{L}$; h) $\mathrm{CH}_{2} \mathrm{Cl}_{2}$ als Lösungsmittel; i) Edukt Konzentration 0.02 $\mathrm{Mol} / \mathrm{L} ; \mathrm{j})$ Alle Reaktion wurde mehrmals wiederholt. 
Was uns überrascht ist, dass die neu initiierten Produkte in ähnlichen Enantiomerenüberschüssen und gleichen absoluten Konfigurationen wie die 15 Mol-\% Produkt-Katalysator hergestellt wurden (Einträge 1-4; 9-12 Tabelle 19). Höhere effektive Enantiomerenüberschüsse wurden durch Einsatz großer Mengen von Produkt-Katalysatoren erzielt, in den Einträgen 1316 wurden der Produkt-Katalysator in 30 und 50 Mol-\% mit 98\% ee eingesetzt, sodass die neu gebildeten Produkte in bis zu 96\% ee vorkommen; diese Ergebnisse entsprechen dem von Soai mitgeteilten metallhaltigen System. ${ }^{157}$ Mit DMSO als Lösungsmittel (Eintrag 4, Tabelle 19) sind die Ergebnisse unter gleichen Bedingungen nur wenig besser als in Aceton (Eintrag 2, Tabelle 19). In Eintrag 18 haben wir zum Beispiel Methylenchlorid als Lösungsmittel mehrere Male ausprobiert, wobei der Produkt-Katalysator mit 99\% ee (S-Konfiguration) in 25 Mol-\% zugegeben wurde. Trotzdem bildete sich nur 4-6.56\% Produkt mit 98\% ee in 4 Tagen.

Um zu wissen, wie im Verlauf des Autokatalyse-Prozesses der Initiator (Produkt-Katalysator) oder überhaupt die Stöchiometrie eine bedeutende Rolle spielt, haben wir dann weniger Initiator (1-15 Mol-\%) mit 98\% ee (S-Konfiguration) bei der Mannich Reaktion zugegeben. Die Ergebnisse zeigen (Einträge 2-8), dass die Ausbeute nicht besonders von der Menge des zugegebenen Produkt-Katalysators und der Reaktionszeit abhängt, der Enantiomerenüberschuss verringert sich jedoch deswegen deutlich (Einträge 7-8, Tabelle 19).

Wir nehmen deswegen an, dass die chirale Induktion ausschließlich auf die sehr kleine Menge des Initiators (nämlich des Produkt-Katalysators) zurückgeführt werden kann. Außerdem wurde die optimale Reaktionszeit auf vier Tage bestimmt (vgl. Eintrag 2 mit 3; 5 mit 6 und 7 mit 8 Tabelle 19). Vergleichen wir den Enantiomerenüberschuss von Eintrag 5 (28\%) mit 6 (23\%) und Eintrag 7 (29\%) mit 8 (23\%), finden wir, dass die Reaktion umso weniger enantioselektiv verläuft, je länger die Reaktionszeit ist. Die lange Reaktionszeit könnte unter dieser Reaktionsbedingung eine Razemisierung verursachen. Eine andere Ursache kann auch die Reversibilität der Reaktion sein. Wir haben gleichermaßen beobachtet, dass das reine Produkt 102 mit $98 \%$ ee bei $-21^{0} \mathrm{C}$ nach drei Monaten nur noch $53 \%$ ee aufwies. In den Zeiträumen von 4 Tagen bei Raumtemperatur gab es jedoch keine Verringerung des Enantiomerenüberschusses. Unter den Reaktionsbedingungen selbst razemisierte das Produkt also nicht.

Wir haben weiter untersucht, wie die Mannich-Reaktion von Temperatur und dem Enantiomerenüberschuss des Initiators beeinflusst wird. Für die Einträge 9-11 in der Tabelle 19 wurde die Reaktion bei $0^{\circ} \mathrm{C}$, mit einer Edukt-Konzentration von $0.5 \mathrm{Mol} / \mathrm{L}$ und ProduktKatalysator mit 25\%, 55\% und 75\% ee in Aceton durchgeführt. Das Produkt wurde so in Ausbeuten von 25-27\% und Enantiomerenüberschüssen mit 25\%, 56\% und 69\% erhalten. Die Ausbeute wird stärker als der Enantiomerenüberschuss von der Reaktionstemperatur beeinflusst. 
(vgl. Eintrag 2 mit Einträgen 9-11, Tabelle 19). Mit der Gibbs-Helmholtz-Gleichung kann man beweisen, dass die Reaktion bei niedrigeren Temperaturen enantioselektiver als bei höheren Temperaturen abläuft. Unsere Untersuchung zeigt aber, dass die Reaktion bei niedriger Temperatur nicht besser als bei höherer ist.

Der Produkt-Katalysator übt eine effektive Initiation für die Chiralitäts-Übertragung auf das chemisch identische Produkt aus (Tabelle 19). Die Chiralitätsübertragung ist aber nicht optimal, weil die Konkurrenz-Reaktion, die nicht katalytisch verläuft, auch signifikant zur Ausbeute beitragen kann. Um die Induktion und den Mechanismus zu klären, haben wir mehrere Experimente durchgeführt: das reine Produkt 102 mit 98\% ee und $S$-Konfiguration wurde in Aceton (Konzentration $0.25 \mathrm{Mol} / \mathrm{L}$ ), ohne zu rühren, bei RT 4 Tage stehengelassen; dann wurde das Lösungsmittel Aceton im Vakuum entfernt. Der Rückstand wurde durch NMR, HPLC, und ESI-MS analysiert. Die Ergebnisse werden in Tabelle 20 zusammengestellt.

Tabelle 20 Bestimmung der Reversiblität der Mannich-Reaktion

\begin{tabular}{|c|l|l|l|c|l|l|}
\hline Eintrag & NMR-(1) & NMR-(2) & ESI-MS(1) & $\begin{array}{c}\text { ESI- } \\
\text { MS(2) }\end{array}$ & HPLC-(1) & HPLC-(2) $^{\mathrm{b}}$ \\
\hline 1 & kein Edukt & mit Edukt & kein Edukt & mit Edukt & $98 \%(S)$ & $98 \%(S)$ \\
\hline 2 & kein Edukt & mit Edukt & kein Edukt & mit Edukt & $0.8 \%(S)$ & $1.3 \%(S)$ \\
\hline 3 & kein Edukt & mit Edukt & kein Edukt & mit Edukt & $2.96 \%(R)$ & $0.92 \%(R)$ \\
\hline 4 & kein Edukt & mit Edukt & - & - & $0.88 \%(S)$ & $1.82 \%(S)$ \\
\hline 5 & kein Edukt & mit Edukt & $3 \%^{\mathrm{d}}$ & $27 \%^{\mathrm{d}}$ & $97.48 \%(S)$ & $97.96 \%(S)$ \\
\hline
\end{tabular}

a) Die Messung vor Beginn des Experiments; b) Die Messung nach 4 Tagen stehen;

c) Konzentration $0.25 \mathrm{Mol} / \mathrm{L}$; d) Peak-Intensität

Im Allgemeinen zeigen die Ergebnisse, dass die Reaktion reversibel ist. Die Verbindung 102 war laut Messung mit NMR und ESI-MS zu Beginn sauber. Diese wurde zum einen enantiomerenrein (Eintrag 1) oder als fast razemische Mischung eingesetzt (Eintrag 2, 3). Nachdem die Lösung 4 Tage stehengelassen wurde, war laut Messung Edukt entstanden (Einträge 1-3, Tabelle 20). Eintrag 5 zeigt nach 4 Tagen mehr Edukt als vorher. Interessant ist, dass es eine Tendenz gibt: beim Stehen lassen scheint es so zu sein, dass das $R$-Isomer des Produkts sich in das $S$-Isomer umwandelt, weil der Enantiomerenüberschuss des Produkts mit $S$-Konfiguration höher als Beginn des Experiments ist. (Eintrag 2, 4, 5 Tabelle 20). Auch im Eintrag 3 zeigt sich eine Verringerung des Enantiomerenüberschusses der $R$-Konfiguration. Immerhin ist es hier ganz klar, dass die untersuchte Mannich Reaktion reversibel ist. 
Ein Beispiel des ESI-MS-Spektrums wird in Abb. 27 gegeben. Die enantiomerenreine Probe mit $98 \%$ ee (S-Konfiguration) wurde 4 Tage stehengelassen. Wir haben außer den Produktpeaks $266.1[\mathrm{M}+\mathrm{H}]^{+}, 288.0[\mathrm{M}+\mathrm{Na}]^{+}$und $552.8[\mathrm{M}+2 \mathrm{Na}]^{2+}$ noch zwei wichtige Peaks gefunden, einer ist 371.7 [Enamin $\left.+2 \mathrm{Na}^{+}+2 \mathrm{H}^{+}+\mathrm{NH}_{4}{ }^{+}\right]$mit $58 \%$ Intensität. Das Enamin bildet sich aus Produkt 102 mit Aceton, der andere ist 495.0 [Edukt 101+Produkt 102+ $\mathrm{Na}^{+}$] mit $17 \%$ Intensität (Abb. 27). Dies ist ein sehr wichtiger Beleg für die Anwesenheit des Produkt-EduktDimers im Reaktionssystem.

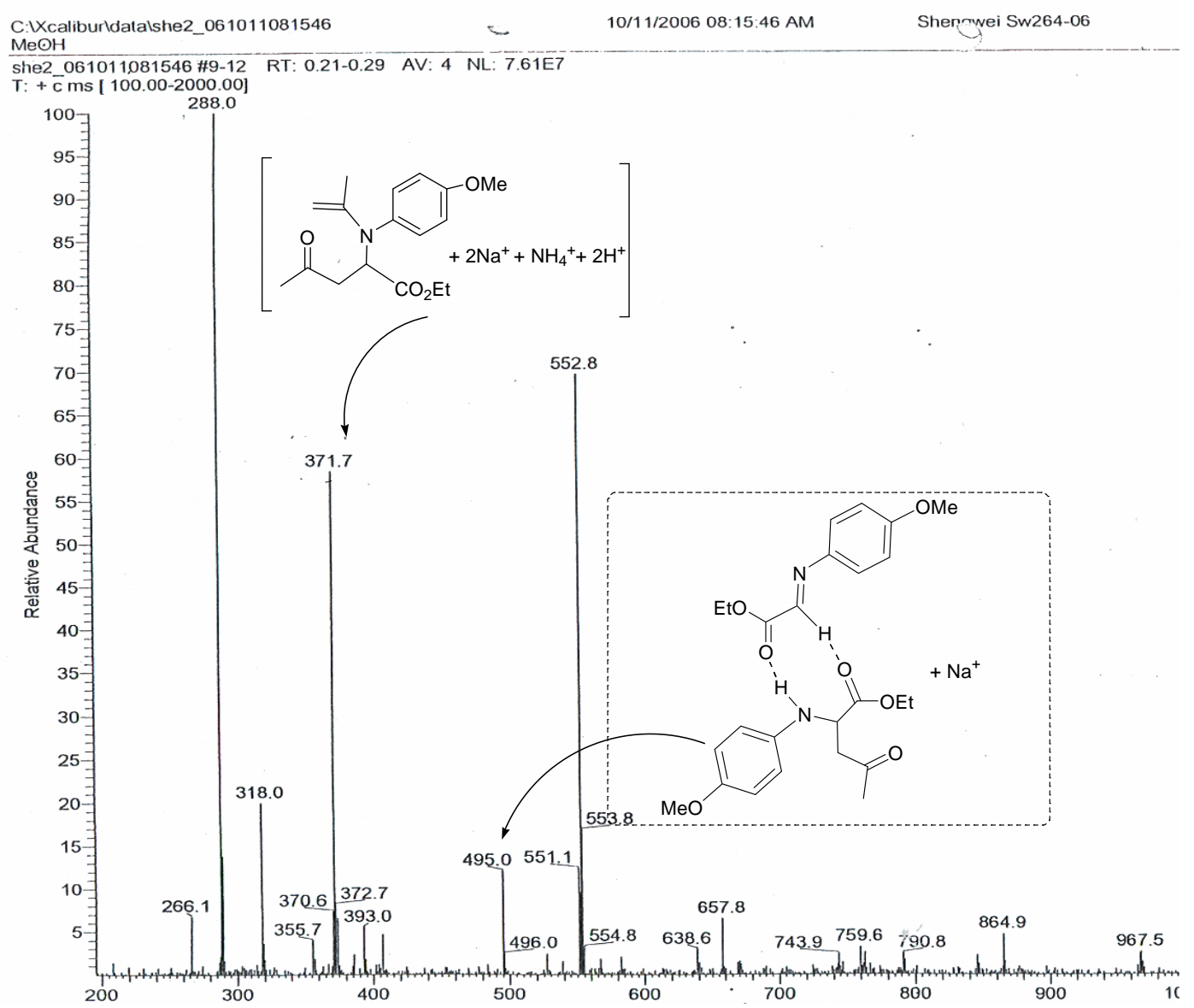

Abbildung 27. ESI-MS-Spektrum der reinen Verbindung 102 nach 4 Tagen in Aceton

Davon ausgehend haben wir den autokatalytischen Reaktionsmechanismus in Schema 66 vorgeschlagen. Drei Möglichkeiten der Komplexbildung könnten im Reaktionssystem auftauchen. Je nachdem Produkt welcher Konfiguration mit dem Edukt zusammen trifft, bildet sich bei a) der E-S-Komplex mit dem überschüssigen $S$-Isomer, wenn beispielsweise das $S$ Isomer als Produkt-Katalysator zugegeben wurde. Im Gegensatz dazu entsteht E- $R$ (bei b) mit dem überschüssigen $R$-Isomer, wenn reines $R$-Isomer als Initiator zugegeben wird. a) und b) 
werden als Begründung für den Reaktionsverlauf angenommen. Beim Fall c) wurde racemischer Produkt-Katalysator zugesetzt. Die Reversibilität der Reaktion und die Umwandlung von Edukt und Produkt-Isomeren ( $S$ - und $R$-Konfiguration) werden nicht ausgeschlossen (d, Schema 66).

Im Prinzip kann die Mannich Reaktion katalytisch durch die von Produkt-Katalysator und Aceton gebildete Enamin-Intermediat ablaufen. ${ }^{172}$ Obwohl der Peak vom Enamin tatsächlich in ESI-MS erscheint (Abb. 27, $371.7\left[\right.$ Enamin $\left.+2 \mathrm{Na}^{+}+2 \mathrm{H}^{+}+\mathrm{NH}_{4}{ }^{+}\right]$), vermuten wir trotzdem eher eine Substrat-Produkt-Komplexbildung als die Ursache für die Autokatalyse. Wir beobachteten, dass die Aldol-Reaktion von $p$-Nitrobenzaldehyd und Aceton bei der Zugabe von 71-75\% ee Produkt-Katalysators auch mit 3-27\% Ausbeute verlaufen kann, obwohl hier keine EnaminIntermediate gebildet werden konnte.
a) $S, S$ (Produkt) $+2 \mathrm{E} \rightleftharpoons 2 \mathrm{E}-S \Delta \mathrm{G}=3.4$
b) $R, R$ (Produkt) $+2 \mathrm{E} \rightleftharpoons 2 \mathrm{E}-R$
c) $R, S+2 \mathrm{E} \rightleftharpoons 2 \mathrm{E}-R+2 \mathrm{E}-S \triangle \mathrm{G}=3.4$
d) $R \rightleftharpoons \mathrm{E} \rightleftharpoons \mathrm{S}$

Schema 66. a, b) Komplex-Bildung von Edukt (E) mit Produkt-Isomeren ( $S$-und $R$ Konfiguration); c) Umwandlung von Edukt und Produkt-Isomeren ( $S$ - und $R$ - Konfiguration)

Das bedeutet, dass die intermolekulare Wechselwirkung eine Rolle spielt. Die Übergangszustände der Mannich-Reaktion werden deswegen nach unserer Vermutung durch Abb. 28 wiedergegeben. 


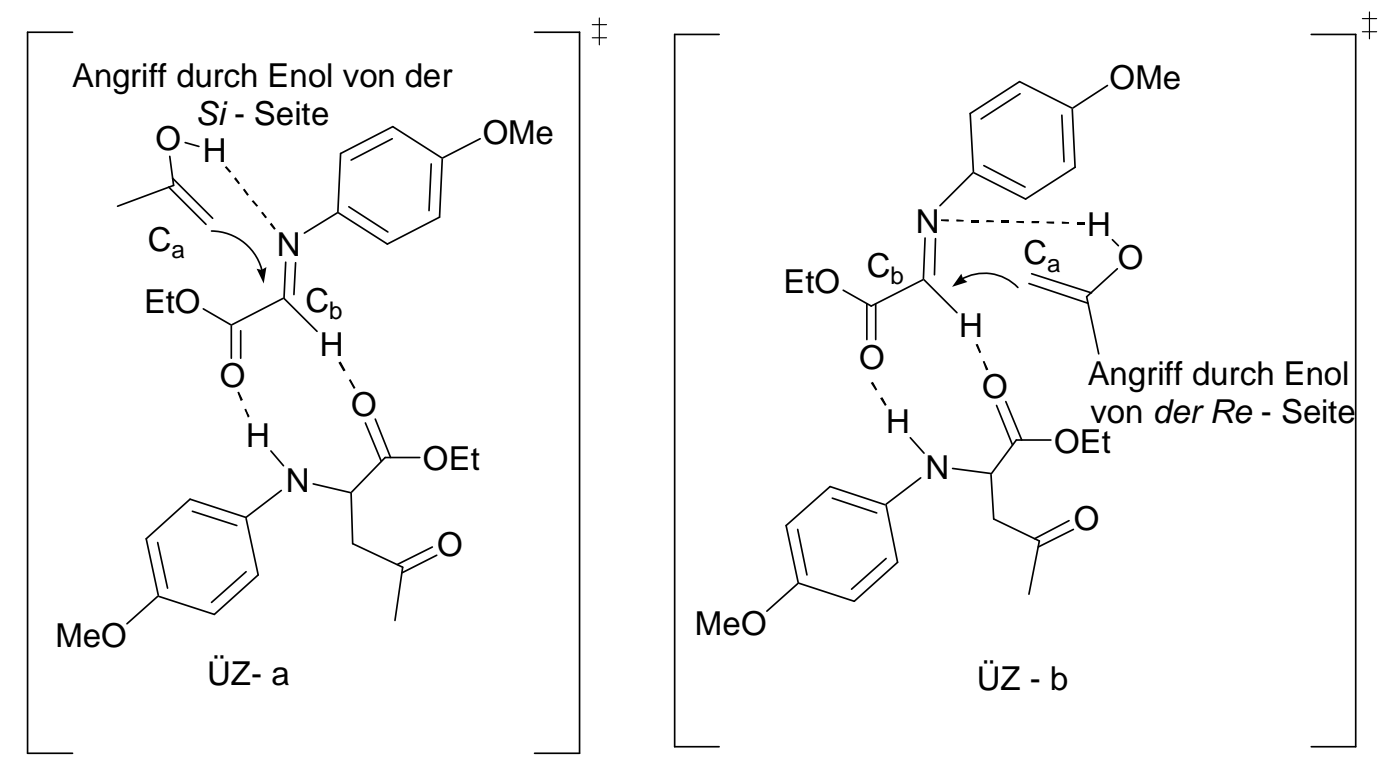

Abbildung 28. ÜZ-a führt zur $S$-Konfiguration und ÜZ-b zur $R$-Konfiguration

Das trans-Edukt (101) bildet eher mit Produkt (102) einen Komplex, der Angriff von Enol (Aceton) am Kohlenstoff des Imins findet nach zwei Möglichkeiten statt, nämlich von der Siund der Re-Seite des Imins.

Diese mit NMR, ESI-MS und HPLC belegten Phänomene motivierten uns, weitere Fragstellungen durch Computer-Berechnungen zu klären (Tabelle 21). ${ }^{173}$ Um unsere intuitiven mechanistischen Annahmen zu bestätigen (Schema 66), sollten die Existenz und die Rolle der betreffenden Spezies weiter aufgeklärt werden. Das Energie-Niveau der jeweiligen Spezies (Tabelle 21) wurde durch das Gaussian 03 Quantumchemiepaket mit DFT (density functional theroy)-Methoden mit dem B3LYP-Funktion und dem 6-31 G Basissatz berechnet. Ein stabiler Übergangs-Zustand für die Bildung der $S$-Konfiguration wurde dadurch bestimmt (Abb. 28, ÜZ. a), obwohl der energetische Unterschied nicht besonders groß ist (Einträge 10 und 11, Tabelle 21). Dies ist aber auch in Übereinstimmung mit Spektren-Messungen (Tabelle 20), das $S$ Isomer entsteht eher.

Es wurde gefunden, dass zumindest für die beiden hetero- $(R, S)$ und homochiralen $(S, S)$ Produkt-Dimere weniger stabil als die entsprechenden Monomere sind (vgl. Eintrag 3 mit 4 und 5, Tabelle 21). Die Bildung des Produkt-Dimers konkurriert in der Komplexbildung des Produkts 
mit dem Edukt, das nur einen Unterschied von $3.2 \mathrm{Kcal} / \mathrm{Mol}$ in Bezug auf das separate Edukt und Produkt aufweist.

Tabelle 21 Die Energien auf B3LYP/6-31G-Niveau der jeweiligen Spezies

\begin{tabular}{|l|l|c|c|}
\hline Eintrag & \multicolumn{1}{|c|}{ Spezies } & $\mathrm{E}_{\mathrm{abs}}[$ Hartree $]$ & $\mathrm{E}_{\text {rel }}\left[\mathrm{Kcal}^{-1}\right]^{\mathrm{a}}$ \\
(NIMAG) $^{\mathrm{b}}$
\end{tabular}

a) Inklusiv ZPE und thermische Korrekturen; b) Nummer der imaginären Frequenzen; c) in Bezug auf zwei Monomer-S-Moleküle; d) katalysierte Reaktion mit Aceton basierend auf der Struktur (S)-83* trans-82 (II) (Abb. 28, ÜZ.a); e) relativ zu Nr.4; f) relativ zu Nr.5; g) für nicht katalysierte Reaktion von Aceton mit trans-82 in der Abwesenheit von Produkt-Katalysator; h) relativ zu Nr.3

Es wird impliziert, dass das Produkt über den trans-Edukt-S-Produkt-Komplex gebildet wird (Tabelle 21, Eintrag 9). Das resultierende Produktdimer ist vermutlich homochiral (Schema 66 a, Hauptreaktionszweig), weil der Übergangszustand für die Anordnung des $S$-Produkts (Eintrag 11 Tabelle 21) $1.8 \mathrm{kcal} / \mathrm{Mol}$ niedriger als die Energie des entsprechenden Übergangszustandes für die Anordnung von $R$-Produkt (Eintrag 10, Tabelle 21) ist. Das heterochirale Dimer kann bei der Reaktion leichter gebildet werden, wenn sich die Produkt und des Produkt-Katalysator mit derselben absoluten Konfiguration nicht gut zusammenlagern können. Für die Regeneration des Edukt-Produkt-Komplexes aus dem freien Substratmolekül und des Produkt-Dimers ist die Energie von $3.4 \mathrm{Kcal} / \mathrm{Mol}$ erforderlich (Schema 66, a). Heterochirale Komplexe befinden sich mit der razemischen Mischung im 
Gleichgewichtszustand (Schema 66, c). Das Produkt als homochirales Dimer und Monomer ist in einigen Fällen nicht an dem katalytischen Schritt beteiligt. Die Entropie-Bevorzugte Razemisierung kann auch durch nicht-katalytische Reaktion auftreten (Schema 66, d).

In einer weiteren Computer-Berechnung wurden Übergangszustände betrachtet (Abb. 24). Die Wasserstoffübertragung vom Enol-Sauerstoffatom zum Stickstoffatom der Schiff-Base initiiert die Annäherung des Methylen- $\mathrm{C}_{\mathrm{a}}$-Atom des Enols in Richtung auf das $\mathrm{C}_{\mathrm{b}}$ des Aldimins (Abb. 28, ÜZ a). Die Reaktionskoordinate wird durch den sechsgliedrigen Übergangszustand repräsentiert, wobei die Distanz von $\mathrm{C}_{\mathrm{a}}-\mathrm{C}_{\mathrm{b}} 2.845 \AA$ A beträgt (Abb. 28, ÜZ a), im Gegensatz dazu beträgt diese Distanz $2.847 \AA$ in ÜZ b. Die jeweiligen berechneten Dipolmomente vom $S$ und $R$ Enantiomer (3.97 und 3.12 Db) bieten eine gute Erklärung für den Einfluss der Polarität des Lösungsmittels (Tabelle 19, vgl. Eintrag 2 mit 4).

Die Produkt-Dimere sind im Gleichgewicht mit kleinen Mengen vom Edukt-Produkt-Komplex (Schema 66 a, b; Tabelle 21, Eintrag 9). Aus zweitem kann das Produkt besser entstehen, zum Beispiel über den Übergangszustand ÜZ a oder alternativ über ÜZ b (Tabelle 21, Einträge 10 und 11; Abb. 28). Es kann (auch thermodynamisch bevorzugt, Schema 66, c) sich auch nivellieren, um das Substrat freizugeben und mehr unaktiviertes meso-Produktdimer zu erzeugen.

Die Höhe des Enantiomerenüberschusses wird von der Stereospezifität des ProduktKatalysators, Racemisierung und der auftretenden unkatalysierten Reaktion (Tabelle 21, Eintrag 12) begrenzt.

Als weitere interessante Untersuchung wurde die Aldol-Reaktion von Aceton und 4-Nitrobenzaldehyd mehrere Male durchgeführt (Tabelle 22), die reduzierten Enatiomerenüberschüsse wurden genau wie bei der Mannich-Reaktion berechnet: $\left(e e_{\mathrm{p}}=\left(\mathrm{n}_{1} /\left(\mathrm{n}_{1}-\mathrm{n}_{0}\right) \cdot\left(e e_{p}-\left(\mathrm{n}_{0} \cdot e e_{0} / \mathrm{n}_{1}\right)\right)\right.\right.$ $e e_{\mathrm{p}}$ : reduzierter Enantiomerenüberschuss der Produkte nach der Reaktion; $\mathrm{n}_{1}$ : insgesamt isolierte Produkt-Menge in Mol $\mathrm{n}_{0}$ : Menge in Mol der Produkte als Initiator; $e e_{p}$ : gemessene $e e$-Werte von isolierten Produkten; $e e_{0}$ : der $e e$-Werte des Produkt-Katalysators.

Im Vergleich zur Mannich-Reaktion verhält sich die Aldol-Reaktion etwas anders. Als Produkt-Katalysator-Menge wurde stufenweise von 1 über 5 bis zu 15 Mol-\% eingesetzt, die Reaktionszeit wurde erst einmal auf 6 Tage begrenzt, unter den gleichen Reaktionsbedingungen (Edukt-Konzentration; gleiche Lösungsmittel und Reaktionstemperatur) wurde die Ausbeute in gleicher Tendenz von 3 über 5 bis auf 7\% gesteigert (Einträge 5-7, Tabelle 22), aber der Enatiomerenüberschuss ist fast genau so wie der des Produkt-Katalysators (74.7\%; 75\%). Mit 1 Mol-\% Produkt-Katalysator bildet sich jedoch ein relativ niedriger Enantiomerenüberschuss 
des Produkts (Eintrag 6, Tabelle 22). Die Edukt-Konzentration wurde dann von 0.5 über 25 bis zu $50 \mathrm{Mol} / \mathrm{L}$ erhöht, im Vergleich zum weniger polaren Toluol (18\%; Eintrag 4, Tabelle 22) resultieren die Reaktion in Aceton in relativ besserer Ausbeute (27\%, Eintrag 3, Tabelle 22, aber das der Enantiomerenüberschuss bleibt fast gleich (73.7\% und 73\% Eintrag 3 und 4). Die unterschiedliche Größe des Enatiomerenüberschusses vom Produkt-Katalysator spielt fast keine entscheidende Rolle bei der Bildung eines neuen Produkts bezüglich Ausbeute und Enantiomerenüberschuss (Einträge 1 und 2, Tabelle 22). Wir haben dann täglich 10\% der Edukt-Menge des Anfangs unter ungleichem Enantiomerenüberschuss (Racemat und 75.8\% ee mit $R$-Konfiguration) von Produkt-Katalysator zugegeben (Einträge 8 und 10), in der wurde der Produkt-Katalysator stufenweise bis 10 Tage vermehrt, die Ergebnisse zeigen, dass die Ausbeute durch den racemischen Produkt-Katalysator (Eintrag 10) höher ist als der asymmetrische (Eintrag 8), der Enantiomerenüberschuss zeigt bei beiden Fällen keine Veränderung. 
Tabelle 22 Aldol-Reaktion katalysiert durch Produkt 3<smiles>CC(=O)CCCCCCCCCCCCC(=O)c1ccc([N+](=O)[O-])cc1</smiles>

\begin{tabular}{|c|c|c|c|c|c|c|c|}
\hline \multirow[t]{2}{*}{ Eintrag } & \multirow{2}{*}{$\begin{array}{l}\text { Edukt- } \\
\text { Konzen. } \\
(\mathrm{Mol} / \mathrm{L})\end{array}$} & \multicolumn{2}{|c|}{$\begin{array}{c}\text { Produkt-Katalysator } \\
\mathbf{3}\end{array}$} & \multirow[t]{2}{*}{ Lösungsmittel } & \multirow[t]{2}{*}{$\begin{array}{c}\text { Zeit } \\
\text { (Tag) }\end{array}$} & \multirow[t]{2}{*}{$\begin{array}{c}\text { Ausbeute }^{\mathrm{a}} \\
(\%)\end{array}$} & \multirow{2}{*}{$\begin{array}{c}e e(\%)^{\mathrm{b}} \\
(\text { reduzierte } e e)^{\mathrm{d}} \\
\text { (Konfig.) }\end{array}$} \\
\hline & & $\begin{array}{c}\text { Menge } \\
(\text { Mol-\%) }\end{array}$ & $\begin{array}{c}e e(\%) \\
\text { (Konfig.) }\end{array}$ & & & & \\
\hline 1 & 25 & 15 & $55(R)$ & DMSO & 6 & 18 & $51.1(48)(R)$ \\
\hline 2 & 25 & 15 & $75.8(R)$ & DMSO & 6 & 19 & $73.2(71)(R)$ \\
\hline 3 & 50 & 15 & $75.8(R)$ & Aceton & 6 & 27 & $73.7(73)(R)$ \\
\hline 4 & 50 & 15 & $75.8(R)$ & Toluol & 6 & 18 & $73.0(R)$ \\
\hline 5 & 0.5 & 5 & $75.8(R)$ & Aceton & 6 & 5 & $74.7(74)(R)$ \\
\hline 6 & 0.5 & 1 & $75.8(R)$ & Aceton & 6 & 3 & $71.1(70)(R)$ \\
\hline 7 & 0.5 & 15 & $75.8(R)$ & Aceton & 6 & 7 & $74(72)(R)$ \\
\hline $8^{c}$ & 0.5 & 15 & $75.8(R)$ & Aceton & 8 & 7 & $75.6(R)$ \\
\hline 9 & 0.5 & 15 & $0,-$ & Aceton & 6 & 11 & 0 \\
\hline $10^{c}$ & 0.5 & 15 & $0,-$ & Aceton & 6 & 25 & 0 \\
\hline
\end{tabular}

a) Absolute Ausbeute ohne eingesetzten Produktkatalysator; b) Analyse durch chirale HPLC (Daicel Chiralpak AS); c) Tägliche Zugabe von 10\% der Edukt-Menge des Anfangs; d) Reduzierte ee-Werte

Die autokatalytische Amplifikation wurde ebenfalls mit der Aldol-Reaktion bewiesen (Tabelle 22), über die Mechanismen wurde keine Computer-Berechnung durchgeführt, aber man kann einen Übergangszustand vermuten, in dem eine Wasserstoffbrückenbildung eine hilfreiche Rolle spielt (Abb. 29). Trotz der geringen Menge der Tautomeren (3-a) des ProduktKatalysators 3 und der (1-a) des Acetons 1, können diese am Übergangszustand der Reaktion beteiligt sein (Abb. 29). Durch die Bildung der Wasserstoffbrückenbindung würde das Kohlenstoffatom am Aldehyd 2 elektrophiler, sodass der nucleophile Angriff durch Enol 1-a (Abb. 29) erleichtert wird. Ein Angriff von der $R e$-Seite führt zur $R$-Konfiguration des Produkts. Ein (hier nicht dargestellter) Angriff von der Si-Seite würde zum S-Produkt führen. 


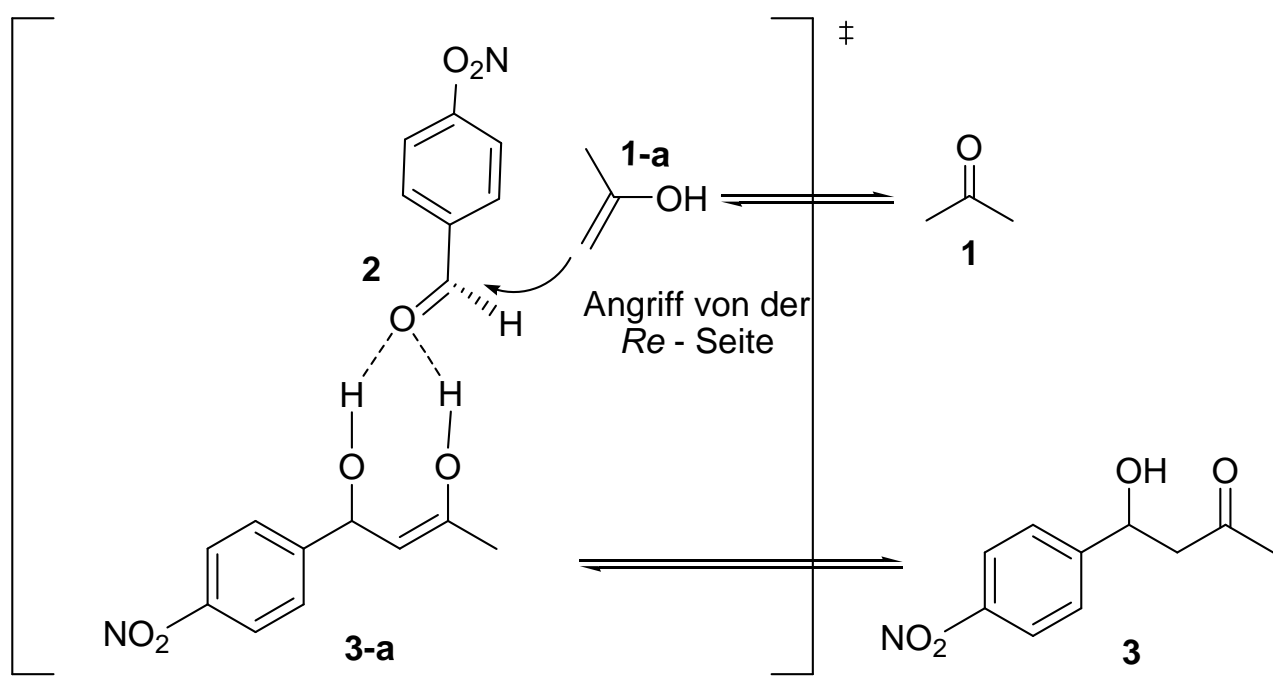

Abbildung 29. Vorgeschlagener Übergangszustand für die autokatalytische Aldol-Reaktion

6.3.2 Die asymmetrische Autokatalyse bei der Mannich und Aldol-Reaktion ohne Zusatz von Produkt-Initiator

Da in der Theorie eine „,spontane asymmetrische Synthese grundsätzlich möglich ist““ ${ }^{149}$ haben wir motiviert durch die Arbeit von Frank, die Mannich und Aldol-Reaktion auch ohne den Einsatz von Produkt-Katalysatoren mehrfach durchgeführt. In der Tabelle 23 sind die Ergebnisse der folgenden Mannich Reaktion zusammengestellt. 


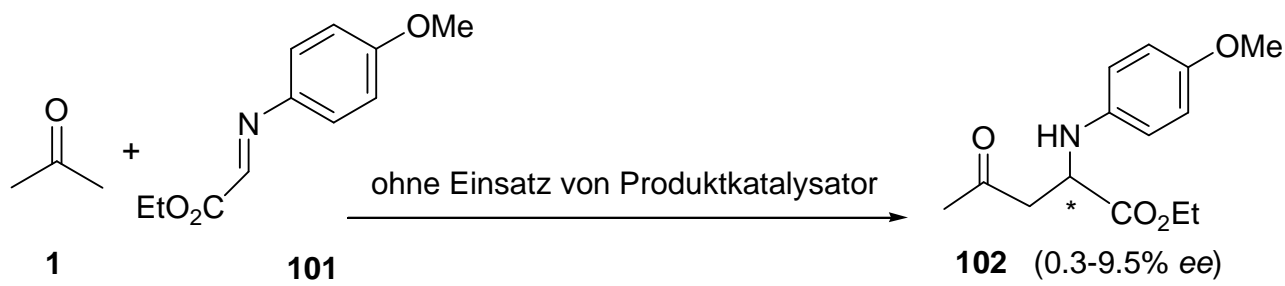

Tabelle 23 Ausbeute und Enantiomerenüberschuss bei der Mannich Reaktion ohne Einsatz von Produkt 102 als Katalysator

\begin{tabular}{|c|c|c|c|c|c|c|}
\hline Eintrag & $\begin{array}{c}\text { Temperatur } \\
\left({ }^{\circ} \mathrm{C}\right)\end{array}$ & Lösungsmittel & $\begin{array}{l}\text { Zeit } \\
\text { (Tag) }\end{array}$ & $\begin{array}{c}\text { Ausbeute } \\
(\%)\end{array}$ & $\begin{array}{c}e e(\%) \\
\text { (Konfig.) } \\
\text { (HPLC) }\end{array}$ & $\begin{array}{c}e e(\%) \\
(\mathrm{Konfig.}) \\
{\left[\mathrm{Eu}(\mathrm{tfc})_{3}\right](0.77 \mathrm{Ä} q)}\end{array}$ \\
\hline $1^{\mathrm{a}}$ & 25 & Aceton & 2 & 20 & $9.0(S)$ & - \\
\hline $2^{\mathrm{a}}$ & 25 & Aceton & 4 & 35 & $0.5(S)$ & - \\
\hline $3^{\mathrm{a}}$ & 25 & Aceton & 6 & 35 & $9.5(S)$ & - \\
\hline $4^{\mathrm{a}}$ & 25 & Aceton & 8 & 36 & $2.6(S)$ & - \\
\hline $5^{\mathrm{a}}$ & 25 & Aceton & 4 & 34 & $6.8(S)$ & - \\
\hline $6^{\mathrm{a}}$ & 25 & Aceton & 4 & 33 & $7.4(S)$ & - \\
\hline $7^{\mathrm{a}}$ & 25 & Aceton & 4 & 32 & $2.6(S)$ & - \\
\hline $8^{\mathrm{a}}$ & 25 & Aceton & 6 & 21 & $3.7(S)$ & \\
\hline $9^{a}$ & 25 & Aceton & 6 & 27 & $7.1(R)$ & \\
\hline $10^{\mathrm{a}}$ & 25 & Aceton & 6 & 20 & $5.6(S)$ & \\
\hline $11^{\mathrm{a}}$ & 25 & Aceton & 4 & 26 & $1.7(R)$ & \\
\hline $12^{\mathrm{a}}$ & 25 & Aceton & 4 & 32 & $2.6(S)$ & \\
\hline $13^{\mathrm{a}}$ & 25 & Aceton & 4 & 33 & $7.0(S)$ & \\
\hline $14^{\mathrm{a}}$ & 25 & Aceton & 4 & 34 & $4.6(S)$ & \\
\hline $15^{\mathrm{a}}$ & 0 & Aceton & 4 & 11 & $4.4(S)$ & - \\
\hline $16^{\mathrm{b}}$ & 0 & Aceton & 4 & 13 & $4.5(R)$ & - \\
\hline $17^{\mathrm{b}}$ & 40 & Aceton & 4 & 17 & $2.5(S)$ & - \\
\hline $18^{\mathrm{c}}$ & 40 & Aceton & 4 & 6 & $5.2(R)$ & - \\
\hline $19^{\mathrm{c}}$ & 40 & Aceton & 4 & 15 & $5.6(R)$ & - \\
\hline $20^{b}$ & 40 & DMSO & 4 & 17 & $0.3(S)$ & - \\
\hline $21^{\mathrm{a}}$ & 25 & DMSO & 19 & 16 & $2.4(S)$ & - \\
\hline $22^{\mathrm{a}}$ & 0 & Toluol & 10 & 15 & $0.3(R)$ & - \\
\hline $23^{\mathrm{a}, \mathrm{d}}$ & 25 & Aceton & 2 & 14 & $5.0(R)$ & - \\
\hline $24^{\mathrm{a}, \mathrm{d}}$ & 25 & Aceton & 4 & 17 & $3.9(R)$ & - \\
\hline $25^{\mathrm{a}, \mathrm{d}}$ & 0 & Aceton & 2 & 12 & $2.0(S)$ & - \\
\hline $26^{\mathrm{a}, \mathrm{d}}$ & -10 & Aceton & 2 & 8 & $3.5(S)$ & - \\
\hline $27^{\mathrm{b}, \mathrm{d}}$ & 25 & DMSO & 4 & 16 & $2.5(R)$ & - \\
\hline $28^{\mathrm{a}}$ & 25 & Aceton & 2 & 11 & $1.5(R)$ & $2.4(R)$ \\
\hline $29^{\mathrm{a}}$ & 25 & Aceton & 2 & 18 & $9.1(S)$ & $9.1(S)$ \\
\hline $30^{\mathrm{a}}$ & 25 & Aceton & 4 & 31 & $9.4(S)$ & $8.2(S)$ \\
\hline $31^{\mathrm{a}}$ & 25 & Aceton & 4 & 13 & $2.1(R)$ & $2.2(R)$ \\
\hline $32^{\mathrm{a}}$ & 25 & Aceton & 6 & 32 & $3.8(S)$ & $3.9(S)$ \\
\hline $33^{\mathrm{a}}$ & 25 & Aceton & 8 & 33 & $2.0(S)$ & $2.4(S)$ \\
\hline $34^{\mathrm{a}}$ & 0 & Aceton & 4 & 8 & $4.6(S)$ & $4.8(S)$ \\
\hline $35^{\mathrm{f}}$ & 25 & Aceton & 4 & 2 & $1.2(S)$ & - \\
\hline
\end{tabular}

a) Edukt Konzentration $0.25 \mathrm{Mol} / \mathrm{L}$; b) Edukt Konzentration $0.50 \mathrm{Mol} / \mathrm{L}$; c) Edukt Konzentration $50 \mathrm{Mol} / \mathrm{L}$; d) Racemisches Produkt 102 in 15Mol-\% als Initiator zugegeben, Ausbeute nach dem Auszug der Initiator-Menge; f) Edukt Konzentration $0.02 \mathrm{Mol} / \mathrm{L}$ 
Der scheinbare Widerspruch zur chemischen Intuition hat uns veranlasst, die MannichReaktion ohne chirale Additive unter absoluten achiralen Bedingungen mehrmals wiederholend durchzuführen (Einträge 1-22; 28-34 Tabelle 23). Überraschend ist, dass wir eine signifikante Enantiomerenüberschuss-Erhöhung von $0.3 \%$ (Einträge 20 und 22) bis zu 9.5\% (Eintrag 3) beobachten. Unter unterschiedlichen Bedingungen sowie verschiedenen Lösungsmitteln, Reaktionszeiten und Temperaturen und auch Edukt-Konzentration bildet sich das Produkt bei der Mannich-Reaktion nach 8 Tagen in mäßigen Ausbeuten bis zu 36\% (Eintrag 4, Tabelle 23). Die Bestimmung des Enantiomerenüberschusses haben wir in der ersten Phase nur durch HPLC gemessen (Einträge 1-27, Tabelle 23), dann haben wir noch einmal mit Hilfe der Komplexbildung von chiralen Produkten und Schiffschem Reagenz (Eu(tfc) $)_{3}$ ) (Europium (Ш)tris-[3-(trifluormethyl-hydroxymethylen)- $d$-camphorat]) (Abb. 30 a) mit ${ }^{1} \mathrm{H}-\mathrm{NMR}$ die $e e$-Werte bestätigt. Als Elektron-Akzeptor bildet $\left(\mathrm{Eu}(\mathrm{tfc})_{3}\right)$-Schiffsches-Reagenz mit dem chiralen Produkt 102 (Elektronen-Donor) einen Komplex so, dass die Chemische Verschiebung zweier Enantiomere des Produkts 102 im ${ }^{1} \mathrm{H}-\mathrm{NMR}$ vergrößert und differenziert werden kann (b. Abb. 31). Um den Enantiomerenüberschuss durch die passende Menge des Schiffschen Reagenzes genau zu bestätigen, wurden $\mathrm{Eu}(\mathrm{tfc})_{3}$ stufenweise von 0.2 über $0.3,0.4,0.5,0.6$ bis zu $0.7 \ddot{A q}$ (gegenüber Produkt) in $\mathrm{CDCl}_{3}$ gemischt und die ${ }^{1} \mathrm{H}-\mathrm{NMR}$ Verschiebung gemessen, anschließend entschieden wir uns, dass 0.77 Äq $\mathrm{Eu}(\mathrm{tfc})_{3}$ relativ zum Produkt die optimale Bedingung ist. In der Abb. 31 zeigt a das ${ }^{1} \mathrm{H}-\mathrm{NMR}$ Signal der Acetylgruppe einer ProduktMischug zweier Enantiomere ohne Zugabe von Schiffschem Reagenz, die laut HPLC-Analyse 42.61\% ee mit $R$-Konfiguration beträgt (c, Abb. 31).

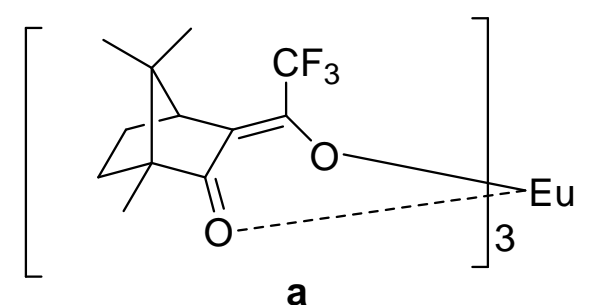

$\mathrm{Eu}(\mathrm{tfc})_{3}$

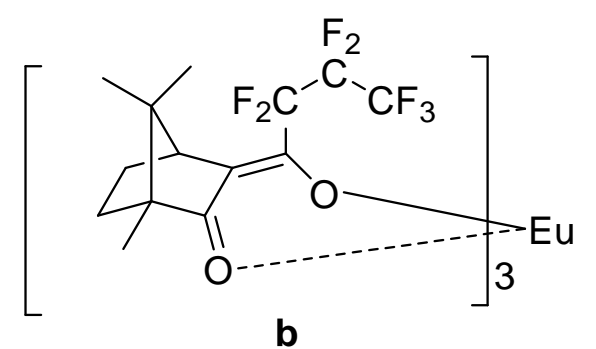

$\mathrm{Eu}(\mathrm{hfc})_{3}$

Abbildung 30. Für die Bestätigung des Enatiomerenüberschusses verwendeten zwei Schiffschen Basen 
während b in der Abb. 31 eine gute Aufspaltung (der Unterschied liegt bei $0.08 \mathrm{ppm}$ ) der chemischen Verschiebung von ${ }^{1} \mathrm{H}-\mathrm{NMR}$ zeigt, dass der Enantiomerenüberschuss nach der Integration einen ähnlichen Wert von $42.8 \%$ besitzt.
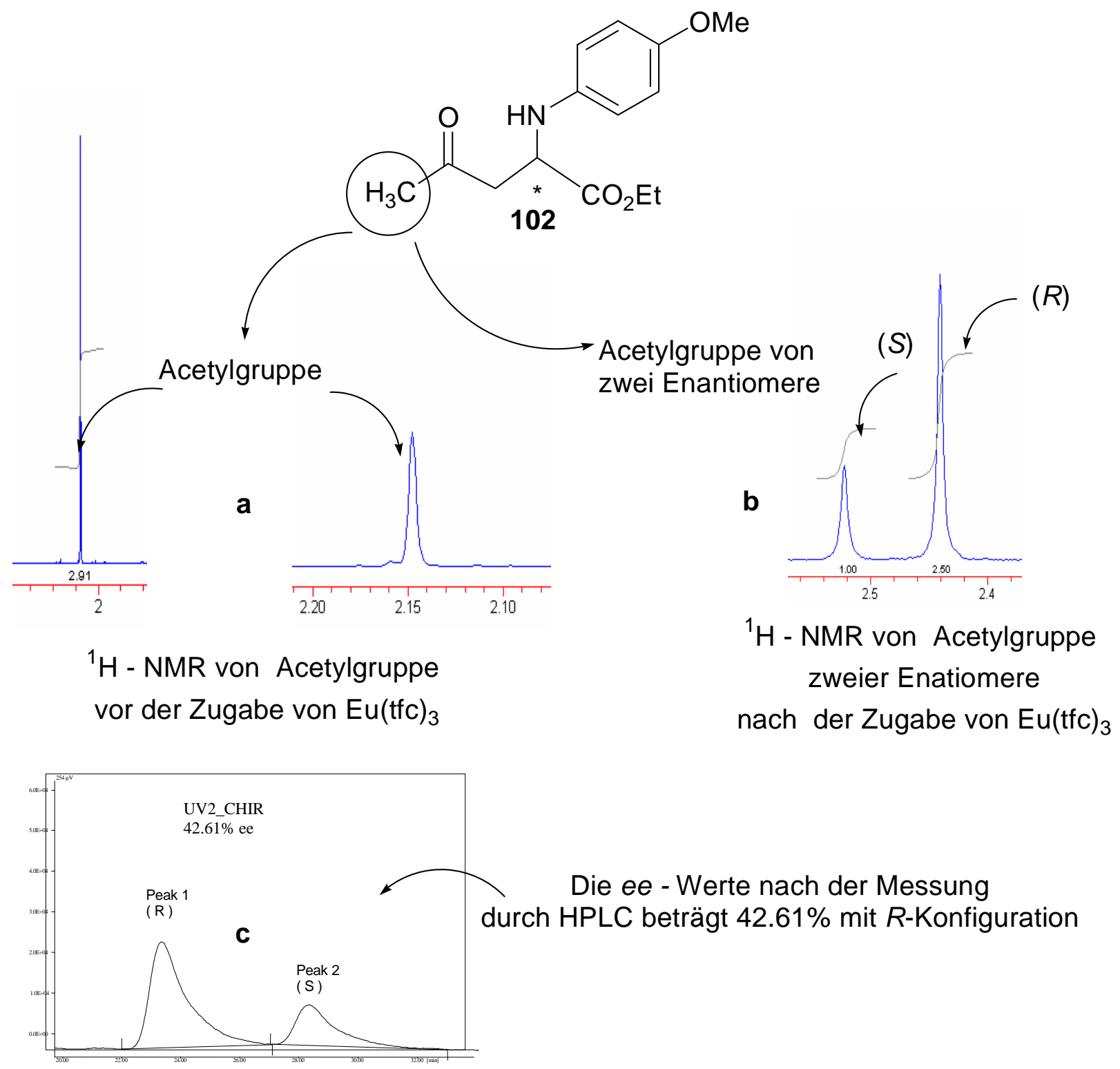

Abbildung 31. Bestätigung von Enantiomerenüberschuss des Produkts 102 durch HPLC und mit Hilfe von $\mathrm{Eu}(\mathrm{hfc})_{3}$

Als illustratives Anwendungsbeispiel (Produkt mit sehr kleinem ee-Werte) zeigt Abb. 32, dass die Aufspaltung der chemischen Verschiebung zweier Enantiomere mit Hilfe des Eu(hfc) $3^{-}$ Reagenzs (Europium (Ш)-tris-[3-(heptafluorpropyl-hydroxymethylen)- $d$-camphorat]) gut bis 0.18 (b, Abb. 32) erschaffen kann, sodass man sehr deutlich den Eantiomerenüberschuss von 
2.17\% berechnen kann, im Vergleich mit dem Eantiomerenüberschuss aus der HPLC-Messung (a, Abb. 32).

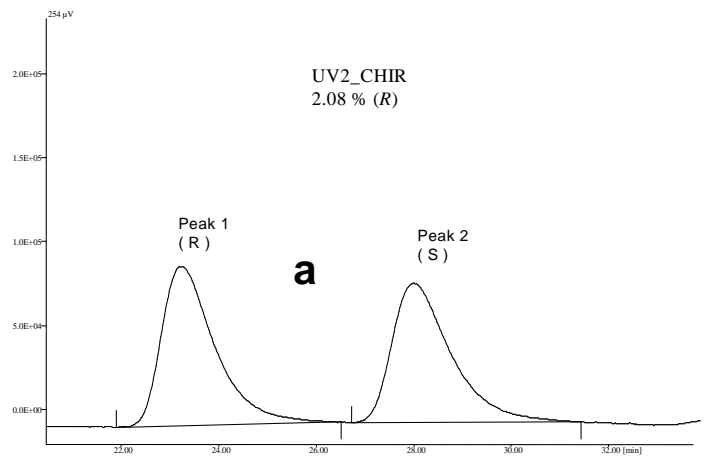

$e=2.08 \%(R)$ aus HPLC - Messung

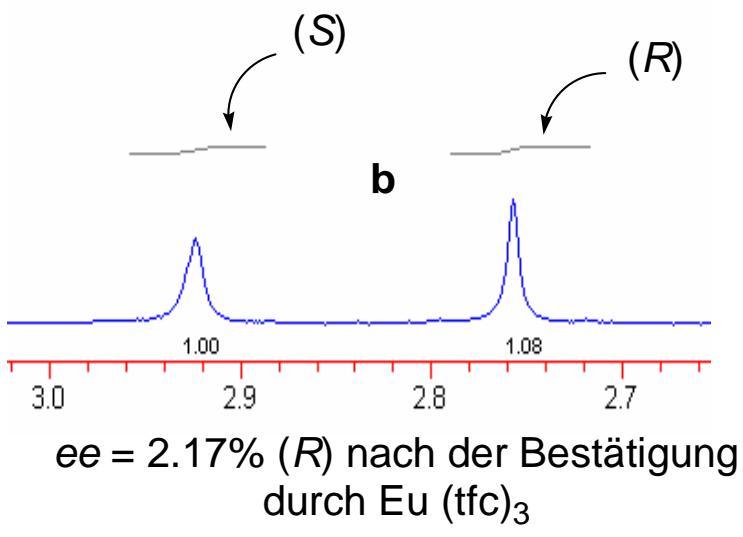

$(S)$

b

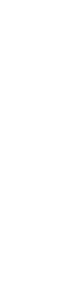

\begin{abstract}
Abbildung 32. Beispiel der Anwendung von $\mathrm{Eu}(\mathrm{tfc})_{3}$ bei Bestätigung von Enantiomerenüberschuss des Produkts 102
\end{abstract}

Die Ergebnisse der Einträge 28-34 in der Tabelle 23 wurden durch o.g. Methoden für die eeWerte nochmals bestätigt. Beide Methoden stimmen generell überein, damit werden unsere früheren Entdeckungen (Einträge 1-27) der spontanen asymmetrischen Synthese auch bekräftigt. Die $R$-Konfiguration ist im Vergleichen zu dem $S$-Enantiomer weniger häufig (11mal $R$, 24-mal $S$ ) vorgekommen. In manchen Fälle resultierte zwar $R$-Konfiguration, die Ausbeute war aber niedriger als bei den anderen Experimenten, bei denen $S$-Isomere gebildet wurden (vgl. Eintrag 1 mit 28; 6 mit 9 und 11 und 31, 17 mit 18, Tabelle 23).

Die Reaktion läuft in weniger polarem Lösungsmittel, beispielsweise Toluol, etwas langsamer $\mathrm{ab}$ und ergibt einen enttäuschenden Enantiomerüberschuss von nur $0.3 \%$ mit $R$-Konfiguration (Eintrag 22, Tabelle 23). Die Abhängigkeit der Enantiomerenüberschusses vom Wechsel der Lösungsmitteln und der Substanz-Konzentration ist ausgeprägter: beispielsweise mit gleicher Substanz-Konzentration (0.5 Mol/L) beim Eintrag 17: $17 \%$ Ausbeute und $2.5 \%$ ee $S$ Konfiguration in Aceton, während beim Eintrag 20: 17\% Ausbeute und 0.3\% ee ebenfalls mit $S$-Konfiguration in DMSO resultiert, während unterschiedliche Substanzkonzentration in gleichem Lösungsmittel (vgl. Eintrag 17: $2.5 \% e e$; Eintrag 18: 5.2\% ee) ergab. Aber die Ausbeute ist von der Substanz-Konzentration abhängiger als vom Wechsel des Lösungsmittels (vgl. Einträge 17 und 18; Einträge 19 und 20). Die Ausbeute bleibt ausnahmsweise fast konstant bei 30\%, nachdem die Reaktion bei Raumtemperatur in Aceton mehrere als 4 Tage 
gelaufen ist (Einträge 2-7; 30, 32 und 33), während die Ausbeute bei der Reaktion nach 2 Tagen signifikant niedriger ist (Eintrag 1, 28, und 29). Mit höherer Edukt-Konzentration in Aceton ergibt sich ein niedrigerer Enantiomerenüberschuss bei höherer Temperatur $40^{\circ} \mathrm{C}$ von 5.2\% und 5.6\% (Einträge 18 und 19). Im Gegensatz dazu wurden höhere ee-Werte von 9.1\% und 9.4\%, ebenfalls in Aceton aber bei Raumtemperatur und mit kleiner Edukt-Konzentration generiert (Einträge 29 und 30). Verringert man die Konzentration bis auf $0.02 \mathrm{Mol} / \mathrm{L}$, ergab sich ein schlechteres Ergebnis (Eintrag 35: 2\% Ausbeute und 1.2\% ee mit S-Konfiguration). Allgemein ist der Temperatur-Effekt nicht schlüssig: zwei Versuche bei erhöhter bzw. erniedrigter Temperatur resultieren in gleich schlechter Ausbeute (vgl. Einträge 10-14, 30 mit 15, 16, 22, 25, 26, 34, alle bei $0^{0} \mathrm{C}$ ) lieferte nicht mehr als $4.6 \%$ ee (Eintrag 34, Tabelle 23). Für Einträge 23-27 in der Tabelle 23 wurden razemische Produkte 102 als Initiatoren mit 15 Mol-\% in der Reaktion eingesetzt, viel niedrigere Ausbeute resultierte dabei in Aceton (Einträge 2326); auch im DMSO verhält es sich genauso (Eintrag 27). Der Enantiomerenüberschuss erstreckt sich von 2.5 bis 5\% (Einträge 27 und 23), das heißt, er ist nicht niedriger als bei den meisten Experimenten, bei denen kein Produkt-Initiator zugegeben wurde. Berechnen wir nun nur den neu gebildeten Enantiomerenüberschuss, das heißt, der Einfluss des zugegebenen racemischen Initiators wurde schon abgezogen. Der dabei der überraschend gebildete Enantiomerenüberschuss bedeutet, dass irgendein Teil der razemischen Mischung im Verlauf der Reaktion deracemisiert hat (Einträge 23-27, Tabelle 23). Dieser Effekt verdeutlicht, dass die Reversibilität bei der Reaktion wichtige ist. Die Zugabe des Produkt-Katalysators ganz am Anfang der Reaktion kann die Gleichgewichtsreaktion zugunsten der Edukte beeinflussen.

Mehrere erstaunliche Resultate, die bei der Mannich-Reaktion beobachtet wurden, wurden ebenfalls bei der Aldol-Reakton von 4-Nitrobenzaldehyd und Aceton mit Additiv von DMSO (0-20.8 Volume\%, Tabelle 24, mit Enantiomerenüberschusse von 2.1 bis zu 50.8\%) beobachtet. In reinem Aceton, wobei kein DMSO als Additiv verwendet wurde, wurde das prochirale Edukt p-Nitrobenzaldehyd bei der beschriebenen Konzentration (Tabelle 24) nicht völlig gelöst (Eintrag 1, 7, 10 und 11, Tabelle 24). Der beste Verlauf der Reaktion ist in dem homogenen System mit DMSO 5.1Volume\% als Additiv in Aceton. Nachdem die Reaktion unter dieser Bedingung 10 Tage gelaufen ist, bildet sich der Enantiomerenüberschuss von bis zu 50.8\% (Eintrag 12, Tabelle 24) mit $S$-Produkt, unter absoluten achiralen Bedingungen. So eine Sensation motiviert uns weiter zu untersuchen. Weitere Bestätigung haben wir durch Zugabe von $\mathrm{Eu}(\mathrm{hfc})_{3}$ Schiffsche Reagenz bei der NMR erhalten, dadurch wurden die ee-Werte zu 65.2\% durch Signalintegration bestimmt (Abb. 33, b). Um optimale Konzentrationsverhältnisse 
zwischen $\mathrm{Eu}(\mathrm{hfc})_{3}$ und Produkt-Proben festzulegen, wurde das Schiffsche Reagenz stufenweise relativ zum Produkt mit 0.1 über 0.2, 0.3, 0.6, 0.9, 1.1 Äq eingesetzt, anschließend wurde 1.1

Tabelle 24. Ausbeute und Enantiomerenüberschuss bei den Aldol-Reaktionen unter Bedingung ohne Einsatz von Produkt 3 als Katalysator

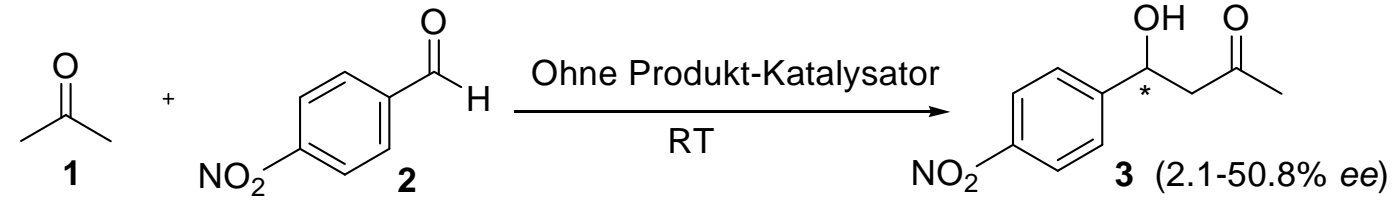

\begin{tabular}{|c|c|c|c|c|c|}
\hline Eintrag & $\begin{array}{c}\text { Edukt } \\
\text { Konzentration } \\
(\text { Mol./L) }\end{array}$ & $\begin{array}{c}\text { DMSO } \\
\text { Additiv } \\
\text { (Volumen \%) }\end{array}$ & $\begin{array}{c}\text { Ausbeute } \\
(\%)\end{array}$ & $\begin{array}{c}e e(\%) \\
\text { (Konfig.) } \\
\text { (HPLC) }\end{array}$ & $\begin{array}{c}e e(\%)^{\mathrm{d}} \\
(\text { Konfig. }) \\
{\left[\mathrm{Eu}(\mathrm{hfc})_{3}\right](1 \mathrm{Aq})}\end{array}$ \\
\hline $1^{b}$ & 0.5 & 0 & 1 & $2.1(R)$ & - \\
\hline $2^{a}$ & 0.5 & 0 & keine & - & - \\
\hline 3 & 3.86 & 15.4 & 10 & $3.6(S)$ & - \\
\hline 4 & 4.18 & 8.4 & 3 & $3.9(S)$ & - \\
\hline 5 & 5.20 & 20.8 & 10 & $5.1(S)$ & - \\
\hline 6 & 5.8 & 11.6 & 3 & $4.1(S)$ & $3.1(S)$ \\
\hline $7^{b}$ & 0.5 & 0 & 1.4 & $2.7(S)$ & - \\
\hline 8 & 3.84 & 15.3 & 11 & $3.4(S)$ & - \\
\hline 9 & 4.16 & 8.3 & 5 & $15.4(S)$ & - \\
\hline $10^{b}$ & 0.5 & 0 & 3 & $9.4(S)$ & - \\
\hline $11^{b}$ & 0.5 & 0 & 1 & $18.5(S)$ & - \\
\hline 12 & 1.28 & 5.1 & 10 & $50.8(S)$ & $65.2(S)$ \\
\hline 13 & 1.32 & 2.1 & 4 & $37.8(S)$ & $42.8(S)$ \\
\hline $14^{\mathrm{c}}$ & 1.28 & 5.2 & 2.5 & $26.9(S)$ & - \\
\hline 15 & 1.36 & 2.6 & 0.5 & $9.4(S)$ & - \\
\hline 16 & 0.67 & 1.3 & 1.0 & $13.1(S)$ & - \\
\hline 17 & 0.66 & 2.6 & 0.6 & $7.2(S)$ & - \\
\hline 18 & 1.28 & 5.1 & 5.7 & $8.7(R)$ & $8.3(R)$ \\
\hline
\end{tabular}

a) Toluol als Lösungsmittel, bei allen anderen Versuchen wurde Aceton als Lösungsmitteln genommen; b) Eine geringfügige beobachtete Trübung konnte dem Edukt-Niederschlag zugeschrieben werden; c) Optische Drehung des Produkts $[\alpha]_{\mathrm{D}}=-31.7^{\circ}\left(\mathrm{c}=0.06, \mathrm{CHCl}_{3}\right)$; d) Die Messung des Enantiomerenüberschusses wurde durch ${ }^{1} \mathrm{H}$ NMR in Anwesenheit von Eu(hfc $)_{3}$ angefertigt. 
a)

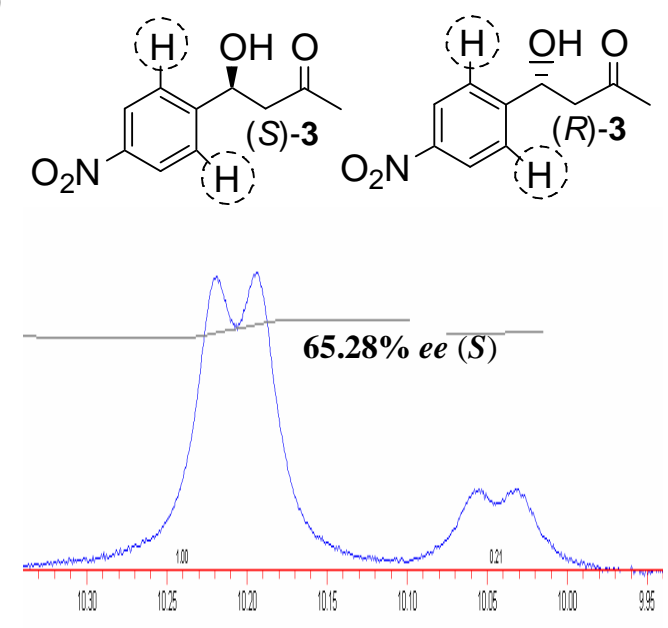

b)

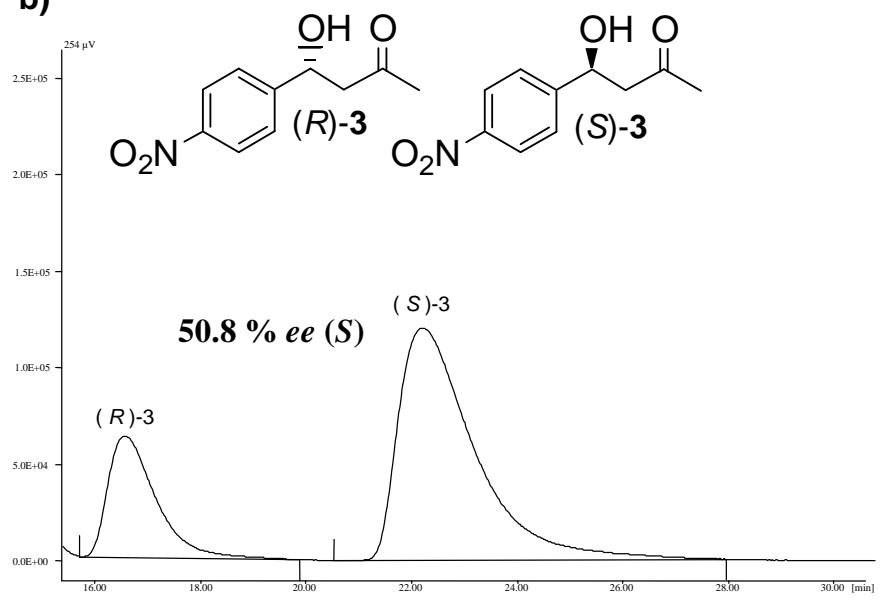

Abbildung 33. Bestätigung von Enantiomerenüberschuss durch HPLC und ${ }^{1} \mathrm{H}-\mathrm{NMR}$ mit Zugabe von $\mathrm{Eu}(\mathrm{hfc})_{3}$

Äq Eu(hfc) ${ }_{3}$ gegenüber dem Produkt für die weitere Bestätigung der Enantiomerenüberschüsse verwendet. Ein ähnliches Ergebnis mit $37.8 \%$ ee wurde durch eine kleine Zugabe von DMSO mit 2.1 Volumen\% reproduziert (Eintrag 13, Tabelle 24), welches wenigstens die bemerkenswerte Erzeugung und Verstärkung der Chiralität in einer vorher symmetrischen Umgebung bekräftigt. Keine Reaktion wurde in Toluol bemerkt (Eintrag 2). Die Ausbeute war im Ganzen niedriger und bewegte sich von 0.5-11\% (Tabelle 24). Die Messung des Enantiomerenüberschusses durch HPLC und NMR Methoden stimmten gut überein (z.B Einträge 6,12, 13 und 18, Tabelle 24). Es gibt nur ganz wenige Experimente, wobei sich das Produkt der Aldol-Reaktion mit $R$-Konfiguration bildet (Einträge. 1 und 18, Tabelle 24).

Während das Bestehen eines Symmetriebrechendes kinetischen Mechanismus für Mannich und Aldol-Reaktion kleine Ungleichheiten im Enantiomerenüberschuss verstärken, sind offensichtlich die genauen Resultate in Bezug auf die Produkt-Konzentration (d. h. $R$ oder $S$ ) verwirrend. Wäre die thermische Fluktuation beispielsweise die primäre Ursache für die kleine chirale Ungleichheit, muss man ein statistisches Resultat mit gleicher Wahrscheinlichkeit für Produkt annehmen. Während die Resultate bei der Mannich-Reaktion mit einer Präferenz für die $S$-Konfiguration des Produkts mehr oder weniger ausglichen sind (Tabelle 23), resultierte bei der Aldol-Reaktion die überwältigende Mehrheit Experimente in S-Produkt (Tabelle 24). Die Ursache kann auch im Reaktionssystem liegen, beispielsweise einer minimaler Verschmutzung mit chiralen Substanzen (entstehend z.B. aus Bakterien) in den ablaufenden 
Reaktionen, die unserer Analyse entgangen sind, oder sogar in physikalischen Einflüssen wie zirkular polarisiertem Licht, ${ }^{152}$ einer Verletzung der Parität in schwache nukleare Kräfte. ${ }^{174}$ Während die meisten Reaktionsmischungen als homogen erscheinen, treten manche, beispielsweise Einträge 1, 7, 10 und 11 in der Tabelle 24 als Suspension auf, wahrscheinlich vom ungelösten Edukt verursacht. Die Miteinbeziehung von fest-, flüssigem PhasenGleichgewicht und andere denkbare wie in Referen ${ }^{154}$ mitgeteilte thermodynamische Effekte können auch ausgeschlossen werden. Manche Reaktionen sind im Dunkel durchgeführt worden, sodass der mögliche Effekt durch zirkular polarisiertes Licht auch ausgeschlossen werden kann.

Theoretische Erklärungen für die biologische Homochiralität gründen sich auf zwei Annahmen: der Ursprung der Chiralität liegt vermutlich zunächst in der prochiralen biologischen Umgebung, und zweitens in seiner Amplifikation zur Enantiomerreinheit. ${ }^{175}$ Ein kinetischer Effekt kann hier lediglich für die asymmetrische Amplifikation als Begründung gelten. Unter achiralen Bedingungen vor allem in einem reversiblen System muss nach genügender Reaktionszeit ein razemisches Produkt gebildet werden. Ein abweichendes Ergebnis stünde im Widerspruch zum 2. Hauptsatz der Thermodynamik. Die organometallische und irreversible Soai Reaktion konnte kaum als „Beweis des Konzeptes“ für die mögliche Rolle der nicht linearen Kinetik in der Entstehung der biologischen Homochiralität der frühen Erde dienen. Mit von Kagans nicht linearem $\mathrm{ML}_{2}$ Modell abgeleiteter Katalysator-Aggregation. ${ }^{176,177}$ Blackmond und Brown erklären die Autokatalyse. ${ }^{178,179}$ Dabei sind nur die homochiralen Dimere, des sich mit dem Produkt bildende Zn-Alkoholat bei der Soai Reaktion katalytisch aktiv. Im Gegensatz hierzu setzt Franks Menchanismus ${ }^{149}$ Reversibilität voraus. In Übereinstimmung mit diesem Mechanismus haben wir durch ESI-MS, HPLC, ${ }^{1} \mathrm{H}-\mathrm{NMR}$ Analyse festgestellt, das Edukt sich aus Produkt-Mischungen bilden kann. 


\section{Synthese von Hybrid-Molekülen aus Naturstoffen}

\subsection{Naturstoffe spielen bei der Entwicklung neuer Wirkstoffe eine wichtige Rolle.}

Es ist eine Tatsache, dass der Mensch die Natur immer als Apotheke benutzt. ${ }^{180}$ Etwa $40 \%$ der Wirkstoffe, die in den letzten Jahren ihre Zulassung erhielten, sind entweder Naturstoffe oder Naturstoffderivate. ${ }^{181}$ In der Krebstherapeutik und als Heilmittel bei Infektion wird ihr Anteil sogar auf über $60 \%$ geschätzt, ${ }^{180}$ darunter sind so bekannte Verbindung wie beispielsweise Colchicin, Penicillin G und Erythromycin A (Abb. 34)<smiles>COc1cc2c(c(OC)c1OC)-c1ccc(OC)c(=O)cc1[C@@H](NC(C)(F)F)CC2</smiles>

Colchicin<smiles>CC1(C)S[C@@H]2C(C(=O)[C@H]2NC(=O)Cc2ccccc2)[C@H]1C(=O)O</smiles>

Penicillin G

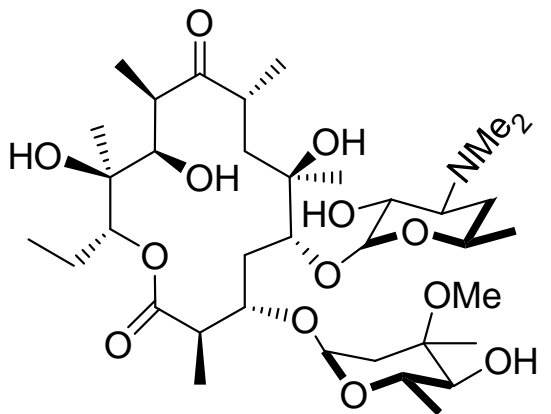

Erythromycin A

Abbildung 34. Beispiel von Naturstoffen, die in der Pharmazie verwendet werden

Colchicin sind in den Samen der Herbstzeitlosen (Colchicum autumale) enthalten. Diese Substanz ist ein so genannter Mitose-Hemmstoff, der die Ausbildung der Spindelfasern hemmt, indem er an freie Mikrotubuli-Untereinheiten bindet und diese nicht mehr für den Spindelfaseraufbau zur Verfügung stehen. ${ }^{182}$ Penicillin ist eines der ältesten Antibiotika und gehört zur Gruppe der $\beta$-Lactam-Antibiotika. Neben der Bakterien abtötenden Wirkung, ist es ein Gegenmittel bei Vergiftungen mit Amanitin, einem Gift der Knollenblätterpilze. ${ }^{180}$ Erythromycin ist ein Makrolid-Antibiotikum mit einem weiten Spektrum gegen grampositive Keime und anaerobe Organismen ${ }^{183}$ und ein Hemmstoff des Cytochroms CYP3A4. ${ }^{180}$ Dadurch wird die Biotransformation von Medikamenten, bei denen dieses Enzym beteiligt ist, z.B. Cyclosporin, Diazepam, Lidocain, Warfarin u. v. a., beeinträchtigt, was zur Wirkstoffakkumulation und zur Verstärkung von Haupt- und Nebenwirkungen führt. ${ }^{183}$ 
Das Wirkungsspektrum von Erythromycin ist mit dem Wirkungsspektrum von einigen Penicillinen vergleichbar, wodurch sich ähnliche Anwendungsgebiete ergeben. Daher kann Erythromycin eingesetzt werden, wenn Allergien gegen $\beta$-Lactam-Antibiotika bestehen oder wenn Resistenzen deren Anwendung verhindern.

Organtransplantationen wären ohne FK-506 oder Rapamycin undenkbar (Abb. 35). Nicht nur die Pharmazie profitiert von Naturstoffen und deren Analoga, sondern auch der moderne Pflanzenschutz. ${ }^{184}$ So spielen diese auch eine wichtige Rolle als hochwirksame Insektizide, beispielsweise Pyretherin oder Fungizide wie Strobilurin A (Abb. 35)

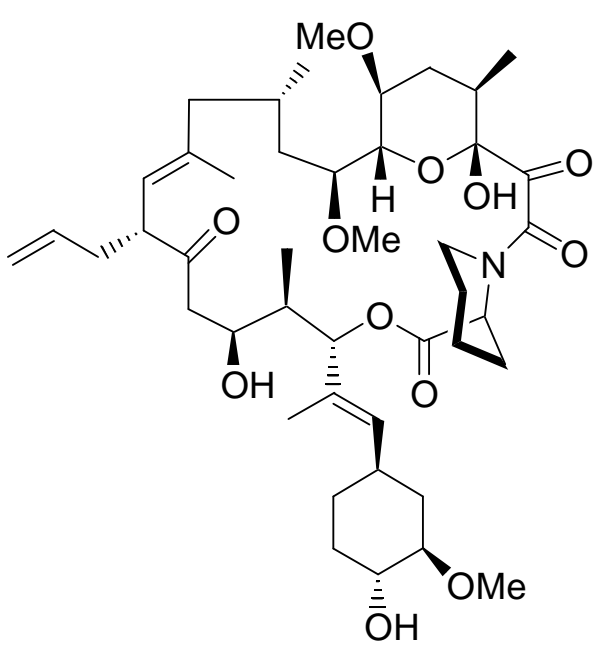

FK-506

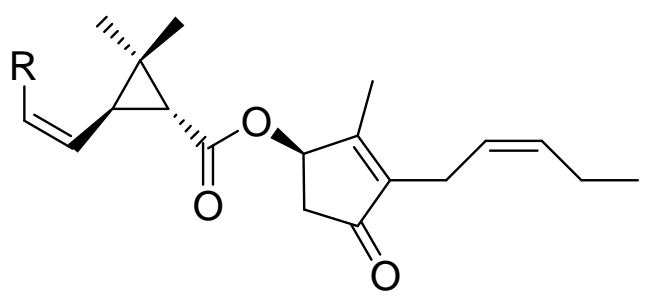

Pyretherin

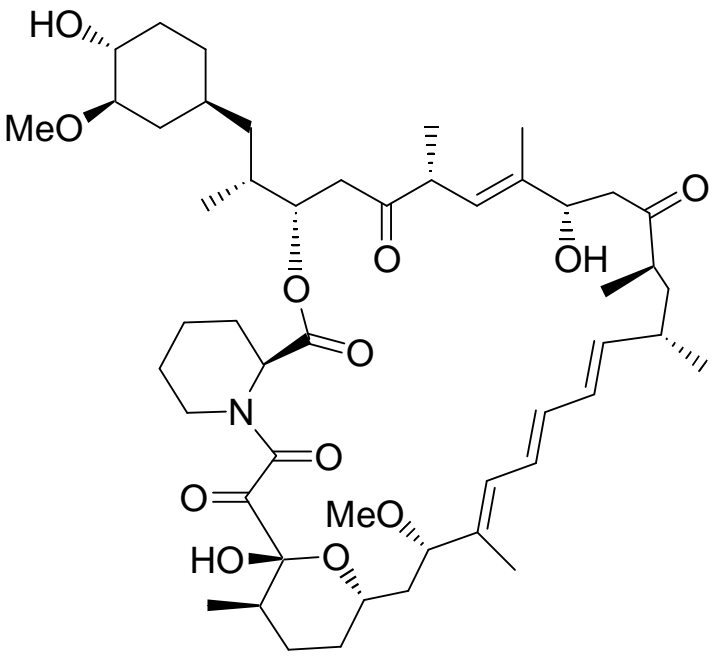

Rapamycin

Strobilurin A

Abbildung 35. Beispiel von Naturstoffen, die bei Organtransplantationen und im modernen Pflanzenschutz eingesetzt werden

Die Synthese von Millionen neuer Verbindungen wird durch die moderne kombinatorische Chemie $^{185}$ in relativ kurzen Zeiträumen erlaubt. Die biologische Aktivität derartiger Substanzen 
lässt sich durch Hochdurchsatz-Screening-Techniken auswerten. ${ }^{186}$ In der kombinatorischen Synthese wurde auch erstmals von der Diversität der Natur profitiert und zwei oder mehr Naturstoffe miteinander zu einem Hybrid kombiniert.

Es stellt sich natürlich die Frage, ob die Naturstoff-Hybride biologisch aktiv sein kann. Mehrere solche Substanzen zeigen, dass sie sogar aktiver als ihre Mutterverbindungen sind. Beispielsweise ist das das Indol-Alkaloid Vincristin (Abb. 36) ein natürlich vorkommender Naturstoffhybrid, der aus Vindolin aufgebaut wird (einem Alkaloid der AspidospermaUntergruppe). ${ }^{181}$ Vincristin ist ein Zytostatikum, das als Mitose-Hemmer in der Chemotherapie zur Behandlung von Krebs eingesetzt wird. Mithilfe dieses Naturstoffhybrids wird die Überlebenschance von Kindern, die an lymphatischer Leukämie erkrankt sind, deutlich verbessert. Im Vergleich zu früher kann diese tödliche Krankheit durch Vincristin mit einer Erfolgsquote von über $60 \%$ geheilt werden.

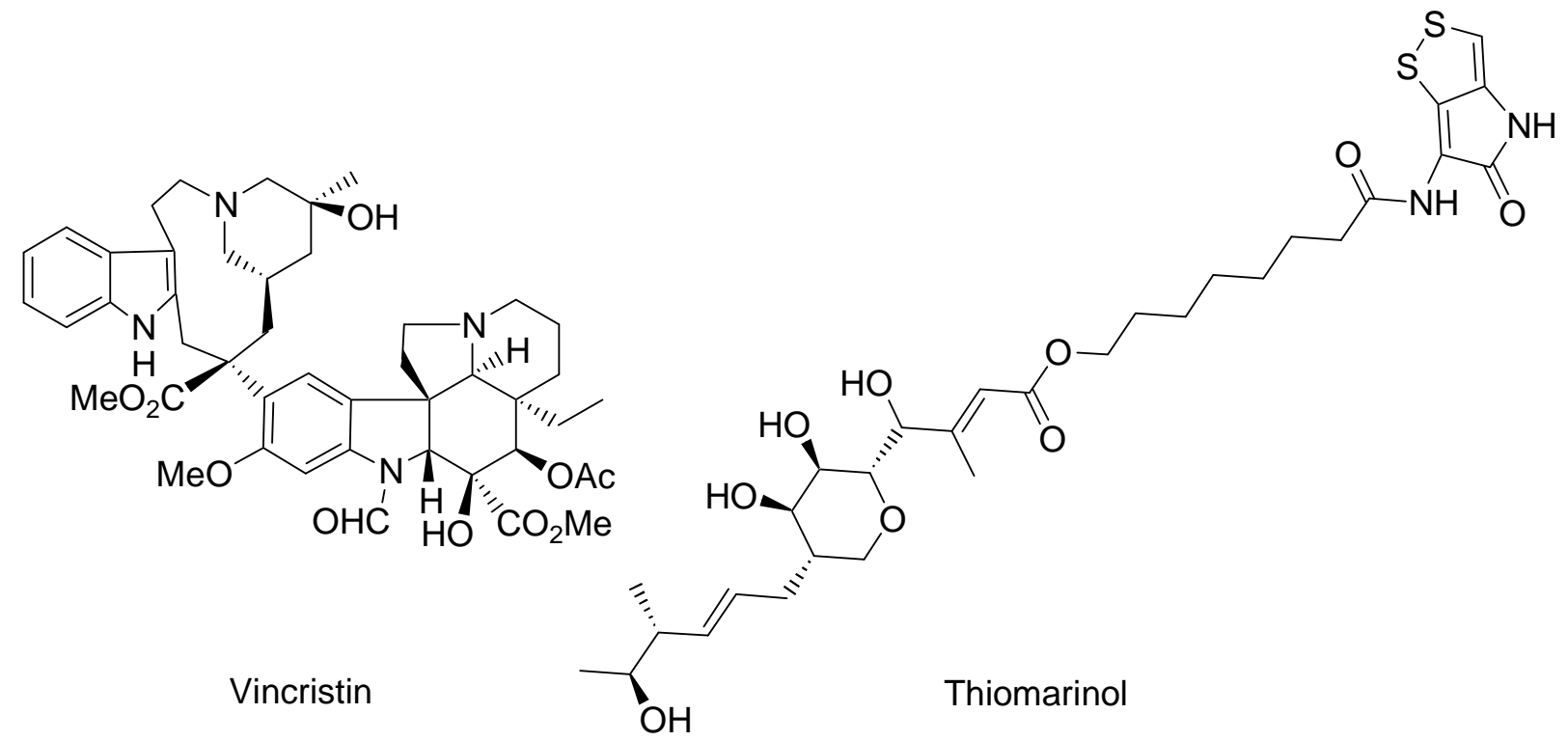<smiles>[R2]C(=O)/C=C(\C)[C@@H]([R1])[C@H]1OC[C@H](C/C=C/[C@@H](C)[C@H](C)O)[C@@H](O)[C@H]1O</smiles><smiles>O=C(CCCCCCCO)Nc1c2sscc-2[nH]c1=O</smiles>

c1:Pseudomonsäure C

$\mathrm{R}_{1}=\left(\mathrm{CH}_{2}\right)_{8} \mathrm{COOH}, \mathrm{R}_{2}=\mathrm{H}$

Holothin

$\mathrm{C}_{2}: \mathrm{R}_{1}=\mathrm{H}, \mathrm{R}_{2}=\mathrm{OH}$

Abbildung 36. Beispiel von natürlich vorkommenden Naturstoffhybriden und ihrer Mutterverbindungen 
Thiomarinol in der Abb. 36 ist ebenfalls ein natürlich vorkommendes Hybrid von Naturstoffen. Es ist ein wirksames Antibiotikum, das aus dem marinen Bakterium Alteromonas rava sp. Nov. SANK 73390 isoliert wurde. ${ }^{187}$ Die Struktur von Thiomarinol ist ein Hybride aus einem Pseudomonsäure-C-Analogon (c2, Abb. 36) und Holothin (Abb. 36). ${ }^{188}$ Entscheidend ist, dass die antibiotische Wirksamkeit gegen Gram-positive und Gram-negative Organismen von Thiomarinol stärker ist als die von pseudomonischen Säuren, bzw. von Pyrroithin Antibiotika.

Realativ neue Naturstoffdimere sind die Naphthylisochinolin-Alkaloide Michell-amin A und B sowie Korundamin A (Abb. 37). ${ }^{189}$

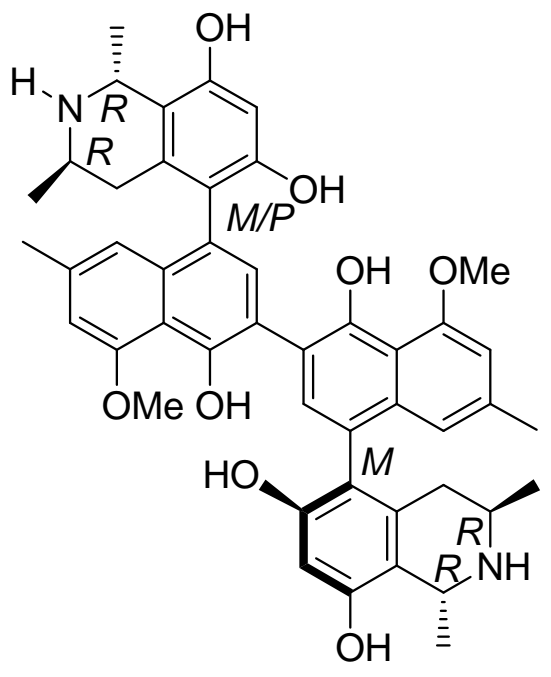

$(-)$-Michellamin A $(M, M)$

$(-)$-Michellamin $\mathrm{B}(M, P)$<smiles>COc1cc(C)cc2c(-c3c(O)cc(O)c4c3C[C@H](C)N[C@@H]4C)ccc(O)c12</smiles>

Korupensamin A<smiles>COc1c2c(cc(O)c1-c1cc(-c3cc(-c4c(O)cc(O)c5c4C[C@H](C)N[C@H]5C)c4cc(C)cc(OC)c4c3OC)c3cc(C)cc(OC)c3c1O)C[C@@H](C)N=C2C</smiles>

Korundamin A<smiles>COc1cc(C)cc2c(-c3c(O)cc4nc(C)nc(C)c4c3OC)cccc12</smiles>

Yaoundamin A

Abbildung 37. Die relativ neue auftretende Naturstoffdimere und ihre Mutterverbindung 
Michellamin A und B sind eigentlich Homodimere des Alkaloids Korupensamin A, der Unterschied ist die unterschiedliche Konfiguration aufgrund einer stereogenen Achse. Im Gegensatz dazu ist Korundamin A das Heterodimer aus Korupensamin A und Yaoundamin A (Abb. 37).

Es wurde bereits bestätigt, dass diese beiden Naphthylisochinolin-Alkaloid-Dimere, Michellamin B und Korundamin A, stärkere Anti-HIV-Aktivität mit EC $_{50}$-Werten von $2 \mu \mathrm{M}$ als die Monomere haben. Es ist auch eine Tatsache, dass Korundamin A in vitro einen $\mathrm{IC}_{50}$-Wert von $1.1 \mu_{\mathrm{gmL}^{-1}}$ gegen den Malariaerreger Plasmodia falciparum aufweist. ${ }^{181}$

\subsection{Ziel der Arbeit}

Eine Vielzahl von exzellenten Literaturstellen zeigte übersichtlich, dass einige der neuen Naturstoffhybride, die entweder biologisch oder chemisch synthetisiert wurden, vielversprechende Aktivitäten aufweisen, die häufig die der Stammverbindungen übersteigen. ${ }^{190}$

Neue biologisch aktivere Verbindungen zu entwickeln ist besonders wichtig im Kampf gegen Krankheiten. Eine neue Strategie für die Wirkstoff-Entdeckung ist die Synthese von Naturstoffhybriden aus der nahezu unbegrenzten Zahl von Naturstoffen.

Betulin 103 (Abb. 38), (3a-Hydroxylmethyl-1-isopropenyl-5a, 5b, 5b, 8, 8, 11a-pentamethylicosahydro-cycleopenta[a] chrysen-9-ol), ist ein reichlich vorhandenes, natürlich vorkommendes Triterpen. Es kommt in der Birke in bis $\mathrm{zu} 30 \%$ des Trockengewichts vor. ${ }^{191}$ Die Wirksamkeit gegen Viren von Betulin beim Herpes-Simplex-Virus Typ 1 (HSV-1) und Art 2 (HSV-2) wurden mit Virenplakette ausgewertet. Die Resultate zeigen an, dass Betulin gegen Infektionen mit HSV-1 und HSV-2 mit EC50-Werten von 0.4 bzw. $4.15 \mu \mathrm{g} / \mathrm{mL}$ wirksam ist. ${ }^{189}$

Ein synergetischer Antivireneffekt zwischen Betulin und Acyclovir (ACV) wurde durch Drogekombination Studien festgestellt. Starke und gemäßigte synergetische antivirale Effekte wurden für Betulin und ACV gegen HSV-1, als die Konzentration von ACV und von Betulin höher als 0.068 und $0.4 \mu \mathrm{g} / \mathrm{mL}$ waren, beobachtet. Synergetische antivirale Effekte wurden auch gegen HSV-2 bei höheren Konzentrationen als HSV-1, nämlich $0.45 \mathrm{microg} / \mathrm{mL}$ von ACV gefunden, das mit $8.4 \mu \mathrm{g} / \mathrm{mL}$ von Betulin kombiniert wurde. ${ }^{192}$ 


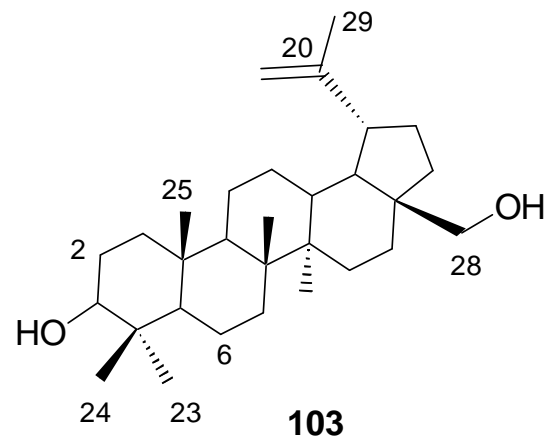

Betulin

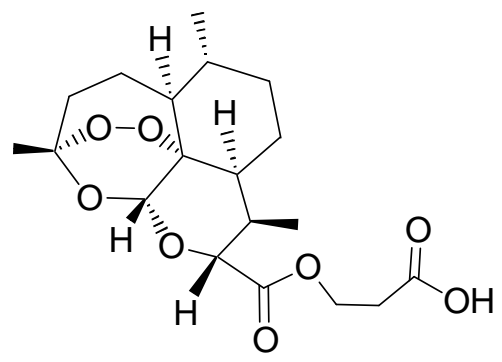

104

Artesunat

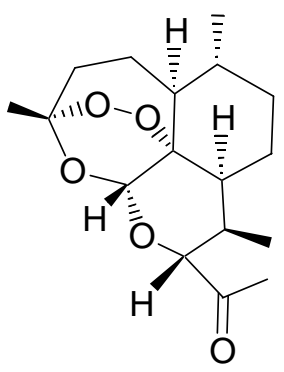

104 a

Artemisinin

Abbildung 38. Beispiele von Naturstoffen und deren Derivate

Artemisinin (104 a, Abb. 38) ist ein sekundärer Pflanzenstoff, chemisch gesehen ein Sesquiterpen, das in den Blättern und Blüten des Einjährigen Beifußes (Artemisia annuna) vorkommt. Charakteristika der Artemisininstruktur sind ein Trioxanringsystem und eine Peroxidbrücke. Es wurde zur Behandlung von Infektionen mit multiresistenten Stämmen von Plasmodium falciparum, dem Erreger der Malaria tropica, eingesetzt. ${ }^{193}$ Aufgrund der Peroxidstruktur ist Artemisinin in Gegenwart hoher Konzentratione von Eisenionen instabil und bildet ein freies Radikal. Solche hohen Konzentrationen werden in Erythrozyten, aber auch in Plasmodien gefunden, die Eisen akkumulieren. Gelangt Artemisinin in mit Plasmodien infizierte Erythrozyten, werden freie Radikale gebildet, und der Parasit wird möglicherweise da-durch getötet.

Artesunat $((3 R, 5 \mathrm{a} S, 6 R, 8 \mathrm{a} S, 9 R, 10 S, 12 R, 12 \mathrm{a} R)$-Decahydro-3,6,9-trimethyl-3,12-epoxy-12Hpy-rano[4,3-j]1,2-benzodioxepisuccinat) (104, Abb. 38) ist ein von Artemisinin partialsynthetisch abgeleitetes Derivat. ${ }^{194}$ Es ist ein leicht und billig zu synthetisierendes Peroxid. Eine Untersuchung ergab, dass das Artemisinin-Derivat Artesunat in Kombination mit anderen Malaria-Medikamenten hoch wirksam ist. ${ }^{195}$ Die Kombination von Artesunat mit Mefloquin hat zu einer anhaltenden Heilungsrate von Malaria mit über 95\% Erfolgsquote geführt. Außerdem wurden ein Vermindung der Plasmodim falciparum Transmission und eine Rückkehr der In-vitro-Sensitivität der Parasiten gegenüber Mefloquin beobachtet. ${ }^{194}$ 
In einer anderen Studie, in der Kinder unter fünf Jahren in Afrika untersucht wurden, wurde die Kombination von Artesunat und Sulfadoxin/Pyrimethamin mit Sulfadoxin/Pyrimethamin allein verglichen. Die Kombination zeigte signifikant bessere Ergebnisse in Bezug auf die Entwicklung von Symptomen, Parasitenreduzierung und Gametozytenträgerrate. ${ }^{196}$

Diese Studien zeigen, dass die Kombination von Artesunat mit einem anderen Medikament vielversprechende Ergebnisse aufzeigen kann. Weitere Studien mit anderen Medikamenten in Kombination mit Artesunat müssen auf ihre Wirksamkeit und Verträglichkeit untersucht werden.

Unser Ziel ist es, eine weitere Kombination von Artesunat und Betulin zu entwickeln und möglicherweise klinisch zu testen.

\subsection{Darstellung von verschiedener Hybride aus Betulin und Artesunat.}

\subsubsection{Synthese des Artesunat-Betulin-28-Acetat-Hybrids $\mathbf{1 0 6}$}

Um die Verbindung $\mathbf{1 0 6}$ erfolgreich darzustellen, ist die Synthese der Verbindung $\mathbf{1 0 5}$ aus der Ausgangssubstanz Betulin (103 Schema 67) notwendig. Eine selektive Veresterung wird im letzten Schritt der Syntheseroute benötigt, um die Hydroxygruppe des primären Alkohols von Betulin zu schützen, wobei Imidazol als Aktivierungsreagenz bei der nucleophilen Addition von Betulin an Acetanhydrid verwendet wurde. ${ }^{197}$ Die Reaktionsmischung wurde in trockenem $\mathrm{CHCl}_{3}$ unter Rückfluss 2 Stunden gerührt. Nach wässriger Aufarbeitung und säulenchromatographischer Reinigung konnte die gewünschte Verbindung $\mathbf{1 0 4}$ in $70 \%$ Ausbeute isoliert werden. Eine zweifache Acetylierung und auch andere Nebenprodukte waren bei der Synthese nicht vermeidbar, vermutlich fand eine intermolekulare Verknüpfung des Betulin ebenfalls statt. Als Anfärbungsmittel für die DC-Kontrolle wurde Anisaldehyd verwendet. Die nun folgende Veresterung von Verbindung 104 mit 105 wurde durch die klassische Methode ${ }^{198}$ mit Aktivierungsmittel DCC und Katalysator DMAP in trockenem $\mathrm{CH}_{2} \mathrm{Cl}_{2}$ durchgeführt. Verbindung 104 wurde allerdings durch DCC und DMAP zunächst aktiviert dann gab man Betulin-Acetat (105) zu. Nachdem 4 Stunden bei RT gerührt wurde, wurde laut DC die Reaktionsmischung aufgearbeitet. Nach der säulenchromatographischen Reinigung an normalem Kieselgel und danach an Sephadex-Gel wurde die gewünschte Verbindung 106 in $45 \%$ Ausbeute als weißer Feststoff erhalten. 


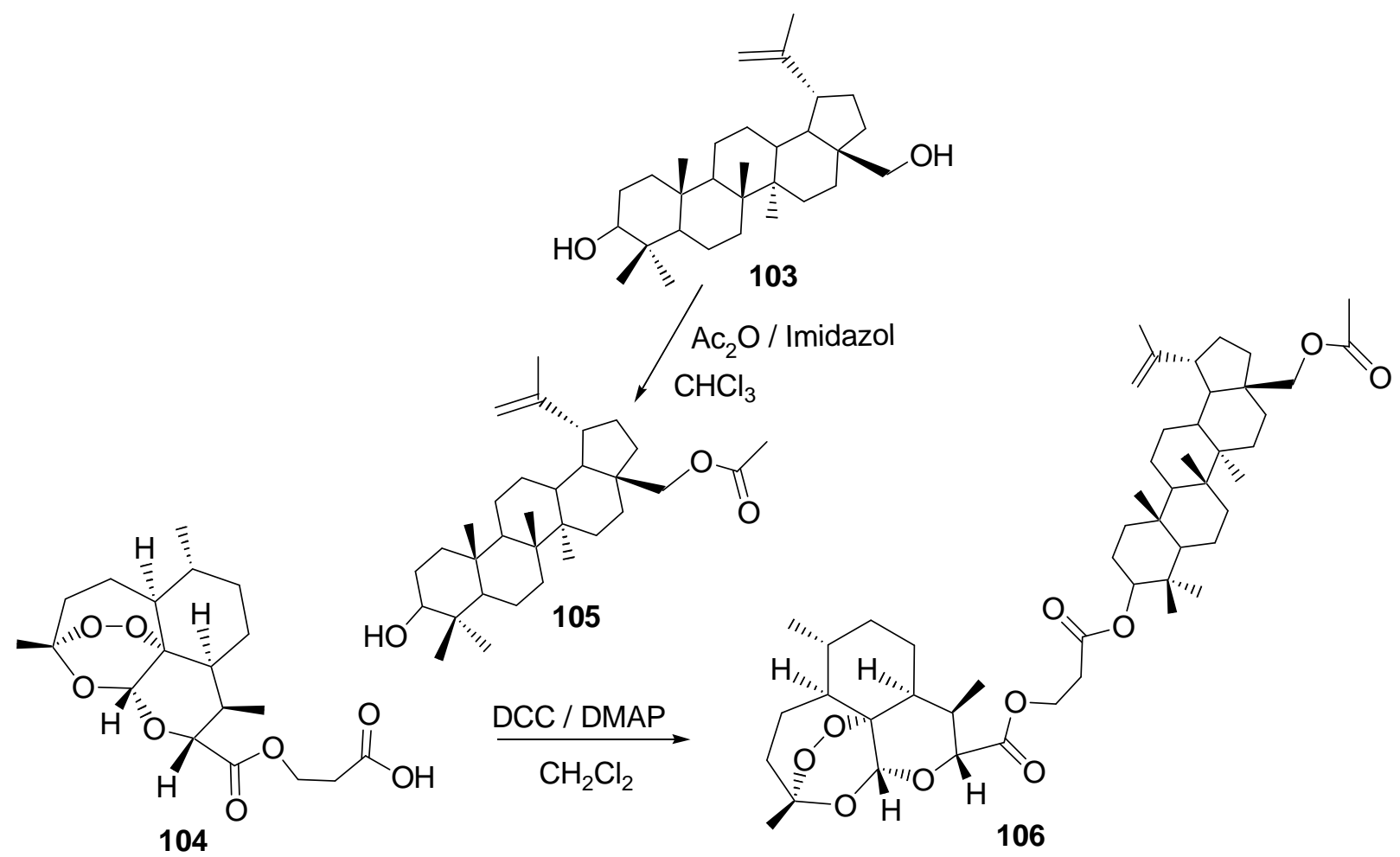

Schema 67. Darstellung der Hybride 106

\subsubsection{Synthese des Betulin-28-Artesunat-Hybrids $\mathbf{1 0 7}$}

Eine weitere Synthese wurde so durchgeführt (Schema 68), dass Betulin mit seinen beiden freien Hydroxygruppen mit Artesunat im Verhältnis 1:1 als Reaktionspartner in trockenem Dichlormethan zur Reaktion gebracht wurde. Man aktivierte Artesunat 104 durch DCC und DMAP, dann gab man Betulin zu, nach 3 Tagen wurde die Reaktionsmischung wässrig aufgearbeitet und chromatographisch an Kieselgel und Sephadex-Gel zwei Mal gereinigt, eine Betulin-28-Artesunat Kombination wurde als Titelverbindung erhalten (nur in 30\% Ausbeute). 


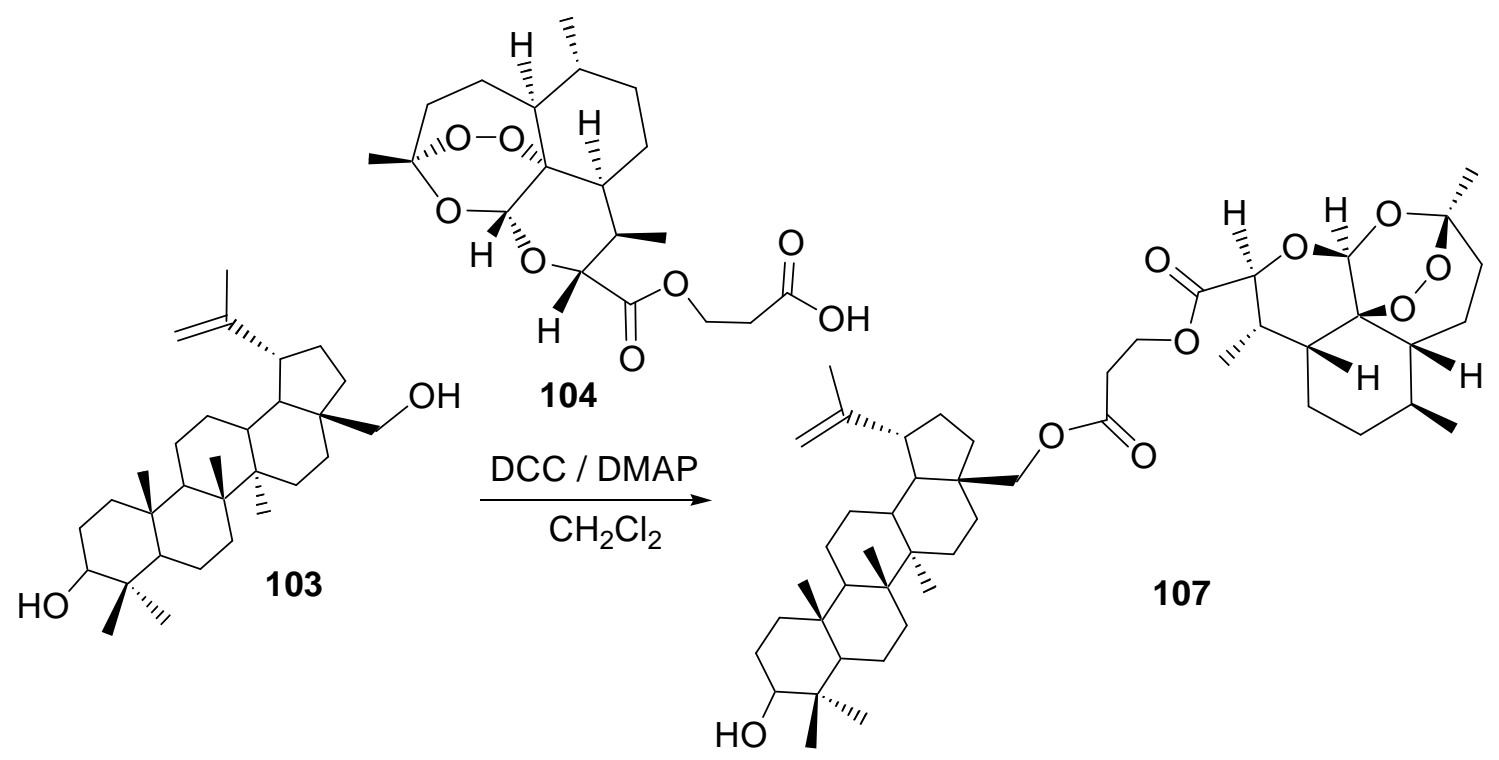

Schema 68. Darstellung der Verbindung 107

\subsubsection{Synthese des Artesunat-2-Betulin-28-Artesunat-Hybrids $\mathbf{1 0 8}$}

Verbindung 108 als Trimer wurde ebenfalls nach literaturbekannter Methode dargestellt (Schema 69). Man gab EDCl und DMAP als Aktivierungsmittel unter Stickstoff bei $0^{\circ} \mathrm{C} z u$

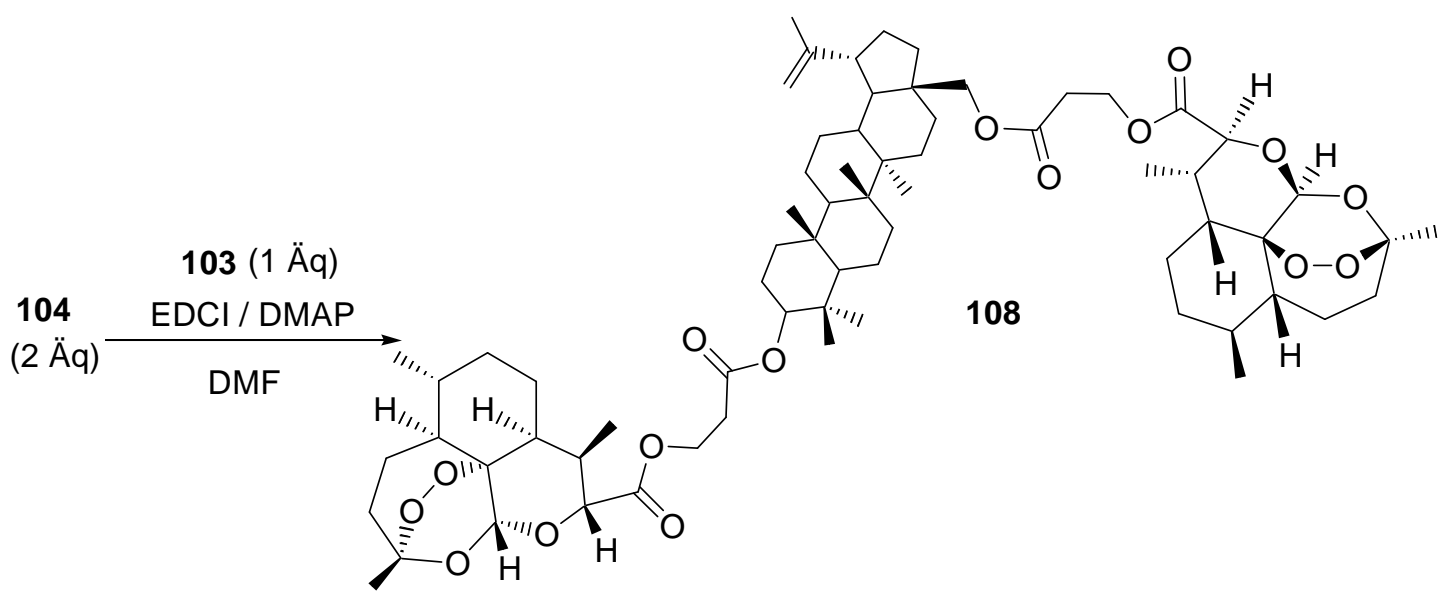

Schema 69. Darstellung der Verbindung 108 
einer Lösung von Artesunat in DMF, nach einer halben Stunde wurde Betulin zugegeben. Nach 5 Stunden wurde die Reaktionsmischung durch wässrige Säure neutralisiert und chromatographisch an Kieselgel und Sephadex-Gel gereinigt, die Titelverbindung wurde in nur $40 \%$ isoliert, eine Kombination von Artesunat und Betulin als Dimer war ebenfalls verwirklicht.

\subsubsection{Darstellung des Artesunat-cyclohexyl-Artesunat-Hybrids 109}

Eine weitere Verbindung 109 wurde so geplant, dass Zwei Artesunat Moleküle durch S,SDiaminocyclohexan als Dimer verknüpft werden sollen (Schema 70). Bei dieser Peptidsynthese wurde eine literaturbekannte Methode verwendet. ${ }^{199}$ Artesunat (2 Äq) wurde durch DCC aktiviert und mithilfe von DMAP doppelt an Diaminocyclohexan gekoppelt, nach der Filtration von Harnstoff wurde die Reaktionsmischung durch wässrige Säure neutralisiert und chromatographisch an Sephadex-Gel gereinigt. Die Titelverbindung wurde nur $\mathrm{zu} 40 \%$ isoliert, die einfache Verknüpfung von Artesunat an Diaminocycleohexan war Nebenprodukt.
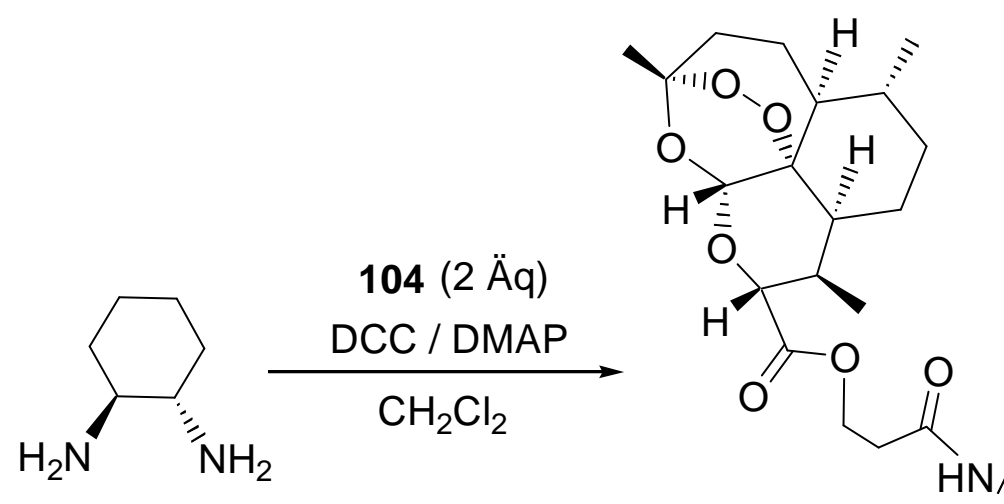<smiles>CNC(=O)CCOC(=O)C(C)(C)[C@H](C)[C@]12CCCCC1C2</smiles>

Schema 70. Darstellung der Verbindung 109 


\subsubsection{Darstellung des Betulin-Dimer-Hybrids 112}

Die Verbindung 111 als benötigtes Edukt für die Synthese der Verbindung 112 wurde zunächst nach einer Patent-Methode ${ }^{200}$ dargestellt, die Hydroxylgruppen der Verbindung 110 wurden durch Triethylamin deprotoniert und durch die Ms-Gruppe geschützt. Betulin (103) wurde in 2 Äq gegenüber der Verbindung 111 in trockenem THF durch die starke Base NaH unter

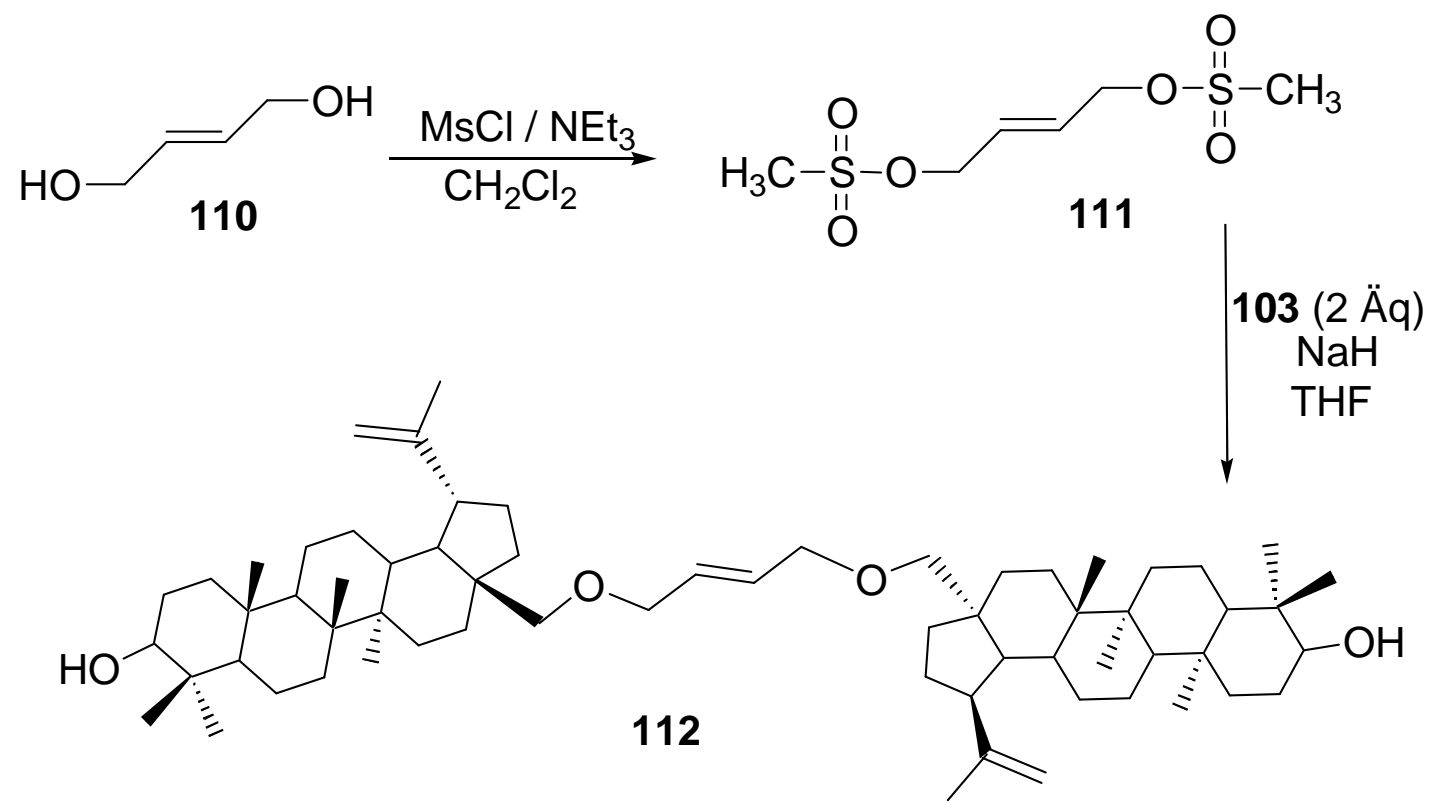

Schema 71. Darstellung der Verbindung 112

Stickstoffatmosphäre deprotoniert, wodurch die zweifache nucleophile Substitution an Verbindung 111 ermöglicht wurde. Nach einer halben Stunde wurde Betulin zugegeben, nach 2 Tagen wurde die Reaktionsmischung durch wässrige Säure neutralisiert und chromatographisch an Kieselgel und Sephadex-Gel gereinigt, die Titelverbindung wurde nur $40 \%$ erhalten. eine einfache nucleophile Substitution an $\mathbf{1 1 1}$ liefert ein Nenbenprodukt. 


\subsubsection{Darstellung des Artesunat-Propyl-Artesunat-Hybrids 114}

Um die Verknüpfung zwischen 104 und 113 zu erreichen, wurde Artesunat erstmal durch Pentafluorphenol bei $-25^{\circ} \mathrm{C}$ mithilfe von DCC in trockenem Ethylacetat aktiviert, das Produkt wurde in guter Ausbeute von $90 \%$ isoliert.

Eine weitere Verknüpfung von 113 (2 Äq) und Diamin 116 (1 ̈̈q) wurde in DMF durchgeführt. Die Mischung wurde unter Stickstoffatmosphäre bei RT 2 Stunden gerührt. Die Reinigung wurde chromatographisch an Kieselgel und Sephadex-Gel angefertigt, die Titelverbindung wurde aber nur in $20 \%$ erhalten, eine einseitige Kombination von Artesunat mit 116 war ein Nebenprodukt.

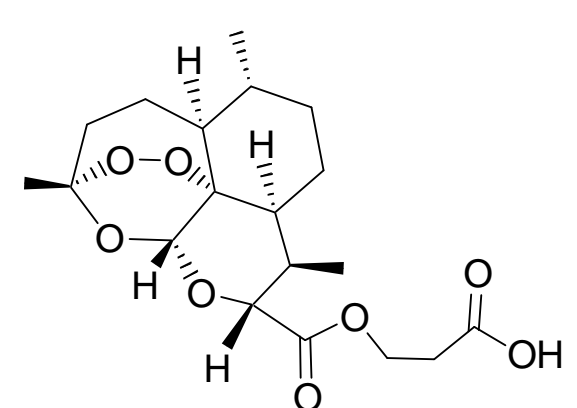

104<smiles>[2H]C(=O)OCCC(=O)Oc1c(F)c(F)c(F)c(F)c1F</smiles>

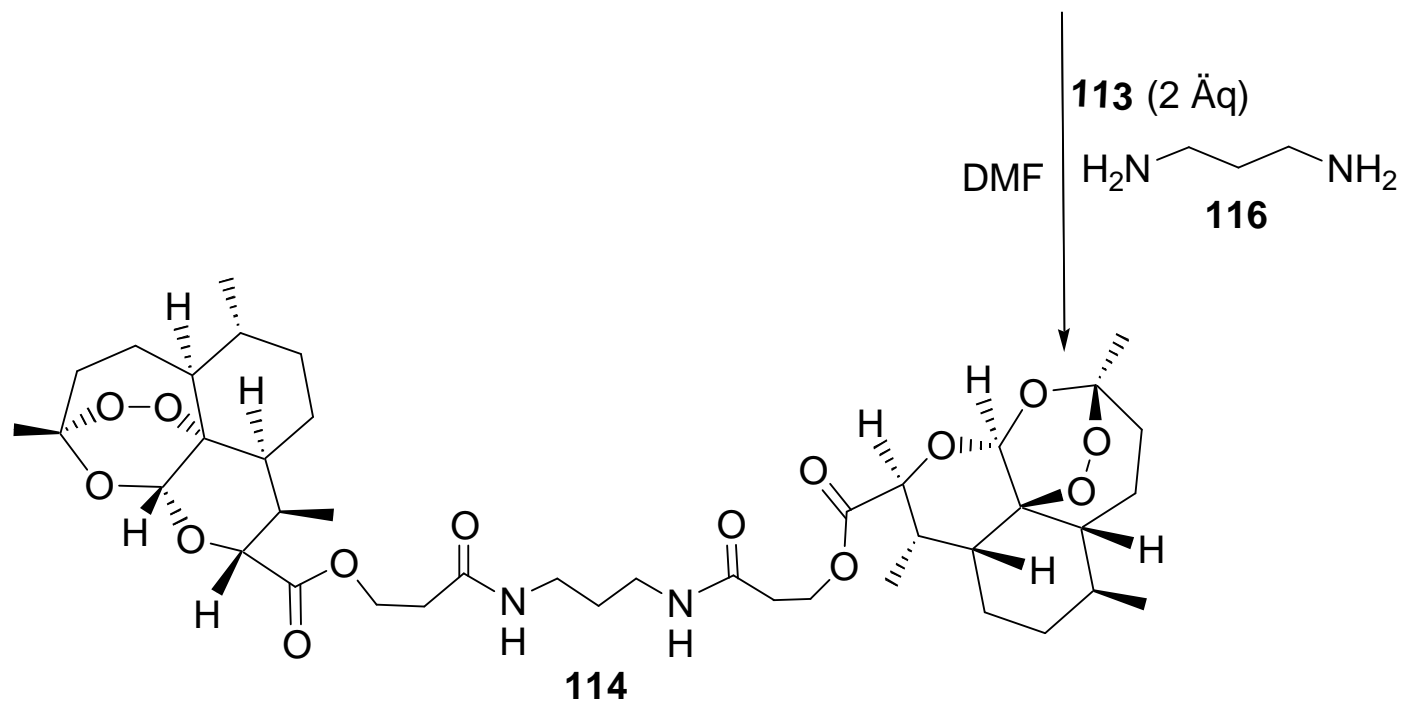

Schema 72. Synthese der Verbindung 114 


\section{$8 \quad$ Zusammenfassung der Arbeit}

Es ist eine Tatsache, dass die Enzyme erstaunlich hoch effiziente und selektive Katalysatoren sind. Enzyme, wie sie in der Natur vorkommen, können aber zu instabil oder auf ihr natürliches Substrat begrenzt sein. Chemiker bemühen sich daher seit langem, die Effizienz und Selektivität von Enzymen mit synthetischen Katalysatoren nachzuahmen.

Überraschenderweise basierten die für diesen Zweck entwickelten Katalysatoren bis vor kurzem fast ausschließlich auf Metallkomplexen, während etwa die Hälfte aller Enzyme völlig metallfrei ist.

Robinson-Annelierung mit L-Prolin und Hydrocyanierung mit Diketopiperazinen waren dabei frühe Beweise, dass Selektivitäten und Spezifitäten nicht ausschließlich an hochmolekulare Enzyme oder Organometallkomplexe als Katalysatoren gekoppelt sind.

Obwohl rein organische Verbindungen seit 95 Jahren als Katalysatoren verwendet wurden, konnten sie sich in der enantioselektiven Katalyse erst seit ungefähr dem Jahr 2000 erfolgreich durchsetzen.

Die chirale organische Katalyse konkurriert dabei nicht mit etablierten Methoden wie, Übergangsmetall- und die Enzymkatalyse, sondern stellt eine wichtige Ergänzung für diese dar. Organokatalysatoren sind oftmals sehr robust gegen Luft oder Feuchtigkeit und zeichnen sich dadurch aus, dass eine toxische Verunreinigung des Reaktionsproduktes durch Metallspuren nicht möglich ist. Chirale Organokatalysatoren sind daher attraktiv für den Einsatz bei der Synthese von Arzneimitteln und anderen bioaktiven Verbindungen.

1) Die Verwendung von kurzen Oligopeptiden als peptidartige Enzym-Mimetika, bei deren Entwicklung Scott Miller eine Vorreiter-Rolle gespielt hat, gehört $\mathrm{zu}$ den jüngsten Forschungsgebieten, welches von ständig wachsendem Interesse für verschiedene wichtige Transformationen ist.

Der „Oligopeptidansatz“ besitzt einige wichtige Vorteile:

Durch Variation der Aminosäuren kann der Katalysator leicht optimiert werden. Ausserdem sind die Strukturen von Oligopeptiden einfacher als die der deutlich komplexeren Enzyme, was sowohl experimentelle als auch theoretische mechanistische Untersuchungen erleichtern kann. 
Die strukturelle Vielfalt, die selbst Peptide mit Dipeptid-Sequenzen ermöglichen, macht diese Klasse von Molekülen vielversprechend für die Entwicklung neuer effektiver chiraler Organokatalysatoren. Wir haben daher unsere Untersuchungen mit den kleinstmöglichen unmodifizierten linearen Peptiden begonnen.

Ein weiterer Grund für unsere Auswahl war die Tatsache, dass in der Mehrheit der literaturbekannten Peptidkatalysatoren, sowohl die Amino- als auch die Säurefunktion verändert oder eliminiert worden ist, und dass nur Prolin-haltige Peptide untersucht wurden. Außerdem sind bis zu diesem Zeitpunkt keine Beispiele der Katalyse mit kurzkettigen unmodifizierten Peptiden mit primärer Aminogruppe bekannt gewesen.

In dieser Arbeit wurde eine größere Anzahl kleinerer Peptide aus natürlichen Aminosäuren mit klassischen Verfahren hergestellt, und als Katalysatoren für die direkte Aldol Reaktion von Nitrobenzaldehyd mit Aceton untersucht.<smiles>CC(=O)C[C@@H](O)c1ccc([N+](=O)[O-])cc1</smiles>

Interessanterweise hat sich unter diesen H-Leu-His-OH (18) als der beste Katalysator bezüglich der Enantioselektivität und der Ausbeute erwiesen (87\% Ausbeute, 71\% ee).

Im Zuge unserer Untersuchungen zu Aldol Reaktionen wurde dabei beispielsweise gefunden, dass Dipeptide mit Aminosäuren (H-His-Phe-OH, H-Leu-His-OH, H-Lys-Phe-OH), welche sowohl einen basischen als auch einen neutralen Rest in den Seitenketten enthalten, im allgemeinen besser geeignet sind, um gute Umsätze und Enantioselektivitäten zu erzeugen, als Dipeptide aus Aminosäuren mit zwei basischen oder zwei neutralen Funktionalitäten in den Seitenketten (H-Lys-His-OH, H-Lys-Arg-OH, H-Leu-Phe-OH):

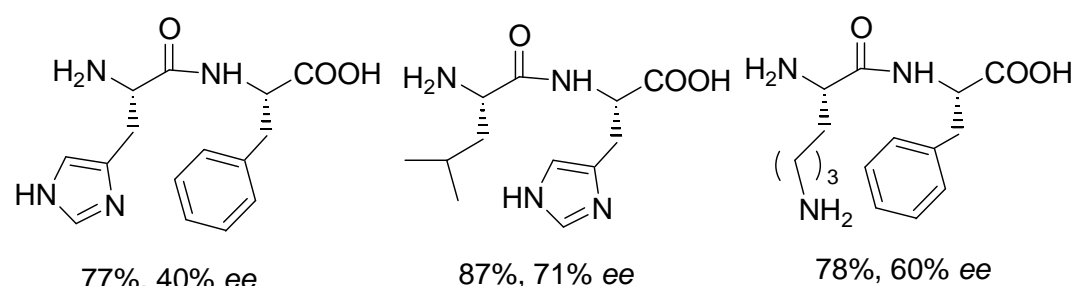

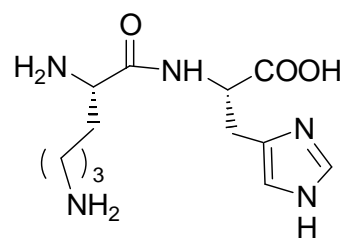

$11 \%, 26 \%$ ee

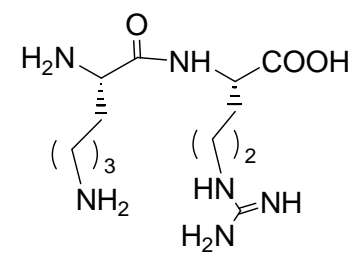

$58 \%, 21 \%$ ee

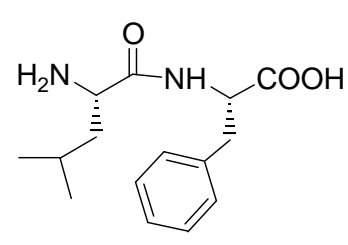

$11 \%, 67 \%$ ee 
Durch Vergleich der Ergebnisse von den drei unten gezeigten Dipeptiden, erscheint klar, dass der Imidazol-Rest der Seitenkette im Histidin eine wichtige Rolle für den Umsatz und die Enantioselektivität spielt.

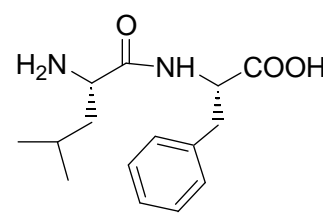

$11 \%, 67 \%$ ee

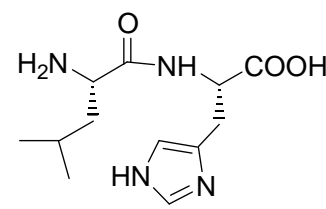

$87 \%, 71 \%$ ee

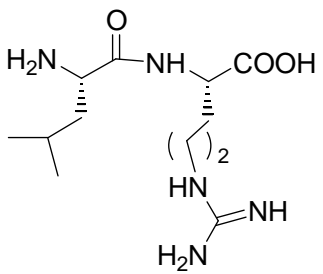

$65 \%, 40 \%$ ee

Auch der Leucin-Rest ist wichtig, da dessen Ersetzung, beispielsweise durch Lys oder Phe, zu einem Aldol Produkt mit niedrigeren Enantioselektivitäten bzw. Ausbeuten führt.

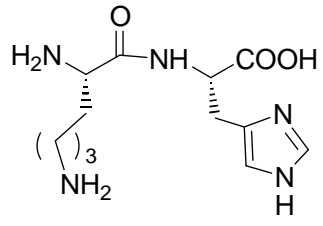

$11 \%, 26 \%$ ee

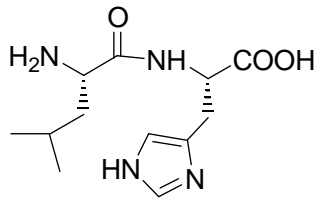

$87 \%, 71 \%$ ee<smiles>N[C@@H](Cc1ccccc1)C(=O)N[C@@H](Cc1c[nH]cn1)C(=O)O</smiles>

$79 \%, 27 \%$ ee

Zusätzlich scheint die Stereoselektivität nicht nur von der Anwesenheit einer passenden Kombination der funktionalen Gruppen der Seitenketten, sondern auch von der passenden Sequenz der Aminosäuren abzuhängen. So ist H-His-Leu-OH viel weniger stereoselektiv $(86 \%, 22 \%$ ee) als H-Leu-His-OH $(87 \%, 71 \%$ ee), welches die umgekehrte Sequenz von Aminosäureresten besitzt.

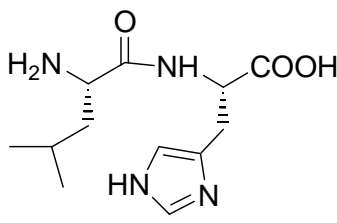

$87 \%, 71 \%$ ee

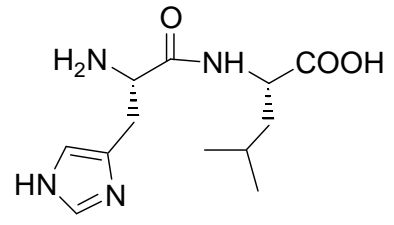

$86 \%, 22 \%$ ee

Der ausgewählte H-Leu-His-OH Katalysator liefert auch für die anderen untersuchten Substrate gute Ausbeuten bis zu 96\% und Enantioselektivitäten bis zu 76\% ee:

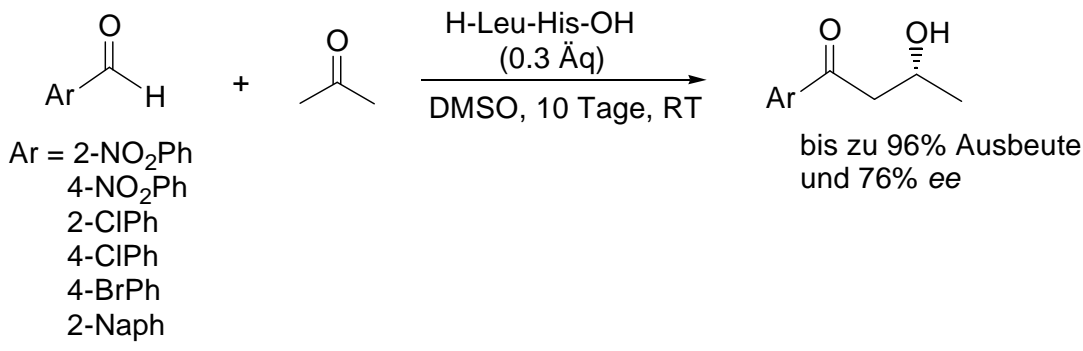


Erwartungsgemäss sind cyclo[Leu-His], und sowohl Z- als auch Methylester-geschützte Derivate, weniger aktiv und stereoselektiv als das lineare und unmodifizierte H-Leu-His-OH, was die Bedeutung der $\mathrm{N}$-terminalen Aminogruppe und auch der C-terminalen Carboxylgruppe für die Katalyse unterstreicht. Anhand unsere Ergebnisse können wir eine Arbeitshypothese für den Leu-His-Katalysator vorschlagen. Das Benzaldehyd kann über Wasserstoffbrückenbindungen mit der NH-Gruppe der Peptidbindung und der Carboxygruppe des Dipeptides aktiviert und orientiert werden. Das an der N-terminalen Aminogruppe gebildete Enamin greift dann das Benzaldehyd von der Re-Seite an. Das kann die bevorzugte Bildung des $R$-Enantiomers erklären.

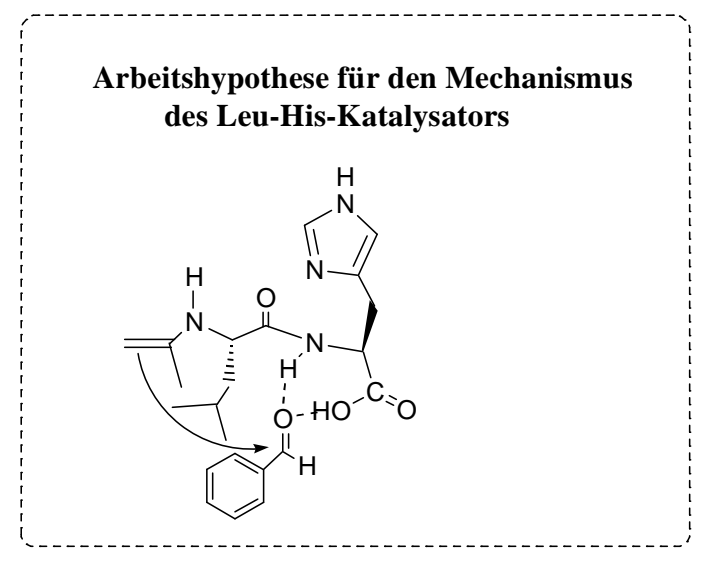

Damit konnten wir zum ersten mal zeigen, dass auch lineare Dipeptide, die eine primäre Aminogruppe enthalten, die Aldol Reaktion enantioselektiv katalysieren können.

2) Auf Grundlage der Überlegung, dass der Akzeptor über nicht-kovalente Wechselwirkungen mit der NH-Gruppe und der Carboxygruppe des Dipeptides aktiviert und orientiert wird, scheint klar, dass ein noch besserer Wasserstoffbrücken-Donor vorteilhaft sein könnte.

Wir haben uns dabei für die Thioharnstoff-Einheit aufgrund ihrer bekannten Acidität als guten Wasserstoffbrücken-Donor entschieden und haben uns deshalb im Weiteren mit solchen bifunktionellen Organokatalysatoren beschäftigt, die sowohl eine nukleophile Aminogruppe als auch eine Thioharnstoff-Einheit enthalten:

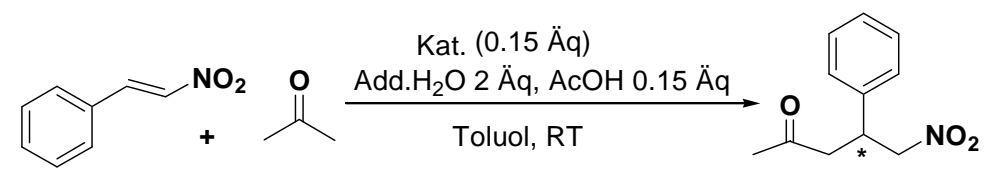




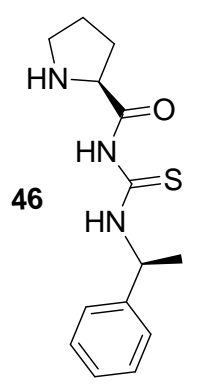

$20 \%$, 0\% ee

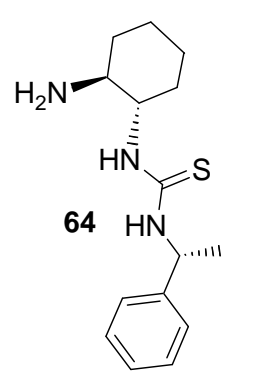

$59 \%, 84 \%$ ee

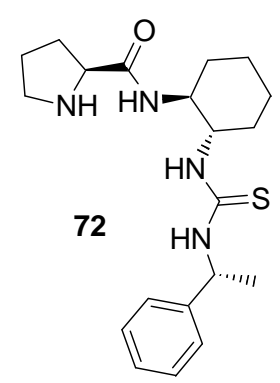

$36 \%, 0 \%$ ee

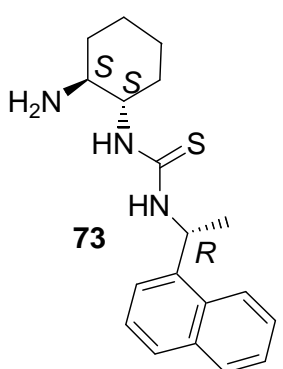

$97 \%, 84 \%$ ee

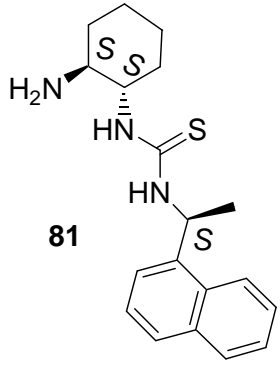

$59 \%, 84 \%$ ee

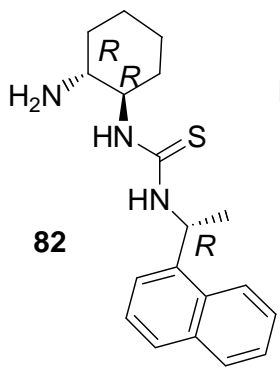

$72 \%, 73 \%$ ee

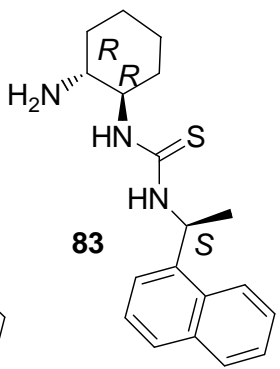

$89 \%, 87 \%$ ee

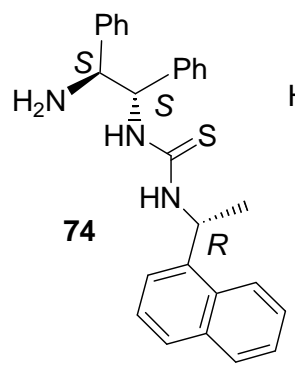

$91 \%, 98 \%$ ee

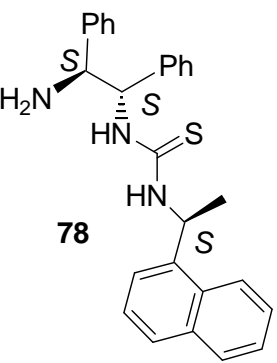

$62 \%, 77 \%$ ee

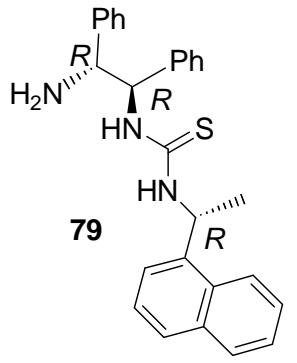

$80 \%, 78 \%$ ee

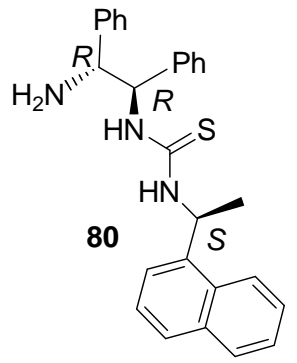

$92 \%, 92 \%$ ee

Wir untersuchten das Potential dieser neuen bifunktionellen Verbindung für die Katalyse in der enantioselektiven Addition von Ketonen an Nitroolefine, welche einen bequemen Zugang zu $\gamma$ Nitroketonen darstellt. $\gamma$-Nitroketone dienen als wertvolle Bausteine in der organischen Synthese.

Eine der zuerst untersuchten Modelreaktionen ist die konjugate Addition von Aceton an trans$\beta$-Nitrostyrol. Diese Reaktion wurde zuerst mit L-Prolin als Katalysator untersucht. Das LProlin und Prolin-haltige literaturbekannte Katalysatoren liefern aber für diese Reaktion nur bis zu $42 \%$ ee. 
Unsere katalytischen Ergebnisse mit den neuen Thioharnstoffverbindungen zeigen, dass für die untersuchte Reaktion die primäre Aminogruppe im bifunktionellen Katalysator besser geeignet ist als Pyrrolidin-Einheit.

Die besten Ergebnisse (98\% Ausbeute, 91\% ee) wurden mit dem primären-Amin-haltigen Katalysator 74, der sowohl Diphenylethylendiamin als auch Naphthylethylamin Substituenten enthält, erzielt. Damit erreichten wir eine bemerkenswerte Verbesserung im ee Wert und in der Ausbeute im Vergleich zu den literaturbekannten Pyrrolidin-basierenden Katalysatoren für die Addition von Aceton an trans- $\beta$-Nitrostyrol.

Die Reaktion hat eine gute Anwendungsbreite. Für alle untersuchten Substrate lieferte der ausgewählte Katalysator Enantioselektivitäten von 90 bis $99 \%$ und Ausbeuten von 82 bis 99\%:

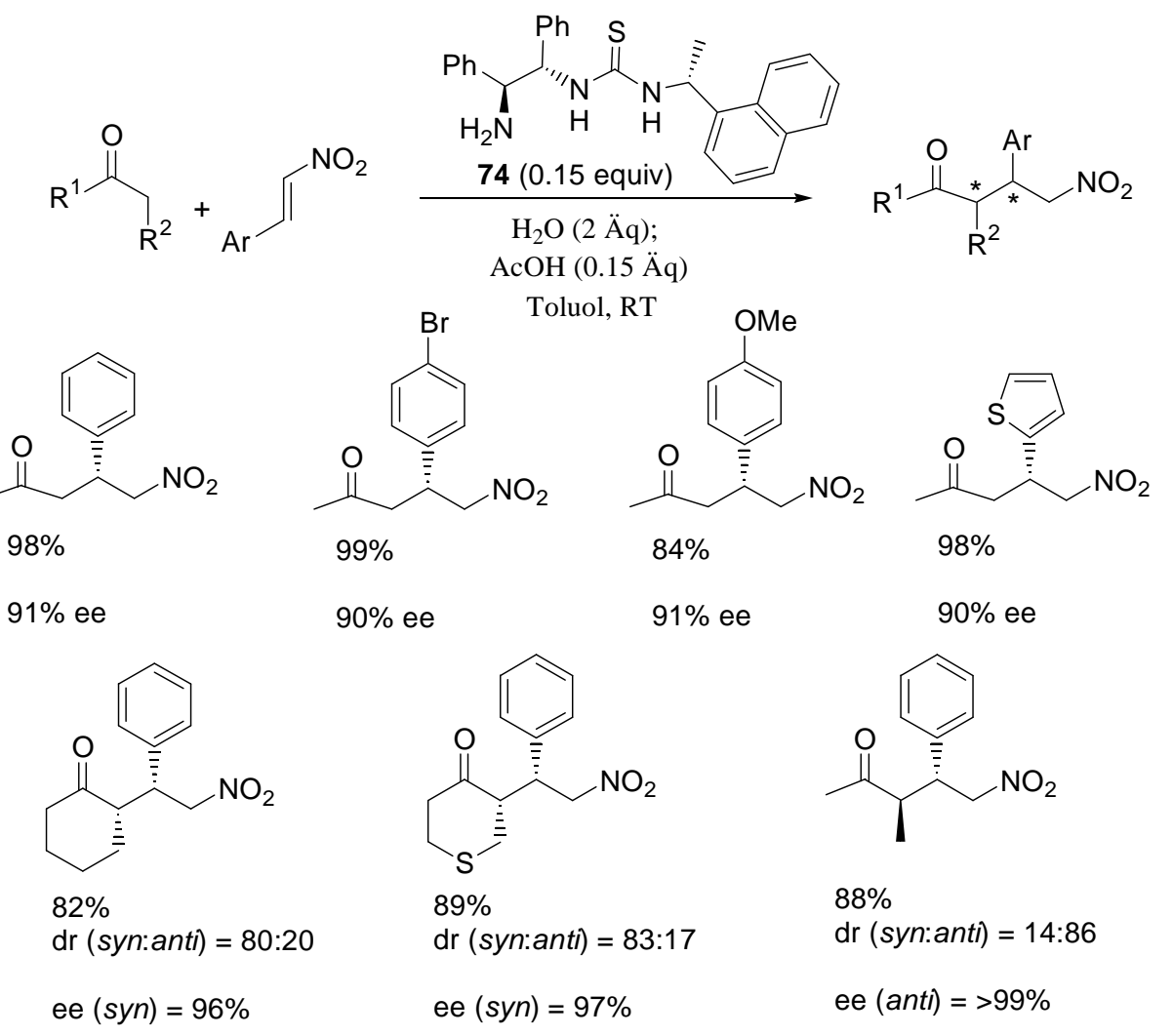

Unsere Ergebnisse bestätigten, dass die Voraussetzung für gute Ausbeuten und Enantioselektivitäten darin besteht, dass der Katalysator sowohl eine Thioharnstoff- als auch eine Aminfunktionalität besitzt. Beide Funktionalitäten sollten sich direkt angrenzend zu den stereogenen Kohlenstoffzentren des chiralen Linkers befinden. Diese Ergebnisse weisen darauf hin, dass die nukleophile Aminogruppe und die Thioharnstoff-Einheit synergetisch wirken.

Somit haben wir zum ersten Mal gezeigt, dass primäre Amin-haltige chirale Thioharnstoffe Additionen von verschiedenen Ketonen an Nitroolefine effektiv katalysieren können. 
Dies stellt ein weiteres Beispiel der Katalyse mittels gleichzeitiger nicht-kovalenter und kovalenter Wechselwirkungen dar.

3) Des weiteren waren wir neugierig, was passieren könnte wenn wir einen Organokatalysator durch das Produkt selbst ersetzen würden. Die Reaktionen in welcher das chirale Produkt alleine als ein Induktor von Chiralität wirkt, besitzen eindeutige Vorteile, da das chirale Produkt bei der Aufarbeitung nicht vom Katalysator abgetrennt werden muss und zum zweiten, weil kein anderer chiraler Katalysator als eben das Produkt selbst involviert ist.

Über die ersten homogenen Reaktionen in denen das Produkt seine eigene Bildung katalysiert, berichtete Soai 1990 (K. Soai, S. Niwa, H. Hori, J. Chem. Soc., Chem. Commun. 1990, 982).

1995 zeigten Soai und Mitarbeiter weiterhin (K. Soai, T. Shibata, H. Morioka, K. Choji, Nature. 1995, 378, 767.), dass in Gegenwart von 20 Mol-\% des Pyrimidylalkohols in $94.8 \%$ ee in der Reaktion des entsprechenden Aldehyds mit Diisopropylzink in 48\% Ausbeute mit 95.7\% ee gebildet wird. Das Produkt automultipliziert sich somit ohne wesentliche Veränderung des Enantiomerenüberschusses. Der Mechanismus dieser Reaktion wurde erst 2001 aufgeklärt und es wurde gezeigt, dass die katalytisch aktive Spezies nicht das Produkt selbst ist, sondern ein homochiraler, dimerer Zn-Komplex, der aus zwei Produkt-Molekülen mit zwei Molekülen des Zinkorganyl-Reagens gebildet wird.

Deshalb haben wir uns gefragt, ob auch das Produkt allein, d.h. ohne Beteiligung von metallischen Spezies, als ein Überträger der Chiralitätsinformation und in einer beliebigen asymmetrischen organischen Reaktion, wie einer Mannich Reaktion, dienen kann.

Wenn zu der Reaktionsmischung 15 mol\% von S- bzw. R-Produkt mit 98\% und 99\% ee, entsprechend, zu Beginn der Reaktion zugesetzt wird, entsteht das neugebildete Produkt in nahezu derselben Enantiomerenreinheit und mit derselben absoluten Konfiguration wie das anfänglich hinzugefügte Mannich Produkt:
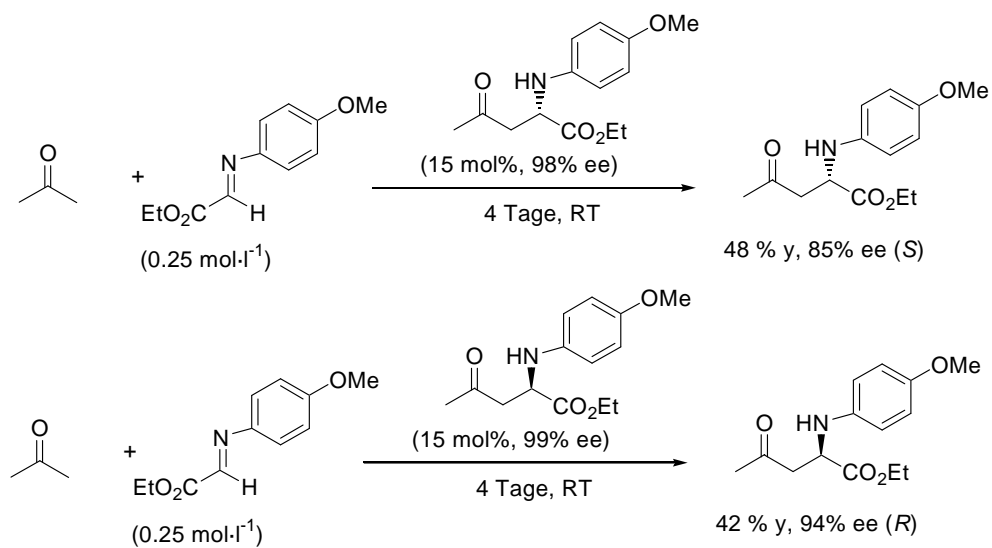

Wir konnten damit zum ersten mal demonstrieren, dass in einem metallfreien System nur das dazugefügte Produkt selbst ausreicht, um mittels nicht-kovalenter Wechselwirkungen mit dem 
Edukt hohe Enantiomerenüberschüsse zu erreichen, was auch rechnerisch untersucht worden ist. Das heißt: Produkt und Katalysator sind identisch:
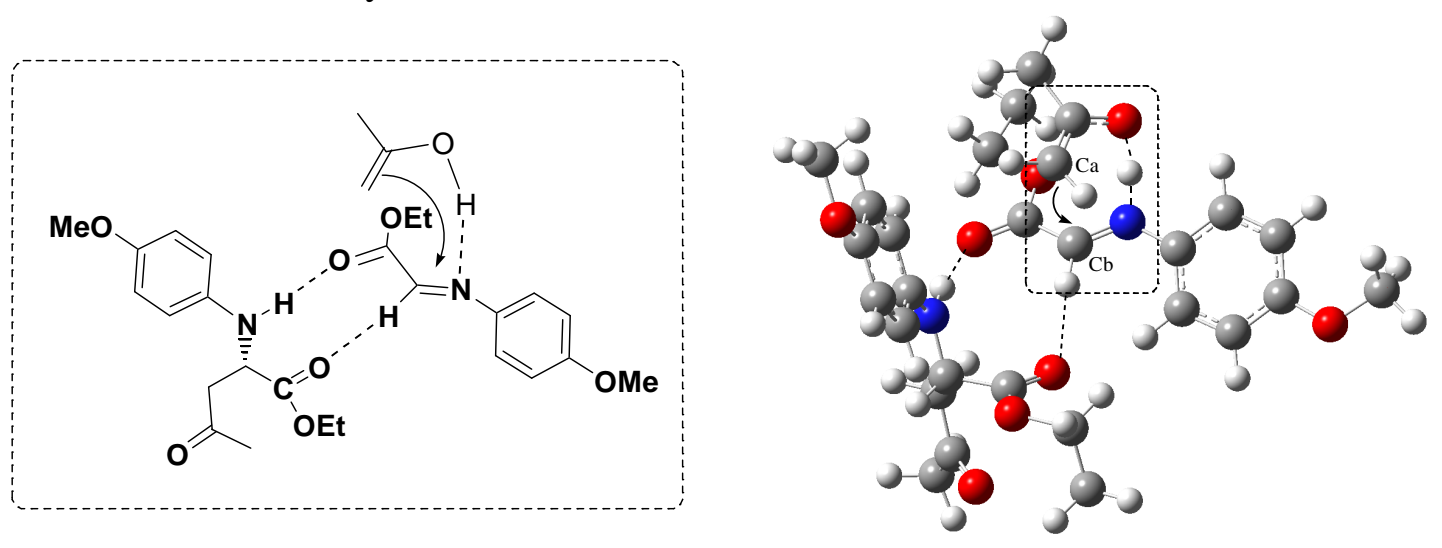

4) Ein bedeutsames Ziel in der organischen Chemie ist die Entwicklung neuer Typen pharmakologisch wirksamer Substanzen. Eine der neuesten Methoden, dieses Ziel zu erreichen, ist die Entwicklung von Hybriden, gebildet aus verschiedenen Naturstoffen (Tietze, H. P. Bell, S. Chandrasekhar, Angew. Chem. Int. Ed.. 2003, 42,3996). Da dieser Ansatz ziemlich neu ist, sind nur einige wenige Beispiele in der Literatur bekannt, hauptsächlich für die Entwicklung von neuen Antitumor-Agenzien und Antibiotika.

Die Therapie der Malaria ist eine der großen Herausforderungen der modernen Medizin. Ein möglicher und vielversprechender Ansatz, der von uns hier verfolgt wird, ist die Entwicklung von Hybridmolekülen auf Basis von bekannten Naturstoffanaloga in Zusammenarbeit mit der Universität Heidelberg, Zentrum für Molekulare Biologie.

Ein bekannter Wirkstoff, der bereits gegen Malaria angewandt wird, und ausserdem auch zytotoxische Aktivität in Krebszellen zeigt, ist Artesunat (semisynthetische Derivat des Artemisinins).

In den letzten Teil der Doktorarbeit wurde daher die Synthese von Artesunat- und Betulinhaltigen biologisch aktiven Hybridmolekülen durchgeführt. Aus sechs von uns hergestellten und hier gezeigten Artesunat-haltigen Hybridnaturstoffen hat sich Verbindung 114 als sehr aktiv gegen den Malariaerreger erwiesen. 


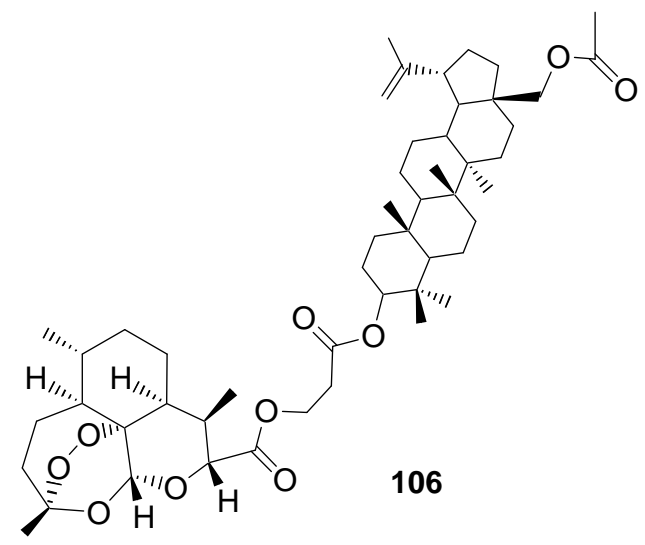

Weißer Feststoff, 55\% Ausbeute $[\alpha]^{20}{ }_{D}=+15.0^{\circ}\left(\mathrm{c}=0.167, \mathrm{CHCl}_{3}\right)$.

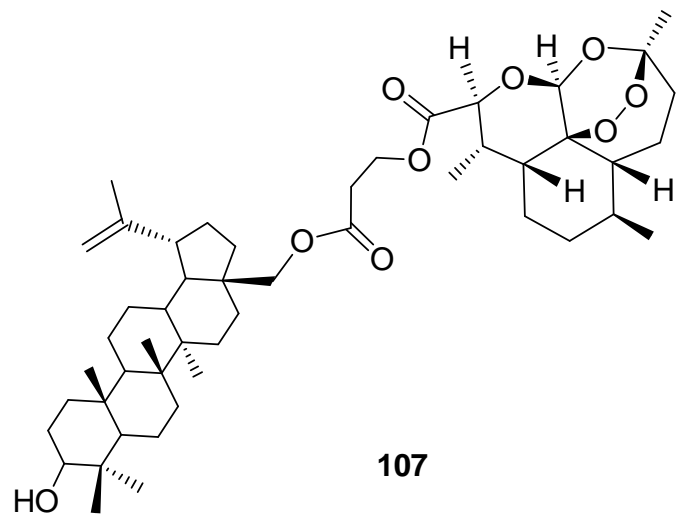

Weißer Feststoff, 54\% Ausbeute $[\alpha]^{20}{ }_{D}=+12.6^{\circ}\left(\mathrm{c}=0.127, \mathrm{CHCl}_{3}\right)$.

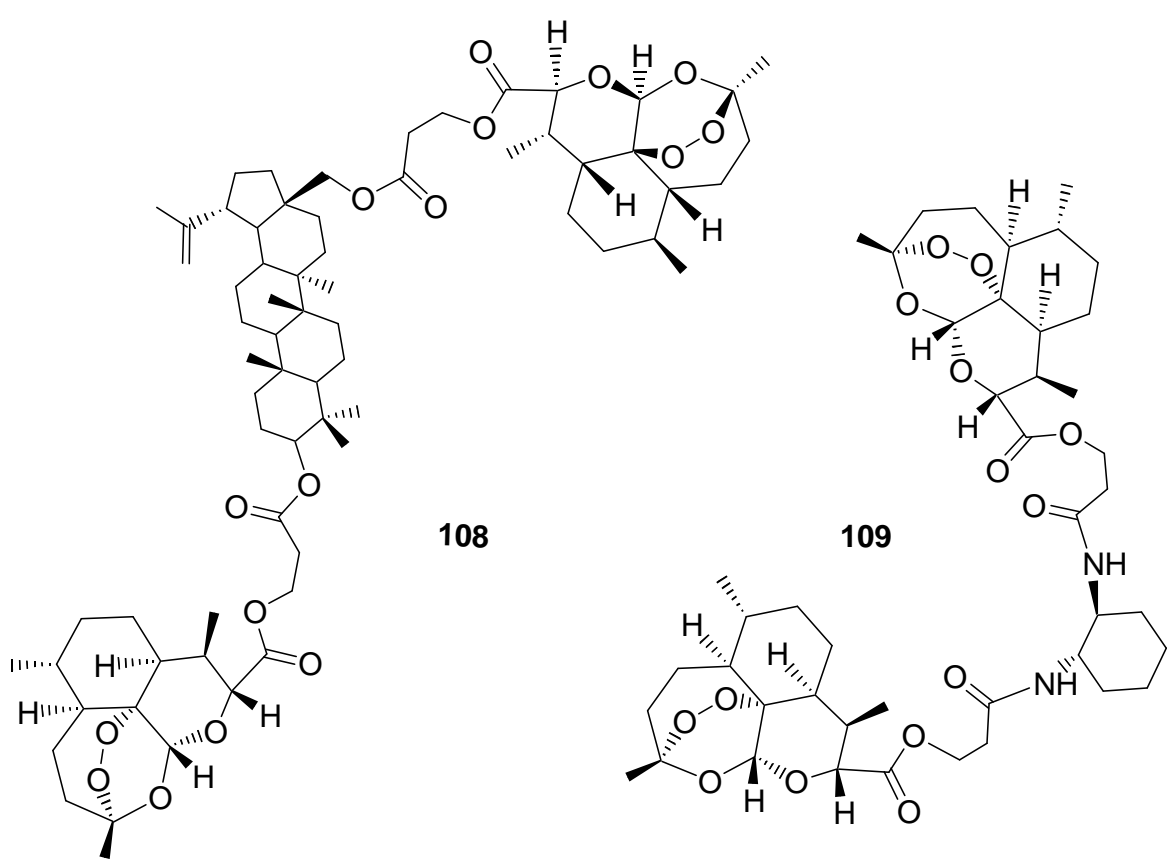

Weißer Feststoff, 61\% Ausbeute $[\alpha]^{20}{ }_{D}=+18.3^{\circ}\left(\mathrm{c}=0.109, \mathrm{CHCl}_{3}\right)$.
Weißer Feststoff, 54\% Ausbeute $[\alpha]^{20}{ }_{\mathrm{D}}=+18.3^{\circ}\left(\mathrm{c}=1.45, \mathrm{CHCl}_{3}\right)$. 


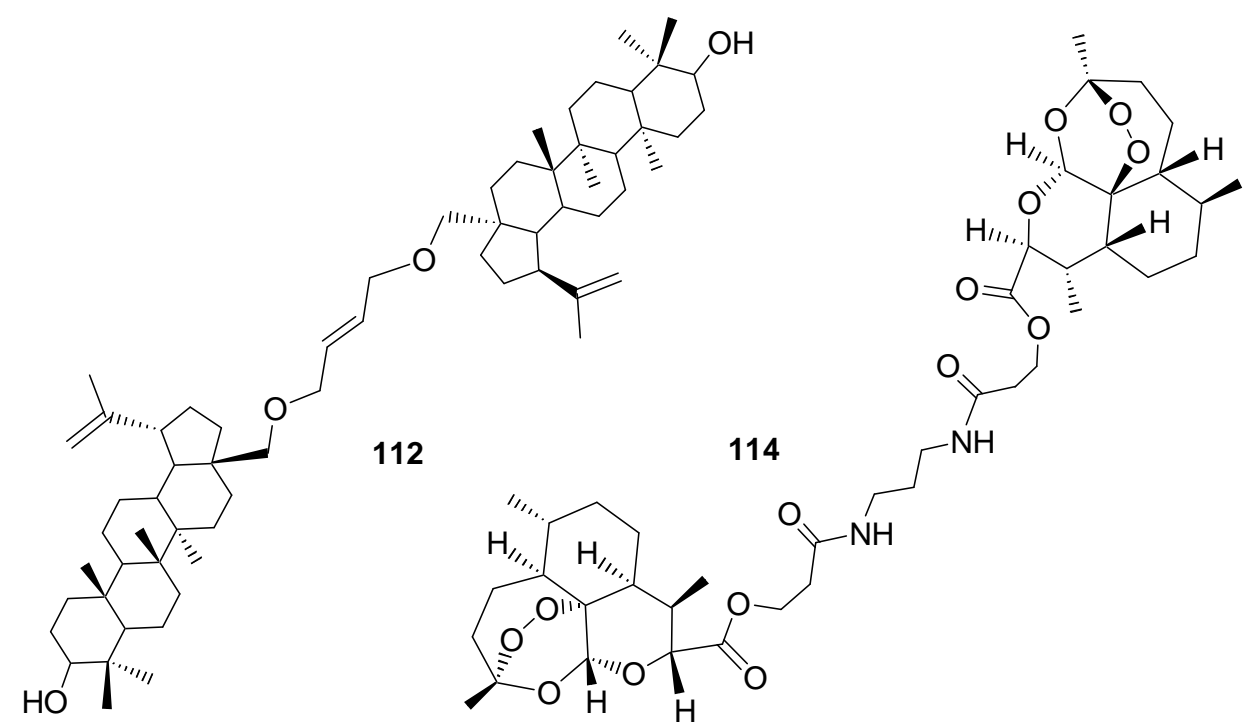

Weißer Feststoff, 54\% Ausbeute $[\alpha]^{20}{ }_{\mathrm{D}}=-2.0^{\circ}\left(\mathrm{c}=0.1, \mathrm{CHCl}_{3}\right)$.
Weißer Feststoff, 10\% Ausbeute $[\alpha]^{20}{ }_{D}=+18.6^{\circ}\left(\mathrm{c}=1.45, \mathrm{CHCl}_{3}\right.$ 


\section{Experimenteller Teil}

\subsection{Allgemeine Methoden}

Alle Umsetzungen wurden, soweit notwendig, in ausgeheizten Glas-Appareturen unter einem leichten Intergasüberdruck (Argon oder Stickstoff) durchgeführt. Die Substanzen wurden von der Firma Merck; Aldrich; Acros und Fluka bezogen, falls nötig, wurden diese unter Stickstoff gesetzt und bei $4{ }^{\circ} \mathrm{C}$ aufbewahrt. Die käuflichen Substanzen wurden, falls nicht anders angegeben, ohne weitere Reinigung eingesetzt. Für Reaktionen wurden meistens käuflichen Lösungsmitteln des Reinheitsgrades p.a. oder höher verwendet. Falls nötwendig wurden diese vor ihrer Verwendung entsprechend den üblichen Methoden getrocknet. ${ }^{201} n$-Hexan und $i$ Propanol wurde in der Qualität für HPLC von der Firma Fluka oder Acros bezogen.

\subsection{Instrumentelle Analytik und verwendete Geräte.}

Drehwerte: Drehwerte wurden in einem Polarimeter Modell 241 der Firma Perkin-Elmer gemessen. Der spezifische Drehwert errechnet sich nach folgender Formel:

$$
[\alpha]_{\mathrm{D}}^{20}=\frac{\alpha .100}{C . I}
$$

Hierbei sind $\alpha$ der gemessene Drehwert bei $20^{\circ} \mathrm{C}$ und der Wellenlänge $589 \mathrm{~nm}$ (Natrium-DLinie), $c$ die Konzentration in [g/100 mL] und $l$ die Küvettenlänge in [dm].

${ }^{1}$ H-NMR-Spektrum: Die ${ }^{1}$ H-NMR-Spektren wurden mit den Modellen Mercury-300 (300 MHz), Unity-300 (300 Hz) und Inova-600 (600 MHz) der Firma Varian und dem Modell Amx300 (300 MHz) der Firma Brucker in deuerierten Lösungsmitteln aufgenommen. Die chemischen Verschiebungen sind in der $\delta$-Skala angegeben. Als interner Standard diente Tetramethylsilan $\left(\mathrm{TMS}, \delta_{\mathrm{TMS}}=0.00\right)$ oder das verwendete Lösungsmittel. Die Multiplizität der Signale erster Ordnung wurde durch folgende Abkürzungen gekennzeichnet: s (Sigulett), d (Dublett), t (Triplett), q (Quartett), quint (Quintett), sext (Sextett), sept (Septett), dd (Dublett von Dublett), dt (Dublett von Triplett) usw. Signale, die durch Überlagerung oder Anteile 
höherer Ordnung nicht interpretierbar waren, wurden mit m (Multiplett) bezeichnet und breite Signale durch den Zusatz br. indiziert. Die kopplungskonstanten $J$ sind in Hertz [Hz] angegeben.

${ }^{13}$ C-NMR-Spektrum: Die ${ }^{13}$ C-NMR-Spektren wurden mit den Modellen Mercury-200 (50 Hz), VXr-200 (50 Hz), Unity-300 (75 MHz) und Inova-600 (150 MHz) der Firam Varian sowie dem Modell Amx-300 (75 MHz) der Firma Brucker aufgenommen. Die schemische Verschiebung sind in der $\delta$-Skala angegeben. Als interner Standard diente $\mathrm{CDCl}_{3}(\delta=77.00 \mathrm{ppm}) \mathrm{bzw}$. das jeweilig verwendete deutierte Lösungsmittel.

Massenspektren: Die Massenspektren wurden mit den Modellem MAT 95 (EI-MS, EI-HRMS, DCI) der Firma Finnigan und Apex IV (ESI-HRMS) der Firma Brucker Daltronik aufgenommen. Als Ionisierungsmethoden kamen die Elektronenstoßionisation (EI, 70eV), die direkte chemische Ionisation mit $\mathrm{NH}_{3}$ (DCI) und die Elektronensprayionisation (ESI) zum Einsatz. In Klammer sind die relativen Intensitäten bezogen auf den Basispesk $(I=100 \%)$ nagegeben.

\subsubsection{Chromatographische Methoden}

Dünnschichtchromatographie $(D C)$ : Es wurden DC-Fertigfolien SIL G/UV 254 der Firma Macherey-Nagel \& Co. KG mit einer Schichtdicke von $0.25 \mathrm{~mm}$ verwendet. Angegeben sind $R_{\mathrm{f}}$-Werte (Laufhöhe realtiv zur Laufmittelfront). Als Abkürzungen für die verwendete Lösungsmittel dienen: EE (Essigsäureethylester), Hex.(n-Hexan). Neben der UV-Detektion dienten Ninhydrin-Lösung (500 mL Ethanol, 3.00 mL Essigsäure, 1.00 g Ninhydrin), $\mathrm{KMnO}_{4}-\mathrm{Lösung}$ (200 ml Wasser, $2.00 \mathrm{~g} \mathrm{KMnO}_{4}, 13.3 \mathrm{~g} \mathrm{~K}_{2} \mathrm{CO}_{3}, 3.30 \mathrm{~mL}$ 5\% Äq. NaOH) oder AnisaldehydSchwefelsäure (0.5mL Anisaldehyd in $50 \mathrm{~mL}$ Eisessig und $1 \mathrm{~mL}$ Konz. Schwefel) mit anschließendem Erhitzen mit einem Heißluftfön als Färbmethoden. Auch eine 10\%ige Molybdatophosphorsäure-Lösung in Methanol und eine Vanillin-Schwefelsäure-Lösung (0.5 g Vanillin, 3 mL konz. Schwefelsäure, $10 \mathrm{~mL}$ Eisessig und $85 \mathrm{~mL}$ Methanol) wurden als Anfärbereagenzien verwendet.

Präparative Dünnschichtchromatographie $(P D C)$ : Für die Herstellung der mit Kieselgel beschichtete Glasplatte wurde die Fertigmischung P/UV 254 der Firma Macherey-Nagel \& Co. $K G$ verwendet. Für 10 Platten $(20 \times 20 \mathrm{~cm}, 1-2 \mathrm{~mm}$ Schichtdicke) wurden $200 \mathrm{~g}$ Kieselgelmischung mit $460 \mathrm{~mL}$ demineralisiertem wasser aufgeschlemmt. Das Gemisch wurde gleich- 
mäßig auf die Glasplatten verteilt, 1 Tag bei Raumtemperatur und $4 \mathrm{~h}$ bei $120^{\circ} \mathrm{C}$ getrocknet. In Abhängigkeit vom Trennproblem wurden bis 200 mg Substanz auf einer Platte aufgetragen.

Säulenchromatographie (SC): Säulenchromatographische Trennungen wurden mit Kieselgel 60 (Korngröße 0.040-0.063 mm oder Korngröße 0.063-0.200 mm) der Firma Macherey-Nagel \& Co. $K G$ durchgeführt.

Hochleistungsflüssigkeitschromatigraphie (HPLC): Für analytische Trennungen wurde eine HPLC-Anlage der Firma Knauer (bestehend aus einem AS-2055 Plus Sampler, einer LG-158004 Mischkammer, einer PU-2080 Plus Pumpe und einem MD-2010 Plus Multiwavelensth Detector) in Kombination mit einer Säule des Typs Daicel Chiralpak AS (AD) verwendet. Angegeben sind die Retentionszeiten $\mathrm{R}_{\mathrm{t}}$ in $\min$. Als Laufmittel wurden Isopropanol und $n$ Hexan in HPLC-Qualität verwendet.

\subsection{Darstellung der Peptide für Aldol-Reaktion}

Alle mit Z-, bzw Boc-Gruppe geschützten Peptide wurde durch klassiche Methoden ${ }^{77}$ dargestellt. Für die Entfernung der Schutzgruppe wurden folgene Methoden genommen.

Methode A: Zu einer gerührten Lösung von Z-dipeptid (514 mg, $1.15 \mathrm{mmol}$ ) in trock-enem $\mathrm{MeOH}$ wurde $\mathrm{Pd} / \mathrm{C}$ (51.4 mg) zugegeben. Diese Suspension wurde dann unter Wasserstoffatomosphäre bis $20 \mathrm{~h}$ bei RT gerührt. Die Reaktion wurde mittels DC-Kontrolle verfolgt (MeOH: EE = 1:1, mögliche Anfärbungsmitteln: Nihydrin-, $\mathrm{KMnO}_{4^{-}}$, Vanillin-, Molybdatophosphorsäure-Lösung)

Anschliessend wurde $\mathrm{Pd} / \mathrm{C}$ durch Celite abfiltriert. Das Lösungsmittel wurde im Vakumm entfernt. Nach einer Reinigung durch Säulenchromatographie an Kieselgel (MeOH:EE = 1:1) wurde die jeweilige Titelverbindung als weisser Feststoff erhalten (bis zu 98\% Ausbeute).

Methode B: Dowex wurde zu einer gerührter Lösung von (H-Leu-His-OMe)HCl-Salz (100 mg) in Wasser $(5.00 \mathrm{~mL})$ portionsweise bis zu einem $\mathrm{pH}$ von 7 zugegeben. Das Wasser wurde im Vakuum entfernt. Nach dem Trockenen wurde die Zielverbindung (bis zu 70\% von Ausbeute) als weisser Feststoff erhalten.

Methode C: Unter Stickstoff wurde TFA (4-10 Tropfen) zu einer Lösung von H-Leu(Boc)His-OMe $(50 \mathrm{mg})$ in trockenem $\mathrm{CH}_{2} \mathrm{Cl}_{2}(2 \mathrm{~mL})$ bei $0^{0} \mathrm{C}$ zugetropft. Die Reaktionsmischung wurde dann bei RT unter DC-Kontrolle (Anfärbemittel: Anisaldehyd, $\mathrm{KMnO}_{4}$ ) bis $1.5 \mathrm{~h}$ gerührt. 
Anschliessend wurde ungebrauchte THA entfernt. Das Lösungsmittel wurde im Vakumm abgezogen. Der Rückstand wurde in Wasser gelöst, und das Produkt mit kaltem Ether ausgefällt. Der gebildte Nierderschlag wurde abfiltriert und mehrmals mit kaltem Ether gewaschen. Nach weiterem Trocknen wurde die Titelverbindung (bis zu 70\% Ausbeute) als weisser Feststoff erhalten.

9.3.1 H-Leu-His-OMe (19)<smiles>COC(=O)[C@H](Cc1c[nH]cn1)NC(=O)[C@H](N)CC(C)C</smiles>

Verbindung 19 wurde nach Methode C aus H-Leu(Boc)-His-OMe mit 70\% Ausbeute, und nach Methode A aus H-Leu(Z)-His-OMe in 95\%iger Ausbeute synthetisiert.

$R_{\mathrm{f}}=0.35(\mathrm{MeOH}: \mathrm{EE}=1: 1)$

${ }^{1}$ H-NMR (300 MHz, DMSO): $\delta=0.80$ (d, $\left.J=6.0 \mathrm{~Hz}, 6 \mathrm{H}, 2 \mathrm{CH}_{3}\right), 0.91-1.11(\mathrm{~m}, 2 \mathrm{H}), 1.21$ 1.41 (m, $1 \mathrm{H}), 2.50$ (br. s $2 \mathrm{H}, \mathrm{NH}_{2}$ ), 2.80-3.20 (m, $2 \mathrm{H}$ ), 3.50 (s, $\left.3 \mathrm{H},-\mathrm{COOCH}_{3}\right), 4.10-3.50$ (m, $1 \mathrm{H}), 4,0-4,4$ (m, 1 H), 7.00 (s, 1 H), 7.80 (s, 1H), 9.01 (br. s, $1 \mathrm{H}, \mathrm{NH}), 11.8$ (br. s, $1 \mathrm{H}, \mathrm{NH}$ ).

${ }^{13}$ C-NMR (75.5 MHz, DMSO): $\delta=21.60,22.41,43.92,56,1,31.21,50,4,56.80,123.0,134.8$, $135.9,174.7,172.0$.

MS (ESI): $\mathrm{m} / \mathrm{z}(\%)=283.1(100)[\mathrm{M}+\mathrm{H}]^{+}, 564.9(25)[2 \mathrm{M}+\mathrm{H}]^{+}, 587.0(35)[2 \mathrm{M}+\mathrm{Na}]^{+}$ 
9.3.2 H-Leu-His-OH (18)<smiles>CC(C)C[C@H](N)C(=O)N[C@@H](Cc1c[nH]cn1)C(=O)O</smiles>

Nach der Methode A für Verbindung 18 wurde H-Leu(Z)-His-OH (50.0 mg, 0.120 mmol) als Edukt eingesetzte und Produkt (32.3 mg, $0.12 \mathrm{mmol}$, 97\%) als weisser Feststoff erhalten.

$R_{\mathrm{f}}=0.35(\mathrm{MeOH}: \mathrm{EE}=1: 1)$

${ }^{1}$ H-NMR (300 MHz, DMSO): $\delta=1.01\left(\mathrm{~d}, J=6.0 \mathrm{~Hz}, 6 \mathrm{H}, 2 \mathrm{CH}_{3}\right), 1.21-1.42$ (br, s, $\left.2 \mathrm{H}\right), 1.60-$ 1.80 (m, $1 \mathrm{H}), 2.00$ (br.s, $\left.2 \mathrm{H}, \mathrm{NH}_{2}\right), 2.81-3.02$ (m, $\left.2 \mathrm{H}\right), 3.1-3.5(\mathrm{~m}, 1 \mathrm{H}), 4.01-4.44(\mathrm{~m}, 1 \mathrm{H})$, 6.80 (s, 1H), 7.6 (s, 1 H), 7.91 (br.s, 1H, NH), 8.22 (br. s, 1 H, NH ), 11.81 (br. s, 1 H, COOH). ${ }^{13}$ C-NMR (75.5 MHz, DMSO): $\delta=21.60,22.41,43.92,56,1,31.21,50,4,56.80,123.0,134.8$, $135.9,174.7,172.0$.

MS (ESI): $\mathrm{m} / \mathrm{z}(\%)=269.2(100)[\mathrm{M}+\mathrm{H}]^{+}$.

$\mathrm{C}_{12} \mathrm{H}_{20} \mathrm{~N}_{4} \mathrm{O}_{3}(268.3124)$

ber.: $269.16082[\mathrm{M}+\mathrm{H}]^{+}$

gef.: 269.16085 (ESI-HRMS)

\subsubsection{H-Lys-Leu-OH (30)}<smiles>CC(C)C[C@H](NC(=O)[C@H](N)CCCCN)C(=O)O</smiles>

Das Produkt wurde erst nach Methode C dargestellt, 100 mg H-Lys(Boc)-Leu-OH wurden eingesetzt und $57.6 \mathrm{mg}(80 \%)$ H-Lys-Leu-OH wurden erhalten. 
Als zweite Darstellungsmethoden der Verbindung 30 wurde Methode A angewendet (100 mg) H-Lys(Z)-Leu-OH wurden eingesetzt und die Zielverbindung (63.9 mg, $0.25 \mathrm{mmol}, 97 \%$ ) als weissen Feststoff erhalten.

$R_{\mathrm{f}}=0.33(\mathrm{MeOH}: \mathrm{EE}=1: 1)$

${ }^{1} \mathbf{H}-\mathbf{N M R}\left(300 \mathrm{MHz}, \mathrm{CD}_{3} \mathrm{OD}\right): \delta=0.95\left(\mathrm{~d}, J=6.0 \mathrm{~Hz}, 6 \mathrm{H} 2-\mathrm{CH}_{3}\right), 1.40-1.65(\mathrm{~m}, 9 \mathrm{H}$,$) ), 2.80$ (t, $J=4.8 \mathrm{~Hz}, 2 \mathrm{H}), 3.35-3.56(\mathrm{~m}, 1 \mathrm{H}), 4.28(\mathrm{dd}, J=3.0,5.8 \mathrm{~Hz} 1 \mathrm{H}), 8.00$ (br. s, $1 \mathrm{H}, \mathrm{NH})$, 11.0 (br. s, $1 \mathrm{H}, \mathrm{COOH}$ ).

${ }^{13}$ C-NMR (75.5 MHz, $\left.\mathrm{CD}_{3} \mathrm{OD}\right): \delta=20.71,22.90,22.52,32.10,34.31,40.31,42.12,52.32$, $54.52,171.1,174.9$.

$[\alpha]_{\mathrm{D}}^{20}=-8.1(\mathrm{c}=0.32, \mathrm{MeOH})$

9.3.4 H-Lys-Tyr-OH (29)

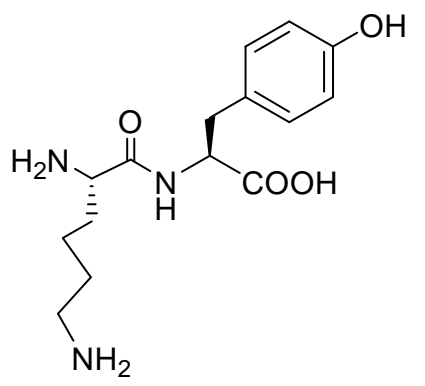

Amberlyst A-26 (OH) (ion exchange resin 0.35mm) (5 mg) wurde zuerst in eine Säule gefüllt. Eine Lösung von (H-Lys-Tyr-OH)Ac $(80.0 \mathrm{mg})$ in Wasser $(20.0 \mathrm{~mL})$ wurde langsam durch die Säule gespült. Anschliessend wurde mehrmals mit Wasser nachgespült. Das Wasser wurde im Vakuum entfernt, und das Produkt erhalten $(55.6 \mathrm{mg}, 1.80 \mathrm{mmol}, 70 \%)$. Als zweiter Versuch wurde das Peptid-Salz zuerst in Wasser gelöst und Amberlyst portionsweise unter Rühren zugegeben, bis ein $\mathrm{pH}$ von 8 gemessen wurde. Amberlyst wurde abfiltriert. Nach der Entfernung von Wasser und Trocknen erhielt man ähnliche Ergebnisse wie beim vorherigen Experiment.

$R_{\mathrm{f}}=0.35(\mathrm{MeOH}: \mathrm{EE}=1: 1)$

${ }^{1}$ H-NMR (300 MHz, D $\left.2 \mathrm{O}\right): \delta=1.20-1.28$ (m, $\left.2 \mathrm{H}\right), 1.58-1.72(\mathrm{~m}, 4 \mathrm{H}), 2.00$ (br. s, $2 \mathrm{H}, \mathrm{NH}_{2}$ ) 2.50 (br. s, $\left.2 \mathrm{H}, \mathrm{N} H_{2}\right), 2.82(\mathrm{~d}, J=4.5,2 \mathrm{H}), 2.65-3.01(\mathrm{~m}, 2 \mathrm{H}), 3.20(\mathrm{dd}, J=6.3,12.3 \mathrm{~Hz}, 1$ 
H), $3.44(\mathrm{t}, J=6.0 \mathrm{~Hz}, 1 \mathrm{H}), 4.45(\mathrm{t}, J=6.3 \mathrm{~Hz}, 1 \mathrm{H}), 5.0(\mathrm{~s}, 1 \mathrm{H}), 6.87(\mathrm{~m}, 2 \mathrm{H}), 7.21(\mathrm{~m}, 2 \mathrm{H})$, 11.0 (br. s, $1 \mathrm{H}, \mathrm{COOH}$ )

${ }^{13}$ C-NMR (75.5 MHz, $\left.\mathrm{D}_{2} \mathrm{O}\right): \delta=21.60,33.72,34.53,36.72,42.31,58.90,59.72,115.6,129.3$, 132.8, 174.7, 177.0.

$[\alpha]_{\mathrm{D}}^{20}=+38.1(\mathrm{c}=0.25, \mathrm{MeOH})$

\subsection{Allgemeine Methoden der Durchführung der Aldol-Reaktion}

$\mathrm{Zu}$ einer Mischung von trockenem DMSO (4.00 mL) und Aceton (1.00 mL) wurde das Dipeptide als Katalysator (30 Mol-\%, Additive: 10 Mol-\%) zugegeben und für 20 Minuten bei RT gerührt. Man gab dann die entsprechenden Aldehyde $(0.500 \mathrm{~mol})$ zu. Die Reaktionsmischung wurde 4 h-12 Tagen unter Stickstoffatomsphäre bei RT gerührt.

Anschließend wurde die Reaktionsmischung mit gesättigter $\mathrm{NH}_{4} \mathrm{Cl}$-Lösung neutralisiert, das Lösungsmittel wurde im Vakuum entfernt. Der Rückstand wurde mit Essigsäuerethylester extrahiert und die vereinigten Extrakte über $\mathrm{MgSO}_{4}$ getrocknet. Die Rohprodukte wurden mittels Dünneschichtchromatographie (Hexan:Ethylacetat 1:1) gereinigt. Die Enantiomerenüberschüsse wurden mittels HPLC (Daicel Chiralpak AS-Säule, $n$-Hexan: $i$-Propanol 75:25, flow rate $1 \mathrm{~mL} / \mathrm{min}$ ) bestimmt, und mit Literatur-Daten verglichen.

9.4.1 (4R)-4-(4-Nitrophenyl)-4-hydroxyl-2-butanon (3)<smiles>CC(=O)C[C@H](O)c1ccc([N+](=O)[O-])cc1</smiles>

$R_{\mathrm{f}}=0.45$ (Hexan: $\left.\mathrm{EE}=1: 1\right)$

${ }^{1}$ H-NMR $\left(300 \mathrm{MHz}, \mathrm{CDCl}_{3}\right): \delta=2.21\left(\mathrm{~s}, 3 \mathrm{H}, \mathrm{CH}_{3}\right), 2.82-2.84(\mathrm{~m}, 2 \mathrm{H}), 3.55$ (br. s, $\left.1 \mathrm{H}, \mathrm{OH}\right)$, 5.25-5.26 (m, $1 \mathrm{H}), 7.50-7.53$ (m, $2 \mathrm{H}, \mathrm{Ph}-H), 8.18-8.21$ (m, $2 \mathrm{H}, \mathrm{Ph}-H)$. 
HPLC (Daicel Chiralpak AS-Säule, $n$-Hexan: $i$-Propanol 75:25, flow rate $1 \mathrm{~mL} / \mathrm{min}$ ); $\lambda=$ $254 \mathrm{~nm}: t_{R}($ major $)=18.84 \mathrm{~min}, t_{R}($ minor $)=26.58 \mathrm{~min} . \lambda=210 \mathrm{~nm}: t_{R}($ major $)=18.67 \mathrm{~min}, t_{R}$ $($ minor $)=26.40 \mathrm{~min}$.

9.4.2 (4R)-4-(2-Nitrophenyl)-4-hydroxyl-2-butanon (11)<smiles>CC(=O)C[C@H](O)c1ccccc1[N+](=O)[O-]</smiles>

$R_{\mathrm{f}}=0.45$ (Hexan: $\left.\mathrm{EE}=1: 1\right)$

${ }^{1} \mathbf{H}-\mathbf{N M R}\left(300 \mathrm{MHz}, \mathrm{CDCl}_{3}\right): \delta=2.21\left(\mathrm{~s}, 3 \mathrm{H}, \mathrm{CH}_{3}\right), 2.65-2.75(\mathrm{~m}, 1 \mathrm{H}), 3.07-3.14(\mathrm{~m}, 1 \mathrm{H})$, $3.75(\mathrm{~d}, J=3.3 \mathrm{~Hz}, 1 \mathrm{H}), 5.60-5.65(\mathrm{~m}, 1 \mathrm{H}), 7.41-7.44(\mathrm{~m}, 1 \mathrm{H}, \mathrm{Ph}-H), 7.64(\mathrm{~m}, 1 \mathrm{H}, \mathrm{Ph}-H)$, 7.85-7.95 (m, $2 \mathrm{H}, \mathrm{Ph}-H)$.

HPLC (Daicel Chiralpak AS -Säule, $n$-Hexan: $i$-Propanol 75:25, flow rate $1 \mathrm{~mL} / \mathrm{min}$ ); $\lambda=210$ $\mathrm{nm}: t_{R}($ major $)=14.85 \min , t_{R}($ minor $)=11.46 \min . \lambda=254 \mathrm{~nm}: t_{R}($ major $)=15.01 \min , t_{R}$ $(\operatorname{minor})=11.61 \mathrm{~min}$.

9.4.3 (4R)-4-(2-Naphtyl) 4-hydroxyl-2-butanon (15)

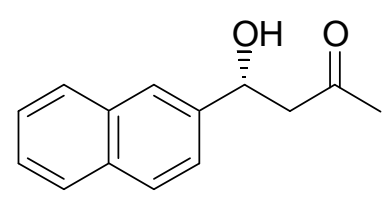

$R_{\mathrm{f}}=0.35$ (Hexan: $\left.\mathrm{EE}=1: 1\right)$

${ }^{1} \mathbf{H}-\mathbf{N M R}\left(300 \mathrm{MHz}, \mathrm{CDCl}_{3}\right): \delta=2.20\left(\mathrm{~s}, 3 \mathrm{H}, \mathrm{CH}_{3}\right), 2.91-2.95(\mathrm{~m}, 2 \mathrm{H})$, 5.29-5.34 (m, $\left.1 \mathrm{H}\right)$, 7.43-7.48 (m, 3 H, Naphtyl- $H$ ), 7.80-7.83 (m, 4 H, Naphtyl- $H$ ).

HPLC (Daicel Chiralpak AS-Säule, $n$-Hexan: $i$ - Propanol 90:10 flow rate $1 \mathrm{~mL} / \mathrm{min}, \lambda=254$ $\mathrm{nm}): t_{R}($ major $)=21.95 \mathrm{~min}, t_{R}($ minor $)=24.08 \mathrm{~min} ; \lambda=210 \mathrm{~nm}: t_{R}($ major $)=21.84 \mathrm{~min}, t_{R}$ $($ minor $)=23.98 \mathrm{~min}$. 
9.4.4 (4R)-(4-Chlorphenyl)-4-hydroxyl-2-butanon (13)<smiles>CC(=O)C[C@H](O)c1ccc(Cl)cc1</smiles>

$R_{\mathrm{f}}=0.45$ (Hexan: $\left.\mathrm{EE}=1: 1\right)$

${ }^{1}$ H-NMR (300 MHz, DMSO): $\delta=2.11\left(\mathrm{~s}, 3 \mathrm{H}, \mathrm{CH}_{3}\right), 2.68-2.72(\mathrm{~m}, 2 \mathrm{H}), 5.00-5.11(\mathrm{~m}, 1 \mathrm{H})$, $5.42(\mathrm{~d}, J=4.5 \mathrm{~Hz}, 1 \mathrm{H}, \mathrm{OH}), 7.37(\mathrm{~m}, 4 \mathrm{H}, \mathrm{Ph}-H)$.

HPLC (Daicel Chiralpak AS-Säule, $n$-Hexan: $i$-Propanol 75:25, flow rate $1 \mathrm{~mL} / \mathrm{min}$ ); $\lambda=210$ $\mathrm{nm}: t_{R}($ major $)=8.82 \mathrm{~min}, t_{R}($ minor $)=10.86 \min$.

\subsection{5 (4R)-4-(Penyl)-4-hydroxyl-2-butanon (16)}

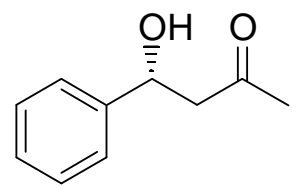

$R_{\mathrm{f}}=0.35$ (Hexan: $\left.\mathrm{EE}=1: 1\right)$

${ }^{1} \mathbf{H}$ - NMR $\left(300 \mathrm{MHz}, \mathrm{CDCl}_{3}\right): \delta=2.18\left(\mathrm{~s}, 3 \mathrm{H}, \mathrm{CH}_{3}\right), 2.82-2.87(\mathrm{~m}, 2 \mathrm{H}), 5.19-5.21(\mathrm{~m}, 1 \mathrm{H})$, $5.30(\mathrm{~d}, J=5.1 \mathrm{~Hz}, 1 \mathrm{H}, \mathrm{OH}), 7.24-7.34(\mathrm{~m}, 5 \mathrm{H}, \mathrm{Ph}-H)$.

HPLC (Daicel Chiralpak AS-Säule, $n$-Hexan: $i$-Propanol 90:10, flow rate $1 \mathrm{~mL} / \mathrm{min}$ ); $\lambda=254$ $\mathrm{nm}: t_{R}($ major $)=16.64 \mathrm{~min}, t_{R}($ minor $)=20.76 \mathrm{~min} ; \lambda=210 \mathrm{~nm}: t_{R}($ major $)=16.51 \mathrm{~min}, t_{R}$ $(\operatorname{minor})=20.66 \mathrm{~min}$.

9.4.6 (4R)-4-(2-Chlorphenyl)-4-hydroxyl-2-butanon (12)<smiles>CC(=O)C[C@H](O)c1ccccc1Cl</smiles>

$R_{\mathrm{f}}=0.45($ Hexan: $\mathrm{EE}=1: 1)$ 
${ }^{1}$ H- NMR (300 MHz, DMSO): $\delta=2.16\left(\mathrm{~s}, 3 \mathrm{H}, \mathrm{CH}_{3}\right), 2.62-2.65(\mathrm{~m}, 2 \mathrm{H}), 5.33-5.35$ (m, $\left.1 \mathrm{H}\right)$, $5.52(\mathrm{~d}, J=5.1 \mathrm{~Hz}, 1 \mathrm{H}, \mathrm{OH}), 7.27-7.40(\mathrm{~m}, 3 \mathrm{H}), 7.59-7.62(\mathrm{~m}, 1 \mathrm{H})$.

HPLC (Daicel Chiralpak AS-Säule, $n$-Hexan: $i$-Propanol 80:20, flow rate $1 \mathrm{~mL} / \mathrm{min}$ ); $\lambda=210$ $\mathrm{nm}: t_{R}($ major $)=7.78 \mathrm{~min}, t_{R}($ minor $)=9.41 \mathrm{~min}$.

9.4.7 (4R)-(4-Bromphenyl)-4-hydroxyl-2-butanon (14)<smiles>CC(=O)C[C@H](O)c1ccc(Br)cc1</smiles>

$R_{\mathrm{f}}=0.45($ Hexan: $\mathrm{EE}=1: 1)$

${ }^{1} \mathbf{H}$ NMR $\left(300 \mathrm{MHz}, \mathrm{CDCl}_{3}\right): \delta=2.19\left(\mathrm{~s}, 3 \mathrm{H}, \mathrm{CH}_{3}\right), 2.80-2.82(\mathrm{~m}, 2 \mathrm{H}), 5.08-5.12(\mathrm{~m}, 1 \mathrm{H})$, $7.42(\mathrm{~m}, 4 \mathrm{H})$.

HPLC (Daicel Chiralpak AS -Säule, $n$-Hexan: $i$-Propanol 75:25, flow rate $1 \mathrm{~mL} / \mathrm{min}$ ) $\lambda=210$ $\mathrm{nm}: t_{R}($ major $)=9.43 \mathrm{~min}, t_{R}($ minor $)=11.67 \mathrm{~min}$.

\subsection{2-[Hydroxy-(2-nitro-phenyl)-methyl]-acryl säure methyl ester (67)}

\section{Allgemeine Methoden der Baylis-Hillman Reaktion:}

$\mathrm{Zu}$ einer Mischung von Dipeptide (30 Mol-\%, Additive 10-20 Mol-\%) trockenem DMSO (1 mMol Aldehyde auf 2 mL DMSO) wurde Vinylketon (10 Äq) bei RT zugetropft. Nach einen halben Stunde Rühren wurde der Aldehyde zugegeben. Die Reaktionsmischung wurde dann bei RT 6h-5 Tagen gerührt.

Anschließend wurde die Reaktionsmischung mit gesättigter $\mathrm{NH}_{4} \mathrm{Cl}$-Lösung neutralisiert, das Lösungsmittel wurde im Vakuum entfernt. Der Rückstand wurde mit Essigsäuerethylester extrahiert und über $\mathrm{MgSO}_{4}$ getrocknet. Die Rohprodukte wurden mittels PräparativDünneschichtchromatographie (Hexan:Ethylacetat 1:1) gereinigt. Die Enantiomerenüberschüsse wurden durch ein Daicel Chiralpak AS-Säule n-Hexan:i-Propanol 75:25, flow rate $1 \mathrm{~mL} / \mathrm{min}$ ) bestimmt und mit Literatur-Daten verglichen. 
9.5.1 3-(Hydroxy(2-nitrophenyl)methyl)but-3-en-2-on<smiles>CC(=O)C(=O)C(O)c1ccccc1[N+](=O)[O-]</smiles>

$R_{\mathrm{f}}=0.45$ (Hexan: $\left.\mathrm{EE}=1: 1\right)$

${ }^{1}$ H-NMR (300 MHz, $\mathrm{CDCl}_{3}$ ): $\delta=2.35$ (s, $3 \mathrm{H}, \mathrm{CH}_{3}$ ), 3.5 (br. s 1H, OH), 5.68 (s, $1 \mathrm{H}$ ), 6.18 (s, $1 \mathrm{H}), 6.20(\mathrm{~s}, 1 \mathrm{H}), 7.42(\mathrm{t}, J=5.2 \mathrm{~Hz}, 1 \mathrm{H}, \mathrm{Ph}-H), 7.62(\mathrm{t}, J=5.2 \mathrm{~Hz}, 1 \mathrm{H}, \mathrm{Ph}-H), 7.78(\mathrm{~d}, J=$ $6.5 \mathrm{~Hz}, 1 \mathrm{H}, \mathrm{Ph}-H), 7.88(\mathrm{~d}, J=6.7 \mathrm{~Hz}, 1 \mathrm{H}, \mathrm{Ph}-H)$.

HPLC (Daicel Chiralpak AS -Säule, $n$-Hexan: $i$-Propanol 75:25, flow rate $1 \mathrm{~mL} / \mathrm{min}$ ) $\lambda=210$ $\mathrm{nm}: t_{R}($ major $)=9.43 \mathrm{~min}, t_{R}($ minor $)=11.67 \mathrm{~min}$.

9.5.2 2-(Hydroxy(2-nitrophenyl)methyl)cyclohex-2-enon<smiles>O=C1CCCC=C1C(O)c1ccccc1[N+](=O)[O-]</smiles>

$R_{\mathrm{f}}=0.35$ (Hexan: $\left.\mathrm{EE}=1: 1\right)$

${ }^{1} \mathbf{H}-\mathbf{N M R}\left(300 \mathrm{MHz}, \mathrm{CDCl}_{3}\right): \delta=1.44(\mathrm{~m}, 2 \mathrm{H}), 2.00(\mathrm{~m}, 2 \mathrm{H}), 2.94(\mathrm{~m}, 4 \mathrm{H}), 5.18(\mathrm{~s}, 1 \mathrm{H})$, $6.76(\mathrm{~m}, 1 \mathrm{H}), 7.45$ (t, $J=5.2 \mathrm{~Hz}, 2 \mathrm{H}, \mathrm{Ph}-H), 8.12$ (t, $J=5.2 \mathrm{~Hz}, 1 \mathrm{H}$, Vinyl- $H$ ).

HPLC (Daicel Chiralpak AS-Säule, n-Hexan: i-Propanol 75:25, flow rate $1 \mathrm{~mL} / \mathrm{min}$ ) $\lambda=210$ $\mathrm{nm}: t_{R}($ major $)=11.21 \mathrm{~min}, t_{R}($ minor $)=13.67 \mathrm{~min}$. 


\subsection{Synthese der Thioharnstoffhaltigen Katalysatoren}

9.6.1 (S)-1-(2-Phenoxyacetyl)pyrrolidin-2-carbonsäure

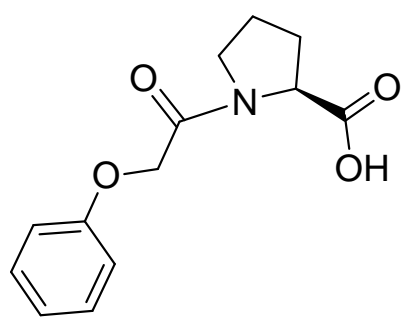

$\mathrm{Zu}$ einer Lösung von $(S)$-Prolin $(5.75 \mathrm{~g}, 0.05 \mathrm{~mol})$, Natriumhydrogencarbonat $(10.1 \mathrm{~g})$ in Wasser (150 mL) wurde eine Lösung von Benzyloxylcarbonylchlorid (11.8 g) in Toluol (23 mL) gegeben. Die Reaktionsmischung wurde bei Raumtemperatur 2 Stunden gerührt. Dann wurde Natriumhydrogencarbonat (5.04 g) und Benzyloxylcarbonylchlorid (11.8 g, 45\% in Toluol) noch ein weites Mal hinzugegeben und die Mischung $1.5 \mathrm{~h}$ lang bei Raumtemperatur gerührt. Anschliessend wurde die Reaktionsmischung mit Ether $(2$ x $30 \mathrm{~mL})$ gewaschen, und die wässrige Phase wurde anschließend mit $6 \mathrm{M} \mathrm{HCl}$ bis ein $\mathrm{pH}$ von 2-3 erreicht wurde. Die Mischung wurde dann mit Ethylacetat (4 x $100 \mathrm{~mL}$ ) extrahiert und die organische Phase mit Wasser $(30 \mathrm{~mL})$ und gesättigter $\mathrm{NaCl}$-Lösung gewaschen und über $\mathrm{Na}_{2} \mathrm{SO}_{4}$ getrocknet. Das Lösungsmittel wurde im Vakuum entfernt $(S)$-N-(benzyl-carbonyl) Prolin (12.0 g, 4.82 mmol, 96\%) als Titelverbindung erhalten.

$\boldsymbol{R}_{\mathbf{f}}=0.5($ Hex.:EE $=1: 4)$

${ }^{1}$ H-NMR (300 MHz, $\mathrm{CDCl}_{3}$ ): $\delta=0.88-2.26$ (m, $\left.4 \mathrm{H}\right), 3.43-3.61(\mathrm{~m}, 2 \mathrm{H}), 4.34-4.43$ (m, $\left.1 \mathrm{H}\right)$, 5.11-5.21(m, $2 \mathrm{H}), 7.24-7.34$ (m, $5 \mathrm{H}, \mathrm{Ph}-H), 9.2$ (br, s, $1 \mathrm{H}, \mathrm{COOH})$. $[\alpha]^{20}=-78.0^{\circ}\left(\mathrm{c}=0.40, \mathrm{CHCl}_{3}\right)$. 
9.6.2 1-(2-Phenoxy-acetyl)-pyrrolidine-2-carbonylchlorid (53)

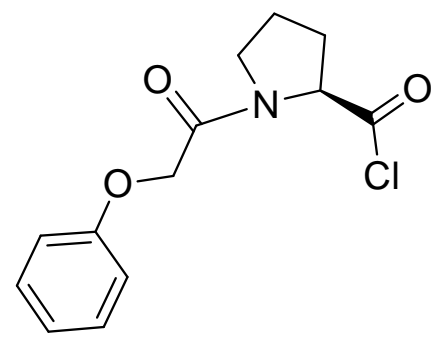

$\mathrm{Zu}$ einer Lösung von (S)-1-(2-phenoxyacetyl)pyrrolidine-2-carbonsäure (1.76 g, 1 Äq, 7.07 $\mathrm{mmol})$ in trockenem Toluol $(20 \mathrm{~mL})$ fügt man tropfenweise im Überschuss Thionylchlorid (1.00 mL, $1.64 \mathrm{~g}, 2$ Äq) bei Raumtemperatur hinzu. Anschließend wurde die Reakionsmischung $2 \mathrm{~h}$ bei $80^{\circ} \mathrm{C}$ unter $\mathrm{N}_{2}$-Atomsphäre gerührt. Das Lösungsmittel wurde verdampft und 1-(2-Phenoxy-acetyl)-pyrrolidine-2-carbonyl chlorid als hellgelbes Öl erhalten. Im ${ }^{1} \mathrm{H}-\mathrm{NMR}$ wurde eine Reinheit von über 96\% (1.85 g, $0.69 \mathrm{Mol})$ gefunden und diese Verbindung wurde ohne weitere Reinigung für weitere Reaktion eingesetzt.

$\boldsymbol{R}_{\mathbf{f}}=0.60($ Hex $.: \mathrm{EE}=1: 1)$

${ }^{1}$ H-NMR (300MHz, $\left.\mathrm{CDCl}_{3}\right): \delta=1.88-2.26(\mathrm{~m}, 4 \mathrm{H}), 3.43-3.61(\mathrm{~m}, 2 \mathrm{H}), 4.34-4.43(\mathrm{~m}, 1 \mathrm{H})$, 5.11-5.21 (m, 2H), 7.24-7.34 (m, 5H, Ph- H).

9.6.3 1-[1-(2-Phenoxy-acetyl)-pyrrolidine-2-carbonyl]-3-(1-phenyl-ethyl)-thioharnstoff (55)

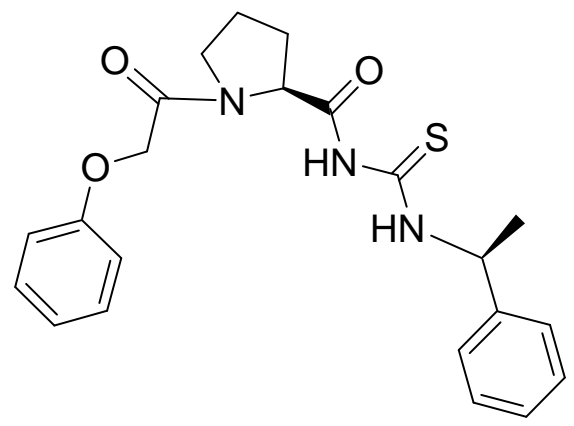

Unter Stickstoffatmosphäre wurde eine Lösung von 1-(2-Phenoxy-acetyl)-pyrrolidine-2carbonyl chlorid (1.89 g, $7.07 \mathrm{mmol}, 1 \mathrm{Äq})$ in trockendem Aceton $(1 \mathrm{~mL})$ tropfenweise zu einer Lösung von Ammoniumthiocyanat (548 mg, $7.07 \mathrm{mmol}, 1$ Äq) in trockendem Aceton (3 
$\mathrm{mL}$ )bei $60^{\circ} \mathrm{C}$ zugetropft. Die Mischung wurde weitere $50 \mathrm{~min}$ gerührt. Danach wurde eine Lösung von (S)- $\alpha$-Methylbenzylamine (856 mg, $7.07 \mathrm{mmol}, 901 \mathrm{~mL}, 1$ Äq) in Aceton (1.5 mL) tropfenweise hinzugegeben. Nachdem die Reaktionsmischung für $2 \mathrm{~h}$ bei $65^{\circ} \mathrm{C}$ gerührt wurde, schüttete man es ins Wasser $(15 \mathrm{~mL})$ und extrahierte mit Methylenchlorid $(3 \mathrm{x} 15 \mathrm{~mL})$. Die Kombinierten organischen Phasen wurden mit gesättigter $\mathrm{NaCl}$-Lösung gewaschen und über $\mathrm{Na}_{2} \mathrm{SO}_{4}$ getrocknet. Das Lösungsmittel wurde im Vakuum entfernt. Das Rohprodukt wurde durch Säulenchromatographie (Hex:EE = 1:1) an Kieselgel gereinigt. Titelverbindung (886 mg, $3.20 \mathrm{mmol}, 30 \%$ ) wurde als gelber Feststoff erhalten.

$\boldsymbol{R}_{\mathbf{f}}=0.55($ Hex.: $\mathrm{EE}=1: 1)$

${ }^{1}$ H-NMR (300 MHz, DMSO): $\delta=1.50-1.53$ (d, $J=6$ Hz, $\left.3 \mathrm{H}\right), 1.53-1.91$ (m, $\left.3 \mathrm{H}\right), 2.21-2.31$ (m, $1 \mathrm{H}), 3.28-3.45$ (m, $2 \mathrm{H}), 4.5$ (m, $1 \mathrm{H}), 4.94-5.07$ (m, $2 \mathrm{H})$, 5.45-5.48 (m, $1 \mathrm{H})$, 7.10-7.31 (m, 3 H), 7.32-7.37 (m, 7 H), 10.89 (br. s. $1 \mathrm{H}), 11.42$ (br. s, $1 \mathrm{H}$ ).

$\mathrm{C}_{22} \mathrm{H}_{25} \mathrm{~N}_{3} \mathrm{O}_{3} \mathrm{~S} \quad$ ber. $278.13216[\mathrm{M}+\mathrm{H}]^{+}$ gef. 278.13218 [ESI-HRMS]

9.6.4 1-(1-Phenyl-ethyl)-3-(pyrrolidin-2-carbonyl)-thioharnstoff (46)<smiles>C[C@H](NC(=S)NC(=O)[C@@H]1CCCN1)c1ccccc1</smiles>

Unter Stickstoff wurde $\mathrm{HBr} / \mathrm{HOAc}(200 \mathrm{~mL}$, 33\% $\mathrm{HBr}-\mathrm{HOAc})$ bei $0^{\circ} \mathrm{C} \mathrm{zu}$ einer Lösung von Verbindung 55 (100 mg, $0.200 \mathrm{mmol})$ in $\mathrm{CH}_{2} \mathrm{Cl}_{2}(1 \mathrm{~mL})$ getropft. Nachdem die Mischung bei $0^{\circ} \mathrm{C} 30$ min gerührt wurde, wurde sie weiter bei Raumtemperatur eine Stunde gerührt. Zu der Reaktionsmischung gab man anschließend trockenen Ether (2 mL). Das Rohprodukt wurde als weißer Niederschlag erhalten. Dieser Niederschlag wurde mit Ether mehrmals gewaschen und dann in Wasser $(1 \mathrm{~mL})$ gelöst. Danach wurde die Lösung mit gesättigter $\mathrm{NaHCO}_{3}$-Lösung behandelt bis sich ein $\mathrm{pH} \mathrm{8-9} \mathrm{von} \mathrm{einstellte.} \mathrm{Die} \mathrm{Reaktionsmischung} \mathrm{wurde} \mathrm{mehrmals} \mathrm{mit}$ Ethylacetat extrahiert. Die vereingten organischen Phasen wurden mit gesättigter NaCl-Lösung gewaschen und über $\mathrm{Na}_{2} \mathrm{SO}_{4}$ getrocknet. Das Lösungsmittel wurde im Vakumm entfernt. Das Rohprodukt wurde durch Säulenchromatographie an Kieselgel (Hexan: Ethylacetat $=1: 1$ ) 
gereinigt. Die Titelverbindung wurde als dunkelgelber Feststoff (45.0 mg, $0.12 \mathrm{mmol}, 67 \%$ ) erhalten.

$\boldsymbol{R}_{\mathbf{f}}=0.65($ Hex. : $\mathrm{EE}=1: 1)$

${ }^{1}$ H-NMR (300 MHz, DMSO): $\delta=1.52$ (d, $J=6 \mathrm{~Hz} 3 \mathrm{H}, \mathrm{CH}_{3}$ ), 1.60-1.66 (m, $2 \mathrm{H}$ ), 1.75-1.76 (m, $1 \mathrm{H}), 1.99-2.02(\mathrm{~m}, 1 \mathrm{H}), 2.74-2.79$ (m,1 H), 2.87-2.92 (m, $1 \mathrm{H}), 3.74-3.79$ (m, $1 \mathrm{H})$, 5.445.55 (m, 1 H), 7.29-7.38 (m, 5 H, Ph- $H$ ), 10.82 (br, s, 1 H, NH).

MS (ESI): $m / z(\%)=278.0(100)\left[\mathrm{M}+\mathrm{H}^{+}\right]$.

$\begin{array}{ll}\mathrm{C}_{14} \mathrm{H}_{19} \mathrm{~N}_{3} \mathrm{OS} & \text { ber. } 278.13216[\mathrm{M}+\mathrm{H}]^{+} \\ & \text {gef. } 278.13218(\mathrm{ESI}-\mathrm{HRMS}) \\ {[\alpha]^{20}{ }_{\mathrm{D}}=-54.5^{\circ}\left(\mathrm{c}, 0.33, \mathrm{CHCl}_{3}\right) .}\end{array}$

9.6.5 1-Methyl-pyrrolidin-2-carbonsäure (59)<smiles>CN1CCC[C@H]1C(=O)O</smiles>

$\mathrm{Zu}$ einer Lösung von L-Prolin $(1.0 \mathrm{~g}, 8.6 \mathrm{mmol})$ in distlliertem MeOH wurde wässriges Formaldehyd (0.70 mL, $9.52 \mathrm{mmol})$ zugegeben. Es wurde Pd/C-Katalysator $250 \mathrm{mg}$ zugegeben. Nach einigen Minuten. unten Rühren wurde die Suspension unter Wasserstoffatomsphäre über Nacht gerührt. Der Katalysator wurde über Celite abfiltriert, und der Rückstand mehre Mal mit $\mathrm{MeOH}$ gewaschen. Das Lösungsmittel wurde im Vakumm entfernt. Das Rohprodukt bildet sich in Etahnol:Benzol $(1: 1,50 \mathrm{~mL})$ als Niederschlage. Das reine Produkt wurde aus Methanol und Ether umkristallisiert. Das reine Produkt (899 mg, $6.95 \mathrm{mmol}, 80 \%$ ) wurde als feine Nadeln erhalten.

$R_{\mathrm{f}}=0.35(\mathrm{MeOH}: \mathrm{EE}=1: 1)$

${ }^{1}$ H-NMR (300 MHz, $\left.\mathrm{D}_{2} \mathrm{O}\right): \delta=1.99-1.79(\mathrm{~m}, 3 \mathrm{H}), 2.29-2.34(\mathrm{~m}, 1 \mathrm{H}), 2.73\left(\mathrm{~s}, 3 \mathrm{H}, \mathrm{CH}_{3}\right), 2.91$ -3.00 (m, 1H), $3.64-3.72(\mathrm{~m}, 2 \mathrm{H}), 5.45-5.55(\mathrm{~m}, 1 \mathrm{H}), 11.0$ (br. s, $1 \mathrm{H}, \mathrm{COOH})$.

${ }^{13}$ C-NMR (75.5 MHz, $\left.\mathrm{CDCl}_{3}\right): \delta=21.37,28.34,40.23,55.83,70.18,173.06$. 
MS $(\mathrm{ESI}) \mathrm{m} / \mathrm{z}(\%)=130.07(100)[\mathrm{M}+\mathrm{H}]^{+}$.

9.6.6 1-Methyl-pyrrolidine-2-carbonsäuramid (60)<smiles>CN1CCC[C@H]1C(N)=O</smiles>

Unter Stickstoff wurde Pyridin (1.92 mL) and $\mathrm{Boc}_{2} \mathrm{O}(11.5 \mathrm{~g}, 149 \mathrm{mmol}) \mathrm{zu}$ einer Lösung von 1-Methyl-pyrrolidine-2-carbonsäure (59) $(5.00 \mathrm{~g}, 38.4 \mathrm{mmol})$ in Dioxan (50 mL) gegeben. Nach ein halben Stunde Rühren wurde Ammoniumhydrogencarbonat (3.84 g, 48.4 mmol) zugegeben. Die Reaktionsmischung wurde dann noch bei Raumtemperatur $2 \mathrm{~h}$ gerührt.

Anschliessend gab man zu dieser Mischung $50 \mathrm{~mL}$ Ethylacetat und $20 \mathrm{~mL}$ Wasser. Die wässrige Phase wurde mehre Male mit Ethylacetat extrahiert. Die vereinigten organischen Phasen wurden mit 2\% HCl $(10 \mathrm{~mL})$, Wasser $(10 \mathrm{~mL})$ und gesättigter NaCl-Lösung $(10 \mathrm{~mL})$ gewaschen. und über $\mathrm{Na}_{2} \mathrm{SO}_{4}$ getrocknet. Das Lösungsmittel wurde im Vakuum entfernt. Das reine Produkt (3.45 g, $2.70 \mathrm{mmol}, 70 \%$ ) wurde aus Aceton umkristalliesiert.

$R_{\mathrm{f}}=0.35(\mathrm{MeOH}: \mathrm{EE}=1: 1)$

${ }^{1}$ H-NMR (300 MHz, DMSO): $\delta=1.63-1.75(\mathrm{~m}, 3 \mathrm{H}), 2.0-2.08(\mathrm{~m}, 1 \mathrm{H}), 2.17-2.24(\mathrm{~m}, 4 \mathrm{H})$, 2.59-2.62 (m, 1H), 2.73 (s, 3H, $\mathrm{CH}_{3}$ ), 2.97-3.03 (m, 1H), 6.95 (br, s 2H, NH $H_{2}$.

${ }^{13}$ C-NMR (150 MHz, DMSO): $\delta=23.15,30,05,40.99,55.95,68.85,175.4$.

MS (ESI): $m / z(\%)=151.0(75)\left[\mathrm{M}+\mathrm{Na}^{+}\right], 278.9(48)\left[2 \mathrm{M}+\mathrm{Na}^{+}\right]$. 
9.6.7 ((S)-(1-Methyl-pyrrolidin-2-yl)-methylamin (61)<smiles>CN1CCC[C@H]1CN</smiles>

Unter Stickstoff wurde eine Suspension von $\mathrm{LiAlH}_{4}(489 \mathrm{mg}, 12.8 \mathrm{mmol})$ in THF $(20 \mathrm{~mL}) \mathrm{zu}$ (8.00 mL Ether) hinzugefügt. 1-Methyl-pyrrolidine-2-carbonsäureamid (60) (548 mg, 4.29 mmol) in THF (23.0 mL) wurde tropfenweise innerhalb von 30 Minuten dazu gegeben. Diese Mischung wurde bei Raumtemperatur $1 \mathrm{~h}$, anschließend bei reflux über Nacht unter Argon gerührt. Die erhaltene gelbe Suspension wurde auf Raumtemperatur abgekühlt und das Gemisch vorsichtig durch Zugabe von gesättigter $\mathrm{Na}_{2} \mathrm{SO}_{4}$-Lösung (1 mL) hydrolysiert. Anorganische Salze wurden durch Filtration entfernt und mit $\mathrm{Et}_{2} \mathrm{O}$ nachgespült. Die vereinigten organischen Phasen wurden mit $2 \% \mathrm{HCl}(1 \mathrm{~mL})$, Wasser $(3 \mathrm{~mL})$ und gesättigter NaCl-Lösung (3 mL) gewaschen und über $\mathrm{Na}_{2} \mathrm{SO}_{4}$ getrocknet. Das Lösungsmittel wurde im Vakuum entfernt. Durch Säulenchromatographie an RP-Gel erhielt man die Titelverbindung (250 mg, 2.19 mmol, $51 \%$ ) als farblose Flüssigkeit.

$\boldsymbol{R}_{\mathbf{f}}=0.3\left(\mathrm{EE}: \mathrm{MeOH}=1: 1\right.$, Anfärbungsmittel: $\left.\mathrm{KMnO}_{4}\right)$.

${ }^{1} \mathbf{H}-\mathbf{N M R}\left(300 \mathrm{MHz}, \mathrm{CDCl}_{3}\right): \delta=1.57-1.82(\mathrm{~m}, 4 \mathrm{H}), 1.93-2.22(\mathrm{~m}, 2 \mathrm{H}), 2.32$ (s $3 \mathrm{H}, \mathrm{CH}_{3}$ ), 2.62-3.0 (m, 2H), 3.00-3.06 (m, 1H), 4.80 (br., $2 \mathrm{H}, \mathrm{NH}_{2}$ ).

${ }^{13}$ C-NMR (150 MHz, DMSO): $\delta=23.15,30.05,36.99,45.80,51.55,68.85$.

EI (MS): $m / z(\%)=84.1(100),\left[\mathrm{M}-\mathrm{CH}_{2} \mathrm{NH}_{2}\right]$.

$[\alpha]^{20}{ }_{\mathrm{D}}=-66.1^{\circ}(\mathrm{c}, 0.366, \mathrm{MeOH})$.

9.6.8 (1-Isothiocyanato-ethyl)-benzol (57)

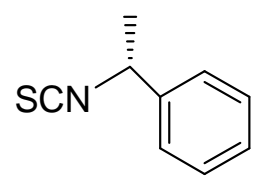

Unter Stickstoff wurde DCC (8.10 g, 39.2 mmol, 1 Äq) zu einer Lösung von (R)-1-Phenylethylamin (5 mL, $39.2 \mathrm{mmol}, 1 \mathrm{Äq})$ in Trocknem Ether $(50 \mathrm{~mL})$ bei $-20^{0} \mathrm{C}$ zugegeben. Nach 
einigen Minuten Rühren wurde eine Suspension entstehen und es wurde $\mathrm{CS}_{2}$ (15 mL) in Eher (5 $\mathrm{mL)}$ tropfenweise bei gleicher Temperatur zugegeben. Die Reaktionsmischung wurde dann langsame bis Raumtemperatur erwärmt und über Nacht gerührt. Anschließend wurde der Niederschlag abfiltriert. Dieser Niederschlag wurde mehrere male mit Ether gewaschen. Das Lösungsmittel wurde im Vakuum entfernt. Das Rohprodukt wurde durch Säulenchromatographie an Kieselgel (Hex: $\mathrm{EE}=95: 5)$ gereinigt. Das Produkt (6.38 g, $3.91 \mathrm{mmol}, 99.8 \%$ ) wurde als farbloses Öl erhalten.

$R_{\mathrm{f}}=0.65(100 \%$ Hexan)

${ }^{1}$ H-NMR (300 MHz, DMSO): $\delta=1.60$ (d, $J=6 \mathrm{~Hz}, 3 \mathrm{H}, \mathrm{CH}_{3}$ ), 5.21 (q. $\left.J=6.4 \mathrm{~Hz}, 1 \mathrm{H}\right), 7.25$ $7.32(\mathrm{~m}, 5 \mathrm{H}, \mathrm{Ph}-H)$.

${ }^{13}$ C-NMR (50 MHz, DMSO): $\delta=24.15,56.38,125.59,128.17,128.85,140.18$. $[\alpha]^{20}{ }_{\mathrm{D}}=-16.4^{\circ}\left(\mathrm{c}, 2.9, \mathrm{CHCl}_{3}\right)$.

9.6.9 1-(1-Methyl-pyrrolidin-2-ylmethyl)-3-(1-phenyl-ethyl)-thioharnstoff (49)<smiles>C[C@H](NC(=S)NC[C@@H]1CCCN1C)c1ccccc1</smiles>

Unter Stickstoff wurde eine Lösung von (1-Isothiocyanato-ethyl)-benzol (57) (258 mg, 1.58 mmol, 1 Äq) in trochee Toluol (6 mL) zu einer Lösung von ((S)-(1-Methyl-pyrrolidin-2-yl)methylamin (61) (180 mg, $1.58 \mathrm{mmol}, 1$ Äq) in trockenem Toluen (6 mL) bei Raumtemperatur tropfenweise zugegeben. Die Mischung wurde bei Raumtemperatur unter Argon $4 \mathrm{~h}$ gerührt. Anschliessend wurde das Lösungsmittel im Vakumm entfernt. Das Rohprodukt wurde durch Säulenchromatographie an Kieselgel gereinigt. Die Titelverbindung (393 mg, 90\%) wurde als weisser Feststoff erhalten.

$\boldsymbol{R}_{\mathbf{f}}=0.33(\mathrm{EE}: \mathrm{EtOH}=1: 1)$ 
${ }^{1}$ H-NMR (300 MHz, DMSO): $\delta=1.37-1.39$ (d, $\left.J=6 \mathrm{~Hz}, 3 \mathrm{H}, \mathrm{CH}_{3}\right)$, 1.43-1.75 (m, $\left.1 \mathrm{H}\right)$, 2.14$2.20(\mathrm{~m}, 1 \mathrm{H}), 2.41-2.51(\mathrm{~m}, 2 \mathrm{H}), 3.19-3.26$ (m, $2 \mathrm{H}), 3.41-3.48$ (m, $2 \mathrm{H}), 5.38$ (q, $J=8 \mathrm{~Hz}, 1$ H), 6.97-7.35 (m, 5H, Ph-H).

ESI $(\mathrm{MS}) m / z(\%)=278.1(100),\left[\mathrm{M}+\mathrm{H}^{+}\right]$.

$[\alpha]^{20}{ }_{\mathrm{D}}=+34.5^{\circ}\left(\mathrm{c}, 0.337, \mathrm{CHCl}_{3}\right)$.

9.6.10 (R)-1-(1-Isothiocyanato-ethyl)-naphthalen (77)<smiles>C[C@H](NS(=O)(=S)c1cccc2ccccc12)c1ccccc1</smiles>

$\mathrm{Zu}$ einer Lösung von (R)-1-(1-naphtyl)ethylamine (1.00 g, $5.80 \mathrm{mmol}, 1$ Äq) in trockenem Ether (5 mL) gab man bei $-10{ }^{\circ} \mathrm{C}$ DCC (1.20 g, $\left.5.80 \mathrm{mmol}, 1 \mathrm{Äq}\right)$ hinzu. Nachdem DCC völlig gelöst war, wurde $\mathrm{CS}_{2}(2.23 \mathrm{~mL})$ innerhalb von 30 Minuten. zugetropft. Die Reaktionsmischung wurde innerhalb von $3 \mathrm{~h}$ auf Raumtemperatur erwärmt und anschließend wurde für weitere $12 \mathrm{~h}$ bei Raumtemperatur gerührt. Der Niederschlag wurde abfiltriert und das Lösungsmittel im Vakuum entfernt. Der Rest wurde in Ether aufgenommen und der Neiderschlag wurde noch mal abfiltriert. Nach Entferen des Lösungmittels wurde das Rohprodukt durch Säulenchromatografie an $\mathrm{SiO}_{2}$ (EE:Hexane 1:9) gereinigt und Verbindung 77 (1.18 g, $5.53 \mathrm{mmol}, 95 \%)$ wurde als farblose Flüssigkeit erhalten.

$R_{\mathrm{f}}=0.7($ Hexan $100 \%)$

${ }^{1}$ H-NMR (300 MHz, [D $]$ DMSO): $\delta=1.77$ (d, $J=6.6 \mathrm{~Hz}, 3 \mathrm{H}, \mathrm{CH}_{3}$ ), 6.05 (q, $J=6.7 \mathrm{~Hz}, 1 \mathrm{H}$ ), 7.54-7.67 (m, 4 H, Ph- $H$ ), 7.93-8.01 (m, 2 H, Ph- $H$ ), 8.10 (d, $J=9$ Hz, $1 \mathrm{H}, \mathrm{Ph}-H)$ ppm.

${ }^{13}$ C-NMR (75.5 MHz, [D $]$ DMSO): $\delta=33.3,28.7,28.3,73.8,74.6,76.4,73.5,72.9,72.7,69.7$, $64.2,82.6 \mathrm{ppm}$.

$[\alpha]^{20}{ }_{D}=-127.2^{\circ}(\mathrm{c}, 0.235$, Aceton $)$. 
9.6.11 (S)-1-(1-Isothiocyanato-ethyl)-naphthalene (77a)<smiles>C[C@H](NS(=O)(=O)c1cccc2ccccc12)c1ccccc1</smiles>

Die Durchführung der Darstellung der Verbindung 77a ist gleich für Verbindung 77.

$R_{\mathrm{f}}=0.7($ Hexan $100 \%)$

${ }^{1}$ H-NMR (300 MHz, [D 6 ]DMSO): $\delta=1.77$ (d, $\left.J=6.6 \mathrm{~Hz}, 3 \mathrm{H}, \mathrm{CH}_{3}\right), 6.05$ (q, $\left.J=6.7 \mathrm{~Hz}, 1 \mathrm{H}\right)$, 7.54-7.67 (m, 4 H, Naphtyl-H), 7.93-8.01 (m, 2 H, Naphtyl-H), 8.10 (d, J = 9 Hz, 1 H, Naphtyl$H) \mathrm{ppm}$.

${ }^{13}$ C-NMR (75.5 MHz, [D $]$ DMSO): $\delta=33.3,28.7,28.3,73.8,74.6,76.4,73.5,72.9,72.7,69.7$, $64.2,82.6 \mathrm{ppm}$.

EI (MS) $(70 \mathrm{eV}): \mathrm{m} / \mathrm{z}(\%)=213.1(18)\left[\mathrm{M}^{+}\right], 155.2(100)$

$[\alpha]^{20}{ }_{D}=+126.0^{\circ}(\mathrm{c}=0.592$, Aceton $)$.

9.6.12 1-(2-Amino-cyclohexyl)-3-(1-phenyl-ethyl)-thioharnstoff (64)

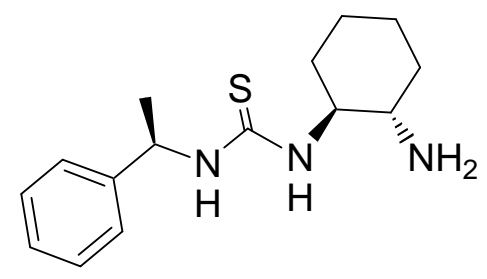

Unter Stickstoff wurde eine Lösung von 1-Isothiocyanato-ethyl)-benzol (57) (1.84 g, $0.01 \mathrm{~mol}$, $1 \ddot{\mathrm{A} q})$ in trocknem $\mathrm{CH}_{2} \mathrm{Cl}_{2}(5 \mathrm{~mL}) \mathrm{zu}$ einer Lösung von kommerzieller $(S, S)$-1,2-Diaminocyclohexan $(1.40 \mathrm{~g}, 0.01 \mathrm{~mol}, 1 \mathrm{~A} q)$ in trockenem $\mathrm{CH}_{2} \mathrm{Cl}_{2}(5 \mathrm{~mL})$ innerhalb von 30 Minuten. zugetropft. Die Reaktionsmischung wurde dann unter Stickstoff $2 \mathrm{~h}$ bei Raumtemperatur gerührt. Das Lösungsmittel wurde im Vakuum entfernt. Das Rohprodukt wurde durch Säulenchro-matographie an Kieselgel (EE:EtOH = 1:1) gereinigt. Das Produkt $(2.07$ g, 7.26 mmol, 61\%) wurde als weisser Feststoff erhalten. 
$\boldsymbol{R}_{\mathbf{f}}=0.3(\mathrm{EE}: \mathrm{EtOH}=1: 1)$.

${ }^{1}$ H-NMR (300 MHz, DMSO): $\delta=1.04-1.27$ (m, $4 \mathrm{H}$ ), 1.39-1.41 (d, $J=6,3 \mathrm{H}, \mathrm{CH}_{3}$ ), 1.581.66 (m, 2 H), 1.75-1.82 (m, $1 \mathrm{H}), 1.94-1.99$ (m, $1 \mathrm{H}), 3.68-3.72(\mathrm{~m}, 1 \mathrm{H}), 5.42-5.45$ (q, $J=6,1$ H), 7.19-7.35 (m, $5 \mathrm{H}, \mathrm{Ph}-H)$.

${ }^{13}$ C-NMR (75MHz, DMSO): $\delta=22.3,24.3,24.4,31.3,34.5,52.2,54.2,59.5,125.9,126.0$, 126.5, 128.1, 144.4, 181.6.

ESI (MS): $\mathrm{m} / \mathrm{z}(\%)=278.2(26)\left[\mathrm{M}+\mathrm{H}^{+}\right], 300.1(48)\left[\mathrm{M}+\mathrm{Na}^{+}\right], 555.0(100)\left[2 \mathrm{M}+\mathrm{H}^{+}\right], 577.0$ (96) $\left[2 \mathrm{M}+\mathrm{Na}^{+}\right]$.

$[\alpha]^{20}{ }_{\mathrm{D}}=-92.5\left(\mathrm{c}, 1.1, \mathrm{CHCl}_{3}\right)$.

9.6.13 2-\{2-[3-(1-Phenyl-ethyl)-thioureido]-cyclohexylcarbamoyl $\}$-pyrrolidine-1carbonsäure benzyl ester (75)

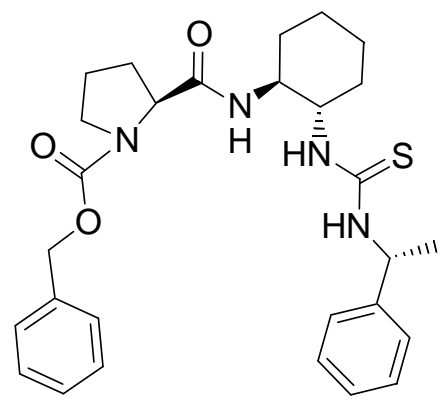

$\mathrm{Zu}$ einer Lösung von $(S)$-1-(2-phenoxyacetyl) pyrrolidine-2-carbonsäure (0.70 g, $2.8 \mathrm{mmol}, 1.3$ $\ddot{\mathrm{A} q}$ ) in trockenem $\mathrm{CH}_{2} \mathrm{Cl}_{2}(2 \mathrm{~mL}$ ) wurde eine Lösung von DMAP (52.9 mg, $0.43 \mathrm{mmol}, 0.2$ Äq) und DCC (715 mg, $3.46 \mathrm{mmol}, 1.6 \mathrm{Äq})$ in einer Mischung von $\mathrm{CH}_{2} \mathrm{Cl}_{2}$ und DMF (2:1, $\left.9 \mathrm{~mL}\right)$ zugetropft. Nach 40 Minuten. Rühren wurde die Verbindung 1-(2-Amino-cyclohexyl)-3-(1phenyl-ethyl)-thiourea (600 mg, $2.16 \mathrm{mmol}, 1$ Äq) portionsweise zugegeben. Die Reaktionsmischung wurde $2 \mathrm{~h}$ bei Raumtemperatur gerührt. Anschliessend wurde der gebildet Niederschlag abfiltriert und mit $\mathrm{CH}_{2} \mathrm{Cl}_{2}$ mehre Male gewaschen. Die vereinigten organischen Phasen wurde mit gesättigter $\mathrm{NH}_{4} \mathrm{Cl}(5 \mathrm{~mL})$ Lösung, Wasser $(5 \mathrm{~mL})$ und gesättigter $\mathrm{NaCl}$-Lösung (5 $\mathrm{mL}$ ) gewaschen und über $\mathrm{Na}_{2} \mathrm{SO}_{4}$ getrocknet. Das Lösungsmittel wurde im Vakumm entfernt. Durch eine Reinigung mittels Säulenchromatographie an Kieselgel mit Gradientem (Hex : EE =1:1-1:2-1:3-1:4) wurde die Titelverbindung (795 mg, $1.57 \mathrm{mmol}, 72 \%$ ) als weisser Feststoff erhalten. 
$R_{\mathrm{f}}=0.5(\mathrm{Hex} .: \mathrm{EE}=1: 4)$

${ }^{1}$ H-NMR (300 MHz, [D $]$ DMSO): $\delta=1.05-1.31$ (m, $\left.6 \mathrm{H}\right), 1.37$ (d, J=6 Hz, $3 \mathrm{H}, \mathrm{CH}_{3}$ ), 1.50$1.76(\mathrm{~m}, 7 \mathrm{H}), 1.89-1.99(\mathrm{~m}, 1 \mathrm{H}), 3.27-3.34(\mathrm{~m}, 1 \mathrm{H}), 3.52-3.55(\mathrm{~m}, 1 \mathrm{H}), 4.00-4.11(\mathrm{~m}, 1 \mathrm{H})$, 4.89-5.05 (m, 2 H), 5.38-5.42 (q, $J=6 \mathrm{~Hz}, 1 \mathrm{H}), 7.12-7.54$ (m, $10 \mathrm{H}, \mathrm{Ph}-H), 7.83-7.98$ (m, $3 \mathrm{H}$, $\mathrm{Ph}-H)$.

${ }^{13}$ C-NMR (75.5 MHz, [D 6 DMSO): $\delta=153.7,153.8,137.1,136.9,128.4,128.2,128.1,127.7$, 127.5, 127.4, 126.9, 126.7, 126.1, 65.7, 65.6, 59.6, 59.1, 51.4, 47.1, 46.4, 31.2, 30.2, 24.4, 23.6, $22.9,22.5$.

ESI(MS): $\mathrm{m} / \mathrm{z}(\%)=531(100)\left[\mathrm{M}^{+}+\mathrm{Na}^{+}\right]$.

9.6.14 Pyrrolidine-2-carbonsäure\{2-[3-(1-phenyl-ethyl)-thioureido]-cyclohexyl \}amid (72)

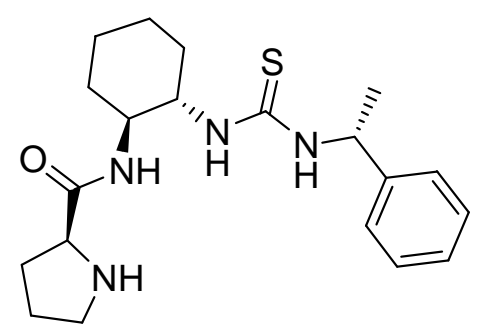

$\mathrm{Zu}$ einer Mischung aus $\mathrm{HBr} / \mathrm{HOAc}(870 \mu \mathrm{L}$, 33\% HBr-HOAc) wurde eine Lösung von Verbindung $75(400 \mathrm{mg}, 0.78 \mathrm{mmol})$ in trockenem $\mathrm{CH}_{2} \mathrm{Cl}_{2}(1 \mathrm{~mL})$ bei $0^{\circ} \mathrm{C}$ tropfenweise hinzugefügt. Nachdem die Mischung bei $0^{\circ} \mathrm{C} 30$ Minuten lang gerührt wurde, wurde sie weitere 40 Minuten. bei Raumtemperatur gerührt. Dann wurde trockener Ether ( $8 \mathrm{~mL}$ ) hinzugegeben, und der entstandene weisse nichtkristallierte Feststoff mit Ether ( 3 x $3 \mathrm{~mL}$ ) mehrmals gewaschen. Anschliessend wurde der Niederschlag in bidest. Wasser (1 mL) gelöst and mit gesättigter $\mathrm{NaHCO}_{3}$-Lösung auf $\mathrm{pH}$ 8-9 gebracht. Die Mischung wurde mehrmals mit Ethylacetat extrahiert. Die vereinigten organischen Phasen wurde über $\mathrm{Na}_{2} \mathrm{SO}_{4}$ getrocknet. Das Lösungsmittel wurde im Vakuum entfernt. Nach weiterer Reinigung mittels Säulenchromatographie (Hex:EE = 1:1) an Kieselgel wurde die Titelverbindung (45.0 mg, $0.01 \mathrm{mmol}$, $67 \%$ ) als dunkelgelber Feststoff erhalten.

$\boldsymbol{R}_{\mathbf{f}}=0.55(\mathrm{Hex}: \mathrm{EHE}=1: 1)$

${ }^{1}$ H-NMR (300 MHz, DMSO): $\delta=1.13-1.24$ (m, $5 \mathrm{H}$ ), 1.37 (d, $J=6 \mathrm{~Hz}, 3 \mathrm{H}, \mathrm{CH}_{3}$ ), 1.48-1.52 (m, 2 H), 1.56-1.62 (m, 2 H), 1.77-1.79 (m, 2 H), 1.81-1.99 (m, 1 H), 2.51-2.73 (m, 2 H), 3.16- 
$3.30(\mathrm{~m}, 3 \mathrm{H}), 3.48-3.54(\mathrm{~m}, 1 \mathrm{H}), 4.10-4.12(\mathrm{~m}, 1 \mathrm{H}), 5.35-5.37$ (q, $J=6 \mathrm{~Hz}, 1 \mathrm{H}), 7.16-7.42$ (m, $5 \mathrm{H}, \mathrm{Ph}-H$ ), 7.78-7.90 (m, $1 \mathrm{H}, \mathrm{Ph}-H$ ).

${ }^{13}$ C-NMR (150 MHz, DMSO): $\delta=153.7,153.8,137.1,136.9,128.4,128.2,128.1,127.7$, $127.5,127.4,126.9,126.7,126.1,65.7,65.6$, 59.6, 59.1, 51.4, 47.1, 46.4, 31.2, 30.2, $24.4,23.6,22.9,22.5$.

ESI $(\mathrm{MS}): \mathrm{m} / \mathrm{z}(\%)=375.2(100)\left[\mathrm{M}+\mathrm{H}^{+}\right], 398.2(5)\left[\mathrm{M}+\mathrm{Na}^{+}\right]$.

$\mathrm{C}_{20} \mathrm{H}_{30} \mathrm{~N}_{4} \mathrm{OS} \quad$ ber. $375.22131\left[\mathrm{M}+\mathrm{H}^{+}\right]$ gef. 375.22136, and 376.22467 (ESI-HR-MS)

$[\alpha]^{20}{ }_{D}=-80.0\left(\mathrm{c}, 0.42, \mathrm{CHCl}_{3}\right)$.

9.6.15 1-(1-Phenyl-ethyl)-3-\{2-[3-(1-phenyl-ethyl)-thioureido]-cyclohexyl $\}$-thioharnstoff (47)<smiles>C[C@H](NC(=S)N[C@H]1CCCC[C@H]1NC(=S)N[C@H](C)c1ccccc1)c1ccccc1</smiles>

Die Darstellung für Verbindung 47 wurde nach den Synthesemethoden der Verbindung 64 dürchgeführt. Das Produkt wurde als heller gelber Feststoff (50\% Ausbeute) erhalten.

$\boldsymbol{R}_{\mathbf{f}}=0.5(\mathrm{EE}: \mathrm{EtOH}=1: 1)$

${ }^{1}$ H-NMR (300 MHz, DMSO): $\delta=0.94-1.23$ (m, $\left.4 \mathrm{H}\right), 1.25$ (d, $J=6 \mathrm{~Hz}, 6 \mathrm{H}, 2 \mathrm{CH}_{3}$ ), 1.551.65 (m, 2 H), 1.55-2.05 (m, 1 H), 1.94-1.99 (m, 2 H), 4.00-4.20 (m, 1 H), 5.40 (q, $J=6,2$ H), 7.19-7.35 (m, $10 \mathrm{H}, \mathrm{Ph}-H$ ), 7.82 (br. s, $1 \mathrm{H}, \mathrm{NH}$ ).

${ }^{13}$ C-NMR (75 MHz, DMSO): $\delta=22.3,24.4,28.3$, , 56.2, 59.5, 125.9, 126.0, 127.5, 128.3.

MS (ESI): $\mathrm{m} / \mathrm{z}(\%)=463.2(100)[\mathrm{M}+\mathrm{Na}]^{+}, 902.9(90)[2 \mathrm{M}+\mathrm{Na}]^{+}$. 
9.6.16 1-(2-Amino-cyclohexyl)-3-(1-naphthalen-1-yl-ethyl)-thiourea (73)

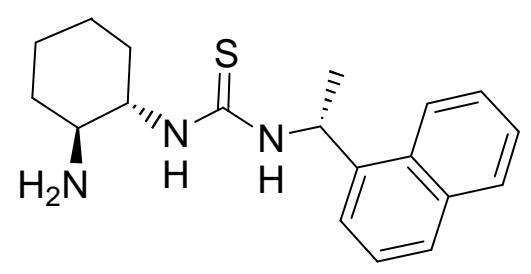

Die Darstellung für Verbindung 73 wurde nach den Synthesemethoden der Verbindung 64 durchgeführt. (R)-1-(1-Isothiocyanato-ethyl)-naphthalen (77) wurde als Elektrophil und Diaminocyclohexan als Nucleophil eingesetzt.

Das Produkt wurde als heller gelber Feststoff erhalten (71\% Ausbeute).

$\boldsymbol{R}_{\mathbf{f}}=0.4($ Hex. : $\mathrm{EE}=1: 1)$

${ }^{1}$ H NMR (300 MHz, [D $]$ DMSO): $\delta=1.12-1.26(\mathrm{~m}, 5 \mathrm{H}), 1.56\left(\mathrm{~d}, J=6.9 \mathrm{~Hz}, 3 \mathrm{H}, \mathrm{CH}_{3}\right), 1.77-$ $1.80(\mathrm{~m}, 1 \mathrm{H}), 1.95-1.99(\mathrm{~m}, 1 \mathrm{H}), 2.37-2.45(\mathrm{~m}, 1 \mathrm{H}), 2.81-2.85(\mathrm{~m}, 1 \mathrm{H}), 3.74-3.75(\mathrm{~m}, 1 \mathrm{H})$, 6.18-6.20 (q, $J=6.9$ Hz, 1 H), 7.20-7.23 (br. s, 1H, NH), 7.48-7.58 (m, 4 H, Naphtyl- $H$ ), 7.82$7.85(\mathrm{~d}, J=9.0 \mathrm{~Hz}, 1 \mathrm{H}$, Naphtyl-H), 7.90-7.95 (m, $1 \mathrm{H}$, Naphtyl-H), 8.12-8.19 (m, $1 \mathrm{H}$, Naphtyl-H) ppm.

${ }^{13}$ C NMR (75.5 MHz, [D 6 ]DMSO): $\delta=21.01,24.22,24.39,31.32,34.23,54.31,59.30,122.55$, $123.47,125.35,125.53,126.03,127.30,128.49,130.59,133.36,139.82,181.5$ ppm.

ESI (MS): $m / z(\%)=328.1(100)[\mathrm{M}+\mathrm{H}]^{+}, 654.9(70)[2 \mathrm{M}+\mathrm{H}]^{+}$.

$\mathrm{C}_{19} \mathrm{H}_{25} \mathrm{~N}_{3} \mathrm{~S} \quad$ bre. $328.18419[\mathrm{M}+\mathrm{H}]^{+}$ gef. 328.18425 (ESI-HRMS)

$[\alpha]^{20}{ }_{D}=-124.1^{\circ}\left(\mathrm{c}=0.61, \mathrm{CHCl}_{3}\right)$. 
9.6.17 1-(2-Amino-cyclohexyl)-3-(1-naphthalen-1-yl-ethyl)-thiourea (81)

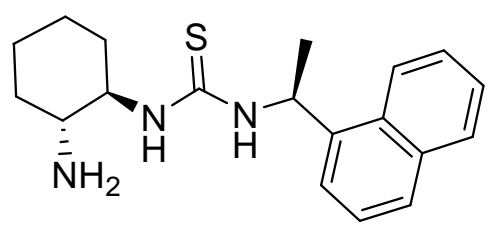

Die Darstellung für Verbindung 81 wurde nach den Synthesemethoden der Verbindung 64 durchgeführt. (S)-1-(1-Isothiocyanato-ethyl)-naphthalen (77a) wurde als Elektrophil Diaminocyclohexan als Nucleophil eingesetzt.

Das Produkt wurde als heller gelber Feststoff (71\% Ausbeute) erhalten.

$\boldsymbol{R}_{\mathbf{f}}=0.4($ Hex. $: \mathrm{EE}=1: 1)$

${ }^{1}$ H NMR (300 MHz, [D 6 ]DMSO): $\delta=1.12-1.26$ (m, $\left.5 \mathrm{H}\right), 1.54\left(\mathrm{~d}, J=6.9 \mathrm{~Hz}, 3 \mathrm{H}, \mathrm{CH}_{3}\right), 1.77-$ $1.80(\mathrm{~m}, 1 \mathrm{H}), 1.95-1.99(\mathrm{~m}, 1 \mathrm{H}), 2.37-2.45$ (m, $1 \mathrm{H}), 2.8-2.85(\mathrm{~m}, 1 \mathrm{H}), 3.74-3.75(\mathrm{~m}, 1 \mathrm{H})$, 6.24 (q, $J=6.9 \mathrm{~Hz}, 1 \mathrm{H}$ ), 7.20 (br. s, $1 \mathrm{H}, \mathrm{NH}), 7.48-7.58$ (m, $4 \mathrm{H}, \mathrm{Naphtyl}-H), 7.84$ (d, $J=9.0$ Hz, 1 H, Naphtyl-H), 7.90-7.95 (m, 1 H, Naphtyl- $H$ ), 8.12-8.19 (m, 1 H, Naphtyl- $H$ ) ppm.

${ }^{13}$ C NMR (75.5 MHz, [D $]$ DMSO): $\delta=21.01,24.22,24.39,31.32,34.23,54.31,59.30,122.55$, $123.47,125.35,125.53,126.03,127.30,128.49,130.59,133.36,139.82,181.5$ ppm.

ESI (MS): $m / z=328.0(100)[\mathrm{M}+\mathrm{H}]^{+}$.

$\mathrm{C}_{19} \mathrm{H}_{25} \mathrm{~N}_{3} \mathrm{~S} \quad$ bre. $328.18419[\mathrm{M}+\mathrm{H}]^{+}$

gef. 328.18432 (ESI-HRMS)

$[\alpha]^{20}{ }_{\mathrm{D}}=+114.3^{\circ}\left(\mathrm{c}=0.3, \mathrm{CHCl}_{3}\right)$.

9.6.18 1-(2-Amino-cyclohexyl)-3-(1-naphthalen-1-yl-ethyl)-thiourea (82)<smiles>C[C@H](NC(=S)N[C@@H]1CCCC[C@H]1N)c1cccc2ccccc12</smiles>

Die Darstellung für Verbindung 82 wurde nach den Synthesemethoden der Verbindung 64 durchgeführt. (R)-1-(1-Isothiocyanato-ethyl)-naphthalen (77) wurde als Elektrophil und Diaminocyclohexan als Nucleophil eingesetzt. 
Das Produkt erscheint als heller gelber Feststoff (70\% Ausbeute).

$\boldsymbol{R}_{\mathbf{f}}=0.4($ Hex. : $\mathrm{EE}=1: 1)$

${ }^{1}$ H NMR (300 MHz, [D 6 ]DMSO): $\delta=1.12-1.26$ (m, $\left.5 \mathrm{H}\right), 1.55\left(\mathrm{~d}, J=6.9 \mathrm{~Hz}, 3 \mathrm{H}, \mathrm{CH}_{3}\right), 1.77-$ $1.80(\mathrm{~m}, 1 \mathrm{H}), 1.95-1.99(\mathrm{~m}, 1 \mathrm{H}), 2.37-2.45$ (m, $1 \mathrm{H}), 2.8-2.85(\mathrm{~m}, 1 \mathrm{H}), 3.74-3.75(\mathrm{~m}, 1 \mathrm{H})$, 6.24 (q, $J=6.9 \mathrm{~Hz}, 1 \mathrm{H}$ ), 7.20-7.23 (br. s, $1 \mathrm{H}, \mathrm{NH}), 7.48-7.58$ (m, $4 \mathrm{H}, \mathrm{Naphtyl}-H), 7.84$ (d, $J$ $=9.0$ Hz, 1 H, Naphtyl- $H$ ), 7.90-7.95 (m, 1 H, Naphtyl- $H$ ), 8.12-8.19 (m, 1 H, Naphtyl-H) ppm. ${ }^{13}$ C NMR (75.5 MHz, [D $]$ DMSO): $\delta=21.01,24.22,24.39,31.32,34.23,54.31,59.30,122.55$, $123.47,125.35,125.53,126.03,127.30,128.49,130.59$, 133.36, 139.82, 181.5 ppm.

ESI $(\mathrm{MS}): m / z(\%)=328.1(75)[\mathrm{M}+\mathrm{H}]^{+}, 350.1[\mathrm{M}+\mathrm{Na}]^{+}, 655.90(78)[2 \mathrm{M}+\mathrm{H}]^{+}$, $677.0[2 \mathrm{M}+\mathrm{Na}]^{+}$. $[\alpha]^{20}{ }_{D}=+41.3^{\circ}\left(\mathrm{c}=1.0, \mathrm{CHCl}_{3}\right)$.

9.6.19 1-(2-Amino-cyclohexyl)-3-(1-naphthalen-1-yl-ethyl)-thiourea (83)

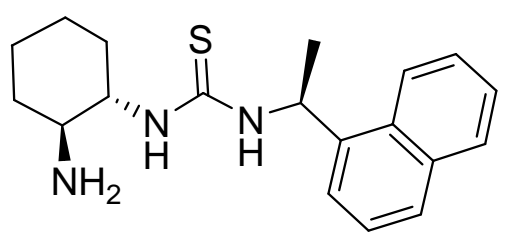

Die Darstellung für Verbindung 83 wurde nach den Synthesemethoden der Verbindung 64 durchgeführt. (S)-1-(1-Isothiocyanato-ethyl)-naphthalen (77a) wurde als Elektrophil und Diaminocyclohexan als Nucleophil eingesetzt.

Das Produkt wurde als heller gelber Feststoff (69\% Ausbeute) erhalten.

$\boldsymbol{R}_{\mathbf{f}}=0.4($ Hex. : $\mathrm{EE}=1: 1)$

${ }^{1} \mathbf{H}$ NMR (300 MHz, [D 6 DMSO): $\delta=1.12-1.26(\mathrm{~m}, 5 \mathrm{H}), 1.54\left(\mathrm{~d}, J=6.9 \mathrm{~Hz}, 3 \mathrm{H}, \mathrm{CH}_{3}\right), 1.77-$ $1.80(\mathrm{~m}, 1 \mathrm{H}), 1.95-1.99(\mathrm{~m}, 1 \mathrm{H}), 2.37-2.45$ (m, $1 \mathrm{H}), 2.8-2.85(\mathrm{~m}, 1 \mathrm{H}), 3.74-3.75(\mathrm{~m}, 1 \mathrm{H})$, 6.24 (q, $J=6.9 \mathrm{~Hz}, 1 \mathrm{H}$ ), 7.20-7.23 (br. s, $1 \mathrm{H}, \mathrm{N} H$ ), 7.48-7.58 (m, 4 H, Naphtyl- $H$ ), 7.84 (d, $J$ $=9.0 \mathrm{~Hz}, 1 \mathrm{H}$, Naphtyl-H), 7.90-7.95 (m, 1 H, Naphtyl- $H$ ), 8.12-8.19 (m, 1 H, Naphtyl-H) ppm. 
${ }^{13}$ C NMR (75.5 MHz, [D $]$ DMSO): $\delta=21.01,24.22,24.39,31.32,34.23,54.31,59.30,122.55$, $123.47,125.35,125.53,126.03,127.30,128.49,130.59,133.36,139.82,181.5$ ppm.

ESI (MS): $m / z(\%)=328.1(100)[\mathrm{M}+\mathrm{H}]^{+}, 654.9(70)[2 \mathrm{M}+\mathrm{H}]^{+}$.

$\mathrm{C}_{19} \mathrm{H}_{25} \mathrm{~N}_{3} \mathrm{~S} \quad$ bre. $328.18419[\mathrm{M}+\mathrm{H}]^{+}$ gef. 328.18433 (ESI-HRMS)

$[\alpha]^{20}{ }_{D}=-34.4^{\circ}\left(\mathrm{c}=0.25, \mathrm{CHCl}_{3}\right)$.

9.6.20 1-(2-Amino-1, 2-diphenyl-ethyl)-3-(1-naphthalen-1-yl-ethyl)-thiourea (74)

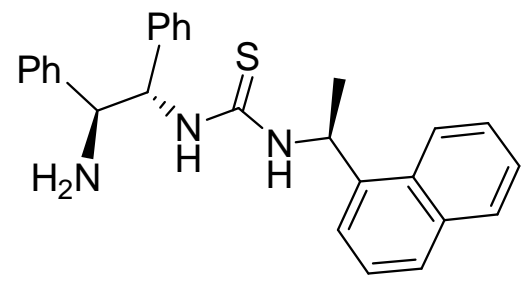

Die Darstellung für Verbindung 74 wurde nach den Synthesemethoden der Verbindung 64 durchgeführt. (S)-1-(1-Isothiocyanato-ethyl)-naphthalen (77a) wurde als Elektrophil (1S, 2S)1,2-Diphenylethane-1,2-diamin als Nucleophil eingesetzt.

Das Produkt wurde als heller gelber Feststoff (80\% Ausbeute) erhalten.

$R_{\mathrm{f}}=0.4($ Hex. $: \mathrm{EE}=1: 1)$

${ }^{1}$ H NMR (300 MHz, [D $\left.\left.{ }_{6}\right] \mathrm{DMSO}\right): \delta=1.51\left(\mathrm{~d}, J=6.0 \mathrm{~Hz}, 3 \mathrm{H}, \mathrm{CH}_{3}\right), 1.65$ (s, br, $2 \mathrm{H}, \mathrm{NH} \mathrm{H}_{2}$ ), 4.25 (m, $1 \mathrm{H}, \mathrm{CH}$ ), 5.5 (br. s, $1 \mathrm{H}, \mathrm{CH}$ ), 6.05 (br. s, $1 \mathrm{H}, \mathrm{CH}$ ), 7.18-7.32 (m, $11 \mathrm{H}$, Naphtyl-H), 7.50-7.54 (m, 4 H, Ph-H), 7.81 (s, 1 H, Naphtyl- $H$ ), 7.91 (s, 1 H, Ph- $H), 8.12-8.14$ (m, 1 H, Naphtyl-H), 8.22 (br. s, NH) ppm.

${ }^{13}$ C NMR (75.5 MHz, [D 6 DMSO): $\delta=21.12,59.41,59.61,122.2,123.3,125.3,125.5,126.1$, $126.5,126.6,127.0,127.2,127.6,127.9,128.4,130.4,133.3,143.1 \mathrm{ppm}$.

ESI (MS): $m / z(\%)=426.1(40)[\mathrm{M}+\mathrm{H}]^{+}, 448.1(35)[\mathrm{M}+\mathrm{Na}]^{+}, 851.0(30)[2 \mathrm{M}+\mathrm{H}]^{+}$.

$\mathrm{C}_{27} \mathrm{H}_{27} \mathrm{~N}_{3} \mathrm{~S} \quad$ ber. $426.19985[\mathrm{M}+\mathrm{H}]^{+}$ gef. 426.19981 (ESI-HRMS)

$[\alpha]^{20}{ }_{D}=-128.4^{\circ}\left(\mathrm{c}=0.162, \mathrm{CHCl}_{3}\right)$. 
9.6.21 1-(2-Amino-1, 2-diphenyl-ethyl)-3-(1-naphthalen-1-yl-ethyl)-thiourea (79)

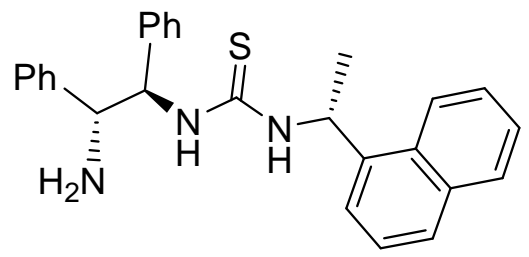

Die Darstellung für Verbindung 79 wurde nach den Synthesemethoden der Verbindung 64 durchgeführt. $(R)$-1-(1-Isothiocyanato-ethyl)-naphthalen (77) wurde als Elektrophil $(1 R, 2 R)$ 1,2-Diphenylethane-1,2-diamin als Nucleophil eingesetzt. Das Produkt wurde als heller gelber Feststoff (78\% Ausbeute) erhalten.

$\boldsymbol{R}_{\mathbf{f}}=0.4($ Hex. : $\mathrm{EE}=1: 1)$

${ }^{1}$ H NMR (300 MHz, [D $\mathrm{D}_{6}$ DMSO): $\delta=1.51(\mathrm{~d}, J=6.0 \mathrm{~Hz}, 3 \mathrm{H}), 1.65$ (s, br, 2H, NH ), 4.25 (br. s, 1H), 5.5 (br. s, 1H), 6.05 (br. s, 1H), 7.18-7.32 (m, 11H), 7.50-7.54 (m, 4H), 7.81(br. s, 1H), 7.91 (br. s, 1H), 8.12-8.14 (m, 1H), 8.22 (br. s, NH) ppm.

${ }^{13}$ C NMR (75.5 MHz, [D 6 DMSO): $\delta=21.12,59.43,59.61,122.2,123.3,125.3,125.5,126.1$, $126.5,126.6,127.0,127.2,127.6,127.9,128.4,130.4,133.3,143.1 \mathrm{ppm}$.

ESI (MS): $m / z(\%)=426.1(40)[\mathrm{M}+\mathrm{H}]^{+}, 448.1(35)[\mathrm{M}+\mathrm{Na}]^{+}, 851.0[2 \mathrm{M}+\mathrm{H}]^{+}$.

$\mathrm{C}_{27} \mathrm{H}_{27} \mathrm{~N}_{3} \mathrm{~S} \quad$ ber. $426.19985[\mathrm{M}+\mathrm{H}]^{+}$ gef. 426.19981 (ESI-HRMS)

$[\alpha]^{20}{ }_{D}=+41.3^{\circ}\left(\mathrm{c}=0.6, \mathrm{CHCl}_{3}\right)$.

9.6.22 1-(2-Amino-1, 2-diphenyl-ethyl)-3-(1-naphthalen-1-yl-ethyl)-thiourea (80)

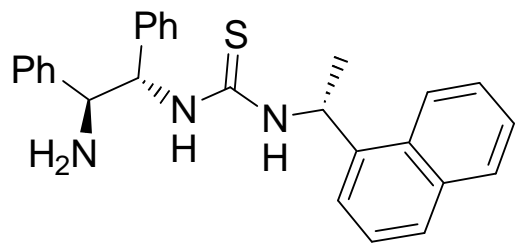

Die Darstellung für Verbindung 80 wurde nach den Synthesemethoden der Verbindung 64 durchgeführt. (R)-1-(1-Isothiocyanato-ethyl)-naphthalene (77) wurde als Elektrophil $(1 S, 2 S)$ - 
1,2-Diphenylethan-1,2-diamin als Nucleophil eingesetzt. Das Produkt wurde als heller gelber Feststoff (80\% Ausbeute) erhalten.

$\boldsymbol{R}_{\mathbf{f}}=0.4($ Hex. $: \mathrm{EE}=1: 1)$

${ }^{1}$ H NMR (300 MHz, [D $\left.\left.{ }_{6}\right] \mathrm{DMSO}\right): \delta=1.51\left(\mathrm{~d}, J=6.0 \mathrm{~Hz}, 3 \mathrm{H}, \mathrm{CH}_{3}\right), 1.65\left(\mathrm{~s}, \mathrm{br}, 2 \mathrm{H}, \mathrm{N} H_{2}\right)$, 4.25 (m, 1 H, CH), 5.5 (br. s, 1 H, CH), 6.05 (br. s, 1 H, CH), 7.18-7.32 (m, 11 H, Naphtyl-H), 7.50-7.54 (m, 4 H, Ph-H), 7.81 (s, 1 H, Naphtyl-H), 7.91 (s, 1 H, Ph-H), 8.12-8.14 (m, 1 H, Naphtyl- $H$ ), 8.22 (br. s, NH) ppm.

${ }^{13}$ C NMR (75.5 MHz, [D 6 DMSO): $\delta=21.12,59.41,59.62,122.2,123.3,125.3,125.5,126.1$, $126.5,126.6,127.0,127.2,127.6,127.9,128.4,130.4,133.3,143.1 \mathrm{ppm}$.

ESI (MS): $m / z(\%)=426.1(40)[\mathrm{M}+\mathrm{H}]^{+}, 448.1(35)[\mathrm{M}+\mathrm{Na}]^{+}, 851.0[2 \mathrm{M}+\mathrm{H}]^{+}$.

$\mathrm{C}_{27} \mathrm{H}_{27} \mathrm{~N}_{3} \mathrm{~S} \quad$ ber. $426.19985[\mathrm{M}+\mathrm{H}]^{+}$ gef. 426.19981 (ESI-HRMS)

$[\alpha]^{20}{ }_{D}=-128.1^{\circ}\left(\mathrm{c}=0.61, \mathrm{CHCl}_{3}\right)$.

9.6.23 1-(2-Amino-1,2-diphenyl-ethyl)-3-(1-naphthalen-1-yl-ethyl)-thiourea (78)

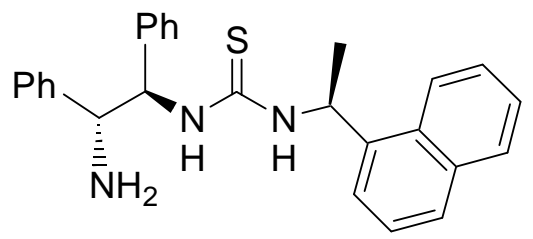

Die Darstellung für Verbindung 78 wurde nach den Synthesemethoden der Verbindung 64 durchgeführt. $(S)$-1-(1-Isothiocyanato-ethyl)-naphthalen (77a) wurde als Elektrophil $(1 R, 2 R)$ 1,2-Diphenylethane-1,2-diamin als Nucleophil eingesetzt.

Das Produkt wurde als heller gelber Feststoff (80\% Ausbeute) erhalten.

$\boldsymbol{R}_{\mathbf{f}}=0.4($ Hex. : $\mathrm{EE}=1: 1)$

${ }^{1} \mathbf{H}$ NMR (300 MHz, [D $\left.\left.{ }_{6}\right] \mathrm{DMSO}\right): \delta=1.51\left(\mathrm{~d}, J=6.0 \mathrm{~Hz}, 3 \mathrm{H}, \mathrm{CH}_{3}\right), 1.65\left(\mathrm{~s}, \mathrm{br}, 2 \mathrm{H}, \mathrm{N} H_{2}\right)$, 4.25 (m, $1 \mathrm{H}, \mathrm{CH}$ ), 5.5 (br. s, $1 \mathrm{H}, \mathrm{CH}$ ), 6.05 (br. s, $1 \mathrm{H}, \mathrm{CH}), 7.18-7.32$ (m, $11 \mathrm{H}$, Naphtyl-H), 7.50-7.54 (m, 4 H, Ph-H), 7.81 (s, 1 H, Naphtyl-H), 7.91 (s, 1 H, Ph- $H$ ), 8.12-8.14 (m, 1 H, Naphtyl-H), 8.22 (br. s, NH) ppm. 
${ }^{13}$ C NMR (75.5 MHz, [D 6 DMSO): $\delta=21.12,59.42,59.61,122.2,123.3,125.3,125.5,126.1$, $126.5,126.6,127.0,127.2,127.6,127.9,128.4,130.4,133.3,143.1 \mathrm{ppm}$.

ESI (MS): $m / z(\%)=426.1(40)[\mathrm{M}+\mathrm{H}]^{+}, 448.1(35)[\mathrm{M}+\mathrm{Na}]^{+}, 851.0[2 \mathrm{M}+\mathrm{H}]^{+}$.

$\mathrm{C}_{27} \mathrm{H}_{27} \mathrm{~N}_{3} \mathrm{~S} \quad$ ber. $426.19985[\mathrm{M}+\mathrm{H}]^{+}$ gef. 426.19981 (ESI-HRMS)

$[\alpha]^{20}{ }_{D}=+114.3^{\circ}\left(\mathrm{c}=0.4, \mathrm{CHCl}_{3}\right)$.

\subsection{Allgemeine Methoden für Michael-Addition}

$\mathrm{Zu}$ einer Lösung von Katalysator (0.15 $\ddot{\mathrm{A} q}$ ) und Keton (10 Äq) in Toluol (Olefin: $0.27 \mathrm{~mol} / \mathrm{L}$ ) wurde $\mathrm{H}_{2} \mathrm{O}(2 \ddot{\mathrm{A} q})$, AcOH (0.15 ̈̈q) zugegeben. Nach 15 Minuten Rühren wurde das Nitroolefin (1 $\ddot{A q}$ ) zugegeben. Die Reaktionsmischung wurde weiter bei Raumtemperatur für 23 Tage gerührt. Anschliessend wurde das Lösungsmittel im Vakuum entfernt und das Rohprodukt durch Chromatographie an Kieselgel sowie präparative DC gereinigt (Hex. : EE = 1:1). Der Enantiomerenüberschuss wurde mittels HPLC (Daicel Chiralpak AS-Säule) bestimmt, das Verhältnis von syn und anti der Diastereomere wurde mit ${ }^{1} \mathrm{H}-\mathrm{NMR}$-Spektrum verglichen.

9.7.1 5-Nitro-4-phenyl-pentan-2-on (91)<smiles>CC(=O)CC(C[N+](=O)[O-])c1ccccc1</smiles>

Weisser Feststoff.

$R_{\mathrm{f}}=0.35$ (Hexan: $\left.\mathrm{EE}=1: 1\right)$

${ }^{1} \mathbf{H}-\mathbf{N M R}\left(300 \mathrm{MHz}, \mathrm{CDCl}_{3}\right): \delta=2.09$; $\left(\mathrm{s}, 3 \mathrm{H}, \mathrm{CH}_{3}\right) ; 2.89(\mathrm{~d}, J=7.5 \mathrm{~Hz}, 2 \mathrm{H}) ; 3.97(t t, J=$ $6.75 \mathrm{~Hz}, 1 \mathrm{H}), 4.59(\mathrm{dd}, J=7.8,12.6 \mathrm{~Hz} ; 1 \mathrm{H}) ; 4.69$ (dd, $J=6.3,12.3 \mathrm{~Hz}, 1 \mathrm{H}) ; 7.18-7.34(\mathrm{~m}, 5$ $\mathrm{H}, \mathrm{Ph}-H)$.

${ }^{13}$ C-NMR (75.5 MHz, $\left.\mathrm{CDCl}_{3}\right): \delta=30.39,39.01,46.10,79.43,127.36,127.90,129.06,138.76$, 205.38. 
$[\alpha]^{20}{ }_{\mathrm{D}}=-3.0^{\circ}\left(\mathrm{c}=0.3, \mathrm{CHCl}_{3}\right)$.

HPLC (Daicel Chiralpak AS-Säule, $n$-Hexan: $i$-Propanol 75:25, flow rate $1 \mathrm{~mL} / \mathrm{min}, \lambda=$ $210 \mathrm{~nm}): t_{R}($ major $)=9.43 \min , t_{R}($ minor $)=11.67 \mathrm{~min}$.

9.7.2-(2-Nitro-1-phenyl-ethyl)-cyclohexanon (88)

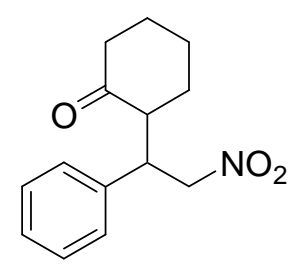

Weisser Feststoff.

$R_{\mathrm{f}}=0.5$ (Hexan: $\left.\mathrm{EE}=1: 1\right)$

${ }^{1} \mathbf{H}$-NMR (300 MHz, $\left.\mathrm{CDCl}_{3}\right): \delta=0.99-1.30(\mathrm{~m}, 2 \mathrm{H}) ; 1.5-1.8(\mathrm{~m}, 3 \mathrm{H}) ; 2.02-2.11$ (m, $\left.2 \mathrm{H}\right)$; 2.30-2.62 (m, $2 \mathrm{H}) ; 3.72(\mathrm{ddd}, J=4.8 \mathrm{~Hz} ; 1 \mathrm{H}) ; 4.59(\mathrm{dd}, J=9.6,12.3 \mathrm{~Hz}, 1 \mathrm{H}) ; 4.92(\mathrm{dd}, J=$ 4.5, $12.3 \mathrm{~Hz}, 1 \mathrm{H}) ; 7.12-7.33$ (m, $5 \mathrm{H}, \mathrm{Ph}-H)$.

${ }^{13}$ C-NMR (75.5 MHz, $\left.\mathrm{CDCl}_{3}\right): \delta=25.01,28.52,33.20,42.73,43.91,52.50,78.87,127.76$, $128.14,128.33,128.73,128.92,137.70,211.94$.

HPLC (Daicel Chiralpak AS-Säule, $n$-Hexan: $i$-Propanol 75:25, flow rate $1 \mathrm{~mL} / \mathrm{min}$ ) $\lambda=210$ $\mathrm{nm}: t_{R}($ major $)=9.43 \mathrm{~min}, t_{R}($ minor $)=11.67 \mathrm{~min}$.

9.7.3 3-(2-Nitro-1-phenyl-ethyl)-tetrahydro-thiopyran-4-on (90)<smiles>O=C1CCSCC1C(C[N+](=O)[O-])c1ccccc1</smiles>

Heller kaffeefarbener Feststoff 
$R_{\mathrm{f}}=0.45$ (Hexan: $\left.\mathrm{EE}=1: 1\right)$

${ }^{1}$ H-NMR $\left(300 \mathrm{MHz}, \mathrm{CDCl}_{3}\right): \delta=2.35(\mathrm{dd}, J=9.5 ; 13.5 \mathrm{~Hz} ; 1 \mathrm{H}) ; 2.45(\mathrm{dd}, J=4.8 ; 13.5 \mathrm{~Hz} ; 1$ H); 2.87-2.95 (m, $1 \mathrm{H})$; 2.90-3.00 (m, $2 \mathrm{H})$; 3.09-3.01 (m, $1 \mathrm{H})$; 3.92-3.99 (m, $2 \mathrm{H})$; 4.60 (dd, $J$ = 9.6; $12.6 \mathrm{~Hz}, 1 \mathrm{H}) ; 4.80$ (dd, $J=4.8 \mathrm{~Hz} ; 12 \mathrm{~Hz} ; 1 \mathrm{H}) .7 .16-7.28(\mathrm{~m}, 5 \mathrm{H}, \mathrm{Ph}-H)$.

${ }^{13}$ C-NMR (75.5 MHz, $\left.\mathrm{CDCl}_{3}\right): \delta=27.21,29.28,30.22,42.21,56.00,79.21,126.1,128.9$, 138.7, 211.5.

HPLC (Daicel Chiralpak AS-Säule, $n$-Hexan: $i$-Propanol 75:25, flow rate $1 \mathrm{~mL} / \mathrm{min}$ ) $\lambda=210 \mathrm{~nm}$ : $t_{R}($ major $)=9.43 \mathrm{~min}, t_{R}($ minor $)=11.67 \mathrm{~min}$.

9.7.4 2-(2-Nitro-1-phenyl-ethyl)-cycloheptanon (89)

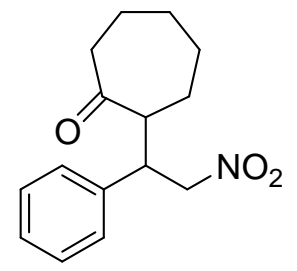

Weisser Feststoff.

$R_{\mathrm{f}}=0.5$ (Hexan: $\left.\mathrm{EE}=1: 1\right)$

${ }^{1}$ H-NMR (300 MHz, $\mathrm{CDCl}_{3}$ ): $\delta=1.12-1.24$ (m, $\left.4 \mathrm{H}\right)$; 1.86-1.88 (m, $4 \mathrm{H} \mathrm{),} \mathrm{2.49-2.54} \mathrm{(m,} 2 \mathrm{H}$ ); 2.95-2.99 (m, $1 \mathrm{H}) ; 3.65$ (dd, $J=4 \mathrm{~Hz}, 2.1 \mathrm{~Hz}, 1 \mathrm{H})$; 4.59-4.64 (m, $2 \mathrm{H}), 7.14-7.34$ (m, 5H, Ph$H)$.

${ }^{13}$ C-NMR (75.5 MHz, $\left.\mathrm{CDCl}_{3}\right): \delta=24.21,25.11,29.62,30.60,31.82,42.41,51.50,126.0$, $128.1,128.6,139.3,214.8$.

MS (ESI): $\mathrm{m} / \mathrm{z}(\%)=284.0(32)[\mathrm{M}+\mathrm{Na}]^{+}, 545.2(100)[2 \mathrm{M}+\mathrm{Na}]^{+}$.

HPLC (Daicel Chiralpak AS-Säule, $n$-Hexan: $i$-Propanol 75:25, flow rate $1 \mathrm{~mL} / \mathrm{min}, \lambda=210$ $\mathrm{nm}): t_{R}($ major $)=9.43 \mathrm{~min}, t_{R}($ minor $)=11.67 \mathrm{~min}$. 
9.7.5 3-Methyl-5-nitro-4-phenyl-pentan-2-on (92)<smiles>CC(=O)C(C)C(C[N+](=O)[O-])c1ccccc1</smiles>

Gelb dickes Öl.

$R_{\mathrm{f}}=0.35$ (Hexan: $\left.\mathrm{EE}=1: 1\right)$

${ }^{1} \mathbf{H}-\mathbf{N M R}\left(300 \mathrm{MHz}, \mathrm{CDCl}_{3}\right.$ ): $\delta=1.19$ (d. $J=4 \mathrm{~Hz}, 3 \mathrm{H}, \mathrm{CH}_{3}$ ), 1.87 (s, $3 \mathrm{H}, \mathrm{CH}_{3}$ ), 3.15 (q. $J=$ $3.2 \mathrm{~Hz}, 1 \mathrm{H}), 3.81(\mathrm{~m}, 1 \mathrm{H}), 4.75(\mathrm{dd}, J=8.5 \mathrm{~Hz}, 2.3 \mathrm{~Hz}, 1 \mathrm{H}), 7.15-7.27$ (m, $5 \mathrm{H}, \mathrm{Ph}-H$ ).

${ }^{13}$ C-NMR $\left(75.5 \mathrm{MHz}, \mathrm{CDCl}_{3}\right): \delta=18.20,28.70,32.51,50.81,79.41,126.1,128.2,128.9$, 138.7, 209.6.

HPLC (Daicel Chiralpak AS-Säule, $n$-Hexan: $i$-Propanol 90:10, flow rate $1 \mathrm{~mL} / \mathrm{min}, \lambda=210$ $\mathrm{nm})$ : anti: $t_{R}($ major $)=18.77 \mathrm{~min}, t_{R}($ minor $)=15.72 \mathrm{~min}$.

9.7.6 3-Hydroxy-5-nitro-4-phenyl pentan-2-on (93)<smiles>CC(=O)C(O)C(C[N+](=O)[O-])c1ccccc1</smiles>

Gelbe Flüssigkeit.

$R_{\mathrm{f}}=0.35$ (Hexan: $\left.\mathrm{EE}=1: 1\right)$

${ }^{1} \mathbf{H}-\mathbf{N M R}\left(300 \mathrm{MHz}, \mathrm{CDCl}_{3}\right): \delta=2.05\left(\mathrm{~s}, 3 \mathrm{H}, \mathrm{CH}_{3}\right), 3.68-3.70(\mathrm{~d}, J=6 \mathrm{~Hz}, 1 \mathrm{H}), 4.05(\mathrm{dd}, J$ $=8.2,2.5 \mathrm{~Hz}, 1 \mathrm{H}), 7.20-7.38(\mathrm{~m}, 5 \mathrm{H}, \mathrm{Ph}-H)$.

${ }^{13}$ C-NMR $\left(300 \mathrm{MHz}, \mathrm{CDCl}_{3}\right): \delta=25.47,45.68,46.87,78.65,127.9,128.3,128.5,128.6,128.9$, 129.3, 133.6, 137.0, 206.0. 
HPLC (Daicel Chiralpak OD-Säule, $n$-Hexan: $i$-Propanol 75:25, flow rate $1 \mathrm{~mL} / \mathrm{min}, \lambda=210$ $\mathrm{nm}): \operatorname{syn}: t_{R}($ major $)=9.27 \mathrm{~min}, t_{R}($ minor $)=17.55 \mathrm{~min} ;$ anti: $t_{R}($ major $)=14.18 \mathrm{~min}, t_{R}($ minor $)$ $=28.25 \mathrm{~min}$.

9.7.7 4-(4-Bromo-phenyl)-5-nitro-pentan-2-on (96)<smiles>CC(=O)CC(C[N+](=O)[O-])c1ccc(Br)cc1</smiles>

Farblosser Feststoff.

$R_{\mathrm{f}}=0.45$ (Hexan: $\left.\mathrm{EE}=1: 1\right)$

${ }^{1}$ H-NMR $\left(300 \mathrm{MHz}, \mathrm{CDCl}_{3}\right): \delta=2.11\left(\mathrm{~s}, 3 \mathrm{H}, \mathrm{CH}_{3}\right) ; 2.87(\mathrm{~d}, J=6 \mathrm{~Hz}, 2 \mathrm{H}) ; 3.91$ (tt, $J=7.5$ $\mathrm{Hz}, 1 \mathrm{H}$ ); 4.56 (dd, $J=8.1 ; 12.3 \mathrm{~Hz} ; 1 \mathrm{H}) ; 4.65(\mathrm{dd}, J=6.3 ; 12.3 \mathrm{~Hz} ; 1 \mathrm{H}) ; 7.06-7.10$ (m, $2 \mathrm{H}$, $\mathrm{Ph}-H) ; 7.41-7.46$ (m, $2 \mathrm{H}, \mathrm{Ph}-H$ ).

${ }^{13}$ C-NMR (75.5 MHz, $\left.\mathrm{CDCl}_{3}\right): \delta=27.90,31.20,81.92,120.3,128.4,131.4,147.6,201.7$.

HPLC (Daicel Chiralpak AS -Säule, $n$-Hexan: $i$-Propanol 75:25, flow rate $1 \mathrm{~mL} / \mathrm{min}$ ) $\lambda=210$ $\mathrm{nm}: t_{R}$ (major) $=9.43 \mathrm{~min}, t_{R}($ minor $)=11.67 \mathrm{~min}$.

$[\alpha]^{20}{ }_{D}=-2.2^{\circ}\left(\mathrm{c}=0.225, \mathrm{CHCl}_{3}\right)$.

9.7.8 4-(4-Methoxy-phenyl)-5-nitro-pentan-2-on (97)<smiles>COc1ccc(C(CC(C)=O)C[N+](=O)[O-])cc1</smiles>

Weisser Feststoff. 
$R_{\mathrm{f}}=0.45$ (Hexan: $\left.\mathrm{EE}=1: 1\right)$

${ }^{1} \mathbf{H}-\mathbf{N M R}\left(300 \mathrm{MHz}, \mathrm{CDCl}_{3}\right): \delta=2.81\left(\mathrm{~s}, 3 \mathrm{H}, \mathrm{CH}_{3}\right) ; 2.87(\mathrm{~d}, J=9 \mathrm{~Hz}, 2 \mathrm{H}) ; 3.76(\mathrm{~s}, 3 \mathrm{H}$, $\left.\mathrm{OCH}_{3}\right) ; 3.89(\mathrm{tt}, J=6.75 \mathrm{~Hz}, 1 \mathrm{H}) ; 4.56(\mathrm{dd}, J=7.8 ; 12.0 \mathrm{~Hz} ; 1 \mathrm{H}) ; 4.65(\mathrm{dd}, J=6.9 ; 12.0 \mathrm{~Hz}$; $1 \mathrm{H})$; 6.81-6.86 (m, $2 \mathrm{H}, \mathrm{Ph}-H)$; 7.09-7.14 (m, $2 \mathrm{H}, \mathrm{Ph}-H)$.

${ }^{13}$ C-NMR (75.5 MHz, $\left.\mathrm{CDCl}_{3}\right): \delta=27.90,31.21,48.10,55.90,81.91,114.0,127.2,140.9$, 157.9, 201.1.

HPLC (Daicel Chiralpak AS-Säule, $n$-Hexan: $i$-Propanol 75:25, flow rate $1 \mathrm{~mL} / \mathrm{min}$ ) $\lambda=210$ $\mathrm{nm}: t_{R}($ major $)=9.43 \mathrm{~min}, t_{R}($ minor $)=11.67 \mathrm{~min}$.

$[\alpha]^{20}=-4.9^{\circ}\left(\mathrm{c}=0.185, \mathrm{CHCl}_{3}\right)$.

9.7.9 5-Nitro-4-thiophen-2-yl-pentan-2-one (98)

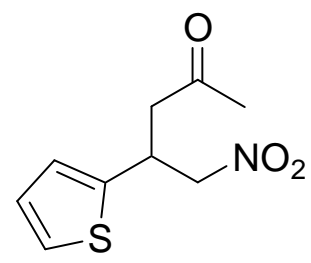

Heller kaffeeabener Feststoff.

$R_{\mathrm{f}}=0.45$ (Hexan: $\left.\mathrm{EE}=1: 1\right)$

${ }^{1} \mathbf{H}$-NMR $\left(300 \mathrm{MHz}, \mathrm{CDCl}_{3}\right): \delta=2.14\left(\mathrm{~s}, 3 \mathrm{H}, \mathrm{CH}_{3}\right) ; 2.95(\mathrm{~d}, J=9 \mathrm{~Hz}, 2 \mathrm{H}) ; 4.40$ (tt, $J=7.5$ $\mathrm{Hz}, 1 \mathrm{H}) ; 4.59(\mathrm{dd}, J=7.5 ; 12.3 \mathrm{~Hz} ; 1 \mathrm{H}) ; 4.69(\mathrm{dd}, J=6.3 ; 12.3 \mathrm{~Hz} ; 1 \mathrm{H}) ; 6.88-6.93(\mathrm{~m}, 2 \mathrm{H})$; 7.18-7.24 (m, 1H).

${ }^{13}$ C-NMR (75.5 MHz, $\left.\mathrm{CDCl}_{3}\right): \delta=28.69,31.21,48.81,82.67,123.6,126.7,126.9,138.8$, 207.7 .

HPLC (Daicel Chiralpak AS-Säule, $n$-Hexan: $i$-Propanol 75:25, flow rate $1 \mathrm{~mL} / \mathrm{min}$ ) $\lambda=210$ $\mathrm{nm}: t_{R}($ major $)=9.43 \mathrm{~min}, t_{R}($ minor $)=11.67 \mathrm{~min}$.

$[\alpha]^{20}{ }_{\mathrm{D}}=+3.3^{\circ}\left(\mathrm{c}=0.3, \mathrm{CHCl}_{3}\right)$. 
9.7.10 2-Isopropyl-4-nitro-3-phenylbutanal (100)<smiles>CC(C)C(C=O)C(C[N+](=O)[O-])c1ccccc1</smiles>

Gelbe Flüssigkeit.

$R_{\mathrm{f}}=0.35$ (Hexan: $\mathrm{EE}=1: 1$ )

${ }^{1} \mathbf{H}$-NMR $\left(300 \mathrm{MHz}, \mathrm{CDCl}_{3}\right): \delta=0.88\left(\mathrm{~d}, J=6.95 \mathrm{~Hz}, 3 \mathrm{H}, \mathrm{CH}_{3}\right), 1.10(\mathrm{~d}, J=7.14 \mathrm{~Hz}, 3 \mathrm{H}$, $\left.\mathrm{CH}_{3}\right), 1.40-1.62(\mathrm{~m}, 1 \mathrm{H}), 2.78-2.80(\mathrm{~m}, 1 \mathrm{H}), 3.82-3.85$ (m, $\left.2 \mathrm{H}\right), 4.50-4.60(\mathrm{~m}, 2 \mathrm{H}), 7.17-7.38$ (m, $5 \mathrm{H}, \mathrm{Ph}-H), 9.92(\mathrm{~d}, J=2.19 \mathrm{~Hz}, 1 \mathrm{H}, \mathrm{CHO})$.

${ }^{13}$ C-NMR (75.5 MHz, $\left.\mathrm{CDCl}_{3}\right): \delta=16.99,19.07,21.63,21.91,40.96,58.79,78.98,127.9$, 128.0, 128.3, 129.1, 137.1, 204.3.

\subsection{Allgemeine Methoden für autokatalytische Mannich Reaktionen}

Unter Stickstoff wurde Methoxy-phenylimino-essigsäureethylester (101, 1 Äq) in entsprechende Lösungsmittel gelöst sodass die jeweilige Konzentration erhalten wurden.

\begin{tabular}{|l|l|}
\hline Lösungsmittel & Konzentration (Mol/L) \\
\hline Aceton & $0.02,0.25,0.5,50$ \\
\hline DMSO & $0.02,0.25,0.5,50$ \\
\hline Toluol & $0.02,0.25,0.5,50$ \\
\hline $\mathrm{CH}_{2} \mathrm{Cl}_{2}$ & $0.02,0.25,0.5,50$ \\
\hline
\end{tabular}

Danach wurde eine Lösung des Produkt-Katalysators (102) in jeweiliges Lösungmittel zugegeben. Die Reaktionsmischung wurde dann unter Stickstoff-atomsphäre 2-4 Tage gerührt. Anschliessend wurde das Lösungsmittel im Vakuum entfernt. Der Rest wurde mittels präparativer DC (Hex:EE: $\left.\mathrm{CH}_{2} \mathrm{Cl}_{2}=1: 1: 1\right)$ unter Stichstoffatomsphäre isoliert. Der Enantiomerenüberschuss wurde mittels HPLC (Daicel Chiralpak AD-Säule, $n$-Hexan: $i$-Propanol 95:5, flow rate $1 \mathrm{~mL} / \mathrm{min}$ ) bestimmt. 
9.8.1 (4-Methoxy-phenylimino)-essigsäureethylester (101)

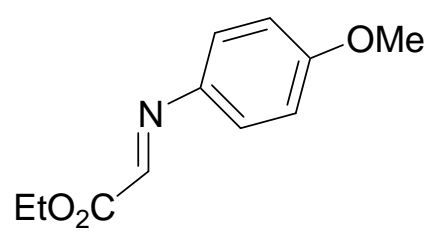

Unter Stickstoff wurde eine Lösung von Anisidin (2.90 g, $24.0 \mathrm{mmol}, 1$ Äq) in trockenem $\mathrm{CH}_{2} \mathrm{Cl}_{2}(15 \mathrm{~mL})$ zu einer Lösung von Glyoxylat $(4.76 \mathrm{~mL}, 24.0 \mathrm{mmol}, 1 \mathrm{Äq}, 55 \%$ in Toluol) in trockenem $\mathrm{CH}_{2} \mathrm{Cl}_{2}(3 \mathrm{~mL})$ innerhalb $1 \mathrm{~h}$ zugetropft. Nachdem die Reaktionsmischung bei Raumtemperatur unter Stickstoffatomsphäre $1 \mathrm{~h}$ gerührt wurde. Wurde Molekularsieb (4 ̊́, $5 \mathrm{~g})$ zugegeben. Die Reaktionsmischung wurde weiter bei $40^{\circ} \mathrm{C}$ weiter $2 \mathrm{~h}$ gerührt. Anschliessend wurde das Molekülarsiebe unter Stichstoffatomsphäre abfiltriert und das Lösungsmittel im Vakuum entfernt. Nach einer chromatographischen Reinigung $\left(\mathrm{CH}_{2} \mathrm{Cl}_{2}\right)$ an Kieselgel wurde die Titelverbindung als helles leicht gelbliches Öl $(4.72 \mathrm{~g}, 96 \%)$ erhalten.

$R_{\mathrm{f}}=0.55$ (Hexan: $\left.\mathrm{CH}_{2} \mathrm{Cl}_{2}: \mathrm{EE}=1: 1: 1\right)$

${ }^{1} \mathbf{H}$-NMR $\left(300 \mathrm{MHz}, \mathrm{CDCl}_{3}\right): \delta=1.38\left(\mathrm{t}, J=7.5 \mathrm{~Hz}, 3 \mathrm{H}, \mathrm{CH}_{2} \mathrm{CH}_{3}\right), 3.81\left(\mathrm{~s}, 3 \mathrm{H}, \mathrm{OCH}_{3}\right), 4.40$ (q. $\left.J=7.0 \mathrm{~Hz}, 2 \mathrm{H}, \mathrm{CH}_{2} \mathrm{CH}_{3}\right), 6.85-6.88(\mathrm{~m}, 2 \mathrm{H}, \mathrm{Ph}-H), 7.35-7.38(\mathrm{~m}, 2 \mathrm{H}, \mathrm{Ph}-H), 7.76$ (s, 1 $\mathrm{H})$.

MS (ESI): $\mathrm{m} / \mathrm{z}(\%)=208.10(100)[\mathrm{M}+\mathrm{H}]^{+}$.

${ }^{13}$ C-NMR (75.5 MHz, $\left.\mathrm{CDCl}_{3}\right): \delta=26.14,55.91,61.10,115.6,141.3,159.2,161.2,163.3$.

9.8.2 2-(4-Methoxy-phenylamino)-4-oxo-pentylsäureethylester (102)<smiles>CCOC(=O)C(CC(C)=O)Nc1ccc(OC)cc1</smiles>

Unter Stickstoff wurde das Edukt 101 und Aceton in entsprechendem Lösungsmittel mit verschiedener Menge von Produkt 102 (mit unterschiedlichen Enantiomerenüberschüssen) 
gemischt. Die Reaktionsmischung wurde unter Stickstoffatomsphäre bei unterschiedlicher Temperatur weiter 2-4 Tagen gerührt.

\begin{tabular}{|l|c|c|c|}
\hline $\begin{array}{l}\text { Produkt-Kat.102 } \\
\text { Menge }(e e \% \text { Konfig. })\end{array}$ & Lösungsmittel & $\begin{array}{c}\text { Konzentration } \\
(\mathrm{Mol} / \mathrm{L})\end{array}$ & $\begin{array}{c}\text { Temperatur } \\
\left({ }^{\circ} \mathrm{C}\right)\end{array}$ \\
\hline $1,15,25,30,50$ Mol-\%, $98 \%$ ee $(S)$ & Aceton & $0.02,0.25,0.5,25,50$ & $40,25,0,-10$ \\
\hline 15 Mol-\%, 98 \% ee $(S)$ & DMSO & $0.02,0.25,0.5,25,50$ & 25 \\
\hline 15 Mol-\%, $98 \%$ ee $(S)$ & Toloul & $0.02,0.25,0.5,25,50$ & 25 \\
\hline 15 Mol-\%, $98 \%$ ee $(S)$ & Aceton & $0.25,0.5,25$ & 25 \\
\hline
\end{tabular}

Anschliessend wurde das Lösungsmittel entfernt, das Rohprodukt durch Säulenchromatographie an Kieselgel oder durch präpartive DC gereinigt. Der Enantiomerenüberschuss wurde erst mittels HPLC (Daicel Chiralpak AD-Säule, $n$-Hexan : $i$-Propanol 95:5 flow rat $1 \mathrm{~mL} / \mathrm{min}$ ) bestimmt. Als zweite Methode wurde durch die Zugabe von [Eu(tfc $\left.)_{3}\right](0.6$ Äq) in die ProduktLösung $\left(\mathrm{CHCl}_{3}\right)$ ein Diasteromerengemisch erzeugt, welches mittels ${ }^{1} \mathrm{H}-\mathrm{NMR}-$ Spektrum bestimmt wurde.

$\boldsymbol{R}_{\mathbf{f}}=0.65\left(\mathrm{Hex}: \mathrm{EE}: \mathrm{CH}_{2} \mathrm{Cl}_{2}=1: 1: 1\right)$

${ }^{1} \mathbf{H}$-NMR $\left(300 \mathrm{MHz}, \mathrm{CDCl}_{3}\right): \delta=1.20\left(\mathrm{t}, J=7.2 \mathrm{~Hz}, 3 \mathrm{H}, \mathrm{CH}_{2} \mathrm{CH}_{3}\right), 2.16\left(\mathrm{~s}, 3 \mathrm{H}, \mathrm{COCH}_{3}\right)$, $2.93(\mathrm{~d}, J=9.0 \mathrm{~Hz}, 2 \mathrm{H}), 3.71\left(\mathrm{~s}, 3 \mathrm{H}, \mathrm{OCH}_{3}\right) 4.08$ (br., s, $\left.1 \mathrm{H}, \mathrm{NH}\right), 4.17$ (q, J = 7.0 Hz, $2 \mathrm{H}$, $\left.\mathrm{CH}_{2} \mathrm{CH}_{3}\right), 4.29$ (t, $\left.J=6 \mathrm{~Hz}, 1 \mathrm{H}\right), 6.61-6.62(\mathrm{~m}, 2 \mathrm{H}, \mathrm{Ph}-H), 6.63-6.76$ (m, $\left.2 \mathrm{H}, \mathrm{Ph}-H\right)$.

${ }^{13}$ C-NMR (75.5 MHz, $\left.\mathrm{CDCl}_{3}\right): \delta=13.61,24.53,44.62,56.21,57.31,59.53,113.3,114.9$, 135.8, 150.4, 172.0, 207.1.

MS (ESI): $\mathrm{m} / \mathrm{z}(\%)=288.0(100)[\mathrm{M}+\mathrm{Na}]^{+}, 553[2 \mathrm{M}+\mathrm{Na}]^{+}$. 


\subsection{Synthese von Hybride-Moleküle aus Naturstoffen.}

9.9.1 ((1R,3aS,5aR,5bR,11aR)-icosahydro-9-hydroxy-5a,5b,8,8,11a-pentamethyl-1-(prop1-en-2-yl)-1H-cyclopenta[ $\alpha]$ chrysen-3a-yl)methylacetat (105)

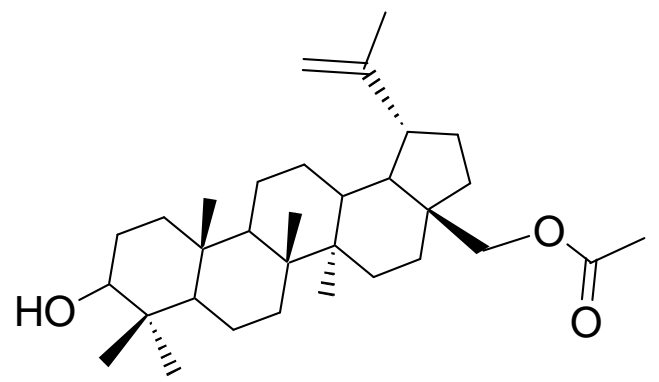

$\mathrm{Zu}$ einer Lösung von Betulin $(88.0 \mathrm{mg}, 0.20 \mathrm{mmol})$ in $\mathrm{CHCl}_{3}$ wurde Imidazol $(28.0 \mathrm{mg}, 0.40$ mmol) zugegeben. Nach einer halben Stunde wurde Acetanhydrid (20 $\mu \mathrm{L}, 22 \mathrm{mg}, 0.22 \mathrm{mmol}$, 1.1 Äq) hinzugegeben. Die Reaktionsmischung wurde weiter unter Rückfluss mittels DCKontrolle (Anfärbungsmittel: Anisaldehyd) bis $2 \mathrm{~h}$ gerührt. Nach dem Abkühlen bis $0^{\circ} \mathrm{C}$ wurde die Reaktionsmischung durch $2 \% \mathrm{HCl}(10 \mathrm{~mL})$ neutralisiert und mit $\mathrm{CH}_{2} \mathrm{Cl}_{2}(3 \times 10 \mathrm{~mL})$ extrahiert. Die vereinigten organischen Phasen wurden mit gesättigter NaCl-Lösung (10 mL) gewaschen und über $\mathrm{MgSO}_{4}$ getrocknet. Das Lösungsmittel wurde in Vakuum entfernt. Der Rückstand wurde an Kieselgel absorbiert und durch Säulenchromatographie über Kieselgel mit einem Gradienten (Hexan zu Ethylacetat 5:1 bis 3:1) gereinigt. Die Titelverbindung (53.0 mg, $0.11 \mathrm{mmol}, 56 \%$ ) wurde als weißer Feststoff erhalten.

$\boldsymbol{R}_{\mathbf{f}}=0.45(\operatorname{Hex}: \mathrm{EE}=1: 1)$

${ }^{1} \mathbf{H}$-NMR $\left(300 \mathrm{MHz}, \mathrm{CDCl}_{3}\right): \delta=0.78\left(\mathrm{~s}, 3 \mathrm{H}, \mathrm{CH}_{3}\right), 0.82\left(\mathrm{~s}, 3 \mathrm{H}, \mathrm{CH}_{3}\right), 0.84-0.90(\mathrm{~m}, 6 \mathrm{H})$, 0.95 (s, $\left.3 \mathrm{H}, \mathrm{CH}_{3}\right), 1.00$ (s, $\left.3 \mathrm{H}, \mathrm{CH}_{3}\right), 1.01-1.21(\mathrm{~m}, 6 \mathrm{H}), 1.25$ (s, $\left.6 \mathrm{H}, 2 \mathrm{CH}_{3}\right), 1.26-1.52$ (m, 4 H), $1.62\left(\mathrm{~s}, 3 \mathrm{H}, \mathrm{CH}_{3}\right), 1.65-2.00(\mathrm{~m}, 6 \mathrm{H}), 2.08(\mathrm{~s}, 2 \mathrm{H}), 3.15(\mathrm{dd}, J=10.8,4.8 \mathrm{~Hz}, 1 \mathrm{H}), 3.82$ $(\mathrm{d}, J=9 \mathrm{~Hz}, 1 \mathrm{H}), 4.22(\mathrm{dd}, J=1.5,12.3 \mathrm{~Hz}, 1 \mathrm{H}), 4.60(\mathrm{dd}, J=1.2,2.4 \mathrm{~Hz}, 2 \mathrm{H})$.

MS (ESI): $\mathrm{m} / \mathrm{z}(\%)=484.5(90)$. $[\alpha]^{20}{ }_{D}=+10.3^{\circ}\left(\mathrm{c}=0.14, \mathrm{CHCl}_{3}\right)$. 


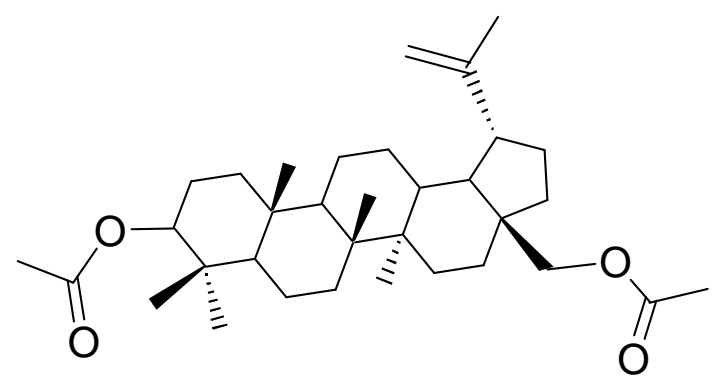

Als Nebenprodukt entstanden (25 mg, 30\%). Weißer Feststoff.

$\boldsymbol{R}_{\mathbf{f}}=0.55($ Hex: $\mathrm{EE}=1: 1)$

${ }^{1} \mathbf{H}-\mathbf{N M R}\left(300 \mathrm{MHz}, \mathrm{CDCl}_{3}\right): \delta=0.82\left(\mathrm{~s}, 3 \mathrm{H}, \mathrm{CH}_{3}\right), 0.84-0.91(\mathrm{~m}, 6 \mathrm{H}), 0.92\left(\mathrm{~s}, 3 \mathrm{H}, \mathrm{CH}_{3}\right)$, 0.95 (s, $\left.3 \mathrm{H}, \mathrm{CH}_{3}\right), 1.0\left(\mathrm{~s}, 3 \mathrm{H}, \mathrm{CH}_{3}\right), 1.01-1.21(\mathrm{~m}, 6 \mathrm{H}), 1.25(\mathrm{~s}, 4 \mathrm{H}), 1.26-1.51(\mathrm{~m}, 4 \mathrm{H}), 1.62$ $\left(\mathrm{s}, 3 \mathrm{H}, \mathrm{CH}_{3}\right), 1.65-2.00(\mathrm{~m}, 6 \mathrm{H}), 2.08\left(\mathrm{~s}, 6 \mathrm{H}, 2 \mathrm{CH}_{3}\right), 2.41(\mathrm{~d}, J=9 \mathrm{~Hz}, 4 \mathrm{H}), 3.80(\mathrm{dd}, J=$ $10.8,4.8 \mathrm{~Hz}, 1 \mathrm{H}), 4.2(\mathrm{~d}, J=9 \mathrm{~Hz}, 1 \mathrm{H}), 4.45(\mathrm{dd}, J=1.5,12.3 \mathrm{~Hz}, 1 \mathrm{H}), 4.60$ (dd, $J=1.2,2.4$ $\mathrm{Hz}, 2 \mathrm{H})$.

MS (EI): m/z (\%) = $526.5(30), 466.5$ (100) $\left[\mathrm{M}-\mathrm{CH}_{3} \mathrm{CO}-\mathrm{CH}_{3}\right]$.

9.9.2 Verbindung 106 (Artesunat-Betulin-28-Acetet)

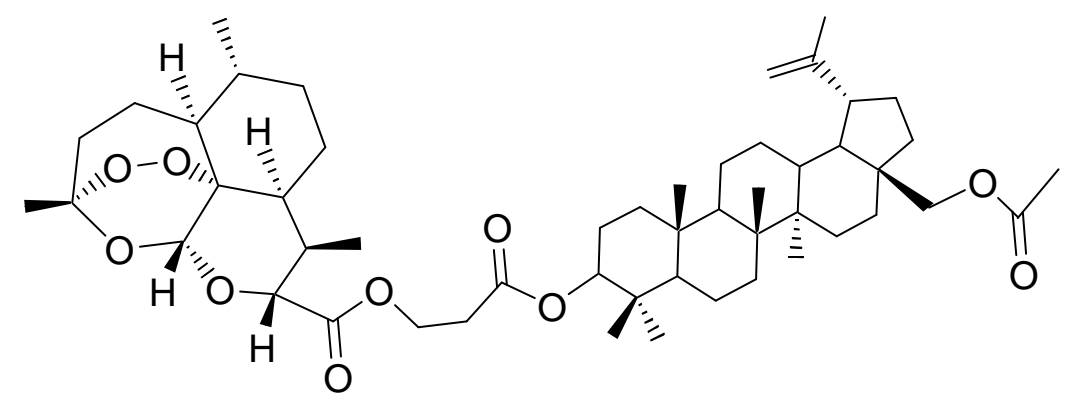

Unter Argon wurde Artesunat $(34.5 \mathrm{mg}, 0.09 \mathrm{mmol}, 0.83 \ddot{\mathrm{Aq}})$ in trockenem $\mathrm{CH}_{2} \mathrm{Cl}_{2}(3 \mathrm{~mL})$ gelöst. Eine Aktivierung des Artesunats wurde durch Zugabe von DCC (23.5 mg, $0.11 \mathrm{mmol}$, 1.20 Äq) und DMAP (6.60 mg, 0.40 Äq) ausgelöst. Nach einer halben Stunde Rühren wurde eine Lösung von Betulin (50.0 mg, $0.10 \mathrm{mmol}, 1 \mathrm{Äq})$ in trockenem $\mathrm{CH}_{2} \mathrm{Cl}_{2}(3 \mathrm{~mL})$ innerhalb von 5 Minuten zugetropft. Die Reaktionsmischung wurde unter Stickstoff über Nacht gerührt. Anschliessend wurde der Niederschlag abfiltriert. Die Mutterlauge wurde mit 10\% $\mathrm{HCl}(10 \mathrm{~mL})$ 
bei $0^{\circ} \mathrm{C}$ neutralisiert und mit $\mathrm{CH}_{2} \mathrm{Cl}_{2}(3 \times 30 \mathrm{~mL})$ extrahiert. Die verreinigten organischen Phasen wurden mit gesättigter $\mathrm{NaCl}$-Lösung gewaschen und über $\mathrm{Na}_{2} \mathrm{SO}_{4}$ getrocknet. Das Rohprodukt wurde zuerst durch Säulenchromatographie an Kieselgel mit einem Gradienten (Hex:EE = 3:1-1:1) und danach an Sephadex-Gel $\left(\mathrm{CHCl}_{3}\right)$ gereinigt. Die Titelverbindung wurde als weißer Feststoff ( $45.2 \mathrm{mg}, 0.05 \mathrm{mmol}, 55 \%$ ) erhalten.

$\boldsymbol{R}_{\mathbf{f}}=0.65($ Hex.: $\mathrm{EE}=1: 1)$

${ }^{1}$ H-NMR (300 MHz, $\left.\mathrm{CDCl}_{3}\right): \delta=0.71-0.79(\mathrm{~m}, 6 \mathrm{H}), 0.8\left(\mathrm{~s}, 6 \mathrm{H}, 2 \mathrm{CH}_{3}\right), 0.82-0.93(\mathrm{~m}, 11 \mathrm{H})$, 0.95 (s, $\left.3 \mathrm{H}, \mathrm{CH}_{3}\right), 1.0$ (s, $\left.3 \mathrm{H}, \mathrm{CH}_{3}\right), 1.2\left(\mathrm{~s}, 3 \mathrm{H}, \mathrm{CH}_{3}\right), 1.4\left(\mathrm{~s}, 3 \mathrm{H}, \mathrm{CH}_{3}\right), 1.42-1.60$ (m, $\left.10 \mathrm{H}\right)$, $1.62\left(\mathrm{~s}, 3 \mathrm{H}, \mathrm{CH}_{3}\right), 1.65-2.00(\mathrm{~m}, 7 \mathrm{H}), 2.2\left(\mathrm{~s}, 3 \mathrm{H}, \mathrm{CH}_{3}\right), 2.22-2.85(\mathrm{~m}, 6 \mathrm{H}), 3.81(\mathrm{~d}, J=2.2$ $\left.\mathrm{Hz}, 3 \mathrm{H}, \mathrm{CH}_{3}\right), 3.85(\mathrm{~d}, J=11.4 \mathrm{~Hz}, 1 \mathrm{H}), 4.11(\mathrm{q}, J=2.45 \mathrm{~Hz}, 1 \mathrm{H}), 4.22(\mathrm{~d}, J=10.8,1 \mathrm{H})$, 4.40-4.55 (m, $1 \mathrm{H}), 4.69$ (dd, $J=1.5,11.4 \mathrm{~Hz}, 2 \mathrm{H}), 5.40$ (s, $1 \mathrm{H}, \mathrm{CH}), 5.76$ (d, $J=9.9 \mathrm{~Hz}, 2 \mathrm{H})$.

${ }^{13}$ C-NMR $\left(150 \mathrm{MHz}, \mathrm{CDCl}_{3}\right): \delta=37.24,37.52,37.80,38.31,40.85,42.66,45.21,46.27,47.68$, $48.73,50.23,51.54,55.34,60.38,62.78,80.09,81.33$, 91.46, 92.07, 104.4, 109.7, 150.1, 171.2, 171.6, 171.8 .

MS (ESI): $\mathrm{m} / \mathrm{z}(\%)=873.4(20)[\mathrm{M}+\mathrm{Na}]^{+}, 1723.5(100)[2 \mathrm{M}+\mathrm{Na}]^{+}$.

$\mathrm{C}_{51} \mathrm{H}_{78} \mathrm{O}_{10} \quad$ ber. $868.59332[\mathrm{M}+\mathrm{H}]^{+}$ gef. 868.59339, 868.59653, 870.59960 (ESI-HRMS).

$[\alpha]^{20}{ }_{\mathrm{D}}=+15.0^{\circ}\left(\mathrm{c}=0.167, \mathrm{CHCl}_{3}\right)$.

Smp. $130-136^{\circ} \mathrm{C}$

9.9.3 Verbindung 107 (Betulin-28-Artesunat)

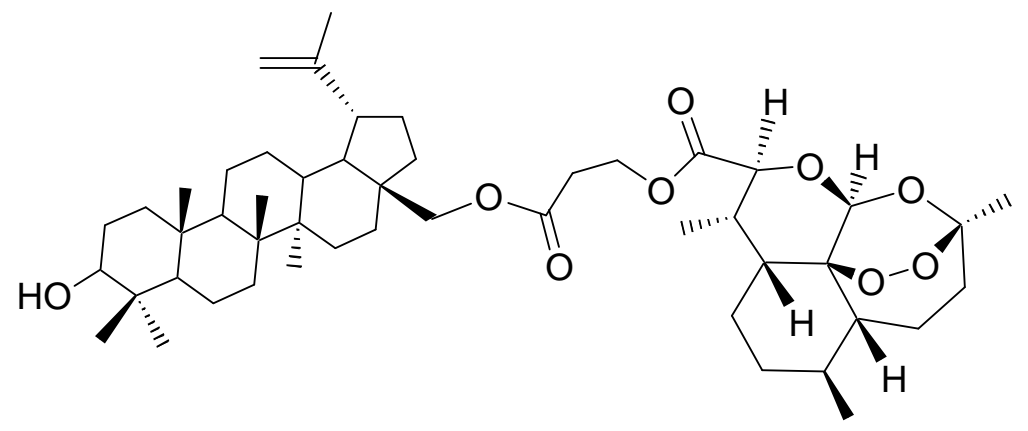

Unter Stickstoff wurde Artesunat $(51.8 \mathrm{mg}, 0.13 \mathrm{mmol}, 1 \mathrm{Äq})$ in trockenem $\mathrm{CH}_{2} \mathrm{Cl}_{2}(3 \mathrm{~mL})$ gelöst. Eine Aktivierung des Artesunats wurde durch Zugabe von DCC (23.5 mg, $0.11 \mathrm{mmol}$, 
1.20 Äq) und DMAP (6.60 mg, 0.40 Äq) ausgelöst. Nach halber Stunde Rühren wurde eine Lösung von Betulin (60.0 mg, $0.14 \mathrm{mmol}, 1$ Äq) in getrocknetem Dichlormethan (3 mL) innerhalb von 5 Minuten zugetropft. Die Reaktionsmischung wurde weiter unter Stickstoffatomsphäre 3 Tage gerührt. Anschliessend wurde der Niederschlag abfiltriert. Die Mutterlauge wurde mit $10 \% \mathrm{HCl}(10 \mathrm{~mL})$ bei $0^{\circ} \mathrm{C}$ neutralisiert und durch $\mathrm{CH}_{2} \mathrm{Cl}_{2}(3 \times 50 \mathrm{~mL})$ extrahiert. Die verreinigten organischen Phasen wurde durch gesättigte NaCl-Lösung gewaschen und über $\mathrm{Na}_{2} \mathrm{SO}_{4}$ getrocknet. Das Rohprodukt wurde zuerst durch Säulenchromatographie an Kieselgel mit einem Gradienten (Hex:EE = 3:1-1:1) und danach an Sephadex-Gel $\left(\mathrm{CHCl}_{3}\right)$ gereinigt. Die Titelverbindung wurde als weißer Feststoff $(45.0 \mathrm{mg}$, $0.06 \mathrm{mmol}, 54 \%$ ) erhalten.

$\boldsymbol{R}_{\mathbf{f}}=0.5($ Hex.: $\mathrm{EE}=1: 1)$

${ }^{1}$ H-NMR (300 MHz, $\left.\mathrm{CDCl}_{3}\right): \delta=0.71-0.79(\mathrm{~m}, 6 \mathrm{H}), 0.8\left(\mathrm{~s}, 6 \mathrm{H}, \mathrm{CH}_{3}\right), 0.82-0.93(\mathrm{~m}, 11 \mathrm{H})$, 0.95 (s, $\left.3 \mathrm{H}, \mathrm{CH}_{3}\right), 1.00$ (s, $\left.3 \mathrm{H}, \mathrm{CH}_{3}\right), 1.21$ (s, $\left.3 \mathrm{H}, \mathrm{CH}_{3}\right), 1.4\left(\mathrm{~s}, 3 \mathrm{H}, \mathrm{CH}_{3}\right), 1.42-1.58(\mathrm{~m}, 6 \mathrm{H})$, $1.62\left(\mathrm{~s}, 3 \mathrm{H}, \mathrm{CH}_{3}\right), 1.70-2.0(\mathrm{~m}, 10 \mathrm{H}), 2.21\left(\mathrm{~s}, 3 \mathrm{H}, \mathrm{CH}_{3}\right), 2.22-2.85(\mathrm{~m}, 10 \mathrm{H}), 3.8$ (d, J = 11.4 $\mathrm{Hz}, 1 \mathrm{H}, \mathrm{CH}), 4.11$ (q, $J=2.45 \mathrm{~Hz}, 1 \mathrm{H}, \mathrm{CH}), 4.22$ (d, $J=10.8,1 \mathrm{H}, \mathrm{CH}), 4.40-4.55(\mathrm{~m}, 1 \mathrm{H})$, $4.69(\mathrm{dd}, J=1.5,11.4 \mathrm{~Hz}, 2 \mathrm{H}), 5.4\left(\mathrm{~s}, 1 \mathrm{H}, \mathrm{CH}_{3}\right), 5.76\left(\mathrm{~d}, J=9.9 \mathrm{~Hz}, 2 \mathrm{H}, \mathrm{CH}_{2}\right)$.

${ }^{13}$ C-NMR $\left(150 \mathrm{MHz}, \mathrm{CDCl}_{3}\right): \delta=37.25,37.55,38.67,38.83,40.84,42.67,45.21,46.36,47.65$, 48.77, 50.33, 51.53, 55.25, 63.06, 78.96, 80.11, 91.49, 92.12, 104.4, 109.8, 150.2, 171.1, 172.5. MS (ESI): $\mathrm{m} / \mathrm{z}(\%)=831.4(45)[\mathrm{M}+\mathrm{Na}]^{+}, 1639.6(100)[2 \mathrm{M}+\mathrm{Na}]^{+}$. $[\alpha]^{20}{ }_{D}=+12.6^{\circ}\left(\mathrm{c}=0.127, \mathrm{CHCl}_{3}\right)$.

Smp. $131.5-145^{\circ} \mathrm{C}$ 
9.9.4 Synthese der Verbindung $\mathbf{1 0 8}$ (Artsunat-Betulin-Artesunat)

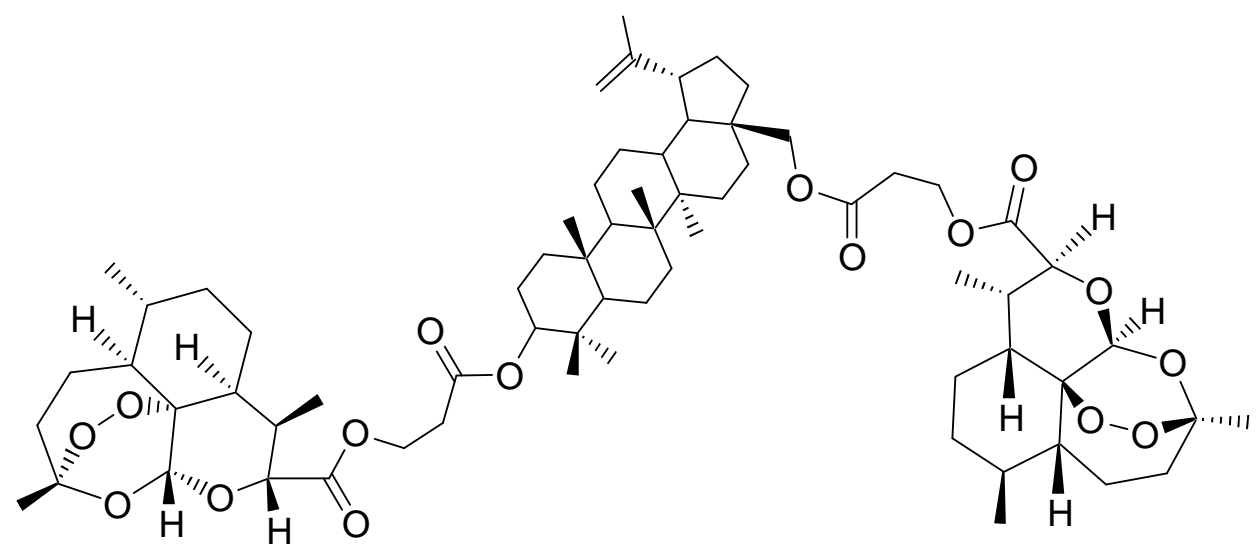

Unter Stickstoff wurde Artesunat (42.8 mg, $0.09 \mathrm{mmol}, 2.00$ Äq) in trockenem DMF (3 mL) gelöst. Dann gab man EDCI (21.4 mg, 0.09 mmol, 2.00 Äq) und DMAP (4.65 mg, 0.04 mmol, $0.41 \ddot{A} q)$ in die Lösung hinzu und löste dadurch die Aktivierung von Artesunat aus. Nach 40 Minuten Rühren wurde eine Lösung von Betulin $(21.4 \mathrm{mg}, 0.05 \mathrm{mmol}, 1$ Äq) in getrocknetem DMF (3 mL) innerhalb von 5 Minuten zugetropft. Die Reaktionsmischung wurde unter Stickstoff 2 Tage gerührt.

Anschließend wurde die Reaktionsmischung mit $\mathrm{H}_{2} \mathrm{O}$ :EE (1:1) und 5\% HCl-Lösung bei $0^{\circ} \mathrm{C}$ gewaschen. Dann wurde die wässrige Phase mit Ethylacetat (3 x 15mL) extrahiert. Die vereinigten organischen Phasen wurden mit Wasser und gesättigter NaCl-Lösung gewaschen. über $\mathrm{Na}_{2} \mathrm{SO}_{4}$ getrocknet. Das Rohprodukt wurde zuerst durch Säulenchromatographie an Kieselgel mit einem Gradienten (Hex:EE = 3:1-1:1) und danach an Sephadex-Gel $\left(\mathrm{CHCl}_{3}\right)$ gereinigt. Die Titelverbindung wurde als weißer Feststoff (25.2 mg, 0.02mmol, 61\%) erhalten.

$\boldsymbol{R}_{\mathbf{f}}=0.5($ Hex.: $\mathrm{EE}=1: 1)$

${ }^{1} \mathbf{H}-\mathbf{N M R}\left(300 \mathrm{MHz}, \mathrm{CDCl}_{3}\right): \delta=0.71-0.79(\mathrm{~m}, 6 \mathrm{H}), 0.8\left(\mathrm{~s}, 6 \mathrm{H}, \mathrm{CH}_{3}\right), 0.82-0.93(\mathrm{~m}, 11 \mathrm{H})$, 0.95 (s, 3 H, $\mathrm{CH}_{3}$ ), 1.00 (s, $\left.3 \mathrm{H}, \mathrm{CH}_{3}\right), 1.21$ (s, $3 \mathrm{H}, \mathrm{CH}_{3}$ ), 1.40 (s, $\left.3 \mathrm{H}, \mathrm{CH}_{3}\right), 1.42-1.58$ (m, 20 H), $1.62\left(\mathrm{~s}, 3 \mathrm{H}, \mathrm{CH}_{3}\right), 1.70-2.0(\mathrm{~m}, 20 \mathrm{H}), 2.20\left(\mathrm{~s}, 3 \mathrm{H}, \mathrm{CH}_{3}\right), 2.22-2.85(\mathrm{~m}, 10 \mathrm{H}), 3.80(\mathrm{~d}, J=$ $11.4 \mathrm{~Hz}, 1 \mathrm{H}, \mathrm{CH}), 4.21(\mathrm{~d}, J=11.1 \mathrm{~Hz}, 1 \mathrm{H}, \mathrm{CH}), 4.45$ (q, $J=2.45 \mathrm{~Hz}, 1 \mathrm{H}, \mathrm{CH}), 4.67(\mathrm{dd}, J=$ 1.5, $\left.11.4 \mathrm{~Hz}, 2 \mathrm{H}, \mathrm{CH}_{2}\right), 5.40\left(\mathrm{~d}, 1 \mathrm{~Hz}, 2 \mathrm{H}, \mathrm{CH}_{2}\right), 5.76\left(\mathrm{dd}, J=2.5,9.9 \mathrm{~Hz}, 2 \mathrm{H}, \mathrm{CH}_{2}\right) .5 .98(\mathrm{dd}$, $\left.J=1.2,9.6 \mathrm{~Hz}, 2 \mathrm{H}, \mathrm{CH}_{2}\right)$. 
${ }^{13}$ C-NMR (150 MHz, $\left.\mathrm{CDCl}_{3}\right): \delta=37.5,37.77,38.27,40.81,42.62,45.17,46.32,47.64,48.72$, 50.19, 51.50, 55.31, 60.34, 63.02, 80.06, 81.30, 91.42, 91.45, 92.03, 92.08, 104.3, 104.4, 109.8, 150.1, 171.1, 171.1, 171.1, 171.7, 172.4 .

MS (ESI): $\mathrm{m} / \mathrm{z}(\%)=1197.6(100)[\mathrm{M}+\mathrm{Na}]^{+}$.

$[\alpha]^{20}{ }_{\mathrm{D}}=+18.3^{\circ}\left(\mathrm{c}=0.109, \mathrm{CHCl}_{3}\right)$.

Smp. $180-183{ }^{\circ} \mathrm{C}$

9.9.5 Verbindung $\mathbf{1 0 9}$

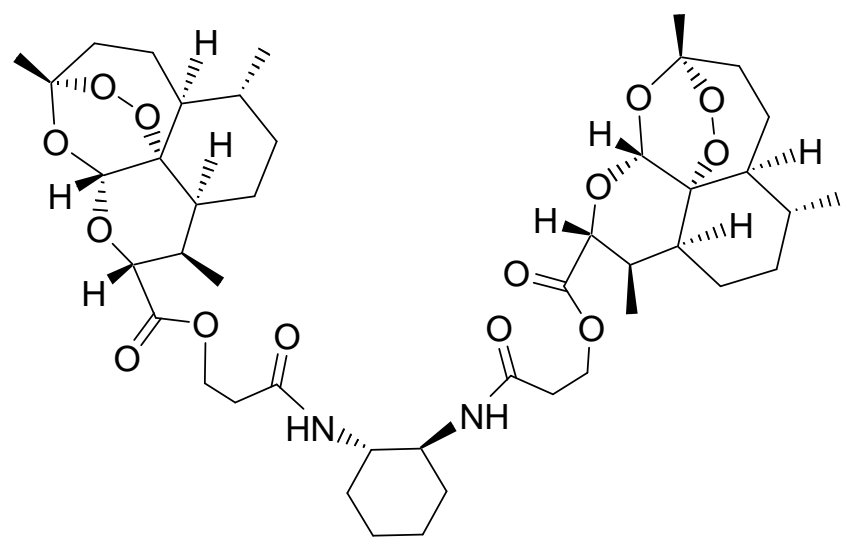

Unter Stickstoff wurde Artesunat (342 mg, $0.88 \mathrm{mmol}, 2 \ddot{\mathrm{Aq}}$ ) in trockenem $\mathrm{CH}_{2} \mathrm{Cl}_{2}(3 \mathrm{~mL})$ gelöst. Eine Aktivierung des Artesunats wurde durch Zugabe von DCC (298 mg, 1.40 mmol, 3.2 Äq) und DMAP (21.4 mg, $0.17 \mathrm{mmol} 0.40$ Äq) ausgelöst. Nach einer halben Stunde Rühren wurde eine Lösung von Betulin $(60.0 \mathrm{mg}, 0.13 \mathrm{mmol}, 1$ Äq) in getrocknetem Dichlormethan (3 $\mathrm{mL}$ ) innerhalb von 5 Minuten zugetropft. Die Reaktionsmischung wurde unter Stickstoff 3 Tage gerührt.

Niederschlag wurde abfiltriert, die Mutterlauge mit verdünnter $\mathrm{HCl}$ bei $0^{\circ} \mathrm{C}$ neutralisiert. Man extrahierte mit $\mathrm{CH}_{2} \mathrm{Cl}_{2}$ (3 x $\left.50 \mathrm{~mL}\right)$, und die organische Phase wurde mit gesättigter NaClLösung gewaschen. Über $\mathrm{Na}_{2} \mathrm{SO}_{4}$ getrocknet. Das Rohprodukt wurde zuerst durch Säulenchromatographie an Kieselgel mit einem Gradienten (Hex:EE = 3:1-1:1) und danach an Sephadex-Gel $\left(\mathrm{CHCl}_{3}\right)$ gereinigt. Die Titelverbindung wurde als weißer Feststoff (45.0 mg, $0.05 \mathrm{mmol}, 54 \%$ ) erhalten.

$\boldsymbol{R}_{f}=0.65(\mathrm{Hex}: \mathrm{EE}=1: 1)$ 
${ }^{1} \mathbf{H}-\mathbf{N M R}\left(300 \mathrm{MHz}, \mathrm{CDCl}_{3}\right): \delta=0.80-1.20(\mathrm{~m}, 13 \mathrm{H}), 1.22-1.23(\mathrm{~m}, 7 \mathrm{H}), 1.20-1.30(\mathrm{~m}, 16 \mathrm{H})$, $1.44\left(\mathrm{~d}, J=2.7 \mathrm{~Hz}, 9 \mathrm{H}, 3 \mathrm{CH}_{3}\right), 1.46-2.04(\mathrm{~m}, 11 \mathrm{H}), 1.99-2.05(\mathrm{~m}, 3 \mathrm{H}), 2.58-2.62$ (m, $\left.2 \mathrm{H}\right)$, 2.78-2.80 (m, $1 \mathrm{H}), 4.50-4.80(\mathrm{~m}, 1 \mathrm{H}), 5.27-5.30(\mathrm{~m}, 1 \mathrm{H}), 5.37\left(\mathrm{~s}, 3 \mathrm{H}, \mathrm{CH}_{3}\right), 5.58(\mathrm{~s}, 3 \mathrm{H}$, $\mathrm{CH}_{3}$ ).

${ }^{13}$ C-NMR (150 MHz, $\left.\mathrm{CDCl}_{3}\right): \delta=12.00,20.19,21.98,24.55,24.69,25.32,25.43,25.93$, 26.18, 29.65, 30.59, 30.84, 31.84, 32.41, 32.57, 34.04, 36.18, 37.26, 45.17, 49.92, 51.51, 80.09, 91.53, 92.29, 104.4, 153.9, 172.1 .

MS (ESI): $\mathrm{m} / \mathrm{z}(\%)=869.3(100)[\mathrm{M}+\mathrm{Na}]^{+}$.

$\mathrm{C}_{44} \mathrm{H}_{66} \mathrm{~N}_{2} \mathrm{O}_{14} \quad$ ber. $864.48523\left[\mathrm{M}+\mathrm{NH}_{4}\right]^{+}$. gef. 864.48559, 865..48905, 866,49153, 869. 44055 (ESI-HRMS).

$[\alpha]^{20}{ }_{D}=+18.3^{\circ}\left(\mathrm{c}=1.45, \mathrm{CHCl}_{3}\right)$.

9.9.6 (E)-But-2-enyl-1,4-dimethanesulfonat (111)

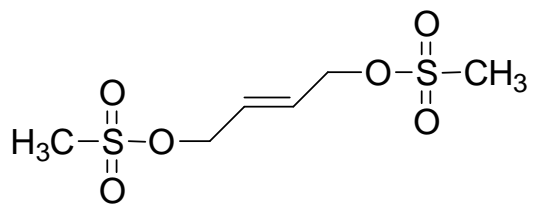

Unter Stickstoff wurde 1,4-Butendiol (8.22 mL, $0.10 \mathrm{mmol}, 1 \ddot{\mathrm{Aq}})$ in trockenem $\mathrm{CH}_{2} \mathrm{Cl}_{2}(38 \mathrm{~mL})$ gelöst. Diese Lösung wurde bis auf $0^{\circ} \mathrm{C}$ abgekühlt und dann $\mathrm{NEt}_{3}$ zugegeben. Nach einer halben Stunde Rühren wurde $\mathrm{MsCl}$ (17.1 mL, $0.22 \mathrm{mmol}, 2.20$ Äq) innerhalb 30 Minuten zugetropft. Die Reaktionsmischung als Suspension wurde bei $0^{\circ} \mathrm{C}$ unter DC-Kontrolle (Anfärbungsmittel Anisaldehyd) $3 \mathrm{~h}$ gerührt. Anschließend wurde die Reaktion durch Zugabe bei $0^{\circ} \mathrm{C}$ von verdünnter $\mathrm{HCl}$-Lösung beendet. Der Niederschlag wurde abfiltriert und die Mutterlauge mit Ethylacetat (3 x $50 \mathrm{~mL}$ ) extrahiert. Das Lösungsmittel wurde im Vakuum entfernt. Der Rückstand wurde chromatographisch an Kieselgel (100\% Ethylacetat) gereinigt. Die Titelverbindung wurde als kaffeefarbenes Öl (106 g, 0.43 Mol 76\%) erhalten.

$\boldsymbol{R}_{f}=0.65(100 \% \mathrm{EE})$

${ }^{1}$ H-NMR $\left(300 \mathrm{MHz}, \mathrm{CDCl}_{3}\right): \delta=3.02\left(\mathrm{~s}, 6 \mathrm{H}, 2 \mathrm{CH}_{3}\right), 4.82\left(\mathrm{dd}, J=1.2,7.5 \mathrm{~Hz}, 4 \mathrm{H}, 2 \mathrm{CH}_{2}\right)$, 5.76-5.82 (m, $2 \mathrm{H}, 2 \mathrm{CH})$.

${ }^{13}$ C-NMR $\left(150 \mathrm{MHz}, \mathrm{CDCl}_{3}\right): \delta=38.02,65.43,129.8$.

MS (ESI): $\mathrm{m} / \mathrm{z}(\%)=267.28(37)[\mathrm{M}+\mathrm{Na}]^{+}, 511.58[2 \mathrm{M}+\mathrm{Na}]^{+}$. 
9.9.7 Dibetulin (112)

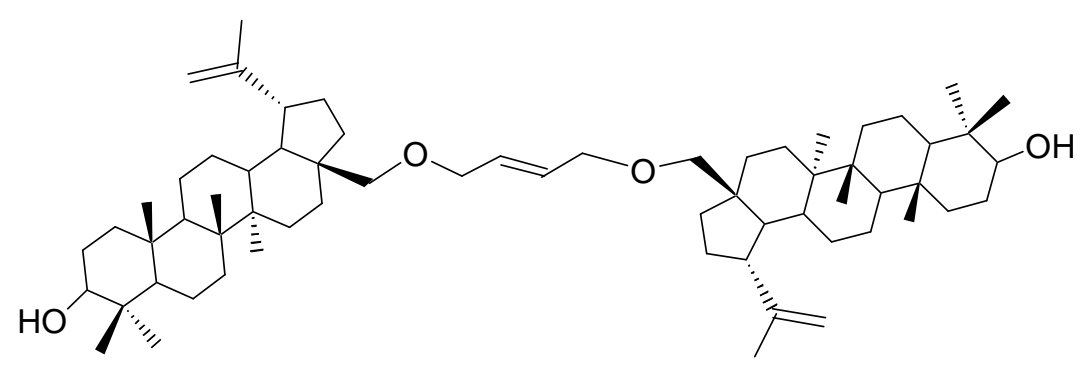

Unter Stickstoff wurde Betulin (100 mg, $0.23 \mathrm{mmol}, 2$ Äq) in trockenem THF (2 mL) gelöst. Man gab NaH-Suspension (5.10 mg, 80\% in Parafineöl, $0.17 \mathrm{mmol}, 1.50$ Äq) dazu. Nach einer Stunde Rühren wurde Dimesylat (27.5 mg, $0.11 \mathrm{mmol}, 1$ Äq) in THF (3 mL) innerhalb von einer halben Stunde zugetropft. Die Reaktionsmischung wurde bei $40^{\circ} \mathrm{C}$ unter DC-Kontrolle (Anfärbungsmittel Anisadhyd) $24 \mathrm{~h}$ gerührt. Anschließend wurde die Reaktion bei $0^{\circ} \mathrm{C}$ durch Zugabe von verdünnter $\mathrm{HCl}$-Lösung beendet, und mit $\mathrm{CH}_{2} \mathrm{Cl}_{2}(3 \times 20 \mathrm{~mL})$ extrahiert. Die vereinigten organischen Phasen wurden mit gesättigter $\mathrm{NaCl}$-Lösung gewaschen und über $\mathrm{Na}_{2} \mathrm{SO}_{4}$ getrocknet. Das Rohprodukt wurde zuerst durch Säulenchromatographie an Kieselgel mit einem Gradienten (Hex:EE = 5:1-5:3) und danach an Sephadex-Gel $\left(\mathrm{CHCl}_{3}: \mathrm{MeOH} 9: 1\right)$ gereinigt. Die Titelverbindung wurde als weißer Feststoff (45.0 mg, 0.047 mmol, 54\%) erhalten.

$\boldsymbol{R}_{f}=0.65($ Hex. $: \mathrm{EE}=3: 1)$

${ }^{1} \mathbf{H}-\mathbf{N M R}\left(300 \mathrm{MHz}, \mathrm{CDCl}_{3}\right): \delta=0.60\left(\mathrm{~s}, 3 \mathrm{H}, \mathrm{CH}_{3}\right), 0.70-1.20(\mathrm{~m}, 18 \mathrm{H}), 1.3\left(\mathrm{~s}, 3 \mathrm{H}, \mathrm{CH}_{3}\right)$, 1.2-1.7 (m, $50 \mathrm{H}), 1.60-2.00(\mathrm{~m}, 2 \mathrm{H}), 2.52\left(\mathrm{~s}, 6 \mathrm{H}, 2 \mathrm{CH}_{3}\right), 3.15(\mathrm{dd}, J=4.8,10.8 \mathrm{~Hz}, 2 \mathrm{H}, 2$ $\mathrm{CH}), 3.32(\mathrm{~d}, J=10.2 \mathrm{~Hz}, 2 \mathrm{H}, 2 \mathrm{CH}), 3.38(\mathrm{dd}, J=2.1,11.7 \mathrm{~Hz}, 2 \mathrm{H}, 2 \mathrm{CH}), 4.55(\mathrm{dd}, J=1.8$, $\left.2.4 \mathrm{~Hz}, 2 \mathrm{H}, \mathrm{CH}_{2}\right), 4.65\left(\mathrm{~d}, 2.4 \mathrm{~Hz}, 2 \mathrm{H}, \mathrm{CH}_{2}\right)$.

${ }^{13}$ C-NMR (150MHz, $\left.\mathrm{CDCl}_{3}\right): \delta=14.73,15.30,16.09,18.27,19.05,20.79,25.16,27.00,27.97$, 29.12, 29.70, 33.94, 34.18, 37.12, 38.66, 38.84, 40.87, 42.68, 47.75, 48.70, 50.35, 55.24, 60.51, 78.96, 109.6, 115.8, 131.7, 150.4.

MS (DCI): $\mathrm{m} / \mathrm{z}(\%)=869.3(100)\left[\mathrm{M}-\mathrm{C}_{6} \mathrm{H}_{12}\right]^{+}$.

$[\alpha]^{20}{ }_{\mathrm{D}}=-2.0^{\circ}\left(\mathrm{c}=0.1, \mathrm{CHCl}_{3}\right)$. 
9.9.8 Artesunatpentaflorphenylester (113)

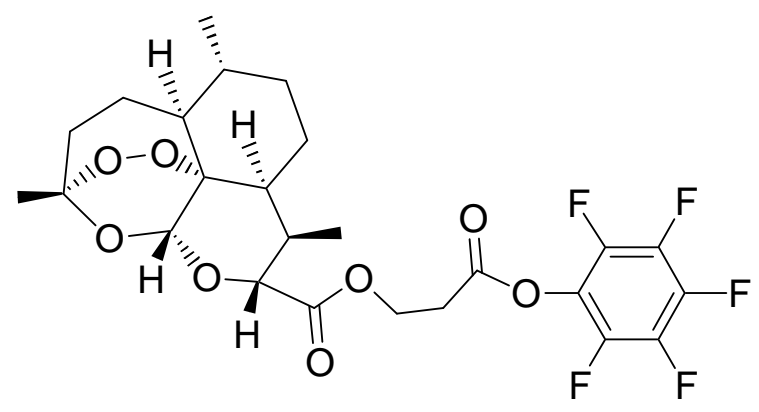

Unter Stickstoff wurde HOPFP (315 mg, $1.71 \mathrm{mmol}, 1.16$ Äq) mit getrocknetem Ethylacetat (5 $\mathrm{mL}$ ) gelöst. Artesunat (564 mg, $1.47 \mathrm{mmol}, 1$ Äq) wurde in trockenem Chloroform gelöst. Man mischt die beiden Lösungen bei -10 bis $-20^{\circ} \mathrm{C}$. Dann gab man die Lösung $\left(-20^{\circ} \mathrm{C}\right)$ von DCC (315 mg, $1.52 \mathrm{mmol}, 1.03$ Äq) in trockenem Ethylacetat (5 mL) hinzu. Diese Mischung wurde auf $0^{\circ} \mathrm{C}$ erwärmt und über Nacht bei $0^{\circ} \mathrm{C}$ stehen gelassen.

Anschließend wurde der Niederschlag abfiltriert und das Lösungsmittel im Vakuum entfernt. Nach einer säulenchromatographischen Reinigung wurde das Produkt $(717$ mg, $1.30 \mathrm{mMol}$, $90 \%$ ) erhalten.

$\boldsymbol{R}_{\boldsymbol{f}}=0.55$ (Hex. : $\left.\mathrm{EE}=3: 1\right)$

${ }^{1}$ H-NMR (300 MHz, DMSO ): $\delta=0.76\left(\mathrm{~d}, J=6.9 \mathrm{~Hz}, 3 \mathrm{H}, \mathrm{CH}_{3}\right), 0.90(\mathrm{~d}, J=6.0 \mathrm{~Hz}, 3 \mathrm{H}$, $\left.\mathrm{CH}_{3}\right), 1.16-1.19$ (m, $\left.1 \mathrm{H}\right), 3.17\left(\mathrm{~s}, 3 \mathrm{H}, \mathrm{CH}_{3}\right), 1.43-1.64(\mathrm{~m}, 5 \mathrm{H}), 1.78-1.85$ (m, $\left.2 \mathrm{H}\right), 2.01-2.02$ (m, $2 \mathrm{H}), 2.06-2.38(\mathrm{~m}, 2 \mathrm{H}), 2.84\left(\mathrm{dd}, J=5.1,7.8 \mathrm{~Hz}, 2 \mathrm{H}, \mathrm{CH}_{2}\right), 3.07$ (dd, $J=4.5,7.2 \mathrm{~Hz}, 2$ $\mathrm{H}), 5.57(\mathrm{~s}, 1 \mathrm{H}, \mathrm{CH}), 5.71(\mathrm{~d}, J=9.6 \mathrm{~Hz}, 1 \mathrm{H}, \mathrm{CH})$

${ }^{13}$ C-NMR (150 MHz, DMSO ): $\delta=11.5,11.6,19.93,20.91,24.10,25.39,25.42,27.74,28.29$, $28.41,28.69,31.53,31.57,33.63,35.82,35.88,38.86,44.50,44.53,51.06,79.74,79.76,90.55$, $91.67,92.01,103.4,168.5,170.3,170.8,173.0$. 
9.9.9 Artesunat-propyldiamin-Peptid (114)

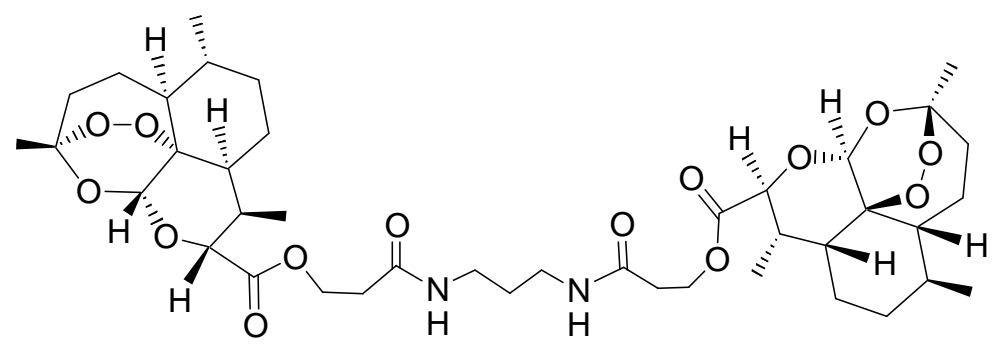

Unter Stickstoff wurde Art-PfP (320 mg, $0.58 \mathrm{mmol}, 2.02$ Äq) in DMF (1 mL) gelöst. die Lösung von Diaminocyclohexan (32.8 mg, $0.28 \mathrm{mmol}, 1$ Äq) in DMF (1 mL) innerhalb von halber Stunde zugetropft. Diese Reaktionsmischung wurde $2 \mathrm{~h}$ bei Raumtemperatur gerührt. Anschließend wurde das Lösungsmittel im Vakuum entfernt. Das Rohprodukt wurde zuerst durch Säulenchromatographie an Kieselgel $\left(\mathrm{CHCl}_{3}: \mathrm{MeOH}=9: 1\right)$ und danach an Sephadex-Gel $\left(\mathrm{CHCl}_{3}\right)$ gereinigt. Die Titelverbindung wurde als weißer Feststoff (43.9 mg, 0.55 mmol, 10\%) erhalten.

$\boldsymbol{R}_{\mathbf{f}}=0.33(\mathrm{Hex}: \mathrm{EE}=1: 1)$

${ }^{1}$ H-NMR (300 MHz, DMSO): $\delta=0.80-1.12$ (m, 14 H), 1.20-1.51 (m, $\left.13 \mathrm{H}\right), 1.58-1.98$ (m, 14 H), 2.41-2.60 (m, $10 \mathrm{H}), 2.62-2.82(\mathrm{~m}, 5 \mathrm{H}), 5.40(\mathrm{~s}, 2 \mathrm{H}, 2 \mathrm{CH}), 5.72(\mathrm{~d}, J=9.9 \mathrm{~Hz} ; 2 \mathrm{H}), 6.43$ (m, $2 \mathrm{H}$ ).

${ }^{13}$ C-NMR (150 MHz, DMSO): $\delta=36.59$, 36.85, 37.23, 37.34, 37.45, 44.27, 45.13, 45.39, 51.48, 52.45, 60.48, 80.10, 81.11, 87.77, 91.18, 91.49, 91.54, 92.30, 92.35, 94.62, 96.38, 104.1, $104.5,105.1,172.0,172.4$.

MS (ESI): $\mathrm{m} / \mathrm{z}(\%)=829.3(100)[\mathrm{M}+\mathrm{Na}]^{+}, 1634.9(25)[2 \mathrm{M}+\mathrm{Na}]^{+}$. $[\alpha]^{20}{ }_{D}=18.6^{\circ}\left(\mathrm{c}=1.45, \mathrm{CHCl}_{3}\right)$. 


\section{Abkürzungsverzeichnis}

\begin{tabular}{|c|c|}
\hline Abb. & Abbildung \\
\hline Ac & Acetyl \\
\hline $\mathrm{AcOH}$ & Essigsäure \\
\hline$\ddot{\mathrm{Aq}}$ & Äquivalente \\
\hline $\mathrm{Ar}$ & Aryl \\
\hline Art. & $\begin{array}{l}\text { Artesunat: } \quad(3 R, 5 \mathrm{a} S, 6 R, 8 \mathrm{a} S, 9 R, 10 S, 12 R, 12 \mathrm{a} R) \text {-Decahydro-3,6,9-trimethyl-3,12- } \\
\text { epoxy-12H-pyrano[4,3-j]1,2-benzodioxepisuccinat }\end{array}$ \\
\hline Aus. & Ausbeute \\
\hline ber. & Berechnet \\
\hline binap & 2-(Diphenylphosphino)-1-(2-(diphenylphosphino)naphthalen-1-yl)naphthalene \\
\hline Boc & tert-Butoxylcarbonyl \\
\hline $\mathrm{Bu}$ & Butyl \\
\hline Betulin & $\begin{array}{l}\text { 3a-Hydroxymethyl-1-isopropenyl-5a,5b,8,8,11a-pentamethyl-icosahydro- } \\
\text { cyclopenta[a]chrysen-9-ol }\end{array}$ \\
\hline$c$ & Konzentration \\
\hline $\mathrm{DABCO}$ & 1.4-Diazabicyclo[2.2.2]octan \\
\hline DBU & 1,8-Diazabicyclo[5.4.0]-undec-7-en \\
\hline $\mathrm{DC}$ & Dünnschichtchromatographie \\
\hline$\overline{\mathrm{DCC}}$ & $N, N$-Dicylclohexylcarbodiimid \\
\hline DCI & direkte chemische Ionisation \\
\hline DIBAH & Diisobutylaluminiunhydrid \\
\hline DIPAM & (Ethyl)diisopropylamin \\
\hline DMAP & 4-(Dimethylamino)pyridin \\
\hline$\overline{\mathrm{DMF}}$ & Dimethylformamid \\
\hline$\left[\mathrm{D}_{6}\right] \mathrm{DMSO}$ & Hexadeuterodimethylsulfoxid \\
\hline $\mathrm{dr}$ & Diastereomerenverhältnis \\
\hline $\mathrm{EC}_{50}$ & effektive Wirstoffkonzentration, siehe $\mathrm{ED}_{50}$ \\
\hline $\mathrm{ED}_{50}$ & $\begin{array}{l}\text { effektive Wirstoffdosis, bei der } 50 \% \text { der maximalen Wirkung auftritt oder } 50 \% \\
\text { der Testpopulation eine bestimmte Wirkung zeigt }\end{array}$ \\
\hline EDCI & $N$-Ethyl- $N, N$-(dimethylaminopropyl)carbodiimid \\
\hline$e e$ & Enantiomerenüberschuss \\
\hline
\end{tabular}




\begin{tabular}{|c|c|}
\hline $\mathrm{EE}$ & Essigsäureethylester \\
\hline EI & Elektronenstoßionisation \\
\hline ESI & Elektrospray-Ionisation \\
\hline $\mathrm{Et}$ & Ethyl \\
\hline $\mathrm{EtOH}$ & Ethanol \\
\hline $\mathrm{Eu}(\mathrm{hfc})_{3}$ & Europium (Ш)-tris-[3-(heptafluorpropyl-hydroxymethylen)- $d$ - camphorat] \\
\hline $\mathrm{Eu}(\mathrm{tfc})_{3}$ & Europium (Ш)-tris-[3-(trifluormethyl-hydroxymethylen)- $d$ - camphorat] \\
\hline gef. & gefunden \\
\hline Hex & Hexan \\
\hline HPLC & Hochleistungsflüssigkeitschromatographie \\
\hline HR & Hochauflösung \\
\hline $\mathrm{Hz}$ & Hertz \\
\hline$i$-Bu & Isobutyl \\
\hline$J$ & Skalare Kopplungskonstante \\
\hline Kat. & Katalysator \\
\hline konz. & Konzentriert \\
\hline$m$ & meta \\
\hline $\mathrm{Me}$ & Methyl \\
\hline $\mathrm{MeOH}$ & Methanol \\
\hline MS & Massenspektroskopie \\
\hline $\mathrm{MsCl}$ & Methansulfonsäurechlorid \\
\hline NMR & nuclear magnetic resonance \\
\hline$o$ & ortho \\
\hline Piv & 2,2-Dimethyl-propylcarbonyl \\
\hline$p$ & para \\
\hline pfp & 2,3,4,5-pentafluorphenyl \\
\hline HO-pfp & 2,3,4,5-Pentafluorphenol \\
\hline $\mathrm{IC}_{50}$ & Wirkstoffkonzentration, bei der 50\% Inhibierung (z.B. eines Enzyms) auftritt \\
\hline $\mathrm{Ph}$ & Phenyl \\
\hline PMB & p-Methoxybenzyl \\
\hline ppm & parts per million \\
\hline Py. & Pyridin \\
\hline Red. & Reduzierte Zeit \\
\hline
\end{tabular}




\begin{tabular}{|l|l|}
\hline$R_{\mathrm{f}}$ & Retentionswerte für DC \\
\hline$R_{\mathrm{t}}$ & Retentionszeite für HPLC \\
\hline RP & reverse Phase \\
\hline RT & Raum- bzw. Umgebungstemperatur \\
\hline $\mathrm{s}$ & Singulett \\
\hline TFA & Trifluroessigsäure \\
\hline Tem. & Temperatur \\
\hline THF & Tetrahydrofuran \\
\hline t & Triplett \\
\hline TBS & tert-Butyldimethylsilyl \\
\hline TMS & Tetramethylsilan \\
\hline Tr & Triphenylmethyl \\
\hline Um. & Umsatz \\
\hline UV & Ultraviolett-Spektroskopie \\
\hline vgl. & vergleichen \\
\hline Z & Benzyloxylcarbonyl \\
\hline
\end{tabular}




\section{Publikationen}

1) Evidence of Asymmetric Autocatalysis in Organocatalytic Reactions. M. Mauksch, S. B.

Tsogoeva, I. M. Martynova, S.-W. Wie, Angew. Chem. Int. Ed. 2007, 46, 393; Angew. Chem. 2007, 119, 397.

2) New highly enantioselective thiourea-based bifunctional organocatalysts for nitro-Michael addition. S.-W, Wei, D.A. Yalalov, S. B. Tsogoeva, S. Schmatz, Catalysis Today. 2007, 121, $151-157$.

3) Highly enantioselective addition of ketones to nitroolefins catalyzed by new thiourea-amine bifunctional organocatalysts. S. B. Tsogoeva, S.-W. Wei, Chem. Commun. 2006, 1451.

4) S.B. Tsogoeva, S.-W, Wei, (S)-Histidine-based Dipeptides as Organic Catalysts for Direct Asymmetric Aldol Reactions. Tetrahedron: Asymmetry. 2005, 16, 1947. 


\section{Literaturverzeichnis}

1 a) Organikum 22 Auflag, 2004, WILEY-VCH-Verlag GmbH, Weinheim, 173.b).

Organikum 22 Auflag, 2004, WILEY-VCH-Verlag GmbH, Weinheim, 175-176; c) Adam, Sobanski, Roland Schiieder, Fritz Vögtle: Topologische Stereochemie und Chiralität Chemie in unserer Zeit, 34(3), S.160-169 (2000), ISSN. 0009-2851, d).

KlausRoth: Eine unendliche chemische Geschichte, Chemie in unserer Zeit, 2005, 3 , 212-218; W.H.de Camo,Chirality 1989, 322, 499.

2 a) Neue Übersichtartikel: a) S. C. Stinson, „Chira Drug“, Chem. Eng. News. 1992, 28, Sept., S. 46; b) R. Crossley, Tetrahedron 1992, 48 (38), 8155. c) Hutt, AJ, TanSc: Drug chirality and clinical significance. Drugs 1996; 52(Suppl 5) 1-12.

3 D. Enders, "Forming asymmetric C-C bonds" Chemtech 1981, August, S. 504.

4 a) J. Crosby, „Synthesis of Optically Active Compounds: A Large ScalePerspective”, Tetrahedron 1991, 47, (27), 4789.

$5 \quad$ R.S Cahn, C. Ingold, V. Prelog, Angew. Chem, 1966, 78, 413.

6 a). Adam Sobanski, Roland Schmieder, Fritz Vögtle: Topologische Stereochemie und Chiralität. Chemie in unserer Zeit 34(3), S. 160-169 (2000), ISSN.0009-2851; b). Klaus Roth: Eine unendliche chemische Geschichte, Chemie in unserer Zeit 2005, 3, 212-218 ;W. c). H. de Camp, Chirality 1989, 322, 499; d) D. A. Evans, Studies in Asymmetric Synthesis - The Development of Practical Chiral Enolate Synthons In: Aldrichimica Acta. Bd. 15, 1982, S. 23; e) R. Brückner, Reaktionsmechanismen, Elsevier, Heidelberg 2004, ISBN 978-382741590.

7 Vollhardt, K. P. C., Schore, N.E,: Organische chemie; 3, Auf., Wiley-VCH Verlag GmbH, Weinheim, 2000.

8 Hans-Jürgen Federsel Chemie in unserer Zeit 27. Jahrg, 1993. Nr.21.R.S Cahn, C. Ingold, V. Prelog, Angew. Chem, 1966, 78, 413.

9 Atkinson, P.S. Stereoslective Synthesis, Wiley \& Suns, Lonon, 1995.

$10 \quad$ Spion, C.; Beaulieu, C. Angew. Chem. 2000, 112, 2006.

11 a) B. List, R. A. Lerner, C. F. Barbas Ш, J. Am. Chem. Soc. 2000, 122, 2395-2396; b) T. Bui, C. F. Barbas Ш, Tetrahedron Lett. 2000, 41, 6951-6954.

12 P. I. Dalko, L. Moisan, Angew. Chem. 2001, 113, 3840-3864; Peter I. Dalko, L. Moisan, Angew. Chem. Int.Ed. 2001, 40, 3726-3748.

13 a) P. Langer, Angew. Chem. 2000, 112, 3177-3188; Angew. Chem.Int. Ed. 2000, 39, 30493052; b) E, Ciganek, Org. React. 1997, 51, 201-350. 
14 Y.Iwabuchi, M. Nakatani, N. Yokoyama, S. Hatekeyama, J. Am. Chem. Soc. 1999, 121, 10219-10220.

15 F. Ameer, S.E Drewes, S. Freese, P. T. Kaye, Synth. Commum. 1988, 18,495-500.

16 William S. Knowles Angew. Chem. 2002, 114, 2096-2107 (Asymmetrische Hydrierungen ( Nobel-Vertrag)

17 R.Noyori, Angew. Chem. 2002, 114, 2108; Angew. Chem. Int.Ed. 2002, 41, 2008.

18 K. B. Sharpless, Angew. Chem. 2002, 114, 2126; Angew. Chem. Int.Ed. 2002, 41, 2024.

19 Peter I. Dalko und Lionel Moisan, Angew. Chem. 2001, 113, 3840-3864.

20 R. Greslow, Science 1982, 218, 532-537.

21 B. Funini, L.O. Arèan, Chem, Soc. Rev. 1999, 28, 373-382.

22 a) M. Yamaguchi, T. Shiraischi, M. Hirama, J. Org. Chem. 1996, 61, 3520-3530; b) M. Yamaguchi, Y. Igaraschi, R. S. Reddy, T. Schiraschi, M. Hirama, Tetrahedron 1997, 53, 11223-11226; c) M. Yamaguchi, T. Shiraischi, Y. Igaraschi, M. Hirama, Tetrahedron Lett. 1994, 35, 8233-8236.

23 J. Seayad; B. List, Org. Biomol. Chem., 2005, 3, 719-724.

24 a) S. E. Denmark, R. A. Stavenger, K. -T. Wong, J. Org. Chem. 1998, 63, 918-919; b). S.

E. Denmark, R. A. Stavenger, K. -T. Wong, Tetrahedron 1998, 54, 10389-10402; c) S. E. Denmark, R. A. Stavenger, K. -T.Wong, x. Su, J. Am. Chem. Soc. 1999, 121, 4982-4991; d) S. E. Denmark, R. A. Stavenger, Acc.Chem. Res. 2000, 33, 432-440; e). S. E. Denmark, R. A. Stavenger, J. Am. Chem. Soc. 2000, 122, 8837-8847.

a) M. J. Ơ Donnell, W. D. Bennett and S. Wu, J. A. C. S, 1989, 111, 2353-2355; b) M. J. O Donnell, Acc. Chem. Res. 2004, 37, 506-517.

K. Tanaka, A. Mori, S. Inoue, J. Org. Chem. 1990, 55, 181-185.

a). M.S. Sigman, E. N. Jacobsen, J. Am. Chem. Soc. 1998, 120, 4901-4902; b). M. S. Sigman, P. Vacha, E. N. Jacobsen, Angew. Chem. 2000, 112, 1336-1338.

A.G. Wenzel, E. N. Jacobsen, J. Am. Chem. Soc. 2002, 124, 12964-12965.

29 G. D. Joly, E. N. Jacobsen, J. Am. Chem. Soc. 2004, 126, 4102-4103.

30 M. S. Taylor, E. N. Jacobsen, J. Am. Chem. Soc. 2004, 126, 10558-10559.

31 Jun-an Ma; Dominque Cahard, Angew. Chem., 2004, 116, 4666-4683.

a) Msawamura, Chem. Rev. 1992, 92, 857-871. b) H. Steinhagen, G. Helmechen, Angew. Chem. 1996, 108, 2489-2492; Angew. Chem. Int. Ed. 1996, 35, 2339-2342. c) M. Shibasaki; H. Sasa, T. Arai, Angew. Chem. 1997, 109, 1290-1301; Angew. Chem. Int. Ed. 1997, 36, 2339-1236-1256. d) E. K. van den Beuken, B. L. Ferina, Tetrahedron 2001, 57, 
12985-13011; e) G. J. Rowlands, Tetrahedron 2001, 57, 1865-18821; f). H. Gröger, Chem. Eur. J. 2001, 7, 5246-5251; g). M. Shibasaki, N. Yoshikawa, Chem. Rev. 2002, 102, $2187-$ 2209.

33 L. F. Tietze, H. P. Bell, S. Chandrasekhar, Angew. Chem. 2003, 115, 4128-4160; L. F. Tietz, H. P. Bell, S. Chandrasekhar, Angew. Chem. Int. Ed. 2003, 42, 3996-4028.

34 Oku, J.; Ito, N. ; Inoue, S. Makromol. Chem. 1982, 183, 579-586.

35 Tannaka, K.; Mori, A.; Inoue, S., J. Org. Chem. 1990, 55, 181-185.

36 Iyer, M. S.; Gigstad, K. M.; Mandv, N. D.; Lipton, M. , J. Am. Chem. Soc. 1996, 118, 4910-4911.

37 R. Wiechert, Nachricht aus der Chemie, 2003, 51, Juli-August.

38 Sigman, M. S.; Vachal, P.; Jacobsen, E. N. Angew. Chem. 2000, 112, 1336-1338, Angew. Chem. Int. Ed. 2000, 39, 1279-1281.

39 Vachal, P.; Jacobsen, E. N. J. Am. Chem. Soc. 2002, 124, 10012-10014.

40 Review: Jarvo, E. R.; Miller, S. J. Tetraheron 2002, 58, 2481-2495.

41 Review: Groeger, H.; Wilken, J.; Berkessel, A. In simple Amino Acide and Schort-chain Peptides as Efficient Metalfree Catalysts in Asymmetrc Synthesis; Schmalz, H.-G.,Wirth, T., Eds.; Organic Synthesis highlights V.; WILEY-VCH: Weinheim, 2003, pp 178-186.

42 Review: Tsogoeva, S. B. Lett. Org. Chem. 2005, 2, 208-213.

43 Horstmann, T. E.; Guerin; D. J.; Miller, S. J. Angew. Chem. 2000, 112, 3781-3784, Angew. Chem. Int. Ed. 2000, 39, 3635-3638.

44 Guerin; D. J.; Miller, S. J. J. Am. Chem. Soc. 2002, 124, 2134-2136.

45 Tsogoeva, S. B.; Jagtap, S. B.; Ardemasova, Z. A., Kalikhevich, V. N. Eur. J. Org. Chem. 2004, 4014-4019.

a). B. R. Sculimbrene, S. J. Miller, J. Am. Chem. Soc. 2001, 123, 10125-10126, b) B. R. Sculimbrene, A. J. Morgen, S. J. Miller, J. Am. Chem. Soc. 2002, 124, 11653-11656.

52 For a Reviw: Billington, D. C. The Inositol Phosphates: Chemical Syntheses und Biological Significance; VCH: New York, 1993. 
53 Imbriglio, J. E.; Vasbinder, M. M.; Miller, S. J. Org. Lett. 2003, 121, 4306-4307.

54 Vogel, E. M. Groger, H.; Shibasaki, M. Angew. Chem. Int. Ed. 1999, 38, 1570-1577.

55 Basavaih, D.; rao, A. J., Satyanarayana, T. Chem. Rev. 2003, 103, 811-891.

56 Langer, P. Angew. Chem. Int.Ed. 2000, 39, 3049-3052.

57 Walsch, L. M.; Winn, C. L.; Goodman, J. M. Tetrahedron Lett. 2002, 43, 8219-8222.

58 Oishi, T.; H. Hirma, M. Tetrahedron Asymmetry 1995, 6, 1241-1244.

59 Harry, J., B. List Synlett, 2003, 12, 1901-1902.

60 D. F. Cauble, V. Lynch, M. J. Krische, J. Org. Chem. 2003, 68, 15-21.

61 T. Bach, B. Grosch, T. strassner, E. Herdtweck, J. Org. Chem. 2003, 68, 1107-1116.

62 P. R. Bently, W. Kroutil, J. A. Littelchild, S. M. Roberts, chirality, 1997, 9, 198.

63 R. W. Flood, T. P. Geller, S. A. Petty, S. M. Roberts, J. Skidomore, M. Volk, Org. Lett. 2001, 3, 683 .

64 P.E. Coffey, K. -H. Drauz, S. M. Roberts, J. Skidmore, J. A. Smith, Chem. Commun. 2001, 2330.

65 T. D. Machajewski; H. Wang, C.H.; Angew. Chem. Int. Ed. 2000, 39, 1352.

66 T. Mukaiyama, Angew. Chem. Int. Ed. 2004, 43, 5590.

67 a) Yamada, Y. M. A.; Yoshikava, N.; Sasai, H.; Shibasaki, M. Angew. Chem. Int. Ed. 1997, 36, 1871; b) Yamada, Y. M. A.; Shibasaki, M. Tetrahedron Lett. 1998, 39, 5561; c)Yoshikava, N.; Yamada, Y. M. A.; Das, J.; Sasai, H.; Shibasaki, M. J. Am. Chem. Soc. 1999, 121, 4168.

68 a) Torst, B. M.; Ito, H. J. Am. Chem. Soc. 2000, 122, 12003. b) Torst, B. M.; Ito, H.; Silcoff, E. R. Ito, H. J. Am. Chem. Soc. 2001, 123, 3367.

69 a) List, B.; Lerner, R. A.; Barbas, C. F. Ш. J. Am. Chem. Soc. 2000, 122, 2395. b). Skachivel, K.; Notz, W.; Bui, T.; Barbas, C. F. Ш. J. Am. Chem. Soc. 2001, 123, 5260. c) Notz, W.; List, B. J. Am. Chem. Soc. 2000, 122, 7386.

70 Tang, Z.; Jiang, F.; Yu, L.-T.; Cui, X.; Gong, L.-Z. ; Mi, A.-Q.; Jiang, Y.-Z; Wu, Y. -D. J. Am. Chem. Soc. 2003, 125, 5262-5263.

71 Martin, H. J.; List, B. Synlett 2003, 1901-902.

72 Kofoed, J.; Nielsen, J.; Reymond, J.-L. Boorg. Med. Chem. Lett. 2003, 13, 2445-2447.

73 Shi, L.-X.; Sun, Q.; Ge, Z.-M. ; Zhu, Y.-Q; Cheng, T.-M.; Li, R.-T. Synlett 2004, 22152217.

74 Szöllösi, G.; London, G.; Balàspiri, L.; Somlai, C.; Bartók, M. Chirality 2003, 15, 90-96. 
75 a) Tannaka, K.; Mori, A.; Inoue, S., J. Org. Chem. 1990, 55, 181-185. b) Mori, A.; Ikeda, Y.; Kinoshita, K.; Inoue, S. Chem. Lett. 1989, 2119-2122. c) Ito, N; Inoue, S. Makromol. Chem. 1982, 183, 579-586.

76 R. Brückner; Reaktionsmechanimen, 3 Auflag, ISBN, 3-8274-1579-9, Spain, 296-299.

77 S. Kazuki, A. Hayao, K. Tesuo, I. Nobuo, Belletin of Chemical Society of Japan, 1977, 50 (8), 1999-2004. b) O. Hideo, I. Ken, J. Yoshiko, Belletin of Chemical Society of Japan, 1964, 37 (10), 1471-7.

78 Skthivel, K.; Notz, W.; Bui, T.; Barbas, C. F.; Ш, J. Am. Chem. Soc. 2001, 123, 52605267.

79 B. List, Synlett, 2001, No. 11, 1675-1686, ISSN 0936-5214, Thieme Stuttgart New York.

80 K. Tanaka, A. Mori, S. Inoue, J. Org.chem. 1990, 55, 181-185.

81 Begońa, Aguilera, L.B.Wolf; P. Niezypor, F. P. J. T. Rutjes, H. S. Overkleeft, J. C. M. van Hest, H. E. Schoemacker, B. Wang, J. C. Mol, A. Fürster, M. Overhand, G. A. van der Marel, J. H. vav Boom, J. Org. Chem. 2001, 3584-3589.

82 a) Vogel, E. M.; Gröger, H., Shibasaki, M. Angew. Chem. 1999, 111, 1672-1680. Angew. Chem. Int. Ed. 1999, 38, 1570-1577; b)M. Kitamura, T. Ohkuma, S. Inoue, N., Sayo, H., Kumobayaschi, S. Akutagawa, T. Ohta, H. Takaya, R. Noyori, J. Am. Chem. Soc. 1998, 110, 629-631.

83 S. Inoue, H. Takaya, K. Tani, S. Otsuka, R. Noyori, J. Am. Chem. Soc. 1998, 112, $4897-$ 4950.

84 a) T. Artatani, Y. Yoneyoschi, T. Nagasa, Tetrahedron Lett. 1977, 2599-2602; b) T. Artatani, Y. Yoneyoschi, T. Nagasa, Tetrahedron Lett. 1982, 23, 685-688.

a) T. Kasuki, K. B. Scharpless, J. Am. Chem. Soc. 1980, 102, 5974-5976. b). E. N. Jocobsen in Comprehensive organometallic Chemistry $\Pi$, vol, 12 (Eds.: E. W. Abel, F. G. Stone, E. Wilkinson), Pergamon, New York, 1995, p. 1097.

86 H. -U. Blaser, B. Pugin, F. Spindler in Applied Homogeneous Catalysis with Organometallic Compounds, Vol. 2 (Eds. B. Cornlis, W. A. Herrmann), CCH, Weinheim, 1996, p. 1097.

Vogel, E. M.; Gröger, H.; Shibasaki, M. Angew. Chem. 1999, 111, 1672-1680. Angew. Chem. Int. Ed. 1999, 38, 1570-1577.

89 P. Diedizic, W-B. Zhao, J. Hāgren, A. Cŏrdova, Org. Biomol. Chem. 2006, 4, 38-40.

90 Imbriglio, J. E.; Vasbinder, M. M.; Miller, S. J. Org. Lett. 2003, 121, 4306-4307. 
Y. Sohtome, A. Tanatani, Y. Hschimoto, K. Nagasawa, Tetradedron Lett, 2004, 45, 55895592.

Y. Sohtome, A. Tanatani, Y. Hschimoto, K. Nagasawa, Tetradedron Lett., 2004, 45, $5589-5592$.

93 Lett, 2002, 12, 2674.

94 Von Jean-Marie, C, A, Fürst, W. Meier, Helv. Chim. Acta, 1976, 59, 6, Nr.197. 37, 1986-2012.

J. E. Macor, J. Blake, C. B. Fox, C. John, B. K.Koe, J. M. C. 1992, 35, No, 23, 4503-4505.

Tetrahedron Asymmetry, 1999, 10, 713-719.

V. F. Pozdnev, Tetrahedron Lett. 1995, 36, No. 39, 7115-7118.

L. Aureli, J. S. Box, R. T. C. Brownlee, A. B. Hughes, M. M. Sleebs, J. Org. Chem. 2003, $68,2652-2667$.

V. F. Pozdnev, Tetrahedron Lett. 1995, 36, No. 39, 7115-7118.

M. B. Sassaman, J. Giowaneli, V. K. Sood, W. C. Eckelman, Bioorg. Med. Chem. 1998, 6, $1759-1766$

D. H. R. Barton, C. Tachdjian, Tetrahedron, 1992, 48, No. 35, 7091-7108.

Hassan, H. Y. Ei-kussi, N. A. Farghary Z. S. Chem. Pharm. Bull., 1998, 46, 865-866.

V. K. Aggarwal, I. Emme, S. Y. Fulford, J. Org. Chem. 2003, 68, 692-700.

a). S. Itsuno, K. Ito, A. Hirao, S. Nakahama, N. Yamazaki, Perkin, Trans. 1, 1983, $1673-$ 1676; b). S. Itsuno, K. Ito, A. Hirao, S. Nakahama, J. Chem. Soc. Chem. Commun. , 1983, 469-470.

E. J. Corey, C. J. Helal, Angew. Chem. 1998, 110, 2092-2118. Angew. Chem. Int. Ed. 1998,

M. P. Sibi, G. R. Cook, P. Liu, Tetrahedron Lett. 1999, 40, 2477-2480.

J. M. Brunel, O. pardigon, B. Faure, G. Buono, J. Chem. Soc. Chem. Commun. 1992, $287-$ 288.

a) G. Buono, O. Chiodi, M. Wills, Synlett, 1999, 377-388, b) M. Wills, M. Gamble, M. Palmer, A. Smith, J. Studley, J. Kenny, J. Mol. Catal. A. Chem. 1999, 146, 139-148.

Für ein Beispiel intramolekulare prolinkatalysierte Aldol-Reaktion siehe: a) Z. G. Hajos, D. R. Parrisch, J. Org. Chem. 1974, 39, 1615-1621; b) W. Notz, B. List, J. Am. Chem. Soc. 2000, 112, 7386-7387. c) K. Sakthivel; W. Notz, T. Bui, C. F. Barbas Ш, J. Am. Chem. Soc. 2001, 113, 5260-5271; C. Pidathala, L. Hoang, N. Vignola, B. List, Angew. Chem. 2003, 115, 2891-2894. Angew. Chem. Int. Ed. 2003, 42, 2785-2788. 
110 a) L. Hong, S. Bahmanyar, K. N. Houk, B. List, J. Am. Chem. Soc. 2003, 125, 16-17; b) S. Bahmanyar, K. N. Houk, H. J. Martin, B. List, J. Am. Chem. Soc. 2003, 125, 2475-2479.

Z. Tang, F. jiang, L.-T. Yu, X. Cui, L.-Z. Gong, A. Q. Mi, Y.-Z. Jiang, Y.-D.-Wu, J. Am. Chem. Soc. 2003, 125, 5262-5263.

112 T. Okino, S. Nakamura, T. Furukawa, Y. Takemoto, Org. Lett, 2004, 6, 625-627.

113 J. Wang, H. Li, X. Yu, L. Zu, W. Wang, Org. Lett. 2005, 7, 4293-4296.

114 G. D. Joly, E. N. Jacobsen, J. Am. Chem. Soc. 2004, 126, 4102-4103.

115 R. F. Pratt, Science 1989, 246, 917.

L. Maier, Diel, P. Phosphorus, Sulfor, and Silicon 1991, 57, 57.

Kolodiazhnyi, O. I. Tetrahedron Asymmetry, 1998, 9, 1279.

M. S. Sigman, E. N. Jacobsen, J. Am. Chem. Soc. 1998, 120, 4901.

M. S. Sigman, P. Vachal, E. N. Jacobsen, Angew. Chem. 2000, 112, 1336. Angew. Chem. Int. Ed. 2000, 39, 1279.

\section{1, 42, 4441}

131 a) H. J. Martin, B. List, Synlett 2003, 1901; b) O. Andrey, A. Aleyakis, A. Tomassini, G. Bernardinelli, Adv. Synth. Catal. 2004, 346, 1147; c) D. Terakado, M. Takano, T. Oriyama, Chem. Lett. 2005, 34, 962; d) W. Wang, J. Wang, T. Li, Angew. Chem. 2005, 117, 1393, Angew Chem. Int. Ed. 2005, 44, 1369.

132 a) A. J. A. Cobb, D. A. Longbotton, D. M. Shaw, S. V. Ley, Chem. Commun. 2004, 1808; b) C. E. T. Mitchell, A. J. A. Cobb, S. V. Ley, Synlett 2005, 611; c) A. J. A. Cobb, D. M. Shaw, D. A. Longbotton, J. B. Gold, S. V. Ley, Org. Biomol. Chem. 2005, 3, 84. 
133 T. Ishii, S. Fujioka, Y. Sekiguchi, H. Kotsuki, J. Am. Chem. Soc. 2004, 126, 9958.

134 a) J. -A, Ma, D. Cahard, Angew. Chem., 2004, 116, 4666, Angew. Chem. Int. Ed. 2004, 43, 4556, b) M. Shibaski, N. Yishikawa, Chem. Rev. 2002, 102, 2187; c) H. Gröger, Chem. Eur. J., 2001, 7, 5246; d) M. Shibaski, H. Sasai, T. Arai, Angew. Chem., 1997, 1290, Angew. Chem. Int. Ed. 1997, 1236.

135 a) P.I. Dalko, L. Moisan, Angew. Chem., 2004, 116, 5248, Angew. Chem. Int. Ed. 2004, 43, 5138; b) P. M. Pihko; Angew. Chem., 2004, 116, 2110, Angew. Chem. Int. Ed. 2004, 43, 2062; c) J. Seayad, B. List, Org. Biomol. Chem. 2005, 3, 719.

136 Referenz 13 bei: S. B. Tsogoeva, S.-W, Wei, Chem. Commun. 2006, 1451.

137 S. B. Tsogoeva, D. A. Yalalov, M. J. Hateley, C. Weckbecker, K. Huthmacher, Eur. J. Org. Chem., 2005, 4995.

138 a) A. Córdova, W. Zou, I, Ibrahem, E. Reyes, M. Engqvist, W. -W, Liao, Chem. Commun. 2005, 3586, b) B. List, Synlett, 2001, 1675.

139 a) P. R. Schreiner, A. Wittkopp, Org. Lett, 2002, 4, 217; b)Y. Hoashi, T. Okino, Y. Takemoto, Angew. Chem., 2005, 117, 4100, Angew. Chem. Int. Ed. 2005, 44, 4032; c) A. Wittkopp, P. R. Schreiner, Chem.-Eur. J. 2003, 9, 407; d) P. R. Schreiner, Chem. Soc. Rev. 2003, 32, 289.

140 D. Ma, K. Cheng Tetradedron Asymmetry 1999, 10, 713-719.

141 S.-W. Wei, D. A. Yalalov; S. B. Tsogoeva, S. Schmatz, Catalysis Today 2007, 121, 151157.

142 a) T. Okino, Y. Hoashi, T. Furukawa, X. Xu, Y. Takemoto, J. Am. Chem. Soc. 2005, 127, 119; b) T. Okino, Y. Hoashi, Y. Takemoto, J. Am. Chem. Soc. 2003, 125, 12672; c) Y. Hoashi, T. Okino, Y. Takemoto, Angew. Chem. 2005, 117, 4100, Angew. Chem. Int. Ed. 2005, 44, 4032.

143 B. List, P. Pojarliv, H. J. Martin, Org. Lett, 2001, 3, 2423.

144 A. Alexakis, O. Andrey, Org. Lett, 2002, 4, 3611.

145 Y. Xu, A. Córdova, Chem. Commun. 2006, 460.

146 K. Soai, T. Schibata, I. Sato, Acc. Chem. Res. 2000, 33, 382.

147 C. Bolm, F. Bienewald, A. Seger, Angew. Chem. 1996, 108, 1767, Angew. Chem. Int. Ed. 1996, 35, 1657.

148 a) H. Wynberg Chimia, 1989, 43, 156; b) H. Wynberg, J. Marcromol. Sci. Chem. A, 1989, 26, 1033.

149 F. C. Frank, Biochim. Biophy. Acta 1953, 11, 459. 
150 B. L. Feringa, R. A. van Delden, Angew Chem. Int. Ed. 1999, 38, 3418-3439.

151 A. Moradpour, J. F. Nicoud, G. Balavoine, H. Kagen, G. Tsoucaris, J. Am. Chem. Soc. 1971, 93, 2353-2354.

152 M. Klussmann, H. iwamura, S. P. Mathew, D. H. Wells, U. Pandya, A. armstrong, D. G. Blackmond, Nature, 2006, 441, 621-623.

153 P. Gerike, Naturwissenschaft, 1975, 62, 38-39.

154 D. Seebach, R. Amstutz, J. D. Dunitz, Helv, Chim. Acta, 1981, 64, 2622.

155 D. Seebach, P. Robert, Angew. Chem., 1988, 100, 1685, Angew. Chem. Int. Ed. 1988, 27, 1624.

156 A. H. Aberts, H. Wynberg, J. Am. Chem. Soc. 1989, 111, 7265-7266.

157 K. Soai, S. Niwa, H. Hori, J. Chem. Soc., Chem. Commun. 1990, 982-983.

158 K. Soai, S. Niwa, H. Hori, Tetrahedron Asymmetry 1994, 5, 789.

159 I. Sato, H. Urabe, S. Ischiguro, T. Schibara, K. Soai, Angew. Chem., 2003, 115, 329, Angew Chem. Int. Ed. 2003, 42, 315.

160 M. Szlosek, B. Figadère, Angew. Chem., 2000, 115, 1869, Angew. Chem. Int. Ed. 2000, 39, 1799.

161 H. Fujisawa, T. Nakagawa, T. Mukaiyama, Adv. Synth. Catal. 2004, 346, 1241.

162 D. Sievers, G. von Kiedrowski, Nature, 1994, 369, 221.

163 a) C. Bolm, F. Bienewald, A. Seger, Angew. Chem., 1996, 108, 1767, Angew. Chem. Int. Ed. 1996, 35, 1657. b) H. Danda, H. Nischikawa, K. Otaka, J. Org. Chem. 1991, 56, 6740.

164 K. Soai, T. Shibata, T. Morika, K. Choji, Nature, 1995, 378, 767-768.

165 D. A. Singleton, L. K. Vo, J. Am. Chem. Soc. 2002, 124, 10010-10011.

166 K. Tennakone, L. P. M. P. Orig. of Life and Evol. Ofthe Biosph. 1993, 23, 137-143.

167 P. Decker, Origins of Optical Activity in Nature (D. C. ed. Walker, Elsevier, Amsterdam, 1979.

168 Y. Saito, H. Hyuga, J. Phys. Soc. Japan, 2004, 73, 33-35.

169 R. Plasson, H. Bersini, A. Commeyras, Proc. Natl. Acad. Sci. USA 2004, 101, $16733-$ 16738.

170 A. Córdova, W. Notz, G. Zhong, J. M. Betancort, C. F. Barbas Ш, J. Am. Chem. Soc. 2002, $114,1842-1843$.

171 M. Mauksch, S. B. Tsogoeave, I: M, Martynova, S.-W.Wei, Angew. Chem. Int.Ed. 2006, 45, 1-5; Angew. Chem., 2007, 119, 397-400.

172 B. List, Chem. Commun. 2006, 819. 
M. Mauksch, S. B. Tsogoeva, I.M. Martynova, S.-W, Wei , Angew. Chem., 2007, 119, 397-400, Angew. Chem. Int. Ed. 2007, 46, 393-396.

174

175

176 Soc. 2001, 123, 10103-10104.

H. P. Bell, S. Chandrasekhar, Angew. Chem. Int. Ed. 2003, 42, 3996-4028.

181

a) G. M. Cragg, D. J. Newman, K. M. Snadr, J. Nat. Prod. 1997, 60, 52-62; b) A. Zeeck, G. Bach, H. Terlau, Internist 2001, 42, 1422-1427, c) L. F. Tietze, H. P. Bell, S. Chandrasekhar, Angew. Chem. 2003, 115, 4128-4160; L. F. Tietze, H. P. Bell, S. Chandrasekhar, Angew. Chem. Int. Ed. 2003, 42, 3996-4028.

\section{Science 1993, 262, 1546.}

Rev. 1999, 19, 543-558, c) R. McDaniel, S. Ebert-Khosla, D. A. Hopwood, C. Khosla,

G. R. Robertson, J. Field, B. Goodwin, S. Bierach, M. tran, A. Lehnert, C. Liddle, Molecular Pharmacology, 2003, 64, 42-50.

W. A. Ray, K. T. Murray, S. Meredith, S. S. narasimhulu, K. hall, C. M. Stein, N. Engl. J. Med. 2004, 351, 1089-1096.

J. Setter, F. Lieb, Angew. Chem. 2000, 112, 1792-1812; Angew. Chem. Int. Ed. 2000, 39, 1724-1744.

P. Arya. M. Back, Curr. Opin. Chem. Biol. 2001, 5, 292-301.

S. L. Schreiber, Science, 2000, 287, 1964-1969.

H. Shiozawa, A. Shimada, S. Takahashi, J. Antibiotics 1997, 50, 449-452.

H. Shioozawa, T. Kagasaki, T. Kinoshita, H. Haruyama, H. Domon, Y. Utsui, K. Kodama, S. Takahashi, J. Antibiotics 1993, 46, 1834-1842.

Y. F. Hallock, J. H. Cardellina П, M. Schäffer, G. Bringmann, G. Francois, M. R. Boyd, Bioorg. Med. Chem. Lett. 1998, 8, 1729-1734.

a) C. J. Tsoi, C. Khosla, Chem. Biol. 1995, 2, 355-362, b) L. Katz, R. McDaniel, Med. res. M. M. Ơconnel, M. D. Bentely, C. S. Campbell, B. J. W. Cole, Phytochemistry 1988, 27, 2175-2176. 
192 Y. Gong, K. M. Raj, C.A. Luscombe, I. Gadawski, T. Tam, J. Chu, D. Gibson, R. Carlson, S. L. Sacks, Antiviral Res. 2004, 64, 127-130.

193 K. W. Cheng, P. J. Lahad, w.-I. Kuo, A. Lapuk, K.Yamada, Nature medicine 2004, 10, 1251-1256.

194 T. Effert, A. Sauerbarey, A. Olbrich, E. Gebhart, P. Rauch, H. O. Weber, J. G. Hengstler, M.-E. Halatsch, M. volm, K.-D. tew, Mol. Pharmacol. 2003, 64, 382-394.

195 C. Lügendorf, C. Rojanawatsirivet, G. Wernsdorfer, J. Sirichaisinthop, H. Kollaritsch, W. H. Wernsdorfer, The Mid.Eur.J. of. Med. 2006, 118, 70-76.

196 Zitat aus Report of a WHO Technical Consultation on Antimalarial Combination Therapy, WHO, 4-5 April, 2001.

197 a) L.F. Tietze, H. Heinzin, P. Moyna, Liebigs Ann. Chem. 1991, 1245-1249; b) Y. H. Deng, J. Org. Chem. 2002, 67, 2864-2873.

198 G. B. jones, G. Hynd, M. Wright, A. Purohit, G. W. Plourde П R. S. Hiber, J. E. Mathews, A. Li, M. W. Kilgore, G. J. Bubley, M. Yancisin, M. A. Brown, J. Org. Chem. 2001, 66, 3688-3695.

199 R. Boulch, A. Scheuer, P. Mosset, R. W. Saalfrank, Tetrahedron Lett. 2000, 41, 1023-1026.

200 Christnsen, et al, United States Patent, 1979, No. 13.

201 Organikum, 22. Auflag, 742-776. 


\section{Danksagung}

An dieser Stelle möchte ich allen bedanken, die auf unterschiedlichste Art und Weise zum Gelingen dieser Arbeit beigetragen haben.

Für die stets wohlwollende Unterstützung danke ich allen Mitarbeitern der Analytikabteilung unsers Instituts, insbesondere der NMR-Abteilung. Martin Weitemeyer, Ulrich Leohardt, Christiane Siebert, Carola Zolke und natürlich Reinhard Machinek danke ich für die Messung der NMR-Spektren sowie Frau Györgyi Udvarnoki und Herrn Dr. Holm Frauendorf für die Aufnahme von Massenspektren.

Allen Mitgliedern der Arbeitgruppe danke ich für Hilfsbereitsschaft und die gute Zusammenarbeit während der gesamten Zeit.

Für das gründliche Korrekturlesen dieser Arbeit danke ich besonders Sabine Hermann, Matthias Freund, Martin Burthardt, Michael Mauksch und Florian Seidel.

Mein ganz besonderer Dank gilt meinem Mann, der mich in aller stressigen Situationen unterstützt hat und nie die Geduld verloren. Ich danke meinen Eltern und meiner Tochter für moralische Unterstützung 